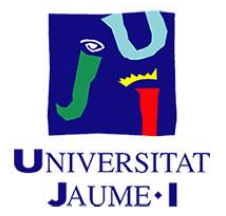

UNIVERSITAT JAUME I FACULTAD DE HUMANIDADES PROGRAMA DE DOCTORADO EN FILOLOGÍA Y CULTURAS EUROPEAS

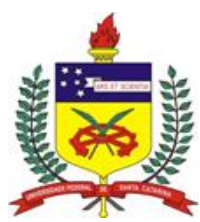

UNIVERSIDADE FEDERAL DE SANTA CATARINA CENTRO DE COMUNICAÇÃO E EXPRESSÃO PROGRAMA DE PÓSGRADUAÇÃO EM LINGUÍSTICA

\title{
LA INTERFERENCIA COMO PRINCIPAL FUENTE DE ERRORES LINGÜÍSTICOS EN DOCENTES BRASILEÑOS DE ELE: CARACTERIZACIÓN Y ESTUDIO DE LOS ERRORES LÉXICOS
}

Sabrina Lafuente Gimenez

Florianópolis/Castellón de la Plana 2017 

Sabrina Lafuente Gimenez

\section{LA INTERFERENCIA COMO PRINCIPAL FUENTE DE ERRORES LINGÜÍSTICOS EN DOCENTES BRASILEÑOS DE ELE: CARACTERIZACIÓN Y ESTUDIO DE LOS ERRORES LÉXICOS}

Tesis sometida como requisito final para la obtención del Título de Doctora en Lingüística por la Universidad Federal de Santa Catarina y el Título de Doctora por la Universitat Jaume I en régimen de co-tutela.

Orientadores: Profa. Dra. Adja Balbino de Amorim Barbieri Durão (UFSC - Brasil) e Prof. Dr. José Luis Blas Arroyo (UJI España).

Florianópolis/Castellón de la Plana 2017 



\section{LA INTERFERENCIA COMO PRINCIPAL FUENTE DE ERRORES LINGÜÍSTICOS EN DOCENTES BRASILEÑOS DE ELE: CARACTERIZACIÓN Y ESTUDIO DE LOS ERRORES LÉXICOS}

Esta Tese foi julgada adequada para obtenção do Título de "Doutora em Linguística", pelo Programa de Pós-Graduação em Linguística, da Universidade Federal de Santa Catarina, e para a obtenção do título de "Doutora" pelo Programa de DoctoradoenFilología y Culturas Europeas da Universitat Jaume I e aprovada em sua forma final por ambas instituições.

Florianópolis, 25 de abril de 2017.

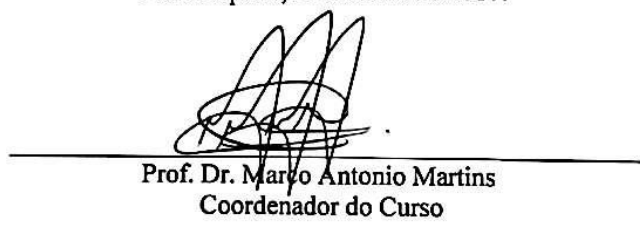

\section{Banca Examinadora:}

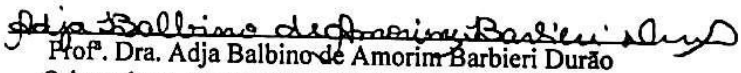
Orientadora - Universidade Federal de Santa Catarina

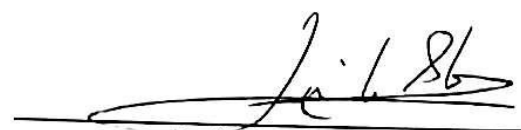

Prơ. Dr. José LuisBlas Arroyo

Orientador - Universitat Jaume I 

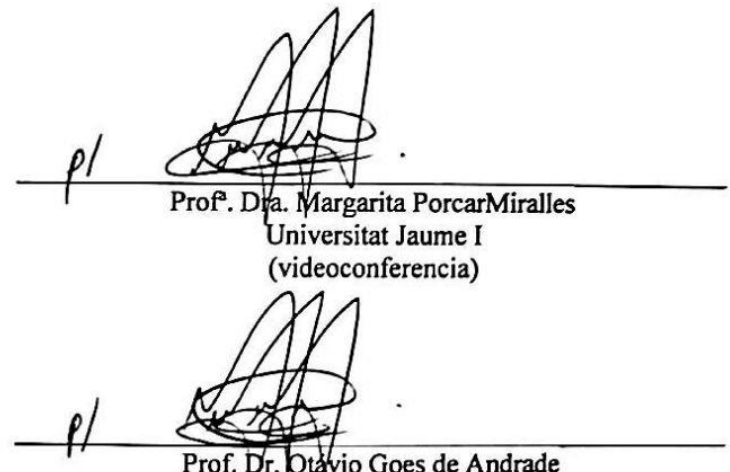

Prof. Dr. Dtâvio Goes de Andrade

Universidade Universidade Estadual de Londrina

(videoconferencia)

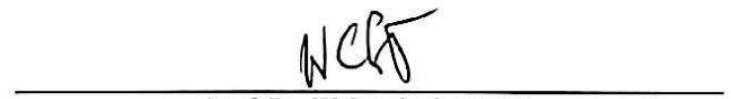

Prof. Dr. Walter Carlos Costa

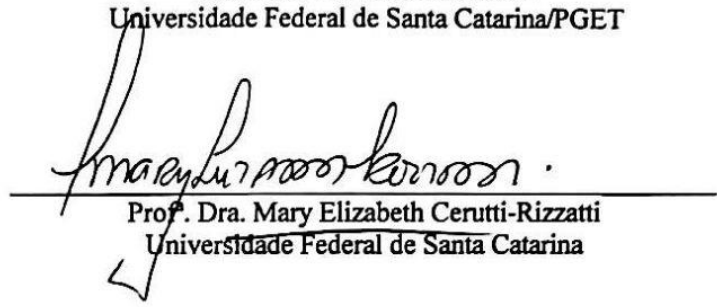

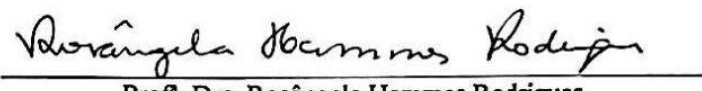

Prof'. Dra. Rosângela Hammes Rodrigues

Universidade Federal de Santa Catarina 
Para Rafa, quien tiene Cum Laude en paciencia y compañerismo. 



\section{AGRADECIMIENTOS}

Siempre pensé que escribir los agradecimientos sería la parte más amena de la tesis. Hoy veo lo muy equivocada que estaba. Ello se debe a que uno no quiere cometer el error de dejar a gente importante sin citar, aunque cuando llevas tanto tiempo en la vida académica esto parece casi imposible $y$, además, curiosamente, parece que las palabras no sean suficientes para cumplir su función.

Quisiera empezar entonces agradeciendo a los profesores que de alguna manera me influenciaron para que llegara a este punto en el que me encuentro ahora. Uno de ellos es el profesor Philippe Humblé, quien conocí en UFSC en la asignatura de lexicografía del Mestrado em Estudos de Tradução y que luego se hizo mi tutor del trabajo final. Philippe es una inspiración, no solo por su capacidad como profesor e investigador, sino por la calidad humana que atesora, lo que lo convierte una persona muy especial. Él me inspiró la curiosidad por los diccionarios y me adentró en el mundo de la investigación, un camino sin vuelta atrás y por el cual le estaré siempre muy agradecida.

Unos pocos años antes, otro profesor y tutor depositó su confianza en mí: Hamilton Wielewick. En aquel entonces era apenas una niña de 17 años en el segundo curso de la carrera de Licenciatura em Língua Estrangeira - Espanhol de la Universidade Regional do Estado do Rio Grande do Sul (UNIJUí). Hamilton me dio la oportunidad de empezar en la investigación, primeramente como voluntaria y luego concediéndome una beca PIBIX, la cual cambió mi vida y seguramente me condujo hasta aquí. Por su voto de confianza, su ejemplo, su paciencia, sus palabras de ánimo, por haberme dado tanto le estaré eternamente agradecida.

Sobre el camino que ahora se encierra, haciendo una retrospectiva, vemos que empezó hace aproximadamente 10 años, en esta misma universidad donde ahora leo la tesis. En aquel entonces, empecé como "aluna especial" en el Doutorado em Lingüística de la Universidadade Federal de Santa Catarina (UFSC). Después de aquellas primeras asignaturas que me sirvieron de inspiración para emprender un nuevo camino, me mudé a España, dónde pasé por dos universidades más.

Respecto a mi estancia en la primera, la Universidad Autónoma de Madrid, debo transmitir mis agradecimientos a Rachel Wittaker, profesora que me acogió de manera tan cariñosa y me ayudó a diseñar los primeros pasos de esta investigación, cuando ni 
siquiera sabía que lo que quería estudiar tenía nombre y ya estaba ampliamente recogido por la lingüística aplicada. Mis agradecimientos a ella no se limitan solamente al plano académico, sino también al personal, puesto que tuvo enorme paciencia en trabajar conmigo a distancia y no desistir de mí mientras tenía que dividirme entre el trabajo y las responsabilidades académicas.

En este mismo sentido debo agradecer enormemente a mi compañera de doctorado Tere Dávolos, quien más de una vez me ayudó con los trámites en la UAM cuando el trabajo no me permitía acudir a la secretaría y siempre me daba ánimos cuando yo misma tenía dudas de si este era el camino.

En la segunda universidad en la que estuve, la Universitat Jaume I, tuve la inmensa suerte de encontrarme con el profesor José Luis Blas Arroyo, quien me acogió muy amablemente y condujo de manera impecable la investigación que vemos en estas páginas. No fueron pocos los percances que tuvimos en estos 6 años de investigación y José Luis demostró ser un ejemplo de persona y profesional en todos los sentidos. Con él aprendí no solamente cuestiones de sociolingüística, de lengua española o acerca del modo de proceder en una investigación científica, sino también cómo la humildad puede engrandecer incluso a los que ya están en lo más alto. Por todo ello, se lo agradezco con todo mi corazón.

Por fin, no puedo dejar de agradecer a la profesora Adja Durão, también directora de esta tesis, quien aceptó formar parte de este proyecto que ya se encontraba en marcha. Al contrario de los demás profesores citados hasta ahora, los cuales me "cayeron del cielo", a Adja la "elegí a dedo" por su amplia experiencia como profesora e investigadora en el área. Aunque hemos tenido algunas dificultades en todos estos años debido a la distancia principalmente, debo agradecerle por haber aceptado entrar en un proyecto como el nuestro, donde una cotutela internacional tiene sus particularidades, pero al final, creo, ha resultado en un trabajo del cual podemos estar orgullosos.

Quisiera hacer una mención especial a las docentes que aceptaron participar de este estudio, aportándonos un poco de su tiempo y colaborando para que la investigación pudiera llevarse a cabo, pese al carácter un tanto intrusivo de la recolección de datos. A ellas mi más profundo agradecimiento, así como a los directores de las respectivas escuelas, quienes amablemente accedieron a que las clases y entrevistas pudieran ser grabadas en el mismo entorno de trabajo de las profesoras. Agradezco también a los miembros del 
tribunal, quienes aceptaron participar en la evaluación de este trabajo, colaborando con mi formación académica.

Debo también agradecer a mis compañeros del Departamento de Letras Estrangeiras de la Universidad Federal de Sergipe (UFS), quienes me han apoyado en todo momento para que pudiera pasar dos años en España llevando a cabo parte de esta tesis doctoral. En especial, quiero agradecer a los miembros del Grupo de Investigação em Diálogos Interculturais e Linguísticos, quienes me han apoyado incondicionalmente en diversos ámbitos durante estos 4 años que llevo trabajando en la UFS.

En lo personal, quiero aquí agradecer a mi familia, quien estuvo a mi lado todos estos años en la distancia, en especial a mi madre, Maria, mi mayor impulsora, por todos los esfuerzos, los sacrificios, por creer en mí desde siempre, por estar a mi lado. $Y$ también a mi hermano Tiago, sin el cual quizá no hubiese podido llegar a España de la manera que llegué y comenzar este sueño que hoy se torna realidad. Mi prima Claudia por las bonitas palabras de ánimo, de las que 'calientan' el alma. A mi familia política por apoyarme siempre, vibrar con mis conquistas, motivarme, aceptar y entender mis ausencias. En especial a Jeanine, siempre disponible a ayudarme de buen corazón con las gestiones en la UJl y a Katy, por la ayuda con los temás más tecnológicos.

Gracias a todos los amigos que me escucharon, me animaron, me ofrecieron un hombro en el que apoyarme en los momentos difíciles, son demasiados para nombrarlos a todos, aunque ellos saben quiénes son. En especial mi más profundo agradecimiento a Elisângela Deboni, Elis, una hermana que me ilumina los días más grises, gracias por estar ahí siempre para mí. Gracias a Emy Soares, Vanessa Nunes por hacerme ver que no estaba sola en las angustias que conlleva escribir una tesis, por convencerme que hay vida después de la defensa, por ayudarme en momentos realmente difíciles (e incluyo en esta última parte también a los amigos Rômulo, Carolina y Thiago). Gracias igualmente a Aline Vione por el compañerismo y las revisiones de las traducciones al inglés.

Dejo por último a mi marido, Rafa. Confieso que, paradójicamente, aunque mi área sea la de "letras" no hay manera de que pueda dejar por escrito con palabras lo mucho que te agradezco por todo lo que me has dado en todos estos años, por el apoyo incondicional, por creer en mí aun cuando yo no lo hacía. Tu dedicación no se puede agradecer en una vida entera, pero espero que este reconocimiento público te sirva de aliento (aunque sé que tú no lo necesitas). Te quiero y te admiro. No hubiese llegado hasta 
aquí de esta forma sin tu ayuda. Gracias por todo. Gracias a Dios por todo lo que me ha concedido y por ponerte en mi camino. 


\section{[Para Recobrar] \\ Francisco Luis Bernárdez}

Si para recobrar lo recobrado debí perder primero lo perdido, si para conseguir lo conseguido tuve que soportar lo soportado,

si para estar ahora enamorado fue menester haber estado herido, tengo por bien sufrido lo sufrido, tengo por bien llorado lo llorado.

Porque después de todo he comprobado que no se goza bien de lo gozado sino después de haberlo padecido.

Porque después de todo he comprendido por lo que el árbol tiene de florido vive de lo que tiene sepultado. 

Quien no conoce las lenguas extranjeras nada sabe de la suya propia. Johann Wolfgang von Goethe

El hombre es tantas veces hombre cuanto es el número de lenguas que ha aprendido. Carlos I de España 



\section{RESUMEN}

En el campo de la enseñanza de las lengua próximas, y, más específicamente en el contexto portugués-español, contemplamos la dificultad por parte de los aprendices- incluso en niveles supuestamente avanzados de conocimiento de la lengua extranjeraen desprenderse de la interferencia de la lengua materna (LM), dificultad ampliamente documentada en los estudios del área (ALMEIDA FILHO, 1995; ANDRADE NETA, 2000; CAMORLINGA, 2005; CELADA 2002, 2008; GANCEDO ÁLVAREZ, 2002; GOETTENAUER, 2005; SALINAS, 2005). En el caso que nos ocupa, el de la formación de profesores de español en Brasil, existe una preocupación creciente acerca del input que puede ofrecerse a los estudiantes como resultado de este rasgo intrínseco del aprendizaje de las lenguas próximas. Por este motivo, en la presente tesis doctoral, hemos investigado cuáles son las principales características de los discursos orales que muestran los profesores de español como lengua extranjera en una región del sur del país en relación con la interferencia del portugués. La recolección de datos se realizó a través de la grabación de clases y entrevistas orales. Para el análisis de los datos nos basamos en el método de análisis de errores y en la lingüística contrastiva mediante el contraste entre diferentes obras lexicográficas, así como en la lingüística de corpus. El carácter de la investigación es cuantitativo y cualitativo, buscando, por un lado, estudiar la frecuencia de errores y, por otro lado, describir y explicar los distintos tipos de errores léxicos a partir de una adaptación del modelo taxonómico de Durão (2007). Los resultados muestran que: (i) los docentes poseen una interlengua (SELINKER, 1974) caracterizada por un alto índice de desvíos tanto inter como intralingüísticos (ii) en la interlengua de los profesores analizados los errores interlingüísticos son la mayoría en comparación con los intralingüísticos; (iii) en relación a lo errores interlingüísticos, los lexicales son los más frecuentes, y de ellos prevalecen los errores de sustitución (directa y por analogía). Desde el punto de vista pedagógico, las conclusiones del estudio apuntan, por un lado, a la necesidad de llevar a cabo cursos de formación continua como un medio para desarrollar más adecuadamente la competencia lingüística de los profesores; y, por otro, sugieren una readecuación de los programas de grado de formación docente de ELE, basada en las características específicas que implica aprender un idioma próximo. 
Palabras-clave: interferencia; lenguas próximas; análisis de errores; lingüística contrastiva; español lengua extranjera. 


\section{ABSTRACT}

In the field of language teaching and, more specifically, PortugueseSpanish context, we contemplate the difficulties for some students even in more advanced levels of knowledge of a foreign language in breaking away from the interferences of the mother tongue (L1). Such difficulties are broadly documented in studies in the area (ALMEIDA FILHO, 1995; ANDRADE NETA, 2000; CAMORLINGA, 2005; CELADA 2002, 2008; GANCEDO ÁLVAREZ, 2002; GOETTENAUER, 2005; SALINAS, 2005). For this reason, for Spanish teacher trainers in Brazil, there is a growing concern about the input that may be offered to students because of this intrinsic feature of learning similar languages. Therefore, in this doctoral thesis, we investigate the main characteristics of the oral speech of Spanish teachers as foreign a language in a group of teachers in the country's southern region. We had as main objective identifying at what extent the interference was present. The data was obtained through recordings of classes and oral interviews. The data analysis was based on the method of error analysis and contrastive linguistic through the contrast of different dictionaries, as well as the corpus linguistic. The nature of this research is quantitative and qualitative and seeks, in one hand, studying the frequency of errors and, on the other hand, describing and explaining the different types of lexical errors from an adaptation of the taxonomic model of Durão (2007). The results show that: (i) teachers have an interlanguage (SELINKER, 1974) characterized by a high rate of inter and intralinguistics errors; (ii) interlinguistics errors are more common than intralinguistics errors; (iii) in relation to the interlinguistic errors, lexical errors are more frequent and substitution errors prevail (direct and by analogy). From the pedagogical point of view, the conclusions of this study suggest, in one hand, the need of conducting continuous training courses to develop more adequately the linguistic competence of teachers; and, on the other hand, advise a readjustment of degree programs for teacher training, based on specific features that involves learning a language.

Key-words: interference; similar languages; error analysis; contrastive linguistic, Spanish as a foreign language. 



\section{RESUMO}

No campo do ensino das línguas próximas, e mais especificamente no caso português-espanhol, observamos a dificuldade por parte dos aprendizes, mesmo em níveis mais elevados de conhecimento da língua estrangeira, em se desprenderem de alguns aspectos específicos da interferência (DURÃO, 2008) da língua materna (LM), dificuldade amplamente documentada em estudos da área (ALMEIDA FILHO, 1995; ANDRADE NETA, 2000; CAMORLINGA, 2005; CELADA 2002, 2008; GANCEDO ÁLVAREZ, 2002; GOETTENAUER, 2005; SALINAS, 2005). Por esta razão, para os formadores de professores de espanhol no Brasil existe uma crescente preocupação sobre o insumo que pode ser oferecido aos alunos como resultado desta natureza intrínseca da aprendizagem das línguas próximas. Assim, na presente tese doutoral, investigamos quais são as principais características dos discursos orais que mostram os professores de espanhol como língua estrangeira de um grupo de professores de espanhol como língua estrangeira (ELE) da região sul do país, com o objetivo de identificar em que medida a interferência se fazia presente. Como objetivos gerais, tínhamos: a) averiguar se no discurso oral da população estudada, professores brasileiros de espanhol como língua estrangeira, se apresentavam erros de interferência da língua materna; b) verificar se os erros interlinguísticos eram mais frequentes que os intralinguísticos; c) explicar os erros interlinguísticos mais comuns. E, como objetivos específicos: a) identificar os erros inter e intralinguísticos; b) delimitar os erros interlinguísticos mais frequentes por categorias gramaticais; c) identificar os tipos de erros interlinguísticos de caráter léxicosemânticos e sua frequência; d) analisar contrastivamente os erros léxicos a fim de comprovar sua origem etiológica; e) comprovar de que maneira os diferentes dicionários especializados tratavam os erros de interferência léxica aqui analisados. A coleta de dados foi realizada através da gravação de aulas e entrevistas orais. Para a análise dos dados nos apoiamos no método de análise de erros e na linguística contrastiva mediante o contraste de diferentes obras lexicográficas, bem como na linguística de corpus. A natureza da pesquisa é quantitativa e qualitativa procurando, por um lado, estudar a frequência de erros e, por outro, descrevê-los e explicálos. Os resultados mostram que: (i) os professores apresentam uma interlíngua (SELINKER, 1974) caracterizada por uma elevada taxa de desvios tanto inter como intralinguísticos; (ii) os erros 
interlinguísticos são amplamente mais frequentes em comparação aos intralinguisticos; (iii) no caso de erros interlinguísticos, os desvios lexicais são os mais reiterados, e deles prevalecem os erros de substituição (direta e por analogia), seguido de valores muito menos expressivos de erros de criação de palavra nova e de calco. Do ponto de vista pedagógico, a discussão aponta, por um lado, para a necessidade do desenvolvimento de cursos de formação contínua com base nas dificuldades específicas do grupo estudado com o propósito de desenvolver a sua competência linguística, e, por outro, sugerem a necessidade de uma revisão dos programas político pedagógicos das licenciaturas de ELE a fim de fornecer o suporte linguístico necessário para o desenvolvimento da língua espanhola no qual se trabalhem as dificuldades específicas dos alunos brasileiros.

Palavras-chave: interferência; línguas próximas, análise de erros, linguística contrastiva, espanhol como língua estrangeira; 


\section{LISTA DE GRÁFICOS}

Gráfico 1: Porcentaje de investigaciones por niveles del análisis. 139 Gráfico 2: Distribución de las investigaciones por campo y grado. 140

Gráfico 3: Tipo de canales de producción de los corpus. 141

Gráfico 4: Investigaciones por titulación. 141

Gráfico 5: Evolución de los trabajos académicos a través de los años. 142

Gráfico 6: Uso de la LM en el contexto de recogida de datos 258

Gráfico 7: Uso de la LM según el contexto comunicativo. 259

Gráfico 8: Uso de la LM por sujeto. 263

Gráfico 9: Origen etiológico de los errores. 265

Gráfico 10: Número de errores por contexto de recogida..............266

Gráfico 11: Etiología de los errores por contexto de recogida.......267

Gráfico 12: Errores interlingüísticos gramaticales.........................268

Gráfico 13: Errores léxicos x otras categorías. ............................269

Gráfico 14: Tipos de errores léxicos y sus proporciones. ..............270

Gráfico 15: Totales de transferencias directas..............................273

Gráfico 16: Totales de errores de creación de palabra nueva.......367 



\section{LISTA DE TABLAS}

Tabla 1: Tipos de transferencia. Adaptado de Salazar (2006, p. 54-

57).

Tabla 2: Tipos de errores según diferentes criterios. ..................... 158

Tabla 3: Errores de tipo etiológico...............................................159

Tabla 4: Errores interlingüísticos. Adaptado de Durão (2007).......164

Tabla 5: Adaptación de los errores de sustitución de Durão (2007.

Tabla 6: Errores interlingüísticos analizados en nuestro estudio, adaptados de Durão (2007)...

Tabla 7: Errores de criterio gramatical. Adaptada de Corder (1973, apud DURÃO, 2007, p. 17)....................................................176

Tabla 8: Criterio lingüístico (CORDER, 1981b, p. 36)................... 179

Tabla 9: Grado de aceptabilidad y adecuación. Adaptada de Corder (1981b. p. 41).

Tabla 10: Errores de criterio pedagógico.

Tabla 11: Errores de criterio pedagógico (adaptado de Durão, 2007,

p. 18)

Tabla 12: Criterios y tipos de errores analizados en el estudio. ....186

Tabla 13: Interferencia vocablo "escreberon". 198

Tabla 14: Errores léxicos de interferencia considerados en nuestro estudio. 221

Tabla 15: Perfil de los sujetos I. .............................................226

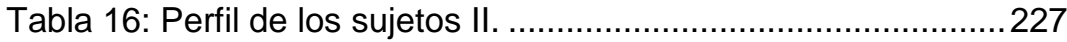

Tabla 17: Perfil de los sujetos III. ...............................................228

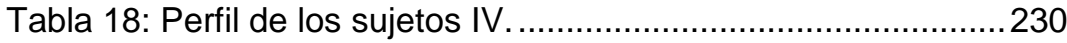

Tabla 19: Tiempo de clases grabadas por sujeto. .........................233

Tabla 20: Tiempo de entrevista grabada por sujeto........................234

Tabla 21: Totales de horas de grabación por sujeto......................235

Tabla 22: Total de palabras que constituyen el corpus..................236

Tabla 23: Tiempo x número de palabras de clases. .......................237

Tabla 24: Tiempo x número de palabras de entrevistas. ...............238

Tabla 25: Total de horas $x$ total de palabras.................................239

Tabla 26: Signos adoptados para la transcripción. ........................240

Tabla 27: Tipos de etiquetas uso LM. ...........................................243

Tabla 28: Signos utilizados en el banco de errores. ......................247

Tabla 29: Usos de la LM en clase...............................................260

Tabla 30: Uso de la LM en las entrevistas. ..................................262

Tabla 31: Número de errores x número de etiquetas. ....................264

Tabla 32: Totales de errores del estudio........................................265

Tabla 33: Tipos de errores interlingüísticos. ...............................268 
Tabla 34: Totales de errores léxicos por tipos...............................270

Tabla 35: Errores de sustitución directa de nexos y formas

periféricas.

Tabla 36: Errores de substitución directa de verbos formalmente similares

Tabla 37: Errores de substitución directa de verbos formalmente disímiles.

Tabla 38: Verbos irregulares en ambas lenguas.

282

Tabla 39: Verbos regulares en portugués e irregulares en español.

Tabla 40: Verbos regulares en ambas lenguas. 283

Tabla 41: Errores de substitución directa de vocabulario

Tabla 42: Errores de substitución directa de adverbios. ................290

Tabla 43: Errores de substitución directa de pronombres..............291

Tabla 44: Errores de substitución directa de determinantes. .........293

Tabla 45: Determinantes masculinos portugués x español............294

Tabla 46: Otros errores de analogía...........................................296

Tabla 47: Errores de producción por analogía. .............................298

Tabla 48: Errores por analogía, grupo I......................................300

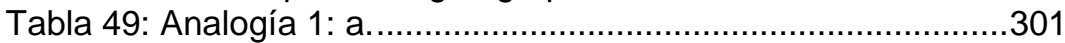

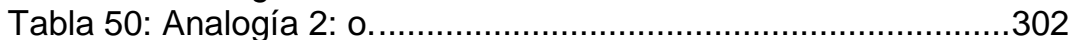

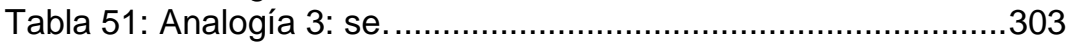

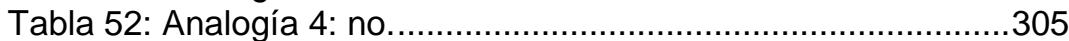

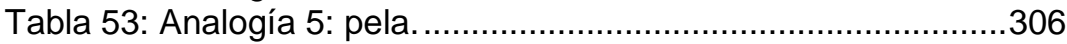

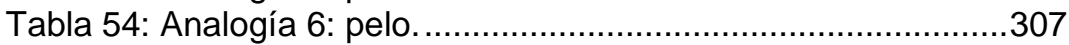

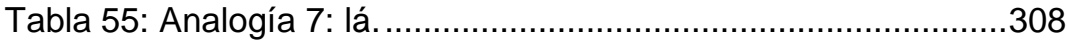

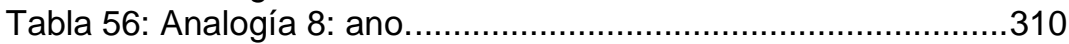

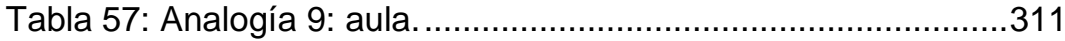

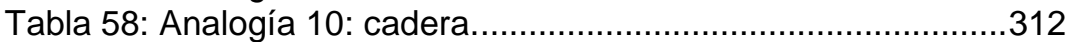

Tabla 59: Analogía 11: legenda................................................313

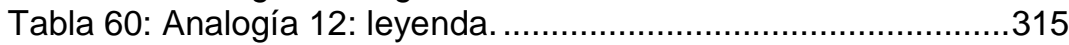

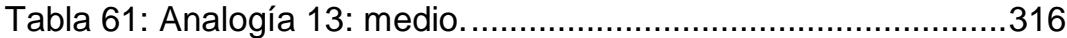

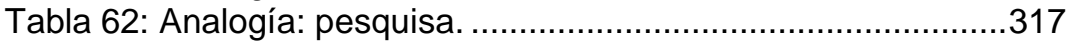

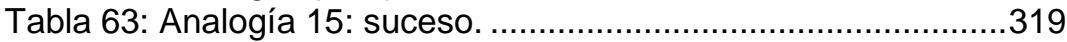

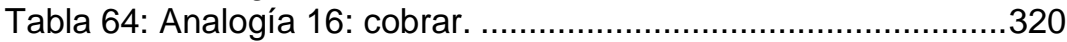

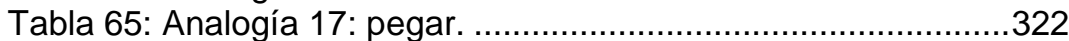

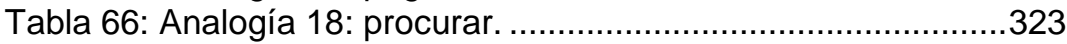

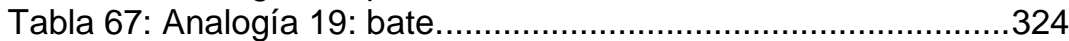

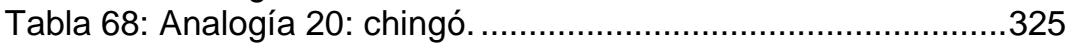

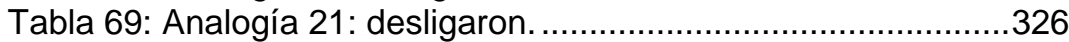

Tabla 70: Analogía 22: viró...........................................................328

Tabla 71: Errores por analogía, grupo II.....................................329

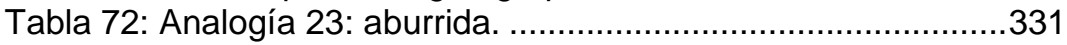


Tabla 73: Analogía 24: prontos. ………………………................333

Tabla 74: Analogía 25: mismo.....................................................336

Tabla 75: Analogía 26: cedo. ………………………………......338

Tabla 76: Analogía 27: dupla. ......................................................340

Tabla 77: Analogía 28: escrita........................................................34

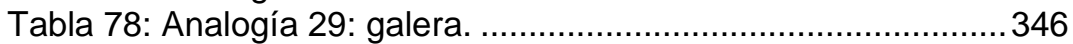

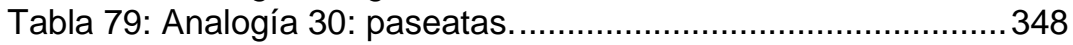

Tabla 80: Analogía 31: pronuncia. …………………………........349

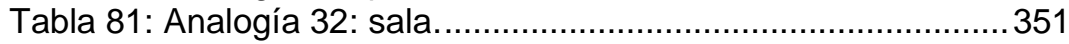

Tabla 82: Analogía 33: serie. .....................................................353

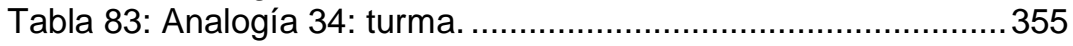

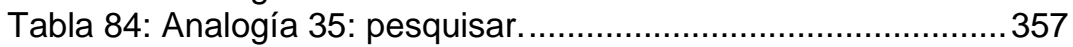

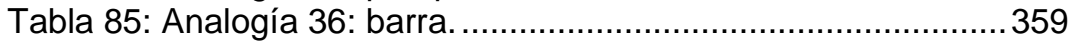

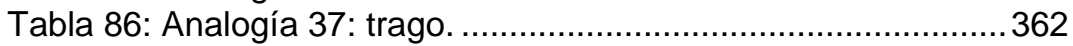

Tabla 87: Analogía 38: período..................................................... 365

Tabla 88: Errores de creación de palabra nueva por creación

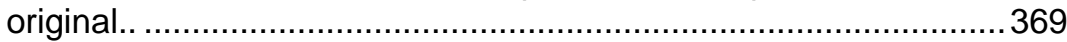

Tabla 89: Creación original por confusión con el lexema o su flexión: llove.

Tabla 90: Creación original por confusión con el lexema o su flexión: dicer.

Tabla 91: Creación original por confusión con el lexema o su flexión: escreber. 371

Tabla 92: Creación original por confusión con el lexema o su flexión: escreberon. 371

Tabla 93: Creación original por confusión con el lexema o su flexión: corregindo. 372

Tabla 94: Creación original por confusión con el lexema o su flexión: oindo. 372

Tabla 95: Creación original por confusión con el lexema o su flexión:

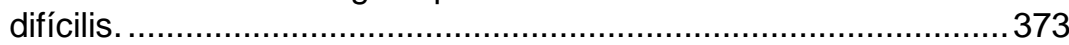
Tabla 96: Creación original por derivación: dificuldad. ....................374 Tabla 97: Creación original por palabra primitiva: entón..................375 Tabla 98 : Errores de creación original por traducción prestada. ..377 Tabla 99: Traducción prestada por confusión con la base, el tema o su flexión. 378

Tabla 100: Traducción prestada por confusión con la base, el tema o su flexión: faleció y pedió. 378

Tabla 101: Traducción prestada por confusión con la base, el tema o su flexión: levé. 379

Tabla 102: Traducción prestada por confusión con la base, el tema o su flexión: demonstrarles. 
Tabla 103: Traducción prestada por flexión - realización de diptongo. 380

Tabla 104: Traducción prestada por flexión - realización de diptongo: abriron. 381

Tabla 105: Traducción prestada por flexión - realización de diptongo: comprenderon, deron, entenderon. 382

Tabla 106: Traducción prestada por base portuguesa y derivación española I. 383

Tabla 107: Traducción prestada por base portuguesa y derivación española: antecipación y questión. 384

Tabla 108: Traducción prestada por base portuguesa y derivación española aprofundizar, estabelecimiento, linguaje, solenidad y aquisición. 386

Tabla 109: Traducción prestada por base portuguesa y derivación española: satisfación, producción, interación. 388

Tabla 110: Traducción prestada de palabra primitiva. 388

Tabla 111: Traducción prestada de palabra primitiva: vontad y ciudade. 389

Tabla 112: Traducción prestada de palabra primitiva: doncela......390

Tabla 113: Traducción prestada por composición: trabalinguas....391

Tabla 114: Errores de calco. 393

Tabla 115: Calco 1: En la hora. 395

Tabla 116: Calco 2: En una buena...............................................397

Tabla 117: Calco 3: Un monte. 399

Tabla 118: Calco 4: Encima de..................................................402

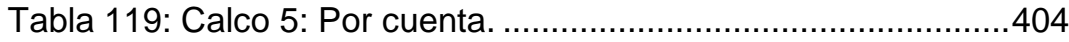

Tabla 120: Calco 6: Por extenso. .................................................405

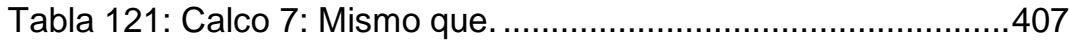

Tabla 122: Calco 8: Misma cosa. ..................................................409

Tabla 123: Calco 9: Mismo así. ...................................................410

Tabla 124: Calco 10: Hacer la llamada. ........................................412

Tabla 125: Calco 11: Dar una miradita..........................................414

Tabla 126: Calco 12: Sentir falta. ................................................416

Tabla 127: Calco 13: A cata. .........................................................419

Tabla 128: Calco 14: Consejo de clase.....................................421 


\section{LISTA DE FIGURAS}

Ilustración 1: Modelo de Competencia Comunicativa de Canale (1983). 


$A C$ - Análisis Contrastivo
AE - Análisis de Errores
El - Expresiones idiomáticas
ELE - Español Lengua Extranjera
FA - Falsos Amigos
FC - Falsos Cognados
GU - Gramática Universal
HN - Hablante Nativo
HNN - Hablante No Nativo
$\mathrm{IL}$ - Interlengua
LAD - Language Adquisition Device
LC - Lingüística Contrastiva
LE - Lengua Extranjera
LM - Lengua Materna
LO - Lengua Objeto
L1 - Primela Lengua/Lengua Materna
L2 - Segunda Lengua
PB - Portugués Brasileño
UF - Unidades Fraseológicas 

0. INTRODUCCIÓN. 41

0.1 OBJETIVOS DE LA INVESTIGACIÓN …………............................. 44

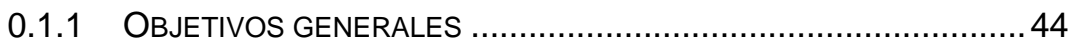

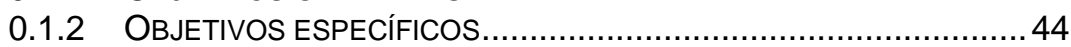

0.2 ¿POR QUÉ ESTUDIAR LA INTERFERENCIA EN EL DISCURSO ORAL DE

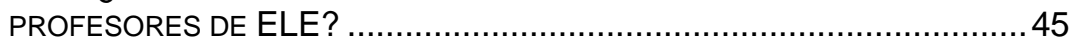

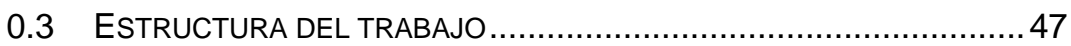

\section{Apartado I: Planteamientos teóricos}

\section{PRINCIPIOS SOBRE EL APRENDIZAJE DE LENGUAS}

EXTRANJERAS.

1.1. LA GRAMÁTICA UNIVERSAL Y EL APRENDIZAJE DE LE POR ADULTOS.

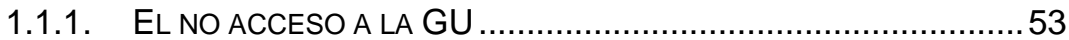

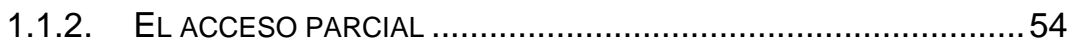

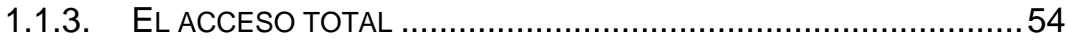

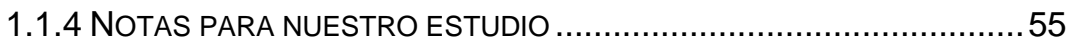

1.2 LA HIPÓTESIS DEL "INPUT"..............................................56

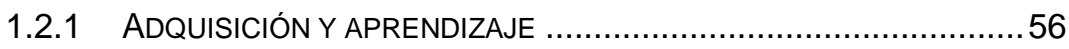

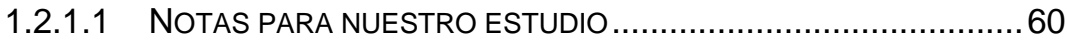

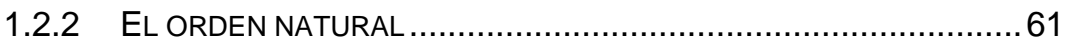

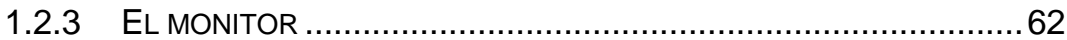

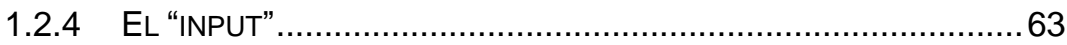

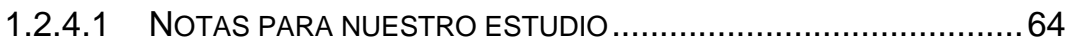

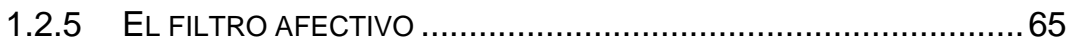

1.2.5.1 NOTAS PARA NUESTRO ESTUDIO .......................................66

1.3 EL BILINGÜISMO Y LAS COMPETENCIAS DEL HABLANTE

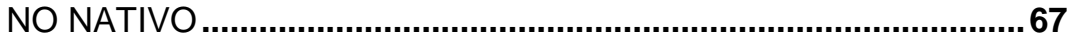

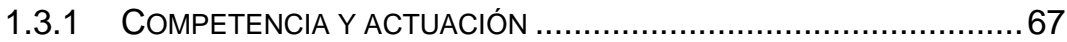

1.3.2 COMPETENCIA LINGÜÍSTICA Y COMPETENCIA COMUNICATIVA ......68

1.3.3 EL MODELO DE COMPETENCIA COMUNICATIVA DE CANALE (1983) .

1.3.3.1 NOTAS PARA NUESTRO ESTUDIO .......................................73

1.3.4 EL HABLANTE NO NATIVO: BILINGÜISMO Y COMPETENCIAS ..........73

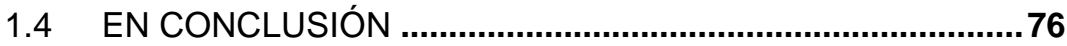

2. LA TRANSFERENCIA Y EL SISTEMA LINGÜÍSTICO NO NATIVO 
2.2 UN RECORRIDO HISTÓRICO DESDE LA PERSPECTIVA

DE LA TRANSFERENCIA LINGÜÍSTICA: DEL ANÁLISIS CONTRASTIVO AL ANÁLISIS DE ERRORES .

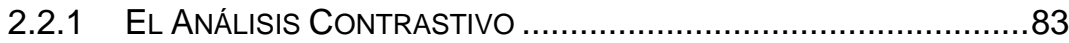

2.2.2 EL ANÁLISIS DE ERRORES ..................................................87

2.2.3 DE LA VERSIÓN DÉBIL A LA VERSIÓN FUERTE DEL ANÁLISIS

CONTRASTIVO: ¿SE PUEDEN FUNDIR EL AC Y EL AE? .........................91

2.2.4 NOTAS PARA NUESTRO ESTUDIO ........................................94

2.3 LA INTERFERENCIA LINGÜÍSTICA: ALGUNAS

CONSIDERACIONES TERMINOLÓGICAS ...................................95

2.3.1 NOTAS PARA NUESTRO ESTUDIO ............................................99

2.4 LA INTERLENGUA ...........................................................100

2.4.1 NOTAS PARA NUESTRO ESTUDIO .......................................102

2.4.2 CARACTERÍSTICAS DE LA INTERLENGUA..............................102

2.4.2.1 NOTAS PARA NUESTRO ESTUDIO ....................................105

2.5 LA FOSILIZACIÓN .............................................................109

2.5.1 ORÍGENES DE LA FOSILIZACIÓN ......................................111

2.5.1.1 NOTAS PARA NUESTRO ESTUDIO ....................................115

2.5.2 LA INVESTIGACIÓN DE LA INTERLENGUA Y DE LA FOSILIZACIÓN:

PROBLEMAS TEÓRICOS, METODOLÓGICOS Y NUEVAS PERSPECTIVAS....116

2.6 EN CONCLUSIÓN.........................................................118

3. INTERFERENCIA Y LENGUAS PRÓXIMAS: EL CASO PORTUGUÉS/ESPAÑOL

3.1 INTERFERENCIA Y APRENDIZAJE DE LENGUAS

PRÓXIMAS

3.2 LA PROXIMIDAD INTERLINGÜÍSTICA PORTUGUÉS-

ESPAÑOL: ¿FACILITADORA O DIFICULTADORA DEL

APRENDIZAJE?

3.3 TRAMPAS Y CREENCIAS EN TORNO A LA SIMILITUD: UN BREVE RECORRIDO HISTÓRICO.

3.4 CERCANÍA LINGÜÍSTICA Y FORMACIÓN DE

PROFESORES DE ELE

3.5 UNA REVISIÓN BIBLIOGRÁFICA SOBRE LA

INTERFERENCIA DEL PORTUGUÉS BRASILEÑO (PB) EN EL ESPAÑOL COMO LENGUA EXTRANJERA.

3.5.1 ACERCA DE LOS CAMPOS DE ESTUDIO DE LA INTERFERENCIA...139

3.5.1.1 NOTAS PARA NUESTRO ESTUDIO

3.5.2 TRABAJOS PIONEROS EN EL ANÁLISIS DE ERRORES DEL ESPAÑOL

COMO LENGUA EXTRANJERA

3.6 PERSPECTIVAS FUTURAS PARA LA ENSEÑANZA DE ELE

EN BRASIL 
4. HACIA UNA DELIMITACIÓN Y CATEGORIZACIÓN DEL ERROR.

4.1 CARACTERIZACIÓN DEL ERROR ......................................151

4.1.1 ERROR, EQUIVOCACIÓN Y FALTA ....................................... 154

4.1.1.1 NOTAS PARA NUESTRO ESTUDIO .................................. 157

4.2 HACIA UN MODELO DE CLASIFICACIÓN DE ERRORES......

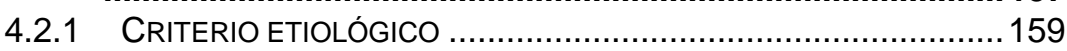

4.2.1.1 ERRORES INTRALINGUALES E INTERLINGUALES................... 159

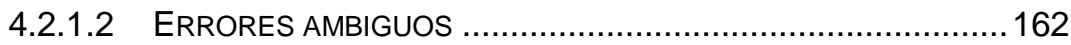

4.2.1.3 TIPOS DE ERRORES INTERLINGUALES ...............................163

4.2.1.3.1 Errores de producción .............................................. 164

4.2.1.3.2 Errores de subproducción ..........................................168

4.2.1.3.3 Errores de superproducción ......................................170

4.2.1.3.4 Errores por mala interpretación ................................... 171

4.2.1.3.5 Errores por hipercorrección........................................172

4.2.1.4 CLASIFICACIÓN DE LOS ERRORES INTERLINGUALES APLICADOS A NUESTRO ESTUDIO .................................................................. 173

4.2.1.5 ORIGEN DE LOS ERRORES INTERLINGUALES ......................174

4.2.2 CRITERIOS GRAMATICAL Y LINGÜÍSTICO...............................175

4.2.2.1 ACEPTABILIDAD Y ADECUACIÓN APLICADAS A NUESTRO ESTUDIO

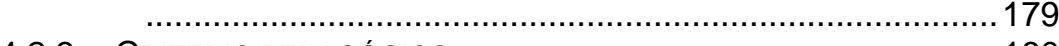

4.2.3 CRITERIO PEDAGÓGICO........................................................ 180

4.2.3.1 NOTAS PARA NUESTRO ESTUDIO ................................... 182

4.2.4 CRITERIO COMUNICATIVO .................................................. 183

4.2.4.1 NOTAS PARA NUESTRO ESTUDIO ..................................... 184

4.3 EN CONCLUSIÓN ..........................................................185

4.3.1 ALGUNAS CONSIDERACIONES ADICIONALES SOBRE LOS ERRORES

DE NUESTRO ESTUDIO ................................................................ 187

4.3.1.1 ERRORES VISIBLES VERSUS OCULTOS..............................187

4.3.1.2 RECONSTRUCCIÓN AUTORIZADA VERSUS PLAUSIBLE.............188

4.3.1.3 EL PAPEL DE LA INTERPRETACIÓN ....................................190

5. ALGUNAS CUESTIONES TEÓRICAS SOBRE EL LÉXICO APLICADAS A NUESTRO ESTUDIO ..........................................193

5.1 INTRODUCCIÓN .............................................................193

5.2 FORMACIÓN DE PALABRAS ...........................................195

5.2.1 NOTAS PARA NUESTRO ESTUDIO ....................................... 198

5.3 FALSOS AMIGOS, FALSOS COGNADOS, HETEROSEMÁNTICOS..............................................................199 
5.3.2 UN POCO DE HISTORIA: EL ORIGEN DE LA CONFUSIÓN

TERMINOLÓGICA ......................................................................203

5.3.3 NOTAS PARA NUESTRO ESTUDIO .......................................207

5.4 UNIDADES FRASEOLÓGICAS .......................................209

5.4.1 LA FRASEOLOGÍA Y EL FRASEOLOGISMO ..............................209

5.4 .2 LAS EXPRESIONES IDIOMÁTICAS ......................................212

5.4.2.1 ENSEÑANZA Y APRENDIZAJE DE LAS UNIDADES FRASEOLÓGICAS

EN

5.5 EN CONCLUSIÓN..........................................................219

Apartado II: análisis de la interlengua

6. ASPECTOS METODOLÓGICOS ........................................223

6.1 METODOLOGÍA DEL ANÁLISIS DE ERRORES..................223

6.2 POBLACIÓN.........................................................................225

6.2.1 PERFIL SOCIOLÓGICO, FORMATIVO Y PROFESIONAL.................226

6.3 EL CORPUS ....................................................................230

6.3.1 COMPILACIÓN DEL CORPUS ............................................230

6.3.1.1 LA RECOLECCIÓN DE DATOS ........................................231

6.3.1.2 TIEMPOS DE GRABACIÓN ............................................232

6.3.1.3 LONGITUD DE LAS MUESTRAS......................................235

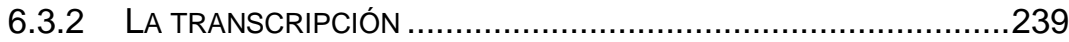

6.3.2.1 CONVENCIONES DE LA TRANSCRIPCIÓN ..............................239

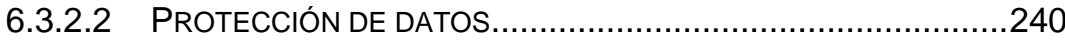

6.3.2.3 PECULIARIDADES SOBRE LAS TRANSCRIPCIONES EN NUESTRO

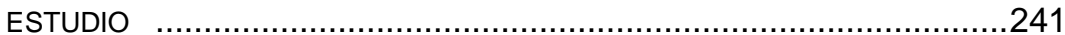

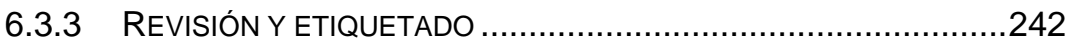

6.3.4 EL ACCESO ............................................................244

6.4 IDENTIFICACIÓN, CLASIFICACIÓN Y DESCRIPCIÓN DE LOS ERRORES ......................................................................245

6.4.1 IDENTIFICACIÓN ...........................................................245

6.4.2 CLASIFICACIÓN Y DESCRIPCIÓN Y DE LOS ERRORES ................245

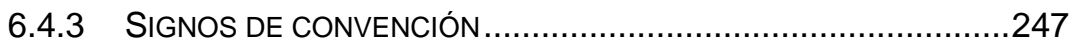

6.4.4 VARIEDADES LINGÜÍSTICAS ............................................248

6.5 OBRAS LEXICOGRÁFICAS ............................................250

6.5.1 DICCIONARIOS MONOLINGÜES.........................................250

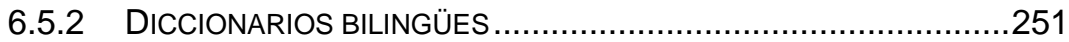

6.5.3 DICCIONARIOS DE HETEROSEMÁNTICOS .............................253

6.5.4 DICCIONARIOS DE LOCUCIONES .......................................255

7. RESULTADOS ......................................................................257 
7.1 DATOS GENERALES ..........................................................257

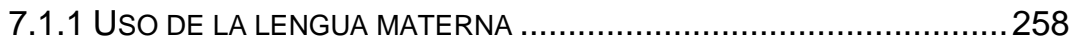

7.1.2 VALORES TOTALES ENCONTRADOS .......................................264

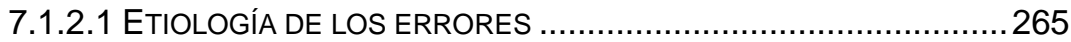

7.1.2.2 ERRORES POR CONTEXTO DE RECOGIDA ............................266

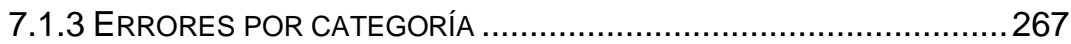

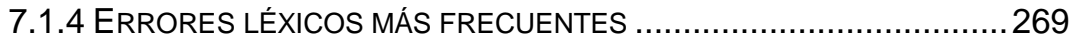

7.1.4.1 TIPOS DE ERRORES LÉXICOS ..........................................269

7.2 CLASIFICACIÓN Y ANÁLISIS DE LOS ERRORES LÉXICOS 271

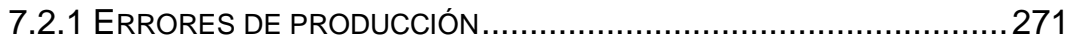

7.2.1.1 ERRORES DE SUSTITUCIÓN............................................272

7.2.1.1.1 Errores de sustitución directa......................................272

7.2.1.1.1.1 Nexos y formas periféricas ..................................274

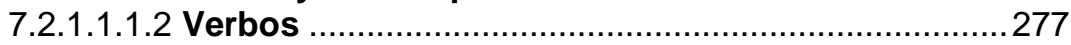

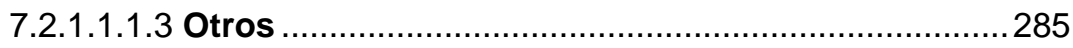

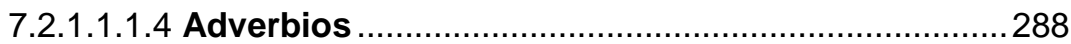

7.2.1.1.1.5 Pronombres ..................................................... 291

7.2.1.1.1.6 Determinantes......................................................292

7.2.1.1.2 Errores de sustitución por analogía...............................295

7.2.1.1.2.1 Errores explicados por medio de diccionarios

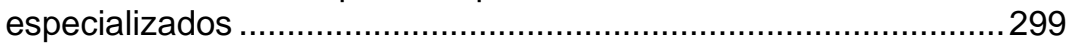

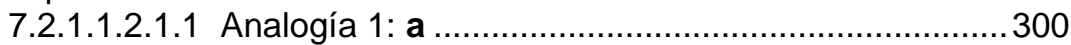

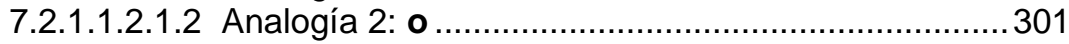

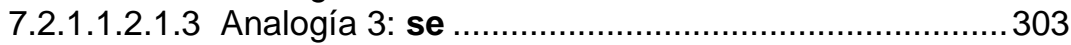

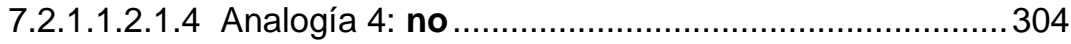

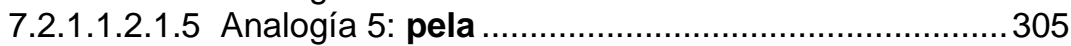

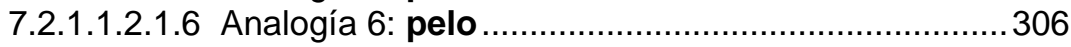

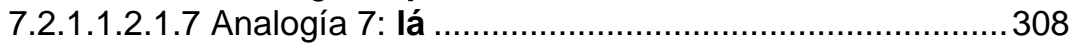

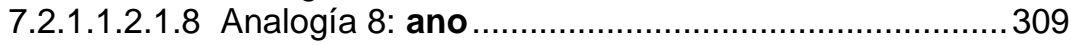

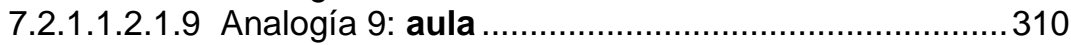

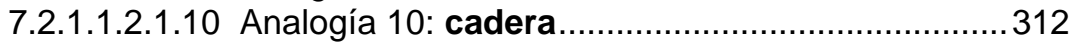

7.2.1.1.2.1.11 Analogía 11: legenda........................................ 313

7.2.1.1.2.1.12 Analogía 12: leyenda ........................................314

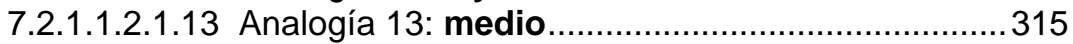

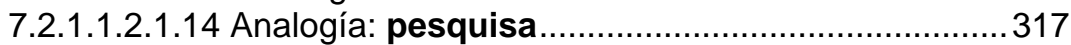

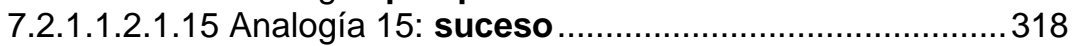

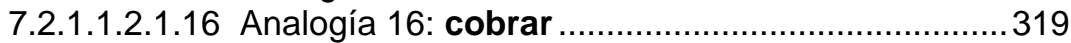

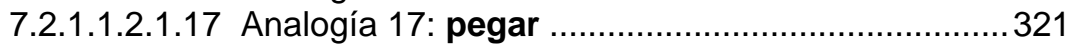

7.2.1.1.2.1.18 Analogía 18: procurar ......................................... 323

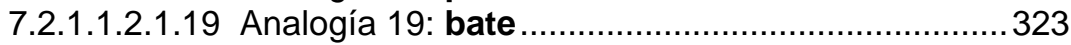

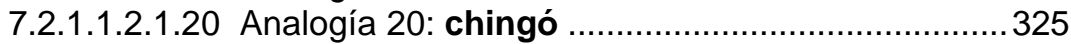

7.2.1.1.2.1.21 Analogía 21: desligaron ..................................... 326 
7.2.1.1.2.1.22 Analogía 22: viró ...............................................327

7.2.1.1.2.2 Errores explicados por medio de otros diccionarios....328

7.2.1.1.2.2.1 Analogía 23: aburrida ..........................................329

7.2.1.1.2.2.2 Analogía 24: prontos .........................................332

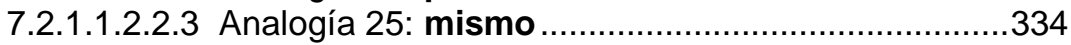

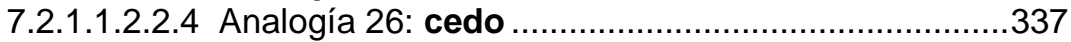

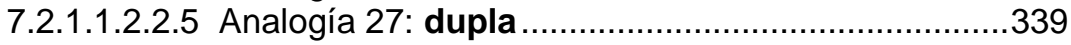

7.2.1.1.2.2.6 Analogía 28: escrita ..........................................340

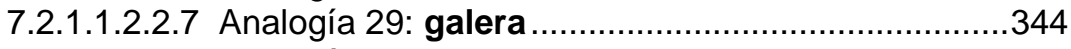

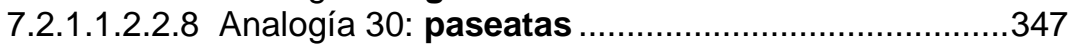

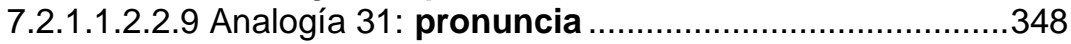

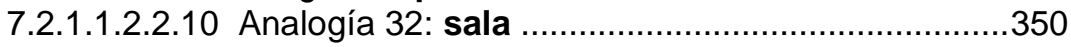

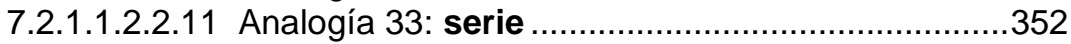

7.2.1.1.2.2.12 Analogía 34: turma .........................................354

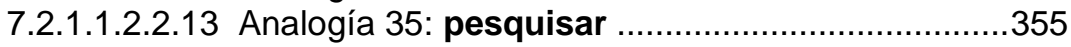

7.2.1.1.2.2.14 Analogía 36: barra ...........................................358

7.2.1.1.2.2.15 Analogía 37: trago ............................................360

7.2.1.1.2.3 Errores explicados por medio de otras fuentes............362

7.2.1.1.2.3.1 Analogía 38: período ...............................................363

7.2.1.2 ERRORES POR CREACIÓN DE PALABRA NUEVA........................366

7.2.1.2.1 Errores de creación de palabra nueva por creación original

368

7.2.1.2.1.1 Creación original por confusión con el lexema o su flexión

.

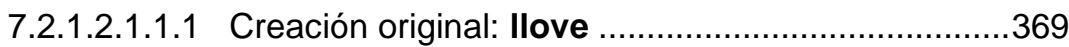

7.2.1.2.1.1.2 Creación original: dicer ........................................370

7.2.1.2.1.1.3 Creación original: escreber..................................370

7.2.1.2.1.1.4 Creación original: escreberon ...............................371

7.2.1.2.1.1.5 Creación original: corregindo ...............................371

7.2.1.2.1.1.6 Creación original: oindo .....................................372

7.2.1.2.1.1.7 Creación original: difícilis ....................................373

7.2.1.2.1.2 Creación original por derivación .................................373

7.2.1.2.1.2.1 Creación original: dificuldad..................................373

7.2.1.2.1.3 Creación original de palabra primitiva ..........................374

7.2.1.2.1.3.1 Creación original: entón ........................................374

7.2.1.2.2 Errores de creación de palabra nueva por traducción

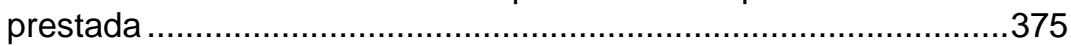

7.2.1.2.2.1 Traducción prestada por base portuguesa y flexión

española ................................................................................377

7.2.1.2.2.1.1 Traducción prestada por confusión con la base, el tema

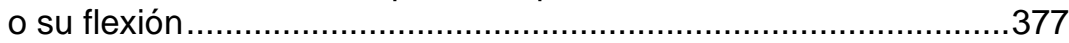

7.2.1.2.2.1.1.1 Traducción prestada: faleció y pedió....................378

7.2.1.2.2.1.1.2 Traducción prestada: levé....................................379 
7.2.1.2.2.1.1.3 Traducción prestada: demonstrarles.

7.2.1.2.2.1.2 Traducción prestada por flexión - realización de diptongo.

7.2.1.2.1.2.1 Traducción prestada: abriron

380

7.2.1.2.2.1.2.2 Traducción prestada: comprenderon, deron, entenderon

7.2.1.2.2.2 Traducción prestada por base portuguesa y derivación

española 382

7.2.1.2.2.2.1 Traducción prestada: antecipación y questión .....383

7.2.1.2.2.2.2 Traducción prestada: aprofundizar,

estabelecimiento, linguaje, solenidad y aquisición 385

7.2.1.2.2.2.3 Traducción prestada: satisfación, produción, interación.

7.2.1.2.2.3. Traducción prestada de palabra primitiva. 388

7.2.1.2.2.3.1 Traducción prestada: vontad y ciudade 388

7.2.1.2.2.3.2 Traducción prestada: doncela 390

7.2.1.2.2.4 Traducción prestada por composición 390

7.2.1.2.2.4.1 Traducción prestada: trabalinguas 390

7.2.1.3 ERRORES DE CALCO. 391

7.2.1.3.1 Calco 1: En la hora 393

7.2.1.3.2 Calco 2: En una buena 396

7.2.1.3.3 Calco 3: Un monte. 398

7.2.1.3.4 Calco 4: Encima de 400

7.2.1.3.5 Calco 5: Por cuenta 403

7.2.1.3.6 Calco 6: Por extenso 405

7.2.1.3.7 Calco 7: Mismo que 406

7.2.1.3.8 Calco 8: Misma cosa 408

7.2.1.3.9 Calco 9: Mismo así 410

7.2.1.3.10 Calco 10: Hacer la llamada

7.2.1.3.11 Calco 11: Dar una miradita 413

7.2.1.3.12 Calco 12: Sentir falta 415

7.2.1.3.13 Calco 13: A cata 417

7.2.1.3.14 Calco 14: Consejo de clase 419 


\section{ALGUNAS CONCLUSIONES Y CONSIDERACIONES}

FINALES.

8.1. NUESTRAS HIPÓTESIS Y OBJETIVOS

8.2. LIMITACIONES DEL ESTUDIO

8.3. CONSIDERACIONES FINALES SOBRE LA FORMACIÓN DE

PROFESORES DE ELE

BIBLIOGRAFÍA

ANEXOS

1. PROGRAMA DE ASIGNATURAS DEL GRADO:

LICENCIATURA EM LINNGUA ESTRANGEIRA - ESPANHOL 459

2. MODELO DE TÉRMINOS DE COMPROMISO

3. TRANSCRIPCIÓN DE LAS CLASES.

4. TRANSCRIPCIÓN DE LAS ENTREVISTAS 459

5. GUÍA PARA LAS ENTREVISTAS 459

6. BANCO DE ERRORES GRAMATICALES 459

7. BANCO DE ERRORES LÉXICOS 459

8. LISTA DE TESIS Y DISERTACIONES REVISADAS EN EL APARTADO 3.5 


\section{INTRODUCCIÓN}

Como aprendiz de español como lengua extranjera (ELE), y luego en calidad de profesora de esta misma lengua, siempre nos llamó la atención la influencia que la lengua materna (LM) ejercía sobre el conocimiento de la lengua objeto (LO). De esta manera, la inclinación a investigar los aspectos referentes a la interferencia lingüística de una a otra lengua apareció muy pronto entre nuestros intereses académicos y científicos, motivada por la observación repetida de este fenómeno, tanto en el uso del idioma en contextos de inmersión como en su enseñanza en contextos más formales. Más concretamente, podríamos decir que el presente estudio nació por dos razones muy específicas: una personal y otra profesional.

La razón personal surge a partir de nuestra propia experiencia con la inmersión lingüística. Durante nuestros años de residencia en España, nos dimos cuenta de que, aunque tuviéramos un nivel alto de competencia en la LO y llevásemos varios años utilizando la lengua española (e, incluso hubiésemos suprimido prácticamente el uso del portugués en el período que vivimos allá), había errores que se nos "escapaban" y la mayoría de ellos tenían como causa principal la influencia de nuestro portugués nativo. A partir de ahí, observando nuestra propia interlengua, y, posteriormente, las interlenguas de otros sujetos brasileños usuarios del español como lengua extranjera residentes en aquel país, nos percatamos de que esta no era una característica exclusivamente personal, sino más bien recurrente entre los hablantes no nativos (HNN), con independencia de su grado de conocimiento lingüístico.

Así, el germen del presente estudio nació de una manera intuitiva, a raíz de una situación particular muy concreta de la investigadora, y fue tomando forma gradualmente según íbamos observando con más atención la incidencia de este fenómeno, aunque al principio de una manera informal. Ahora bien, nuestra situación era la de un contexto de inmersión completa en la lengua de destino, en el cual el idioma extranjero (para nosotros) se convertía prácticamente en el único vehículo de comunicación cotidiano. Así que, pensamos: si esto sucede en las situaciones más propicias para el aprendizaje de una segunda lengua ¿qué podemos encontrar en contextos ajenos a la inmersión como los que caracterizan normalmente a la enseñanza formal de la lengua?

De esta manera, dado que, durante nuestra estancia en España, perfeccionábamos nuestra preparación como formadores 
de profesores de ELE, nos pareció interesante profundizar sobre la manera en que la LM podría influir en la interlengua (IL) de aquellos individuos que ya habían concluido el grado de formación docente, es decir, los profesores de ELE que aprendieron el idioma en una situación formal, diferente, pues, al contexto más natural de la inmersión lingüística.

Ya de vuelta en Brasil, y en calidad de formadora de profesores de español como lengua extranjera en la Universidade Federal de Sergipe, pudimos comprobar in locuo cómo incluso los alumnos de niveles más avanzados mostraban numerosas dificultades relacionadas con la influencia de la LM. Este hecho acabó por convencernos de que un estudio como el presente podría tener interés no solo para nuestra propia labor como formadora de enseñantes de lengua española, sino, en general también, para esta área de la lingüística aplicada.

En las fases iniciales del trabajo, al revisar los estudios previos sobre este ámbito temático, nos percatamos de dos datos: (i) aunque el análisis de la interlengua de aprendices de español en Brasil hubiera sido bastante fructífera, y hubiese dado un número considerable de trabajos académicos sobre interferencias fonéticas, gramaticales o léxicas, prácticamente no había estudios que analizaran la interlengua de los docentes de español en ejercicio y, menos aún, que cuantificasen y comparasen la incidencia de errores inter e intralingüísticos de aprendices brasileños de español; (ii) algunos teóricos defendían que el porcentaje de errores de interferencias era prácticamente insignificante en comparación con otros tipos.

Respecto a este último aspecto, los datos encontrados en la bibliografía resultaban desalentadores y parecían ir en contra de nuestras intuiciones iniciales. Y es que la mayoría de ellos afirmaba que los errores interlinguales son menos frecuentes que los intralinguales. No obstante, nos dimos cuenta de que, por un lado, la mayoría de estos estudios se llevaron a cabo con aprendices de lenguas lejanas como podemos observar en: Hanania y Grandman (1977) árabe-inglés (lengua de partida-lengua de llegada); d'Anglejan y Tucker (1975) francés-inglés; Valdman (1975) inglésfrancés; Scott y Tucker (1974) árabe-inglés (estudios citados en DULAY ET AL., 1982). Y, por otro lado, la principal investigación que cuestionó la relevancia de los errores interlinguales, el conocido estudio de 1974 de Dulay y Burt (apud DULAY ET AL., 1982) se realizó con niños, que además eran también aprendices de lenguas lejanas (los investigadores analizaron una media de 500 errores 
cometidos por 179 niños de habla hispana aprendices de inglés, obteniendo tan solo $5 \%$ de este tipo de errores).

En resumen, tales estudios se dedicaban a lenguas distantes y/o al aprendizaje de LE por parte de los niños, por lo que sus resultados no tenían que ser necesariamente idénticos a los nuestros, ya que nuestro interés se dirigía hacia la investigación de lenguas mucho más próximas entre sí, y, además, en el habla de los adultos.

Además, por nuestra experiencia personal y profesional, intuíamos que la interferencia de la LM jugaba un importante papel, tanto en la cantidad como en la variedad de los errores de los hablantes no nativos. De ahí que pensáramos que podríamos transformar aquellas intuiciones personales iniciales en un proyecto que pudiera contribuir a nuestra labor en la formación docente.

Decidimos entonces transformar esta preocupación personal y profesional, hasta entonces puramente intuitiva, en un proyecto de investigación científica: el trabajo de tesis doctoral que se presenta en estas páginas. Nuestra hipótesis era que la interferencia representaba una de las principales causas explicativas de los numerosos errores hallados en el habla de las docentes, y que los diferentes tipos de esta encontrados en el corpus podrían ser sistemáticos, puesto que los componentes de la muestra tenían una misma LM y partían de una formación inicial similar.

De este modo, nos proponíamos averiguar en qué medida se presentan signos de interferencia de la lengua materna en el discurso oral de profesores brasileños de español como lengua extranjera. Teníamos interés en identificar y explicar los errores, así como reconocer qué tipos eran más frecuentes en el marco de las diferentes subcompetencias: fonética, gramatical y léxico-semántica. También, delimitaríamos qué tipos de errores eran más frecuentes en relación con el criterio etiológico, es decir, intra o interlingüísticos ${ }^{1}$. Sin embargo, tras la recogida de datos, derivada del trabajo de campo correspondiente (véase Capítulo 6), algunos hechos nos llevaron a modificar levemente algunos aspectos de la investigación.

\footnotetext{
${ }^{1}$ Para ello, en un principio, además de las grabaciones, pensamos diseñar un cuestionario en el que se pudiera reflejar el conocimiento gramatical de las docentes, el cual al final no lo llevamos a cabo, debido a que el volumen de datos de las grabaciones ya era lo suficiente extenso para nuestra investigación.
} 


\subsection{Objetivos de la investigación}

En efecto, una vez llevada a cabo la recogida de los datos e identificados los principales errores, nos topamos con algunos obstáculos importantes. El primero de ellos, y, probablemente, el más importante, fue que el volumen de errores encontrado en el corpus resultó ser muy superior a lo que esperábamos inicialmente $y$, en todo caso, a aquello que podríamos tratar de manera realista en una tesis doctoral. Ello nos obligó a tomar algunas decisiones con el fin de limitar de manera coherente un trabajo de estas características. Como consecuencia de ello, en el presente estudio realizamos un análisis exhaustivo de un grupo específico de errores, los de carácter léxico-semántico, por ser estos los más frecuentes.

\subsubsection{Objetivos generales}

Con base en lo antedicho, hemos alterado en parte los objetivos del estudio. El nuevo propósito tenía como función analizar la interferencia incidente en la interlengua de los profesores de lengua española, y por tanto pretendíamos: a) averiguar si en el discurso oral de la población estudiada, profesores brasileños de español como lengua extranjera, se presentaban errores de interferencia de la lengua materna; b) verificar si los errores interlingüísticos eran más frecuentes que los intralingüísticos; c) explicar los errores interlingüísticos más comunes.

\subsubsection{Objetivos específicos}

Para llegar a los objetivos generales necesitábamos alcanzar una serie de objetivos más específicos, como:

a) Identificar los errores inter e intralingüísticos;

b) Delimitar los errores interlingüísticos más frecuentes por categorías gramaticales;

c) Identificar los tipos de errores interlingüísticos de carácter léxico-semánticos y su frecuencia;

d) Analizar contrastivamente los errores léxicos a fin de comprobar su origen etiológico;

e) Comprobar de qué manera los diferentes diccionarios especializados trataban los errores de interferencia léxica aquí analizados. 


\section{2 ¿Por qué estudiar la interferencia en el discurso oral de profesores de ELE?}

Además de los motivos comentados anteriormente, hay otros que se suman al interés por estudiar la interferencia en el discurso de los profesores de lengua española. Estos tienen que ver con la expansión de los grados de formación de profesores en Brasil. $Y$ es que, con motivo de la promulgación de la Ley $11.161 / 2005$, recientemente derogada por la MP $746 / 16^{2}$, y que obligaba a los centros de enseñanza a ofrecer la asignatura de lengua española en la enseñanza media como materia de libre elección para los alumnos, los grados de formación de profesores experimentaron un incremento de estudiantes nunca visto con anterioridad. Por otro lado, algunos investigadores y formadores con amplia experiencia, como Paraquett (2009), han alertado sobre la práctica inexistencia de estudios que revisen cómo están compuestos esos grados y cómo se está llevando a cabo la formación, tanto didáctica como lingüística, de los futuros docentes:

Penso que faltam pesquisas que representem a realidade brasileira quanto ao que se privilegia em cursos de formação de professores. E, se o problema é sério nas universidades públicas, temo que seja pior nas privadas e, principalmente, naquelas que estão fora dos grandes centros urbanos. Pode ser preconceito de minha parte, e tomara que seja, mas por isso sinto falta de pesquisas que nos deem respostas a essas dúvidas. Como está a formação de professores de espanhol no Brasil? Está aí uma excelente pergunta para quem se apresente como candidato a um curso de mestrado ou doutorado, pois sem saber a realidade com a qual convivemos e sem conhecer as atuais tendências metodológicas e as novas formas de abordar a língua, não trocaremos de lugar. (PARAQUETT, 2009, p. 136)

\footnotetext{
${ }^{2}$ Disponible en: http://www25.senado.leg.br/web/atividade/materias//materia/126992, accedido el 10/03/207.
} 
La advertencia de esta autora, quien se hace eco de la alarma de otros muchos formadores de profesores de español en Brasil, es muy pertinente para nosotros, puesto que va al encuentro de lo que realmente nos gustaría averiguar con nuestro estudio. Está claro que no nos dedicaremos a todos los aspectos que componen los programas de formación de profesores, pero la intención es poder aportar nuevos datos referentes a la formación lingüística. En otro momento del trabajo mencionado, Paraquett (2009) hace referencia también a este aspecto, en relación a los candidatos de las oposiciones para plazas de profesor en las universidades, dato que corrobora nuestra intuición inicial de que el conocimiento de los docentes es, muchas veces, inferior a lo esperado:

Por fim, o terceiro e último aspecto que quero ressaltar com o objetivo de sugerir estratégias que nos ajudem a cumprir nosso papel se refere à formação de professores. E neste campo, a protagonista é a universidade brasileira, seja ela pública ou privada. Como consequência de minha longa experiência e também porque o MEC está convocando concursos públicos para as universidades federais, tenho percorrido o país, participando de bancas que avaliam os candidatos que se apresentam. E nem sempre volto feliz à minha casa, pois tenho encontrado dois tipos de problema: candidatos mal preparados $\mathrm{e}$ programas mal formulados. (PARAQUETT, 2009, p. 136)

En definitiva, nos preocupa el hecho de que, si realmente la interferencia de la lengua materna es un factor tan relevante en el aprendizaje de lenguas próximas como intuimos, estamos ante un aspecto educativo lo suficientemente importante como para que sea considerado en la enseñanza del español como lengua extranjera en Brasil y, más específicamente, en la formación lingüística de sus futuros profesores. Sin embargo, aunque los estudios acerca de la interferencia han proliferado indudablemente en los últimos años en Brasil, puede que la enseñanza del idioma necesite dedicar aún una mayor atención en este aspecto.

Junto a esto, pretendemos también contribuir a que los estudios sobre la proximidad lingüística no queden estancados, un hecho demasiado recurrente en la práctica y por motivos como los 
que apunta Sánchez Iglesias (2003, p. 405). En efecto, este autor recuerda que la investigación sobre este tema suele orillarse en la comunidad científica, al no presentar - en apariencia - problemas didácticos o datos relevantes para el estudio de la adquisición de segundas lenguas. Sin embargo, tanto los datos de su investigación (entre estudiantes italianos de ELE) como tantas otras que revisaremos en este trabajo (incluida la nuestra sobre profesores brasileños de ELE), apuntan, precisamente, a lo contrario.

\subsection{Estructura del trabajo}

Cuando nos propusimos estudiar los errores, desde el principio tuvimos claro que no podríamos limitar nuestra tarea a una mera descripción superficial de estos y a su consideración como simples "trasgresiones de la norma". Por el contrario, entendíamos que son muchos los factores que explican las incorrecciones en el proceso de aprendizaje de un idioma extranjero y, por ello, necesitábamos abordar una serie compleja de aspectos teóricos relacionados con ese mismo aprendizaje. Estos aparecen resumidos en los cinco primeros capítulos del trabajo, los cuales comprenden la primera parte de nuestro estudio: "Planteamientos teóricos". A continuación resumimos brevemente su contenido.

En primer lugar, intentamos aclarar qué entendemos por aprender una LE, y para ello hemos revisado los aspectos más relevantes de algunas teorías bien conocidas sobre la adquisición de las lenguas extranjeras. En el Capítulo 1, Principios sobre el aprendizaje de lenguas extranjeras, abordamos esas teorías, que fundamentan nuestro trabajo, y su concepción acerca de la dualidad adquisición/aprendizaje.

A continuación, abordaremos los principales conceptos que están en la base de nuestra investigación, como las nociones de interlengua, los tipos de transferencia -con particular atención a la interferencia -, así como la fosilización. También aquí incluimos una revisión sobre los principios y métodos del Análisis Contrastivo y el Análisis de Errores. Todo ello lo recogemos en el Capítulo 2, La transferencia y el sistema lingüístico no nativo.

En el Capítulo 3, Interferencia, lenguas próximas y el caso portugués/español, discutimos cuestiones fundamentales para nuestro estudio, como las particularidades que supone aprender una lengua cercana, y, específicamente, el español como lengua extranjera por brasileños. Un aspecto central en este capítulo es la discusión acerca de la supuesta facilidad que entraña aprender 
español en Brasil y su (negativa) influencia en el aprendizaje de ELE. Por último, revisaremos también en este apartado los principales trabajos académicos que han abordado la interferencia del portugués en el aprendizaje de español.

Como es lógico, en un trabajo que trata sobre análisis de errores, resulta imprescindible una revisión del propio concepto de error, así como de los diferentes tipos que encontramos en la bibliografía. Esta tarea la llevamos a cabo en el capítulo 4, Hacia una delimitación y categorización del error. En él, daremos cuenta también de la categorización que utilizamos en este trabajo respecto a los errores de interferencia.

Por último, en el capítulo 5, Algunas cuestiones teóricas sobre el léxico aplicadas a nuestro estudio, con el que se cierra el apartado teórico de la tesis, traemos al primer plano diversos conceptos relacionados con algunas formaciones léxicas específicas que hemos encontrado en nuestro estudio. Se trata de categorías como los heterosemánticos, las unidades fraseológicas y la formación de palabras.

Sentadas las bases teóricas de la investigación, iniciamos un segundo bloque, el de análisis empírico de la interlengua, con el Capítulo 6: Aspectos metodológicos. En él, nos ocuparemos de dar cuenta de aspectos diversos, como las principales características de los sujetos participantes, la construcción del corpus, los principales detalles acerca de la manera de identificar, clasificar y describir los errores, y la presentación de las obras lexicográficas utilizadas para el contraste lingüístico.

Ya en el Capítulo 7, Resultados, exponemos, por un lado, los datos generales referentes al uso de la lengua materna por los sujetos, los valores totales de los errores encontrados y la presentación de los errores léxicos más frecuentes. $\mathrm{Y}, \mathrm{a}$ continuación, realizamos un análisis exhaustivo de los errores léxicos hallados en el corpus. En esta sección, partimos inicialmente de las clases de errores delimitados por Durão (2007), y los analizamos con detalle, estableciendo para ello contrastes lingüísticos minuciosos a partir de diferentes obras lexicográficas.

Por último, en el capítulo 8, Algunas conclusiones $y$ consideraciones finales, sintetizamos los principales resultados obtenidos, al tiempo que realizamos diversas consideraciones tanto en relación con la enseñanza del español en Brasil como de la formación de profesores.

Para finalizar este apartado introductorio quiséramos subrayar algunas particularidades que presenta el trabajo. En primer lugar, conviene recordar que la tesis doctoral es el resultado de un 
convenio de cotutela, basado en una investigación que se inició en la Universitat Jaume I de Castellón - España, bajo la supervisión del profesor Dr. José Luis Blas Arroyo, y a la cual se unió, dos años más tarde, la Universidad Federal de Santa Catarina de Florianópolis Brasil, con la profesora Dra. Adja Durão en calidad de supervisora brasileña. Este hecho puede generar alguna perplejidad a los ojos de los lectores, especialmente brasileños. Nos referimos, por ejemplo, a la decisión de escribirla en español, y a "defenderla" -en esa misma lengua- en Brasil, decisiones ambas, sin embargo, que aparecían claramente estipuladas en el acuerdo reseñado entre ambas universidades. Y lo mismo sucede con la adopción de una normativa europea de buenas prácticas para la investigación en lingüística aplicada, pues fue durante nuestra estancia en España cuando se inició el trabajo de campo que sirvió para la compilación del corpus, una tarea ya completada cuando la universidad de Santa Catarina se sumó al convenio (para más detalles sobre esta cuestión. véase el Capítulo 6). 
50 


\section{PRINCIPIOS SOBRE EL APRENDIZAJE DE LENGUAS EXTRANJERAS}

El objetivo de este capítulo es exponer las principales teorías que fundamentan nuestra investigación y que, entendemos, son las que explican de manera más adecuada los procesos de adquisición/aprendizaje de una lengua extranjera (LE). Empezaremos por describir los principios más destacados de la teoría de la Gramática Universal y su aplicación al aprendizaje de lenguas extranjeras por parte de adultos (apartado 1.1). Más adelante (apartado 1.2), disertaremos sobre los aspectos más relevantes para nuestra investigación de la conocida como Hipótesis del "Input". Por último, haremos también algunas consideraciones sobre los conceptos de bilingüismo y de las competencias del hablante no nativo (apartado 1.3), relacionados también con nuestro estudio.

\subsection{La Gramática Universal y el aprendizaje de LE por adultos ${ }^{3}$.}

Aunque la teoría de la Gramática Universal (GU) planteada por Chomsky (1965) no está considerada como una teoría de adquisición de la lengua propiamente dicha por autores como White $(2003, \text { p. } 36)^{4}-$ ni tampoco del todo original para otros como Corder $(1967)^{5}$-, es incuestionable la revolución que supuso para la

\footnotetext{
${ }^{3}$ Por motivos de espacio, nos limitaremos a describir unas pocas características de la teoría de la Gramática Universal, poniendo de relieve los aspectos más vinculados a nuestro objeto de estudio.

${ }^{4}$ White (2003) argumenta que hay una cierta confusión entre los términos Gramática Universal y Dispositivo de Adquisición del Lenguaje, lo que da margen a interpretar, indebidamente, que la GU es una teoría de adquisición de lenguas. Para la autora, una teoría de este tipo debe, necesariamente, incluir principios de aprendizaje y procesamiento del lenguaje, los cuales no están presentes en la teoría de la Gramática Universal.

${ }^{5}$ Corder (1967) recuerda que ya Palmer, en su libro The principles of language study, publicado en 1922, sostenía que todos estamos dotados de una capacidad natural para aprender lenguas y que tal capacidad se mantiene latente después de haber aprendido la primera lengua. Por consiguiente, el adulto es tan capaz de aprender una lengua extranjera como un niño.
} 
lingüística moderna, por su intento en explicar la naturaleza de la representación gramatical en el lenguaje.

Chomsky buscaba describir la "facultad del lenguaje" mediante un estudio exhaustivo de la lengua materna, apoyado en tres cuestiones fundamentales: ¿qué es el conocimiento del lenguaje? ¿cómo se adquiere? ¿cómo se utiliza? (CHOMSKY 1985, p. 17). Para el autor, existe una Gramática Universal formada por las propiedades biológicas inherentes al cerebro humano, cuya función se compara a los demás órganos de nuestro cuerpo: "We may usefully think of the language faculty, the number faculty, and others as 'mental organs', analogous to the heart or the visual system or the system of motor coordination and planning." (CHOMSKY 1980, p. 39).

La GU no da cuenta apenas de las reglas de una determinada lengua, sino de una serie de principios universales innatos de carácter sintáctico, semántico o fonológico, dotados por la propia naturaleza humana y aplicables a todas las lenguas (CHOMSKY, 1965, p. 28). Uno de los principales argumentos de esta teoría reside en la observación de que los niños con un déficit de estímulos verbales también aprenden su LM, por lo que el input por sí solo no es condición suficiente para que aprendan un idioma y descubran ciertas reglas. De esta manera, si el input no determina el output, no sería posible aprender un idioma sin tener acceso a una serie de principios innatos, pertenecientes a la Gramática Universal. Para ello, sería ncesario un mecanismo de adquisición del lenguaje (Language Acquisition Device - LAD) (CHOMSKY, 1965, p. 47), responsable del aprendizaje de la lengua e independiente de los estímulos recibidos, en el que se ubicarían los ingredientes universales capaces de llevar a cabo la adquisición de cualquier lengua existente.

El autor sostiene la teoría del LAD de acuerdo con la interpretación del aprendizaje de pensadores clásicos como Descartes (1647), Lord Herbert (1624), Humboldt (1836) y Platón, quienes, a lo largo de la historia, han coincidido enen la existencia de ideas o pensamientos innatos a la cognición humana (CHOMSKY, 1965, p. 47-51). Transferidos al campo del aprendizaje de lenguas, estos presupuestos fundamentan la teoría mentalista de que el lenguaje se desarrolla a través de la exposición a la lengua, pero ocurre principalmente por mediación de un dispositivo innato. En razón de ello, Chomsky (1965, p. 51) sostiene que no se puede enseñar una lengua, sino ofrecer las condiciones para que el LAD sea activado y el aprendizaje ocurra. 
Pese a que la teoría de la GU está ampliamente aceptada por la comunidad científica en relación a la adquisición de la LM, en el debate sobre la adquisición de lenguas extranjeras existe una amplia discusión acerca de su disponibilidad. En pocas palabras, se debate si esta tendría algún papel en el aprendizaje/adquisición de una L2/LE por parte de individuos adultos (COOK, LONG, y MCDONOUGH, 1979; COOK, 1985, 1994; ELLIS, 1985; CLASHEN y MUYSKEN, 1986; SCHACHTER, 1989; BLEY-VROMAN, 1990; SCHWARTZ y SPROUSE, 1996; HAWKINS y CHAN, 1997; WHITE, 2003). Actualmente, existen tres corrientes que plantean la cuestión de manera distinta: la primera defiende que la GU no está disponible para la adquisición/aprendizaje de la L2/LE; la segunda propone que la GU está tan solo parcialmente disponible; y la tercera defiende que la GU estaría totalmente disponible. Veamos cada una de ellas con más detalle.

\subsubsection{El no acceso a la GU}

En opinión de algunos autores, la GU estaría disponible solamente para el aprendizaje de la lengua materna. Entre los principales defensores de esa hipótesis, que defiende la imposibilidad de acceso a la GU por parte de los adultos, figuran Schachter (1989), Bley-Vroman (1990) y Clashen y Muysken (1986), entre otros. Schachter (1989), por ejemplo, ha investigado el acceso a la GU a partir de un experimento que comparó el enjuiciamiento de hablantes nativos y aprendices adultos de inglés como lengua extranjera sobre los mecanismos de las "wh movement"6. Los resultados del experimento llevaron a la conclusión de que los aprendices adultos de L2 no tenían acceso a la GU y, por tanto, no alcanzarían el mismo nivel de producción/comprensión que los hablantes nativos. Por su parte, Bley-Vroman (1990) sostiene también que la adquisición de L2 se da directamente a través de la L1, sin que la GU entre en acción. Esto se justificaría por que en los adultos, el LAD ya no está operativo. Por último, Clashen y Muysken (1986) opinan que las lenguas se aprenden mediante procedimientos cognitivos, y el proceso de aprendizaje de la L2

\footnotetext{
${ }^{6}$ Mecanismo de sintaxis de la lengua inglesa que permite expresar una pregunta (o formar una cláusula relativa). Schachter (1989) investigó la utilización de una partícula pronominal en las oraciones en inglés que contienen las Wh-word (who, whom, which, whose).
} 
viene condicionado por mecanismos responsables de otros tipos de aprendizaje humano, los cuales no tienen vínculo alguno con la GU.

\subsubsection{El acceso parcial}

Para Hawkins y Chan (1997, p. 216) existe una parte de la GU que se torna inaccesible en la adquisición de la L2 de adultos. Esta hipótesis, nombrada de Failed Functional Features sugiere que en un primer momento, los aprendices usan la sintaxis de la L1 con ítems lexicales de la L2. En un segundo momento, los aprendientes se alejan de la L1 para emplear un dispositivo restringido por la GU, que denominan "gramáticas posibles". Por tanto, en un primer momento la adquisición de una L2 está condicionada por los parámetros de la $L 1$, de manera que, cuando hay características funcionales que no están accesibles, los adultos construyen una alternativa. Según los autores, los resultados de tales adaptaciones muestran que los aprendices muchas veces aceptan una violación de los principios universales porque hay un déficit en las representaciones sintácticas de la lengua extranjera, debido a que no se pueden adquirir los rasgos que no están presentes en su lengua materna.

\subsubsection{El acceso total}

Contraria a las hipótesis 1 y 2, la teoría del acceso total, defendida por ejemplo por Ellis (1985) y Cook (1998), sostiene que los aprendices pueden acceder a la GU durante todo el proceso de aprendizaje, ya que esta se halla presente y constantemente disponible independientemente de la lengua materna o de cuál sea la lengua objeto (LO). Los parámetros de aprendizaje son los mismos para todas las lenguas, incluso en la edad adulta, y la adquisición de la lengua se puede dar siempre que haya contacto con la lengua objeto.

Con unos supuestos muy similares, Schwartz y Sprouse (1996) han defendido la hipótesis del Full Transfer/Full Access, según la cual la gramática de la lengua materna es la base de la interlengua $(\mathrm{IL})^{7}$ de los estudiantes de la $\mathrm{L} 2$, estando la GU permanentemente accesible. Dicho de otra manera, en los estadios iniciales, los aprendientes tienden a adoptar la representación que

\footnotetext{
${ }^{7}$ Para una revisión del concepto de interlengua véase el Capítulo 2.
} 
ya tienen de su L1; sin embargo, cuando el input no se ajusta a la gramática de la $L 1$, aquellos reestructurarían el contenido mediante la puesta en acción de la GU.

De acuerdo con los autores citados, (ELLIS,1985; SCHWARTZ y SPROUSE, 1996; COOK, 1998), así como otros como White (2003), tanto la GU como la L1 se encuentran igualmente accesibles en el aprendizaje de una lengua extranjera. La L1 se halla más presente en los estadios iniciales del aprendizaje, mientras que la GU permanece accesible siempre y cuando el input no sea suficiente para dar cuenta del aprendizaje de cualquier lengua.

White (2003) recuerda que las investigaciones más recientes están más volcadas en el intento de comprender los procesos implicados en la construcción de la interlengua, y parecen haber dejado ya atrás la duda sobre si la interlengua de los aprendices tiene acceso o no a la GU, asumiendo que esta conexión realmente existe.

\subsubsection{Notas para nuestro estudio}

En lo que concierne a nuestro estudio, y de acuerdo con los autores citados anteriormente (ELLIS,1985; SCHWARTZ y SPROUSE, 1996; COOK, 1998; WHITE, 2003) entendemos que tanto la GU como la L1 se encuentran igualmente accesibles en el aprendizaje de una lengua extranjera. La L1 se halla más presente en los estadios iniciales del aprendizaje, mientras que la GU permanece accesible siempre y cuando el input no sea suficiente.

Entendemos, que la L1 tiene un papel activo en la $L 2$, que puede ocurrir de varias maneras distintas, como las mencionadas por Fernández (1991, p. 25):

1. como conocimiento preexistente al que se acude estratégicamente" en la comunicación; 2. como fuente de una interferencia, también estratégica. Integrada en los mismos procesos de "construcción creativa" de la lengua;

3. como mediadora entre la L2 y la gramática universal;

4. integrada en el marco de los universales lingüísticos.

Sin embargo, además de la lengua materna y de la gramática universal, existen otros factores relevantes en el 
aprendizaje que habrá que tener en cuenta, como detallaremos a continuación.

\subsection{La Hipótesis del "Input"}

Una de las teorías más discutidas en el campo de la adquisición de lenguas y, en particular, de las lenguas extranjeras, es la llamada "Hipótesis del Input". En la introducción a su libro seminal, The Input Hypothesis: issues and implications, el propio Krashen (1985, p. vii) aclara que él no es exactamente el creador de esta hipótesis, pero sí quien la redefinió a partir de diversas teorías ya vigentes en el momento de la publicación de su trabajo ${ }^{8}$.

Krashen defiende que adquirimos el lenguaje de una manera increíblemente simple: entendiendo mensajes. A continuación presentaremos las principales propiedades que conforman su teoría.

\subsubsection{Adquisición y aprendizaje}

Una de las características centrales de la teoría del Input de Krashen (1985, p. 39-41) es la utilización de la dicotomía adquisición/aprendizaje ${ }^{9}$. Según el autor, existen dos medios independientes y distintos de aprender una lengua. El primero, la adquisición, es un proceso "natural" e inconsciente que lleva a la internalización de las formas lingüísticas en la mente del hablante. El ejemplo más paradigmático es el de los niños, quienes adquieren sus lenguas maternas con el objetivo de participar en las situaciones de comunicación real. Dicho proceso está orientado, sobre todo, al significado y no a la forma. El aprendizaje, al contrario, es un proceso consciente y explícito, y está relacionado con el aspecto formal de la lengua. Es casi siempre impulsado en contextos institucionales, como los centros de enseñanza, y consiste en "saber" sobre el lenguaje, o, lo que es lo mismo, reflexionar sobre él.

\footnotetext{
${ }^{8}$ En la primera sección del libro, Krashen (1985: vii) cita ya algunas fuentes de su teoría, destacando que la suya es una adaptación de versiones de la Hipótesis del Input de otros autores, entre los cuales destaca Macnamara (1972).

${ }^{9}$ En puridad, la distinción entre adquisición y aprendizaje no es originaria de Krashen. Un par de décadas antes, Lambert (1966) defendía ya la utilidad de reconocer la singularidad de cada proceso y, en el mismo sentido, Carroll (1966) argumentaba que el aprendizaje se podía beneficiar de los estudios sobre la adquisición del lenguaje (CORDER 1967).
} 
Algunos de los principales aspectos del ambiente formal son la presencia de una secuencia de contenidos previamente establecidos por la institución, delimitados por un plan de estudios o el aislamiento de las reglas y la corrección de los errores, rasgos ausentes en los contextos de adquisición.

En consecuencia, podemos distinguir entre adquirir y aprender una lengua, en el sentido de que en el aprendizaje es posible monitorizar los procesos y lo estudiado, mientras que en la adquisición estos procesos resultan inconscientes. Se ha especulado que los niños emplean el primer sistema para adquirir la L1, mientras que los adultos aprendices de L2 se benefician solamente del segundo. No obstante, Krashen no defiende exactamente eso. En sus palabras:

Se ha sugerido aquí que, mientras que los niños adquieren inevitablemente la lengua, los adultos pueden adquirirla o aprenderla. Según esto, el aula ideal será aquella en la que se posibiliten estos dos procesos. Los profesores con experiencia lo saben bien: el proceso de construcción creativa se estimula mediante ejercicios contextualizados y la oportunidad de usar la lengua natural (véase, e. g., Dulay y Burt, 1975), mientras que la presentación de las reglas gramaticales y la corrección selectiva de los errores sería eficaz para los usuarios del monitor. (KRASHEN 1977, p. 151)

Como se puede observar claramente en la cita, Krashen admite que los adultos también pueden adquirir una L2 y ello porque, en su opinión, existe un paralelismo entre la adquisición de L1 y L2 en adultos. Del mismo modo, afirma que los adultos también pueden tener acceso a la construcción creativa del lenguaje, basándose, para ello, en la existencia de diversos estudios que han demostrado que los errores de los adultos aprendices de L2 son muy parecidos a los que cometen los niños al adquirir su LM. Todo ello, sería indicio, pues, de que los adultos también pueden adquirir una L2:

La prueba más espectacular de que existe adquisición en los adultos proviene, sin embargo, de los estudios que muestran que bajo ciertas condiciones los adultos que aprenden una L2 tienen un orden de dificultad para los aspectos de la gramática de la L2 muy similar al que encontramos en los niños, lo que 
indica que existe algún parecido entre el procesamiento del lenguaje que realizan los niños y los adultos. Los detalles de estos estudios, que serán discutidos más adelante, nos proporcionan pruebas directas a favor de la utilización del modelo del monitor para dar cuenta de la actuación de los adultos en L2. (KRASHEN, 1977, p. 146)

No obstante, algunas de las críticas más serias que se han hecho a la dicotomía adquisición/aprendizaje proceden del hecho de que no siempre se pueden determinar los límites de algunas de las características fundamentales de estas dos actividades, como, por ejemplo, la distinción entre contextos formales o informales, 0 , principalmente, la relevancia del factor edad. La distinción que realiza el autor es más clara si comparamos contextos de inmersión con aquellos de no inmersión. No obstante, estas críticas tienen que ver, sobre todo con aquellos entornos plurilingües donde las lenguas se aprenden de manera simultánea en la escuela, pero también en sociedad, y en diferentes estadios del desarrollo de los aprendices. En consecuencia, la dicotomía aún genera discusión en la comunidad científica ${ }^{10}$.

Otra crítica es la de McLaughlin (1978), quien cuestiona la explicación del aprendizaje y la adquisición en relación con los estados de consciencia (procesos conscientes o inconscientes) para dos actividades que son, a su juicio, actos de comportamiento (MCLAUGHLIN, 1978, p. 163-166). Para él, la memoria tiene un papel central y es responsable en gran medida de la distinción en estos dos procesos. De esta manera, propone una nueva teoría con base en el almacenamiento a largo y corto plazo de la memoria, distinguiendo entre procesos controlados y autónomos.

${ }^{10}$ Sobre los límites biológicos impuestos por la edad en la adquisición de una L2, sobre los cuales Krashen está en desacuerdo, hay que remontarse a la célebre investigación de Lenneberg (1967). Una explicación detallada sobre la posición de Krashen y los efectos de la edad en la adquisición de las lenguas extranjeras puede encontrarse en Dulay, Burt y Krashen (1982) y Krashen (1985). Otros autores, como Ellis (1985), también niegan la existencia de un período crítico, e investigaciones más recientes en el campo de la neurociencia (LÖVDÉN ET AL., 2010; MÅRTENSSON ET AL., 2012; SCHLEGEL, RUDELSON, Y TSE, 2012) evidencian la plasticidad de diferentes campos del cerebro ligados al aprendizaje de lenguas extranjeras en adultos, poniendo así en entredicho la teoría de Lenneberg. 
Bialystok (1978) también propone un modelo teórico para el aprendizaje de lenguas como alternativa a los postulados de Krashen y McLaughlin que se divide en tres niveles: a) el aducto, que sería la experiencia en el contacto con la L2; b) el conocimiento, tanto implícito (almacenamiento de la información necesaria para comprender y producir la LE) como explícito (que hace posible la utilización del primero); y pragmático y cultural; c) el educto, que se compone de la comprensión, la producción y el uso de estrategias (BIALYSTOK, 1978, p. 184-185). El modelo sugiere, ante todo, la necesidad de atender a las diferencias individuales de los aprendices, además de hacer hincapié en la enseñanza de estrategias de aprendizaje que den cuenta de las formas específicas del uso de la lengua y sus modalidades (comprensión y producción).

Otros autores también han resaltado las características de cada actividad. Corder (1967, p. 33), por ejemplo, no establece ninguna distinción terminológica del tipo adquisición/aprendizaje, sino que señala que hay diferencias entre aprender una LM y una L2. Entre ellas:
a) El aprendizaje de la LM es inevitable, mientras que no lo es el de la L2;
b) El aprendizaje de la LM es parte de la maduración del niño, mientras que aprender la L2 generalmente es algo que ocurre después de que aquel proceso haya acabado;
c) La motivación para aprender una primera lengua es muy distinta de la que existe cuando se aprende una segunda.

Aunque definir las diferencias entre LE y L2 no figure entre los objetivos de Krashen, la dicotomía adquisición/aprendizaje requiere precisar estos dos términos, y por esa razón haremos aquí un breve inciso. Como hemos visto, la L2 está relacionada con los contextos de adquisición así como los entornos del bilingüismo social, mientras que la LE está ligada a los contextos formales de aprendizaje de la lengua meta. No es raro que los investigadores las usen como sinónimos, aunque no se refieran, necesariamente, a los mismos procesos (BARALO, 1999, p. 22), motivo por el cual nos parece ser imprescindible establecer esa diferenciación. 
Aunque haya recibido diversas críticas ${ }^{11}$, que han dividido en parte a la comunidad científica, la dicotomía propuesta por Krashen sigue vigente en la actualidad y tiene el indiscutible mérito de haber logrado que se reflexione de manera exhaustiva acerca de los procesos involucrados en el aprendizaje de una L2. La distinción entre los dos procesos ha hecho que se entiendan los problemas de la enseñanza de lenguas extranjeras tanto desde el punto de vista didáctico como también desde la perspectiva intrínseca a la adquisición y el aprendizaje, dos modalidades que tienen características distintas y son indisociables de la cognición humana.

\subsubsection{Notas para nuestro estudio}

Para nuestro estudio, lo más destacable de tal dicotomía es la posibilidad de ubicar el contexto de aprendizaje de nuestros sujetos y con ello aproximarnos a los procesos que utilizan en el uso de la LO. Nuestra investigación se sitúa en el marco del análisis de errores, pero no por ello debemos descuidar el entorno de aprendizaje de la LE si queremos entender los errores de actuación de nuestros sujetos de una manera más detallada. No nos pararemos a discutir si su conocimiento de la lengua española es aprendido o adquirido, puesto que no es el objeto de esta tesis, pero nos parece fundamental diferenciar el entorno de aprendizaje, el cual, desde el punto de vista de las teorías discutidas aquí, no encaja en un contexto de adquisición natural. También por la misma razón, aplicaremos los términos "lengua extranjera" (a partir de aquí LE) y "lengua objeto" (a partir de aquí LO) para la lengua española utilizada por los sujetos de nuestro estudio, puesto que entendemos que está insertada en un contexto formal de aprendizaje, como hemos visto en este apartado.

\footnotetext{
11 Tarone (1983), a su vez, cuestiona la naturaleza de la variabilidad de la interlengua en la teoría del input, en relación con los universales lingüísticos y, principalmente, con el concepto de monitor. Como alternativa, propone la teoría del "Paradigma de la Capacidad Contínua", que daría cuenta de los "fallos" de la Hipótesis del Input.
} 


\subsubsection{El orden natural}

La hipótesis del orden natural es uno de los pilares de la teoría del input y, por esta razón, nos parece pertinente describirla aquí, aunque de manera muy sucinta, puesto que no será aplicada a este estudio.

Según Krashen (1985, p. 1) la hipótesis del orden natural se fundamenta en los postulados de Corder (1967), y sostiene que se adquieren las reglas de un idioma en un orden predecible, de manera que algunas reglas tienden a ser aprendidas antes que otras. Así, por ejemplo, en la lengua inglesa el orden sujeto-verboobjeto, así como la terminación ing en el gerundio de los verbos se aprende antes que los tiempos verbales simples (como señalan DULAY, BURT, y KRASHEN, 1982, p. 200). Para Krashen (1977), la adquisición de una $\mathrm{L} 2$ se da mediante un proceso creativo que tiene una serie de estadios comunes para los aprendices, independientemente de su lengua materna. Esos estadios dan lugar al uso de estrategias universales y cada etapa de la adquisición avanza hacia el conjunto de reglas de la lengua objeto que poseen los hablantes nativos.

Otros investigadores han intentado corroborar los postulados del orden natural en diferentes experimentos, aunque no sin controversia. McLaughlin (1978, p. 174), por ejemplo, uno de los principales críticos de la teoría del Input, argumentó que los resultados de las investigaciones acerca de los morfemas llevadas a cabo hasta la publicación de su artículo no confirmaban la hipótesis de Krashen ${ }^{12}$. En concreto, esos resultados mostraban las estructuras usadas con más frecuencia o las que suelen causar mayor dificultad, pero no necesariamente su orden de adquisición. Para el investigador, uno de los puntos positivos de la teoría de Krashen, en lo que concierne al orden natural, es el descubrimiento de que existe un orden de dificultad de ciertos morfemas y que hay que orientarse más a la comunicación y menos a la forma y a la corrección de errores (MCLAUGHLIN, 1978, p. 174).

${ }^{12}$ En el trabajo que mencionamos, McLaughlin (1978, p. 174) cita una serie de investigaciones llevadas a cabo respecto para el análisis de la adquisición de los morfemas con el fin de de confirmar o refutar la Hipótesis del Input. No nos extenderemos aquí sobre este tema, así que nos conformaremos con recordar que la discusión sobre el orden natural y los diversos puntos de la Hipótesis del Input ha sido prolongada y aún a día de hoy no se ha agotado en la bibliografía especializada. 
Años más tarde, Fernández (1997, p. 23) recordaba también la existencia de numerosas investigaciones que habían destacado la existencia de una secuencia universal independiente de la LM del aprendiz, lo que implica la presencia de un orden y un ritmo universales en cada etapa. En un contexto formal de enseñanza, el orden natural parece no estar influenciado por el orden en que los contenidos se presentan en clase. Así, un estudio de profesores de inglés en Panamá, del que dan cuenta Dulay, Burt, y Krashen (1982), muestra que los estudiantes de nivel inicial en conversaciones espontáneas no usan la "s" marcadora de la tercera persona (ej. She likes papayas), ni tampoco la forma has (frente a have). $\mathrm{Y}$ ello pese a que esos alumnos han estudiado exhaustivamente las reglas.

En definitiva, parece que, aunque en las fases iniciales del aprendizaje los alumnos aprendan las reglas presentadas en clase de manera esforzada y consciente, la adquisición de estas solo ocurrirá cuando estén verdaderamente preparados para ello, lo cual sucederá en una fase posterior, lo que reforzaría la hipótesis del orden natural.

\subsubsection{El monitor}

Esta hipótesis se fundamenta en el argumento de que nuestra habilidad para producir enunciados en otro idioma reside en la competencia adquirida por nuestro subconsciente. Existirían dos condiciones necesarias para el uso del monitor: por un lado, la consciencia sobre la corrección y, por otro, el conocimiento de las reglas de la lengua objeto. La consciencia tendría el papel de "editor" o "monitor", o sea, se encargaría de hacer correcciones, cambiar la producción del sistema adquirido antes del habla oral o escrita, y, en algunos casos, corregir las producciones ya realizadas (KRASHEN, 1985, p. 2).

De esta manera, los principios de esta hipótesis afirman que la adquisición es la responsable de las producciones de los adultos aprendices de L2, y que el aprendizaje es el dispositivo que tiene la función de vigilar el sistema adquirido:

Los fenómenos mencionados más arriba, así como ciertos resultados experimentales, se pueden explicar postulando un modelo en el cual la producción de los adultos en L2 es posible gracias al sistema adquirido, actuando 
el aprendizaje sólo como un monitor que, cuando las condiciones lo permiten, inspecciona, y a veces altera, el educto del sistema adquirido. (KRASHEN 1977, p. 145)

Para ese autor, una de las virtudes más destacables del modelo del monitor, y que, al mismo tiempo, demuestra su validez, es la capacidad de predecir la existencia de variación en el uso que hacen respecto a lo aprendido en la L2 (monitor) los adultos:

El modelo predice que el grado de utilización consciente del monitor por parte de los hablantes será variable. En uno de los extremos estarán los que parecen utilizar el monitor siempre que sea posible, y que, por consiguiente, muestran una actuación variable." (KRASHEN, 1977, p. 148) (...) "En el otro extremo se sitúan los adultos que no parecen utilizar nunca el monitor, incluso cuando las condiciones se lo permiten. Tales hablantes de L2, como los que adquieren la primera lengua, no están incluidos por la corrección de errores (que se dirige directamente al monitor), y raramente utilizan el conocimiento lingüístico consciente en su actuación en L2. (KRASHEN, 1977, p. 149)

Con todo, habría algunas posibilidades más, como los hablantes que admiten que las reglas son importantes en la actuación de la L2, pero no las usan; o, en sentido contrario, los sujetos que tienen una preocupación tan grande por usar las reglas que les impide hablar con fluidez. Estas consideraciones sobre el uso del monitor son especialmente interesantes para nuestro estudio, una vez que pueden revelarse como uno de los elementos responsables de la variación en la interlengua de los aprendices.

\subsubsection{El “input”}

La hipótesis del input sostiene que la única manera de aprender una lengua es teniendo acceso a mensajes comprensibles (KRASHEN, 1985, p. 2). De esta manera, el habla es el resultado de la adquisición y emerge de la comprensión de los mensajes. Los humanos progresan en su aprendizaje en un orden natural (ver subapartado 1.2.2) porque entienden las estructuras que escuchan 
en su entorno. En consonancia, con las estructuras entendibles se incluyen estructuras nuevas, las cuales una vez entendidas llevan al próximo nivel de competencia (i+1). Es decir, los seres humanos son capaces de entender el lenguaje aunque aparezcan en ellas estructuras gramaticales desconocidas; lo hacen con la ayuda del contexto. Si el input es suficiente, la gramática necesaria se genera automáticamente, ya que es el ingrediente esencial para que el aprendizaje de una lengua se desencadene, el cual, combinado con el procesador interno del lenguaje - LAD, acaba por generar la adquisición. Esa hipótesis se sustenta en dos principios:

a) El habla es el resultado de la adquisición, no su razón. $O$ sea, es la consecuencia de la construcción de la competencia a través del input comprensible.

b) $\quad \mathrm{Si}$ el input es comprensible y hay cantidad suficiente del mismo, la gramática se deriva automáticamente. Por esa razón los profesores de lengua no deberían preocuparse por enseñar explícitamente la próxima estructura dentro del orden natural del aprendizaje: la gramática vendrá proporcionada en las cantidades necesarias y automáticamente revisada si el estudiante recibe una cantidad suficiente de input comprensible. (KRASHEN 1985, p. 2)

EI LAD sirve como una especie de procesador, el cual genera posibles reglas de acuerdo con procedimientos innatos. Esto no significa que todo lo que se escuche o se comprenda logrará alcanzar este dispositivo. Este funciona de la misma manera en todos los humanos, aunque hay diferencias en el estilo cognitivo, las cuales tienen un marcado papel en el proceso de adquisición y aprendizaje de las lenguas extranjeras. Dicho de otra manera, aunque hay diversas fuentes, contextos de input, mensajes, lenguas y características individuales, el LAD tiene la función de desencadenar el lenguaje humano.

\subsubsection{Notas para nuestro estudio}

Aunque exista una dificultad indudable en definir, por un lado, el nivel lingüístico del alumno (i) y, por otro lado, el input comprensible en cada nivel $(+1)$, la hipótesis del input nos parece 
muy interesante para nuestro estudio, puesto que lo más normal es que, en un contexto formal de aprendizaje, el input sea especialmente cuidado por los profesores, para hacerlo comprensible a sus alumnos ${ }^{13} \mathrm{y}$, además, restringido, con especial atención a la forma. De esta manera, entendemos que nuestros sujetos, al aprender el idioma extranjero en tal contexto, donde el contenido y las muestras de lengua son controlados por el profesor, recibieron el "mismo" input y mayoritariamente a través de las clases. Más allá de esto, la posibilidad de expandir el conocimiento de la LO está, por tanto, condicionada por los propósitos individuales de los aprendices, y por sus hábitos de estudio fuera de clase. Todos estos factores, entre otros, deberán ser considerados a la hora de analizar las producciones de los sujetos, puesto que difieren enormemente de un contexto de inmersión, donde el aprendizaje ocurre de manera más espontánea o inconsciente en el sentido descrito por Krashen (1985).

\subsubsection{El filtro afectivo}

El input comprensible es necesario para que haya adquisición, pero este no es su único ingrediente. Según Krashen (1985), el individuo necesita estar "abierto" al input y, para ello, el filtro afectivo es el dispositivo que regula el aprendizaje y la utilización del mensaje recibido. Cuando el filtro afectivo está alto, el aprendiente puede entender lo que oye o lee, pero el input no alcanza el dispositivo de adquisición de lenguaje. Esto puede ocurrir cuando el alumno está poco motivado, con baja autoestima o ansioso (Krashen, 1985, p. 3). Por el contrario, cuando el filtro afectivo está bajo, el aprendiente no está preocupado por la posibilidad de fallar en el proceso de aprendizaje. Ello suele ocurrir, por ejemplo, cuando el aprendiente se halla tan envuelto en el mensaje que se olvida temporalmente de que está escuchando o leyendo otra lengua, o cuando considera que aprender la LO le ayudará a incluirse en un grupo social. Investigadores como Schumann (1976) han relacionado este último aspecto con el desarrollo de la interlengua en contextos de inmersión, defendiendo

${ }^{13}$ Aquí cabría la discusión acerca de lo que es realmente comprensible o no, pero nos centraremos en que en los contextos formales el alumno recibe un input pensado para ser comprensible, planificado por el profesor en cada etapa del aprendizaje, lo que no ocurre necesariamente en un contexto de inmersión. 
que procesos como la pidginización ${ }^{14}$ tienen lugar en los sujetos en los que prevalece la distancia psicológica y social en relación con la L2.

La importancia del filtro afectivo para la teoría del input está basada en el postulado de que las personas solo adquieren una segunda lengua cuando obtienen un input comprensible y su filtro afectivo está lo suficientemente bajo como para permitir que el contenido "entre" de memoria. De esta manera, la adquisición es inevitable, pues el LAD se pone en marcha de manera automática, como lo hace cualquier otro órgano del cuerpo humano. En palabras del autor:

In other words, comprehensible input is the essential ingredient for second-language acquisition. All other factors thought to encourage or cause second-language acquisition work only when they contribute to comprehensible input and/or a low affective filter. (KRASHEN 1985, p. 4)

\subsubsection{Notas para nuestro estudio}

Pese a que la discusión sobre el filtro afectivo está ampliamente asentada en la comunidad científica, al ser el nuestro un análisis de la actuación, quizá la hipótesis que más detalles nos puede proporcionar sobre ésta sea la del "filtro de salida" (KRASHEN, 1985, p. 45). La diferencia con respecto al filtro afectivo, es que, si bien los factores de interferencia son los mismos, el primero concierne a la entrada del input, mientras que el segundo está relacionado con la realización de lo que se sabe. El filtro de salida intenta explicar por qué a menudo no se observa a través de

\footnotetext{
${ }^{14}$ Schumann estudiaba el aprendizaje de la LE en contexto de inmersión y entendía una "lengua pidgin" como una forma de habla simplificada utilizada por personas con el objetivo de comunicarse entre sí. La estructura gramatical de esta forma de habla se caracteriza por la falta de morfología flexiva y la tendencia a eliminar las transformaciones gramaticales (SCHUMANN, 1976, p. 127). La pidginización estaría presente en el principio del aprendizaje de la lengua segunda de manera natural y persistiría en condiciones de distancia psicológica o social de la lengua meta. En otras palabras, cuanto menor es la identificación o el sentimiento de inclusión social/cultural en el país de inmersión, mayor es la probabilidad de que la lengua utilizada tenga características alejadas de la lengua meta.
} 
la actuación de los aprendices la competencia que realmente poseen, 0 , en otras palabras, por qué en sus producciones orales 0 escritas no reflejan todo lo que han aprendido. Sobre esto, Krashen (1985, p. 46) subraya que, cuando el foco está en la forma, y no en el sentido, o cuando existe un alto nivel de ansiedad, el filtro de salida puede subir, dificultando, por ello, la producción del aprendiz.

\subsection{El bilingüismo y las competencias del hablante no nativo}

Entendemos que los conceptos que hemos presentado hasta ahora son fundamentales para conocer el estado de la cuestión sobre la adquisición de lenguas extranjeras. Estos nos proporcionan un acercamiento más preciso para entender los procesos que utilizan los estudiantes al tratar de hacer uso de la LE que aprenden. Los contenidos de esta sección se complementan con otros que aluden a las diversas competencias de las que parte el hablante. De este modo, en lo que sigue, realizaremos un breve repaso de algunas nociones que han hecho fortuna en la lingüística del último medio siglo, como los de competencia y actuación (CHOMSKY, 1965); competencia lingüística (CHOMSKY, 1965) y comunicativa (HYMES, 1971); el modelo de competencia comunicativa (CANALE, 1983); y las competencias del hablante no nativo (COOK, 1992; 1997).

\subsubsection{Competencia y actuación}

Como es sabido, Chomsky (1965) desarrolló los conceptos de competencia y actuación dentro de su teoría de la competencia lingüística. Para ese autor, la competencia es, grosso modo, lo que un hablante de una lengua sabe de modo implícito. La actuación (performance), por su parte, es lo que hace con lo que sabe (CHOMSKY, 1965, p. 4). Chomsky estaba especialmente interesado por todo lo que se refería a lo implícito, es decir, a la competencia. Decía que en el sentido técnico, la teoría lingüística es mentalista, por ello intentaba descubrir la realidad mental que subyace al comportamiento natural (CHOMSKY, 1965, p. 4). Con todo, en otro trabajo (CHOMSKY 1977), describía la importancia de estudiar la actuación para llegar a la competencia: 
La actuación proporciona datos para la investigación de la competencia. Al mismo tiempo, un interés primario por la competencia no supone descuidar los hechos de la actuación y el problema de explicar estos hechos. Por el contrario, es difícil entender cómo puede estudiarse seriamente la actuación si no es sobre la base de una teoría explícita de la competencia que la subyace y, de hecho, las contribuciones a la comprensión de la actuación han sido en gran parte subproductos del estudio de las gramáticas que representan la competencia. (CHOMSKY 1977, p. 130)

La teoría de la competencia lingüística está asentada en el concepto de hablante nativo ideal. El hablante nativo ideal hipotético albergaría el conocimiento perfecto de su lengua, cuya actuación no se ve afectada por circunstancias tales como las limitaciones de la memoria, las distracciones, los cambios de atención y de interés, etc. (CHOMSKY, 1965, p. 3). Como recuerda Cenoz (2004), esta abstracción hacia un hablante ideal motivó la principal crítica que se hizo hacia el modelo, y que encontramos en autores como Lyons (1970), Campbell y Wales (1970) y Hymes (1972), entre otros (apud CENOZ, 2004: 450). Esos autores consideraban inadecuado limitar la competencia lingüística a un hablante ideal o a una sociedad homogénea, cuando en realidad la mayoría de los humanos vivimos en situaciones comunicativas plurilingües. A pesar de esta visión reduccionista de la competencia del hablante, los postulados de Chomsky representan un punto de partida indudable hacia enfoques posteriores. Por ejemplo, la discusión sobre la competencia lingüística favoreció la introducción del concepto de competencia comunicativa como criterio fundamental en los contextos de adquisición y enseñanza de lenguas (CENOZ, 2004).

\subsubsection{Competencia lingüística y competencia comunicativa}

La concepción de competencia comunicativa tiene gran relevancia dentro de la Lingüística Aplicada, principalmente en lo que concierne al estudio de las segundas lenguas y a su enseñanza. Esta noción tiene un carácter interdisciplinar, puesto que tiene origen en la gramática generativa, pero recibió influencia de otras disciplinas como la antropología y la sociolingüística (CENOZ 2004, 
p. 449). En el contexto de aprendizaje de lenguas busca dar respuestas a las siguientes preguntas: ¿en qué consiste aprender una lengua? ¿Qué conocimientos, capacidades o destrezas se necesitan para hablar una lengua? ¿Cuál es el objetivo de la enseñanza de lenguas? (CENOZ 2004, p. 449).

Hymes (1971) fue uno de los principales impulsores de este nuevo concepto. Abogaba por que el análisis de la actuación debería tener en cuenta los rasgos socioculturales de los aprendices y criticaba que la actuación se concibiera como una "adulteración de la competencia ideal" en la teoría de Chomsky (1965) (HYMES, 1971 , p. 29) ${ }^{15}$. A diferencia del concepto de competencia lingüística de Chomsky, la competencia comunicativa incluye la importancia no solo de la gramaticalidad de las oraciones, sino también de la adecuación de los enunciados a los contextos socioculturales en los que se utilizan.

Según la situación, los hablantes pueden usar diferentes registros, considerando los factores que intervienen en la comunicación, como, por ejemplo, las características de los interlocutores, o las relaciones que les unen a estos. Así, los conceptos de aceptabilidad y gramaticalidad forman parte de la competencia comunicativa. Hymes (1971, p. 37) distingue cuatro puntos para entender el lenguaje integrado en la cultura:

a) Si (y en qué grado) algo resulta formalmente posible;

b) Si (y en qué grado) algo es factible en virtud de los medios de actuación disponibles;

c) Si (y en qué grado) algo resulta apropiado (adecuado, afortunado, exitoso) en relación con el contexto en el que utiliza y evalúa;

d) Si (y en qué grado) algo se da en realidad, se efectúa verdaderamente, y lo que ello conlleva.

Sobre el primer punto, Hymes se refiere a si un enunciado concreto es gramaticalmente posible dentro de la cultura. Si es factible, depende ya de las características psicolingüísticas del hablante (como el procesamiento de la información o la limitación de

${ }^{15}$ Como vemos, Hymes y Chomsky entienden la competencia y la actuación de manera muy distinta. De hecho, Hymes (1971) realizó duras críticas a las definiciones de ambos conceptos ofrecidas por Chomsky (1965), las cuales sobrepasan los objetivos y límites de nuestro estudio, por lo que no las discutiremos aquí en profundidad. 
memoria, por ejemplo), lo que se acercaría a lo que entendemos por la actuación en Chomsky (1965). Por su parte, lo apropiado o adecuado de un enunciado está intrínsecamente relacionado con el contexto en que se utiliza; de este modo, tiene relación con dos esferas complementarias: la lingüística y la cultural. Y, por último, "puede que algo resulte posible, factible, apropiado y no llegue a ocurrir" (HYMES, 1971, p. 41). El grado en que algo se da en realidad tiene relación con la capacidad del usuario, aunque sea de manera inconsciente, de predecir o intuir si una estructura es utilizada también por otros usuarios en determinada situación. En el caso del aprendizaje de lenguas extranjeras, se identificaría, por ejemplo, con la impresión que los hablantes de la L2 tienen de que una determinada estructura "suena mal o bien" en la lengua objeto.

En suma, y como subrayan Canale y Swain (1980, p. 16), en estos cuatro puntos se identifican cuatro perspectivas complementarias: la gramatical, la psicolingüística, la sociolingüística y la probabilística.

Autores como Cenoz (2004, p. 452) hacen hincapié en que la conceptualización de las competencias lingüística y comunicativa está relacionada con dos perspectivas distintas que muchas veces se confunden. Mientras que Chomsky entendía la competencia como el conocimiento gramatical, un estado mental que subyace a la lengua, Hymes la interpreta como una habilidad para usar esa lengua. El conocimiento gramatical es un recurso, un componente de la competencia comunicativa que se convierte en uso.

La misma autora defiende también que la competencia comunicativa no es simplemente una extensión de la competencia lingüística, o, una serie de reglas que se han sumado a una teoría existente, sino un concepto cualitativamente distinto. De este modo, el concepto de competencia lingüística es intrapersonal, y se refiere al conocimiento de determinadas reglas de forma innata, de base biológica y de carácter absoluto, mientras que la competencia comunicativa es interpersonal, representa la habilidad para utilizar el conocimiento de la lengua, tiene dinamicidad y depende de la negociación de significado habida entre los interlocutores (CENOZ 2004, p. 451-452).

\subsubsection{El modelo de competencia comunicativa de Canale} (1983) 
Para Cenoz (2004), entre los principales modelos que han desarrollado la noción de competencia comunicativa se encuentran los propuestos por Canale y Swain (1980), Bachman (1990) y CelceMurcia, Dörnyei y Thurrell (1995). En esta sección, nos centraremos en el primero de ellos, más específicamente en la revisión hecha del modelo inicial por Canale (1983), puesto que es la que mejor se adapta a los intereses de nuestro estudio.

En la propuesta inicial de Canale y Swain (1980), fruto de las observaciones del modelo de inmersión lingüística adoptado en Canadá desde los años setenta del pasado siglo, los autores profundizaban en las teorías sobre la competencia comunicativa desarrolladas hasta el momento de la publicación de su artículo, que, a su juicio, no abarcaban todos los aspectos necesarios para especificar unas habilidades comunicativas mínimas (CANALE y SWAIN, 1980, p. 10). De esta manera, en su propuesta distinguían tres componentes de la competencia comunicativa: el gramatical, el estratégico y el sociolingüístico. De este último, Canale (1983) desgajó el componente discursivo, transformando el modelo inicial en cuatro subcompetencias que conforman el esquema que podemos observar en la siguiente figura:

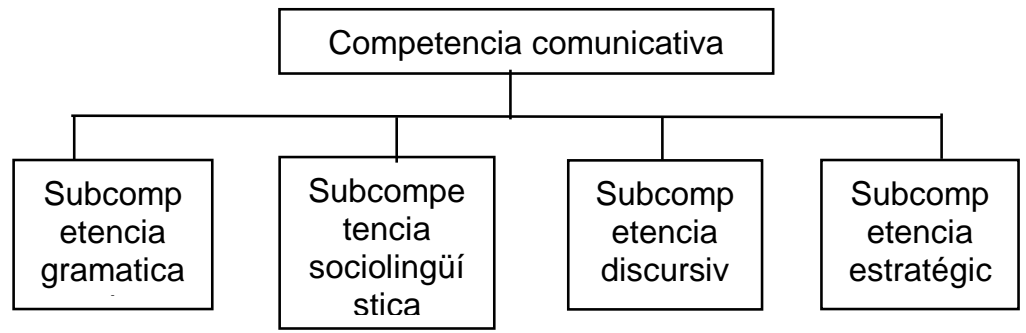

Ilustración 1: Modelo de Competencia Comunicativa de Canale (1983).

La subcompetencia gramatical implica el conocimiento del código (verbal o no verbal) en todos sus niveles: la formación de palabras y frases, la pronunciación, la ortografía y la semántica (CANALE, 1983, p. 66). En otras palabras, la subcompetencia gramatical, es la responsable de utilizar y entender el sistema de forma adecuada. Una muestra de ello sería, por ejemplo, el conocimiento de que enunciados como "Yo soy en esta ciudad de visita" son incorrectos en español. Durante mucho tiempo, el desarrollo de la competencia gramatical fue el único objetivo de la enseñanza de LE, pero, tras la incorporación de la competencia 
comunicativa al debate, la enseñanza de la gramática y su norma se vieron visiblemente afectadas. Hoy en día, la subcompetencia gramatical tiene reconocida la importancia que indudablemente tiene, aunque esta comparte con las demás subcompetencias el espacio de acción necesario para facilitar/concretar la comunicación.

La subcompetencia sociolingüística, por otro lado, se rige por las normas de uso y de discurso según las diferentes situaciones sociales, las cuales requieren diferentes comportamientos lingüísticos. Tales situaciones especifican el empleo de una oración en función del contexto. Para Canale (1983, p. 67), la adecuación de los enunciados está asociada a la adecuación al significado y la forma, por eso, un nivel bajo de competencia social puede apreciarse, por ejemplo, cuando un joven le dice a una persona mayor: ¿Qué pasa tío, qué hora es?, en lugar de dirigirse a él con un enunciado más apropiado: Oiga señor ¿me podría decir qué hora es? Gracias a la competencia sociolingüística -en definitiva, de saberes socio-lingüísticos- somos conscientes de que tenemos que cambiar el discurso de un registro formal a otro informal o viceversa, dependiendo de la distancia social que exista entre los interlocutores. Los cimientos de la competencia sociolingüística son la lengua, la cultura y la sociedad, vistas como un conjunto indisociable. El conocimiento de ese conjunto es fundamental para que haya efectiva comunicación.

Como se ha indicado anteriormente, la subcompetencia discursiva fue separada de la competencia sociolingüística en una segunda revisión hecha por el propio Canale (1983). Esta se refiere a "la manera en que se combinan las formas gramaticales y significados para lograr un texto hablado o escrito en diferentes géneros" (CANALE,1983, p. 68). De esta forma, los diferentes enunciados se unen para formar un todo coherente y cohesionado, facilitando de esta manera la comprensión del texto. El objetivo principal aquí es, pues, desarrollar la habilidad de producir diferentes géneros de discurso, tanto orales como escritos, de manera cohesionada, coherente, adecuada a la situación comunicativa y correcta desde el punto de vista de la estructuración del código.

La subcompetencia estratégica, por su parte, se caracteriza por permitir formar una serie de maniobras verbales y no verbales requeridas para compensar las posibles dificultades comunicativas, derivadas de una competencia o actuación deficientes por parte del hablante (CANALE, 1983, p. 69). Estas deficiencias son fácilmente observables tanto en estudiantes de lenguas como en hablantes nativos, y son empleadas para hacer frente a una falta de conocimiento de determinados signos lingüísticos que surgen en el 
acto de la comunicación. Algunos ejemplos de esta competencia estratégica podrían ser: utilizar gestos, parafrasear o describir un objeto cuando no se sabe o no se recuerda su nombre, etc.

\subsubsection{Notas para nuestro estudio}

En resumen, desde el punto de vista de la competencia comunicativa, se entiende que los estudiantes no deben desarrollar tan solo aspectos formales de la lengua, como se predicó en un pasado, sino que, al mismo tiempo que desarrollan ese tipo de conocimientos, deben aprender a interactuar adecuadamente en diferentes contextos. Para ello, son necesarios diferentes tipos de conocimientos enmarcados dentro del concepto más general de competencia comunicativa.

En la comunidad científica, existe un animado debate acerca de si los aprendices deberían alcanzar un grado de competencia comunicativa al mismo nivel que los nativos, punto de especial interés para nuestro estudio. La perspectiva según la cual los aprendices deben lograr una competencia nativa en la lengua meta es conocida como la visión monolingüe del bilingüismo y ha sido criticada por autores como Cook (1992), el cual propone el término multicompetencia en oposición a una única competencia del aprendiz, eso es, no comparable con las competencias del hablante nativo, como veremos en el apartado siguiente.

\subsubsection{El hablante no nativo: bilingüismo y competencias}

La discusión sobre las competencias que el hablante no nativo debería poseer ha estado presente en los debates científicos de los últimos años. Como hemos mencionado en el apartado anterior, Cook (1992) ha criticado la visión monolingüe del bilingüismo, por la cual los aprendices de una lengua deberían perseguir la misma competencia que un nativo. De hecho, para este autor (véase también en el mismo sentido GROSJEAN, 1992 y EDWARDS, 1994) un bilingüe o plurilingüe que sea completamente equilibrado resulta excepcional.

Paradójicamente, en la enseñanza reglamentaria de LE, se suele tener como referencia la competencia monolingüe, así como el modelo del hablante ideal de la lengua extranjera de la lingüística generativa. Resultado de ello es la sensación de fracaso en la enseñanza, puesto que el aprendiente casi nunca llega a alcanzar el 
nivel de hablante ideal. Todo eso hace que muchas veces la enseñanza de lenguas se considere deficitaria, ya que no se toma en cuenta las necesidades reales de los aprendices, ni considera la competencia real que puede llegar a tener un estudiante de lenguas (CENOZ, 2004).

Una visión contraria al bilingüismo ideal fue presentada por Grosjean (1992 apud CENOZ, 2004, p. 459), quien propuso un modelo holístico de las competencias. Según este estudioso, la lengua de los bilingües no debería compararse con las competencias monolingües, sino con el repertorio total de los hablantes, puesto que los bilingües son hablantes especiales que han desarrollado sus competencias comunicativas en dos lenguas según el contexto en que las han aprendido y utilizado. Así, dos o más lenguas formarían un único sistema lingüístico, en lugar de un sistema para cada lengua adquirida.

En la misma línea de pensamiento, Cook (1992) describe el término multicompetencia, que se caracteriza por ser una forma única de competencia no comparable a la de un hablante nativo. Al igual que Grosjean, Cook entiende la multicompetencia como un estado de la mente que tiene dos gramáticas o el conocimiento total de las lenguas del hablante, en oposición a una mente con una única lengua. Desde su punto de vista, el usuario de L2 debe verse desde la perspectiva de sus diferencias más que por sus deficiencias. Sobre estas últimas, Cook (1997) realiza una dura crítica al hecho de que algunos investigadores fomenten la idea de fracaso basada en el intento fallido de llegar a una competencia similar a la de un hablante nativo. Para ello, presenta una colección de citas recogidas en una serie de trabajos hasta el momento de la publicación de su artículo. Estas son algunas de las más representativas (COOK, 1997, p. 3):

a. Failure to acquire the target language grammar is typical. (Birdsong, 1992, p. 706).

b. Learners often failed initially to produce correct sentences and instead displayed language that was markedly deviant from target language norms. (Ellis, 1994, p. 15)

c. In L2 acquisition, on the other hand, it is common for the learner to fail to acquire the target language fully. (White, 1989, p. 41)

d. Children generally achieve full competence (in any language they are exposed to) whereas adults usually fail to become native speakers. (Felix, 1987, p. 140) 
e. Very few L2 learners appear to be fully successful in the way that native speakers are. (Towell y Hawkins, 1994, p. 14)

$\mathrm{f}$. The lack of general guaranteed success is the most striking characteristic of adult foreign language learning. (Bley-Vroman, 1989, p. 43).

g. The universal success of FLA and ... the relatively poor outcome of instructed SLA. (Doughty, 1991, p. 433)

h. Unfortunately, language mastery is not often the outcome of SLA. (Larsen- Freeman y Long, 1991, p. 153)

El problema del fracaso está, sin duda, en la expectativa de que el aprendiz de L2 debe alcanzar el nivel lingüístico del hablante nativo, como se comprueba en las citas recién expuestas. $\mathrm{Y}$, lamentablemente, mientras intentemos seguir comparando los dos sistemas, afirmaciones inapropiadas como las anteriores seguirán formando parte de las investigaciones en Lingüística Aplicada. Nuestra posición, basada en las ideas de Cook, (1973; 1977; 1992; 1997) es que el usuario de L2 no alcanzará, efectivamente, el nivel de hablante nativo, pero no por ello debemos hablar de "fracaso", o de un "deficiente nativo" (COOK, 1997, p. 5). De esta manera, los bilingües no deben considerarse meros imitadores de la L1, ya que albergan formas únicas de competencia. En uno de sus trabajos más importantes, Cook (1992) presenta una serie de argumentos, fundamentados en diversas investigaciones empíricas, que demostrarían, efectivamente, que los usuarios de una L2 poseen un sistema lingüístico único:

a) La L1 y L2 comparten el mismo léxico;

b) El procesamiento de la $L 2$ no puede ser disociado de la L1;

c) L1 y L2 se encuentran en las mismas áreas en el cerebro;

d) Los bilingües tienen conocimientos distintos de la L1 que los monolingües;

Aunque el concepto de multicompetencia no esté totalmente asentado en la bibliografía especializada ${ }^{16}$, lo cierto es que invita a reflexionar sobre qué grado de competencia podemos llegar a

${ }^{16}$ Para autores como Cenoz (2004), aunque el concepto resulte de gran interés, aún debe desarrollarse a nivel práctico, en el sentido de que es necesario que se encuentren formas de medir la multicompetencia como un todo, para que pueda estudiarse a fondo. 
adquirir en una o más lenguas extranjeras. De acuerdo con Gómez Martínez (2004, p. 154), las principales aportaciones de la teoría de la multicompetencia son:

a) Se lleva a cabo una reevaluación de la idea del hablante nativo como norma a seguir, a favor de la defensa del aprendiz o usuario de segundas lenguas en beneficio propio;

b) La transferencia se entiende como un proceso bidireccional en el que la L1 influye sobre la L2 (concepto tradicional), pero que también tiene lugar en sentido contrario;

c) Dos son las principales repercusiones en la enseñanza de segundas lenguas: por un lado, el objetivo a conseguir no es llegar a la perfección de un hablante nativo, sino ser un experto o un hablante competente en la L2; por otro lado, recuperar el uso de la lengua materna, el cual desempeña un papel muy importante a pesar del ostracismo al que estaba sometido.

La multicompetencia es, claramente, una perspectiva distinta a las propuestas sobre la competencia que veíamos en el apartado anterior, puesto que da por sentado que las posibilidades de llegar a niveles de adquisición nativos son muy bajas. La misma noción de interlengua (SELINKER, 1972), tan ampliamente aceptada, refleja, en el fondo, esta misma idea.

\subsection{En conclusión}

En este breve recorrido sobre las teorías de la adquisición de lenguas extranjeras, hemos debatido sobre las principales características del aprendizaje de una L2. A través de él, hemos visto que la lengua materna tiene, manifiestamente, un papel activo en el aprendizaje de la lengua extranjera, aunque haya aún cierta discusión sobre hasta qué punto tanto la L1 como la Gramática Universal actúan en este proceso. Respecto a esto, hemos señalado que, para diversos autores, (ELLIS,1985; SCHWARTZ y SPROUSE, 1996; COOK, 1998; WHITE, 2003), tanto la GU como la L1 están disponibles y funcionan de manera complementaria.

Hemos visto también, que además de la $L 1$ y la GU, existen otros mecanismos que influyen en el aprendizaje de una L2, como 
los que presenta Krashen en su Teoría del Input. En lo que concierne a esta hipótesis, tiene especial interés para nosotros la discusión respecto a las diferencias entre aprender un idioma en un contexto de inmersión o formal, puesto que son dos entornos que proporcionan características distintas al aprendiz. Como hemos visto en este recorrido teórico, tanto en el contexto formal de la enseñanza de lenguas extranjeras ${ }^{17}$ como en los más naturales del bilingüismo social o la inmersión lingüística, el aprendizaje de la lengua objeto se ve afectado por una serie de razones tanto intrínsecas como extrínsecas al aprendiz. Estas hacen que las competencias del hablante no nativo puedan variar en relación a quienes han aprendido la L2/LE en un contexto de inmersión o de bilingüismo social. En nuestro caso, es evidente que los sujetos del estudio aprendieron la LE en un entorno formal, en el cual el input ofrecido era reducido y cuidado, es decir, controlado básicamente por el profesor y según unos objetivos delimitados específicamente para un determinado grupo, lo que afectará innegablemente al aprendizaje.

También hemos contemplado en esta sección otros factores que afectan el aprendizaje de las lenguas y que deben ser cuidadosamente analizados tanto por los profesores como por los investigadores, para que las necesidades de los estudiantes sean tenidas en cuenta como se merecen, y así estos puedan lograr el éxito en los usos comunicativos de la lengua objeto. No obstante, no todo depende del profesor o del contexto de clase, y el interés del alumno y su comportamiento fuera del ámbito formal ante la lengua meta pueden afectar decisivamente a la competencia comunicativa alcanzada.

En lo que se refiere a la actuación de nuestros sujetos, la teoría del "filtro de salida" nos ofrece una reflexión muy pertinente para nuestro estudio, lo que ha servido, entre otras cosas, para llevar a cabo la recolección de las muestras de habla (ver Capítulo 6). Y es que, como ya destacara Krashen, no siempre conseguimos expresar todo lo que sabemos de una lengua extranjera, ya sea por determinadas características personales (timidez, introversión, etc.), ya por otras más ocasionales, como la ansiedad, el nerviosismo, etc. Todo ello suele ocurrir, según hemos visto, cuando nos centramos en la forma y no en el contenido del mensaje que estamos transmitiendo.

\footnotetext{
${ }^{17}$ Es decir, aquellos contextos donde no hay propiamente contacto de lenguas y donde la lengua meta no se utiliza como vehículo de comunicación en la comunidad estudiada.
} 
Para finalizar, una última intención con este capítulo era la de traer al primer plano la discusión sobre las necesidades debidas a las restricciones del input en contextos no naturales, y reflexionar sobre qué sería un modelo realista del bilingüismo en estos casos. De todo esto, para nosotros tiene una especial relevancia el debate acerca de las competencias del usuario de la L2 y la comparación con el hablante no nativo o el hablante ideal. Ello hace posible entender el bilingüismo en relación con las características personales y los objetivos comunicativos del usuario.

En este sentido, el concepto de multicompetencia, ligado principalmente a la noción de diferentes niveles de competencia, así como la concepción de bilingüismo disociada del hablante ideal y del bilingüismo ideal, parece ser la salida más realista para los individuos que han aprendido una lengua en contextos formales. 


\section{LA TRANSFERENCIA Y EL SISTEMA LINGÜÍSTICO NO NATIVO}

Sentadas las bases teóricas sobre la adquisición de la L2/LE que fundamentan nuestra investigación, trataremos de detallar ahora conceptos más específicos ligados a la influencia de la lengua materna en este complejo proceso. Empezaremos examinando la definición de transferencia y sus especificidades (apartado 2.1), luego haremos un recorrido histórico desde el Análisis Contrastivo (AC) hasta el Análisis de Errores (AE) (apartado 2.2) y, a continuación, analizaremos algunas cuestiones terminológicas referentes a la interferencia lingüística. En los dos últimos bloques nos dedicaremos a describir el concepto y las características de la interlengua (apartado 2.4) y la fosilización (apartado 2.5).

En este capítulo, pretendemos discutir las propiedades del aprendizaje de lenguas extranjeras (entendido este en un contexto formal de enseñanza), así como reconocer cómo ha cambiado la perspectiva sobre la interferencia de la lengua materna en la lengua objeto a lo largo del tiempo y cómo se concibe hoy, puesto que esta es el eje central de nuestro estudio. De la misma manera, pretendemos trazar las propiedades del sistema lingüístico de los hablantes no nativos, las cuales subyacen en la investigación que presentamos en estas páginas.

\subsection{Hacia una definición de la transferencia}

El concepto de transferencia nació en el seno de la psicología para definir situaciones en las que el sujeto aplica su conocimiento previo en circunstancias similares, 0 , en otras palabras, cómo la forma de resolver un problema influye en la manera en que se resuelve otro (Mayer y Wittrock, 1996, apud DURÃO, 2007 p. 34).

En el marco de la cognición humana, no parece ser difícil reconocer que un aprendizaje se ve influenciado por otro, puesto que de manera consciente o inconsciente estamos constantemente relacionando nuestros saberes. Este procedimiento que optimiza nuestros procesos cognitivos, economiza tiempo y facilita el aprendizaje a través del conocimiento previo, puede llamarse transferencia. 
En la psicología, la transferencia de conocimientos de una tarea a otra ha sido ampliamente investigada en sus más variadas formas. Salazar (2006, p. 54-57) presenta hasta 13 modelos provenientes de diversos autores, y que varían de acuerdo con seis parámetros, algunos de los cuales también podrían aplicarse al aprendizaje de una LE. Los presentamos de manera esquemática en el siguiente cuadro:

\begin{tabular}{|c|c|c|}
\hline Parámetro & $\begin{array}{c}\text { Tipo de } \\
\text { transferencia }\end{array}$ & Características \\
\hline \multirow{3}{*}{$\begin{array}{l}\text { Carácter } \\
\text { utilitario } \\
\text { (beneficio/ } \\
\text { prejuicio) } \\
\text { (Chaplin y } \\
\text { Krawiec, } \\
\text { 1984; Bichler } \\
\text { y Snowman, } \\
\text { 1992) }\end{array}$} & Positiva & $\begin{array}{l}\text { El aprendizaje previo beneficia o } \\
\text { facilita alguna ejecución } \\
\text { subsiguiente. }\end{array}$ \\
\hline & Negativa & $\begin{array}{l}\text { El aprendizaje anterior obstaculiza } \\
\text { de alguna manera o interfiere en el } \\
\text { aprendizaje nuevo. }\end{array}$ \\
\hline & $\begin{array}{l}\text { Nula } \\
\text { (Wittig, 1991; } \\
\text { Schunk, 1997 }\end{array}$ & $\begin{array}{l}\text { Ausencia de efecto alguno del } \\
\text { aprendizaje anterior. }\end{array}$ \\
\hline \multirow{2}{*}{$\begin{array}{l}\text { Grado de } \\
\text { similitud entre } \\
\text { tareas } \\
\text { (Schunk, } \\
\text { 1997; Wool- } \\
\text { folk, 1999; } \\
\text { Santrock, } \\
\text { 2002) }\end{array}$} & Cercana & $\begin{array}{l}\text { Las situaciones formales de } \\
\text { aprendizaje son semejantes a la } \\
\text { situación de transferencia. }\end{array}$ \\
\hline & Lejana & $\begin{array}{l}\text { Transferir el aprendizaje previo a } \\
\text { una situación que es muy diferente } \\
\text { de aquella en la que el aprendizaje } \\
\text { original tuvo lugar. }\end{array}$ \\
\hline \multirow{2}{*}{$\begin{array}{l}\text { Proporción de } \\
\text { conocimientos } \\
\text { transferidos } \\
\text { (Roger, 1986) }\end{array}$} & Literal & $\begin{array}{l}\text { Transferir tal cual una habilidad o } \\
\text { un conocimiento a otra tarea. }\end{array}$ \\
\hline & Figurada & $\begin{array}{l}\text { Utilizar solo algún aspecto de los } \\
\text { conocimientos generales para } \\
\text { reflexionar o aprender de cierto } \\
\text { problema. }\end{array}$ \\
\hline $\begin{array}{l}\text { Grado de } \\
\text { relación de } \\
\text { complejidad } \\
\text { (Bichler y }\end{array}$ & Vertical & $\begin{array}{l}\text { Una capacidad previamente } \\
\text { aprendida contribuye de una } \\
\text { manera directa a la adquisición de } \\
\text { una capacidad más compleja. }\end{array}$ \\
\hline
\end{tabular}




\begin{tabular}{|c|c|c|c|}
\hline $\begin{array}{l}\text { Snowman, } \\
1992\end{array}$ & Lateral & \multicolumn{2}{|c|}{$\begin{array}{l}\text { Una capacidad previamente } \\
\text { aprendida se utiliza para resolver } \\
\text { un problema similar a los } \\
\text { problemas que se han encontrado } \\
\text { durante el aprendizaje inicial, pero } \\
\text { en un contexto diferente. }\end{array}$} \\
\hline \multirow[t]{4}{*}{$\begin{array}{l}\text { Grado de } \\
\text { consciencia } \\
\text { del sujeto } \\
\text { (Salomón y } \\
\text { Perkins, } \\
\text { 1989) }\end{array}$} & $\begin{array}{l}\text { De baja } \\
\text { profundidad }\end{array}$ & \multicolumn{2}{|c|}{$\begin{array}{l}\text { El aprendizaje previo, de manera } \\
\text { automática e inconsciente, se } \\
\text { transfiere a otra situación, lo cual } \\
\text { casi siempre ocurre con la práctica } \\
\text { de habilidades que casi no } \\
\text { requieren del pensamiento } \\
\text { reflexivo. }\end{array}$} \\
\hline & $\begin{array}{l}\text { De alta } \\
\text { profundidad }\end{array}$ & \multicolumn{2}{|c|}{$\begin{array}{l}\text { Los estudiantes de manera } \\
\text { consciente establecen conexiones } \\
\text { entre lo que han aprendido en una } \\
\text { situación previa y la nueva } \\
\text { situación de aprendizaje. Es } \\
\text { consciente y requiere de atención y } \\
\text { de cierto esfuerzo mental. }\end{array}$} \\
\hline & & $\begin{array}{l}\text { De } \\
\text { alcance } \\
\text { posterior }\end{array}$ & $\begin{array}{l}\text { El sujeto piensa acerca } \\
\text { de las posibilidades de } \\
\text { aplicación de lo que ha } \\
\text { aprendido en } \\
\text { situaciones futuras. }\end{array}$ \\
\hline & & $\begin{array}{l}\text { De } \\
\text { alcance } \\
\text { anterior }\end{array}$ & $\begin{array}{l}\text { El sujeto mira hacia } \\
\text { atrás, hacia una } \\
\text { situación previa en } \\
\text { busca de } \\
\text { información que le } \\
\text { ayudará a resolver un } \\
\text { problema en el } \\
\text { presente }\end{array}$ \\
\hline
\end{tabular}

Tabla 1: Tipos de transferencia. Adaptado de Salazar (2006, p. 54-57).

De acuerdo con la autora (SALAZAR, 2006 p. 58), de las transferencias presentadas, aquellas que tendrían una relación más estrecha con el desarrollo de las destrezas lingüísticas serían estas: positiva, negativa, cercana, lejana, de alta profundidad y de alcance anterior (SALAZAR, 2006 p. 58). Esos seis tipos de transferencias se basan en procesos cognitivos conscientes e inconscientes, y 
tienen relación con un elemento en común: lo que se transfiere es, en todos los casos, material lingüístico. Salazar (2006, p. 58) explica que la transferencia positiva, por ejemplo, hace que las destrezas de la L1 faciliten la adquisición de la $\mathrm{L} 2$ en relación al tiempo y el esfuerzo requeridos. La transferencia negativa, por su parte, permite al docente, al menos en hipótesis, predecir algunos de los aspectos con los que los alumnos suelen tener mayor dificultad, lo que, en consecuencia, facilita trabajar de manera preventiva. Para la autora (Ibid, p. 58), los principios de la transferencia cercana y lejana ayudan a los alumnos a determinar cuán similares o diferentes son los conocimientos nuevos de los ya adquiridos. Según Salazar (op cit.), la instrucción de la transferencia de alta profundidad permite que las experiencias previas de aprendizaje sean asociadas y conectadas con las nuevas, de manera consciente -lo que difiere de los demás tipos de transferencia-, lo que supone una importante ayuda en el aprendizaje de la L2. Finalmente, el conocimiento de la transferencia de alcance anterior, que es parte de la transferencia de alta profundidad y, por lo tanto, también de carácter consciente, es la responsable de que los alumnos miren hacia el pasado en busca de experiencias vividas en la L1 y con ello puedan resolver sus problemas con la L2.

La transferencia de elementos verbales de una lengua a otra se conoce como "transferencia lingüística". A pesar de ser solamente uno de los complejos procesos que se dan cita en el aprendizaje de una lengua extranjera/L2, la transferencia lingüística ha suscitado diversas interpretaciones y con ellas también denominaciones diversas, que se han ido utilizando a lo largo de los años para identificar el mismo fenómeno: Interference (WEINREICH, 1953), transfer (LADO, 1957), borrowing (CORDER, 1978), Cross-linguistic influence, (KELLERMAN, 1986), Interlingual errors (DULAY, ET. AL., 1982), bidirectional transfer (ELLIS, 2008), entre otros.

Gass y Selinker (1992, p. 5) afirman que muchas de las preguntas sobre la transferencia que hacía Selinker al principio de sus investigaciones, a finales de los años sesenta, seguían siendo discutidas a finales de los años 90, en los días de la publicación de su libro: ¿qué es transferible? ¿Cómo ocurre la transferencia lingüística? ¿Qué tipos de transferencias lingüísticas tienen lugar preferentemente? En definitiva, parece que, pese al largo camino recorrido desde las primeras investigaciones sobre la transferencia, los cuestionamientos de Selinker siguen vigentes y continúan guiando numerosos estudios. En el siguiente apartado, veremos 
parte de este recorrido bajo dos perspectivas que marcaron tanto la didáctica como las investigaciones sobre la adquisición de las lenguas extranjeras: el Análisis Contrastivo y el Análisis de Errores.

\subsection{Un recorrido histórico desde la perspectiva de la transferencia lingüística: Del Análisis Contrastivo al Análisis de Errores}

En este apartado revisaremos cómo los conceptos de transferencia, interferencia y error se han entrelazado a menudo, y cómo han ido cambiando a lo largo del tiempo. También verificaremos qué aportaciones nos han brindado el Análisis de Errores y el Análisis Contrastivo, tanto a nivel didáctico como desde el punto de vista de la investigación, este último, de especial interés para nosotros.

\subsubsection{El Análisis Contrastivo}

Aunque las primeras observaciones sobre la interferencia provienen del siglo XIX (Payrató, 1985, apud BLAS ARROYO, 1991, p. 266), fue en las décadas de los 40 y 50 cuando empezó a discutirse su papel en el aprendizaje de las lenguas extranjeras de manera más precisa. Tres fueron los precursores de lo que hoy conocemos como Análisis Contrastivo: Fries, con la obra "Teaching and learning english as a foreign language" publicada en 1945, Weinreich (1953) con su libro "Languages in contact", y Lado (1957), con la obra "Linguistics across cultures".

Weinreich (1953) examinó los problemas de la transferencia negativa, introduciendo el término interferencia de forma marcada en su obra. El foco de su estudio eran las lenguas en contacto en las situaciones de bilingüismo o multilingüismo social, en las que la lengua se concibe como un producto del contacto social ${ }^{18}$ entre los hablantes de una misma comunidad. En este contexto, la interferencia se produce cuando se incluyen elementos de una lengua en el habla de otras, generando de ese modo un desvío con

${ }^{18}$ Estudiosos como Blas Arroyo (1991) y Durão (2008) consideran a Weinreich uno de los precursores de la sociolingüística por entender el lenguaje como fruto del contacto social, sobre todo en un momento en que la lengua era concebida a través del prisma del estructuralismo y el conductismo. 
respecto a las normas de estas últimas en todos los niveles del análisis: fonológico, morfológico, sintáctico o léxico. Con todo, Weinreich se centró únicamente en el aspecto negativo de la influencia de la LM y no se interesó por el papel positivo que las transferencias pueden desempeñar.

El AC, fundamentado en el conductismo y su visión del aprendizaje por asociación y estímulo-respuesta-refuerzo-hábito, consideraba el influjo de la LM como sinónimo de impedimento, o dicho de otra manera, se entendía esta como la principal causa de los errores cometidos por los estudiantes (BARALO, 1999, p. 36). Para los conductistas, la transferencia era un proceso automático, incontrolado e inconsciente de los hábitos adquiridos, aplicados al intento de producir nuevas respuestas a nuevos estímulos (DULAY ET AL., 1982, p. 101). En este sentido, las transferencias se dividían en dos tipos: positivas y negativas. En palabras de Dulay, et al. (1982, p. 101) ambos tipos están ligados al procesamiento automático e inconsciente del conocimiento antiguo en nuevas situaciones de aprendizaje, pero:

- "Positive transfer" results in correct performance because the new behaviour is the same as the old.

- "Negative transfer" refers of those instances of transfer which result in error because old, habitual behaviour is different from the new behaviour that is being learned.

Los defensores del AC, como Fries (apud LADO, 1957) y Lado (1957), también argumentaban que los principales problemas al aprender una lengua extranjera no surgen de la propia lengua en sí, sino de un conjunto de hábitos creados por la lengua materna, como podemos observar en el prefacio al libro de Lado (1957), escrito por el mismo Fries:

Learning a second language, therefore, constitutes a very different task from learning the first language. The basic problems arise not out of any essential difficulty in the features of the new language themselves but primarily out of special "set" created by the first language habits. (LADO, 1957, prefacio) 
La lengua materna tenía, por tanto, un papel fundamental y limitador en el aprendizaje de una LE, tanto a nivel gramatical como léxico o fonético (LADO, 1957, p. 81), y, en consecuencia, todos los errores se consideraban fruto de esta interferencia que la $L 1$ ejerce sobre la lengua meta. Valdman (1966, apud LEE, 1968, p. 187), rescata las cinco premisas del Análisis Contrastivo:

1. that the prime cause, or even the sole cause, of difficulty and error in foreignlanguage learning is interference coming from the learners' native language;

2. that the difficulties are chiefly, or wholly, due to the differences between the two languages;

3. that the greater these differences are the more acute the learning difficulties will be;

4. that the results of a comparison between the two languages are needed to predict the difficulties and errors which will occur in learning the foreign language;

5. that what there is to teach can best be found by comparing the two languages and then subtracting what is common to them, so that 'what the student has to learn equals the sum of the differences established by the contrastive analysis'.

Según los principios psicolingüísticos relacionados con esta corriente, fundamentados sobre todo en la concepción conductista del lenguaje de Skinner (1926, apud DURÃO, 2004, p. 21-22), el aprendizaje de la L2 se desarrolla básicamente a partir de la imitación del habla del nativo o del profesor. La repetición de las estructuras lingüísticas, consideradas como un hábito (LADO, 1957, p. 57-59) lleva al aprendizaje de la lengua, y, por ello, hay que centrarse en los aciertos y no en los errores. De ahí la idea de que el error necesita ser evitado, ya que puede generar hábitos incorrectos. Para impedir errores como los descritos por Valdman, los investigadores proponen un método basado en la elaboración de cuadros que expliciten la similitud y la disparidad entre la lengua materna y la L2, siguiendo para ello los siguientes pasos, según (FERNÁNDEZ, 1995, p. 205):

1. Descripción formal de las lenguas analizadas;

2. Selección de las áreas a ser comparadas; 
3. Comparación entre las diferencias y similitudes;

4. Predicción de los posibles errores.

En las clases, el fundamento era la repetición de frases y la reiteración de los puntos previstos como más complicados de aprender y que podrían transformarse en errores perpetuos (FERNÁNDEZ, 1995, p. 206). Sobre la aplicación del método del AC a la enseñanza de lenguas, Lado $(1957, \mathrm{~s} / \mathrm{n})$ sostenía que la utilidad del análisis contrastivo radicaba en la posibilidad de predecir y describir patrones lingüísticos que causan dificultades o no en el aprendizaje. Ello se consigue a través de la comparación entre la lengua y la cultura nativa por un lado, y la lengua y la cultura objeto por otro.

Como señala Durão (2008, p. 77), la teoría de Lado defendió el estudio de la transferencia como una potente herramienta para la enseñanza de lenguas bajo la premisa de que cualquier conocimiento lingüístico previo al aprendizaje de una LE (ya sea la LM u otra lengua adquirida) le afectaría innegablemente.

Pese a que el $A C$ ejerció gran influencia en la metodología de la enseñanza de la L2 durante más de 20 años, en los años 70 y 80 del pasado siglo surgieron nuevas aportaciones tanto en la lingüística general como en la psicolingüística y la sociolingüística, que suponían una fuerte crítica a los planteamientos del AC (FERNÁNDEZ, 1995, p. 206). Así, diversos trabajos empíricos (CORDER, 1981; DULAY ET AL., 1982; ELLIS, 1985), demostraron que los métodos desarrollados por el AC fallaban en su principal objetivo: el de evitar los errores. Al mismo tiempo, la validez del conductismo, base teórica del AC, empezaba a ser cuestionada.

Entre las principales reacciones críticas al análisis contrastivo figuran las investigaciones de Dulay y Burt (1974b), quienes fueron los primeros en debatir sobre los errores ambiguos, aquellos que se pueden producir por transferencia o por el desarrollo de la L2. Estas investigadoras cuestionaban la validez de las teorías sobre la interferencia, argumentando a partir de sus estudios con niños solo un porcentaje muy pequeño (3\%) de los errores de los aprendices eran realmente fruto de la interferencia. Defendían, por el contrario, que la adquisición de la $\mathrm{L} 2$ se produce a través de principios innatos y no a través del molde ejercido por la L1 (DULAY y BURT, 1974a, p. 121).

Aunque el porcentaje tan bajo de interferencias encontrado en el estudio de Dulay y Burt (1974b) se deba, probablemente, a que es un estudio realizado con niños, y a pesar de que hoy en día todavía perviva la discrepancia sobre la validez de sus hipótesis, 
para Gass y Selinker (1992, p. 6) el principal argumento de Dulay y Burt, conocido como $\mathrm{L} 2=\mathrm{L} 1$, supuso una enriquecedora discusión sobre el análisis contrastivo.

Incluso una de las más conspicuas defensoras del AC, Schachter (1974, p. 197), reconoció al menos dos fallos importantes en la teoría: (i) el AC se centró demasiado en los errores predictivos y muy poco en lo que realmente hacen los alumnos; (ii) existían pruebas suficientes para sostener que la LM no es la única responsable de los errores.

En resumen, podríamos decir que el AC desarrolló una manera de identificar los errores potenciales de los aprendices mediante la metodología contrastiva, pero esta no era suficiente para explicar todos los tipos encontrados por los estudiosos (BARALO, 1999, p. 37). Había, por tanto, una necesidad de examinar los errores de los aprendices desde un punto de vista más amplio y en el que se tuvieran en cuenta otras causas posibles. Así, con una reevaluación de la metodología del AC, y también de la propia concepción del error $-y$, consecuentemente, del papel de la transferencia- nació el Análisis de Errores, paradigma que abordamos a continuación.

\subsubsection{El Análisis de Errores}

El análisis de errores, desarrollado sobre todo por Corder (1967) y que nació apoyado en la teoría de la Gramática Universal de Chomsky (1965), el concepto de Competencia Comunicativa (HYMES, 1971) surgió, como hemos comentado, como una reacción al Análisis Contrastivo (LADO, 1957), y aportó un amplio abanico de explicaciones para muchos tipos de desvíos lingüísticos que no podían ser explicados cabalmente por el AC (DULAY ET AL., 1982, p. 140-141).

Desde que Corder introdujo a finales de los años 60 los primeros argumentos acerca de la importancia de valorar los errores de los aprendices en su célebre artículo: "The significance of learners' errors" (CORDER, 1967), la concepción de estos cambió tan radicalmente que pasó a convertirse en uno de los principales focos de investigación en el seno del aprendizaje de segundas lenguas. Como indicábamos anteriormente, antes de Corder, el error tenía una connotación negativa y por ello se rechazaba su papel en 
el aprendizaje. A partir de sus postulados ${ }^{19}$, sin embargo, por primera vez, tanto investigadores como profesores empezaron a utilizar las producciones de los alumnos como base tanto para construcciones teóricas como para la práctica docente.

La principal diferencia entre la metodología de trabajo del $A E$ y la del $A C$ residía en que, mientras que este último comparaba la lengua nativa del aprendiz con la lengua meta, el Análisis de Errores examinaba contrastivamente las producciones de los aprendientes con la L2. La metodología utilizada por el AE consistía básicamente en la propuesta de Corder (1971b): (i) identificación de los errores; (ii) catalogación y descripción; (iii) explicación;

Corder (1981b, p. 35) defendía también que el Análisis de Errores es, por un lado, una técnica experimental para la validación de la teoría de la transferencia propuesta por el $A C$, o lo que es lo mismo, el AE sirve para confirmar o refutar las predicciones basadas en el contraste interlingüístico. Pero al mismo tiempo, el AE es también una metodología de investigación de los procesos psicolingüísticos del aprendizaje del lenguaje, en el sentido de que busca estudiar las estrategias empleadas por los aprendices.

En relación con la distancia interlingüística, Corder (1983, p. 21 ), entendía que hay una clara relación entre la velocidad del aprendizaje y la lejanía estructural entre la lengua materna y la lengua extranjera. De esta manera, cuanto mayor sea la similitud entre la L1 y la L2, más rápido se aprenderá, por la "ayuda" que la lengua materna puede ofrecer en la adquisición de la lengua extranjera. La LM serviría como un simplificador de las propiedades y características de la lengua meta, y funcionaría como los cimientos del aprendizaje, aportando un papel predominantemente heurístico y facilitador. Al contrario, cuanto más distante esté la lengua materna con respecto a la lengua objeto, más tiempo llevará aprender esta última. También sobre la función de la LM, Corder (1983, p. 21), aboga por que la lengua materna no parece jugar un papel decisivo en estadios iniciales del desarrollo de la LO, pero cobra importancia en momentos más avanzados. En este sentido, la transferencia es una estrategia de comunicación, es decir, un fenómeno de actuación y no exactamente un proceso de aprendizaje.

${ }^{19}$ Una recopilación de los trabajos más importantes e impulsores del cambio de perspectiva sobre el error en el aprendizaje de lenguas extranjeras se encuentra en su libro Error analysis and interlanguage (CORDER, 1981). 
Sobre la aportación del análisis de errores a la investigación de las lenguas extranjeras, Fernández (1995, p. 207) argumenta que la perspectiva del error es la más significativa:

El cambio, o mejor, la revolución más importante de esta corriente es, sobre todo, la nueva concepción de los errores, que se valoran ahora, además de como paso obligado para llegar a apropiarse de la lengua, como índices del proceso que sigue el aprendiz en ese camino; proceso y camino que constituyen una de las grandes cuestiones sobre las que giran las investigaciones sobre el aprendizaje en general y el de las lenguas, en particular. (FERNÁNDEZ, 1995, p. 207)

Asimismo, hay, según esta autora, una aportación importante desde el punto de vista didáctico, ya que el error ha pasado de ser considerado como "un pecado" a valorarse como un paso obligado en el aprendizaje de las lenguas extranjeras. Los enfoques comunicativos habrían sido los principales impulsores de esta actitud, a través de la exposición del alumno a la práctica de situaciones auténticas de comunicación (FERNÁNDEZ, 1995, p. 207).

Según Vázquez (1992, p. 105), el análisis de errores también ha contribuido a esclarecer y determinar con mayor rigor dos conceptos: el de "dificultad real" en el aprendizaje, y el de "nivel" lingüístico. Según la investigadora, los trabajos de los años 70 y 80 han demostrado que:

1. Analizar y clasificar errores constituye un método eficaz para evaluar el proceso de aprendizaje y las metodologías de enseñanza, así como también para determinar los factores que influyen sobre el éxito o fracaso de los mismos.

2. Indagar sobre las causas y el origen de los errores es la condición indispensable para diferenciar entre procesos naturales de aprendizaje y las consecuencias de la instrucción formal. 
3. Es posible desmitificar la importancia de ciertos errores en áreas consideradas tradicionalmente complejas.

4. Es conveniente aplicar la noción de error transitorio, fosilizable y fosilizado a la organización del currículum, puesto que facilitaría la determinación de niveles dentro de los cuales tomar decisiones en cuanto a qué, cómo y cuándo corregir. (Vázquez, 1992, p. 105)

La teoría del análisis de errores sufrió también algunas críticas, como, por ejemplo, el hecho que no llegara a definir toda la interlengua, sino tan solo los aspectos más idiosincrásicos de esta, es decir, los errores (FERNÁNDEZ, 1997, p. 22). Por su parte, Dulay et al. (1982, p. 141) consideran que existen tres problemas principales en el $\mathrm{AE}$ :

1. La confusión entre la explicación y la descripción de los errores;

2. La dificultad en precisar y especificar las categorías de errores;

3. La simplicidad en la categorización de las causas de los errores de los aprendices, principalmente porque se centraba únicamente en los problemas del aprendiz y no tenía en cuenta sus logros o avances.

Según Otero Gutiérrez (2008, p. 3), el AE no reconocía la importancia de estrategias bien conocidas hoy en día como cruciales para los aprendientes, como las de "evasión" ${ }^{20}$, que llevan al hablante a evitar, consciente 0 inconscientemente, aquellas estructuras en las cuales no se siente seguro; o las de "compensación", que conducen a los aprendices a parafrasear las estructuras con las que tienen más dificultad.

En suma, a pesar de juicios críticos como los anteriores, el análisis de errores fue un intento significativo de considerar los errores de los aprendientes que no se podrían explicar a través de la

${ }^{20}$ La "evasión" fue tratada por primera vez por Schachter (1974), con el nombre de "inhibición", como veremos más detalladamente en el subapartado siguiente. 
teoría del Análisis Contrastivo, y supuso una importante contribución para tomar conciencia del origen múltiple de aquellos. Asimismo, cabe destacar entre sus méritos, el haber sabido promover la idea del error como un proceso natural del aprendizaje, en lugar de como una inadecuación en la interlengua de los aprendices (DULAY ET AL., 1982, p. 138-141).

\subsubsection{De la versión débil a la versión fuerte del Análisis Contrastivo: ¿se pueden fundir el AC y el AE?}

Como se ha visto hasta ahora, la diferencia entre el Análisis Contrastivo y el Análisis de Errores salta a la luz, tanto en lo que concierne a las teorías de adquisición del lenguaje que los fundamentan, como en su metodología para el análisis de los datos. No obstante, aunque parezcan corrientes antagónicas, algunos autores, como Wardhaugh (1970), han establecido puentes entre ellas a fin de encontrar un método adecuado para sus necesidades investigadoras.

Lo anterior ha llevado a dividir el Análisis Contrastivo entre una versión fuerte (también llamada "a priori" o "predictiva") y una versión débil (denominada asimismo como "a posteriori" o "explicativa"). La versión "fuerte" corresponde a los constructos teóricos del AC "puro", defendidos por Fries (1945) y Lado (1957), los cuales se basaban en describir y predecir los errores de los aprendices de L2 apoyados en la comparación entre los sistemas lingüísticos de la LM y la L2, según lo explicado en el subapartado 2.2.1.

Gradman (1971 apud SCHACHTER, 1974, p. 196), quien escribió su tesis sobre el Análisis Contrastivo, propuso la terminología "a priori" y "a posteriori" utilizada más tarde de manera asidua por Schachter (1974), una de las defensoras más fervorosas del Análisis Contrastivo. Uno de los principales argumentos en defensa del AC destacado por Schachter es que, el hecho de que los sujetos no produzcan las estructuras previstas por el AC no es motivo suficiente para su rechazo, puesto que muchas veces tales estructuras no aparecen sencillamente por el recurso a la inhibición $^{21}$. En otras palabras, los estudiantes evitan reproducir aquellas estructuras con las que tienen dificultad, una estrategia que

\footnotetext{
${ }^{21}$ Eckman (1977) también subrayó en sus estudios la importancia de considerar la inhibición.
} 
es fundamental en el aprendizaje y que, sin embargo, es ignorada por el Análisis de Errores:

\begin{abstract}
El alumno aparentemente construye hipótesis acerca de L2 basadas en el conocimiento que tiene de su propia lengua. Si las construcciones son similares en la mente del alumno, transferirá la estrategia utilizada en su lengua nativa a la lengua objeto. Si son radicalmente diferentes, o bien rechazará la construcción nueva o bien la utilizará solo con una extrema precaución. Por otra parte, el análisis de errores sin predicciones "a priori" no es capaz de dar cuenta del fenómeno de la inhibición. Si un estudiante no produce las construcciones que considera difíciles, será imposible llevar a cabo un Análisis de Errores en el que basar nuestra explicación. (SCHACHTER, 1974, p. 203)
\end{abstract}

A pesar de los esfuerzos de Schachter por defender la versión "fuerte" del AC, esta fue criticada por varios autores, como Wardhaugh (1970), quien incluso llegó a tachar de "impracticable y poco realista" (WARDHAUGH, 1970, p. 43) y "útil solo para quien esté dispuesto a ser muy ingenuo en cuestiones lingüísticas" (WARDHAUGH, 1970, p. 49). Wardhaugh criticaba a los investigadores que declaraban fundamentar sus trabajos en el AC, porque, en su opinión, resulta imposible describir y comparar dos sistemas lingüísticos con el poder de precisión necesario que la teoría contrastiva requiere. Para este autor, los investigadores acaban usando más la intuición que una teoría explícita de predicción de las dificultades.

Otra crítica de envergadura puede observarse en las siguientes palabras de Nemser (1971), quien argumenta que el método del AC fuerte falla principalmente porque el comportamiento del alumno no puede describirse sin referencia a su sistema aproximado (interlengua):

La versión fuerte afirma que el comportamiento del alumno se puede predecir mediante una comparación entre la L1 y la LO. No obstante, inmediatamente surgen problemas, entre los que se incluyen: (i) diferentes análisis llevan a predicciones diferentes; (ii) las predicciones son, a menudo, ambiguas, y (iii) los diferentes 
niveles de la estructura lingüística son interdependientes, por lo que las predicciones acerca de la interferencia fónica, por ejemplo, deben tenerse en cuenta no solo para los sistemas fonológicos de la L1 y la LO, sino también para sus niveles morfofonémicos, gramatical y léxico. Han sido escasos los intentos serios de confirmar la validez de esa teoría e incluso algunas de las investigaciones reconstrucciones ex post facto como pruebas a favor del poder predictivo. Los pocos estudios serios realizados sobre la validez de la versión fuerte nos hacen dudar de su poder predictivo. (NEMSER, 1971, p. 57-58)

Como reacción a los fallos del AC "fuerte", nació el AC "débil", también considerado como un subcomponente del $\mathrm{AE}$ (SCHACHTER, 1974, p. 197). Su principal característica residía en que los investigadores buscaban establecer una correlación directa entre la LM y la L2 sin la predicción de los errores. En esta versión, el investigador utiliza la observación de los errores y la lingüística comparativa para entender y explicar la producción de los aprendices. La diferencia está, básicamente en el foco: "EI AC 'a priori' es neutro en cuanto a la comprensión y la producción, mientras que su versión 'a posteriori' se basa en la producción" (Schachter, 1974, p. 204).

Para Wardhaugh (1970), la versión débil tiene sus ventajas porque necesita menos de la teoría lingüística, ya que "parte de las evidencias reales de la interferencia de la LM, como la traducción imperfecta, las dificultades de aprendizaje, los acentos extranjeros residuales, etc." (WARDHAUGH, 1970, p. 46). No obstante, a pesar de estas duras críticas al modelo del AC fuerte, Wardhaugh estaba de acuerdo com Schachter (1974) en al menos un punto central: el reconocimiento de que los sistemas fonéticos de dos o más lenguas no son comparables. Contraria a esta visión, son autores como Eckman (1977), que fundamenta su conocida "Teoría de lo marcado"22, precisamente en estudios fonéticos.

${ }^{22}$ En palabras de Liceras (1992, p. 208): "Eckman defiende que su hipótesis supone un intento de resolver el problema de origen inter o extralingüístico de los errores que se producen en el aprendizaje de la L2 porque permite 
En resumen, entendemos que la versión débil fue un intento de adaptar el AC a las nuevas demandas de la lingüística y la didáctica, (donde la lengua ya no era concebida como un conjunto de hábitos) y para ello hubo un empeño en relacionarlo con la metodología del AE. Ahora bien, algunos autores, como Sánchez Iglesias (2003) y Alba Quiñones (2009), defienden que con esta adaptación se produjo una importante confusión epistemológica entre ambos. Esta opinión, que compartimos, llama la atención sobre el hecho de que se han mezclado una hipótesis teórica (AC) y un tipo de análisis de datos (AE). En las palabras de Baralo (2009), el análisis de errores puede ser considerado:

[...] una técnica de observación, identificación, análisis, clasificación e interpretación de las producciones idiosincrásicas de los hablantes no nativos, en cualquier situación espontánea o controlada de respuesta lingüística [...]. (BARALO, 2009, p. 1)

Para Alba Quiñones (2009, p. 2), hubo una secuencia cronológica en el desarrollo del AC y AE, pero no por ello deben confundirse con, necesariamente, dos teorías lingüísticas. Según esta autora (Ibid., p. 2), el Análisis de Errores nació de la necesidad de superar los fallos del AC, y, si bien tiene una base cognitivista y psicolingüística indudable, parece haber prosperado sobre todo por su propuesta metodológica. Tanto es así que, como hemos visto, fue incorporado a la versión débil del AC y hoy día es fácilmente observable su aplicación en diversos tipos de trabajos, con las más diferentes bases teóricas ${ }^{23}$.

\subsubsection{Notas para nuestro estudio}

Para terminar, aunque a menudo no se suela destacar la contribución del $A C$ a la investigación de la adquisición de segundas lenguas, es incuestionable que la corriente impulsó el desarrollo

ponerlos en relación con lo de la L1 a partir del principio del marcado tipológico y, al mismo tiempo, tiene en cuenta el papel de la L1."

${ }^{23}$ Baralo (2009, p. 2), por ejemplo, cita una serie de investigaciones de distinta naturaleza en las cuales el AE se ha utilizado como una "herramienta imprescindible para obtener datos que permitan confirmar o refutar las hipótesis de la investigación realizadas". 
científico de este campo de la lingüística, aunque fuera de manera más teórica que práctica, es decir, más dirigida al profesor de lenguas que a su aplicación en el aula (y de ahí algunas de sus mayores críticas), como destaca Santos Gargallo (1992, p. 63). La misma autora (Ibid., p. 67) también señala que el AC "constituye el fundamento y origen" de los estudios de interlengua que se llevan a cabo hoy día y que no se habría llegado a ellos sin los postulados de Lado y Fries.

Otra gran aportación es el concepto de transferencia que, como hemos visto, ha ido cambiando a lo largo de la historia, pero que hasta entonces no se tenía en cuenta ni didáctica ni científicamente (ALBA QUIÑONES, 2009, p. 2). Como contrapartida, el $A E$ sigue siendo hoy una de las corrientes metodológicas más aceptadas, si bien, como ya apuntaba Schachter (1974, p. 205), no debemos olvidar que una única metodología no es suficiente para dar respuesta a todas cuestiones referentes a la adquisición de la L2.

Por ello, defendemos en este estudio que los supuestos de la Lingüística Contrastiva ${ }^{24}$ (LC) y del Análisis de Errores son fundamentales en el estudio de la adquisición de L2, y, más específicamente, en el examen de los casos de interferencia. Con el auxilio de ambos paradigmas, podemos entender mejor los patrones que adoptan los errores de los estudiantes de una misma lengua extranjera, y que, además, parten de una misma lengua materna. Por otro lado, el interés por investigar la influencia de la L1 se justifica, como hemos podido comprobar en este recorrido teórico e histórico, por el papel innegable que tiene en la "apropiación" de la lengua meta.

\subsection{La interferencia lingüística: algunas consideraciones terminológicas}

Aunque, como hemos visto, el estudio de la transferencia lingüística tomó impulso a partir de los años 50, para Blas Arroyo,

${ }^{24}$ La lingüística contrastiva de nuestros días, que nació con el AC de antaño, permite un análisis del aprendizaje de lenguas extranjeras ligado a otras disciplinas de la linguística aplicada. Para Vez (2004, p. 152) la LC es una de las aportaciones más positivas del estructuralismo funcionalista, que, a través de la interdisciplinariedad lingüístico-psicológica, permite analizar las relaciones entre dos sistemas lingüísticos distintos, idea que compartimos. 
(1991, p. 266), el empleo del término interferencia ${ }^{25}$ en la lingüística ocurrió bastantes años antes, con los trabajos de Sandfeld (1936) y Jakobson (1936). Para el autor, el término nació bajo la óptica negativa del error, y la imprecisión de su concepto ha contribuido a que se mantengan numerosas discrepancias sobre muchos aspectos relacionados con ella.

En este sentido, Dulay et al. (1982, p. 98) argumentan que la interferencia ha sido usada en referencia a dos tipos de fenómenos distintos: uno, esencialmente psicológico (influencia de los hábitos antiguos sobre el nuevo aprendizaje); y otro, de naturaleza más sociológica (basado en la interacción de las lenguas en contacto). Según las autoras (DULAY ET AL., 1982, p. 98), hay, pues, una clara diferencia entre los trabajos de, Weinreich (1953) y Haugen (1970), por un lado, y el concepto de interferencia utilizado por el Análisis Contrastivo. Esa discrepancia se concentra en tres aspectos distintos: (i) su relación con la LM; (ii) la jerarquía de las lenguas aprendidas; y (iii) la relación entre la interferencia y el bilingüismo.

Respecto al primer aspecto, hay que recordar que para Weinreich y Haugen, la interferencia es básicamente un fenómeno sociolingüístico, mientras que para el $A C$ se trata de un fenómeno psicológico de transferencia de la lengua materna. Por ejemplo, Weinreich (1953, p. 1) define con estas palabras la interferencia:

Those instances of deviation from de norms of either language which occur in the speech of bilinguals as a result of their familiarity whith more than one language, i. e., as a result of languages in contact.

En contrapartida, Lado (1957, p. 58), afirma:

We know from the observation of many cases that grammatical structures of the native language tends to be transferred to the foreing language. The student tends to transfer the sentence forms, modification devices, the

${ }^{25}$ Van Overbecke (1976) (apud BLAS ARROYO, 1991, p. 265), afirma que el concepto de interferencia proviene de la física y hace referencia al "encuentro de dos movimientos ondulatorios con el resultado de un reforzamiento o por el contrario, de una anulación de la onda", concepto del cual se apropiaron otras ciencias como la electrónica, la pedagogía, la psicología y la lingüística. 
number, gender, and case patterns of this native language.

Comparando las dos citas, podemos comprobar, efectivamente, cómo los autores se refieren a dos contextos distintos. Mientras que Weinreich habla de una interferencia basada en hablantes bilingues de las lenguas en contacto en situaciones de bilingüismo social, Lado se refiere al contexto formal de aprendizaje de una lengua extranjera. En el primer caso no es tan importante la $\mathrm{L} 1$ del usuario, puesto que tanto la L1 como la L2 pueden causar interferencia una sobre otra. En el segundo, la LM es necesariamente causa de la interferencia en la LE.

El segundo aspecto distintivo, el orden de aprendizaje de las lenguas estudiadas, está también estrechamente relacionado con las citas anteriores. Mientras que Weinreich alude a las lenguas en contacto en un contexto natural bilingüe, Lado presenta los términos "lengua nativa", "lengua extranjera" y "estudiante" lo que nos remite, claramente, a una jerarquía en el aprendizaje: LM - LE. Por otro lado, para el estudio de las lenguas en contacto no siempre es posible hacer una distinción clara en el orden de aprendizaje L1 - L2.

El tercer y último aspecto distintivo está relacionado con la comunicación y el estatus bilingüe o no de los interlocutores. Por ejemplo, Weinreich y Haugen argumentan que, cuando los interlocutores son bilingües, la interferencia aparece de manera muy frecuente, pero cuando son monolingües la presencia de esta baja significativamente. Sobre este aspecto, Blas Arroyo (1991, p. 268) subraya el hecho de que ya Weinreich (1953) se percatara de que "la interferencia no era una simple cuestión de préstamos efímeros de una lengua a otra, sino un fenómeno sistemático que ocurría en el habla de las comunidades bilingües". ${ }^{26}$ En otras palabras, desde un punto de vista sociológico, la interferencia se ve como algo natural e intrínseco al bilingüismo. No obstante, para el AC las circunstancias se invierten, eso es, cuanto más cerca esté el aprendiente del bilingüismo, menos interferencia de la LM debería presentar en su discurso. Esto ocurre porque una mayor incidencia

\footnotetext{
${ }^{26}$ Tanto es así, que fueron creados los términos "integración” y "convergencia" para abarcar el fenómeno de la influencia de una lengua en otra en las comunidades bilingües. Un mayor acercamiento a estos aspectos de las lenguas en contacto puede encontrarse en Blas Arroyo (1991, p. 271-279; 2004, p. 603-610).
} 
de las interferencias se entiende como una señal de menor nivel lingüistico.

Aunque las diferencias no sean siempre fáciles de delimitar, parece, en suma, que las dos perspectivas son significativamente distintas. Para la sociolingüística, la interferencia no es un problema necesariamente, mientras que para el $A C$ es un sinónimo de impedimiento. Esta concepción negativa de la interferencia es polémica y procede del conductismo, como hemos visto anteriormente.

No obstante, hoy en día, en el campo de la adquisición de lenguas extranjeras, la interferencia es concebida solamente como uno más de los aspectos que conforman el complejo proceso de aprendizaje. Una vez detectada, puede ser, efectivamente, uno de los indicativos de la lejanía de la interlengua del aprendiz respecto de la LO, pero en la actualidad, la interferencia ha dejado de considerarse como algo esencialmente nocivo. De hecho, Dulay et al. (1982, p. 96) indicaban ya en los años ochenta que la LM no debía considerarse como una "molesta" interferencia en el esfuerzo de adquirir una $L 2$, sino que, vista de una manera más respetable, representa una pieza importante en el proceso de apropiación de la L2. En el mismo sentido, autoras como Baralo (1999) ${ }^{27}$, González (1999) y Durão (2007) argumentan que actualmente la transferencia ${ }^{28}$ ha dejado de entenderse como un simple proceso mecánico de transposición de datos, y ha pasado a aceptarse desde un punto de vista más cognitivo. Esta caracterización, con la cual estamos básicamente de acuerdo, se puede entender mejor con la siguiente cita de Durão (2007, p. 37):

Hoy en día, en la mayoría de los estudios, la transferencia ha perdido los matices conductuales que le dio la Psicología conductista y se ha revestido de una naturaleza cognitiva, la cual entiende que el aprendiz está dotado de la capacidad de hacer uso, entre otros aspectos, de sus conocimientos lingüísticos previos y de factores afectivos y

${ }^{27}$ Baralo (1999, p. 46) considera la transferencia como una estrategia universal que surge cuando hay inestabilidad en el aprendizaje, y suele aparecer cuando la L2 presenta un rasgo marcado, mientras que en la LM la misma estructura es más universal.

${ }^{28}$ Las autoras citadas se refieren explícitamente a la "transferencia" (positivas y negativas). No obstante, el término interferencia experimentó el mismo cambio de perspectiva. 
socioculturales para construir sus enunciados. O sea, la transferencia ya no se ve como una simple transposición de las formas de la LM a la LO, sino como un mecanismo cognitivo del que el aprendiz echa mano y que puede dotar su interlengua de diferentes perfiles.

\subsubsection{Notas para nuestro estudio}

Aunque Baralo (1999), González (1999) y Durão (2007) señalen en sus estudios que la interferencia es parte integrante de la transferencia, desafortunadamente, no siempre es lo que observamos en los trabajos del área. Por el contrario, los términos transferencia/interferencia se usan indistintamente en referencia a los fenómenos de transferencia negativa, lo que causa una cierta confusión en la bibliografía especializada.

Por esta razón, nos gustaría aclarar aquí, que en nuestro estudio investigaremos la interferencia ${ }^{29}$ (transferencia negativa ${ }^{30}$ ) entendida como un fenómeno que es parte de la de la transferencia. Lo haremos desde la perspectiva psicolingüística de la adquisición de las lenguas extranjeras, en la cual la transferencia no se concibe como un procedimiento mecánico, sino psicológico y lingüístico, de manera que activa los conocimientos de la LM del aprendiz, así como los de otras lenguas conocidas con el fin de impulsar la LE (Faerch y Kasper, 1987; Kellerman, 1978; apud DURÂO, 2005, p. 132). Asimismo, consideramos la transferencia como una estrategia psicolingüística para facilitar el aprendizaje de la LE (McLaughin, 1987 apud DURÃO, 2005, p. 132). Tales definiciones están conectadas con la concepción tanto de la transferencia como de la interferencia/transferencia negativa discutidas aquí anteriormente (DULAY ET AL., 1982; BARALO, 1999; y DURÃO, 2007; OLDIN,

${ }^{29}$ Corder (1983) en su artículo "A role for the mother tongue", decidió no usar el término "interferencia" en sus trabajos puesto que, para él, este invocaba el papel de la LM defendido por el AC. No obstante, tal como explicamos en este subapartado, al emplear el término "interferencia" en nuestro estudio, estamos adoptando un punto de vista más contemporáneo, alejado de las concepciones conductistas sobre la lengua y el aprendizaje.

${ }^{30}$ Utilizaremos los términos interferencia, transferencia negativa, errores interlingüísticos y errores interlinguales (DULAY ET AL., 1982, p. 171) como sinónimos en nuestros análisis. En el Capítulo 4 retomaremos algunos aspectos de estos errores. 
2003), y de ellas nos serviremos para los análisis de los errores de nuestros sujetos.

Acerca de qué áreas son más susceptibles a la transferencia, entendemos, como Oldin (2003, p. 437) y Henriques (2005, p. 169), que esta afecta a todos los niveles lingüísticos. En concreto, Oldin (2003, p. 437) menciona las esferas de la pragmática, la retórica, la semántica, la sintaxis, la morfología, la fonología, la fonética y hasta la ortografía.

En la próxima sección, hablaremos del sistema lingüístico de los hablantes no nativos, sistema que ha sido ampliamente investigado y discutido en la bibliografía científica, y en el que tanto la transferencia como la interferencia representan algunas de sus características más constitutivas. Entender las propiedades de la interlengua es de capital importancia para nuestro estudio, puesto que este es el sistema que utilizan los sujetos de nuestra investigación.

\subsection{La interlengua}

Según Fernández (1997, p. 21), las descripciones de la interlengua comenzaron en el entorno del Análisis de Errores, impulsadas por una preocupación didáctica que terminó por extenderse a la investigación sobre la adquisición de las lenguas. Diferentes autores se ocuparon de su definición, entre ellos, los más destacados son: Corder (1967, p. 10), quien la denominó competencia transitoria y algunos años más tarde, dialecto idiosincrático, o, más específicamente, dialecto transicional (Corder, 1971 b, p. 22). Por su parte, Nemser (1971, p. 52) habló también de un sistema aproximado, pero fue Selinker (1972, p. 32) quien finalmente terminaría bautizándola con el término que luego ha hecho más fortuna, interlengua.

Como la nomenclatura sugiere, el reconocimiento del sistema no nativo como tal está claramente planteado en esos tres trabajos, aunque con sesgos distintivos. Para Frauenfelder et al. (1980, apud FERNÁNDEZ, 1997, p. 19), en esa diversidad terminológica residen tres nociones comunes: la idea de sistema (identidad abstracta que se desprende de las producciones de los aprendices, interpretado como un dialecto, puesto que es sistemático), la idea de evolución (puesto que es un estadio transitorio, dotado de momentos sucesivos y evolutivos hacia una lengua meta); y, finalmente, la idea de especificidad (puesto que es idiosincrático del aprendiz). 
Selinker (1972, p. 35) describe la interlengua ${ }^{31}$ como el sistema lingüístico independiente que crean los aprendices en el proceso de adquisición de una lengua. Su artículo "Interlanguage" fue fundamental para impulsar la investigación empírica del lenguaje de los aprendices, y desde entonces han sido muchos los investigadores que han intentado explicar tal sistema. Según Liceras (1996), esta definición ha sido ampliamente aceptada por la comunidad científica por diversas razones:

No es una coincidencia que el término interlengua que acuña Selinker (1972) haya sido el que ha prevalecido entre los estudiosos de la L2 frente a los otros dos acuñados por Corder y Nemser porque, además de ser mucho más neutro y autosuficiente, va ligado a un intento muy serio de sentar las premisas que llevarán a la inclusión de la disciplina de la adquisición del L2, como disciplina autónoma, en las ciencias cognitivas. (LICERAS, 1996, p. 41)

El principal objetivo del análisis de la interlengua constituye un intento de explicar los errores de los aprendices de acuerdo con su propio sistema lingüístico. Según esta perspectiva, se considera el término "error" dudoso, ya que solo puede utilizarse si comparamos las producciones de los aprendices con la lengua objeto y no con su propio sistema. Así, desde el punto de vista del aprendiente, las verdaderas normas son las construidas por él mismo, y estas constituyen su interlengua (ELLIS, 1985, p. 51).

Sobre los límites de la interlengua, Durão (2007, p. 28) defiende que esta empieza con el contacto del aprendiz con la lengua extranjera, y se desarrolla mientras la lengua materna y la lengua meta coexisten. En otras palabras, todo el continuum del aprendizaje de la LE, desde sus orígenes hasta que es posible definir la lengua objeto, es decir, hasta que la LO es identificable como tal, caracteriza la interlengua.

${ }^{31}$ Según Durão (2007, p. 23), el origen del término interlengua se remonta al comienzos del siglo XX, cuando Giuseppe Piano (1903) lo creó a partir de una lengua artificial basada en la gramática y el vocabulario del latín. 


\subsubsection{Notas para nuestro estudio}

En relación con nuestro trabajo, entendemos que la noción de interlengua está entrelazada con el concepto de bilingüismo y las competencias del hablante no nativo, expuestos en el capítulo anterior. En efecto, la idea de que exista una interlengua está relacionada con el grado de bilingüismo de los usuarios de L2. El nivel de lengua extranjera que puedan tener los sujetos está condicionado por diferentes factores, tanto individuales como intrínsecos a la interlengua, como los que hemos discutido hasta ahora. La interlengua de los profesores de español no nativos, que puede estar más o menos cerca de la lengua meta, es pues, nuestro objeto de estudio.

Entre las principales características que definen los sistemas lingüísticos no nativos, independiente de su lengua materna, se encuentran la permeabilidad, la dinamicidad y la sistematicidad Ellis (1985, p. 50-51). Estas singularidades, que definen la interlengua como tal, así como la estructura latente del lenguaje (SELINKER, 1972, p. 32), serán discutidas en el siguiente subapartado.

\subsubsection{Características de la interlengua}

Los principios teóricos propuestos por Selinker (1972, p. 32) sostienen que existiría una estructura psicológica latente que se activa cuando el adulto aprende una LE. Esta estructura psicológica, que no tiene una programación genética como la Gramática Universal, difiere de la estructura latente del lenguaje (Lenneberg, 1967 apud SELINKER, p. 33), responsable de la adquisición de la lengua materna. Para el autor, solamente un porcentaje muy pequeño ${ }^{32}$ de los adultos utilizaría la estructura latente del lenguaje para alcanzar el dominio de la L2, mientras que el resto emplearía la estructura psicológica latente, que es la responsable de la

${ }^{32}$ Selinker (1972, p. 34) habla de un 5\% de adultos que llegan a tener éxito completo en el aprendizaje de una L2 y un 95\% que no alcanza ese dominio. Aunque la distinción entre un sistema latente del lenguaje y un sistema psicológico latente haya llegado a ser una idea bastante aceptada sobre las diferencias en el aprendizaje de una LM y una L2, no nos parece que sea tan fácil cuantificar la "tasa de éxito" en el aprendizaje de una L2, lo que hace que los valores presentados por el autor sean cuestionables. 
construcción de la interlengua, por lo que esos aprendices no llegarían a alcanzar la competencia de un hablante nativo ${ }^{33}$.

Ellis (1985, p. 50-51) reconoció otras características destacables de la interlengua, como la permeabilidad, la dinamicidad y la sistematicidad (en el mismo sentido, véanse también ADJÉMIAN, 1982; TARONE, 1983; ELLIS, 1985; DURÃO, 2007; FERNÁNDEZ, 2009). Según Ellis, (1985, p. 50) la permeabilidad juega un papel fundamental en el aprendizaje, y ocurre porque las reglas que constituyen el conocimiento lingüístico no son fijas en ningún nivel, sino cambiantes, puesto que están abiertas a la corrección. Para Adjémian (1982, p. 249), la permeabilidad posibilita que el input siga reestructurando el sistema, haciendo evolucionar así la interlengua hacia nuevos estadios. El resultado de la pérdida de la permeabilidad es el estancamiento del sistema y la fosilización (FERNÁNDEZ, 2009, p. 2). En todo caso, la permeabilidad viene siendo objeto de desacuerdo entre los especialistas desde hace muchos años, principalmente en lo que concierne a si es una propiedad de todos los sistemas lingüísticos o solo de los no nativos ${ }^{34}$.

Según Ellis (1985, p. 50), la interlengua también es dinámica, porque está cambiando constantemente. El paso de nivel no ocurre de manera brusca, sino que sigue un proceso de verificación del sistema lingüístico con el fin de poner a prueba y acomodar nuevas hipótesis. En la visión del autor, la dinamicidad requiere un proceso continuo de idas y venidas en el contraste entre la LM, la LO y las estrategias de aprendizaje. Esto quiere decir que el aprendizaje no es lineal, sino que una estructura aprendida puede ser comprobada una y otra vez, dependiendo de las relaciones que establezca el aprendiz entre los elementos aprendidos y los nuevos con el fin de acercarse a la LO. A esa dinamicidad se le atribuye el carácter creativo de la interlengua (SANTOS GARGALLO, 1992, p. 128), el cual permite que la IL vaya avanzando en sucesivas etapas y aumentando su complejidad.

Por otro lado, la interlengua también varía sistemáticamente (TARONE, 1983; ELLIS, 1985; BARTUREN, 2000). Ello es así porque sus estadios siguen un camino más o menos predecible

${ }^{33}$ La discusión sobre la competencia del hablante nativo ha sido presentada en el Capítulo 1 (subapartado 1.3.4). No obstante, Selinker pretendía que los aprendices alcanzasen la competencia del hablante "ideal".

34 Autores como Adjémian (1982) y Liceras (1996) hacen un repaso detallado sobre esta problemática, la cual, sin embargo, por no ser nuestro objetivo, no será desarrollada aquí. 
dentro de su propia gramática, pudiendo ser descrita y reconocida. Para Durão (2007, p. 45):

Si la interlengua tiene sistematicidad, ella no es un sistema lingüístico caótico; por tanto, muchos de los errores que aparecen en ella son propios del conocimiento parcial de los aprendices en cada etapa de aprendizaje lingüístico, de ahí que su observación pueda llevar a identificar sus distintas etapas de procesamiento.

Para esta autora, la interlengua presenta sistematicidad, pero tiene menos consistencia interna que las lenguas naturales por la falta de "conocimiento autónomo" (DURÃO, 2007, p. 46). Dicho conocimiento sería aquél que "se adquiere naturalmente en las comunidades lingüísticas maternas, las cuales legan una capacidad intuitiva de enjuiciamiento de la gramaticalidad y adecuación sociolingüística y discursivo-cultural de los enunciados" (DURÃO, 2007 , p. 46). En este sentido, la autora argumenta que el conocimiento de los aprendices no llega a ser autónomo porque tienen acceso de manera artificial a la lengua que estudian (en contextos formales).

En este último principio de la sistematicidad es donde reside uno de los principales temas de investigación sobre la interlengua, de modo que cabe preguntarse por qué la actuación sobre la lengua creada por los aprendices es tan variada, tornándose imprecisa y de difícil análisis (ELLIS, 1985, p. 71-72).

En el ámbito de la variabilidad, se han llevado a cabo diversos trabajos (un resumen en DURÃO, 2007, p. 47-52), con el objeto de explicar dos tipos de variación: la no sistemática y la sistemática (ELLIS, 1985, p. 75-81). La primera tiene que ver con la actuación y por ello no está fundamentada en principios o reglas; en otras palabras, tiene un alto grado de libertad, y es muy frecuente en las primeras etapas de la adquisición, cuando la interlengua cambia rápidamente para acomodar nuevos conocimientos. Por esta razón, se puede decir que es una variabilidad "volátil", es decir, que no presenta sistematicidad.

Por otro lado, la variabilidad sistemática, de la cual nos ocuparemos en este estudio, es aquella que presenta signos en común dentro de una variación normal de la interlengua. Esta se divide, a su vez, en dos: la variación individual, resultado de la 
confluencia de diversos factores intrínsecos al aprendiz/usuario de la LO, así como de su estado emocional o mental; y la variación contextual, constituida por una serie de conocimientos que tienen los usuarios de una LO y que están relacionados con su competencia comunicativa (BARTUREN, 2000, p. 156). Dentro de esta, se incluye la variación estilística, la cual se explica por un mayor o menor grado de atención a la forma.

En este sentido, como demuestra Barturen (Ibid., 156), aunque la mayoría de las investigaciones se hayan centrado en el nivel de la fonología, las conclusiones de estas se han generalizado hasta alcanzar una interpretación más global. De ahí que, en el estadio actual de los estudios sobre el aprendizaje de lenguas, parece haber un consenso respecto a que en la interlengua se genera una variación de los estilos de habla, desde el más formal, caracterizado por un grado máximo de atención a la forma, al más informal, donde se presenta una atención mínima a esta. Algunos autores, como los recogidos en el artículo de Barturen (Ibid., 156) ${ }^{35}$, argumentan que una mayor atención a la forma y la consecución de estilos más cuidados dan lugar a variedades más cercanas a la LO. Como contrapartida, menos atención a la forma y un estilo más espontáneo llevarían a la aparición de desviaciones. No obstante, los estudios recogidos por la autora suelen variar en los objetivos y métodos de análisis de las muestras, uno de los motivos por los cuales no suelen coincidir respecto a qué estilo (más/menos cuidado) presenta una variación más sistemática.

\subsubsection{Notas para nuestro estudio}

Para nuestro estudio, utilizaremos parte de los constructos sobre la variabilidad estilística provenientes de las aportaciones de Tarone, una de las investigadoras más destacadas en el estudio de este tema. Esta autora propone que el lenguaje cambia según el contexto de interacción (Tarone, 1979 apud TARONE, 1983, p. 278) y sostiene que la interlengua es un continuum de estilos determinados por la atención que se presta al habla (en el mismo sentido, véase también Ellis, 1985, p. 47-73). Del mismo modo, Tarone considera que la interlengua se muestra más sistemática

${ }^{35}$ En una revisión de los estudios sobre la variabilidad, Barturen (2000) destaca las principales investigaciones que fundamentan el argumento estilo cuidado $=$ aproximación a la lengua meta. Sin embargo, no las detallaremos aquí porque escapan a los límites de nuestro trabajo. 
cuando el aprendiz presta menor atención a su habla. Para defender esta posición, desarrolló el Paradigma de la Capacidad Continua (Tarone, 1979; 1982, apud TARONE, 1983, p. 264), el cual se basaba en los axiomas establecidos por Labov (1969) para el estudio de la variación socioestilística en las comunidades de habla, y que aplicados a la interlengua (IL) suponen que:
a) no hay hablantes de un estilo único. Todos los hablantes utilizan variantes lingüísticas o fonéticas cuando la situación o el tema cambian;
b) es posible clasificar los estilos de un hablante a lo largo de una dimensión continua definida por la atención que se pone al hablar;
c) en el estilo "vernáculo", dónde se pone una atención mínima en el habla, se revelan los modelos fonológicos y gramaticales más regulares y sistemáticos. Los demás estilos tienden a mostrar mayor variabilidad. (TARONE, 1983, p. 278)

Tarone (1983), sostuvo que cuando el aprendiz se centra más en el contenido los errores aparecen con más frecuencia. Por lo tanto, un estado más alerta a la forma equivaldría a un mayor cuidado en la adecuación de la lengua objeto, mientras que una menor atención a la forma (estilo vernáculo) posibilitaría la aparición de errores. La autora también defendió que la técnica de recogida de datos influye en la producción de la IL (TARONE 1983; p. 270), o lo que es lo mismo, estudios con técnicas distintas obtienen resultados distintos, puesto que hay una variabilidad sistemática en la producción de la interlengua en función de las pruebas que se realicen, debido al continuum de estilos presente en las IL.

Sobre la relación directa entre la tarea requerida y la variabilidad de la interlengua, Torijano Pérez (2004, p. 38) destaca también que, dependiendo del contexto y de la tarea lingüística que tenga que llevar a cabo el hablante, pueden aparecer diferentes tipos de errores debido a la posibilidad de controlar o no su discurso. En otras palabras, el autor sugiere que cuando se dan situaciones en las que se puede controlar y revisar la actuación, la probabilidad de que ocurran errores será menor. Por otro lado, si el hablante se encuentra en una situación oral espontánea, en la que existe la necesidad de entablar una conversación y no hay la posibilidad de revisar su discurso, pueden aparecer los errores espontáneos: 
[...] en el caso de actuaciones en que se puede controlar y revisar, sin presión de tiempo, dónde puede monitorizar su producción, la probabilidad de que cometa menos errores gramaticales y de vocabulario será mayor, si ha interiorizado las reglas que subyacen la generación de esas estructuras. Este tipo de situaciones pueden encontrarse en el ambiente formal de clase donde el aprendiz dispone de tiempo para elaborar sus escritos y poner en orden sus ideas al emitir una opinión. Pero si se encuentra en una situación de comunicación oral en la que tiene que participar produciendo y respondiendo a estímulos y no posee tiempo para controlar y corregir su discurso, será más fácil y frecuente que se produzca algún tipo de error que se suponía erradicado. (TORIJANO PÉREZ, 2004, p. 38)

Compartimos la idea del autor de que a través de situaciones comunicativas orales, en las cuales las posibilidades de revisar la actuación se reduce, los errores aparecen de manera más espontánea. Por esta razón hemos optado por un corpus oral. Ahora bien, aunque los dos contextos sean orales, entendemos que hay una ligera diferencia entre la atención a la forma y un estilo más cuidado o más vernáculo discutido anteriormente (TARONE, 1983). Es decir, si establecemos la analogía con las situaciones vividas por los alumnos de lengua extranjera descritos por Torijano Pérez con los sujetos de nuestro estudio, profesores no nativos de español lengua extranjera (ELE) en el contexto de recogida de datos en clase, entendemos que estos tienen un entorno lingüístico más o menos controlable, puesto que su discurso está preparado o acomodado para su utilización en este ambiente. Es, de alguna manera, un discurso controlable, puesto que es el profesor el que modera lo que dice y cómo quiere decirlo, principalmente en aquellas clases más estructurales, basadas en la corrección de ejercicios, lecturas de textos y explicaciones gramaticales, tal como se da en la mayoría de las clases grabadas en este estudio. Consideramos, además, que una mayor atención a la forma puede encontrarse en una clase de lengua extranjera, dónde la LO es, a su vez, el vehículo de comunicación y el objeto de estudio (lo que también resultaría en una menor aparición de errores, según hemos visto ya en la teoría de Tarone, 1983). 
Por otro lado, en una entrevista no sucede necesariamente lo mismo. El entrevistado está en una posición quizá más relajada, puesto que no tiene que prestar atención a diversos componentes discursivos y laborales. En una entrevista, la atención está más centrada en el contenido que en la forma, ya que el entrevistado suele estar más pendiente tanto del argumento del entrevistador como del suyo propio. En nuestro caso, aunque sepan el tema de la entrevista, los docentes desconocen las cuestiones específicas de esta, entre otras razones porque es semiestructurada y de carácter más bien "informal". Por tanto, la opción de monitorizar y controlar su habla se ve especialmente reducida en comparación con el ambiente que hay en la clase. Como hemos visto anteriormente, para Tarone (1983), una mayor atención al contenido aumenta la posibilidad de que se observe un desvío de las normas de la LO. Para Torijano Pérez (2004) una disminución del control sobre la actuación, proporciona la aparición de errores espontáneos. De ahí que entendemos que en la entrevista las posibilidades de que aparezcan otro tipos de errores, incluso los fosilizados/fosilizables, son mayores y de un mayor valor representativo para nuestro estudio.

Como señala Durão (2007, p. 48), estudios posteriores a los de Tarone (1983) y Ellis (1985) destacaron que la atención a la forma no era el único factor relevante para explicar la variabilidad de las interlenguas. Otras características, como la función comunicativa, el ambiente lingüístico, el grado de formalidad, así como la habilidad para ajustar el habla de acuerdo con las exigencias de la situación fueron propuestas por la misma Tarone (1985, apud DURÃO, p. 48). Por ello, entendemos que es igualmente relevante tener en cuenta estas variables en nuestro análisis.

También conforme señala Medina Rivera (1999, apud BLAS ARROYO, 2005, p 51-52), la mayoría de los trabajos que tratan de la variación estilística no tiene en cuenta la relación existente entre el locutor y su interlocutor, o entre el entrevistador y el entrevistado. Por eso, Medina Rivera propone que algunos factores deben ser considerados en las investigaciones del continuum lingüístico, tales como:

1) la situación comunicativa (conversación individual, conversación en grupo y presentación oral);

2) el género discursivo; 
3) el tema de la conversación. (Medina Rivera, 1999, apud BLAS ARROYO, 2005, p. 52)

Con base en estos aspectos, el autor comprobó, en una investigación acerca de dos variables fonológicas en el español hablado en Puerto Rico, que el estilo vernáculo era más frecuente en las conversaciones entre conocidos. También descubrió que las formas vernáculas se dan más en conversaciones llevadas a cabo en grupos y en las secuencias dialogales. Por otro lado, las presentaciones orales, los discursos narrativos, argumentativos y expositivos suelen potenciar más el uso de la variante estándar.

Creemos que estos hallazgos de Medina Rivera, aunque provenientes del campo fonológico, deberían ser también tenidos en cuenta en los estudios de los análisis de errores, puesto que son factores que pueden interferir en los resultados. Así, entendemos que, las consideraciones del autor, aplicadas a nuestro estudio, deberían hacer que en las clases se intentara usar una variante más formal, donde sobresalen discursos narrativos, argumentativos y expositivos. En contrapartida, en las entrevistas, es decir, en las secuencias dialogales, el uso de una forma vernácula (debido a una menor atención a la forma), se hará más evidente. Hay que añadir además, que según Medina Rivera (Ibid., p. 52), aquellos sujetos que desconocían a la investigadora intentaban mantener el diálogo con mayor atención a la forma que los conocidos.

\subsection{La fosilización}

Hasta en las producciones de hablantes no nativos con niveles muy altos de competencia comunicativa, no es raro observar la presencia de formas inusuales comparadas con las que utiliza un hablante nativo, y de las que aquí también daremos cuenta. Aunque no sea el objeto principal de esta investigación, indirectamente nos vemos implicados también en el debate sobre la fosilización, pues no en vano algunos autores (como, por ejemplo Vázquez, 1992; y Sheen, 1980 y Mukattash, 1986, apud DURÃO, 2000, p. 54) consideran la transferencia como uno de sus principales motivos. Como veremos en el Capítulo 4, no trataremos de los errores fosilizados, pero sí identificaremos aquellos que consideramos "fosilizables". Por ello, consideramos pertinente la discusión que sigue. Así mismo, dada su transcendencia para los estudios sobre la adquisición de lenguas no nativas y su importancia en las investigaciones sobre la interlengua, hemos optado por dedicarle 
este breve apartado. El objetivo es discutir sus principales características, sus posibles orígenes, y reflexionar sobre los problemas intrínsecos a su investigación.

La fosilización fue ampliamente discutida por Selinker (1972) como parte de su teoría de la interlengua. Este autor la definía como la tendencia del aprendiz 0 usuario de una lengua segunda/extranjera a conservar en su interlengua ciertas reglas o subsistemas lingüísticos que no pertenecen a una LO dada. Selinker entendía la fosilización como parte indisociable de la IL, o, más bien, una norma suya (SELINKER, 1972, p. 36) y por ello dedicó gran parte de la teoría de la interlengua a su descripción. Además, consideraba esta uno de los fenómenos más interesantes de la IL y estimaba que una teoría adecuada del aprendizaje de lenguas debería, necesariamente, poder explicar la reaparición regular de estructuras lingüísticas que no pertenecen a la LO (SELINKER, 1972, p. 36-37).

Para el autor, la fosilización se sitúa también en la estructura psicológica latente, y parece independiente de los años de exposición a la L2/LE, emergiendo incluso en individuos que tienen un amplio conocimiento de la lengua. Las estructuras fosilizables tienden a permanecer y resurgir en la actuación, incluso cuando parecen haber sido erradicadas. Durão (2000) presenta las características de la fosilización y la importancia de su estudio en la introducción de su artículo "A fossilização de erros: o estado da questão":

A intenção de trazer à luz estas reflexões relaciona-se ao fato de que o fenômeno é visto como um dos traços principais das interlínguas, de ser um elemento característico do processo de aquisição/aprendizagem das L2/LE, não acontecendo na aquisição das línguas maternas/primeiras línguas $(\mathrm{LM} / \mathrm{L} 1)$ e, acima de tudo, porque a fossilização tem a virtude de poder atuar como elemento bloqueador da progressão esperada ou da produção fluída nessa LO. (DURÃO, 2000, p. 47)

Long (2003, p. 487) afirma que el concepto de fosilización ha sido extensamente aceptado como un fenómeno psicológico y que tiene una importante consideración teórica y práctica. No obstante, la fosilización puede tener varios orígenes, y por ello estudiarla puede convertirse en una tarea ingrata para los 
investigadores. Algunas de estas particularidades, que la convierten un fenómeno complejo, se recogen en el próximo subapartado.

\subsubsection{Orígenes de la fosilización}

Selinker (1972, p. 37) presenta cinco procesos centrales en el aprendizaje de segundas lenguas, los cuales subyacen en las estructuras fosilizables. El autor revela que hay muchos otros procesos que pueden interferir igualmente en la fosilización de las estructuras lingüísticas (SELINKER 1972, p. 41), pero se centra en estos cinco, puesto que son, a su juicio, los más destacables. Estos procesos, una vez combinados, pueden generar la fosilización en la interlengua de los aprendices:

1. transferencia lingüística: la responsable de la transferencia de reglas y subsistemas de la L1 a la L2/LE;

2. transferencia de instrucción: difiere de la transferencia lingüística en el sentido de que los responsables de los errores son los materiales utilizados en el aprendizaje 0 bien las explicaciones del profesor.

3. estrategias de aprendizaje de L2: ocurre siempre que el hablante se da cuenta, de manera inconsciente 0 no, de que necesita compensar algún aspecto del cual no posee suficiente competencia en la LO.

4. estrategias de comunicación en L2: son las estrategias referentes a la necesidad comunicativa del hablante. Selinker (1972, p. 37) señala que tales estrategias están operativas siempre que haya una necesidad real de comunicación.

5. Hipergeneralización de las reglas de la LO: ocurre cuando hay una clara e inequívoca generalización de la norma de la lengua objeto.

Sobre los errores del punto 1, que son los que más interesan a nuestra investigación, Selinker y Lakshmanan (1992, p. 212) afirman que la fosilización no ocurre solamente cuando hay transferencia, sino que obedece a una combinación de factores. En el intento de explicar estas combinaciones, estos autores desarrollan 
la hipótesis sobre el "Principio de efectos múltiples" (Multiple Effects Principle) (SELINKER y LAKSHMANAN, 1992, p. 198), una respuesta, siquiera parcial, sobre el problema de la fosilización. Según este principio, la fosilización ocurre cuando dos o más factores de la adquisición de lenguas extranjeras interfieren en el aprendizaje, siendo (o no) la transferencia uno de ellos. Por otro lado, aunque para estos autores la transferencia no sea la única causa de la fosilización, algunos estudios (Sheen, 1980 y Mukattash, 1986, apud DURÃO, 2000, p. 54) sugieren que los errores encontrados en la interlengua de los estudiantes provenientes de la transferencia lingüística tienden a fosilizarse en una proporción mayor que otros. Más rotunda es aun Vázquez (1992, p. 107), quien argumenta que la transferencia suele ser la principal causa de los errores fosilizables y fosilizados.

De ahí viene la preocupación de los educadores en actuar sobre estas estructuras de forma planificada, ya que algunas parecen no olvidarse nunca del todo en la interlengua de los aprendices, pese a que aparentemente hayan sido tratadas $y$ eliminadas. Según Selinker y Lakshmanan (1992, p. 212), para entender y tratar la fosilización se deben desarrollar más investigaciones en cuatro puntos principales:

1. Aparición temprana de la fosilización en casos de input reducido;

2. Dificultad de erradicar ciertos fenómenos de la interlengua;

3. Estudios longitudinales de un individuo, cuidadosamente diseñados para seguir el desarrollo de la IL.

4. El motivo de que algunas estructuras tiendan a fosilizarse y otras no, aun habiendo abundante input.

En el capítulo 1 hemos discutido la Teoría del Input. No obstante, conviene rescatar aquí las cinco premisas de su autor (KRASHEN, 1985) sobre las causas de la fosilización, las cuales tienen especial interés para nosotros y que sintetizamos a continuación: la cantidad del input, su calidad, el filtro afectivo, el filtro de salida y la adquisición de formas desviantes.

Para él, la primera y más obvia causa de fosilización se da cuando el estudiante no recibe input comprensible en cantidad apropiada. Suele ocurrir cuando el estudiante no vive en el país de la LO y tiene poco acceso a hablantes nativos, así como a material 
auténtico. También ocurre con inmigrantes con poco contacto con nativos (KRASHEN, 1985, p. 43).

El segundo motivo que apunta Krashen (1985, p. 43-44) es la calidad inapropiada de input. Esto ocurre cuando el input es suficiente, pero no se suministra en la medida correcta $(i+1)$; también puede suceder cuando un aprendiz domina un cierto campo de la lengua, pero no recibe input suficiente para dominar otros. Un ejemplo representativo sería el de aquellos hombres de negocios que dominan bien su esfera de actuación, pero no consiguen entablar una comunicación efectiva sobre otros temas que no sean los del trabajo, puesto que están insertados en un entorno comunicativo dentro de un mismo campo, donde el input y al output suelen estar muy controlados.

El tercer origen descrito es el filtro afectivo (KRASHEN, 1985 , p. 44), el cual explica por qué la adquisición no ocurre aún en aprendices que disponen de cantidad y calidad suficiente de input. El filtro afectivo abarca las variaciones en los perfiles de aprendices y sus preferencias en el aprendizaje, es decir, lo que puede aumentar el filtro para algunos alumnos, puede bajarlo en otros, y de ahí su complejidad. Desde esta perspectiva, Krashen (Ibid., p. 54) alerta sobre la relación entre la necesidad comunicativa y la fosilización. Dicho de otra manera, los aprendices podrían estancar su aprendizaje cuando entienden que ya no necesitan mejorar su interlengua para comunicarse. Esto llevaría a la fosilización de algunas formas de la LM, cuando el filtro afectivo esté alto. A este respecto, otros autores como Selinker (1972), Corder (1976), Schumann (1976) y Baralo (1999) se han manifestado también favorables a la idea de que la percepción de "competencia comunicativa" alcanzada puede hacer que el hablante paralice el desarrollo de su interlengua.

La cuarta razón de la fosilización está relacionada con la hipótesis del filtro de salida (KRASHEN, 1985, p. 44-45). Esta intenta explicar por qué los usuarios de una LE no son capaces de realizar todo lo que saben. Esto ocurre cuando el foco está en la forma y no en el sentido, haciendo que suba el filtro de salida y dificultando la actuación. La diferencia con el filtro afectivo, es que ese último tiene que ver con la entrada del input, mientras que el filtro de salida está más relacionado con la realización de lo que se sabe.

La última causa de la fosilización sería la adquisición de formas desviantes (KRASHEN, 1985, p. 46-49). Esto puede ocurrir de dos maneras distintas: una, en un contexto formal y otra, en un contexto informal de aprendizaje. La primera se presenta cuando el 
único input que recibe el estudiante es el de clase, el profesor no nativo no posee un alto nivel de lengua y los compañeros tienen igualmente una interlengua. Este input puede estar constituido por errores de diversos orígenes, entre los que se incluye la LM. El problema está en que el alumno reconocerá este input como una muestra de la LO y lo adquirirá tal como lo ha recibido. Para Krashen (Ibid., p. 46-49), estas formas erróneas adquiridas a través de la instrucción son difíciles o, incluso en algunos casos, imposibles de olvidar. La segunda forma en que se pueden adquirir formas desviantes de la lengua tiene lugar cuando en un contexto natural o informal el aprendiz recibe grandes cantidades de input incomprensible. Sobrevivir en tal entorno puede llevar al hablante a producir frases memorizadas y al uso de la LM. En algunos casos, la cantidad de input comprensible es tan pequeña que se limita a lo que el propio hablante $u$ otras personas en la misma situación producen.

Sea cual sea la causa de la fosilización, erradicarla no parece una tarea sencilla. Según Krashen (1985, p. 48), de los cinco tipos de fosilización examinados, las "formas desviantes" parecen ser las más difícilmente subsanables. Un posible medio de lograr que los alumnos aprendan la lengua de manera adecuada es proporcionando grandes cantidades de input adecuado y correcto, que serán útiles cuando los filtros afectivos y de salida estén bajos. En este caso, los aprendices serían bilingües, puesto que habrían adquirido dos lenguas: la desviante y la real (KRASHEN, 1985, p. 49).

En un contexto de enseñanza formal, el uso de materiales auténticos y de interés de los alumnos puede ser un soporte importante en esta tarea, siempre que estén acordes con cada nivel. De esta manera, una de las principales funciones de la clase de LE es proveer al alumno con una cantidad de input lingüístico comprensible y de calidad (KRASHEN, 1985, p. 48).

Para Baralo (2004, p. 9), existen todavía otras causas de la fosilización: las estrategias de aprendizaje y de comunicación, la predisposición a suprimir elementos gramaticales (ej. artículos) de sus producciones, la tendencia a la hipergeneralización de las reglas de la lengua objeto, factores personales o la propia ignorancia. Otras, relacionadas con factores sociales o psicológicos intrínsecos al aprendiz podrían ser la edad, la lengua y culturas de procedencia, la motivación y actitud ante el aprendizaje, las creencias, los estilos cognitivos, la capacidad de riesgo, la tolerancia, la autonomía u otros factores vinculados al entorno (FERNÁNDEZ, 2009, p. 51). 
La fosilización puede aparecer, además, a raíz de otros factores, como, por ejemplo, las que Torijano Pérez (2004, p. 38) denomina "situaciones psicológicas especiales", como escasa atención, una mayor preocupación por el contenido que por la forma, estados de cansancio o ansiedad, así como en contextos fácilmente asociados a los del lapsus. Por otro lado, también podría aparecer, aunque menos habitualmente, en situaciones en las que el individuo se encuentra en un estado de relajación máxima (SELINKER, 1972, p. 36).

\subsubsection{Notas para nuestro estudio}

En conclusión, para nuestro estudio, el considerar los orígenes de los errores persistentes en las producciones de los profesores nos puede conducir a entenderlos de manera más significativa y menos superficial. Aunque se tengan en cuenta, obviamente, los factores personales, no es posible detectarlos con el tipo de metodología que empleamos (aunque tampoco es nuestro objetivo), pero consideramos que tener presente su existencia es fundamental para el estudio de los errores de transferencia. De igual manera, que los sujetos tengan la misma LM y hayan tenido prácticamente la misma formación inicial, nos puede dar algunas pistas sobre algunos de los errores "fosilizables" que presentan, y su origen puede discutirse en el marco de las teorías que presentamos aquí, principalmente las referidas a la interferencia de Selinker y Lakshmanan (1992) así como a la Teoría del Input (KRASHEN, 1985).

Sobre la investigación de la interlengua y más precisamente sobre la fosilización, el mismo Selinker (1972) ha traído a la luz una serie de obstáculos intrínsecos a la tarea, muchos de los cuales siguen hoy plenamente vigentes. Los presentamos brevemente a continuación, con vistas a reflexionar sobre la complejidad de la labor y a nuestra convicción de que esta tiene que estar necesariamente fundamentada en unos constructos teóricos bien definidos sobre la adquisición de las lenguas. 


\subsubsection{La investigación de la interlengua y de la fosilización: problemas teóricos, metodológicos y nuevas perspectivas.}

Como podemos observar en una revisión sobre las investigaciones referentes a la fosilización hecha por Durão (2007, p. 53-58), uno de los principales problemas observado en su estudio es que no existe un modelo completo que pueda explicar con claridad todos los procesos implicados en este fenómeno. Por este motivo, cada teoría en su ámbito específico de investigación aporta diferentes respuestas para diferentes preguntas, con el empleo de diferentes metodologías. Esa variación ha supuesto un incremento exponencial del volumen de información disponible, pero casi siempre desde perspectivas heterogéneas y por ello no siempre comparables. Lin (2005, apud DURÃO, 2007, p. 58) llega a decir que la mayoría de los estudios son especulaciones meramente teóricas y que por ello sus hipótesis no se pueden ni confirmar ni rechazar.

No obstante, nos gustaría discutir al respecto uno de los argumentos más discutidos sobre la fosilización: su posible la inmutabilidad. Para el creador de la teoría, Selinker (1972, p. 36), las estructuras fosilizadas son perpetuas y casi inmutables, y aunque desaparezcan temporalmente, siempre resurgen.

Como contrapartida, autores como Durão (2000, p. 56), con quienes compartimos el mismo punto de vista, defienden que aunque la fosilización pueda actuar como bloqueador del aprendizaje o de la actuación, no tiene por qué ser la etapa final del proceso de adquisición de la LO, sino un estadio que, afortunadamente, puede modificarse siempre que exista motivación suficiente para ello. En consonancia con la autora, entendemos que no se debe, por tanto, considerar los errores recurrentes como un fracaso en el aprendizaje, sino una adaptación del sujeto a sus necesidades, y que son reversibles en cualquier etapa del proceso.

Selinker (1972, p. 41-47) presenta aún otros cinco problemas centrales en la investigación sobre la fosilización. El primero es que muchas veces no se puede determinar con precisión la fuente de los errores fosilizados. Un ejemplo podría ser la dificultad en delimitar los casos de los errores de transferencia lingüística y de transferencia de instrucción, o de ambas. Para el autor, aunque existan tales limitaciones, el intento de delimitar el origen de los errores debe perseverar, puesto que puede proporcionar datos relevantes para los estudios de la interlengua. 
El segundo problema señalado es la dificultad en averiguar si las estructuras fosilizables son predecibles o reconocibles. Selinker (1972, p. 42) afirma que esta es un área difícil de dilucidar, puesto que el estudio de la fosilización es descriptivo y no explicativo. No obstante, defiende que las descripciones de las interlenguas apuntan inevitablemente hacia un camino de predicción de los errores cometidos por sus usuarios, y que el pronóstico es fundamental para la construcción de una teoría seria sobre el aprendizaje de las LE.

La tercera dificultad reside en entender cómo ocurre el éxito de la competencia del hablante de una determinada LO. Con la expresión "éxito" el autor no está pensando necesariamente en aquellos aprendices minoritarios que logran aprender la $L 2$ a través de la estructura latente, los cuales Selinker (1972, p. 43-44) considera que aprenden como un hablante nativo, tal como hemos visto en el apartado anterior. Por el contrario, el éxito al que se refiere es el logrado por los aprendientes que hacen uso de la estructura psicológica latente, o sea, los que necesitan reorganizar su aprendizaje para que la IL coincida con la lengua meta. Descifrar cómo el alumno realiza tales reorganizaciones con vistas a identificarlas con la LO es fundamental para entender la interlengua. Para el autor, tal proceso, de carácter psicolingüístico es, sin duda, uno de los mayores retos a los que se enfrentan los investigadores de la lingüística aplicada.

La siguiente problemática sería aquella relacionada con averiguar cuáles son las unidades relevantes de la estructura psicológica latente y si hay pruebas de su existencia. Selinker (1972, p. 44-47) defiende que es necesario encontrar la manera de conectar las teorías lingüísticas y las de la psicología del aprendizaje con el fin de diseñar experimentos que comprueben la existencia o no de la estructura psicológica latente. Tal reto solo es posible comparando y analizando las producciones de los tres sistemas lingüísticos: LM, IL y LO.

La última dificultad concierne a la creación de las mismas condiciones experimentales para los tres sistemas lingüísticos (LM, IL y LO) con una unidad que los identifique interlingüísticamente. Selinker (1972, p. 47) propone una técnica de entrevista como ejemplo de cómo se pueden conseguir ciertos tipos de oraciones de estructuras comparables en cada lengua. Para él, este sería un gran paso para descubrir las estructuras lingüísticas bajo la estructura psicológica latente.

Otros autores como Jordens (1980, p. 227) también han defendido la posición de Selinker en relación a la necesidad de 
vincular las teorías lingüísticas y psicológicas en el intento de interpretar la IL y su sistema subyacente, si bien Jordens sostiene que no hay que comparar la IL con la LM y la LO, sino interpretarla como un sistema lingüístico independiente:

Una categorización basada únicamente en una comparación entre las producciones de la IL y las de las L1 y L2 es tan imposible como la explicación entre de los motivos e intenciones del comportamiento de los miembros de una cierta comunidad sobre la base de los parecidos con el comportamiento de los miembros de otra comunidad. (JORDENS, 1980, p. 228)

Para el autor (JORDENS, 1980, p. 229), otro inconveniente es que la mayoría de los estudios sobre la IL, y especialmente sobre sus errores, se describen de una manera interpretativa y no explicativa. En otras palabras, significa que los investigadores interpretan los resultados de acuerdo con una categorización dada, pero no realizan una confrontación con los principios subyacentes de la IL. Sin embargo, una investigación con una "adecuación explicativa" (JORDENS, 1980, p. 229) debería estar basada en las teorías de adquisición de la lengua y tener en cuenta los procesos psicológicos necesarios para la construcción de la IL.

\subsection{En conclusión}

En este recorrido teórico teníamos como propósito acercarnos a los aspectos centrales de nuestra investigación: la interferencia y la interlengua. Hemos visto un panorama histórico del Análisis Contrastivo y del Análisis de Errores y de cómo ambos paradigmas pueden complementarse. Asimismo, hemos defendido que los estudios fundamentados en el $A E$ y la Lingüística Contrastiva son fundamentales para la investigación de la interferencia, como el nuestro.

También hemos presentado las diferentes concepciones de "transferencia" e "interferencia" y hemos analizado cómo se confunden o adaptan en diferentes estudios en función de sus concepciones acerca de la lengua y el aprendizaje. Hemos partido de los estadios iniciales asociados al conductismo hasta la 
actualidad, cuando la transferencia se entiende ya como una estrategia psicolingüística que tiene como principal finalidad la de facilitar el aprendizaje de la L2/LE. De la misma manera, hemos definido la concepción de "interferencia" en la que nos apoyamos, y la hemos caracterizado como una de las piezas fundamentales que conforman el aprendizaje de las L2/LE, así como parte de la transferencia como proceso psicolingüístico, alejada de aquella visión conductista que tenía al principio. Así, la interferencia, transferencia negativa, o los errores interlingüísticos son parte integrante de los aspectos cognitivos del aprendizaje, ya sea a través de estrategias conscientes 0 inconscientes ya sea convirtiéndose en ocasiones en una estrategia comunicativa.

En lo que concierne a la "interlengua", hemos presentado su definición a partir de su principal difusor (SELINKER, 1972), esto es, como el sistema lingüístico que formulan los aprendientes en el proceso de adquisición de una lengua. A partir de aquí, hemos debatido sobre sus principales características: la permeabilidad, la dinamicidad y la sistematicidad. Hemos defendido que la noción de interlengua está también enlazada a la noción de bilingüismo que discutíamos en el capítulo anterior. En otras palabras, los límites de la interlengua están estrictamente ligados a la propia definición de bilingüismo ( $\mathrm{y}$ el controvertido debate acerca de su medición) que tiene el investigador. Hemos sostenido que entendemos nuestro objeto de estudio como la interlengua de profesores de español no nativos, cada cual con su nivel de bilingüismo individual.

Sobre la variabilidad estilística de estos sistemas, hemos considerado que dependiendo del contexto de recogida del corpus podrían aparecer diferentes errores, puesto que en las clases podría haber un estilo más cuidado (más cercano a la LO), mientras en las entrevistas un estilo vernáculo prevalecería y de esta forma otros tipos de errores podrían manifestarse. Esas diferencias respecto a la atención a la forma justifican la recogida de datos en dos ambientes distintos, así como la grabación del discurso oral se justifica por el hecho de que el habla en este registro, está, por lo general, menos controlada que la escrita, motivo por el cual los errores surgen de manera más espontánea.

Otro aspecto muy debatido por la comunidad científica, y que también hemos resaltado en esta sección, es el relativo a la fosilización. Aunque no sea el objetivo principal de este trabajo investigar los errores fosilizados, entendemos que la interferencia es uno de los principales causantes de este fenómeno, motivo por el cual se hacía imperioso discutirla. Por este motivo, hemos realizado una breve revisión de sus principales características, y hemos hecho 
hincapié en el hecho de que, dado el carácter sincrónico del estudio, no podemos concretar qué errores están fosilizados. Con todo, sí podemos delimitar los errores más fosilizables a partir de la frecuencia del error, información que resulta de gran utilidad para la didáctica de ELE.

Para finalizar, hemos considerado los problemas en la investigación de la fosilización y de la interlengua, y, con ello, consideramos que nuestro estudio está ubicado en el marco que apunta Jordens (1980), puesto que estamos de acuerdo con el autor en que, sin las teorías de la adquisición, las cuales sirven de soporte para la investigación de la interlengua, los resultados de un estudio como el nuestro perderían su aplicación pragmática en la didáctica de las lenguas. Sin esta conexión con los postulados teóricos, el producto de la investigación sería un listado de errores que, al estar desconectado de los fundamentos de la adquisición del lenguaje, perdería su valor reflexivo. Esta reflexión sobre los procesos subyacentes a la actuación es uno de los objetivos centrales para nosotros, dada su inestimable aportación a nuestra práctica, tanto en calidad de investigadores como en la de profesores del español como lengua extranjera. Por este motivo, estos dos capítulos introductorios han intentado elucidar nuestras bases teóricas sobre los aspectos centrales de la investigación de las lenguas extranjeras, las cuales nos han permitido diseñar este estudio, así como nos han proporcionado los constructos teóricos con los cuales podremos reflexionar sobre los resultados encontrados.

De esta manera, dando continuidad a la revisión de los principios teóricos que fundamentan este trabajo, en el próximo capítulo nos acercaremos un paso más al objeto de nuestro estudio. Como hemos visto en este capítulo 2, el aprendizaje de una lengua extranjera llevado a cabo principalmente por adultos, está condicionado, en cierto modo, por la lengua materna del aprendiente. En el Capítulo 3, entenderemos las características de aprender un idioma próximo y más específicamente aquellos a los que nos dedicamos en esta investigación: el portugués y el español. 


\section{INTERFERENCIA Y LENGUAS PRÓXIMAS: EL CASO PORTUGUÉS/ESPAÑOL}

En este tercer capítulo nos adentraremos en la discusión sobre las características intrínsecas del aprendizaje de lenguas próximas y, más específicamente, del español por parte de brasileños, como es el caso de los sujetos de nuestro estudio. Al igual que otros autores antes que nosotros, entendemos que las interferencias son una de las principales causas de las dificultades de los aprendices de lenguas próximas, motivo por el cual dedicamos un capítulo específico a este tema.

Entrando en detalle, en el primer subapartado de esta sección (3.1) discutiremos la relación entre el concepto de interferencia y el aprendizaje de una lengua próxima. Luego revisaremos las características de la proximidad existente entre el portugués y el español (3.2); y, a continuación, disertaremos sobre las creencias al respecto de la similitud entre estas dos lenguas (3.3). También revisaremos las dificultades para alcanzar un nivel lingüístico elevado y sus implicaciones para la formación de profesores de ELE y, más específicamente, para la enseñanza del español en Brasil (3.4). En 3.5 daremos cuenta del recorrido de las principales investigaciones acerca de las interferencias del portugués en la lengua española y, más concretamente, de las más relacionadas con la presente investigación. Y ya en el último subapartado (3.6), realizaremos unas breves consideraciones sobre las perspectivas futuras para la enseñanza de ELE en Brasil.

\subsection{Interferencia y aprendizaje de lenguas próximas}

Han pasado ya casi 25 años desde la aparición de los estudios seminales en el área del análisis de errores del español, llevados a cabo por Fernández (1991), Vázquez (1991) y Santos Gargallo (1991). Como ha señalado esta última (SANTOS GARGALLO, 2004a, p. 392), la década de los 90 ha sido especialmente fructífera para el análisis de errores aplicado al estudio de la interlengua de estudiantes de español. Además de las tesis doctorales citadas, otros trabajos pioneros abrieron el camino hacia la investigación del aprendizaje del español como lengua extranjera. Como ejemplo de aquellos dedicados a los aprendices lusohablantes, Santos Gargallo (2004, p. 392) cita las tesis de 
Benedetti (1993), Durão (1998) y Torijano Pérez (2002). Según la autora, las investigaciones de la década de los 90 y principios de 2000 impulsaron el desarrollo tanto didáctico como científico de la lingüística aplicada a la enseñanza del español como lengua extranjera (ELE) y desde entonces el estudio sobre la interlengua de los aprendices de ELE ha servido para ayudar a entender con más detalle el papel de la lengua materna y de las interferencias en este proceso.

Con ello, también hemos podido ver, entre otras cosas, el desarrollo de estudios que apuntan a las particularidades tanto de la investigación como del aprendizaje de las lenguas afines en contextos formales. Uno de esos estudios es el llevado a cabo por Sánchez Iglesias (2003), quién en su tesis doctoral analizó los errores de italianos aprendices de español. Este autor puso de relieve la problemática existente en los estudios de lenguas afines, muy parecida a la que presentaremos aquí, referente a la supuesta facilidad que supone aprender una lengua próxima, y también que la investigación del aprendizaje de las lenguas cercanas es un tema en cierta medida ignorado por la comunidad científica, porque no parece presentar problemas didácticos o datos relevantes para el estudio de la adquisición (SÁNCHEZ IGLESIAS, 2003, p. 405).

En relación con lo expuesto anteriormente, algunos autores como Fernández (1991, apud FERNÁNDEZ, 1997) han defendido que una de las principales diferencias entre la interlengua de los aprendices de lenguas próximas y la de lenguas distantes sería la preponderancia en la primera de la interferencia. En el estudio llevado a cabo para la realización de su conocida tesis doctoral sobre estudiantes de español japoneses, árabes, franceses y alemanes en la Escuela Oficial de Idiomas de Madrid, esta autora comprobó que esas interferencias ocurrían, efectivamente, con más frecuencia en las lenguas cuyos aprendices encontraban mayor similitud entre su lengua materna y la lengua meta. De la misma manera, otros estudiosos como Buteau (1970), Wode (1976) y Jackson (1981), citados en Fernández (1997, p. 16) han defendido también, con base en sólidas investigaciones empíricas, que la interferencia ocurre con mayor reiteración entre lenguas próximas.

En el mismo sentido, investigaciones como las de Thiemer (1980), Benedetti (1993) (apud DURÃO, 2005, p. 130), y Durão (1999) han encontrado que en las lenguas tipológicamente cercanas la transferencia interlingüística viene a ser la principal fuente de errores, aunque todos ellos subrayan el hecho de que no es la única. También Camorlinga, quién escribió el primer trabajo de 
posgrado en Brasil sobre el tema ${ }^{36}$ (CAMORLINGA, 1991), destacaba que el principal problema de la proximidad son las interferencias. Para el autor, estas pueden aparecer en cualquier LM, aunque la probabilidad de que ocurran cuando hay afinidad entre las lenguas es mayor (CAMORLINGA, 1997, p. 7). En el caso específico del portugués-español, muchos investigadores han corroborado esa misma premisa y han tratado de esbozar esa proximidad, también llamada "proximidad engañosa" (ALMEIDA FILHO, 1995b), "simetría asimétrica" (CAMORLINGA, 1997), "falsa transparencia" (KULIKOWSKI y GONZÁLEZ, 1999) y "cercanía moderada" (KULIKOWSKI y GONZÁLEZ, 1999; GONZALEZ, 2008). Como veremos en el siguiente apartado, esa proximidad, que es sobre todo léxica, hace que el aprendizaje del español por parte de los brasileños sea muy particular.

\subsection{La proximidad interlingüística portugués-español: ¿facilitadora o dificultadora del aprendizaje?}

El portugués y el español son dos lenguas de un origen común: el latín vulgar ${ }^{37}$; por lo tanto, es normal que se parezcan a su lengua originaria y también entre sí. En una primera mirada, parece evidente la similitud morfológica, sintáctica, semántica y fonéticofonológica entre ambas; sin embargo, la proximidad no se manifiesta en todos los niveles de la misma manera, dándose la mayor semejanza en el léxico (CAMORLINGA, 2005, p. 196). Algunos estudios empíricos como el llevado a cabo por Richman (1965, apud HENRIQUES, 2005, p. 153), demuestran que, entre las lenguas románicas $^{38}$, el español está más cerca del portugués que del italiano y del francés, por ejemplo (véase también ALMEIDA FILHO, 1995b, p. 14).

\footnotetext{
36 Según la investigación que hemos realizado para este estudio y que presentamos en el último apartado de este capítulo.

${ }^{37}$ Este latín vulgar incluía numerosas variedades de la lengua hablada en la península itálica, desde el coloquio pulido hasta el lenguaje profesional o las jergas. Se trata de la lengua que los soldados, colonos y funcionarios romanos llevaron a las regiones conquistadas y diversificada con el tiempo en las llamadas lenguas románicas (CUNHA y CINTRA, 2008, p. 11).

${ }^{38}$ Son lenguas derivadas del latín vulgar (románicas) las siguientes: francés, español, italiano, sardo, provenzal, rético, catalán, portugués, franco-provenzal, dálmata, rumano (CUNHA y CINTRA, 2008, p. 12).
} 
Desde hace tiempo, diversos autores han señalado las particularidades que implica la enseñanza del español a lusohablantes (o vice-versa) debido a esa similitud lingüística (Ulsh, 1971; Lombello, 1983; Hoyos-Andrade, 1993, apud ALMEIDA FILHO, 1995a, p. 9). A este respecto, por ejemplo, investigaciones como la de Ulsh (apud ALMEIDA FILHO, 1995b, p. 15) estiman que el español y el portugués comparten aproximadamente un $85 \%$ del léxico en varios campos semánticos. Henriques (2005, p. 154), por su parte, afirma, con base en un estudio comparativo del léxico entre textos científicos, que el español y el portugués tienen un promedio de casi un $91 \%$ de coincidencia lexical. $Y$, en la misma línea, Almeida Filho (1995b, p. 15) argumenta que son "casi variantes dialectales una de la otra" (traducción nuestra).

Aunque los números encontrados en los estudios mencionados para concretar cuál es el grado exacto de cercanía entre las lenguas puede cuestionarse en ocasiones ${ }^{39}$, parece claro que, en el caso del español y el portugués, tal cercanía es más que evidente. Debido a esa proximidad, sobre todo en el nivel léxico, algunos autores, como Camorlinga (2005) y Salinas (2005), consideran que no existen alumnos lusohablantes "principiantes" en español. Normalmente, esos estudiantes ya tienen adquirida la capacidad de comprender una parte relevante del idioma, tanto en el registro hablado como en el escrito, haciendo uso para ello de estrategias asociativas, principalmente en el nivel escrito, donde las similitudes saltan a la vista. Sobre la similitud en el registro escrito, Almeida Filho (1995b, p. 15) argumenta que, cuanto más educado formalmente se halle el estudiante, es decir, cuanto más instruido esté en la lengua escrita, más fácilmente se adentrará en el aprendizaje de la lengua próxima (ya sea esta el español para los lusohablantes, ya sea en la dirección inversa), puesto que la lengua escrita es más formal y por tanto más similar a la $\mathrm{LO}^{40}$. De igual

${ }^{39}$ Consideramos que el intento de resumir en números la cercanía entre dos lenguas es siempre una tarea compleja. Estos estudios suelen basarse en corpus escritos y, en el caso de Henriques (2005), de textos científicos específicamente, hecho que debería ser tenido en cuenta en el momento de generalizar los resultados de su trabajo, es decir, podría decirse que "en el campo científico, el léxico entre la lengua española y la portuguesa es de una coincidencia del 91\%". Habría que investigar si la misma proporción ocurre en otras esferas y considerar, sobre todo, la lengua hablada.

${ }^{40}$ Según el autor (ALMEIDA FILHO, 1995b, p. 17), esto es comprensible cuando observamos que cuanto más usadas son las lenguas, más irregularidades aparecerán en el uso de determinadas formas. Visto de otra manera, para este 
manera, autores como Camorlinga (1997) argumentan que incluso en la lengua hablada hay pocas diferencias en un nivel básico, lo que favorece el uso de la lengua en clase desde los primeros encuentros:

Nas aulas de espanhol a estudantes brasileiros começamos falando a língua alvo já desde os primeiros encontros. É, pois, indiscutível a facilidade quanto à compreensão ou "uso passivo" da língua". (CAMORLINGA, 1997, p.6) ${ }^{41}$

Entendemos que esa capacidad de comprensión es, sin duda, un aspecto que facilita el aprendizaje en el caso portuguésespañol. Con todo, diversos autores señalan otros elementos facilitadores de ese aprendizaje. Almeida Filho (1995b), por ejemplo, destaca entre los primeros la "capacidad de riesgo", que se desarrolla de manera más natural en los aprendientes de estas lenguas:

Pessoas pouco ansiosas e portadoras da capacidade de risco podem avançar rumo à proficiência na língua-alvo com maior rapidez do que poderiam com línguas tipológicamente mais distantes, como entre Português e Inglês, por exemplo. A capacidade de risco torna mais possível, e mais cedo, a autoajuda, isto é, a capacidade de valer-se da experiência pessoal anterior para fazer avançar o desenvolvimento da língua. (ALMEIDA FILHO, 1995b, p. 15) ${ }^{42}$

autor, si miramos hacia atrás, veremos que las lenguas portuguesa y española se tornan cada vez más parecidas en la medida en que retrocedemos en el tiempo. Esto explicaría por qué las lenguas habladas son más distantes entre sí, mientras que en la escrita se hallan más cercanas.

${ }^{41}$ En las clases de español para estudiantes brasileños empezamos hablando la lengua objeto ya desde los primeros encuentros. Es, pues, indiscutible la facilidad que supone la comprensión o el "uso pasivo" de la lengua. (CAMORLINGA, 1997, p. 6) (traducción nuestra)

42 Personas poco ansiosas y con una capacidad de riesgo elevada pueden progresar hacia la fluidez en la lengua objeto más rápidamente de lo que podrían con lenguas tipológicamente más lejanas, como ocurre, por ejemplo, entre el portugués y el inglés. La capacidad de riesgo hace más posible y, más 
A las ventajas iniciales en la comprensión mencionadas por Camorlinga y la capacidad de riesgo que cita Almeida Filho, se suman también otras, como ciertas estructuras morfosintácticas comunes, el orden S-V-C, la formación del género y el número y el paradigma del sistema verbal (CAMPOS 1999, p.193). Asimismo, otro aspecto facilitador del aprendizaje, según Henriques (2005, p. $170)$, sería la escasa distancia tipológica entre las lenguas. La razón es que esta influye directamente tanto en el ritmo como en el desarrollo lingüístico del aprendiz y, con ello, en su actuación lingüística. Es decir, habría una clara ventaja en el aprendizaje de lenguas afines en comparación con el de las lenguas distantes, puesto que se aprenderían más rápidamente.

Parece evidente que todas las características presentadas hasta ahora, y que aparecen como facilitadoras del aprendizaje, posibilitan que el uso de la LE en clase sea factible desde unas etapas muy básicas con un alto grado de comprensión. Por ese motivo, para algunos autores como Almeida Filho (1995b, p. 15), los lusohablantes aprendientes de español no deben considerarse como "principiantes verdaderos", de ahí que en ocasiones se les haya considerado como "falsos principiantes" (DURÃO, 2004, p. 281).

Ahora bien, algunos estudiosos sostienen que si la proximidad interlingüística facilita y agiliza el proceso inicial del aprendizaje del español por parte de los aprendices brasileños, esa misma similitud también hace que el alumno cometa más errores, debido a las interferencias (Older y Ziahosseiny apud ALMEIDA FILHO, 1995, p. 16; ANDRADE NETA, 2000). En este sentido, Campos (1999, p. 192) subraya con respecto a alumnos brasileños de español que "de las cuatro destrezas presentan mayor dificultad en la expresión escrita y oral, debido a las interferencias del portugués". Otros autores (ALMEIDA FILHO, 1995b; CAMORLINGA, 1997; DURÃO, 2000; ALVAREZ, 2002) comparten la opinión de que las transferencias de la LM que están en la base del "portunhol"43 figuran entre las principales dificultades en el aprendizaje de ELE. Como es sabido, el "portunhol" es el nombre atribuido a la

temprana, la autoayuda, es decir, la habilidad para utilizar la experiencia personal anterior para avanzar en el desarrollo de la lengua. (ALMEIDA FILHO, 1995b, p. 15) (traducción nuestra)

43 Colin Rodea (1999 apud FERREIRA, 1995, p. 39) define el "portunhol" como "la expresión más inmediata del contacto entre las lenguas portuguesa y española" (traducción nuestra), y que puede ser descrita como una interlengua con niveles de fosilización muy avanzados. 
interlengua que producen los brasileños aprendientes de español, y que se caracteriza por un notable grado de estancamiento, así como por niveles de producción muy bajos (ALMEIDA FILHO, 1995b, p. 19). Estos son algunos ejemplos de esta variedad, tomados del estudio de Duarte (1999, p. 82-83):

1. ficavamos jugando las cartas

(nos quedábamos jugando a las cartas)

2. quiero voltar a ver mis amigos

(quiero volver a ver a mis amigos)

3. si algun día encuentrar un bonito rapaz (si algún día encontrar un chico guapo)

Desafortunadamente, estos ejemplos, extraídos de un estudio longitudinal con estudiantes universitarios brasileños aprendientes de español, no son una excepción, llegando a veces a ser la regla en alumnos con conocimientos supuestamente elevados. Y, como ya señalábamos en el capítulo anterior (subapartado 2.5) parece haber consenso en que esto se debe a que los errores causados por interferencia tienden a fosilizarse con más frecuencia (por citar algunos investigadores brasileños sobre el tema, ALMEIDA FILHO, 1995b, p. 18; KULIKOWSKI y GONZÁLEZ, 1999, p. 13).

Uno de los motivos para tal estancamiento podría ser que la proximidad entre el español y el portugués proporciona beneficios para el aprendizaje en un principio, pero se torna una dificultad en los estadios más avanzados, como han destacado diversos estudiosos (ALMEIDA FILHO, 1995b; ANDRADE NETA, 2000; ALVAREZ, 2002; CELADA, 2002; CAMORLINGA, 2005; GOETTENAUER, 2005; SALINAS, 2005; CELADA, 2008). En este sentido, Álvarez (2002) afirma:

Falando de ensino de línguas, especificamente, português ou espanhol não podemos esquecer que a proximidade entre ambas cria o que nós chamamos de benefício no início da aprendizagem, mas que nos estágios mais avançados torna- se uma dificuldade. Isto acontece porque a proximidade e semelhança decorrente contribuem para uma compreensão inicial que pode desinibir o aluno na etapa inicial colocando-o como falso iniciante. Mais tarde, quando o nível de complexidade aumenta, a tendência é a cometer erros que 
podem se tornar fossilizáveis dentro da interlíngua criada pelo aprendiz. (ÁLVAREZ, 2002. p. 1$)^{44}$

No obstante, aunque las investigaciones en esta área hayan sido cuantiosas y fructíferas en los últimos años, como veremos más adelante, parece persistir en el imaginario común un estereotipo acerca del elemento facilitador que entraña la proximidad lingüística, con resultados, sin embargo, claramente negativos en la práctica para el aprendizaje del español por brasileños. De este asunto nos ocupamos a continuación.

\subsection{Trampas y creencias en torno a la similitud: un breve recorrido histórico}

Debido a la proximidad lingüística que destacábamos en el apartado anterior, en Brasil existe la creencia de que el español es una lengua "fácil". Diversos autores han intentado explicar el origen de esta presunción y cómo esta ha perjudicado en cierta medida el estatus de la lengua española en este país. Según Celada y González (2000, p. 37), el origen cabe remontarlo a la publicación de la Gramática de língua espanhola para uso dos brasileiros, de Nascentes en 1934, así como del Manual de Español publicado once años más tarde por de Becker (1945). Ambas obras, precursoras de la enseñanza del español como lengua extranjera para brasileños, establecían una relación equivocada entre proximidad y facilidad.

Esta visión se consolidó con el análisis contrastivo, que, como hemos visto en el Capítulo 2, se apoyaba en el modelo conductista y ejerció una gran influencia en la enseñanza de lenguas. Los modelos predictivos de Lado (1957), basados en los estudios

\footnotetext{
${ }^{44}$ Hablando de la enseñanza de idiomas, especialmente del portugués o español, no debemos olvidar que la proximidad entre ambas crea lo que llamamos de beneficio al principio del aprendizaje, pero que en los estadios más avanzados se convierte en una dificultad. Eso sucede porque la cercanía y la similitud contribuyen a una comprensión inicial que puede desinhibir al estudiante en la etapa inicial, poniéndolo como falso principiante. Más tarde, cuando el nivel de complejidad aumenta, la tendencia es a cometer errores que pueden ser fosilizables dentro de la interlengua creada por el aprendiz. (ÁLVAREZ, 2002. p. 1) (traducción nuestra).
} 
contrastivos, se centraban principalmente en las diferencias entre las lenguas y postulaban que estas serían las únicas dificultades de los aprendices. Este movimiento aplicado a la realidad brasileña contribuyó al asentamiento de la creencia de que al haber "pocas diferencias" entre el portugués y el español, aprender el español sería fácil. En este sentido, Paraquett (2015, p. 33) afirma que durante muchos años aprender español significaba apenas dominar las "pequeñas diferencias léxicas", como los heterosemánticos, los heterogenéricos y los heterotónicos ${ }^{45}$, teniendo como base la repetición y el uso de los modelos audiolinguales. Por otro lado, esta autora recuerda que, hasta la llegada en 1975 del libro Español en directo, de Sánchez, Ríos y Domínguez, no había en la práctica manuales de aprendizaje suficientemente difundidos, de ahí que las obras de Nascentes y Becker tuvieran tanto impacto.

Por su parte, Kulikowski y González (1999) sostienen que esa relación similitud-facilidad ocurrió también por ignorancia acerca de la variación lingüística y cultural asociada al español, de manera que este se entendía exclusivamente como la "lengua de España" o, como mucho, la "lengua de España y América". En definitiva, el español fue representado como una lengua fácil, resumida en unas pocas reglas gramaticales y un listado de palabras que podían ser memorizadas con relativa facilidad.

Como recuerdan Celada y González (2000, p. 39), aunque los trabajos de Nascentes y Becker citados anteriormente empezaron la difusión distorsionada de la analogía similitud-facilidad, el principal problema no estuvo en el discurso de esos manuales precisamente, puesto que sus trabajos se basaban en el entendimiento de lengua existente en el momento en que fueron publicados y por ello eran coherentes con los modelos de enseñanza/aprendizaje de la época. La problemática principal surge por el hecho de que tales supuestos, hoy considerados desfasados, han sido mantenidos prácticamente hasta nuestros días, negando el avance de los estudios en el campo de la lingüística aplicada que apuntan a otros modelos e interpretaciones.

De este modo, cualquiera que haya vivido esa realidad escolar en Brasil puede constatar la existencia de estas impresiones claramente incorrectas sobre el aprendizaje del español. Tanto es así que diferentes autores han dedicado investigaciones sobre el tema. Entre estas, destaca la tesis de Celada (2002), quien estudió los discursos de estudiantes universitarios brasileños de la carrera de letras de la Universidad de São Paulo. Su estudio se distinguió

${ }^{45}$ Para la revisión de estos conceptos véase el apartado 5.3. 
por analizar, desde la perspectiva del análisis del discurso, la visión del estudiante brasileño que considera la lengua española como una lengua fácil. Para ello, la autora hizo un recorrido histórico en el que destacó los principios de la enseñanza del español en el país hasta los días en que su tesis fue publicada, y entre otras conclusiones, defendió que la lengua española es "singularmente extranjera", porque, aunque se parezca en algunos aspectos al portugués, al es al mismo tiempo muy distinta de este, y por eso se entiende como extrañamente familiar. Esa aparente "similitud" le confiere al hablante brasileño cierta familiaridad con el español que con demasiada frecuencia lo convence de la poca o nula necesidad de estudiarlo.

Celada llamó, desde la perspectiva del análisis del discurso, "transporte" a las interferencias del portugués al español y argumentó que los brasileños, de forma general, no reciben las ventajas que la proximidad y facilidad del español prometen en un principio (CELADA, 2002, p. 234). También argumentó que las transferencias ocurren principalmente porque los estudiantes están condicionados por el uso de la oralidad del portugués, que se diferencia en muchos aspectos de la lengua escrita, formal, a la que el español está más próximo (CELADA, 2002, p. 254).

Además del trabajo citado, podemos comprobar que la creencia acerca de la supuesta facilidad de la lengua española entre la población general se halla tan extendida que aparece en numerosos estudios de lingüística aplicada (como es el caso, entre otros, de CAMORLINGA, 1997; KULIKOWSKI Y GONZÁLEZ, 1999; ANDRADE NETA, 2000; CELADA Y GONZÁLEZ, 2000 y CELADA, 2002) (CELADA, 2002)(CELADA, 2002)Incluso podemos encontrarla en documentación gubernamental, como el volumen editado por el Ministerio de Educación de Brasil, ${ }^{46}$ en el que se discuten parámetros para todas las asignaturas de la enseñanza media, incluyendo la asignatura de lengua española y donde aparecen afirmaciones sobre esa lengua, supuestamente derivadas del sentido común que la presentan como una "lengua fácil", y "lengua que no necesita ser estudiada" (BRASIL, 2006, p. 128). Para Almeida Filho (1995b), esa creencia llevada a la práctica se refleja en un sentimiento de "casi hablar" sin esfuerzo, que se consigue

\footnotetext{
${ }^{46}$ En palabras de los organizadores, las “Orientações Curriculares para o Ensino Médio" son un conjunto de reflexiones que proporciona el Ministerio de Educación brasileño con la finalidad de "alimentar la práctica docente". Es decir, es un documento de apoyo al profesorado para su práctica, basado en reflexiones que son frutos de investigaciones en los diversos campos del saber.
} 
principalmente mediante los recursos disponibles de la lengua materna. Esa "facilidad engañosa" es uno de los principales problemas en el estudio de una lengua próxima ${ }^{47}$ :

Esse "quase-falar" invariavelmente leva ao constrangimento de parecer querer dizer sem poder ser bem entendido. O sentimento de "quase-falar" leva alunos mas jovens e autoridades de ensino desavisadas a presumir que o falante de Espanhol nem precisaria aprender o Português - eles já o "sabem" naturalmente. (ALMEIDA FILHO, 1995, p. 12)

Una investigación llevada a cabo por nosotros anteriormente, va en consonancia con lo dicho hasta ahora. En un cuestionario aplicado a profesoras brasileñas de español como lengua extranjera, preguntamos si los alumnos veían la lengua española como "fácil" o "difícil" (GIMENEZ 2011). Las respuestas no dejaban margen a la duda:

(1) Profesora "A": De modo general, los alumnos piensan que no es necesario estudiar el español, dicen que "el español cualquiera lo habla", creen que pueden cambiar el acento y algunas letras, y eso es el español.

(2) Profesora "B": La gran mayoría de los alumnos creen en la facilidad de aprender el español, incluso lo prefieren en el momento de optar entre el español y el inglés. (GIMENEZ, 2011, p. 27)

Se observa con frecuencia que cuando los alumnos tienen que elegir entre estudiar la lengua española y la inglesa muchos se

${ }^{47}$ Aunque el autor se refiera al aprendizaje de portugués como lengua extranjera por hispanohablantes, nos tomamos la libertad de hacer el camino inverso, y aplicar las mismas premisas al lusohablante aprendiz de español, como el mismo Almeida Filho hace, de hecho, en varios momentos de su artículo.

${ }^{48}$ Este "casi-hablar" invariablemente conduce a la vergüenza de parecer querer decir sin poder ser bien entendido. La sensación de "casi-hablar" lleva a los estudiantes más jóvenes y las autoridades educativas más incautas a presumir de que el hablante de español no necesita aprender el portugués - ellos ya lo “saben” naturalmente. (ALMEIDA FILHO, 1995, p. 12) (traducción nuestra) 
decantan por la primera, porque existe la creencia generalizada de que se necesita menos esfuerzo para ser aprendida debido a la proximidad interlingüística, lo que el Ministerio de Educación llama una "engañosa sensación de competencia espontánea" (BRASIL, 2006 , p. 140). Sin embargo, esa ilusión se ve deshecha nada más empezar a estudiar la lengua y la frustración por el desengaño causa muchas veces la pérdida del entusiasmo por aprender:

Da ideia de que não é necessário fazer grande esforço para falar essa língua (que é causa dessa perigosa e enganosa sensação de competência espontânea), que traz para o Espanhol muitos dos que não conseguiram aprender o inglês, por exemplo, os aprendizes passam, muito rapidamente, à ideia de que é impossível aprender essa língua, impossível encontrar os pontos de separação em relação ao Português que garantam que não permanecerão nessa espécie de meio do caminho. (BRASIL, 2006, p. 142)

Volviendo a las creencias de los alumnos, en el cuestionario utilizado en el presente estudio hemos obtenido respuestas muy similares a las observadas por Gimenez (2011), como podemos ver en el ejemplo que transcribimos a continuación, extraído de una de nuestras entrevistas (Anexo 4):

(3) E: ¿cómo ven los alumnos las clases de español? ¿Están motivados?

D5E: yo creo que lo más difícil son las creencias de los alumnos cuanto a las clases de español... porque para ellos es la asignatura que no necesita estudiar... no necesita prestar... tener atención... no necesita hacer las tareas ni los trabajos... entonces lo más difícil es trabajar

\footnotetext{
${ }^{49}$ De la idea de que no es necesario hacer un gran esfuerzo para hablar ese idioma (que es la causa de esa peligrosa y engañosa sensación de competencia espontánea), que trae al español a muchos de los que no podían aprender inglés, por ejemplo, los alumnos pasan, muy rápidamente, a la idea de que es imposible aprender esa lengua, imposible encontrar los puntos de separación en relación al portugués que garanticen que no van a permanecer en esa especie de medio camino. (BRASIL, 2006, p. 142) (traducción nuestra)
} 
con las creencias de ellos. (Anexo 4, apartado 4.5)

Se confirma, pues, que muchos aprendices brasileños parten de la idea de que aprender español resulta fácil y transparente por ser semejante al portugués. No obstante, esta falsa transparencia lleva a la "ilusión de competencia espontánea" (CAMPOS, 1999; CELADA, 2002; 2008), es decir, una sensación de "competencia inmediata" (CELADA y GONZÁLEZ, 2000, p. 42) que suele perjudicar, más que beneficiar, el aprendizaje del idioma, como apuntan Kulikowski Y González (1999):

La tan mentada cercanía facilita presuposiciones que después no se confirman, pero que son muy resistentes (todos entienden todo), en síntesis, crea o permite una transparencia engañosa que se presta a innumerables equívocos y empobrece la lectura, la comprensión, la interpretación y la producción de los aprendientes. (KULIKOWSKI y GONZÁLEZ, 1999, p. 15)

En el mismo sentido, Silva (2005) defiende que esta visión del español como lengua fácil puede llevar tanto a la falsa impresión de que con poco o ningún estudio es sencillo hacerse entender y comprender perfectamente al interlocutor, como a un estado de decepción o desestimulo. Ello ocurre ante la falsa creencia de que el español es fácil y que se aprende rápido, pero es común que a los 4 o 5 años de estudio el aprendiz se frustre ante la precariedad de sus conocimientos y las muchas dudas que arrastra. El no haber realizado una reflexión seria y metódica sobre la lengua es uno de los principales problemas para los brasileños aprendices de español, según la autora. Sobre ese "engaño" que la similitud suele producir, Celada (2008) comenta también lo siguiente:

Por efecto de ese juego de espejamientos, si el brasileño formula anticipaciones sobre tal lengua diciendo que es fácil por ser muy parecida, a medida que la conoce y entra en un proceso de adquisición o de aprendizaje, va concluyendo que es difícil (porque, en general, le resuena como una lengua modelar) $y$, cuando especifica esa dificultad, concluye que 


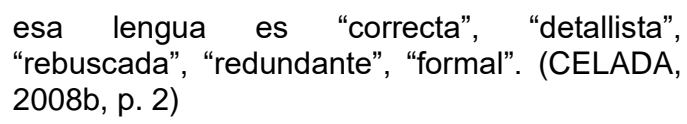
"rebuscada", "redundante", "formal". (CELADA, 2008b, p. 2)

Como detalla la autora, tales anticipaciones sobre el ELE vienen fundadas por la similitud interlingüística y desencadenan un cambio de perspectiva sobre la "facilidad" del aprendizaje del español. En definitiva, parece que las creencias sobre la similitud-facilidad tienen estrecha relación con la dificultad por parte de los brasileños en alcanzar un elevado nivel lingüístico. Como veremos en la sección siguiente, en el caso de la formación docente de ELE no es diferente, puesto que los alumnos de grado suelen tener las mismas creencias, y estas se transforman en una barrera casi insuperable que afecta a su formación.

\subsection{Cercanía lingüística y formación de profesores de ELE}

Sobre las dificultades específicas de alcanzar un alto nivel lingüístico como el que se espera de los sujetos de nuestro estudio, que al fin y al cabo son profesores de español como lengua extranjera, Camorlinga (1997) sostiene que los alumnos, incluso después de tener un buen nivel comunicativo, raramente alcanzan el dominio de aquellos cuya lengua materna es, por ejemplo, el japonés o el alemán, lenguas que, paradójicamente no cuentan con la ventaja inicial que tienen los aprendices brasileños de español. En otro estudio (CAMORLINGA, 2005, p. 1999), señala que cuando se aprende una lengua próxima es muy difícil llegar a obtener un dominio perfecto y rápido de la lengua deseada, lo más habitual es recalar en una interlengua más o menos distante del objetivo. Para este autor, es muy fácil que la fosilización tome asiento, dificultando el progreso en el aprendizaje. En ese sentido, también Ferreira (1995, p. 40) argumenta que, debido a la similitud que facilita el entendimiento, son muchas las evidencias de transferencia negativa y fosilización con origen en la LM. En palabras de Carmolinga:

A experiência ensina que, entrar nesse limbo interlingual é fácil e rápido. Sair dele para adentrar num conhecimento e uso acurado da língua estudada é difícil e demorado. A facilidade, decorrente da proximidade entre a língua de partida e a língua-meta, pode ser uma miragem; mas pode, desde que 
adequadamente trabalhada, tornar-se elemento facilitador. (CAMORLINGA, 2005, p. 204)

Esta facilidad no siempre bien empleada en las clases de ELE lleva, con frecuencia, a que los estudiantes no se den cuenta en la práctica de las diferencias entre los dos idiomas (ALMEIDA FILHO, 1995b, p. 18), creando un verdadero "diálogo de sordos", en el que, como explicaba también Signorini (1998, apud GONZÁLEZ, 2004, p. 30) "[...], no se comprende lo suficiente para entender que no se comprende". Como veremos en nuestro estudio, este "limbo" (CAMORLINGA, 2005) o interlengua cuya principal característica es la interferencia constante de la lengua materna, y de la cual parece muy difícil desprenderse, condiciona también la actuación lingüística de nuestros sujetos.

En el caso de estos, nuestra mirada es más crítica pues ya no se trata de los habituales discentes en todo proceso de aprendizaje, sino del cuerpo docente de ELE en escuelas públicas y privadas, así como en cursos de lenguas, incluidos aquellos que se imparten en la universidad. Muchos de estos profesores, aunque demuestran un gran conocimiento de la LO, no consiguen desprenderse de su LM. Entendemos que uno de los motivos para ello puede ser esta cercanía tipológica tan ampliamente puesta de relieve en los estudios aquí citados, pero que aún sigue siendo un grave impedimento para lograr una competencia comunicativa más elevada.

Sobre la formación de profesores específicamente, área a la que dedicamos nuestro trabajo, Paraquett (2009, p. 136) también señala el problema que supone la presencia de candidatos poco preparados que a menudo se encuentran en las oposiciones para profesores universitarios, así como los currículos de grados que los forman. Parece ser un círculo vicioso que empieza y termina en la formación docente y respecto a eso, claramente, la enseñanza de español en Brasil debería tener en cuenta la proximidad de manera más específica, como ya indicaban Camorlinga (1991) y Salinas (2005).

${ }^{50}$ La experiencia enseña que, entrar en ese limbo interlingüístico es rápido y fácil. Salir de él para entrar en un conocimiento y uso exacto de la lengua estudiada, es difícil y lleva tiempo. La facilidad, fruto de la proximidad entre la lengua de origen y la lengua meta, puede ser un espejismo; pero puede, si está bien concebida, tornarse un elemento facilitador. (CAMORLINGA, 2005, p. 204) (traducción nuestra) 
Sobre el nivel lingüístico alcanzado, Contreras (1998) investigó en su tesina de máster a los profesores en período de prácticas en tres universidades del sur de Brasil y llegó a la conclusión -a través de una serie de análisis de errores y posterior enjuiciamiento por parte de hablantes nativos de Uruguay- de que la lengua española que usaban los futuros profesores no era aceptada por los hablantes nativos. Contreras llamó la atención sobre el input que estos profesores ofrecían a sus alumnos, así como sobre la necesidad de una revisión de los grados de formación de profesores de lengua española, con el fin de adecuar la enseñanza de esta a las necesidades de los futuros docentes y así mejorar su formación, sobre todo lingüística.

El estudio de Contreras daba cuenta de los futuros estudiantes en prácticas, es decir, en los últimos estadios de la carrera. Sin embargo, la investigación bibliográfica llevada a cabo para el presente estudio, nos demuestra que son poco comunes las tesis y tesinas de máster que aborden la interlengua específica de los profesores de lengua española que ya están en ejercicio en Brasil. No obstante, trabajos como el citado anteriormente nos dan una idea aproximada de lo alarmante que es la situación. Un trabajo más reciente (ANICÉZIO, 2012) y el único que hemos encontrado relacionado con profesores en ejercicio, nos muestra que el panorama parece no haber cambiado en los últimos 15 años, si tomamos como referencia el estudio de Contreras (1998). La autora investigó las dificultades enunciativas orales de cinco profesores del centro oeste y sur del país. En el análisis de las entrevistas que llevó a cabo quedó patente la insatisfacción de los profesores con su formación y, en consecuencia, la inseguridad que sentían en su profesión. La revisión de uno de los programas de grado en el que estudiaron estos profesores mostró que la universidad no está adaptada a las necesidades de los futuros docentes, principalmente en lo que concierne al desarrollo de los diferentes niveles lingüísticos que concurren en la enseñanza de la lengua española.

\subsection{Una revisión bibliográfica sobre la interferencia del portugués brasileño (PB) en el español como lengua extranjera}

Como hemos visto hasta ahora, es extensa la lista de trabajos que se han dedicado a los aspectos comparativos entre las dos lenguas, así como los que han analizado la interlengua de los brasileños aprendices de español. No obstante, nos parecía 
importante para nuestra investigación entender qué trabajos abordaban la interferencia específicamente, y qué aspectos de esta analizaban en concreto. Para ello, hemos llevado a cabo una recopilación de las investigaciones llevadas a cabo sobre la interferencia lingüística del portugués lengua materna $(P B)$ en la lengua española como lengua extranjera (ELE) en Brasil ${ }^{51}$. Como objetivos específicos buscamos averiguar qué campos de la interferencia lingüística se han investigado preferentemente y hacer un resumen de los trabajos más destacados hasta el momento de la redacción de esta tesis ${ }^{52}$. Por motivos de espacio hemos optado por insertar la lista de los trabajos investigados en los Anexos 8.

Esta recopilación se realizó en dos etapas distintas y complementarias. En un primer momento, se buscó elaborar una base de datos con los trabajos académicos (tesinas de máster y tesis de doctorado) de los programas de posgrado brasileños. Esto se dio de tres maneras también distintas y complementarias: la primera de ellas se hizo con base en el portal de la "Coordenação de Aperfeiçoamento de Pessoal de Nível Superior" - CAPES ${ }^{53}$, dónde se buscaron tesis y tesinas de máster con las siguientes palabras clave en portugués y español: Interferencia; Lingüística Contrastiva; Análisis de Errores; Español; Transferencia; Interlengua; Fosilización. La primera dificultad que encontramos en esta etapa fue que el referido repositorio estaba en fase de mantenimiento, y por ello solo disponía de las obras referentes a los años de 2011 y 2012. En virtud de ello, decidimos proseguir con la investigación utilizando otras fuentes.

${ }^{51}$ En un primer momento hemos investigado también las tesis y disertaciones llevadas a cabo en las universidades españolas. No obstante, hemos tenido problemas con la página del Ministerio de Educación, Cultura y Deporte, en el apartado de la Base de Datos de Tesis Doctorales - Teseo: https://www.educacion.gob.es/teseo/irGestionarConsulta.do, la cual no daba acceso a los trabajos completos (apenas a los resúmenes), lo que nos dificultó el hacer una investigación como la que hemos llevado a cabo en Brasil. Por ello, los trabajos españoles que citamos en este capítulo son de los pocos a cuyo texto completo hemos podido acceder.

${ }^{52}$ Más detalles de este estudio pueden ser encontrados en GIMENEZ (2016).

${ }^{53} \mathrm{La}$ "Coordenação de Aperfeiçoamento de Pessoal de Nível Superior (Capes)" es una fundación del Ministerio de Educación brasileño (MEC), que tiene como objetivo la expansión y consolidación del posgrado (máster y doctorado). El Banco de Tesis de Capes está disponible desde 2002, y dispone de datos de tesis y tesinas defendidas desde 1987. Su dirección electrónica es: http://bancodeteses.capes.gov.br/. 
Así, en un segundo momento, hemos analizado la base de datos de la "Biblioteca Digital Brasileira de Teses e Dissertações" $(B D T D)^{54}$, desarrollada y mantenida por el "Instituto Brasileiro de Informação em Ciência e Tecnologia" (IBICT) en 2002. Aunque no todas las instituciones de enseñanza superior brasileñas colaboran con la BDTD, entre algunas de sus particularidades está que abarca tesis de brasileños defendidas en el exterior y ofrece todas las obras completas.

Terminada la búsqueda en estas bases de datos, y teniendo en cuenta que ambas presentaban un acceso restringido a la información (la primera, por motivos de mantenimiento, disponía de trabajos defendidos solamente entre 2011 y 2012; y la segunda no abarca la totalidad de las instituciones del país), hemos visto la necesidad de investigar directamente en las páginas web de universidades que tienen programas de posgrado en letras, lingüística, lingüística aplicada y educación, utilizando las mismas palabras clave empleadas anteriormente. Con los datos recogidos en estas tres etapas se determinó nuestra primera base de datos, a partir de la cual fue posible definir la clasificación de los trabajos académicos encontrados, tanto por fecha de lectura como por tema y universidad de procedencia.

En un primer momento, el total de trabajos encontrados fue de 128, aunque después de pasar por un minucioso proceso de lectura de los resúmenes se llegó a un total de 43. De los 128 iniciales, un gran número fue excluido por no contener acceso o bien a los resúmenes o bien al trabajo completo (46) y otra buena cantidad por no encajar completamente con los criterios de búsqueda (39). Teniendo en cuenta que nuestra tesis versa sobre la interferencia lingüística en casos de aprendizaje formal de la LO, hemos excluido las investigaciones basadas en estudios de contacto lingüístico y nos hemos centrado exclusivamente en las investigaciones de carácter dual portugués/español. Todos los demás trabajos que no se ajustaron a estos criterios fueron descartados. El resultado final fue un total de 43 trabajos, de los cuales 13 tesis y 30 tesinas de máster.

Una vez terminada la recolección de las obras, se procedió a etiquetarlas según su campo de estudio lingüístico, de acuerdo con los resúmenes y palabras-clave. En algunos casos hemos tenido que acceder al trabajo para extraer las informaciones necesarias, puesto que los resúmenes no eran del todo completos. Las hemos catalogado cinco grandes grupos, según el área de

\footnotetext{
${ }^{54}$ http://bdtd.ibict.br/vufind/
} 
especificidad de los respectivos trabajos. A saber: morfosintáctico, fonético-fonológico, léxico-semántico, pragmático y discursivo. Otras dos categorías fueron creadas para acomodar otras investigaciones. La primera, denominada varios, incluye trabajos que albergan el análisis de más de una categoría; la segunda, denominada otros, abarca trabajos que no se encuadraban en ninguna de las categorías anteriores $^{55}$. Una vez extraída esta información, se procedió a contabilizar los resultados.

\subsubsection{Acerca de los campos de estudio de la interferencia}

Uno de nuestros objetivos en este punto era averiguar qué campos de la interferencia lingüística se han investigado. Hemos encontrado que los trabajos que se ocupan del nivel fonéticofonológico son los más frecuentes, con un 33\% de las obras, seguido por los estudios de morfosintaxis (23\%). En tercer lugar se encuentran las investigaciones catalogadas con la etiqueta "varios", es decir, aquellas de carácter multidisciplinar, que se dedican a analizar más de un nivel lingüístico (19\%). Los campos léxicosemántico, pragmático y discursivo tienen una presencia minoritaria, así como el campo "otros", en el cual hemos incluido trabajos de diferente índole que no encajaban en los demás grupos. Todo ello se puede apreciar en el gráfico 1:

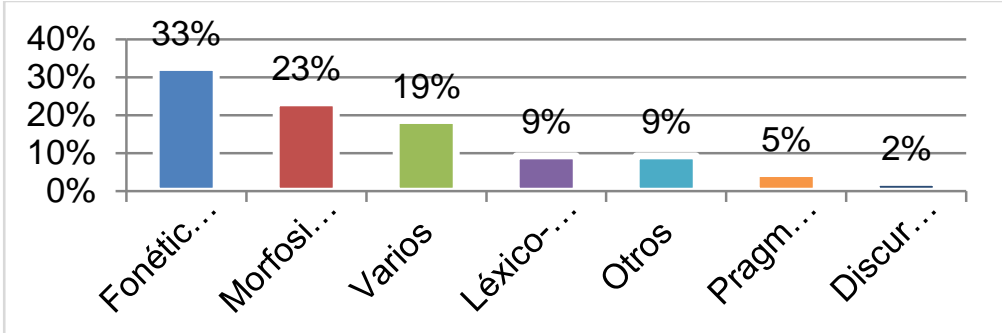

Gráfico 1: Porcentaje de investigaciones por niveles del análisis.

${ }^{55}$ En el campo "otros" hemos incluido los trabajos que versaban acerca de la interferencia lingüística con los siguientes enfoques: Interferencia e identidad lingüística; interferencia y representación mental de la gramática del aprendiz; interferencia en la comprensión y producción de ELE; interferencia y concordancia verbal en la psicolingüística. 
Por otro lado, si comparamos los campos de estudio por grado, veremos que los trabajos de carácter fonético-fonológico representan la mayoría de las investigaciones en el campo del análisis de la interlengua, tanto entre las tesis doctorales (4 en total) como entre las disertaciones de máster (10 en total). En segundo lugar, se encuentran los estudios referentes a aspectos morfosintácticos (8 disertaciones y 2 tesis). En los trabajos en que se aborda más de un aspecto lingüístico, vemos que hay una mayor disparidad (7 disertaciones y 1 tesis). Finalmente, los campos léxicosemántico y pragmáticos son los únicos que presentan igualdad entre ambos grados (2 y 1 , respectivamente).

Por otro lado, las tesis doctorales parecen dedicar más atención a aspectos menos estudiados que las disertaciones (como los aspectos abarcados en el campo "otros" o el nivel léxicosemántico, mientras que lo contrario pasa con los aspectos discursivos, así como los estudios que se dedican a más de uno de esos niveles (incluidos en el campo "varios"), como podemos observar a continuación (gráfico 2):

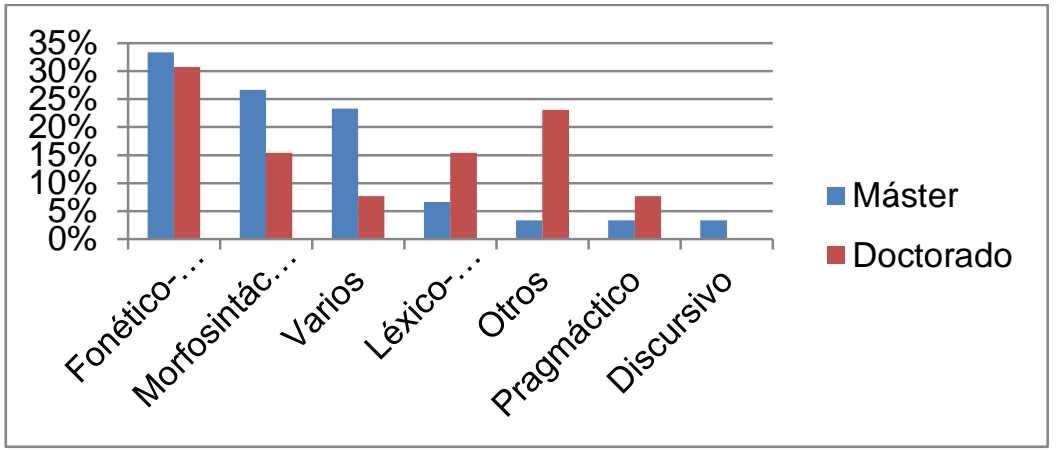

Gráfico 2: Distribución de las investigaciones por campo y grado.

Otro objetivo que perseguíamos en nuestra tesis doctoral era descubrir los tipos de corpus utilizados según su canal de producción (CRUZ PIÑOL, 2012). Estos se pueden clasificar en tres grandes grupos: corpus textuales o escritos, corpus orales (muestras de habla transcrita) y corpus mixtos (muestras de texto escrito y oral). Como resultado, hemos encontrado que los corpus orales (19) son tan usados como los escritos (17). Por el contrario, los corpus mixtos son mucho menos frecuentes (un total de 7). 


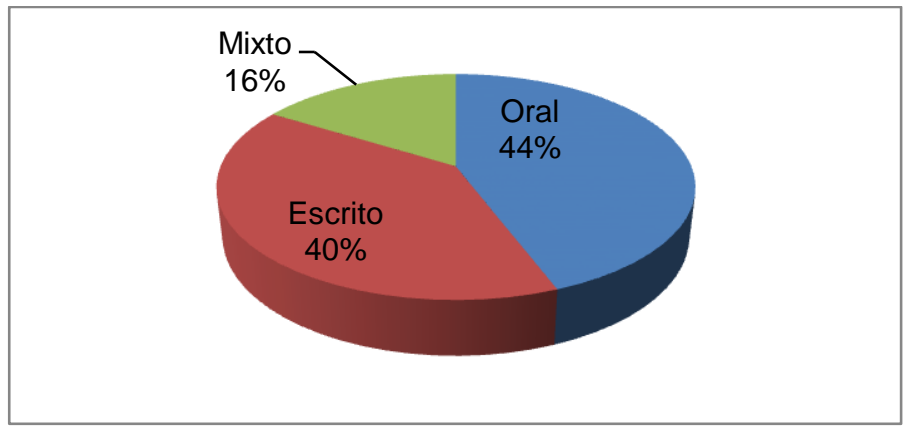

Gráfico 3: Tipo de canales de producción de los corpus.

\subsubsection{Notas para nuestro estudio}

Sintetizando los resultados aquí presentados, podríamos decir que los trabajos sobre la interferencia de la lengua portuguesa en el español como lengua extranjera en contextos formales en Brasil suelen caracterizarse por investigar mayormente los aspectos fonético-fonológico y morfosintácticos, mediante el recurso a corpus escritos y orales en proporciones muy similares. Asimismo, hemos podido constatar que hay un claro predominio de los estudios de máster sobre los de doctorado en este tipo de trabajos, como se advierte en el siguiente gráfico:

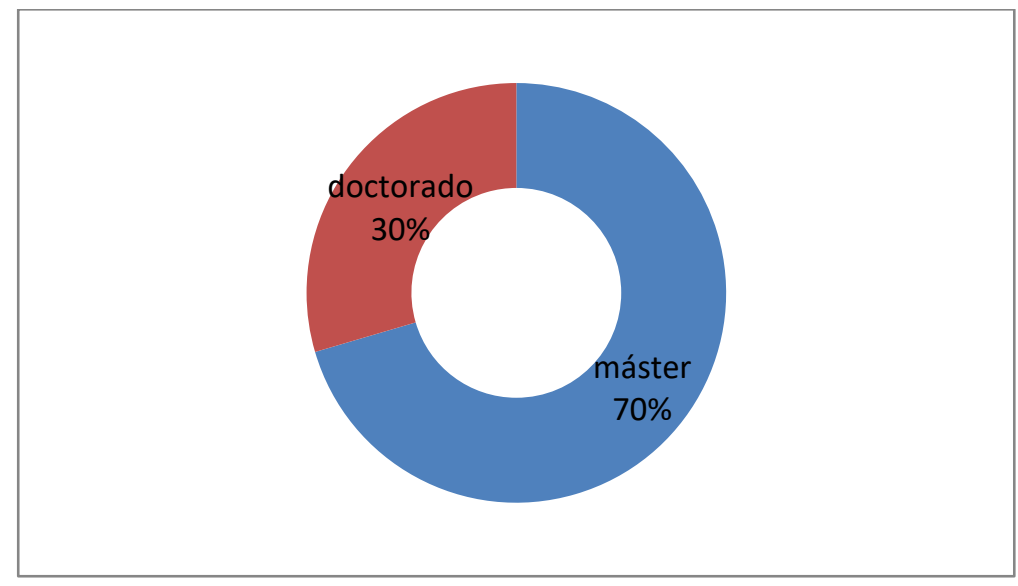

Gráfico 4: Investigaciones por titulación. 
Suponemos que uno de los principales factores que podrían contribuir a esta disparidad sería el número de alumnos matriculados en los cursos de maestría, suelen superar claramente a los de doctorado, y, por tanto, es lógico que el volumen de trabajos del primer tipo sea mayor. Por otro lado, hay que recordar que muchas universidades brasileñas presentan únicamente cursos de máster, lo que también limitaría la continuación de este tipo de estudios en una esfera superior.

Desde el punto de vista cronológico, y como puede apreciarse en el gráfico 5, no existe continuidad. Vemos que en los años 2003 y, sobre todo, 2007 hubo algunos picos importantes de producción, mientras que en los demás años los trabajos de este tipo disminuyeron, llegando incluso a cero en algunos casos (1992, 1993, 1996, 1998, 2004 y 2013). Sin embargo, conviene recordar aquí que en este recuento tan solo hemos tenido en cuenta los trabajos a cuyo resumen o texto completo hemos tenido acceso. Somos conscientes de que, en el período analizado, se han podido llevar a cabo más investigaciones del mismo tenor, y que, por razones ajenas a nuestra voluntad, no aparecen contabilizadas en nuestra relación.

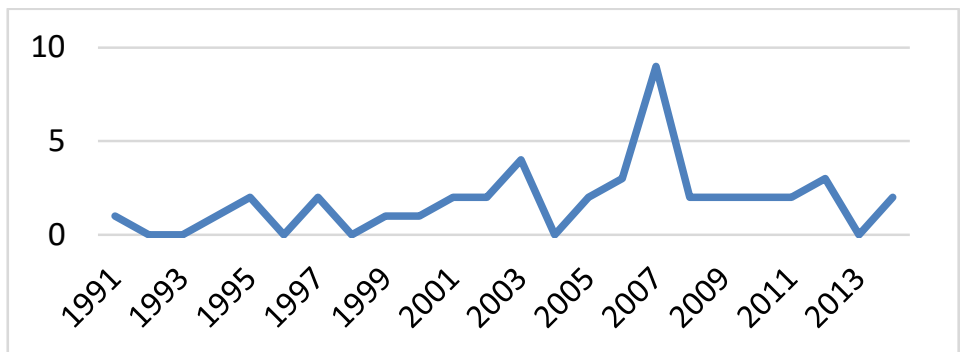

Gráfico 5: Evolución de los trabajos académicos a través de los años.

Por último, queremos destacar que sobre los aspectos léxico-semánticos, aquellos que tienen un especial interés para nosotros, y, sobre los que, como hemos visto en este capítulo, la comunidad académica pone un especial énfasis, figuran, por el contrario, entre los niveles del análisis menos estudiados. Este hecho llama especialmente la atención puesto que se trata de la esfera lingüística que más influye en la visión estereotipada acerca de la "facilidad" del aprendizaje del español por estudiantes brasileños, tal y como hemos visto en este capítulo. En 
consecuencia, parece evidente que son necesarios más estudios que den cuenta de esta similitud y ayuden a entender de qué manera opera en la interlengua de los aprendices.

\subsubsection{Trabajos pioneros en el análisis de errores del español como lengua extranjera}

Para terminar, nos gustaría hacer mención a algunos estudios pioneros en el área, y que sirvieron de referencia para el nuestro. Tal y como hemos señalado anteriormente, en las últimas dos décadas se han publicado numerosos trabajos en torno a las facilidades y dificultades de enseñar y aprender una lengua próxima como el español en Brasil. Además de las investigaciones ya discutidas hasta aquí, nos gustaría reseñar en esta sección las aportaciones de algunos autores que han supuesto un antes y después en la investigación específica sobre las transferencias, como ocurre con las tesis de Eres Fernández $(1998)^{56}$ y González (1994), quien estudió el uso de los pronombres españoles por aprendices brasileños.

No menos importantes son las investigaciones sobre la interlengua y las interferencias del portugués en el aprendizaje de la lengua española de Yokota (2007), quien estudió el objeto directo anafórico mediante un corpus oral y escrito de alumnos universitarios estudiantes de lengua española; Gancedo Álvarez (2008), por su parte, investigó los clíticos dativos mediante la comparación de tres corpus distintos: (i) de español producido por estudiantes brasileños de ELE, (ii) de español producido por nativos uruguayos y (iii) de portugués producido por nativos brasileños. Finalmente, cabe mencionar también la tesis de Bruno (2006), quien analizó las formas uno/a utilizadas en la comprensión y expresión por parte de alumnos brasileños aprendices de español.

Asimismo, hay que destacar las contribuciones inestimables en este ámbito de estudio de diversas tesis defendidas en universidades españolas, y que han contribuido igualmente al desarrollo del análisis de errores de brasileños aprendices de español. Así ocurre con el trabajo pionero de Durão (1998) en la Universidad de Valladolid, quien estudió comparativamente, a través de diversos textos escritos, los errores producidos por estudiantes

\footnotetext{
${ }^{56}$ Esta tesis tuvo un gran impacto en los estudios del área. Lamentablemente, nos fue imposible encontrar el original y por ello no la podemos tratar especificaremos aquí.
} 
brasileños de español y por alumnos españoles aprendices de portugués. En esta lista hay que mencionar igualmente a Torijano Pérez (2002) (tesis leída en Universidad de Salamanca), quien investigó los errores de alumnos brasileños y portugueses en los textos escritos del examen del DELE (Diploma de Español como Lengua Extranjera). Otra investigación destacable es la de Arcos Pavón (2009), en la Universidad Complutense de Madrid, quien estudió mediante cuestionarios orales y escritos los errores cometidos por brasileños estudiantes de español en la producción de verbos que rigen preposición, así como el trabajo de Silva (2010), en la Universidad de Salamanca, quien analizó el uso de algunas estructuras verbales y discursivas españolas entre alumnos universitarios de Brasil.

\subsection{Perspectivas futuras para la enseñanza de ELE en Brasil}

En definitiva, si queremos zanjar la problemática acerca de la formación de los docentes de lengua española en Brasil, la cual se ve, como hemos destacado, fuertemente influenciada tanto por las creencias acerca de la facilidad en el aprendizaje del español como por la interferencia de la LM, debemos, finalmente, intentar entender la similitud entre la lengua española y portuguesa de manera distinta. Para ello, son útiles las palabras de González (2008):

Como se puede ver, resulta peligroso apoyarse simplemente en el estereotipo de la gran semejanza entre el español y el portugués (en este caso, el de Brasil), porque, aun cuando estas semejanzas existen en un nivel superficial de la lengua, otros factores, tanto de naturaleza propiamente lingüística, gramatical, como de funcionamiento discursivo pueden conducir a errores serios de interpretación o incluso a la incomprensión mutua. $Y$ es importante dejar claro que no se trata simplemente de un conjunto de problemas relacionados con las normas gramaticales vigentes, sino con el funcionamiento de las lenguas y con los elementos indispensables para que se produzca la comprensión por parte de los hablantes nativos y se detecten los sentidos 
que se producen a partir del uso de determinadas formas. (GONZÁLEZ, 2008, p. 4)

En el mismo sentido, Celada (2002, p. 261-263) aboga por que la enseñanza del español para brasileños necesita reservar un espacio para romper entre los alumnos con los estereotipos de lengua fácil, puesto que esto puede ralentizar, y hasta detener, el proceso de aprendizaje. Por otro lado, para la autora, hay que trabajar también concienzudamente en la "clausura imaginaria" de aquellos alumnos que han pasado de creer que la lengua es "fácil", a verla como una lengua "correcta, detallista, redundante, complicada, rebuscada, formal y mandona". Es decir, se hace necesario deshacer también esas concepciones frecuentemente atribuidas a la lengua española cuando los alumnos se dan cuenta de que esta no guarda la similitud con el portugués que suponían en un principio.

Además de González y Celada, los trabajos citados hasta ahora han demostrado los inconvenientes de la asociación proximidad-facilidad. Esos investigadores están claramente concienciados de la necesidad de cambiar el imaginario colectivo sobre el aprendizaje del español, así como reforzar la idea de que la lengua necesita ser enseñada desde una perspectiva distinta. Además de esos estudios, nos gustaría mencionar igualmente los documentos oficiales del Ministerio de Educación brasileño, los cuales han tratado de dar una nueva orientación a la enseñanza del español. Estamos hablando de los "Parâmetros Curriculares Nacionais - PCN" (BRASIL, 1998) y las "Orientações Curriculares para o Ensino Médio - OCEM" (BRASIL, 2006a), documentos que rigen la educación básica brasileña y el papel de la lengua extranjera (y más específicamente de la lengua española en el segundo documento) en la enseñanza básica. Aunque los PCN traten la lengua extranjera bajo la óptica de la lectura y reflejen más la enseñanza del inglés, los OCEM tratan categóricamente la problemática que supone entender el español como una lengua fácil y la necesidad de un cambio en este sentido.

Para Paraquett (2015, p. 32), el estudio de la "proximidad" es una cuestión científicamente pertinente, y uno de los temas en los que la lingüística aplicada brasileña más puede colaborar en los estudios hispánicos, ya que ha sido ampliamente investigada en los programas de posgrado en Brasil. Para la autora, es a través del contraste entre lenguas y culturas como se comprenderá el mayor o menor grado de proximidad existente. 
Parece también - y retomaremos esa cuestión en la discusión de los resultados -, que una metodología distinta es necesaria en la enseñanza de las lenguas próximas. En este sentido, estamos de acuerdo con Almeida Filho (1995b) cuando sostiene que:

[...] uma progressão lenta e gradual dos conteúdos baseada na forma e nas estruturas descritas do Português é inapropriada para uma aprendizagem motivante e duradoura reforçando razões de outra natureza (como, por exemplo, a de que o foco na forma impede a aquisição de competência linguísticocomunicativa) (cf. Krashen, 1992). (ALMEIDA FILHO, 1995a, p. 17) ${ }^{57}$

O, en otro lugar:

A familiaridade embutida na proximidade das línguas fala a favor de uma progressão de experiências de conteúdo e de processamento mais ágil e íngreme, possibilitando experiências com áreas de uso comunicativo (Widdowson, 1991), ensino temático ou interdisciplinar (vide Bizón, 1994). Poderia ser ainda mais adversa a solução graduada de fundo áudio-lingualista tomada com relação a grupos de jovens aprendizes. (ALMEIDA FILHO, 1995a, p. 17)

Como indica el autor, el único camino es sensibilizar a los alumnos sobre las características intrínsecas del aprendizaje de las lenguas extranjeras, contribuyendo así a disolver los aspectos más

${ }^{57}$ [...] una progresión lenta y gradual de los contenidos basada en la forma y en las estructuras descritas del portugués es inapropiada para un aprendizaje motivador y duradero reforzando razones de otra naturaleza (como, por ejemplo, la de que el foco en la forma impide la adquisición de la competencia lingüístico-comunicativa) (cf. Krashen, 1992). (ALMEIDA FILHO, 1995a, p. 17) (traducción nuestra)

${ }^{58} \mathrm{La}$ familiaridad incrustada en la proximidad de las lenguas habla en favor de una progresión de experiencias de contenido y procesamientos más ágiles y pronunciados, permitiendo experiencias con áreas de uso comunicativo (Widdowson, 1991), enseñanza temática o interdisciplinarios (véase Bizón, 1994). Podría ser aún más perjudicial la solución gradual de fondo audio-lingual adoptadas en relación a los grupos de jóvenes aprendices. (ALMEIDA FILHO, 1995a, p. 17) (traducción nuestra) 
engañosos de la LO, así como las creencias y estereotipos en torno al "portuñol". A partir de lo dicho hasta ahora, nos gustaría añadir que lo defendido por Almeida Filho se acerca bastante a lo que creemos cuando argumenta que una enseñanza con base en la contrastividad, tanto de elementos lingüísticos como pragmáticos y culturales, parece un sendero adecuado para alcanzar un aprendizaje exitoso en el contexto siempre espinoso de las lenguas próximas (ALMEIDA FILHO, 1995b, p. 18).

Almeida Filho (1995b, p. 18) también subraya que alimentar la consciencia del aprendiente con el foco puesto en la "autocrítica de la propia producción" puede contribuir muy positivamente al aprendizaje de las lenguas próximas ${ }^{59}$. La monitorización consciente puede auxiliar en la sensación de competencia de comunicación, puesto que los alumnos son más conscientes de su actuación, de sus fallos y aciertos, así como de las diferencias entre las lenguas. Mientras que en la enseñanza de leguas más distantes la postura del profesor debe ser la de incentivar a los alumnos, enseñando lo que pueden hacer con lo que ya saben e "ignorando" -en la medida de lo posible- sus errores, en el caso de las lenguas próximas habría que hacer al contrario, mostrando a los alumnos que aún no conocen la lengua tan bien como creen y que pueden actuar en el idioma de una manera incorrecta (ALMEIDA FILHO, 1995b, p. 19).

En este caso, entendemos que la sensibilidad del profesor es clave para conducir la enseñanza de manera motivadora, sin perder el foco en los aspectos lingüísticos que deben ser enseñados, pero llevando al alumno a entender, de manera realista, que la similitud puede, por un lado, facilitar el aprendizaje, pero, por otro, puede ser al mismo tiempo un elemento notablemente perturbador. Esto desemboca, sobre todo, en las transferencias lingüísticas, las cuales son en gran medida responsables de la fosilización y el estancamiento en el aprendizaje.

\subsection{En conclusión}

En este capítulo hemos intentado comprobar, por medio de diversos estudios, la existencia de algunas características específicas en el aprendizaje de lenguas próximas, y más concretamente del español para brasileños. Entre ellas, destacan,

\footnotetext{
${ }^{59}$ Para desarrollar la "autocrítica de la propia producción”, el autor propone una serie de ejercicios que, por motivos de espacio, no citaremos aquí.
} 
en primer lugar, el alto índice de interferencias y su alta probabilidad de fosilización. En segundo lugar, está el hecho de que existe una idea extendida de que, debido a la similitud, el español es fácil de aprender por parte de los brasileños, o incluso, de que se requiere poco o ninguno esfuerzo para ello. Como resultado de estos dos hechos, tenemos el tercero: una dificultad patente para alcanzar un nivel lingüístico elevado, incluso cuando nos referimos a los estudios de grado y a los futuros profesores. Eso ocurre también porque, como hemos visto, en el aprendizaje de las lenguas próximas la similitud sirve como facilitadora al principio, pero, en la medida en que se progresa, se torna un impedimento para conseguir un alto nivel lingüístico.

También hemos señalado que esta creencia sobre la facilidad del idioma tiene un fondo histórico en Brasil, con base en el conductismo, el cual regía la enseñanza en los años en que se empezó a estudiar esta lengua con más asiduidad, manteniéndose la creencia hasta el día de hoy, aunque las bases teóricas y metodologías para la enseñanza de lenguas hayan cambiado substancialmente.

Además, hemos señalado que la investigación de las lenguas próximas parece ser uno de los temas ignorados por la comunidad científica por no presentar problemas didácticos aparentes, todo lo contrario de lo que hemos podido comprobar en estas páginas.

Por estos motivos, hemos defendido que es necesario seguir investigando acerca de las creencias en torno al aprendizaje del español, puesto que, tanto los estudios en esta área científica como la propia experiencia docente nos demuestran que estas pueden ser altamente perjudiciales para los aprendices, y, aún más, para los futuros profesores.

Aunque, como hemos visto, mucho se ha escrito sobre todas estas características, parece que, al menos en algunas regiones de Brasil, poco ha cambiado en los últimos años respecto a la enseñanza-aprendizaje del español en los grados de formación docente. Un ejemplo de ello es la investigación de Anicézio (2012) citada anteriormente, así como los resultados de la nuestra. En el caso de la formación docente, específicamente, nuestro estudio perece indicar que hay mucho aún por hacer. Uno de los caminos para ello es analizar sistemáticamente los errores que siguen cometiendo nuestros alumnos y repensar la forma de auxiliarlos en el proceso de aprendizaje de una lengua tan singular y que posee tantas dificultades ocultas para los brasileños. 
En otra sección de este capítulo (3.5), vimos que aunque la similitud $y$, en consecuencia, la interferencia ocurra principalmente en el nivel léxico, pocos son los estudios que tratan sobre este tema. En este sentido, esperamos que poder aportar nuevos datos relevantes sobre el modo en que las interferencias se traducen en el plano léxico y la manera en que todo ello se relaciona con el nivel lingüístico de nuestros sujetos.

Para ello, analizaremos los errores a partir de unas categorizaciones que serán explicadas en los dos siguientes capítulos. A continuación (Capítulo 4) analizaremos las diferentes concepciones sobre el error, y definiremos el que utilizaremos aquí, así como las particularidades que presenta el análisis de errores en el estudio de las interferencias. Por otro lado, en el último capítulo teórico de este trabajo (Capítulo 5) abordaremos el estudio del léxico, delimitando los conceptos clave para nuestra investigación. 


\section{HACIA UNA DELIMITACIÓN Y CATEGORIZACIÓN DEL ERROR}

Como hemos visto en el Capítulo 2, el error ha pasado de considerarse el gran villano en la visión conductista del aprendizaje y, por ende, del Análisis Contrastivo, a ser visto como un aliado de los profesores e investigadores en el contexto del Análisis de Errores. Así, en una retrospectiva histórica, la lengua materna, tradicionalmente entendida como la principal fuente de confusiones para los aprendices de lengua extranjera, empezó a concebirse como un componente más de los que dispone el alumno para desarrollar su conocimiento en la LE. Ahora bien, como también hemos visto en el Capítulo 3, aunque la LM no es la única fuente de errores, en el caso de lenguas próximas, esta juega un papel innegable, por un lado, como facilitador, pero también, por otro, como potenciador tanto de la producción de errores como de su fosilización.

Llegados a este punto, en lo que sigue discutiremos algunos criterios y taxonomías sobre los errores, y delimitaremos la clasificación que pensamos utilizar en el trabajo. Para ello, comenzamos con una caracterización del error (subapartado 4.1), seguida de una revisión de sus diferentes categorías (subapartado 4.2). Para finalizar, haremos algunas consideraciones sobre el análisis de errores aplicado más específicamente a nuestro estudio (subapartado 4.3).

\subsection{Caracterización del error}

Empezaremos ese capítulo tomando como punto de referencia la valoración que Vázquez (1992, p. 104) realizaba hace unos años acerca del estado en que quedó la concepción de error tras la etapa álgida del AC:

Damos por sabido que la evolución del concepto de error a lo largo de los últimos veinticinco años ha dado por resultado - a la luz de las investigaciones existentes - un concepto con características positivas, 
desprovisto de connotaciones estigmatizantes, por lo menos en el contexto de la clase.

Como la misma autora ha reconocido años más tarde, existe un amplio consenso en la bibliografía de las últimas décadas sobre algunos aspectos relacionados con esta cuestión (VÁZQUEZ, 2007, p. 114):

- Las faltas y los errores pertenecen al proceso de aprendizaje.

- Desde el punto de vista etiológico responden a varias causas (no sólo la distracción, falta de esfuerzo, etc.) sino sobre todo a la interferencia de la L1 y otras L3 y estrategias de regularización, simplificación y generalización.

- Que los errores no se evitan a través de ciertas progresiones gramaticales o de otro tipo, ni siquiera a través de la corrección continua, propia o de quien enseña.

- Que un número considerable de errores responden a la formación de hipótesis que realizan las personas que aprenden.

Como destaca Vázquez (Ibid., p. 140), hay un cierto consenso en la comunidad científica sobre la existencia determinados errores, que se repiten de manera recurrente, así como sobre el hecho de que su aparición es inevitable e indisociable al mismo proceso de aprendizaje de lenguas. Ahora bien, parece que ese consenso no se mantiene cuando los diferentes autores explican qué son en esencia los errores. Véanse, a modo de ejemplo, algunas de las definiciones heterogéneas que podemos encontrar en la bibliografía:

a) "toda transgresión involuntaria de la norma" (FERNÁNDEZ, 1997, p. 27)

b) "uso de elementos lingüísticos o pragmáticos que dificultan o impiden la comprensión del lenguaje" (DURÃO, 2004, p. 53)

C) "una estrategia empleada por niños que adquieren su lengua materna y por individuos que aprenden una segunda lengua" (CORDER, 1967, p. 11)

d) "comportamientos anómalos del lenguaje" (TORIJANO PÉREZ, 2004, p. 21); 
Aunque estamos de acuerdo con Corder (1971b, p. 25) cuando afirma que "cometer errores es una parte inevitable e incluso necesaria en el proceso de aprendizaje", parece indudable que existen varios modos de concebirlos, porque, como veremos en esta sección, su interpretación se ajusta a la variedad de objetivos de las diferentes investigaciones. Sin embargo, esta diversidad conceptual no tiene por qué ser negativa, pues entendemos que diferentes nociones sobre un mismo objeto pueden ser complementarias, y hasta convenientes en estudios sobre el análisis de errores como el que emprendemos aquí.

Comenzamos esta revisión por Fernández (1997, p. 27), quien afirma que el error se concibe como: "toda transgresión involuntaria de la norma establecida en una comunidad dada", aunque para la autora "la norma tampoco es un concepto unívoco", y, por tanto, mantiene que habría que preguntarse si esa definición es aplicable a las desviaciones de los aprendices de lenguas extranjeras. Fernández establece una comparación directa entre el aprendizaje de la LM y el aprendizaje de la LE para definir el error:

(...) así como no se consideran erróneas frases
como "coche nene" en un niño de dos años,
sino producción normal de determinados
estadios del desarrollo, así las producciones
"incorrectas" del aprendiz de una L2 serían
marcas, también, de los diferentes estadios del
proceso de apropiación de una lengua.
(FERNÁNDEZ, 1997, p. 18)

En el mismo sentido, la investigadora defiende que "el mismo concepto de error induce a error" (FERNÁNDEZ, 1997, p. 27), puesto que las producciones de los aprendices deben ser evaluadas según su IL y no desde la lengua objeto. La estudiosa también argumentaba algunos años antes (FERNÁNDEZ, 1995, p. 204) que el error es un paso obligado en la IL del aprendiente, ya que en el fondo es un indicio de las estrategias sucesivas que usa en diversos estadios del aprendizaje hasta hacerse, finalmente, con una competencia aceptable en la lengua meta.

En el intento de alcanzar una caracterización del error que pudiera acomodarse a la enseñanza de LE, Durão (2004) analizó cinco definiciones de diferentes autores (Nikel, 1971; Chun et al, 1981; Liski y Puntanem, 1983; Chaudron; 1988, apud DURÃO, 2004, p. 51-53) para llegar a la conclusión de que cada autor veía el error desde perspectivas diferentes, aunque al mismo tiempo no 
daban explicaciones que se ajustaran cabalmente a la enseñanza/aprendizaje de las LE, sino al aprendizaje en general. En un movimiento aproximativo hacia una definición que pudiera ser aplicada al aprendizaje de LE, la autora propone que "el error corresponde al uso de elementos lingüísticos o pragmáticos que dificultan o impiden la comprensión del lenguaje" (DURÃO, 2004, p. 53).

En otra publicación, y en el mismo sentido que Corder (1981b, p. 41), Durão (2007, p. 31) señala otra característica del error de los estudiantes de LE, y subraya que de la misma manera que la producción de una forma correcta no es una señal ineludible de que esta se haya interiorizado ${ }^{60}$, la aparición de una forma errónea tampoco debe entenderse directamente como un error en sí mismo, ya que algunas de estas son fruto de un proceso de acomodación del aprendizaje y, de esa forma, un error por sí mismo no prueba un estancamiento de la interlengua.

Para Corder (1967, p. 11) "cometer errores es, pues, una estrategia empleada por niños que adquieren su lengua materna y por individuos que aprenden una segunda lengua". De acuerdo con el autor (CORDER, 1967, p. 10-11), los errores tienen importancia en tres esferas:

1. Para el profesor: le dice en qué etapa del aprendizaje está el alumno y en qué posición se encuentra frente a los objetivos del curso.

2. Para el investigador: proporciona evidencias de cómo se aprende una lengua y las estrategias empleadas por el alumno en su proceso.

3. Para el alumno: son indispensables, pues representan uno de los mecanismos principales del aprendizaje, al tiempo que una manera de poner a prueba sus hipótesis acerca de la lengua que están aprendiendo.

\subsubsection{Error, equivocación y falta}

Para Corder (1971b, p. 18-19), un error puede considerarse como tal cuando la desviación es resultado del déficit de

${ }^{60}$ Retomaremos esta cuestión en el último subapartado de ese capítulo (4.3). 
conocimiento o competencia, mientras que la falta es resultado de la actuación y denota una falta de memoria o automaticidad. Para él, las faltas vienen acompañadas de la corrección del propio hablante, mientras que los errores no suelen autocorregirse, puesto que el hablante desconoce las reglas, 0 , en otros casos, ignora que los está cometiendo. Para entender mejor los conceptos propuestos por ese autor, de los cuales nos valemos en este estudio, presentamos a continuación dos ejemplos de faltas y otros dos de errores, extraídos de dos de nuestros sujetos:

(1) D6C4: ... entonces para empezar nuestra clase yo eligí una de las brincadeiras... perdón... un* de los juegos... que se llama teléfono descompuesto...

(2) D8C1: ... la segunda parte es aquella que nós... nosotros miramos* en la última clase...

(3) D6C2: ... entonces gente... hay muchos falsos

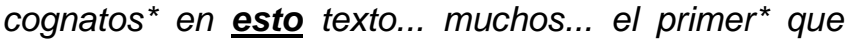
aparece acá es... se acordó... (7)

(4) D9C1: ... y entonces ele está diciendo así... que el hombre no es... no es agradecido... (11)

Podemos observar claramente que tanto en el ejemplo (1) como en el (2), las profesoras corrigen rápidamente su 'falta', incluso en el primer caso pidiendo perdón a los alumnos. A diferencia de los ejemplos (1) y (2), en los casos (3) y (4) no parece haber esa consciencia de error. Tanto es así, que en el caso concreto de (3) no solo no hay corrección, sino que además ocurre hasta en siete ocasiones diferentes. Y en el último ejemplo, el vocablo "ele" (en lugar del correcto "él"), se repite hasta en once momentos distintos.

Por esa evidente diferencia entre el error y la falta, Corder (1967, p. 10) reivindica la importancia de diferenciar entre errores sistemáticos, es decir, aquellos que se relacionan con el conocimiento lingüístico internalizado del hablante, y errores no sistemáticos, o sea, las faltas, las cuales obedecen a "cuestiones accidentales", como la memoria o los estados físicos y psicológicos, y que, por tanto, no tienen tanta importancia en el proceso de aprendizaje. Para Corder (Ibid., p. 10.), es imprescindible distinguir entre ambos tipos de errores, porque solo los sistemáticos nos van a dar la medida de la creación por parte del alumno de reglas para la adquisición de una nueva lengua (son una prueba, en definitiva, de 
que ese alumno está aprendiendo), y del grado de desarrollo de su competencia transitoria (interlengua). Con todo, el problema subsiste porque, según Corder (Ibid., p. 10), hay que saber determinar qué es una falta y qué es un error en el estudio del análisis de errores.

Otros investigadores, como Torijano Pérez (2004), han categorizado el error como "comportamientos anómalos del lenguaje" (TORIJANO PÉREZ, 2004, p. 21), diferenciándolos de otras categorías, como la equivocación y la falta. Según ese estudioso "únicamente debería llamarse error a la desviación sistemática, producida por el hecho de que un estudiante todavía no haya aprendido algo $\mathrm{y}$, consecuentemente, lo expresa mal" (TORIJANO PÉREZ, 2004, p. 21). Entendemos que, para este autor, un error sería, pues, un determinado desvío de la norma lo suficientemente recurrente como para que pueda ser detectado en diversos estadios del aprendizaje. En definitiva, estaríamos ante una aproximación similar al concepto de error sistemático de Corder.

Por su parte, la equivocación sería una "desviación incoherente" (TORIJANO PÉREZ, 2004, p. 23), que demuestra la inseguridad de los aprendices en la producción de ciertas estructuras en la lengua extranjera. Se caracteriza, pues, por una "fluctuación" en la producción por causas no siempre claras, en la cual el estudiante conoce las reglas, pero no es constante en su utilización. En otras palabras, en algunas ocasiones puede utilizar las reglas correctamente y en otras no.

Para Torijano Pérez, (2004, p. 23), aún hay un tercer tipo de error que se distingue de los anteriores: el lapsus. En sus palabras, "se trata de una desviación debida a una falta de concentración, a un fallo de memoria, al cansancio, etc." (TORIJANO PÉREZ, 2004, p. 23). El investigador (TORIJANO PÉREZ, 2004, p. 23) subraya que la principal diferencia entre el lapsus y el resto de conceptos es que aquel no tiene que ver necesariamente con el hecho de haber aprendido o no una forma lingüística, sino más bien con algunos problemas ocasionales en la actividad cerebral que son habituales en los aprendices ( $y$, por nuestra parte, añadiríamos que también en los hablantes nativos).

Entendemos que el concepto de lapsus expuesto por Torijano Pérez (Ibid., p. 23) se corresponde con la falta de Corder (1971b). Para nosotros, la principal diferencia entre la falta/lapsus y la equivocación es que los primeros vienen seguidos de la corrección por parte del hablante, lo que denota su consciencia del error. Por otro lado, en la equivocación el hablante no es consciente de que está cometiendo un error, y por ello no lo rectifica. En la equivocación la forma correcta aún no está totalmente internalizada, 
mientras que en las faltas asistimos a un desvío no sistemático de una forma ya aprendida, ocasionado por factores psicológicos específicos en un momento determinado y que es corregido al instante.

\subsubsection{Notas para nuestro estudio}

Para la investigación que llevamos a cabo, hemos considerado las dos formas, error y equivocación, y hemos tenido cuidado en excluir las faltas/lapsus puesto que no las consideramos un error per se, tal como hacen Corder (1971b) y Torijano Pérez (2004). Para terminar, nos gustaría subrayar que entendemos el error a partir de los conceptos expuestos en esta sección (DURÃO, 2007; FERNÁNDEZ, 1997; CORDER, 1967; 1971b; TORIJANO PÉREZ, 2004), los cuales, a nuestro entender, se complementan bien entre sí y encajan perfectamente en los objetivos que proponemos.

\subsection{Hacia un modelo de clasificación de errores}

Sobre la clasificación de los errores, es conocida la existencia de una amplia variedad de tipos y taxonomías (véase, por ejemplo, CORDER, 1981b; DULAY ET AL., 1982; VÁZQUEZ, 1998; DURÃO, 2004; DURÃO, 2007; ELLIS, 2008). A este respecto, Alba Quiñones (2009) considera que la falta de unidad en los criterios hace que los trabajos que giran en torno al analisis de errores sean difícilmente comparables:

En torno a la categorización de los errores se ha generado mucha controversia, ya que la falta de criterios normalizadores establecidos ha propiciado que puedan encontrarse taxonomías muy diferentes en el estudio de la misma área. Es frecuente que sobre una base más o menos unificada cada uno de los estudios desarrolle su propia clasificación, con unos criterios y unas perspectivas que varían entre autores diferentes. Esta diversidad dificulta y, a veces, imposibilita la comparación entre unos trabajos y otros, pues al establecer una base taxonómica distinta, los resultados son, 
obviamente, diferentes. (ALBA QUIÑONES, 2009, p. 9)

A fin de superar esa dificultad de la que habla Alba Quiñones, y en el intento por delimitar unos criterios más o menos comunes en la bibliografía, que además sean útiles para nuestro objeto de estudio, hemos llegado a una clasificación que toma como base las aportaciones de diferentes autores. Tales criterios aparecen sintetizados en el cuadro de abajo, cuyos detalles desarrollaremos a continuación:

\begin{tabular}{|c|c|}
\hline Criterio etiológico & Interlinguales \\
\hline Richards (1971 apud ELLIS, & Intralinguales \\
\hline $\begin{array}{l}2008, \text { p. } 53) \\
\text { Dulay et al. (1982, p. 171-172) }\end{array}$ & Ambiguos \\
\hline Criterio gramatical & Fonético-fonológico \\
\hline (Corder, 1973 apud DURÃO, & Ortográfico \\
\hline & Morfológico \\
\hline & Sintáctico \\
\hline & Léxico-semántico \\
\hline & Discursivo \\
\hline Criterio lingüístico & Adición \\
\hline (Corder, 1981b, p. 36) & Omisión \\
\hline & Elección \\
\hline & Orden \\
\hline Criterio pedagógico & Comprensión vs. producción \\
\hline Fernández (1995, p. 211-213) & Producción escrita vs. oral \\
\hline Vázquez (1998, p. 40-41) & Individuales vs. colectivos \\
\hline Durão $(2007$, p. 18) & Transitorios vs. permanentes \\
\hline & Fosilizados vs. fosilizables \\
\hline Criterio comunicativo & Globales vs. Locales \\
\hline Burt y Kiparsky (1972, apud & Irritantes \\
\hline DULAY ET AL.,1982, p. 188) & Inhibitorios \\
\hline Dulay et al. (1982, p. 189-193) & Ambiguos \\
\hline Vázquez (1998, p. 44-54) & Estigmatizadores \\
\hline Durão $(2007$, p. 19) & Socioculturales \\
\hline & Pragmáticos \\
\hline
\end{tabular}

Tabla 2: Tipos de errores según diferentes criterios. 


\subsubsection{Criterio etiológico}

El criterio etiológico es aquél que toma como referencia el origen de los errores (DURÃO, 2007, p. 17). Richards (1971 apud ELLIS, 2008, p. 53) describió tres causas o tipos: errores de interferencia, intralinguales y de desarrollo. No obstante, hoy en día existe mayor variación en la tipología de errores derivada de ese criterio, lo que exige una reflexión más detenida sobre su uso. El criterio etiológico es la base de nuestro estudio, y por ello lo desarrollaremos con más detenimiento en esta sección. El cuadro siguiente muestra la variación a la que nos referimos:

\begin{tabular}{|c|c|}
\hline \multirow{3}{*}{$\begin{array}{l}\text { Richards } \\
\text { (1971 apud ELLIS, 2008, p. 53) }\end{array}$} & Interferencia \\
\hline & Intralinguales \\
\hline & Desarrollo \\
\hline \multirow{4}{*}{$\begin{array}{l}\text { Dulay et al. } \\
(1982, \text { p. 163-172) }\end{array}$} & Interlinguales \\
\hline & Desarrollo \\
\hline & Ambiguos \\
\hline & Otros \\
\hline \multirow{3}{*}{$\begin{array}{l}\text { Vázquez } \\
(1991, \text { p. 36-40) }\end{array}$} & Interlinguales \\
\hline & Intralinguales \\
\hline & Simplificación \\
\hline \multirow{5}{*}{$\begin{array}{l}\text { Santos Gargallo } \\
(2004 \text { b, p. 405) }\end{array}$} & Interlinguales \\
\hline & Intralinguales \\
\hline & Simplificación \\
\hline & Globales \\
\hline & Locales \\
\hline
\end{tabular}

Tabla 3: Errores de tipo etiológico.

\subsubsection{Errores intralinguales e interlinguales}

Como hemos visto en el Capítulo 2, los errores interlinguales (interlingüísticos, de transferencia o interferencia, conforme DURÃO, 2004 , p. 81) son aquellos que tienen su origen en la LM del aprendiente. Los errores intralinguales, por otro lado, son aquellos que tienen que ver con el desarrollo de la propia LO (Richards, 1971 apud ELLIS, 2008, p. 53). Estos últimos reflejan una inapropiada generalización de reglas, una aplicación incompleta de las mismas, un fallo en su aprendizaje o su aplicación. Richards (Ibid., p. 53) 
añadió a esos dos errores etiológicos los de desarrollo, es decir, aquellos que ocurren cuando el aprendiente, con su experiencia limitada de la LO, formula y aplica hipótesis de la lengua extranjera que terminan siendo inadecuadas. No obstante, como subraya Ellis (2008, p. 53), estos errores son difíciles de deslindar de los intralinguales. Este autor señala que la principal crítica al modelo de Richards reside en la dificultad que entraña diferenciar con claridad los errores intralinguales de los de desarrollo, o incluso entre los intralinguales y los interlinguales. Para Ellis (Ibid., p. 53), hay errores que son ambiguos con respecto a la fuente, de manera que puede resultar difícil delimitarlos con precisión en muchos estudios.

Sin embargo, autores como Dulay et al. (1982, p. 165) ofrecen otra caracterización de los errores de desarrollo, ya que los interpretan como aquellos que se parecen a los que comete un niño cuando aprende su lengua materna, y que, a nuestro parecer, se parecen a los intralinguales de Richards. Dulay et al. (1982, p. 171172) también han diferenciado entre: a) errores interlinguales, originados por la LM; b) errores ambiguos ${ }^{61}$, los cuales podrían ser tanto de desarrollo como interlingüísticos; y c) otros errores, aquellos que no entran en las categorías anteriores, como los producidos por la creatividad. Entendemos que estos últimos se parecen más por definición a los errores de desarrollo de Richards.

En un recorrido a través de diferentes investigaciones, Ellis (2008, p. 55) señala que, si bien la proporción entre los diferentes tipos de errores suele variar mucho en cada trabajo, se atribuye una mayor responsabilidad a los de origen intralingual. Con todo, según este autor (ELLIS, Ibid., p. 55) hay todavía hoy mucha controversia sobre qué tipos son más frecuentes, lo que obedece a la variedad de estudios y objetivos que se persiguen en cada caso, pero también a los tipos de tareas empleadas para obtener el corpus. Además, algunos errores pueden tener ambas fuentes, lo que obstaculiza su clasificación. Centrándonos en la fuente de errores que investigamos en este estudio, los de transferencia, estos serían más evidentes en las tareas de composición libre, de acuerdo con las tesis de Ellis. Asimismo, otros datos señalados por el autor nos parecieron relevantes para nuestro estudio, como, por ejemplo, que la aparición de transferencias es más frecuente en los niveles fonológico y léxico, pero menos en el gramatical; o que los errores de transferencia son más comunes en el habla de los adultos que en la de los niños (ELLIS, 2008, p. 55).

${ }^{61}$ Los errores de ambas fuentes, llamados ambiguos, se discutirán en el siguiente subapartado. 
Por su parte, Vázquez (1991, p. 40) distingue entre los errores intra/interlingüísticos y los de simplificación, pero, a nuestro juicio, no explica con claridad en qué se diferencian. Del mismo modo, Santos Gargallo (2004b, p. 405), basándose en la clasificación de Vázquez (1986, 1991, 1999 apud SANTOS GARGALLO, 2004b, p. 405), añade al criterio etiológico los errores globales y locales, los cuales suelen incluirse en el criterio comunicativo, como veremos más adelante. No obstante, la autora no justifica su elección y, por ello, no nos queda tampoco demasiado clara su clasificación.

Creemos que ese abanico de interpretaciones respecto a los errores etiológicos tiene su raíz principalmente en lo problemático de definir y clasificar con claridad las desviaciones de origen intralingüístico. A ese respecto, Sánchez Iglesias, (2003, p. 404-405) comenta:

Suele ser habitual la idea de que los errores intralingüísticos se solventan con la progresión hacia nuevas fases del proceso de adquisición, de manera completamente natural. Sin embargo, son muchos los problemas que se relacionan con la caracterización de los errores intralingüísticos, ya que sigue siendo una categoría de manera general inexplorada, incluso difusa, si consideramos diferentes cuestiones, como el hecho de que carece de cualquier realismo psicolingüístico, 0 más sencillamente del hecho de que ni siquiera existe un listado operativo, es decir, que no se reconocen en todos los estudios el mismo número de estrategias ('pseudoestrategias') y tampoco se ha señalado que determinados elementos lingüísticos de la L2 sean regularmente afectados por la misma "estrategia" en términos globales.

Asumiendo la dificultad en definir y clasificar los errores intralingüísticos, Durão (2007, p. 18) establece cuatro categorías que, en su opinión, condensan los principales problemas de este tipo de error: a) por simplificación: se simplifican las reglas de la lengua meta; b) por generalización, sobregeneralización o hipergeneralización: cuando se extienden las reglas de la lengua meta a contextos inapropiados; c) por inducción: ocurre por la forma 
en que un elemento lingüístico fue presentado a los aprendices y cómo lo practicaron; d) por producción excesiva o subproducción: cuando se repiten determinadas estructuras, reiterándolas innecesariamente.

Como podemos ver, aunque algunos autores estén preocupados en definir los errores intralingüísticos, la variedad tipológica de los errores etiológicos, así como, en algunos casos, la brevedad en las descripciones de los mismos, hace que nos encontremos con una importante divergencia en la bibliografía especializada. Por eso, conviene aclarar que, para nuestro estudio, hemos optado por una clasificación personalizada, que, entendemos, atiende mejor a nuestras necesidades específicas. En ese sentido, optamos por utilizar únicamente la dicotomía entre errores interlinguales e intralinguales. Incluidos en los últimos estarían los errores de desarrollo y otros de Dulay et al. (1982) y los errores de desarrollo de Richards (1971 apud ELLIS, 2008, p. 53). Como hemos dicho anteriormente, no vemos con claridad la diferencia entre los errores intralinguales y los de simplificación mencionados por Vázquez (1991). También entendemos que los errores globales y locales (SANTOS GARGALLO, 2004b) pertenecen al criterio comunicativo, y por ello no los incluiremos aquí.

\subsubsection{Errores ambiguos}

Especial interés poseen para nuestro objeto de estudio los errores ambiguos ${ }^{62}$, los cuales podrían ser tanto interlinguales como intralinguales. Los errores pueden considerarse ambiguos cuando reflejan estructuras de la LM del aprendiz, pero, al mismo tiempo, pueden interpretarse también como un desvío del desarrollo natural de la LO.

En nuestro estudio, encontramos también errores de ese tipo, pero hemos preferido clasificarlos dentro de los errores interlinguales, aunque señalados específicamente con la etiqueta "AMB" en nuestro banco de errores. Para Dulay et al. (1982, p. 172),

${ }^{62}$ La importancia de considerar ese tipo de errores es tal que también se ha visto en numerosos estudios de la sociolingüística del español, aunque bajo el nombre de "causación múltiple", tal y como podemos comprobar en los estudios de Blas Arroyo (1988; 1995; 2004). 
diferenciar la categoría ambigua es particularmente importante en la taxonomía comparativa ${ }^{63}$, pues la definición de los errores ambiguos garantiza la claridad de los resultados provenientes del análisis comparativo de errores, y permite que el investigador llegue a conclusiones más precisas sobre los datos. Hemos optado por incluir los errores ambiguos en los interlingüísticos porque entendemos que, aunque puedan tener diferentes orígenes, la probabilidad de que se den por interferencia de la lengua materna en la lengua extranjera se ve aumentada exponencialmente por la proximidad lingüística entre el portugués y el español.

Otra consideración pertinente para nuestro estudio es la que hace Vázquez (1998, p. 28), al aclarar que los errores inter/intralinguales aparecerán en todos "los componentes del sistema" y podrán ser, por tanto, fonológicos, morfológicos, semánticos y pragmáticos. En otras palabras, y haciendo ya alusión al tipo de clasificación que utilizaremos en nuestro estudio, estos errores aparecen en todos las demás clasificaciones expuestas anteriormente de forma simplificada en la tabla 2 (gramatical, lingüística, pedagógica y comunicativa).

\subsubsection{Tipos de errores interlinguales}

Durão (2007, p. 39-44) recoge algunos de los principales errores de interferencia de la lengua materna, los cuales utilizaremos tanto para la identificación de los hallados en nuestro corpus como para su clasificación y análisis. Estos se clasifican en errores: de producción; de subproducción; de superproducción; de mala interpretación; y de hipercorrección. En el cuadro siguiente los mostramos de manera esquemática:

\begin{tabular}{|l|l|l|l|}
\hline \multirow{2}{*}{$\mathbf{1}$} & \multirow{2}{*}{ Producción } & \multicolumn{2}{|l|}{ Sustitución } \\
\cline { 3 - 4 } & & Calco \\
\cline { 3 - 4 } & & $\begin{array}{l}\text { Creación de } \\
\text { palabra nueva }\end{array}$ & $\begin{array}{l}\text { Creación original } \\
\text { Traducción } \\
\text { prestada }\end{array}$ \\
\hline $\mathbf{2}$ & Subproducción & \\
\hline $\mathbf{3}$ & Superproducción & \\
\hline $\mathbf{4}$ & Mala interpretación & \\
\hline $\mathbf{5}$ & Hipercorrección & \\
\hline
\end{tabular}

${ }^{63}$ Entendemos que los autores se refieren a la comparativa inter/intralingual. 
Tabla 4: Errores interlingüísticos. Adaptado de Durão (2007).

Con el fin de adaptar la clasificación a las particularidades de nuestro corpus hemos realizado algunas pequeñas alteraciones con respecto a los errores de producción propuestos por Durão (Ibid., p. 39-44.). Tales alteraciones están detalladas en este capítulo en las secciones correspondientes.

\subsection{Errores de producción} distintos:

Los errores de producción pueden ocurrir en tres casos

a) Sustitución, es decir, uso de formas de la LM en la LO (DURÃO, 2007, p. 39). Para la autora (DURÃO, 2007, p. 39), un ejemplo de esta categoría sería el vocablo línea, como se puede observar en el ejemplo siguiente, extraído de su libro:

(5) Para que pueda hacer el bajo en tus pantalones necesito que me dejes aguja y línea.

La autora (DURÃO, 2007, p.39.) explica que los hablantes nativos del portugués brasileño suelen transferir el vocablo línea de su lengua materna, el cual significa tanto trazo como hilo. En español, el vocablo adecuado para ese contexto sería "hilo", puesto que "línea" significa trazo. Por lo tanto, el uso de la LM como estrategia es evidente. En estos casos, la comunicación no se suele ver comprometida, aunque no siempre es así. Veamos otro ejemplo extraído del corpus de nuestra investigación:

(6) D5E: ... entonces cuando me invitaron a trabajar yo me quedé loca...

Como ocurre en el ejemplo anterior, observamos la utilización de una forma en la LO que comparte significado con otra de la lengua materna, El error por analogía que ocurre en esta situación es que el usuario hace una generalización de los significados del verbo quedar(se). De esta manera, en el ejemplo número 6, apreciamos la utilización de quedarse (loco) con el valor 
de volverse (loco). Eso ocurre porque el verbo quedar(se) tiene muchos semas en común con ficar del portugués. De hecho, hemos encontrado que de las dieciséis acepciones del verbo quedar(se) descritas en el DRAE ${ }^{64}$, nueve coinciden con las de ficar descritas por el Diccionario Aurélio de la Lengua Portuguesa ${ }^{65}$. Así, es posible decir en ambas lenguas: me quedo en casa hoy / fico em casa hoje; ese vestido te queda bien / este vestido fica bem em você; o el camarero se quedó con el vuelto / o garçom ficou com o troco. No obstante, quedar no es un verbo de cambio, motivo por el cual no se utiliza en el contexto que aplica la docente. En este caso lo más correcto sería decir: ...cuando me invitaron a trabajar me volví loca, mientras que en portugués se utilizaría el mismo verbo de los ejemplos anteriores: ... quando me convidaram para trabalhar fiquei louca. Parece evidente que aquí hay una falta de conocimiento de la LO que es suprimida por una sobregeneralización de los usos del verbo quedar por influencia de la lengua materna.

En esta misma categoría de analogía hemos encontrado otro tipo de error, que aunque, a nuestro entender, forma parte del mismo nivel, se diferencia de los errores que acabamos de elucidar de forma substancial. En otras palabras, mientras que en los errores descritos anteriormente ocurre la utilización de un vocablo de la lengua española que no tiene la misma forma en portugués, pero que en las dos lenguas comparten algunos de sus significados, en otros casos ocurre la utilización de un vocablo que posee la misma forma en ambas lenguas, pero que no comparte significado. Veamos un ejemplo de nuestro estudio:

(7) D9C1: ... tiene que pegar el autobús y viajar y de repente $y$ al llegar al dentista tiene que esperar tiempo $y$ tiene ${ }^{*}$ otras personas atendendo*...

El vocablo pegar en portugués significa, entre otras acepciones, "coger, sujetar, agarrar"66 y, en español, "adherir: unir dos cosas con pegamento o producto similar; arrimarse; contagiarse; hacer sufrir" 67 , pero en ningún caso "tomar o coger" un transporte, como en la lengua materna del docente que lo usó. Así,

${ }^{64}$ Consultado en el Diccionario de la Real Academia Española:

http://dle.rae.es/?id=UloraJw, el 12/04/2016.

${ }^{65}$ Versión digital.

${ }^{66}$ (FEIJÓO HOYOS, 1992, p. 81)

67 (FEIJÓO HOYOS, 1992, p. 81 - traducción nuestra) 
mediante el empleo inadecuado de la LM, el oyente puede tener dificultades en descodificar el mensaje. Es decir, a diferencia de los errores anteriores, en este tipo suele haber más problemas comunicativos.

Tenemos aquí, pues, dos tipos de errores distintos, aunque compartan su fuente común: el uso de la analogía de la lengua materna en el empleo de la lengua extranjera. Dada la naturaleza de estos errores, y la necesidad de ser coherentes con la clasificación de Durão (2007, p. 39.) Ilamaremos al primer grupo errores de analogía por el significado y al segundo de analogía por la forma.

En los errores por sustitución también incluiremos los usos literales de la lengua materna (transferencia directa). Veamos un ejemplo:

(8) D2E: ... ella dijo que todo el día están en internet pidiéndole dicas para alimentación y ejercicios...

Como podemos ver, el uso de la LM mediante el vocablo dicas está claro en ese ejemplo, puesto que esta palabra no existe en la lengua objeto. Lo correcto sería el uso de, por ejemplo, "información, indicación, consejo, sugerencia"68. Como veremos, ese tipo de errores es abundante en nuestro corpus y ocurre en todas las categorías gramaticales.

Nos parece importante diferenciar ese tipo de error de producción por sustitución, que llamaremos directa, de los de analogía, descritos anteriormente. $Y$ ello porque que entendemos que hay una diferencia fundamental entre ellos: mientras que en los primeros casos (ejemplo 5 y 6 ) se emplea en la LO una "versión" del vocablo de la LM o una palabra parecida a la materna y que también existe en la lengua extranjera, pero con otro significado (ejemplo 7), en el caso de las transferencias directas, al contrario, se produce el empleo de un vocablo de la LM que no existe en la LO (ejemplo 8). Así, con el objetivo de acomodar la clasificación de errores a las singularidades de nuestro corpus, llamaremos a los primeros casos descritos errores de sustitución por analogía (incluyendo los de forma de significado), y a este último caso, error de sustitución directa. Así, los errores por sustitución se clasificarán de esta manera:

\begin{tabular}{|l|l|}
\hline Errores de sustitución & Analogía \\
\hline
\end{tabular}

${ }^{68}$ (Moreno y González, 2003, p. 339) 
Directa

Tabla 5: Adaptación de los errores de sustitución de Durão (2007).

b) El segundo tipo de error que cita Durão se da por creación de palabra nueva o transferencia creativa, y ocurre cuando el aprendiz crea una palabra en el intento de resolver su falta de conocimiento de la LO (Kumaravadivelu, 1988 apud DURÃO, 2007, p. 40). Existen dos tipos de creación de palabras que se diferencian por el uso o no uso directo de la LO:

i) Creación original: "creación de una palabra que no existe ni en la LM ni en la LO" (DURÃO, 2007, p. 40). Veamos un ejemplo extraído de nuestro estudio:

(9) D8C2: ... después sin tilde... "aun" sin tilde quiere dicer [trad. port]...//

En ese caso el sujeto pudo crear una palabra nueva con la fusión de la lengua materna y la lengua extranjera por medio de los vocablos "dizer" del portugués y su correspondiente en español, "decir". Como resultado tenemos una palabra que no se identifica como perteneciente a ninguna de las dos lenguas, pero que tiene origen en las dos.

ii) Traducción prestada: "creación de un vocablo nuevo a partir de un vocablo de la LM con morfemas propios de la LO" (DURÃO, 2007, p. 40). Lo ejemplificaremos con un error extraído de nuestro estudio:

(10) E: ah... muy bien... eh... ¿en qué año terminaste la universidad?

D8E: * dos mil seis yo... eh... quité* la clase pero... ${ }^{*}$ dos mil siete fue... la... solenidad...//

"Solenidade" es un vocablo portugués que significa "ceremonia pública que torna una cosa solemne". La autora de ese enunciado se refiere en ese caso a la ceremonia de fin de grado en la cual le entregan el título al estudiante. Una de las traducciones al español podría ser "solemnidad", no obstante, esa docente creó un nuevo vocablo, utilizando la palabra del portugués "solenidade", sustituyendo el sufijo portugués "dade" por el español "dad". 
c) La tercera categoría de errores de producción descrita por Durão (2007) sería el calco, el cual se origina cuando hay estructuras muy similares entre la LM y la LE, lo que ocasiona "préstamos de oraciones cortas o de expresiones extranjeras" (DURÃO, 2007, p. 40). Un ejemplo de calco en nuestro estudio sería el siguiente:

(11) D2C6: (...) esta é* una clase del sexto año y es la primera vez que tienen español... casi... cuasi... voy a hacer la llamada vamos a ver... [***...

En esta locución vemos que la docente utilizó la traducción literal de su lengua materna fazer a chamada ${ }^{69}$, que es el acto de llamar por el nombre a las personas presentes en una reunión/clase. No obstante, esta locución no existe en español tal y como se ha utilizado. Existe una locución para el mismo acto, que es pasar lista ${ }^{70}$ en la lengua objeto, es decir, leer en voz alta los nombres de una lista con el fin de comprobar si están presentes. Por tanto, se entiende que hay un calco lingüístico, visto que la docente ha creado una expresión en la LO con base en su lengua materna.

\subsection{Errores de subproducción ${ }^{71}$}

Los errores de subproducción son aquellos que se producen para evitar las formas de la LO. Puede ocurrir, según Kellerman (2000, apud DURÃO, 2007, p. 41) por miedo a la similitud, también conocido como la homoiofobia. Según Kellerman (Ibid., p. 41), ese temor aparece cuando no se tiene seguridad en la expresión de la LE que se quiere utilizar; cuando se conoce la expresión, pero hay dificultades para encajarla en el contexto; o cuando se sabe la expresión pero se evita, porque es inapropiada según las normas de conducta de algunos sectores sociales.

Este tipo de error también recibió el nombre de aprendizaje defensivo (Torijano Pérez, 2004 apud DURÃO, 2007, p. 41), y se

\footnotetext{
${ }^{69}$ Moreno y González (2003b, p. 190).

${ }^{70}$ Penadés Martínez (2002, p. 125).

${ }^{71}$ También nombrados errores de inhibición por Schachter (1974) (véase Capítulo 2, subapartado 2.2.3).
} 
produce por "miedo a cometer errores y hacer el ridículo ante los demás". Ese miedo puede afectar gravemente a la comunicación, puesto que el aprendiz está más preocupado de lo que puede decir sin cometer errores, que de lo que realmente quiere comunicar (DURÃO, 2007, p. 41).

Para Durão (2007, p. 41), los errores de subproducción pueden darse, por un lado, mediante una "petición de ayuda no verbal", utilizando, entre otros recursos, gestos que faciliten la interpretación del interlocutor, y, también por inhibición de la construcción de una oración compleja, dando preferencia a construcciones más simples. Durão (2007, p. 42) argumenta que es bastante común encontrar ese tipo de errores en conversaciones entre hablantes no nativos y nativos cuando el no nativo corta su discurso al intuir que la forma que utiliza proviene de su LM y, enseguida, intenta reconstruirlo.

Hemos podido observar que ese tipo de error es bastante frecuente, principalmente en las entrevistas llevadas a cabo con los sujetos de nuestro estudio. Veamos un ejemplo representativo a continuación:

(12) E: vale... o sea... que no tienes ningún amigo ni conocido ni nadie... [[que hable español]]

D8E: no... no... no... y también los... los compañeros de clase... nosotros no... nos miramos* más*... eh... cada uno se fue as... es muy difícil... es muy difícil...//

El empleo de los puntos suspensivos en la transcripción revela que la docente que produce el enunciado tiene dificultad en mantener la fluidez, lo que parece estar más vinculado a las dificultades con la lengua que con el tema desarrollado. En otras palabras, parece estar más pendiente de la forma que del contenido. Como podemos observar, al final de su respuesta, la hablante empieza una construcción e inmediatamente la abandona, rematando con un "... es muy difícil..." que tiene como objetivo poner fin a su intervención.

En principio, ese tipo de error no tiene, a nuestro entender, demasiada gravedad, puesto que, en el fondo, es también una estrategia comunicativa. Sin embargo, es preocupante cuando ocurre con tanta frecuencia que puede poner en peligro la comprensión, dando como resultado una conversación entrecortada, 
con demasiadas lagunas, y en la que la inferencia del oyente necesita activarse más de lo normal.

\subsection{Errores de superproducción}

Según Durão (2007, p. 43), estos errores ocurren cuando existe un uso reiterado de alguna forma lingüística, como ocurre, por ejemplo, con las muletillas. Según la autora (DURÃO, Ibid., p. 43), el objetivo de ese uso exagerado puede ser una estrategia para ganar tiempo mientras se intenta "formular mentalmente un mensaje". Otras veces, la repetición puede ser un hábito de la LM llevada a la LO. Algunos ejemplos de los errores de superproducción encontrados en nuestro trabajo pueden verse a continuación:

(13) E: ¿qué intentas hacer cuando un grupo no está motivado? Es tan difícil... ¿verdad?

D5E: es difícil pero... así... cuando yo salgo de una clase y percibo que los alumnos no estaban muy motivados yo voy para* casa y me quedo pensando en una próxima clase que... (18)

(14) D7E: ... porque a veces tú enseñas a un niño... le sale muy bien y ahí cuando tiene dieciséis está con una fluidez perfecta y ahí cuando empiezas ya muy tarde todo eso hasta... (50)

En relación con la forma marcada en (13), hemos podido contar hasta en dieciocho ocasiones el uso de "así" ("assim" en la LM) como muletilla en la entrevista con la docente número cinco (D5). Del mismo modo, en las clases de la docente siete (D7) hemos podido constatar dieciséis muestras diferentes de "y ahí" ("e aí" en la LM), y nada menos que treinta y cuatro ocurrencias en la entrevista.

Entendemos que el uso repetitivo de un vocablo o una construcción no resulta un error en sí mismo, pero su utilización indiscriminada y reiterada puede acarrear un error estilístico, como apunta Durão (2007, p. 43). 


\subsection{Errores por mala interpretación}

Como sugiere el nombre, los errores incluidos en esta categoría ocurren cuando se produce un equívoco en el entendimiento de alguna forma o enunciado, de ahí que se conozcan como errores pragmáticos (DURÃO, 2007, p. 43). En nuestra opinión, estos errores tienen que ver con lagunas del conocimiento semántico, pragmático y sociocultural de la lengua objeto, los cuales terminan por generar problemas comunicativos. Veamos un ejemplo da la autora, donde interactúan un hablante nativo (HN) con uno no nativo (HNN) (DURÃO, 2007, p. 43):

(15) (HNN) - ¿Ya te vas a esta hora?

(HN) - Estoy retrasadísima.

$(H N N)$ - ¿No te apetece tomar un café?

$(H N)$ - No, gracias, voy muy mal de tiempo. ¡Ah! he robado un poco del zumo de naranja que tienes en la nevera.

(HNN) - ¿Robarme? Qué exagerada eres, hombre. No tenías que decírmelo. Ya te dije que cojas lo que quieras.

(HN) - No, si lo que te quería decir es que no voy con el estómago vacío. $(H N N)-A h \ldots$

El problema pragmático de esta conversación es que el hablante no nativo interpreta robar en el sentido literal de la palabra, cuando este sentido no encaja con la situación vivida. EI HN utiliza el verbo en el sentido de coger prestado, o tomar para sí, cuando se refiere a que había bebido un poco de zumo de su compañera, puesto que esta ya le había dado permiso con anterioridad. Es una situación en la que el conocimiento cultural del HNN juega un papel importante.

En nuestro corpus no hemos encontrado este tipo de errores. Creemos que ello se debe principalmente a dos motivos: el primero es que en el entorno de las clases de lenguas, los profesores hicieron uso de su competencia de manera que pudiesen dejar constancia de sus conocimientos antes que de sus dudas de tipo pragmático; tampoco había interlocutores que pudiesen generar con su discurso este tipo de dudas en los docentes. Por otro lado, en el entorno de las entrevistas, el contexto era bastante cercano respecto a los conocimientos semánticos, pragmáticos y socioculturales compartidos, o, dicho de otra manera, consideramos 
que en esa situación comunicativa no había diferencias significativas en esos ámbitos que pudieran ocasionar errores de mala interpretación por parte de los sujetos respecto al discurso del entrevistador.

\subsection{Errores por hipercorrección}

Los errores de hipercorrección, de acuerdo con Durão (2007, p. 44), se dan por una corrección extrema de formas que pueden provenir de la LM. Según esa autora (Ibid., p. 44), esto ocurre debido a la preocupación excesiva por la adecuación a la forma y el resultado es la "corrección de lo que estaba correcto". Para nosotros, ese tipo de error es muy común en el proceso de aprendizaje de lenguas próximas, puesto que el grado de similitud suele llevar a una inseguridad sobre la corrección de la LE. Veamos un ejemplo extraído de la presente investigación:

(16) D1E: ... algunos [[alumnos van]] muy bien... muy pocos... mucho... mucho pocos... muy pocos no... mucho pocos...

Es común que los aprendices brasileños hagan la correlación: "mucho" (adv. esp.) = "muito" (adv. port.). No obstante, no hay correspondencia de la forma apocopada "muy" (esp.) en portugués. De esta manera, en el caso que analizamos, ocurre error por hipercorrección de la forma "muy" en lugar de "mucho", llevada por la interferencia de la LM, dónde "muito" es la única posibilidad para esta construcción. Observamos que la docente tiene conocimiento de la forma apocopada, pero las reglas de la LO no están bien interiorizadas, de manera que la construcción "muy pocos" es rechazada en última instancia. Ese también podría ser un caso de error ambiguo (criterio etiológico), pero creemos que la proximidad lingüística hace dudar con más frecuencia a los aprendices en casos como este, dónde la LM y LO tienen una correspondencia parcial. 


\subsubsection{Clasificación de los errores interlinguales aplicados a nuestro estudio}

Hemos visto en el apartado 4.2.1.3 que los errores de origen interlingual descritos por Durão (2007) están divididos en cinco tipos: producción, superproducción, subproducción, mala interpretación e hipercorrección. También hemos demostrado por medio de los ejemplos retirados del corpus, que todos ellos, a excepción de los de mala interpretación, en mayor o menor medida forman parte de la interlengua de nuestros sujetos.

No obstante, no todos los errores interlingüísticos encontrados podrán ser explicados en la presente investigación. Esto ocurre porque, aunque sea evidente que conforman el sistema no nativo de los docentes en cuestión, sería prácticamente imposible darles el tratamiento necesario en un trabajo de estas características debido al volumen de datos recogidos en nuestro corpus de errores.

Por este motivo, nos hemos inclinado por tratar los errores que dieran cuenta de nuestros objetivos referentes al nivel léxico. Para ello, hemos optado por clasificar, describir y explicar los errores de producción, puesto que son los más numerosos y más evidentes, características que no comparten otras categorías como las de superproducción, subproducción e hipercorrección por ejemplo.

Considerando lo antedicho, los errores interlingüísticos analizados obedecerán a la siguiente categorización:

\begin{tabular}{|l|l|l|}
\hline \multirow{4}{*}{$\begin{array}{l}\text { Errores de } \\
\text { producción }\end{array}$} & Sustitución & Analogía \\
\cline { 2 - 3 } & $\begin{array}{l}\text { Creación de } \\
\text { palabra nueva }\end{array}$ & Directa \\
\cline { 2 - 3 } & Calco & Tradución original \\
\hline
\end{tabular}

Tabla 6: Errores interlingüísticos analizados en nuestro estudio, adlaptados de Durão (2007).

Esta clasificación servirá como base para el tratamiento de los datos, detallados en el Capítulo 7. 


\subsubsection{Origen de los errores interlinguales}

Dulay et al. (1982, p. 108) defienden que los errores de interferencia suelen ocurrir por dos motivos distintos cuando están relacionados con factores externos del aprendizaje: (i) condiciones que resultan en el uso prematuro de la L2 y (ii) determinadas tareas de elicitación. Estos dos motivos tienen especial interés en nuestro estudio, por ello los discutiremos aquí.

Sobre el primer factor - condiciones que resultan en el uso prematuro de la $L 2$ - los autores (Ibid., p. 108) señalan que existirían dos contextos distintos: la presión por la actuación y un entorno limitado de la L2. El primer caso ocurre cuando el aprendiz vive en el país de la lengua meta y se ve obligado a usarla aunque no la haya aprendido del todo; también ocurre en contextos formales de aprendizaje, cuando el alumno es obligado a responder a algunas tareas propuestas por el profesor. Sea como fuere, el uso obligado de la lengua extranjera cuando el aprendiz aún no la ha internalizado hace que recurra a la $L 1$, aunque inconscientemente, en el intento de comunicarse (DULAY ET Al., 1982, p. 108-109).

En el segundo caso, el entorno limitado de la L2 también puede provocar el uso de la L1 para suprimir un conocimiento inexistente de algunas estructuras o vocabulario de la lengua meta. Ese contexto incluye la ausencia de compañeros nativos de la L2, (como, por ejemplo, clases de dos horas a la semana basadas en la memorización de vocabulario, el uso exagerado de actividades audiolinguales y el estímulo forzoso a conversaciones entre alumnos que son escasamente proficientes en la LO) (DULAY ET AL., 1982, p. 109). Todo ello genera condiciones artificiales de aprendizaje que facilitan la aparición de este tipo de errores.

Para Dulay et al. (1982, p. 109), en el contexto de enseñanza formal estas condiciones artificiales son, desafortunadamente, inevitables y hacen que los aprendices tengan un "vacío" de estructuras de la L2, que acaban rellenando con la LM. Como veremos en los próximos capítulos, ese es el contexto en el que han aprendido la LE los sujetos de nuestro estudio.

Sobre el segundo factor externo que suele incidir en las interferencias, Dulay et al. (1982, p. 110) citan las tareas de elicitación, las cuales están ligadas a la manera en que se requiere la actuación hablada o escrita de los aprendices. Para los autores (Ibid., p. 10) la elicitacion ha sido poco discutida, pero su influencia es muy importante en la actuación verbal de los alumnos. Para corroborar su teoría, citan el experimento de Lado (1978, apud DULAY ET AL., 1982, p. 110), quien comprobó que las tareas de 
traducción aumentaban el uso de la L1 en detrimento de las tareas de interpretación. Por ese motivo, para los autores, los estudios que se basan únicamente en la traducción o en obtener resultados con una manipulación de la tarea a través de la elicitación estricta no deben utilizarse para validar hipótesis sobre el uso de la L1 en la adquisición de la L2. Por el contrario, lo ideal sería que se utilizaran diferentes tareas.

Las interferencias también podrían obedecer a factores internos, es decir, intrínsecos al aprendiz. En ese caso, Dulay et al., (1982, p. 110) mencionan como origen de los errores de interferencia el uso del monitor ${ }^{72}$. La transferencia de conocimiento ocurre cuando el uso de la consciencia del lenguaje está activo, lo que proporciona que la gramática de la L1 se emplee en la actucación de la L2. El problema ocurre cuando las dos lenguas no coinciden en lo transfererido y es funcion del monitor reparar estos errores. Existen aprendices que poseen una competencia muy alta de la lengua cuando utilizan el monitor. El problema es que al ser un uso consciente del lenguaje, requiere constante vigilancia y atención a la forma y, lógicamente, está limitado por el conocimiento que el estudiante tenga de la lengua extranjera (DULAY ET AL., 1982, p. 111).

\subsubsection{Criterios gramatical y lingüístico}

Según Corder (1973, apud DURÃO, 2007, p. 17) los errores deben analizarse también por niveles gramaticales, como los sintetizados en el siguiente cuadro:

\begin{tabular}{|l|l|}
\hline $\begin{array}{l}\text { Error fonético- } \\
\text { fonológico }\end{array}$ & $\begin{array}{l}\text { Confusiones causadas por oposiciones } \\
\text { fonológicas que no existen en la lengua en } \\
\text { cuestión o aquellas motivadas por la } \\
\text { existencia de sonidos diferentes en la lengua } \\
\text { materna de los estudiantes }\end{array}$ \\
\hline Error ortográfico & Afecta a la forma gráfica de las palabras \\
\hline Error morfológico & Atañe a la forma de las palabras \\
\hline
\end{tabular}

\footnotetext{
${ }^{72}$ El monitor es parte de la teoría del Input de Krashen (1985) y ha sido discutido ya en detalle en el subapartado 1.2.3 del capítulo 1.
} 


\begin{tabular}{|l|l|}
\hline Error sintáctico & Atañe a la construcción de los enunciados \\
\hline $\begin{array}{l}\text { Error léxico } \\
\text { semántico }\end{array}$ & Afecta al significado de las lexías \\
\hline Error discursivo & $\begin{array}{l}\text { Afecta a la constitución discursiva de los } \\
\text { enunciados }\end{array}$ \\
\hline
\end{tabular}

Tabla 7: Errores de criterio gramatical. Adaptada de Corder (1973, apud DURÃO, 2007, p. 17).

En el apartado 3.5 del Capítulo 3 vimos que los errores léxicos, aunque sean considerados por diversos autores como una de las categorías más frecuentes y también de las más peligrosas en el aprendizaje de lenguas próximas, son al mismo tiempo de las menos investigadas, por lo menos en lo que concierne al aprendizaje del español en el ámbito brasileño.

Respecto a la peligrosidad de los errores léxicos en la enseñanza de la lengua extranjera, algunos autores como Vázquez (1992) subrayan los problemas que pueden derivarse en la comunicación:

Es un hecho conocido que -con excepción de los errores de léxico y entonación- el resto de los errores que afectan el componente morfosintáctico no ponen en peligro la comunicación entre hablantes nativos y extranjeros. (VÁZQUEZ, 1992, p. 109)

De la misma manera, Fernández (1997, p. 69) sostiene también que los errores léxicos son los que más dificultan la comunicación. Asimismo, esta investigadora defiende que el dominio léxico "representa una de las dificultades más relevantes en la adquisición de una lengua extranjera, con todo lo que ello conlleva de variedad y complejidad tanto en sus relaciones sintagmáticas como paradigmáticas" (Ibid., p. 69). La propia Fernández y sus colaboradores llevaron a cabo un trabajo de campo en el que una población nativa informaba sobre la dificultad para comprender textos idiosincráticos de los aprendices. Las conclusiones de este

\footnotetext{
${ }^{73}$ Tal como resalta Durão (2007, p. 17), "muchas veces, los errores son a un mismo tiempo morfológicos y sintácticos, cuando afectan, a la vez, a forma y construcción”.
} 
trabajo (Fernández y Rodríguez, 1989, apud FERNÁNDEZ, 1997, p. 32) fueron las siguientes:

1. Los errores no impiden la comprensión global del mensaje, pero la comunicación resulta superficial $y$, a veces, lo más personal, como la ironía o la expresión de un sentimiento, no se capta.

2. Los errores más distorsionantes son los de léxico, y los relacionados con la estructura de la oración (elementos omitidos o sobrantes, uso inadecuado de conectores y problemas de orden).

3. No provocan ninguna confusión los errores aislados referidos al mal uso de las formas verbales (tiempo, aspecto y número), las discordancias nominales y los problemas de empleo del artículo y las preposiciones; la ambigüedad solo se produce, en esos casos, cuando el elemento erróneo genera una estructura próxima en español con un sentido diferente.

4. Casi siempre es la conjunción de diferentes errores lo que produce una frase idiosincrática confusa o inteligible.

En esta cita, comprobamos que, además de las características intrínsecas de los errores léxicos, los autores añaden un punto especial a ser tenido en cuenta, y es que los desvíos más distorsionantes son aquellos que presentan una aglomeración de diferentes tipos de errores. Esta característica la vemos muy a menudo en el discurso de nuestros sujetos, de manera que, aunque los errores léxicos tengan un predominio en el cómputo general, es la suma de diferentes tipos lo que caracteriza fundamentalmente la $\mathrm{IL}$ de los docentes analizados. Con todo, al tratarse de lenguas próximas, la comprensión no siempre se veía seriamente afectada. Veamos un ejemplo, extraído de una de nuestras entrevistas, en el que una docente relata su dificultad al entablar una conversación con unos conocidos nativos:

(17) E: ¿qué echaste de menos en tu formación universitaria? 
D1E: la preparación para quedarse dentro del espacio de sala de aula...

E: la realidad...

D1E: sí... sí... hay mucha... muy... mucha teoría...

E: mucha teoría...

D1E: mucha teoría y poca práctica ¿sí? En el último año de formación en nuestro proyecto final de observación... de estágio...

E: ¿unas prácticas?

D1E: de práctica... fue un desastre...

E: ¿Sí? ¿Por qué?

D1E: porque yo... fue una época en que los profesores de la lengua española de la universidad estaban salindo... entonces había una para todos... entonces ella no era de la cuidad (Ø) que nosotras estábamos... teníamos que hacer la práctica... ella no estaba para nos ayudar y se quedó así... muy bien... listos y se van...//

En el fragmento transcrito es bien visible esa confluencia de errores a la que nos referíamos, en la que se advierte una notable variedad tipológica y etiológico. $\mathrm{Y}$, lamentablemente, no es un fragmento aislado, sino bastante representativo de las IL analizadas.

De regreso a Corder (1981b, p. 36) este define, además, otros cuatro tipos de errores, según un criterio que el autor caracteriza como lingüístico: omisión, adición, selección y orden. El primer tipo, de omisión, se observa cuando algún elemento es suprimido. Los errores de adición, tienen lugar cuando una unidad lingüística se añade al enunciado en un lugar que no le corresponde. El tercer tipo de error, el de selección, ocurre cuando un elemento no es adecuadamente elegido. $Y$ el último tipo, de orden, sucede cuando los elementos presentados son correctos, pero están erróneamente secuenciados. Por otro lado, estos diferentes tipos de errores se clasifican además dentro del nivel lingüístico en el que se cometen (fonético, gramático o léxicosemántico).

Lo anterior puede verse de manera esquemática en la siguiente tabla, que tomamos del propio Corder (1981b: 36):

\begin{tabular}{|l|l|l|l|}
\hline & Fonético/Grafológico & Gramático & $\begin{array}{l}\text { Léxico- } \\
\text { semántico }\end{array}$ \\
\hline Omisión & & & \\
\hline
\end{tabular}




\begin{tabular}{|l|l|l|l|}
\hline Adición & & & \\
\hline Elección & Orden & & \\
\hline
\end{tabular}

Tabla 8: Criterio lingüístico (CORDER, 1981b, p. 36).

\subsubsection{Aceptabilidad y adecuación aplicadas a nuestro estudio}

Corder sostiene que el criterio lingüístico debe respetar los principios de aceptabilidad y adecuación de una oración (CORDER, 1981b, p. 37-42). Según esos principios, una oración puede estar muy bien formada gramaticalmente, pero aun así ser totalmente inadecuada en un contexto determinado, de ahí la importancia de este último al tratar el corpus de errores en las investigaciones (CORDER, 1981b, p. 39). Incluso podría haber también errores debidos a la inaceptabilidad de la forma, aunque esta se adecúe bien al contexto, o, en los casos más extremos, ejemplos de errores tanto por inaceptabilidad como por inadecuación. El único caso exento de error sería el recogido en la primera línea de la tabla 9, dónde se dan cita tanto la aceptabilidad como la adecuación:

\begin{tabular}{|l|l|l|l|}
\hline & Forma & Contexto & Estatus \\
\hline 1 & Aceptable & Adecuado & Libre de error \\
\hline 2 & Aceptable & Inadecuado & Erróneo \\
\hline 3 & Inaceptable & Adecuado & Erróneo \\
\hline 4 & Inaceptable & Inadecuado & Erróneo \\
\hline
\end{tabular}

Tabla 9: Grado de aceptabilidad y adecuación. Adaptada de Corder (1981b. p. 41).

En esta definición de "no error" de Corder (1981b. p. 41), una oración aceptable sería aquella que un hablante nativo usa en determinada situación y es reconocida por otro hablante nativo como perteneciente a su lengua. La capacidad de producir tales enunciados depende, pues, de la competencia del hablante (CORDER, 1981b, p. 39). La adecuación de un tema, al contrario que la aceptabilidad, tiene lugar en la actuación, ya que tiene que ver con el uso que se hace en el contexto (CORDER, 1981b, p. 3940). Para entender mejor los conceptos propuestos por Corder, 
veamos un ejemplo extraído de Fernández (1995, p. 213), en el que un capataz le dice a su jefe:

\section{(18) Oye, súbeme el sueldo.}

La frase es correcta gramaticalmente, pero es absolutamente inadecuada al contexto, por ello, podríamos incluirla en el ejemplo número dos de la clasificación propuesta por Corder (1981, p. 41), plasmada en la tabla 9. En nuestro estudio, todas las construcciones erróneas de los sujetos están ubicadas en la tercera posibilidad mencionada, pues resultan adecuadas para los contextos en que fueron producidos, pero fallan en la forma, como podemos verificar en el siguiente ejemplo extraído de nuestro corpus:

(19) D8C: ... todos tenen que tentar leer el texto $y$ responder $(\boldsymbol{\varnothing})$ las preguntas... contestar $(\underline{(\boldsymbol{O})}$ las preguntas... yo voy a mirar en la próxima clase quién $\underline{\text { le }}$ hizo y quién no $\underline{(\varnothing)}$ hizo...//

En este caso, vemos que el discurso es apropiado al entorno de una clase. La profesora está explicando el ejercicio basado en un texto que los alumnos tienen que preparar para el siguiente día. Desde el punto de vista del contexto comunicativo y sociocultural, el enunciado es totalmente adecuado, pero, a la vez, es inaceptable desde el punto de vista de la forma, puesto que incumple esta mediante una serie errores de diversos tipos.

\subsubsection{Criterio pedagógico}

A propósito de ese criterio hemos observado que existe también una gran variabilidad tanto en su definición como en los errores incluidos en la categoría. Por eso, hemos intentado relacionar algunas de las caracterizaciones encontradas en la bibliografía, a fin de acomodar sus parámetros a las necesidades de nuestro estudio. Para ello, nos apoyaremos en los estudios de Vázquez (1998) y Durão (2007), quienes clasifican ese tipo de errores de acuerdo con los criterios que se esquematizan en el siguiente cuadro: 


\begin{tabular}{|l|l|l|}
\hline Autor & Parámetro & Tipo de error \\
\hline Durão & Tipo de producción & Comprensión vs. producción \\
\cline { 3 - 3 } (2007, p. 18) & & Orales vs. escritos \\
\cline { 3 - 3 } & & Individuales vs. colectivos \\
\hline Vázquez & Permanencia & Fosilizados vs. fosilizables \\
\cline { 3 - 3 }$(1998$, p. 28) & & Globales vs. locales \\
\cline { 3 - 3 } & & Residuales vs. actuales \\
& & $\begin{array}{l}\text { Congruentes } \\
\text { idiosincráticos }\end{array}$ \\
& & Transitorios vs. permanentes \\
\hline
\end{tabular}

Tabla 10: Errores de criterio pedagógico.

Para Durão (2007, p. 18), los errores de criterio pedagógico son los que plasman el "tipo de producción del que parte el analista". Sus detalles pueden verse de manera esquemática en el siguiente cuadro:

\begin{tabular}{|l|l|}
\hline Comprensión & $\begin{array}{l}\text { El objeto de análisis es una comprensión oral o } \\
\text { escrita }\end{array}$ \\
\hline Producción & $\begin{array}{l}\text { El objeto de análisis es una producción oral o } \\
\text { escrita }\end{array}$ \\
\hline Orales & El objeto de análisis es una producción oral \\
\hline Escritos & El objeto de análisis es una producción escrita \\
\hline Individuales & $\begin{array}{l}\text { El objeto de análisis ha sido elaborado por un } \\
\text { único aprendiz }\end{array}$ \\
\hline Colectivos & $\begin{array}{l}\text { El objeto de análisis ha sido elaborado por más } \\
\text { de un aprendiz }\end{array}$ \\
\hline
\end{tabular}

Tabla 11: Errores de criterio pedagógico (adaptado de Durão, 2007, p. 18).

Por lo que a los dos últimos se refiere, Fernández (1995, p. 213) considera que los errores individuales suelen desaparecer "u obedecen a razones de personalidad del alumno o algún tipo de problema específico", mientras que los colectivos son frecuentemente observables en los grupos de aprendices de una misma lengua materna.

Por su parte, Vázquez (1998, p. 40) entiende los errores pedagógicos a través de la noción de "permanencia", es decir, la constancia con la que se repiten determinados errores en cada nivel 
de aprendizaje. En esta clasificación ${ }^{74}$, Vázquez (Ibid., p. 40) incluye los errores transitorios, permanentes, fosilizados, y fosilizables ${ }^{75}$. Los errores transitorios, también llamados eventuales por Fernández (1995, p. 211), serían aquellos que, como el nombre sugiere, se caracterizan por aparecer y desaparecer en un determinado estadio. Son errores de desarrollo, y tienden a desaparecer con la superación de la etapa de aprendizaje. Por el contrario, los errores permanentes o sistemáticos, según Fernández (1997, p. 211), son aquellos que tienen cierta regularidad en un determinado estadio de la IL.

\subsubsection{Notas para nuestro estudio}

Aunque Vázquez (Ibid., p. 40) no explique la diferencia entre los errores fosilizados y fosilizables, los entendemos a partir de los planteamientos ya reseñados en el Capítulo 2, apartado 2.5, que dedicamos al concepto de fosilización. En ese sentido, retomamos aquí la idea de que los errores fosilizables serían aquellos que aparecen con frecuencia, ya sea individual o colectivamente, pero que en un estudio sincrónico como el presente no pueden clasificarse como fosilizados ni transitorios, dado que aparecen en un simple corte temporal. En palabras de Fernández (1995, p. 212):

[...] los errores fosilizables son aquellos que se repiten en fases sucesivas y que ofrecen una mayor resistencia, ya sea por la complejidad misma de la estructura, por un problema de interferencia o por cualquier otra clase de contaminación.

\footnotetext{
${ }^{74}$ Vázquez (1999, p. 40-42) considera que se derivan también de ese criterio los errores globales y locales (los cuales explicaremos en el próximo subapartado), así como los llamados residuales, actuales, congruentes e idiosincráticos. Estos últimos, sin embargo, por escapar de los límites de nuestro trabajo, no se explicarán aquí.

${ }^{75}$ Durão (2007, p. 17) ubica los errores transitorios y permanentes en el criterio etiológico.
} 
Entendemos que sería necesario, por tanto, un estudio transversal para poder caracterizar estos errores de acuerdo con la frecuencia con que aparecen en varios estadios, así como relacionar otras características que puedan incidir en la fosilización. En suma, creemos que solo un análisis cuidadoso de la interlengua de los participantes que tenga en cuenta el conjunto de características del sujeto o grupo estudiado, así como la aplicación de una metodología adecuada con el correspondiente estudio longitudinal, será capaz de revelar sus errores fosilizados. Sin embargo, los datos aislados, sin la verificación de la incidencia de los errores en las diferentes etapas del aprendizaje no son suficientes para indicar la fosilización de determinados desvíos de la norma. Por este motivo, en el presente estudio consideraremos los errores recurrentes como "fosilizables" y no fosilizados.

Acerca de los demás errores de criterio pedagógico, nuestro estudio se ocupará específicamente de aquellos referentes a los parámetros de tipo de producción (Durão, 2007). Así pues, daremos cuenta de los errores relativos a la producción de carácter oral, individual y también colectivo, puesto que el criterio de permanencia (Vázquez, 1988) no puede abarcarse en un estudio sincrónico.

\subsubsection{Criterio comunicativo}

Según Vázquez (1991, p. 44), los errores comunicativos están guiados por criterios distintos a todos los demás tipos de errores. Esto ocurre porque el parámetro más relevante es ahora la dimensión pragmática. En otras palabras, como indican Dulay et al. (1982, p. 189), el criterio comunicativo tiene como guía principal el efecto del error en el receptor del mensaje (escrito o hablado). Su foco está en descubrir qué errores afectan a la comunicación y cuáles no $^{76}$. Según los autores citados (DULAY ET AL.,1982, p. 188), diversos estudios han demostrado que aquellos errores que afectan a la organización de la oración suelen dificultar más la comunicación, mientras que los errores que atañen a un único elemento de la frase no suelen causar tantos problemas. Burt y Kiparsky (1972, apud DULAY ET AL.,1982, p. 188) estuvieron entre los primeros en hablar de tales efectos comunicativos, lo que les

\footnotetext{
${ }^{76}$ En ese sentido, entendemos que los errores de criterio comunicativo están relacionados con la adecuación de Corder (1981b) (véase 4.2.2.1).
} 
llevó a distinguir entre errores globales y locales. Los primeros afectarían al enunciado en su totalidad, mientras que los segundos lo harían solamente sobre algún constituyente.

A partir de esta investigación, se derivaron otras muchas clasificaciones. Citaremos las más importantes, extraídas de Durão (2007), aunque por motivos de espacio, lo haremos de manera resumida. Estas son: Irritantes (Johanson, 1973; Richards, 1973) causaría irritación al receptor; Inhibitorios (Schachter, 1974) cuando se evitan estructuras de la lengua meta; Ambiguos ${ }^{77}$ (Vázquez, 1999) cuando la presencia de un elemento ambiguo genera dificultad en la compresión; Estigmatizadores (Richards, 1973; Johanson, 1973) - cuando el receptor induce juicios de valor sobre una determinada comunidad de habla; Sociocultural - el receptor interpreta de manera errónea el mensaje debido a diferencias en el contexto lingüístico y social entre receptor y emisor; Pragmático - ocurre cuando hay una diferencia entre lo que el emisor intenta transmitir (su intención en el discurso) y lo que el receptor realmente comprende (DURÃO, 2007, p. 19).

La autora (DURÃO, 2007, p. 20) subraya que los aprendices pueden usar las formas erróneas como estrategia de comunicación cuando entienden que no dominan la forma lo suficiente como para comunicarse. En ese caso, sabiendo que no poseen todos los conocimientos para utilizar la lengua con corrección, emplean las formas erróneas conscientemente con el propósito de hacerse entender.

\subsubsection{Notas para nuestro estudio}

No cabe entre los objetivos de nuestra investigación ocuparnos de los errores de criterio comunicativo stricto sensu. No obstante, es innegable que al realizar nuestra tarea de análisis, tal criterio subyace a los demás. En definitiva, considerar si una determinada construcción es error o no, en el fondo siempre está ligado a pronosticar qué efecto tendría en el oyente. De esta manera, aunque no trabajaremos de manera detallada sobre los tipos de errores comunicativos, este será un criterio que nos acompañará a lo largo de todo el proceso de análisis.

\footnotetext{
${ }^{77}$ Estos errores serían distintos a aquellos que denominábamos ambiguos según el criterio etiológico.
} 


\subsection{En conclusión}

En este capítulo teníamos como objetivo hacer un recorrido por los principales criterios y taxonomías utilizadas en la investigación del $\mathrm{AE}$, así como definir cuáles de estos utilizaremos en nuestros análisis. En este repaso, hemos comprobado que hay un gran debate alrededor de la misma definición de error y que su aplicabilidad depende de los objetivos de cada estudio y de los criterios que se consideren en cada caso. Al respecto, hemos argumentado que para nosotros fue fundamental discernir entre error, equivocación y falta, motivo por el cual hemos trabajado solamente con los primeros dos.

Respecto a los criterios para la clasificación de los diferentes errores, hemos visto que los más frecuentes son los siguientes: etiológico, gramatical, lingüístico, pedagógico y comunicativo, y, a partir de ahí, los hemos explicado según las interpretaciones de diferentes autores. En relación con el criterio etiológico, hemos señalado también que en el estudio empírico analizaremos con detalle los errores interlinguales (a los que hemos añadido también algunos que podrían pasar por ambiguos), si bien procederemos también a hacer el recuento de los intralinguales como parte de la investigación cuantitativa.

Dentro de los errores interlinguales hemos presentado una diversidad de tipos, todos ellos recogidos previamente por Durão (2007), de quien hemos adaptado su clasificación para atender a las necesidades de nuestro estudio. De esta manera, analizaremos específicamente los errores interlinguales de producción y sus diferentes tipos: (i) de sustitución por analogía y directa; (ii) de creación de palabra original y traducción prestada; (iii) de calco.

Sobre los errores interlinguales, hemos destacado también que su origen suele estar ligado a factores externos, como un entorno limitado de la L2/LE, la ausencia de compañeros nativos y el aprendizaje en contextos formales, contextos todos ellos inevitablemente artificiales. Y, como factores internos, la principal causa, puede ser el uso exagerado del monitor.

Además, hemos revisado otros tipos de criterios, y hemos definido los que tendremos en cuenta en el estudio, como la clasificación por categorías gramaticales en la primera etapa del análisis y, la categoría específica delos léxico-semánticos en la segunda etapa. 
Como hemos podido constatar en la revisión presentada hasta ahora, los errores léxicos suelen ser los más frecuentes y acostumbran a presentar más problemas para la comunicación. También hemos subrayado la importancia de fijarnos en los principios de aceptabilidad y adecuación respecto a su forma y contexto para definir el error.

Respecto al criterio pedagógico, hemos constatado que existe una gran variabilidad en su delimitación, y que en el presente estudio nos apoyaremos en la categorización realizada por Durão (2007), y más concretamente en los errores de producción, orales, individuales y colectivos. Asimismo, hemos visto que aunque el criterio comunicativo no sea central para nosotros, este subyace a todos los demás, en el sentido de que definir un error siempre conlleva interpretar qué efecto podría tener en el oyente.

Para terminar esa sección, recogemos en el cuadro siguiente el esquema con los criterios de los que nos hemos servido en las diferentes etapas del estudio, a partir de las definiciones que hemos presentado en ese capítulo. También hemos añadido los tipos y subtipos de errores ligados a cada criterio, destacando en gris los que analizaremos en profundidad, es decir, parte de los derivados de los criterios etiológico (interlinguales), gramatical (léxico-semánticos) y pedagógico:

\begin{tabular}{|c|c|c|c|c|}
\hline CRITERIO & TIPOS & & & \\
\hline \multirow{4}{*}{ Etiológico } & \multirow{4}{*}{$\begin{array}{l}\text { Interlinguales } \\
\text { y ambiguos }\end{array}$} & \multirow[t]{4}{*}{ Producción } & Sustitución & Analogía \\
\hline & & & \multirow[t]{2}{*}{$\begin{array}{l}\text { Creación de } \\
\text { palabra nueva }\end{array}$} & $\begin{array}{l}\text { Creación } \\
\text { original }\end{array}$ \\
\hline & & & & $\begin{array}{l}\text { Traducción } \\
\text { prestada }\end{array}$ \\
\hline & & & \multicolumn{2}{|l|}{ Calco } \\
\hline & \multicolumn{4}{|l|}{ Intralinguales } \\
\hline \multirow{3}{*}{ Gramatical } & \multicolumn{4}{|l|}{ Morfológico } \\
\hline & \multicolumn{4}{|l|}{ Sintáctico } \\
\hline & \multicolumn{4}{|c|}{ Léxico-semántico } \\
\hline \multirow{4}{*}{ Lingüístico } & \multicolumn{4}{|c|}{ Adición } \\
\hline & \multicolumn{4}{|l|}{ Omisión } \\
\hline & \multicolumn{4}{|l|}{ Elección } \\
\hline & \multicolumn{4}{|l|}{ Orden } \\
\hline \multirow{5}{*}{ Pedagógico } & \multicolumn{4}{|l|}{ Producción } \\
\hline & \multirow{2}{*}{\multicolumn{4}{|c|}{$\begin{array}{l}\text { Orales } \\
\text { Individuales }\end{array}$}} \\
\hline & & & & \\
\hline & \multicolumn{4}{|l|}{$\begin{array}{l}\text { Individuales } \\
\text { Colectivos }\end{array}$} \\
\hline & \multicolumn{4}{|l|}{ Fosilizables } \\
\hline
\end{tabular}

Tabla 12: Criterios y tipos de errores analizados en el estudio. 


\subsubsection{Algunas consideraciones adicionales sobre los errores de nuestro estudio}

En la investigación que proponemos, tendremos también en cuenta otras cuestiones, además de las discutidas hasta aquí. Las hemos reservado para este último apartado porque guardan especial relación con las particularidades de nuestro corpus y conciernen a la reflexión sobre la tarea del investigador en el campo del análisis de errores.

La primera consideración que hacemos se refiere a los errores visibles y ocultos (CORDER, 1981b), para discutir a continuación cómo practicamos la reconstrucción de los errores (CORDER, 1981b) y el papel de la interpretación en el análisis de estos (CORDER, 1981b; DURÃO, 2004; 2007). Para terminar, presentamos un cuadro esquemático con los diferentes tipos y criterios que utilizaremos en nuestro estudio, tomando como base la tipología presentada en los apartados anteriores de este capítulo.

\subsubsection{Errores visibles versus ocultos}

Como hemos visto anteriormente (subapartado 4.2.2.1), Corder (1981b, p. 41) consideró que las producciones libres de errores eran las aceptables desde el punto de vista de la forma y adecuadas en relación al contexto. Ahora bien, para el autor, con quién coincidimos, (CORDER, op, cit.), que un aprendiz produzca una forma libre de error no es garantía de que realmente la haya aprendido $^{78}$. Para él, existen errores idiosincráticos visibles y ocultos (CORDER, 1971b, p. 21-22). Los errores visibles son aquellos que resultan evidentes por la clara desviación que suponen con respecto a la norma, por lo que es fácil identificarlos. Por otro lado, los errores ocultos son ambiguos y ponen en duda si el aprendiz realmente sabe usar la lengua o fue casualidad su acierto. Por esta razón, Corder argumenta que todas las oraciones deben considerarse idiosincráticas hasta que se pruebe lo contrario (CORDER, 1971b, p. 21).

Aplicando tales consideraciones a nuestro estudio, diremos que en él vamos a trabajar con los llamados errores visibles,

${ }^{78}$ También Durão (2007, p. 31) llama la atención sobre ese aspecto. 
principalmente por la ventaja que entraña el poder identificarlos claramente. Sin embargo, por problemas de espacio y tiempo, no podemos ocuparnos de los errores ocultos, ya que son de dudoso origen y, además, resultan difíciles de reconocer. No obstante, somos conscientes de que las construcciones aquí analizadas son fruto de muestras de habla recogidas en un momento determinado, lo que configura un corpus y unos errores concretos, que podrían ser diferentes en otros contextos.

Recordemos que los errores seleccionados en el corpus son idiosincráticos; en primer lugar, porque, como dice Corder (Ibid., $p$. 21), no es posible afirmar que sean aciertos todos los aciertos, ni errores todos los errores; $y$, en segundo lugar, porque son la consecuencia de unas muestras de habla recogidas en un punto concreto del eje temporal, y en las cuales inciden muchos factores, tanto personales como motivados por el entorno. En el caso de las clases, por ejemplo, por el comportamiento de los alumnos, el contenido trabajado en clase, las actividades, etc., y en el caso de las entrevistas, por el lugar (si había ruido externo, interrupción de terceros, tiempo disponible por cada profesor, etc.).

A partir de estos condicionantes, hemos recogido el corpus que sirve de base al presente estudio y del que hemos extraído los errores visibles con los que trabajaremos. Con todo, somos conscientes de que errores de otro tipo podrían haber aparecido en otras situaciones, y, quizá, errores que ahora son visibles podrían aparecer como ocultos en otras circunstancias.

\subsubsection{Reconstrucción autorizada versus plausible}

Corder (1981b, p. 37-38) también destacó la importancia de la interpretación del investigador en la identificación de los errores de los estudiantes. En relación con este aspecto, argumentaba lo siguiente:

We can see now how crucial interpretation is to the whole methodology of error analysis. The reconstructed sentence is based upon our interpretation of what the learner was trying to say, upon the meaning he was trying to express. The whole success of our description of errors hinges upon the correctness of our interpretation of learner's intentions or meaning. (CORDER, 1981b, p. 37) 
Para lograr una interpretación más aproximada a la ideal, el autor propone dos caminos distintos, dependiendo de la accesibilidad al aprendiz. En el primero, se parte de una interpretación autorizada (CORDER, 1981b, p. 37), en la que se cuestiona directamente al aprendiz qué intentaba decir en su lengua materna, y luego se traduce a la lengua objeto, lo que resultaría en una reconstrucción autorizada (CORDER, 1981b, p. 37). Según el autor (Ibid., p. 37), en caso de no tener la posibilidad de consultar al aprendiz, la interpretación se torna crucial y puede causar equívocos. Para Corder (Ibid., p. 37), en este caso, el conocimiento de la LM nos ayudará a realizar una predicción más precisa. De todas maneras, recuerda que no podemos estar seguros al $100 \%$ de lo que quiso decir el aprendiz. Este tipo de interpretación recibe el nombre interpretación plausible, y su reconstrucción, una reconstrucción plausible (CORDER, 1981b, p. 38).

Así, dentro de las limitaciones que la tarea impone, en ese trabajo trataremos de identificar los errores producidos por los sujetos estableciendo una correspondencia entre lo que dijeron y lo que prendían comunicar, como propone Corder (1981: 37):

[...] we compare his erroneous utterance with a native speaker would have said to express that meaning. We identify errors by comparing original utterances with what I shall call reconstructed utterances, that is, correct utterances having the meaning intended by the learner.

Obviamente, no siempre podemos estar seguros de que estemos haciendo la interpretación correcta acerca de la intención comunicativa del sujeto. Por ello, se hace necesario establecer criterios como la forma y el contexto (CORDER, 1981b, p. 38), relacionando lo que sabemos del sujeto y el nivel de lengua que tiene para realizar una interpretación adecuada. De esta manera, podríamos utilizar interpretaciones plausibles y sus correspondientes reconstrucciones plausibles, que se basan en la intención del hablante y se fundamentan en la norma. Este tipo de interpretación es el que utilizaremos en nuestro estudio. 


\subsubsection{El papel de la interpretación}

Corder (1981b, p. 38), hace hincapié en que, aunque se utilicen diferentes clasificaciones de errores con el fin de alcanzar los objetivos propuestos, y aunque el analista se arme de bases teóricas sólidas y apropiadas, los resultados finales dependen muchas veces de la intrincada tarea que supone la interpretación del investigador. Como subraya también Durão (2004, p. 83):

Identificar o clasificar errores no son cosas sencillas. Todo analista de errores se depara, invariablemente, con la dificultad de especificar qué es el error así como tiene necesidad de establecer criterios de clasificación ajustados al abordaje de enseñanza que utilice y a los propósitos de enseñanza/aprendizaje que tenga como docente.

Otra característica señalada por esta autora (DURÃO, 2007, p. 21) es que la capacidad del investigador para explicar los errores está intrínsecamente ligada a su propia competencia lingüística y comunicativa. Como vemos, en esta compleja tarea tienen importancia muchos factores, como las propias competencias del investigador, y la aplicación de interpretaciones y reconstrucciones plausibles, etc.

Otro obstáculo destacado por Durão (2007, p. 21) en el análisis de errores es el diverso origen de estos (es decir, un mismo error puede encajarse en más de una categoría), lo que implica que el investigador tiene que tomar decisiones en cuanto a su clasificación y análisis en función de sus objetivos. Consecuencia de ello es la disparidad de resultados de las investigaciones sobre un mismo tipo de error.

En esta sección, hemos intentado aclarar cuál es nuestra posición de partida con respecto a la noción de error en relación con las diferentes concepciones encontradas en la bibliografía. Asimismo, hemos querido dar cuenta de las clasificaciones que utilizaremos en nuestro estudio. Ambos son requisitos imprescindibles si aspiramos a la realización de un trabajo coherente. No obstante, entendemos que la interpretación es parte también de la riqueza de este campo de estudio y de ahí que creamos posible la existencia de interpretaciones distintas a las que expondremos aquí. Sin embargo, ello no implica necesariamente 
que una interpretación invalide a otras: al contrario, entendemos que es en la multiplicidad interpretativa donde reside la riqueza del análisis de errores.

En el siguiente capítulo, el último de este recorrido teórico, presentaremos diversos constructos sobre aspectos léxicos específicos que se analizan en nuestro estudio. 
192 


\section{ALGUNAS CUESTIONES TEÓRICAS SOBRE EL LÉXICO APLICADAS A NUESTRO ESTUDIO}

Como en este trabajo tratamos sobre los errores léxicos de los profesores de español como lengua extranjera, parece conveniente abordar en esta sección algunas consideraciones sobre cuestiones teóricas relacionadas con la adquisición del léxico por parte de aprendices no nativos. Para ello, comenzamos con una breve introducción sobre algunos conceptos básicos (subapartado 5.1). A continuación, abordaremos cuestiones más específicas sobre aspectos concretos aplicados a los errores de nuestro estudio, como: la formación de palabras (subapartado 5.2), los heterosemánticos (subapartado 5.3) y las unidades fraseológicas (subapartado 5.4). Por último, concluiremos con algunas observaciones acerca del modo en que estos conceptos teóricos se aplican a los objetivos de nuestro trabajo (subapartado 5.5).

\subsection{Introducción}

La discusión acerca del concepto de "palabra" ha sido bastante prolija (y compleja) en la historia de la lingüística, y parece estar lejos de haber sido resuelta. Como recuerda Alvar Esquerra (2003, p. 22), la definición de esta unidad lingüística es un "continuo punto de debate en el interior de la especulación lingüística". En el mismo sentido, Basilio (1987, p. 11), destaca que la palabra es "una de esas unidades lingüísticas que son muy fáciles de reconocer, pero bastante difíciles de definir si tomamos como base de definición la lengua hablada". ${ }^{79}$ Por su parte, Higueras García (2006) subraya la paradoja que se produce en el seno de la lingüística en torno a esta cuestión:

Uno de los aspectos más apasionantes de la Lingüística es la incapacidad para definir las unidades de análisis con las que trabaja; inconcebible nos parecería que un matemático no pudiera definir el concepto de coseno o el de ecuación, por ejemplo, o que un biólogo no pudiera acotar con precisión el concepto de molécula 0 un médico el de infarto de

${ }^{79}$ Traducción nuestra. 
miocardio; sin embargo, en nuestro campo es habitual que se generen intensos y controvertidos debates cada vez que se intentan precisar conceptos como palabra, lengua, dialecto o colocación. (HIGUERAS GARCÍA, 2006, p. 7)

En una aproximación reciente sobre el tema, Gómez Torrego (2011, p. 20), define la palabra como "una unidad de la lengua que se reconoce por escribirse entre dos espacios en blanco". Aunque esta definición parezca un tanto simplista, ya que restringe la palabra al registro escrito, nos puede servir como punto de partida A continuación, este autor (GÓMEZ TORREGO, 2011, p. 20) sostiene que hay tres características que permiten distinguir unas palabras de otras; ya que estas unidades: (i) tienen significado; (ii) se pueden descomponer en morfemas; y (iii) se combinan entre sí para formar unidades mayores, dentro de las cuales desempeñan una función. Sobre algunos de estos aspectos, volveremos más abajo. Por otro lado, y como recuerdan algunos autores (BARALO 2007, p. 385; ANDRADE y DURÃO 2009, p. 24) la palabra es una unidad léxica que puede reducirse a una sola unidad monoverbal (ej. barriga) o pluriverbal (ej. llenar la barriga).

Otra discusión que afecta a la palabra es su propia posición teórica en relación con el léxico. Así, mientras que este último abarcaría el vocabulario en general, la palabra sería una pieza léxica (monoverbal o pluriverbal) perteneciente al léxico, incluso para algunos "la unidad léxica por excelencia", "una unidad psicolingüística y morfoléxica compleja para el investigador" (BARALO, 2007, p. 385).

Al margen del largo debate en torno a los aspectos aquí reseñados, y sobre los que, por motivos de espacio y oportunidad, no podemos extendernos, al revisar la bibliografía sobre el tema, salta a la vista que el tratamiento del léxico ha pasado de ocupar una posición marginal, a mostrar un notable impulso en los últimos años, especialmente en los estudios sobre la enseñanza de las lenguas extranjeras, (HIGUERAS GARCÍA, 2006, p. 7; XATARA, 2001). Esto ocurre más específicamente con los planteamientos desarrollados a partir del enfoque comunicativo y el paradigma léxico de Lewis (1993, 1997, 2000 apud HIGUERAS GARCÍA, 2006, p. 9).

Como recuerda Higueras García (2006, p. 13), los estudios psicolingüísticos sostienen que la adquisición del léxico no ocurre de manera aislada, con base únicamente en la memorización paulatina, 
sino que este es un proceso cualitativo, gradual, multidimensional, procesual y dinámico. Ello significa que, a medida que se aprende, se van formando redes de relaciones y asociaciones de todo tipo (fonéticas, gráficas, semánticas, morfológicas, sintácticas, enciclopédicas o personales) en las que se asocian y fijan informaciones nuevas a las ya conocidas (HIGUERAS GARCÍA, 2006 , p. 13). A esta compleja red de informaciones también se la conoce con el nombre de lexicón (HIGUERAS GARCÍA, 2006, p. 13).

En el análisis específico del lexicón de los aprendices de español como lengua extranjera, que es el que aquí nos interesa especialmente, Baralo $(1994,1997)$ ocupa un lugar destacado. De hecho, en un estudio pionero sobre la creación de adverbios en mente entre estos aprendices, esta autora comprobó que la lengua materna influía decisivamente en la creación de palabras de la LO, principalmente por medio de la sobregeneralización de reglas procedentes de esa LM (BARALO, 1994). Este tipo de hallazgos son de especial interés para nosotros, y, como veremos, lo dicho por Baralo se confirma en buena medida entre los sujetos de nuestro estudio.

Precisamente, sobre los mecanismos de formación de palabras que constituyen el lexicón, y más concretamente sobre los diferentes recursos utilizados por los sujetos de nuestra investigación, tratamos de forma monográfica en el siguiente subapartado.

\subsection{Formación de palabras}

Es sabido que una característica de las lenguas naturales es la creación de nuevos signos para denominar nuevas realidades. Ese movimiento creativo surge de la necesidad de adecuar las necesidades expresivas y comunicativas al medio donde se vive. Así, para autores como Basilio (1987, p. 66), bajo la perspectiva comunicativa, el lenguaje se basa en dos tipos de mecanismos fundamentales: la formación de palabras y la formación de enunciados.

Desde el prisma comunicativo, la formación de palabras de las lenguas, puede definirse como "el conjunto de procedimientos disponible para esta tarea de acrecentamiento del vocabulario, genera formas nuevas a partir de otras ya existentes en la propia lengua" (ROMERO GUALDA, 2008, p. 112). En este sentido, para Basilio (1987, p. 9), los principales motivos por los que formamos 
palabras son dos: “(...) la utilización de la idea de una palabra en otra clase gramatical; y la necesidad de un incremento semántico en una unidad lexical básica". No obstante, aun quedaría una razón adicional, que, en el fondo, recoge también el sentido de las anteriores:

En último análisis, la razón por la cual formamos palabras es la misma razón por la cual formamos frases: el mecanismo de la lengua siempre procura conseguir el máximo de eficiencia, lo que se traduce en un máximo de flexibilidad en términos de expresión y un mínimo de elementos almacenados en la memoria. Es esa flexibilidad la que nos permite contar con un número enorme de elementos básicos de comunicación sin que tengamos que sobrecargar la memoria con esos mismos elementos (BASILIO, 1987, p. 10) ${ }^{80}$.

Para conseguirlo, las palabras están formadas por unidades de significados más pequeñas, que se combinan de diferentes maneras. A estas unidades las llamamos morfemas. Así, tanto la raíz como los morfemas derivativos o flexivos son parte de una palabra, aunque cada una cumpla funciones distintas en su formación.

Para Romero Gualda (2008, p. 112):

Al profesor de E/L2 le interesa no sólo la creación de palabras nuevas - lo que podría ocupar al estudioso de la neología - sino conocer la descripción léxica del español y de los recursos que éste ha ofrecido y ofrece al hablante; el primer paso es examinar los "procedimientos que intervienen en el desarrollo morfológico de palabras" (Almela, 1999: 31).

Los procedimientos a los que se refiere la autora son, por un lado, los "morfológicos más regulares": afijación, composición y parasíntesis; y, por otro, aquellos que, según la autora, "no están muy bien delimitados", como el acortamiento, las abreviaturas, las siglas y los acrónimos (ROMERO GUALDA, 2008, p. 112).

${ }^{80}$ Traducción nuestra. 
En nuestro estudio, hemos encontrado que los errores de interferencia están afectados a menudo por los procesos de afijación y composición ${ }^{81}$, por ello, haremos aquí una breve discusión acerca de estos dos procesos específicamente.

Los elementos afijados pueden ser de dos tipos: el primero son los morfemas gramaticales, también conocidos por gramemas, morfemas flexivos o desinencias. Como el mismo nombre indica, son constituyentes de la palabra y están dotados de significado gramatical. Estos siempre están ubicados a continuación de la base o raíz y pueden estar unidos o no inmediatamente a ella (ej. niño/niñ-it-o) (ROMERO GUALDA, 2008, p. 115).

El segundo tipo de afijación es el que da cuenta de prefijos $y$ sufijos. Estos se definen en relación a su posición respecto a la raíz. Los prefijos se ubican antes que esta última (ej. per-dur-ar) y los sufijos después (ej. libr-er-o). Antes del sufijo puede haber interfijos, los cuales tienen sobre todo un origen histórico o fonético (ej. panad-er-o) (ROMERO GUALDA, 2008, p. 116).

Otra característica de los sufijos es que pueden cambiar la categoría de la raíz a la que se unen. De este modo, el sufijo puede modificar la clase semántica de la palabra al tiempo que se produce o no un cambio categoría. Así tenemos sufijación exocéntrica tanto cuando se produce un cambio de categoría (ej. celo-celoso), como cuando no la hay (ej. libro-librería). Asimismo, los procesos de sufijación pueden no afectar ni a la clase semántica ni a la categoría del derivado, en cuyo caso hablamos de sufijación endocéntrica (ej. niño-niñito) (ROMERO GUALDA, 2008, p. 118). Por el contrario, los prefijos no tienen esa capacidad y tampoco se funden con la raíz, a diferencia de los sufijos.

Romero Gualda (2008, p. 116-117) recuerda también que en la formación de palabras existen algunas 'anomalías' aparentes, como sucede con las raíces variables de leche/lácteo o con pares de palabas que presentan evolución divergente, como ojo/ocular, y que tienen lugar porque las lenguas son objetos históricos en los cuales las familias léxicas pueden cambiar con el tiempo. Estas tendencias

${ }^{81}$ Sin embargo, no nos ocupamos aquí de la parasíntesis en su interpretación más tradicional, en la cual se combinan composición+derivación, como en picapedrero; pordiosero; ropavejero (ROMERO GUALDA, 2008, p. 162) puesto que no hemos encontrado vocablos resultantes de la interferencia lingüística de este tipo. Por el mismo motivo, tampoco comentaremos los casos formados a partir de la adición simultánea de diversos afijos derivativos cuando los estadios previos no se hallan codificados en la lengua (el caso, por ejemplo, de mileurista, donde no tenemos el paso previo, *mileuro). 
pueden explicarse a través de la información diacrónica, la cual se hace necesaria en el estudio de la formación de palabras, "puesto que es un modo de zanjar problemas que en la sincronía no se sabe cómo resolver" (ROMERO GUALDA, 2008, p. 116). En el mismo sentido, en su Nueva Gramática de la Lengua Española, la Real Academia Española subraya que la formación de palabras del español está repleta de irregularidades que solo pueden explicarse con base en la historia de la lengua (RAE, 2009a, p, 28).

\subsubsection{Notas para nuestro estudio}

Desde la perspectiva de nuestro estudio específicamente, tratamos la formación de palabras bajo el prisma de las creaciones léxicas de la LO fundamentadas en la LM de los sujetos. Estas creaciones están basadas en reglas de formación de palabras de ambas lenguas, una característica común de las interlenguas. Tales creaciones suelen estar ligadas al uso de unas estrategias en las que se recurre tanto a la LM como a las reglas internas de la lengua española y es a partir del análisis contrastivo de tales lenguas como hemos podido entenderlas.

Un ejemplo de ello es el error de creación de palabra nueva, cometido por dos docentes de nuestro estudio en relación con el verbo "escribir". En la ocasión que transcribimos a continuación, una de esas profesoras dice a sus alumnos:

(20) D9C1: sexta... viernes... prueba... escreberon todos... prueba... ¿de qué era?

\begin{tabular}{|l|l|l|l|}
\hline VOCABLO CREADO & $\begin{array}{l}\text { VOCABLO EN LA } \\
\text { LM }\end{array}$ & $\begin{array}{l}\text { VOCABLO EN LA } \\
\text { LO }\end{array}$ \\
\hline Escreberon & Escreveram & Escribieron & \\
\hline
\end{tabular}

Tabla 13: Interferencia vocablo "escreberon".

Con el vocablo escreberon entendemos que la docente crea un nuevo término, mezclando para ello reglas de formación de palabras tanto de la LO como de la LM. Esto se puede apreciar en la 
combinación de la raíz portuguesa, escreb, con la desinencia del pasado española (eron).

Otro tipo de error léxico encontrado en nuestro estudio, el cual difiere sustancialmente de la formación de palabras, es el de los "heterosemánticos". A diferencia del primer mecanismo, mediante el cual los aprendices crean palabras nuevas con elementos tanto de la LO como de la LM, en el segundo se emplean en la LO vocablos que formalmente coinciden en ambas lenguas, pero que no necesariamente tienen los mismos significados o usos. Sobre este grupo tratamos más específicamente en el subapartado siguiente.

\subsection{Falsos amigos, falsos cognados, heterosemánticos}

En lo que se refiere a este conjunto de palabras, también llamados "falsos amigos" (FA), "falsos cognados" y/o "heterosemánticos", al hacer una revisión de la bibliografía especializada, nos damos cuenta de que no hay un consenso entre los autores sobre su significado. En esta sección presentaremos de manera breve algunas de las discusiones implicadas en torno a ellos y definiremos el concepto aplicado a nuestro estudio. Nos parece importante delimitar estas cuestiones aquí, puesto que este tipo de vocablos está relacionado con los errores de sustitución por analogía, el segundo tipo de error más frecuente encontrado en esta investigación (para más detalles, véase el Capítulo 7).

\subsubsection{La diversidad conceptual en las obras lexicográficas}

En ocasiones, los tres conceptos mencionados más arriba son usados como sinónimos. Sin embargo, en un análisis más profundo de las propuestas de diferentes autores vemos que muchas veces no guardan relación. El concepto de "falsos amigos", por ejemplo, es bastante impreciso y abarca una serie demasiado heterogénea de características. Esa variación puede ser observada, por ejemplo, a través de las definiciones contenidas en tres obras lexicográficas especializadas en este tipo de vocablos, todas ellas utilizadas en nuestro estudio.

Para Bosco Monte, autor del Diccionario Ilustrado de Falsas Semelhanças español-português, hay un grupo de vocablos que son "palabras que entre las lenguas española y portuguesa presentan 
similitudes en la escrita pero que difieren en el significado" ${ }^{82}$ (MONTE, 2003, p. 3). El autor, sin embargo, no llega a definir el grupo de palabras como "falsos amigos", y prefiere llamarlo "falsas similitudes", haciendo referencia solamente a la lengua escrita. Tampoco deja claro si forman parte de este grupo los vocablos divergentes en todos los significados (ej. adosar: apoyar, unir; $y$ adoçar: endulzar ${ }^{83}$ ) o solamente en algunos (ej. ampolla/ampola: pequeño recipiente herméticamente cerrado que contiene por lo general una dosis de un medicamento; ampolla/bolha: elevación de la piel por acumulación de líquido ${ }^{84}$ ).

Por otro lado, para FEIJÓO HOYOS (1992) autora del Diccionario de Falsos Amigos del Portugués y del Español, los "falsos amigos" son:

(...) aquellas palabras que por su semejanza ortográfica y/o fónica parecen a primera vista fáciles de ser entendidas, traducidas 0 interpretadas, pero que de hecho esconden peligrosas trampas de sentido para el incauto lector o traductor. (FEIJÓO HOYOS, 1992, p. 8)

Según esta lexicógrafa, existen dos tipos de FA: (i) los más obvios son los "vocablos que, pese a su forma semejante o idéntica, no ofrecen ningún significado común a las dos lenguas confrontadas" (sería el caso de adosar/adoçar anteriormente citado, junto a otros mencionados por la autora, como oca, taller/talher, pala y abate); (ii) los más frecuentes, "palabras que tienen algún o algunos significados comunes y otros diferentes" (sería el caso de ampolla/ampola también mencionado por nosotros con anterioridad). Si bien la primera definición se acerca mucho a la realizada por Monte, Feijóo Hoyos añade una opción alternativa a los "falsos amigos", ya que incluye también aquellos vocablos que comparten algunos significados, aunque sea de forma parcial (FElJóo HOYOS, 1992, p. 8).

Por su parte, los autores del diccionario "¡Ojo! con los falsos amigos" (BECHARA y MOURE 2002, p. 11) sostienen que los falsos amigos "son palabras que tienen formas semejantes o idénticas, pero que divergen en cuando al sentido". Los autores realizan

\footnotetext{
82 Traducción nuestra.

83 (BECHARA y MOURE, 2002, p. 27)

${ }^{84}$ Consultado en http://dle.rae.es/?id=2S9EbmB el 03/01/2007; consultado en el Diccionário Aurélio (versión digital); Bechara y Moure (2002, p. 36).
} 
seguidamente una breve explicación acerca de los cognados para llegar a esta definición del concepto: "[son] 'cognadas' las palabras 'semejantes o idénticas a palabras de nuestra propia lengua tanto en la forma (escrita y/u oral) como en el significado', o aun, "palabras que tienen un origen común, como lo indica el propio término" (BECHARA y MOURE, 2002, p. 10). Añaden también que se trata de palabras semejantes, bien en la grafía, bien en la pronunciación o en ambas (BECHARA y MOURE, 2002, p. 14). De esta manera, los "falsos amigos" serían lo contrario de las palabras cognadas, es decir, palabras parecidas (ya sea con origen en común o no), pero divergentes en su sentido.

Para estos autores, existen tres tipos de "falsos amigos": (i) "formas semejantes con significados totalmente diferentes" (ej. polvo, que en español significa, entre otras cosas, "el residuo que queda de las cosas sólidas", mientras que en portugués corresponden al español "pulpo"); (ii) "formas semejantes con un (o más de un) significado semejante y otro(s) diferente(s)" (ej. cambista, vocablo que significa en las dos lenguas "persona que negocia con el cambio de monedas", pero que en portugués quiere decir también "persona que revende ilegalmente entradas para un espectáculo"); y (iii) "formas semejantes con significados diferentes en el uso actual". En este último caso, Bechara y Moure hacen referencia a los vocablos que tienen un origen común, y que comparten significados procedentes de ese origen (ej. latir del latín glattire, "dar ladridos agudos", es la fuente tanto del significado relativo al "latir del corazón" como al de los "ladridos de un perro"; sin embargo, hoy día encontramos latir el corazón solamente en español, mientras que en portugués este verbo se usa para designar la voz de los perros) (BECHARA y MOURE, 2002, p. 13).

En suma, si comparamos la definición de Bechara y Moure con las anteriores, observamos cómo estos autores traen a la discusión la etimología de los vocablos, un dato que no se observa en las demás obras. Como vemos, en apenas tres obras especializadas, el concepto de FA presenta una variación conceptual considerable.

Otros autores dedicados a trabajos más teóricos sobre el tema han definido también los "falsos amigos" desde otras perspectivas. Este es el caso de Alvar Esquerra (2003), quien sostiene que a veces las diferencias no son necesariamente formales, sino gramaticales, como es el caso de las diferencias de género (ej. sal: nombre femenino en español, masculino en 
portugués ${ }^{85}$ ). La categoría de falso amigo se definiría entonces como el léxico que genera "problemas gráficos, fonéticos y gramaticales" (ALVAR ESQUERRA, 2003, p. 43). En otras palabras, para el autor también formarían parte de los "falsos amigos" los "heterogenéricos" (como el caso de sal presentado anteriormente) y los "heterotónicos" (como, por ejemplo alcohol/álcool ${ }^{86}$ : oxítona en español y paroxítona en portugués), una visión, pues, distinta a la que hemos visto hasta ahora.

Aun así, el autor argumenta en su libro dedicado a la enseñanza del léxico y el uso de diccionario, que "los verdaderos falsos amigos son palabras con parecido formal aunque con valores diferentes" (ALVAR ESQUERRA, 2003, p. 43). Desde nuestro punto de vista, la referencia a un grupo que es "verdadero falso amigo" en relación a otro definido como tal en la misma obra (los heterotónicos y heterogenéricos), enreda, más que aclara, la caracterización de este complejo grupo de palabras.

Una visión todavía más abarcadora -y creemos que mejor fundamentada- es la que encontramos en el Diccionario de Falsos Amigos Português-Espanhol (DIFAPE) (DURÃO ET AL., 2014), en el que su coordinadora define:

A noção postulada em nosso projeto lexicográfico classifica como falsos amigos os pares lemáticos de duas línguas diferentes (neste caso, nomeadamente, o português e o espanhol), iguais ou parecidos no plano mórfico ou fônico, os quais, compartilhando ou não o mesmo étimo, apresentam divergências acentuais, ortográficas, de gênero gramatical, de número gramatical, de regência, léxicas e/ou semânticas. (DURÃO ET AL., 2014)

Como vemos, el concepto de "falsos amigos" de esta obra es mucho más amplio que el de las obras anteriormente mencionadas. En ella se inscriben diversas características citadas tan solo

85 (FANJUL, 2011, p. 212)
${ }^{86}$ (FANJUL, 2011, p. 214)

${ }^{87}$ La noción postulada en nuestro proyecto lexicográfico clasifica como falsos amigos los pares lemáticos de dos lenguas diferentes (en este caso en particular, el portugués y el español), iguales o similares en el plan mórfico o fónico que, compartiendo el mismo étimo, presentan divergencias acentuales, ortográficas, gramaticales, de género gramatical, de número gramatical, de regencia léxicas y/o semánticas. (traducción nuestra). 
parcialmente por otros autores y que aquí alcanzan una mayor sistematicidad. Es, sin duda, una propuesta novedosa y que permite dar cuenta de un gran número de vocablos nunca antes recogidos por un diccionario de falsos amigos (al menos en un diccionario de estas características en Brasil), como es el caso de las diferencias de número (ej. las existencias/o abastecimento ${ }^{88}$ ), el contraste fónico (ej. banalidad/banalidade ${ }^{89}$ ), e incluso los casos de heterotónicos y heterogenéricos (como los ejemplos citados anteriormente, álcool/alcohol y sal, respectivamente). Desafortunadamente, esta obra, que está organizada en tres tomos, aún no había sido publicada en su totalidad en la fecha de defensa de esta tesis. Por esta razón no la hemos podido utilizar para los análisis que presentaremos en el Capítulo 7: Resultados.

Cabe añadir que la dificultad para encontrar un consenso en la definición de FA en las distintas obras lexicográficas está también directamente relacionada con una cierta confusión terminológica/conceptual en torno a grupos de vocablos distintos, tal y como explicamos a continuación.

\subsubsection{Un poco de historia: el origen de la confusión terminológica}

Para establecer mejor los límites conceptuales que utilizaremos en nuestro estudio, nos parece pertinente volver un poco atrás en el tiempo y repasar el origen de los términos que dan título a este apartado, los cuales muchas veces son utilizados erróneamente como sinónimos.

Empezamos este recorrido con Vita (2005, p. 30), quien recuerda que el concepto de "falsos amigos" procede de Francia, y en particular de la obra de Maxime Koessler y Jules Derocquigny, quienes la acuñan en un trabajo de 1928. La definición que encontramos en este trabajo seminal es la siguiente: "[FA] designa palabras de etimología y de forma parecidas, pero de sentido parcial o totalmente diferente" ${ }^{\circ 0}$ (apud VITA, 2005, p. 30). Este concepto hace referencia, por tanto, a aquellas palabras etimológicamente relacionadas, es decir, con una misma familia, pero que poseen significados distintos, ya sea en una de sus acepciones, en alguna de ellas o en todas.

\footnotetext{
${ }^{88}$ (DURÃO ET AL., 2014, p. 62)

${ }^{89}$ (DURÃO ET AL., 2014, p. 62)

90 Traducción nuestra.
} 
Por su parte, Lado definió en 1972 el concepto de "falso cognado", que es distinto al de "falso amigo" (VITA, 2005, p. 31). En este trabajo defendía que los falsos cognados son "palabras en dos lenguas que, aunque puedan parecer, por su forma, familiares en el origen, no presentan ese tipo de relación"11. De esta manera, al contrario que el concepto expuesto anteriormente, los "falsos cognados" son vocablos que parecen tener el mismo origen, puesto que son parecidos, pero que en realidad no tienen relación etimológica, pudiendo divergir total 0 parcialmente en sus significados.

A partir de este hito, Vita (2005) realiza una revisión específica de la evolución del concepto "falso cognado" en la bibliografía lingüística. Tras este examen, observa que el adjetivo "cognado" es comúnmente atribuido a aquellas palabras que, en dos lenguas diferentes, tienen similitud en el significado debido a un origen en común. No obstante, al revisar el término específico "falso cognado", no encuentra relación con el sentido de "cognado" expuesto anteriormente. En otras palabras, algunos de los autores investigados, como Richards y Platt (1992 apud VITA, 2005, p. 34), por ejemplo, describen los "falsos cognados" en el Longman Dictionary of Language Teaching \& Applied Linguistics, como vocablos que tienen la misma forma, o una forma parecida, pero difieren en los significados, y, por tanto, no toman en consideración su origen de las lenguas en contraste (VITA, 2005, p. 33-36), al contrario de lo que proponía Lado para "falsos cognados".

Para finalizar, Vita (2005) llega a la conclusión de que el término "heterosemánticos" probablemente tenga su origen en Brasil, y más concretamente en la gramática de Antenor Nascentes, publicada por primera vez en $1934^{92}$. Su definición para el término es el de "palabras semejantes con significados distintos"93 (VITA, 2005 , p. 32). Como vemos, tal definición no relaciona tampoco las palabras con su origen. El mismo término es empleado también en el libro de texto de Idel Becker de 1967, Manual de español. Para Becker, que sigue los pasos de su antecesor Nascentes, los heterosemánticos serían la mayor dificultad con que se enfrentan los brasileños aprendices de español. Esta idea se fundamenta también en el hecho de que los "heterosemánticos" no guardan necesariamente relación etimológica y en que los brasileños

\footnotetext{
91 Traducción nuestra.

92 En el Capítulo 3 hemos discutido la importancia de la obra de Nascentes (así como la de Becker) para el desarrollo de la enseñanza del español en Brasil.

93 Traducción nuestra.
} 
necesitan superar esas divergencias léxicas entre las lenguas portuguesa y española para dominar con prescision esta última (VITA, 2005, p. 51-52).

Además de las consideraciones de Vita, también hemos encontrado una revisión detallada de los conceptos "falsos cognados" y "falsos amigos" en el trabajo de Sabino (2006), en el que esta autora complementa las ya expuestas por Vita. Tras un exaustivo repaso de la etimología y la definición de los vocablos "falso", "cognado" y "amigo", Sabino llega a la conclusión de que, terminológicamente, no es adecuado utilizar "falso cognado" como sinónimo de "falso amigo". Por un lado, el término "falso amigo", oriundo del francés y que, en su significado original relaciona el parentesco entre las lenguas (como recordaba también Vita), ha sido transferido a otras muchas lenguas, pero en ese proceso el significado original parece haberse perdido. En contrapartida, el término "cognado" tiene origen en el latín cognatun, junción de cum (con) y natus (nato), "significa nascido junto, consanguineo" (SABINO, 2006, p. 252), es decir, unido por una misma familia. Así, analizando las definiciones del concepto "falso" en dos diccionarios de lengua portuguesa (Dicionário Aurélio y Houaiss, ambos publicados en 1999), la autora concluye que el término implica la relación con algo "no verdadero", "falsificado" o "sin fundamento". De este modo, para Sabino, atribuir a un "cognado" el adjetivo "falso" no sería ni lógico ni racional (SABINO, 2006, p. 252). Para ella, la expresión más apropiada sería, por tando, "engañoso", "traicionero", "desleal" o "pérfido".

Por todo eso, Sabino defiende que lo más adecuado para definir aquellos vocablos de dos lenguas etimológicamente relacionados, pero con diferencias en uno o más significados (definición original de "falso amigo"), sería el término "cognado engañoso" (cognato enganoso en portugués). De esta manera, el término "falso cognado" sería perfectamente aceptable para aquellas palabras que no poseen un origen en comun, pero que son formalmente similares. En sus palabras:

Cognatos enganosos são unidades lexicais de duas (ou mais) línguas distintas que, por serem provenientes de um mesmo étimo, são ortográfica e/ou fonologicamente idênticas ou semelhantes, mas que por terem sofrido evoluções semânticas diferentes, possuem sentidos diferentes. Essas mudanças podem ter acontecido em apenas uma das línguas, ou nas duas. Sendo assim, é possível que ambas 
ainda conservem traços semânticos comuns, ou ainda, que os sentidos originariamente apresentados por esses pares de unidades lexicais tenham se distanciado tanto, em ambas as línguas - tornando-se, por vezes, até antagônicos - a ponto de não parecerem ser vocábulos cognatos. (SABINO, 2006, p. 255) ${ }^{94}$

Falsos cognatos são unidades lexicais pertencentes a duas (ou mais) línguas distintas que, apesar de serem provenientes de étimos diferentes resultaram - em conseqüência das evoluções fonéticas que sofreram, ao longo do tempo - em unidades lexicais ortográfica e/ou fonologicamente idênticas ou semelhantes, embora seus valores semânticos sejam bastante distintos. (SABINO, 2006, p. 256) ${ }^{95}$

A nuestro juicio, la diferenciación que realiza la autora es pertienente y creemos que es fundamental, sobre todo en aquellos estudios léxicos en los que el analisis etimológico tiene un papel central. Para nuestra investigación, sin embargo, hemos optado por un parámetro que tenga en cuenta preferentemente los aspectos formales, así como los semánticos y pragmáticos. Entendemos, por tanto, que la distinción entre "falsos cognatos" y "cognados engañosos" a la manera en que la establece Sabino, no es imprescindible para llevar a cabo el tipo de analisis que proponemos. Ciertamente, en el futuro nos gustaría estudiar con más detalle cuáles de los vocablos utilizados por las docentes son

${ }^{94}$ Los cognados engañosos son unidades léxicas de dos (o más) idiomas diferentes que, al provenir de un mismo étimo, son la ortográfica y/o fonológicamente idénticos o similares, pero que por haber sufrido evoluciones semánticas diferentes, tienen significados diferentes. Estos cambios pueden haber ocurrido en apenas una de las lenguas, o ambas. Por lo tanto, es posible que ambas aún conserven trazos semánticos comunes o, incluso, que los sentidos originalmente presentados por estos pares de unidades lexicales se hayan distanciado tanto, en ambas lenguas, que se hayan tornado, a veces, incluso antagónicos, hasta el punto de que no parecen ser vocablos cognados. (Sabino, 2006, p. 255)

${ }^{95}$ Falsos cognados son unidades lexicales pertenecientes a dos (o más) lenguas distintas que, a pesar de ser de diferentes étimos resultaron - como resultado de la evolución fonética que sufrieron, a lo largo del tiempo - en unidades lexicales ortográfica y/o fonológicamente idénticas o semejantes, aunque sus valores semánticos sean muy diferentes. (Sabino, 2006, p. 256) 
"falsos cognados" y cuáles "cognados engañosos", y si hay mayor incidencia de alguno de los dos tipos en el corpus. Mientras tanto, lo que nos disponemos a hacer aquí es contrastar los errores encontrados, con el objetivo de comprobar si son, efectivamente, errores de interferencia, independiente de su origen etimológico.

\subsubsection{Notas para nuestro estudio}

De acuerdo con lo discutido hasta ahora, creemos que el término que más se acerca al enfoque que damos a los dos grupos de unidades léxicas (las etimologicamente cercanas y las distantes) es el de los "heterosemánticos", un término ya frecuente en la bibliografía especializada, como recuerda Vita (2005).

Pensamos que este permite agrupar los dos tipos señalados, y que justifica el estudio que proponemos. Entendemos que una propuesta más abarcadora, como la de Durão et al. (2014), sería igualmente interesante para un trabajo que se ocupara de los "falsos amigos". No obstante, la definición de Durão (2007) sobre los errores de sustitución, de la cual nos servimos para hacer la clasificación de los errores aquí encontrados, no incluye explícitamente los vocablos "heterotónicos", "heterogenéricos" u otros. Por otro lado, en este trabajo nos limitados a la esfera léxicosemántica y, por ende, los aspectos gramaticales no serán discutidos. En suma, la definición de "heterosemánticos", que asumimos en el presente estudio, se acerca bastante a la expuesta por Alvar Esquerra (2003):

Se trata de formas parecidas que poseen sentidos diferentes, incluso opuestos en alguna ocasión. Unas veces se trata, efectivamente, de palabras emparentadas en su origen, pero que en la evolución de las distintas lenguas o en el paso de unas a otras se pronuncian y escriben de distinta manera". (ALVAR ESQUERRA, 2003, p. 42)

Para finalizar, hay que añadir aún otra distinción que creemos relevante para el estudio del tipo de los vocablos que estamos discutiendo. Se trata de las consideraciones realizadas hace unos años por Humblé (2006). Este estudioso introduce en el debate una definicion de "falsos amigos" desde una perspectiva diferente a las que hemos visto hasta ahora, es decir, desde la 
perspectiva del uso comparado entre dos lenguas, y de la cual nos serviremos también. Para Humblé (2006, p. 198), el problema de los "falsos amigos" o "falsos cognados" es que son, en realidad, "palabras que suenan lo mismo, se escriben igual, significan lo mismo, pero se usan de una manera distinta". El autor se basa en un estudio comparativo de tres corpus español y portugués, y termina dividiendo dichos vocablos en cuatro grupos:

El primer tipo es el tradicional: dos palabras son casi idénticas, se escriben casi igual, se pronuncian casi igual, pero sus sentidos son diferentes. El ejemplo clásico es el de exquisito/esquisito.

El segundo tipo es el de palabras que también son casi idénticas, significan lo mismo, pero que se usan en registros diferentes. Es el caso de, por ejemplo, aclarar y esclarecer.

El tercer tipo es el de palabras que también son idénticas y significan grosso modo lo mismo, pero que tienen varias acepciones de las cuales una o algunas son diferentes. Es el caso de lástima.

El cuarto tipo es el de palabras que forman parejas en cada una de las lenguas, con acepciones aparentemente idénticas, pero que funcionan en realidad con restricciones gramaticales o léxicas diferentes. Es el caso de hablar/decir, falar/dizer. (HUMBLÉ, 2006, p. 198)

Sobre esta categorización, nos gustaría destacar un aspecto en especial. $Y$ es que, con su estudio, Humblé llama la atención sobre el hecho de que los "falsos amigos" o "falsos cognados" han sido tradicionalmente tratados como piezas léxicas aisladas. La importancia de investigar el uso de este grupo de vocablos y sus relaciones semánticas es crucial si queremos enseñarlos de manera efectiva, evitando así que se conviertan en una lista más de palabras, que no sirve más que para confundir a los estudiantes. En este sentido, estamos de acuerdo con el autor en que los "falsos amigos" (de acuerdo con nuestra definición, los "heterosemánticos") han sido interpretados de manera equivocada hasta el momento. Al respecto, basta con comprobar cómo los diccionarios especializados 
no dan cuenta de muchos vocablos que quienes estudiamos y enseñamos las lenguas española y portuguesa somos coscientes de que existen. En nuestro estudio veremos, por ejemplo, cómo los errores de sustitución por analogía tienen una presencia elevada, pese a lo cual, hasta un $42 \%$ de estos no consta en las obras lexicográficas consultadas (este número es relativo a los tres primeros tipos de heterosemánticos explicados por Humblé). Este hecho parece corroborar la idea de que necesitamos tratar este grupo de vocablos desde una perspectiva distinta.

Además de las tres clasificaciones citadas anteriormente, y que suman una importante cifra de vocablos que no hemos sido capaces de encontrar en las obras lexicográficas consultadas, hemos decidido incluir también una cuarta de este mismo autor, todavía menos frecuente en la bibliografía especializada. Incluir el último grupo citado por Humblé ("palabras que forman parejas en cada una de las lenguas, con acepciones aparentemente idénticas, pero que funcionan en realidad con restricciones gramaticales o léxicas diferentes") nos parecía fundamental, puesto que tales errores han tenido una gran recurrencia en nuestro estudio (un 33\% del total de los heterosemánticos). Este tipo de heterosemántico es poco explorado como tal, pero tiene indudablemente raíz en la interferenica de la lengua materna y por ello suscitaba un especial interés para nosotros. No obstante, aunque los hayamos identificado y clasificado, por motivos de tiempo y espacio no hemos podido darles el tratamiento deseado, tal como explicaremos más detalladamente en el Capítulo 7.

\subsection{Unidades fraseológicas}

Hemos encontrado un tercer grupo de transferencias en nuestra investigación referente a las unidades fraseológicas (UF), las cuales denominamos errores de substitución por calco, siguiendo la clasificación de Durão (2007).

\subsubsection{La fraseología y el fraseologismo}

Para Penadés Martínez (1999, p. 13), el nacimiento de la fraseología, disciplina que se dedica al estudio de las unidades 
fraseológicas, se produjo en 1905 con la obra de Charles Bally, pero empezó a desarrollarse propiamente a partir de 1928, con el lingüista soviético Polivanov, el cual concebía la fraseología como "una ciencia lingüística que debería ocuparse de los significados individuales de las expresiones fijas". Para Seco et al. (2004, p. XIII) el término "fraseología" hoy día da cuenta de:

(...) todas las combinaciones de palabras que, en su práctica del idioma, no son formadas libremente por el hablante, sino que se le dan ya prefabricadas, como "paquetes" que tienen en la lengua un valor propio establecido por el uso tradicional.

Las "unidades fraseológicas", son "las combinaciones de palabras que muestran un alto grado de fijación en su forma y en su significado" (PENADÉS MARTÍNEZ, 1999, p. 13). Conforme a la autora, muchas veces estas son vistas como sinónimo de "fraseologismo", y engloban un conjunto muy amplio de términos:

Dentro del conecpto recubierto por el término unidad fraseológica o fraseologismo se incluye tanto lo que tradicionalmente se ha denominado dichos, expresiones fijas, expresiones idiomáticas, expresiones sin más, frases, modismos, giros, fórmulas y también fórmulas proverbiales 0 fórmulas comunicativas, idiotismos, locuciones, modos de decir, frases hechas, refranes, adagios, proverbios 0 aforismos, como lo que más modernamente se ha llamado colocaciones, expresiones o unidades pluriverbales, lexicalizadas 0 habitualizadas, y unidades léxicas pluriverbales. (PENADÉS MARTíNEZ, 1999, p. 13)

Pese a que las "unidades fraseológicas" pueden ser, pues, muy variables, Penadés Martínez (1999) destaca que hay ciertas características comunes a todas ellas. La principal es que suponen siempre la combinación de palabras estables o fijas, de la cual se desprenden a su vez dos características marcadas: (i) la fijación formal; y (ii) la fijación semántica o idiomaticidad (PENADÉS MARTÍNEZ, 1999, p. 14-18). 
La fijación formal sería la imposibilidad de alterar los componentes y la relación sintáctica entre ellos. Un ejemplo de este tipo sería: a trancas y barrancas, que no admite a barrancas $y$ trancas. Asimismo, a partir de hay gato encerrado, no se admite hay gata encerrada. La autora (PENADÉS MARTíNEZ, 1999, p. 16) añade que existen cinco grados de fijación, que hay que entender de un modo relativo y no absoluto ${ }^{96}:$ 1) la posibilidad de intercalar elementos no pertenecientes a la combinación fija (ej. estaba a dos velas: estaba, según él, a dos velas y no podía comprar otro coche); 2) la potencial alteración del orden de los componentes (ej. lo mandé a freír espárragos / a freír espárragos lo mandé, por ser antipático y un soberbio); 3) la modificación léxica de alguno de ellos (ej. me dijo con la boca chica / chiquita que me quedara a cenar); 4) la transformación de algunos elementos (ej. puso de relieve la mala situación económica del país / la puesta de relieve de la mala situación económica fue muy criticada); y 5) la posible sustitución de estos (ej. le conté aquel chiste tan gracioso y se caía / moría de risa) (PENADÉS MARTÍNEZ, 1999, p. 16).

Por su parte, la fijación semántica o idiomaticidad se basa en que el sentido de las unidades fraseológicas no se establece a partir de la suma del significado individual de cada uno de sus componentes, sino de un todo unitario (PENADÉS MARTíNEZ 1999). Este principio revela que la fijación tiene estrecha relación con la semántica, dónde los elementos combinados, aunque sean signos lingüísticos aislables en el sistema lingüístico, en combinación uno con el otro, acaban perdiendo su identidad para construir una "unidad de sentido". Lo vemos, por ejemplo, en la UF "comer(se) con los ojos a alguien". Así, en "Juan se come a su novia con los ojos" (PENADÉS MARTíNEZ, 1999, p. 17), el significado de la expresión no se deriva de la adición significativa de las diferentes palabras, sino que es otro bien distinto, no relacionado con el literal.

No obstante, el principio de idiomaticidad también es relativo, puesto que no todas las unidades fraseológicas son, necesariamente, idiomáticas. Veamos otro ejemplo con "brazos abiertos": "nuestros tíos nos recibieron con los brazos abiertos". En este ejemplo, el principio semántico descrito anteriormente se rompe, puesto que el significado de la expresión no es ni literal ni tampoco es un todo semánticamente hablando (PENADÉS MARTÍNEZ, 1999, p. 18).

\footnotetext{
${ }^{96}$ Sobre la fijación formal, Seco et al. (2004, p. XVI) advierten también que esta se rompe con frecuencia, y, por tanto, no debe interpretarse de forma absoluta.
} 
En definitiva, para la autora, tanto la fijación formal como la semántica solo deben entenderse de una manera relativa y nunca absoluta (PENADÉS MARTÍNEZ, 1999, p. 18). En otras palabras, es a través de la combinación y, por tanto, de los diferentes grados que pueden alcanzar estos dos parámetros como podemos entender la fraseología. Por otro lado, hay una ordenación jerárquica entre la fijación formal y la semántica, por la que la segunda va necesariamente unida a la primera (ej. dos velas: estaba a dos velas y no podía comprar otro coche ${ }^{97}$ ). Sin embargo, la fijación formal no necesariamente acompaña a la semántica (ej. lo dicho, dicho: insistió que en lo dicho, dicho y no modificó el contenido del escrito ${ }^{98}$ ). Finalmente, cabe señalar que una unidad fraseológica puede estar constituida por un significado que no es literal ni idiomático (ej. brazos abiertos: nuestros tíos nos recibieron con los brazos abiertos) (PENADÉS MARTíNEZ, 1999, p. 18).

Como vemos, las características de las UF hacen complicado encontrar una definición y una clasificación que satisfaga de forma unánime a toda la comunidad científica. Al mismo tiempo, la complejidad intrínseca de estas unidades las convierte en piezas léxicas complicadas para el aprendizaje, tanto de los alumnos como incluso, de muchos profesores. Quizá por ello Alvar Ezquerra (2003, p. 79) se refiere a la investigación de las unidades pluriverbales como "uno de los capítulos más intrincados en la investigación lingüística”.

\subsubsection{Las expresiones idiomáticas}

De los diferentes tipos de UF que pueden encontrarse en la fraseología, en nuestro estudio nos ocuparemos específicamente de las locuciones, las cuales, entendemos, son las que están incluidas en los errores de producción por calco, según la clasificación de Durão (2007). Seco et al. (2004) definen así las "locuciones en el sentido estricto" en la introducción de su Diccionario fraseológico documentado del español actual: locuciones y modismos españoles:

(...) agrupaciones más o menos fijas de palabras; conjuntos que tienen su función gramatical (nombre, pronombre, adjetivo, verbo,

${ }^{97}$ (PENADÉS MARTÍNEZ, 1999, p. 16)

${ }^{98}$ (PENADÉS MARTÍNEZ, 1999, p. 18) 
adverbio, preposición, etc.) como la tienen las palabras individuales; y que también, como si fuesen palabras individuales, tienen un valor estable propio. Este valor no es la suma de los valores de sus componentes. (SECO ET AL., 2004, p. XII)

En la misma medida que Seco, Penadés Martínez (1999, p. 21) argumenta que es común clasificar las locuciones en función del papel que asumen en la oración, función esta que suele ser relativa a la clase de palabra que corresponde al elemento básico de una locución o de su paráfrasis definitoria. De esta manera, podemos decir que hay tantas clases de locuciones como clases de palabras se reconocen en una lengua (ej. locuciones nominales: curva de la felicidad; adjetivas: ligero de cascos; pronominales: alma viviente; verbales: darse de bofetadas; adverbiales: a coro; prepositivas: en pos de; conjuntivas: ahora bien).

Volviendo a la definición de Seco et al., hay que destacar que estos autores incluyen las colocaciones en el grupo de las locuciones, más específicamente en lo que llaman "locuciones en el sentido amplio", esto es, "combinaciones que tienen algún aspecto en común con las estrictas" (SECO ET AL., 2004, p. XVI) ${ }^{99}$ :

Entre ellas están las asociaciones muy habituales, es decir, prácticamente fijas (en la lingüística se llaman colocaciones), de determinado nombre con determinado verbo, de tal verbo con tal adverbio, etc. En que al menos una de las palabras componentes conserva su significado propio, pero que -igual que las locuciones estrictas- se insertan en el enunciado como un bloque unitario (SECO ET AL., 2004, p. XVI-XVII).

Sin embargo, en el seno de la fraseología, otros autores defienden que hay diferencias substanciales entre locuciones y colocaciones y, por ello, no deberían figurar en el mismo grupo (TAGNIN, 1989, apud BAPTISTA, 2006; CORPAS PASTOR apud

\footnotetext{
${ }^{99}$ Estas últimas serían las definidas anteriormente, esto es, las agrupaciones más o menos fijas de palabras que tienen una función gramatical y un sentido estable propios, no siendo este último la suma de los significados de sus componentes.
} 
PENADÉS MATÍNEZ, 1999; ALVAR EZQUERRA, 2003; HIGUERAS GARCÍA, 2006). Como señala Gómez Molina (2004b, p. 791), existe cierta controversia con respecto a la clasificacion de las unidades pluriverbales, puesto que las diferentes clasificaciones propuestas en la bibliografía están estrechamente liagadas a la concepción de los diferentes grupos de unidades. Para el autor, tal diversidad no favorece el concenso entre los investigadores, lo que deriva en una taxonomía demasiado prolija. El mismo autor clasifica las colocaciones y las expresiones como pertenecientes al grupo de las "expresiones hechas".

Nosotros no entraremos aquí en esta discusión, puesto que consideramos que no es esencial para nuestro estudio. Esto quiere decir que, en el análisis de errores de interferencia que utilizaremos en el presente estudio no haremos distinción explícita entre locuciones y colocaciones, una vez que, como hemos mencionado anteriormente, entendemos que estos dos grupos de UF están incluidos en la clasificación de Durão (2007) para los errores de calco de la que partimos. Durão (2007, p. 40) ${ }^{100}$ define los errores de calco como "prestamos de oraciones cortas o de las expresiones extranjeras". Entendemos, por lo tanto, que con "expresiones extranjeras" la autora se refiere a las "locuciones", y con "oraciones cortas" a lo que Seco et al. (2004, p. XVII) llaman "fórmulas oracionales", es decir:

(...) enunciados de forma fija y sentido peculiar que - a diferencia de las locuciones - no están integrados dentro de una oración funcionando en ella como palabras (nombre, verbo, etc.), sino que funcionan como oraciones por sí mismas $(\ldots)$

Los autores ponen como ejemplo algunas oraciones como: "la verdad es que en todas las partes cuecen habas" (SECO ET AL. 2004 , p. XVII). Aunque estas formen parte de los errores de calco en nuestra clasificación, tales "formulas oracionales" no se encontraron en nuestro estudio, así que trataremos específicamente de las "locuciones".

${ }^{100}$ Una revisión amplia de las colocaciones y su enseñanza a estudiantes de ELE puede hallarse en (HIGUERAS GARCÍA, 2006), quien ha dedicado un trabajo monográfico sobre el tema, y ha puesto también de manifiesto las dificultades que supone definir tanto el concepto como su alcance en los estudios de lingüística y didáctica. 
Algunos tipos de locuciones también se suelen denominar "expresiones idiomáticas" (EI). Estas son, según la definición de Zualaga (1980 apud BAPTISTA, et al., 2005, p. 44) "construcciones cortas que dan un alto relieve al mensaje, texto o al segmento de texto en que se empleen" (ej. un mar de gente ${ }^{101}$ ). Estas "tienen, pues, un sentido literal - la imagen - y un sentido metafórico idiomático o semiidiomático". Además, presentan las siguientes características:

1) son parte del saber lingüístico de la comunidad.

2) están institucionalizadas, estandarizadas y convencionalizadas.

3) son fijadas arbitrariamente por el uso repetido en la comunidad lingüística respectiva, es decir, son reproducidas en el habla como construcciones previamente hechas.

4) las define alguna forma de fijación, es decir, en las unidades fraseológicas está suspendida alguna regla de combinación de los elementos del discurso.

5) se destacan por su estructura material, por su iconicidad y por sus rasgos semánticos peculiares, por comentarios metalingüísticos y por emplearse en forma recortada. (ZUALAGA, 1980 apud BAPTISTA, et al., 2005, p. 43)

Para Xatara (2001), la función de las expresiones idiomáticas (EI) tiene en todos los casos un denominador común, que nosotros aquí denominamos "pragmatismo":

Essas substituições justificam-se pelo prazer de valorizar o pitoresco, de colorir o comum, de ressaltar o gosto do trivial, e, nos termos de Grice (apud Green, 1989), de violar intencionalmente ao menos uma máxima do princípio cooperativo numa interação linguística, a de ser claro, acabando por serem os idiomatismos um circunlóquio das lexias simples, que exigem do interlocutor

${ }^{101}$ (PENADÉS MARTÍNEZ, 1999, p. 21) 
envolvimento com a conotação. (XATARA,

En el caso específico de nuestro estudio, nos hemos percatado de que los errores relacionados con las unidades fraseológicas tienen que ver en su mayoría con la traducción literal de aquellas expresiones existentes en el portugués, las cuales no siempre coinciden con el español. Tales peculiaridades serán abordadas específicamente en el Capítulo 7.

\subsubsection{Enseñanza y aprendizaje de las Unidades Fraseológicas}

Xatara (2001, p. 58) defiende que el conocimiento lexical es esencial puesto que revela con mayor propiedad cuestiones culturales, sistemas de valores, patrones de los hablantes nativos, etc. Las expresiones idiomáticas son parte del saber común y expresan sentimientos, emociones, estilos de pensamiento de los hablantes nativos, piezas fundamentales para los aprendices de lenguas extranjeras acerca de la cultura relacionada con la lengua que están aprendiendo (XATARA, 2001, p. 58). Para la autora, al conocer las $\mathrm{El}$, los estudiantes están ampliando su capacidad comunicativa, con lo que están más cerca de dominar cabalmente una importante parcela del léxico de la LO.

En el mismo sentido, Baptista et al. (2005, p. 44) argumentan:

(...) conviene insistir en que el conocimiento y el empleo adecuado de las expresiones idiomáticas implican el dominio y habilidad de uso de ciertas reglas de organización y adecuación discursiva y pragmática de la lengua. Por otra parte, al conocer y al emplear las expresiones idiomáticas el aprendiz logrará

\footnotetext{
102 Estas sustituciones se justifican por el placer de valorar lo pintoresco, de colorear lo común, resaltar el gusto de lo trivial, y, en los términos de Grice (apud Green, 1989), de violar intencionalmente al menos una máxima del principio cooperativo en la interacción lingüística, la de ser claros, siendo finalmente los idiomatismos un circunloquio de las lexías simples, que requieren del interlocutor envolvimiento con la connotación.
} 
interpretar cómo cambian los sentidos, no se restringirá a una comprensión literal, muchas veces equivocada, de determinados términos.

También Alvar Esquerra (2003, p. 81) destaca que las unidades pluriverbales se presentan en cualquier nivel de la lengua, lo que hace imprescindible su enseñanza. El autor recuerda también que su presencia no es la misma en la lengua escrita que en la hablada, siendo mucho más recurrente en esta última, lo que refuerza la necesidad de que los aprendices las conozcan para facilitar la comunicación.

Además, Alvar Esquerra (2003, p. 81) argumenta que la enseñanza de estas unidades plantea una serie de problemas al profesor, puesto que, aunque son frecuentes en el habla, aun no existen estudios precisos que definan cuáles son las más habituales, ni su adscripción a la lengua oral o escrita. Recae así sobre el profesor decidir cuáles, cuándo y cómo enseñarlas de acuerdo con los intereses y niveles de los alumnos, así como de los materiales didácticos disponibles, como libros de textos, ejercicios, diccionarios, corpus etc., sin olvidar su propia experiencia docente (ALVAR ESQUERRA, 2003, p. 86). En todo caso, de algunos estudios, como el de Ruiz Gurillo (1994, apud ALVAR ESQUERRA, 2003, p. 86), parece desprenderse la escasa utilidad de enseñar estas unidades en los niveles elementales o intermedios, debiendo ser reservadas preferentemente para los más avanzados.

Contraria a esta visión es, sin embargo, Xatara (2001), quien propone una clasificación de las expresiones idiomáticas del francés aplicada a la enseñanza a estudiantes brasileños. A partir de esta clasificación, presenta una serie de ejercicios basados en su grado de dificultad, que incluye los niveles lingüísticos más elementales, el de los llamados "falsos principiantes"103. En lo que concierne a la enseñanza del español, Baptista (2006, p. 4), con base en la clasificación de Xatara, elabora cuatro grados o niveles de dificultad en el aprendizaje de las expresiones idiomáticas por parte de lusohablantes aprendices de español:

1. Expresiones de grado o nivel 1: se incluyen en ese nivel aquellas expresiones idiomáticas que tienen tanto equivalencia

${ }^{103}$ En el Capítulo 3 hemos abordado el concepto de "falsos principiantes" en el aprendizaje de las lenguas próximas. 
literal como idiomática en lengua portuguesa. En español y en portugués son construcciones con correspondencia exacta, es decir, con estructura idéntica o de fácil comprensión y debido a esas características suponen un menor grado de dificultad en términos de enseñanza y de aprendizaje. Por ejemplo: abrir puertas/ abrir portas.

2. Expresiones de grado o nivel 2: presentan equivalencia semejante en portugués, sin embargo no poseen equivalencia lexical total 0 literal en esa lengua, sino aproximada. Además de eso, no sufren cambio en la estructura, en el nivel de lenguaje, en el valor 0 en el efecto comunicativo presentes en español. Por ejemplo: hacer la vista gorda/ fazer vista grossa.

3. Expresiones de grado o nivel 3: se pueden traducir al portugués por una expresión idiomática, aunque de estructura sintáctica y/o unidades lexicales muy diferentes de las que hay en español. Representan una dificultad más acentuada de comprensión y, por lo tanto, suponen una cierta dificultad para la enseñanza y el aprendizaje. Por ejemplo: agarrarse a un clavo ardiendo/ fazer qualquer negócio.

4. Expresiones de grado o nivel 4: no tienen equivalencia idiomática en lengua portuguesa y, por ello, hay que traducirlas por medio de paráfrasis o aclararlas a través de explicaciones o analogías. De ahí que su comprensión puede resultar más compleja y por eso presentarán mayor dificultad en términos de enseñanza y aprendizaje. Por ejemplo: volver a las andadas/cometer os mesmos erros.

La autora, que tiene una dilatada experiencia en la investigación sobre la enseñanza-aprendizaje de las UF por aprendices brasileños de español, propone que estas se enseñen de acuerdo con los diferentes niveles descritos arriba y también que lo hagan a través de cuatro etapas complementarias: a) presentación; b) comprensión; c) utilización; y d) memorización. Todas ellas son etapas que, por 
motivos de espacio, no desarrollaremos aquí, pero que nos parecen de gran importancia para la enseñanza-aprendizaje de dos lenguas próximas como el portugués y el español.

\subsection{En conclusión}

En este capítulo hemos hecho un recorrido por los principales puntos en los que nos apoyamos para el tratamiento de los errores léxicos de nuestro estudio. Al realizar una revisión de estas características, nos hemos topado con infinidad de temas posibles en la investigación del léxico, los cuales están lejos de agotarse, dada la proliferación de estudios sobre el tema en los últimos años.

Así, hemos empezado esbozando los principios de la formación de palabras que abordaremos aquí, como la sufijación o la prefijación. Hemos subrayado también que la formación de palabras está relacionada a la creación de nuevos vocablos con base en la combinación de las reglas de ambas lenguas y que es a partir del análisis contrastivo como podremos entender tales creaciones.

En un segundo momento, hemos discutido sobre la variedad terminológica en torno a conceptos habituales en la lexicografía, como falsos amigos, falsos cognados y heterosemánticos, términos que suelen ser usados como sinónimos, pero que en realidad no lo son. Eso ocurre en parte porque surgen de diferentes perspectivas, en las cuales no siempre se tiene en cuenta el origen etimológico de los vocablos. Y al respecto, hemos indicado que la definición que más se ajusta a los objetivos de nuestro trabajo es la de "heterosemántico", puesto que incluye tanto a los términos etimológicamente cercanos como a los no cercanos. En concreto, el grupo de los heterosemánticos forman parte de los errores de analogía en nuestra categorización.

En este capítulo hemos abarcado también los conceptos de unidad fraseológica y locución. Hemos visto que las primeras dependen del grado de fijación formal y semántica, principios relativos y complejos que hacen de las UF un campo intrincado tanto para los investigadores como (todavía más) para los aprendices de lenguas extranjeras. De la misma manera, la definición en torno a las locuciones tampoco está exenta de controversia. Los errores de calco, que tratamos según la definición de Durão (2007), abarcan tanto las locuciones como las colocaciones, motivo por el cual abarcaremos ambas categorías en este grupo. 
Por último, hemos realizado también un breve recorrido por las características de la enseñanza/aprendizaje de las UF. Respecto a esto, somos conscientes de que, como ya defendía Baralo (2005, p. 1), conocer un ítem léxico por parte de un no nativo requiere de un proceso lento y gradual, formado por una intrincada red de relaciones, ya sean formales y/o semánticas, en las cuales se aprende tanto el significado como la forma. Este complejo proceso requiere diferentes habilidades y está ligado a otros tantos conocimientos necesarios para su funcionamiento.

No obstante, nos gustaría hacer hincapié aquí en que el objetivo de este apartado es el de delimitar conceptos y especificidades de los errores que tratamos, y no entrar en disquisiciones más generales sobre la adquisición y desarrollo del lexicón o la competencia léxica, ya sea de hablantes nativos o extranjeros $^{104}$. En otras palabras, el objetivo es fundamentar teóricamente los grupos de errores que hemos categorizado en el capítulo anterior, donde hemos definido la clasificación que utilizamos para el análisis. Estos presupuestos teóricos se resumen ahora en la tabla siguiente:

\begin{tabular}{|c|c|c|}
\hline \multirow{5}{*}{ 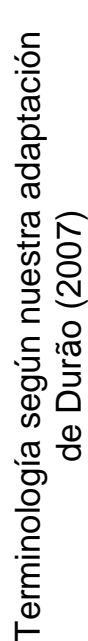 } & \multirow[t]{2}{*}{$\begin{array}{l}\text { Errores } \\
\text { substitución }\end{array}$} & \multirow{2}{*}{$\begin{array}{l}\text { Directa } \\
\text { (uso de vocablos de la } L M \text { en la } \\
\text { LO) } \\
\text { Analogía } \\
\text { (uso de heterosemánticos en la } \\
\text { LO) }\end{array}$} \\
\hline & & \\
\hline & \multirow[t]{2}{*}{$\begin{array}{l}\text { Errores de creación } \\
\text { de palabra nueva }\end{array}$} & $\begin{array}{l}\text { Creación original } \\
\text { (creación de vocablos a partir de } \\
\text { las reglas de formación de } \\
\text { palabras de la } L M \text { y } L O \text { ) }\end{array}$ \\
\hline & & $\begin{array}{l}\text { Traducción prestada } \\
\text { (creación de vocablos a partir de } \\
\text { la traducción de la } L M \text { ) }\end{array}$ \\
\hline & \multicolumn{2}{|c|}{$\begin{array}{l}\text { Errores de calco } \\
\text { (UF traducidas o creadas con base en la LM) }\end{array}$} \\
\hline
\end{tabular}

\footnotetext{
${ }^{104}$ Para estos temas existe una vasta bibliografía, entre cuyos trabajos destacan los de Baralo (1997; 2005; 2007) y Gómez Molina (2004a; 2004b).
} 
Tabla 14: Errores léxicos de interferencia considerados en nuestro estudio.

Para terminar, nos gustaría subrayar la existencia de un grupo particular de interferencias léxicas. Nos referimos al primer tipo de errores que aparece en la tabla 15, los de "sustitución directa", y que en nuestro estudio figuran como los errores más frecuentes. El motivo de no haber discutido este tipo de interferencia en el presente apartado es que las transferencias directas (vocablos intrínsecos de la LM utilizados directamente y sin filtro alguno en la LO) no caracterizan por sí mismas ningún grupo específico estudiado por la lexicología, a diferencia de las demás categorías presentadas en este capítulo, como los diferentes mecanismos de formación de palabras, los heterosemánticos 0 las unidades fraseológicas. Por otro lado, desde el punto de vista de la lingüística aplicada, son errores léxicos muy frecuentes en la interlengua de los aprendices de LE/L2, y su uso masivo demuestra la relativa insuficiencia en el conocimiento lexical de la LO. Como hemos señalado anteriormente, se trata de errores muy recurrentes también en nuestro estudio, razón por la cual serán examinados con detalle en un apartado posterior (Capítulo 7).

Pasaremos ahora al segundo bloque de la tesis, en el cual tratamos los aspectos metodológicos y empíricos específicos de nuestro estudio. 
222 


\section{ASPECTOS METODOLÓGICOS}

En este capítulo tenemos como objetivo dilucidar los principales aspectos metodológicos utilizados en cada etapa del estudio, desde la recogida de los datos hasta la selección y clasificación de los errores que conforman la muestra. En un primer momento, analizaremos las características generales que fundamentan los estudios de análisis de errores y análisis contrastivo como el nuestro (subapartado 6.1), seguido de la presentación de los informantes (subapartado 6.2). A continuación, procederemos a exponer las propiedades del corpus (subapartado 6.3) y revisaremos los procesos de identificación y descripción de los errores (subapartado 6.4). Por último, expondremos las principales características de las obras lexicográficas seleccionadas para los análisis de contraste lingüístico (subapartado 6.5).

\subsection{Metodología del análisis de errores}

Presentaremos en este aparato las características metodológicas del análisis de errores, las cuales fundamentan nuestra investigación. Según Santos Gargallo (2004, p. 399), investigadora que dedica un ensayo a la metodología del análisis de errores, "el método o metodología adoptado para desarrollar una investigación constituye el instrumento abstracto que garantiza su cientificidad y la diferencia de una aportación intuitiva". Mediante estas características abstractas ${ }^{105}$ se garantiza el carácter generalizable y replicable de una investigación. El carácter generalizable hace referencia a la representatividad del mundo real, a través del marco y el corpus de la investigación, mientras que el carácter replicable respalda que un estudio pueda ser repetido con la mayor exactitud posible por otros investigadores (SANTOS GARGALLO, 2004, p. 399).

Esta autora recuerda también que el análisis de errores presenta características de los paradigmas cualitativos y cuantitativos. Esto ocurre porque:

\footnotetext{
${ }^{105}$ La autora establece una diferenciación entre las características abstractas y los instrumentos, los cuáles explicaremos más adelante.
} 
(...) por un lado, estudia la recurrencia numérica de errores y establece una jerarquía de dificultades y, por otro lado, describe, explica y evalúa la cualidad de los mismos para llegar a un conocimiento profundo de los procesos psicológicos subyacentes y para que estos procesos puedan ser contrastados con los procedimientos didácticos. (SANTOS GARGALLO, 2004, p. 399)

Asimismo, el análisis de errores se ubica en el entorno de los estudios de caso, en los cuales se describe la actuación lingüística de los sujetos, con el objetivo tanto de generalizar las conclusiones a la población general como de establecer hipótesis para el desarrollo de investigaciones adicionales (SANTOS GARGALLO, 2004, p. 400). Por tanto, una investigación de esta envergadura deberá seguir una serie de etapas, como las descritas a continuación ${ }^{106}$ (SANTOS GARGALLO, 2004, p. 400), y que recogen fielmente lo que hemos hecho en este trabajo: ${ }^{107}$
a) Compilación del corpus de datos;
b) Identificación de los errores;
c) Descripción de los errores;
d) Clasificación de acuerdo con una taxonomía;
e) Explicación de los errores;
f) Evaluación de los errores;
g) Discusión de los resultados;
h) Implicaciones didácticas para implementar el proceso de enseñanza-aprendizaje.

Además, los estudios de $\mathrm{AE}$ pueden ser diacrónicos 0 sincrónicos (ALBA QUIÑONES, 2009, p. 4). Autores como Ellis (2008, p. 61) han alzado la voz sobre las limitaciones de los trabajos

\footnotetext{
106 Así, como recuerda Fernández (1997, p. 49), la metodología del AE es deudora principalmente de los trabajos de Corder (1971, 1972, 1973), Johansson (1973), Jain (1974), Porquier (1977), Dulay, Burt y Krashen (1982), Slama-Cazacu (1974) y Doca (1981). Basándose en estos trabajos, la autora cita cinco pasos (identificación del error en su contexto, clasificación, descripción, explicación, valoración de la gravedad), los cuales más tarde se amplían a ocho, como los que propone Santo Gargallo (2004).

107 Con la excepción de la etapa " $\mathrm{f}$ " (evaluación de los errores), la cual hace referencia a la gravedad de los errores, algo que no forma parte de nuestros objetivos. Para más información sobre este paso, véase Fernández (1997, p. 31).
} 
sincrónicos con base en el $\mathrm{AE}$, puesto que delimitan los errores de los aprendices en un determinado espacio del tiempo, cuando lo más interesante para la investigación de la enseñanza de lenguas extranjeras sería determinar de qué manera evoluciona el conocimiento de la LE y de la interlengua. Sin embargo, verificar los errores encontrados en el discurso oral de nuestros sujetos desde una perspectiva sincrónica es exactamente el objetivo de esta investigación, pues estos ya no son estudiantes de una lengua extranjera, pero sí la enseñan, de ahí que un estudio diacrónico no tendría demasiado sentido para lo que nos proponemos a hacer. De esta manera, creemos que la metodología de la AE con base en los estudios sincrónicos es la más adecuada para el tipo de análisis que queremos llevar a cabo.

Así, establecidas las bases metodológicas de carácter "abstracto" de nuestra investigación, se hace necesario señalar sus instrumentos, es decir, aquellas técnicas y procedimientos que posibilitan que se realicen las observaciones y el análisis de errores de la interlengua de los sujetos del estudio (SANTOS GARGALLO, 2004, p. 400). A continuación los examinaremos con detalle, empezando por la descripción de la población estudiada y siguiendo por la identificación de los instrumentos y las especificaciones relativas a la primera etapa mencionada por Santos Gargallo: la compilación del corpus de datos.

\subsection{Población}

La población estudiada está integrada por nueve docentes de español como lengua extranjera. En un principio contábamos con un total de diez profesoras, aunque después de realizadas las entrevistas descartamos a una de ellas, puesto que no tenía el mismo perfil formativo que las demás.

Las 9 participantes del estudio provienen de dos localidades de la región sur de Brasil (ljuí y Panambí, en el estado de Rio Grande do Sul). Hasta donde llega nuestro conocimiento, ocho de las nueve participantes (todas de sexo femenino) representaban casi la totalidad de las profesoras de español en centros de enseñanza básica y media de la localidad de ljúí en el momento de la recogida de los datos ${ }^{108}$. Apenas una docente de esta plantilla no pudo ser contactada por la investigadora. En un primer momento, también

\footnotetext{
${ }^{108}$ Hacemos referencia a los docentes nativos brasileños actuantes en tales localidades en la enseñanza formal.
} 
participaron las dos -y únicas- profesoras del municipio vecino de Panambí, aunque una de ellas tuvo que ser descartada posteriormente por los motivos esgrimidos más arriba. En resumen, la muestra global se compone de 8 participantes de ljuí y 1 de Panambí.

El contacto inicial con los sujetos de la investigación se llevó a cabo de una manera informal, ya que eran conocidos de la investigadora al haber sido compañeras de grado en el pasado. Por su parte, algunas de estas participantes iniciales se ofrecieron a ayudarnos a contactar con otros compañeros de profesión para participar en el estudio.

\subsubsection{Perfil sociológico, formativo y profesional ${ }^{109}$}

Los sujetos seleccionados para la investigación trabajan en centros de enseñanza reglada de dos localidades de la región sur de Brasil, de la provincia de Rio Grande do Sul. Todos ellos pertenecen al género femenino, son naturales de la misma región, y tenían edades entre 29 y 51 años en el momento de la realización de las entrevistas (2012). Estos datos se especifican en el cuadro a continuación.

\begin{tabular}{cccccccccc}
\hline Sujeto & D1 & D2 & D3 & D4 & D5 & D6 & D7 & D8 & D9 \\
\hline Edad & 29 & 47 & 33 & 30 & 30 & 31 & 34 & 29 & 54 \\
Género & fem & fem & fem & fem & fem & fem & fem & fem & fem \\
\hline
\end{tabular}

Tabla 15: Perfil de los sujetos I.

En relación con la experiencia docente previa, en el momento de la recolección de datos, las docentes llevaban entre uno y catorce años de profesión, ejerciendo entre 2 y 40 horas de clase semanales. A pesar de estar todas ellas graduadas, algunas estuvieron algunos años sin ejercer la profesión y sin apenas contacto con la lengua española, lo que, en opinión de las entrevistadas, supuso un gran inconveniente en su incorporación al mercado laboral, por falta de familiaridad con la lengua (es el caso de las docentes D1; D3 y D6). Otras, sin embargo, empezaron a

${ }^{109}$ Los datos extraídos para esta sección provienen de las respuestas de los sujetos obtenidas en la entrevista oral llevada a cabo para la compilación del corpus (segundo contexto de recogida). 
ejercer la profesión antes de finalizar la carrera (D2; D7; D8; D9). Los centros donde se grabaron las clases son todos ellos de educación primaria y secundaria, tanto privados y públicos. En la tabla 16 encontramos tales informaciones de manera detallada:

\begin{tabular}{ccccccccccc}
\hline Sujeto & D1 & D2 & D3 & D4 & D5 & D6 & D7 & D8 & D9 \\
\hline $\begin{array}{c}\text { Institu } \\
\text { ción }\end{array}$ & Púb & Púb & Púb & Púb & Priv & Priv & Priv & Púb & Púb \\
$\begin{array}{c}\text { Horas } \\
\text { /clase }\end{array}$ & 28 & 40 & 20 & 40 & 16 & 2 & 34 & 22 & 40 \\
$\begin{array}{c}\text { semanales } \\
\text { Años de } \\
\text { profesión } \\
\text { Año del } \\
\text { termi } \\
\text { no carrera }\end{array}$ & 2008 & 2002 & 2002 & 2003 & 2006 & 2005 & 2004 & 2006 & 2003 \\
\hline
\end{tabular}

Tabla 16: Perfil de los sujetos II.

En cuanto al nivel formativo inicial, una característica común al grupo seleccionado es que los sujetos han cursado la misma carrera $^{110}$, en la misma universidad y con prácticamente los mismos profesores de lengua; incluso algunas de ellas han sido compañeras de clase. La mayoría (7 de 9) declara que ha aprendido español como lengua extranjera mediante las asignaturas del grado, aunque algunas habían recibido algunas nociones básicas de la lengua en el colegio (D1; D6), en cursos de idiomas (D7), o bien viviendo o visitando países de lengua española (D2 y D4). Solamente una de las docentes manifiesta tener un nivel alto de lengua (D9), habiendo aprendido la LE en una escuela de idiomas durante cuatro años. Como es sabido, en Brasil, el acceso a la carrera sin conocimiento previo de la LE es posible porque no se exige un nivel mínimo para acceder a los estudios universitarios. Las diferencias respecto al nivel de conocimiento declarado por ellas mismas ${ }^{111}$ al ingresar en la

\footnotetext{
${ }^{110}$ La carrera se llamaba Licenciatura em língua estrangeira - espanhol, en la Universidade Regional do Noroeste do Estado do Rio Grande do Sul - UNIJUÍ. En una primera versión contaba con 3 años de estudio, aunque luego se reformó con un programa nuevo en el que se incluía un año académico adicional. Actualmente, es un curso extinguido por dicha institución de enseñanza superior.

${ }^{111}$ Nivel subjetivo declarado por las entrevistadas con base en su conocimiento de la LE, es decir, sin una certificación oficial.
} 
universidad están plasmadas en la tabla 17, así como la duración del grado que cursaron:

\begin{tabular}{cccccccccc}
\hline Sujeto & D1 & D2 & D3 & D4 & D5 & D6 & D7 & D8 & D9 \\
\hline $\begin{array}{c}\text { Nivel } \\
\begin{array}{c}\text { lingüístico al } \\
\text { empezar la } \\
\text { carrera }\end{array}\end{array}$ & $\begin{array}{c}\text { bási } \\
\text { co }\end{array}$ & $\begin{array}{c}\text { me } \\
\text { dio }\end{array}$ & $\begin{array}{c}\text { nin } \\
\text { guno }\end{array}$ & $\begin{array}{c}\text { bási } \\
\text { co }\end{array}$ & $\begin{array}{c}\text { nin } \\
\text { guno }\end{array}$ & $\begin{array}{c}\text { bási } \\
\text { co }\end{array}$ & $\begin{array}{c}\text { me } \\
\text { dio }\end{array}$ & $\begin{array}{c}\text { nin } \\
\text { guno }\end{array}$ & alto \\
$\begin{array}{c}\text { Duración del } \\
\text { grado en } \\
\text { años }\end{array}$ & 4 & 3 & 3 & 3 & 4 & 4 & 4 & 4 & 3 \\
\hline
\end{tabular}

Tabla 17: Perfil de los sujetos IIII.

Respecto a este último aspecto, observamos que algunas de las docentes (D2; D3; D4; D9) cursaron una primera versión del grado, en la que se impartían tan solo 3 años y en la que apenas había 6 asignaturas donde la lengua española era objeto de estudio (específicamente, 360 horas). En este programa, había otras tres asignaturas adicionales que incluían el uso de la lengua española de alguna otra forma (en concreto, dos de literatura y una más referente a temas de cultura general), las cuales sumaban otras 180 horas de curso. En total, este primer programa ofrecía 9 asignaturas referentes a la lengua, literatura o temas culturales hispanos, con una carga horaria de 540 horas.

Otras docentes (D1; D5; D6; D7; D8) cursaron una nueva versión del grado, en la cual este se amplió a un año más. En esta nueva versión, había ya un total de 8 asignaturas de lengua española, (con un total de 560 horas de case) y otras 6 adicionales en las que el español se convertía en vehículo de comunicación (estas sumaban en total 360 horas clase más, dos referentes a la producción y comprensión textual en ELE, otra sobre fonética y fonología, una más relacionada con los tópicos de la cultura española y, finalmente, otras dos de literatura). En total, este nuevo programa ofrecía, pues, 14 asignaturas -en lugar de las 9 anteriores-, en las cuales la lengua española era bien el objeto de estudio, bien su principal instrumento. Todo ello se traducía en un volumen importante de horas (920), lo que representaba un $70 \%$ más en relación con el plan de estudios anterior. Ambos programas se pueden ver en el Anexo 1, dónde presentamos las listas de asignaturas de cada uno.

Los datos sobre el perfil formativo de los sujetos son de gran relevancia para nuestra investigación, ya que, si por un lado hubo 
una cierta homogeneidad en cuanto a la formación inicial de las docentes, puesto que estudiaron en los mismos programas de grado, coincidiendo incluso con los mismos profesores, por otro, tenemos dos variantes de un mismo programa, con diferencias importantes en cuanto al número de horas de exposición a la lengua española.

En cuanto a la formación continuada, posterior a la conclusión del grado, cinco de las docentes han revelado estar en posesión de algún tipo de posgrado ${ }^{112}$ en el área de la educación o las letras, aunque no necesariamente relacionado con la lengua española. A saber: D1: posgrado en Metodología de la enseñanza de portugués y lengua extranjera; D3: posgrado en Enseñanza de lenguas extranjeras - español, y cursando en el momento de la entrevista el posgrado en Gestión escolar; D5: cursando posgrado en Neuropsicopedagogía; D7: posgrado en Psicopedagogía; D8: posgrado en Enseñanza de lenguas extranjeras - español.

Estos y otros detalles relativos a la formación de las docentes se incluyen en la tabla siguiente. En ella se puede ver cómo, en relación al contacto con la lengua fuera de su comunidad, dos de ellas nunca habían tenido contacto alguno con un hablante nativo de lengua española (D4; D5) y las demás confiesan tener muy poco o ninguno con hablantes nativos y solo en raras oportunidades pueden utilizar el español como vehículo de comunicación. Ninguna de las profesoras declara haber realizado cursos de formación en países de habla extranjera y apenas una de ellas ha residido en un país de habla hispana, lo que hizo por un período siete años (D2).

\begin{tabular}{cccccccccc}
\hline Sujeto & D1 & D2 & D3 & D4 & D5 & D6 & D7 & D8 & D9 \\
\hline $\begin{array}{c}\text { Posgra } \\
\text { do }\end{array}$ & sí & no & sí & no & no & no & no & sí & no \\
$\begin{array}{c}\text { relacion } \\
\text { ado con } \\
\text { la LE }\end{array}$ & & & & & & & & & \\
$\begin{array}{c}\text { Forma } \\
\text { ción en } \\
\text { el extran }\end{array}$ & no & no & no & no & no & no & no & no & no \\
\hline
\end{tabular}

${ }^{112} \mathrm{El}$ posgrado al que nos referimos se asemeja a los cursos de máster de España. En este caso, se trata de estudios reducidos a un curso escolar, en el que el alumno asiste a una serie de asignaturas y luego desarrolla una pequeña investigación bajo la supervisión de un tutor. En Brasil reciben el nombre de "Especialização Strictu Sensu”. 


\begin{tabular}{cccccccccc}
\hline jero & & & & & & & & & \\
$\begin{array}{c}\text { Contac } \\
\text { to }\end{array}$ & no & po & po & nun & nun & po & po & no & po \\
habitu & & co & co & ca & ca & co & co & & co \\
al con & & & & & & & & & \\
nativos & & & & & & & & & \\
\hline
\end{tabular}

Tabla 18: Perfil de los sujetos IV.

\subsection{El corpus}

Los errores que analizaremos en este trabajo fueron obtenidos de un corpus oral, compuesto por aproximadamente 28 horas de grabación y alrededor de 51.000 palabras. En esta sección describiremos como se construyó dicho corpus, y detallaremos sus características, principalmente en lo que concierne a la transcripción y etiquetado. Para ello, nos hemos apoyado en las propuestas de diversos autores, como Sardinha (1999, 2000; 2002); Sinclair (2004); Thompson (2005); Torruella y Llisterri (1999).

Como recuerda Thompson (2005, p. 73), construir un corpus oral es una tarea compleja, ya que depende de una serie de factores, como la calidad de las grabaciones, el hecho de que los datos grabados representan solamente una parte del acto comunicativo en sí, la elección de unas determinadas convenciones para la transcripción (que a su vez dependen de los objetivos de la investigación), y la necesidad de una planificación específica, puesto que exige una gran cantidad de tiempo y esfuerzo recoger, transcribir y etiquetar las transcripciones. En los subapartados siguientes detallaremos las decisiones tomadas respecto a estos factores.

\subsubsection{Compilación del corpus}

La recogida las grabaciones se realizó entre los meses de septiembre y octubre de 2012, con dos grabadoras SONY IC Recorder ICD - PX 312. Como se ha mencionado ya, aparte de la investigadora, en ellas participaron nueve docentes de español como lengua extranjera en siete escuelas públicas y dos escuelas privadas de los niveles académicos de, primaria y secundaria.

Para la compilación del corpus hemos usado el marco que presenta Thompson (2005) (basado en una primera caracterización 
de Leech, Myers and Thomas, 1995 apud THOMPSON, 2005, p. 74), quien describe cuatro pasos para la construcción de corpus orales, los cuales explicaremos en los subapartados que siguen: (i) recolección de datos; (ii) transcripción; (iii) revisión y etiquetado; (iv) acceso;

\subsubsection{La recolección de datos}

La recolección de los datos se produjo en dos etapas distintas, puesto que construimos dos corpus que luego dieron origen a nuestra base de datos: el de clases y el de entrevistas. En un primer momento, se pidió a las profesoras que grabaran cinco clases de lengua española en el grupo de su elección. Esta petición obedecía al hecho de que, al depender del tipo de actividades programadas, en ese contexto de recogida podría haber diferencias significativas en cuanto a la intervención de las profesoras. De este modo, al solicitar que las docentes grabaran más de un encuentro, tendríamos un abanico mayor de posibilidades de extraer los datos necesarios para nuestra investigación.

En cuanto a la selección de los grupos y de las clases concretas que deberían grabarse, optamos por no interferir en su elección, porque no creíamos que los temas u objetivos desarrollados fueran relevantes para el estudio, interesándonos tan solo por el acceso a una muestra suficientemente amplia y representativa de producción oral por parte de las docentes. Además, nos parecía relevante que los sujetos estuviesen cómodos dentro de esta situación, o, dicho de otra manera, que la recogida de datos en clase fuera lo menos intrusiva posible. Por ello, permitimos que las docentes eligieran el grupo de alumnos y las clases en las que creían que podrían sentirse más naturales, así como el entorno que pudiera ofrecer las mejores condiciones de grabación. Hay que añadir que las grabaciones se realizaron con la supervisión de la investigadora, aunque esta no se hallara presente en las clases, para evitar un potencial incremento de la ansiedad entre las profesoras y los alumnos. En relación con esto, e igualmente con el fin de interferir mínimamente en los resultados de las grabaciones, explicamos a las docentes que teníamos intención de llevar a cabo una investigación a partir de los datos recogidos, pero en ningún 
caso especificamos el ámbito de esa investigación ${ }^{113}$. Las transcripciones de las clases están recogidas en el Anexo 3.

El segundo momento consistió en una entrevista oral a las profesoras, que llevó a cabo la investigadora. Esta entrevista semiestructurada estaba formada por veinticinco preguntas acerca de la formación profesional y la vida laboral de cada una de ellas (el guion general de esa entrevista puede verse en el Anexo 5). Las entrevistas se grabaron en las mismas escuelas donde actuaban las docentes. El papel del entrevistador fue también el de actuante en la entrevista, intentando así propiciar un entorno amigable, donde las entrevistadas pudieran hablar lo más espontáneamente posible sobre los temas cuestionados, e insertando, para ello, informaciones sobre nosotros mismos, y dejando espacio para preguntas realizadas por las propias entrevistadas, a las que, obviamente, contestábamos.

La construcción del cuestionario se ha llevado a cabo a partir de la metodología propuesta por Dörnyei (2003). Se ha dedicado especial atención a los aspectos relativos al tiempo de ejecución, formato, organización, tipo de preguntas y secuencia. Las cuestiones relevantes para la investigación fueron mezcladas con otras de menor interés. Asimismo, cada entrevista posee ligeras variaciones sobre las demás, dependiendo de los temas que surgieron en cada caso. Asimismo, hemos tenido en cuenta la personalidad de cada sujeto y hemos intentado no forzar la conversación, por lo que, como veremos a continuación, aunque hayamos hecho prácticamente las mismas preguntas a todas las entrevistadas, el resultado final ha sido bastante variable en términos de tiempos de grabación y de cantidad de palabras obtenidas.

\subsubsection{Tiempos de grabación}

Terminada la recogida de datos, nos percatamos de dos hechos: (i) el número de horas grabadas por las docentes se asemejaba en su mayoría; (ii) un mayor número de horas no ofrecía necesariamente un mayor número de datos que pudiéramos utilizar en nuestro estudio. Principalmente por este último motivo, en

\footnotetext{
${ }^{113}$ La retención de la información acerca de la naturaleza de la investigación está basada en las "Recomendaciones de buena práctica en Lingüística Aplicada" de la "Asociación británica de lingüística aplicada", disponible en: http://www.baal.org.uk/goodpractice_full_2016.pdf.
} 
ocasiones, vimos la necesidad de solicitar que las docentes volvieran a grabar clases para intentar que hubiese una mayor cantidad de discurso oral. Eso ocurrió porque en alguna ocasión las actividades llevadas a cabo tenían como protagonistas principales a los alumnos (clases basadas en tareas, por ejemplo) y no tanto a la profesora. De esta manera, después de la readecuación de las grabaciones hemos procedido a analizar el material compilado. Veremos que los tiempos son similares a excepción de las docentes D3, con un número muy superior a las demás (casi cinco horas de grabación), y la D7, con poco más de una hora:

\begin{tabular}{|c|c|}
\hline Sujeto & $\begin{array}{c}\text { Tiempo total de } \\
\text { clases } \\
\text { grabadas } \\
2 \mathrm{~h} 10 \mathrm{~min}\end{array}$ \\
\hline D1 & $2 \mathrm{~h} 38 \mathrm{~min}$ \\
\hline D2 & $4 \mathrm{~h} 54 \mathrm{~min}$ \\
\hline D3 & $2 \mathrm{~h} 24 \mathrm{~min}$ \\
\hline D4 & $2 \mathrm{~h} 53 \mathrm{~min}$ \\
\hline D5 & $2 \mathrm{~h} 57 \mathrm{~min}$ \\
\hline D6 & $1 \mathrm{~h} 12 \mathrm{~min}$ \\
\hline D7 & $2 \mathrm{~h} 30 \mathrm{~min}$ \\
\hline D8 & $2 \mathrm{~h} 06 \mathrm{~min}$ \\
\hline D9 & $\mathbf{2 3 h 4 4 m i n}$ \\
\hline TOTAL &
\end{tabular}

Tabla 19: Tiempo de clases grabadas por sujeto.

En lo que se refiere al contexto de las entrevistas, al ser estas de carácter más libre y al depender también en cierta medida de las características personales de los sujetos, como la extroversión, la capacidad comunicativa, el nivel de interacción y la disposición del entrevistado hacia la tarea, obtenemos también una cierta variación en cuanto a las muestras disponibles. Aunque la media de las entrevistas se sitúa entre los 25 y los 30 minutos, algunas se han quedado claramente por debajo (D4, con 15 minutos) o levemente por encima (D2, con 32 minutos), con 
respecto a esas cifras. Todos esos tiempos los podemos ver en el cuadro siguiente.

\begin{tabular}{|c|c|}
\hline Sujeto & $\begin{array}{c}\text { Tiempo de } \\
\text { entrevista }\end{array}$ \\
\hline D1 & $30 \mathrm{~min}$ \\
\hline D2 & $32 \mathrm{~min}$ \\
\hline D3 & $23 \mathrm{~min}$ \\
\hline D4 & $15 \mathrm{~min}$ \\
\hline D5 & $30 \mathrm{~min}$ \\
\hline D6 & $20 \mathrm{~min}$ \\
\hline D7 & $28 \mathrm{~min}$ \\
\hline D8 & $30 \mathrm{~min}$ \\
\hline D9 & $29 \mathrm{~min}$ \\
\hline TOTAL & $3 \mathrm{~h} 57 \mathrm{~min}$ \\
\hline
\end{tabular}

Tabla 20: Tiempo de entrevista grabada por sujeto.

En conjunto, disponemos de un total de 27 horas y 41 minutos de grabación, de las que casi 24 horas provienen de las clases (un $86 \%$ ) y alrededor de 4 horas a las entrevistas (un 14\%). En el cuadro siguiente presentamos el total de horas por sujeto. Como se puede apreciar, la docente D3 aporta, con diferencia, el mayor volumen de habla disponible $(5 \mathrm{~h} 17 \mathrm{~min})$, mientras que la docente D7 se sitúa en el extremo opuesto (1h40min).

\begin{tabular}{|c|c|}
\hline Sujeto & $\begin{array}{c}\text { Total de } \\
\text { grabaciones }\end{array}$ \\
\hline D1 & 2h40min \\
\hline D2 & 3h10min \\
\hline D3 & $5 h 17 m i n$ \\
\hline D4 & 2h39min \\
\hline
\end{tabular}




\begin{tabular}{|c|c|}
\hline D5 & 3h27min \\
\hline D6 & 3h13min \\
\hline D7 & 1h40min \\
\hline D8 & $3 \mathrm{~h}$ \\
\hline D9 & 2h35min \\
\hline TOTAL & 27h41min \\
\hline
\end{tabular}

Tabla 21: Totales de horas de grabación por sujeto.

\subsubsection{Longitud de las muestras}

Como hemos señalado más arriba, el corpus total consta de unas 51.000 palabras, de las cuales un $67 \%$ proceden del contexto en clase y un $33 \%$ de las entrevistas, como podemos observar en el cuadro a continuación, donde se presentan los números totales por sujeto y entorno de recogida. Es importante destacar que en este cómputo se han contabilizado únicamente las palabras correspondientes a los turnos de habla de los docentes, quedando excluidas, por tanto, tanto el habla de los dicentes en los contextos de clases, como el turno de la entrevistadora en el entorno de las entrevistas.

\begin{tabular}{|l|l|l|l|}
\hline Sujetos & Clases & Entrevistas & Total \\
\hline D1 & 1.604 & 1.297 & $\mathbf{2 . 9 0 1}$ \\
\hline D2 & 2.345 & 2.525 & $\mathbf{4 . 8 7 0}$ \\
\hline D3 & 1.077 & 1.080 & $\mathbf{2 . 1 5 7}$ \\
\hline D4 & 2.889 & 924 & $\mathbf{3 . 8 1 3}$ \\
\hline D5 & 3.789 & 2.132 & $\mathbf{5 . 9 2 1}$ \\
\hline D6 & 5.847 & 1.492 & $\mathbf{7 . 3 3 9}$ \\
\hline D7 & 5.078 & 3.397 & $\mathbf{8 . 4 7 5}$ \\
\hline D8 & 6.505 & 3.084 & $\mathbf{9 . 5 8 9}$ \\
\hline
\end{tabular}




\begin{tabular}{|l|l|l|l|}
\hline D9 & 5.081 & 1.049 & $\mathbf{6 . 1 3 0}$ \\
\hline TOTAL & $\mathbf{3 4 . 2 1 5}$ & $\mathbf{1 6 . 9 8 0}$ & $\mathbf{5 1 . 1 9 5}$ \\
\hline
\end{tabular}

Tabla 22: Total de palabras que constituyen el corpus.

Como podemos observar, la docente que más ha utilizado la lengua española en clase es la D8 (6.505), mientras que la mayor utilización en las entrevistas procede de la docente D7 (3.397). Por otro lado, la menor utilización de la lengua en clase corresponde a la docente D3 (1.077) y en la entrevista a la D4 (924). Como vemos en el cuadro, el cómputo de palabras varía considerablemente, pese a lo cual algunas consideraciones deben ser tenidas en cuenta. A este respecto, queremos señalar que presentamos la suma de todas las clases de palabras, es decir, no hemos organizado el cómputo en función de las categorías, como se hizo en otros estudios, como, por ejemplo, en la conocida tesis de Fernández (1997), quien trabajó con muestras escritas de aprendices de ELE. En este trabajo, el cálculo de la extensión de la muestra se hizo a partir de la suma total de palabras, además de otros recuentos más específicos que afectaban a las palabras lexicales, la riqueza léxica y la sintaxis (FERNÁNDEZ, 1997, p. 52). Para nosotros este tipo de recuento resulta muy interesante, aunque no lo hemos podido llevar a cabo por falta de tiempo, puesto que requiere de un etiquetado del corpus que para nosotros ha sido imposible llevar a cabo.

Aun así, el cómputo del total de palabras es especialmente interesante para nosotros, puesto que demuestra que el número de horas de grabación no necesariamente refleja un mayor uso de la lengua. Un ejemplo de ello es la docente D3, quien nos proporciona una notable cantidad de material grabado (4h54min), pese a lo cual utiliza un número de palabras (1.077 palabras) significativamente menor que otras. Por el contrario, la profesora D7, en tan solo 1h12min de grabación, utilizó un total de 5.078 palabras en lengua española (¡casi 5 veces más que D3 en prácticamente una cuarta parte del tiempo!). Tales diferencias quedan aún más evidentes en el gráfico siguiente, en el cual recogemos datos comparativos de los tiempos de clases y el número de palabras:

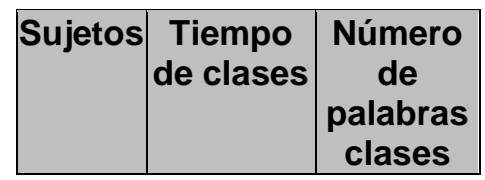




\begin{tabular}{|c|c|c|}
\hline D1 & 2h10min & 1.604 \\
\hline D2 & 2h38min & 2.345 \\
\hline D3 & $4 h 54 m i n$ & 1.077 \\
\hline D4 & $2 \mathrm{~h} 24 \mathrm{~min}$ & 2.889 \\
\hline D5 & 2h53min & 3.789 \\
\hline D6 & 2h57min & 5.847 \\
\hline D7 & $1 \mathrm{~h} 12 \mathrm{~min}$ & 5.078 \\
\hline D8 & 2h30min & 6.505 \\
\hline D9 & 2h06min & 5.081 \\
\hline TOTAL & 23h44min & 34.215 \\
\hline
\end{tabular}

Tabla 23: Tiempo x número de palabras de clases.

Algo parecido ocurre con las entrevistas. También en este entorno hay una variación considerable entre el volumen de palabras utilizadas por los sujetos, si bien aquí sí parece confirmarse la máxima según la cual un menor tiempo de grabación (15min) equivale a un menor número de palabras (924), como sucede con la docente D4. De todas maneras, con otras docentes podemos ver que un tiempo mayor no ha sido suficiente para que utilizasen más la lengua, como ocurre con las docentes D3 (23min y 1.080 palabras) y D9 (29min y 1.049 palabras), quienes se sitúan a considerable distancia de otras, pero en especial de las D7 (28min y 3.397 palabras) y D8 (30min y 3.084 palabras), con diferencia, las más productivas de toda la muestra. Todos estos datos aparecen detallados en la tabla 24:

\begin{tabular}{|c|c|c|}
\hline Sujetos & $\begin{array}{c}\text { Tiempo de } \\
\text { entrevistas }\end{array}$ & $\begin{array}{c}\text { Número de } \\
\text { palabras } \\
\text { entrevistas }\end{array}$ \\
\hline D1 & $30 \mathrm{~min}$ & 1.297 \\
\hline D2 & $32 \mathrm{~min}$ & 2.525 \\
\hline D3 & $23 \mathrm{~min}$ & 1.080 \\
\hline
\end{tabular}




\begin{tabular}{|c|c|c|}
\hline D4 & $15 \mathrm{~min}$ & 924 \\
\hline D5 & $30 \mathrm{~min}$ & 2.132 \\
\hline D6 & $20 \mathrm{~min}$ & 1.492 \\
\hline D7 & $28 \mathrm{~min}$ & 3.397 \\
\hline D8 & $30 \mathrm{~min}$ & 3.084 \\
\hline D9 & $29 \mathrm{~min}$ & 1.049 \\
\hline TOTAL & $3 \mathrm{3h7min}$ & 16.980 \\
\hline
\end{tabular}

Tabla 24: Tiempo x número de palabras de entrevistas.

Finalmente, la suma de clases y entrevistas muestra también una notable variación. En este cómputo general, tenemos de nuevo a la docente D3 como la más extrema, con un mayor número de horas de grabación (5h17min), a las que, sin embargo, corresponden apenas 2.157 palabras (el menor número de todas). En el extremo opuesto se sitúa la D8 (9.589 palabras en 3 horas). El resto de los datos puede verse en la tabla 25 :

\begin{tabular}{|c|c|c|}
\hline Sujetos & $\begin{array}{c}\text { Total de } \\
\text { horas }\end{array}$ & $\begin{array}{c}\text { Total de } \\
\text { palabras }\end{array}$ \\
\hline D8 & 3h & 9.589 \\
\hline D7 & hh40min & 8.475 \\
\hline D6 & 3 h13min & 7.339 \\
\hline D9 & 2 h35min & 6.130 \\
\hline D5 & 3 h27min & 5.921 \\
\hline D2 & $3 h 10 m i n$ & 4.870 \\
\hline D4 & 2 h39min & 3.813 \\
\hline D1 & $2 h 40 m i n$ & 2.901 \\
\hline D3 & 5 h17min & 2.157 \\
\hline
\end{tabular}




\section{\begin{tabular}{l|l|l|} 
TOTAL & 27h41min & 51.195
\end{tabular}}

Tabla 25: Total de horas $\mathrm{x}$ total de palabras.

\subsubsection{La transcripción}

La segunda parte en la construcción de nuestro corpus tuvo como protagonista a la transcripción de las clases y entrevistas grabadas en audio. La transcripción que llevamos a cabo es de tipo ortográfico (THOMPSON, 2005, p. 78), puesto que es no solo la más sencilla, sino también la más apropiada para los propósitos del estudio.

En un primer momento, pensamos utilizar programas de transcripción automáticos, pero al final optamos por llevar a cabo esta tarea de manera manual. Esto obedeció, por un lado, a la complejidad de las grabaciones de las clases, dónde, además de las intervenciones de los alumnos, que resultaban a menudo en fragmentos de habla cruzada y solapamientos continuos, se producían cambios y mezclas de código constantes por parte de las docentes. Por ello, utilizar programas específicos para la transcripción resultó una tarea imposible. Además, para mantener el mismo rigor metodológico, también hemos utilizado la transcripción manual en el entorno de las entrevistas. El único transcriptor ha sido el investigador del estudio.

\subsubsection{Convenciones de la transcripción}

Con la finalidad de organizar el corpus y facilitar la interpretación y el tratamiento de los datos, hemos adoptado (y adaptado) algunos signos de transcripción de Andrade (2011) y Marcuschi (1986). Hemos tenido en especial consideración las premisas de este último autor, quien señala que lo esencial de una transcripción es que "el analista sepa cuáles son sus objetivos y no deje de señalar lo que le parezca conveniente" 114 (MARCUSCHI, 1986, p. 9). Con todo, añade también este autor, la transcripción debe ser al mismo tiempo legible y sin sobrecarga de símbolos complicados. A continuación listamos las convenciones utilizadas y sus significados:

114 Traducción nuestra. 


\begin{tabular}{|c|c|}
\hline Signos & Descripción \\
\hline A & Alumno(s) \\
\hline $\mathrm{D}+\mathrm{n}^{\circ}+\mathrm{C}$ & $\begin{array}{l}\text { Docente, número de identificación del docente, en clase, } \\
\text { número de la clase. Ej.: D1C4; D2C1; D3C2 }\end{array}$ \\
\hline$D+n \div+E$ & $\begin{array}{l}\text { Docente, número de identificación del docente, en } \\
\text { entrevista. Ej.: D1E }\end{array}$ \\
\hline $\mathbf{E}$ & Entrevistador \\
\hline$\left[{ }^{\star \star \star}\right]$ & Nombres personales suprimidos \\
\hline [[ ] ] & Comentario del transcriptor \\
\hline$(())$ & Transcripción dudosa \\
\hline$(\ldots)$ & $\begin{array}{l}\text { Fragmento indescifrable/ habla simultánea/ habla de los } \\
\text { alumnos }\end{array}$ \\
\hline ¿? & Interrogación \\
\hline ¡! & Exclamación \\
\hline $\begin{array}{l}\text { Eh, ah, } \\
\text { oh, aha }\end{array}$ & $\begin{array}{l}\text { Hesitación, atención, llamada de atención y } \\
\text { confirmación, respectivamente }\end{array}$ \\
\hline$\ldots$ & Pausa corta \\
\hline . & Pausa larga \\
\hline sshh & Pedido de silencio \\
\hline cursiva & $\begin{array}{l}\text { Vocablo, nombre o expresión propio del } \\
\text { portugués/español/inglés }\end{array}$ \\
\hline ““ “ & $\begin{array}{l}\text { Habla de una tercera persona citada por alguno de los } \\
\text { interlocutores / referencia a las letras del alfabeto / } \\
\text { vocablo citado }\end{array}$ \\
\hline
\end{tabular}

Tabla 26: Signos adoptados para la transcripción.

\subsubsection{Protección de datos}

Se ha tenido especial cuidado con la protección de los datos personales tanto de las docentes como de los alumnos. Aunque las docentes hayan aceptado participar en el estudio de forma voluntaria, y todas ellas hayan firmado un documento en el cual cedían los derechos para la utilización del material compilado (Anexo 2) ${ }^{115}$, de la transcripción se han suprimido todas las

115 Durante todo el proceso de recogida de datos hemos seguido las "Recomendaciones de buena práctica en Lingüística Aplicada", tal como 
informaciones personales, sustituidas por el signo $\left.{ }^{* * \star}\right]$, como en los ejemplos que vemos a continuación:

(21) D5C: (...) silencio... $\left.{ }^{\star * *}\right]$ guarda el cuaderno ahora...

(22) D9C: $\left[{ }^{* * *}\right] \ldots$ preste atención... primera respuesta... lunes...

En los fragmentos de habla representados en los ejemplos (21) y (22) se observa la supresión del nombre de los alumnos a quienes se dirigen las docentes. De la misma manera, todas las fuentes posibles de identificación de otros participantes en el estudio (incluidas instituciones públicas y privadas), fueron sustituidas por el mismo símbolo $\left.{ }^{\star * *}\right]$ con el fin de proteger su identidad.

\subsubsection{Peculiaridades sobre las transcripciones en nuestro estudio}

Transcribir puede ser una tarea espinosa cuando el objetivo es el análisis de errores. Al concretar esta tarea, nos hemos percatado de que algunas características del registro oral dificultan la detección de ciertos tipos de errores, y por ello hemos tenido que tomar ciertas decisiones con el fin de preservar el rigor metodológico en un estudio de estas características. De la misma manera, nos interesaba evitar al máximo la sobrestimación de los errores de transferencia (ELLIS 2008, p. 353). Tales peculiaridades se describen a continuación.

La primera de ellas es relativa a la preposición "a" pospuesta o antepuesta a palabras que empiezan por la vocal "a". Sabemos que en español, el verbo ir requiere de la preposición "a" para formar la perífrasis verbal incoativa (voy a cantar). No obstante, en portugués no ocurre lo mismo (vou cantar). Este suele ser un error típico en la interlengua de brasileños aprendices de español. No obstante, dada la pronunciación idéntica de la preposición y el fonema /a/ en determinadas construcciones, no nos ha sido posible identificar si este uso ocurrió o no. Un ejemplo representativo es el de (23):

las describe la "Asociación británica de lingüística aplicada", disponible en: http://www.baal.org.uk/goodpractice full 2016.pdf. 
(23) D8E: ... buscaba muchas cosas... pero... además no sabía cómo ia ser... ya no sabía todo...

En el ejemplo transcrito, observamos claramente una interferencia directa del verbo ir portugués flexionado (ia) en lugar del español (iba). En portugués la preposición "a" no es requerida en este caso, pero en español sí. No obstante, para el transcriptor se hace prácticamente imposible identificar si se utiliza o no la preposición. De ahí que, ante la duda, hayamos preferido no marcar estos fragmentos como errores, puesto que no son del todo evidentes.

En otros casos, se adoptaron también las correspondientes precauciones cuando la diferencia entre las dos lenguas era muy sutil, como, por ejemplo en (24):

(24) D2E: ... [[mi suegro]] vendía libros y tenía una biblioteca imensa en casa...

La diferencia formal entre los vocablos del español y portugués es apenas una $/ \mathrm{n} /$ (inmensa en español e imensa en portugués), que no siempre resulta fácil de identificar. En estos casos, tan solo cuando hemos tenido una completa seguridad acerca de la pronunciación del hablante los hemos clasificado como errores. No así cuando no teníamos esa seguridad.

De la misma forma, hemos descartado los fragmentos en los que el habla no estaba suficientemente clara, como conversaciones cruzadas o fragmentos donde la calidad del audio se veía comprometida por diversos motivos. En estos casos, hemos insertado el símbolo (...) en las correspondientes transcripciones.

\subsubsection{Revisión y etiquetado}

Es frecuente que en la organización de los corpus, el etiquetado $y$ las anotaciones se lleven a cabo para facilitar la tarea de reconocimiento por parte de los programas informáticos que sirven para procesar los textos. No obstante, en nuestro caso, en el que llevaríamos a cabo este procesamiento de los datos de forma manual, hemos utilizado también algunas anotaciones y etiquetados por dos motivos fundamentales.

El primero tiene que ver con aquellas aclaraciones necesarias para el entendimiento del contexto donde se produce la 
comunicación. Se trata de anotaciones realizadas en el cuerpo del texto, en las cuales el transcriptor introduce una serie de informaciones contextuales sin las cuales el entendimiento del acto comunicativo se vería comprometido. En nuestro caso, tales informaciones aparecen reflejadas mediante el símbolo [[ ]], como en el siguiente ejemplo:

(25) D3E: no... nunca... el año pasado tuvimos una maestra a través de [ $\left.{ }^{* * *}\right]$ [[nombre de la secretaría de educación]]... que trabajó con nosotras un semestre... veinte horas... vino de $\left.{ }^{* * *}\right]$ [[nombre de la universidad]].

Otros casos en los que se usaron anotaciones de este tipo afectan a eventos discursivos que tuvieron lugar durante la grabación, como interrupciones, ruido externo, comportamiento gestual o paralingüístico de los alumnos, etc.

El segundo motivo tiene que ver con el uso de la lengua materna. Nos costó decidir si marcaríamos o simplemente suprimiríamos los fragmentos en los que la lengua portuguesa aparecía durante las grabaciones, principalmente en las clases, donde eran más frecuentes. En un primer momento pensamos eliminar los fragmentos en los que se utilizaba directamente la lengua materna, puesto que íbamos a trabajar exclusivamente con material español. No obstante, en una revisión detallada de las intervenciones nos percatamos de que podríamos extraer informaciones relevantes del corpus si pudiéramos etiquetarlas de alguna manera. Para ello, hemos clasificado las ocurrencias del portugués en cinco tipos, los cuales se sustituyeron en el corpus por las siguientes etiquetas:

\begin{tabular}{|l|l|l|}
\hline & Etiqueta & Descripción \\
\hline 1 & [comt. port] & $\begin{array}{l}\text { Fragmento/comentario en portugués hecho por el } \\
\text { docente }\end{array}$ \\
\hline 2 & [trad. port] & Fragmento traducido al portugués por el docente \\
\hline 3 & [expl. port] & Fragmento explicado en portugués por el docente \\
\hline 4 & [cuest. port] & $\begin{array}{l}\text { Pregunta o cuestionamiento hecho en portugués por el } \\
\text { docente }\end{array}$ \\
\hline 5 & [orden port] & Orden dado en portugués por el docente \\
\hline
\end{tabular}

Tabla 27: Tipos de etiquetas uso LM. 
Asimismo, una vez llevada a cabo esta tarea, nos dimos cuenta de que las etiquetas eran fundamentales en el intento de aclarar de qué manera y con qué objetivo las docentes hacían uso de la lengua materna en clase. A partir de las etiquetas insertadas en el corpus y con la ayuda del contexto, hemos podido analizar el uso de la LM con más objetividad. Veamos un fragmento en el que aparecen tanto las anotaciones como las etiquetas:

(26) D4C: [[lectura]] escriba los numerales que hay en el texto... [[fin lectura]] ¿qué numerales que* aparecen? aparece* $^{*}$ el once y doce... [[lectura]] escribe por extenso... [[fin lectura]] ¡mucha charla! [trad. port]... [[lectura]] busque pronombres personales... [[fin lectura]] ¿qué pronombres aparecen en el texto? (...) isso... tú... aquí hablamos de saludos... ¿tá? ${ }^{*}(\ldots)$ vosotros... él... usted... tú... [expl. port]... (...) no puede* $^{*}$ ir al baño... [orden port].

En este fragmento, transcrito, anotado y debidamente etiquetado, podemos percibir la fuerte tendencia en el discurso de la mayoría de las profesoras participantes del estudio hacia la utilización del portugués en clase. Tal como vemos en el ejemplo, es muy frecuente que utilicen su lengua materna para dar órdenes o explicaciones sobre las tareas propuestas. Asimismo, cuando se trata de actividades que se encuentran en los libros de texto, es habitual que utilicen la lengua española para realizar su lectura y, a continuación, el portugués para su explicación o traducción.

Quizá esto impida la compilación de muestras de habla más espontáneas en este contexto, puesto que, como hemos visto en los ejemplos, buena parte del discurso en español de las docentes está vinculado a la lectura de los ejercicios y el uso de la lengua materna ocurre cuando hay una necesidad comunicativa. Esto nos lleva a algunas consideraciones adicionales, que abordamos más adelante en los Capítulos 7 y 8.

\subsubsection{El acceso}

El último paso que cita Thompson (2005) es el acceso, es decir, la posibilidad de publicar o incorporar un corpus en otros del mismo estilo. Sobre esta cuestión, debemos decir que nuestro corpus se diseñó exclusivamente para la utilización de esta investigación y por 
ello no está publicado ni en medio impreso o digital alguno. Por tratarse de un corpus pequeño y muy específico, no creemos que sea publicable en estos momentos, aunque no descartamos que en un futuro pueda adaptarse para su incorporación a otros corpus de aprendices más amplios.

\subsection{Identificación, clasificación y descripción de los errores}

En este apartado describiremos de qué manera llevamos a cabo la identificación, descripción y clasificación de los errores, siguiendo para ello los presupuestos de Corder (1981b) discutidos en el Capítulo 4 (subapartado 4.3). Para empezar, nos gustaría señalar que estas tareas se produjeron igualmente de forma manual, aunque en algunas nos servimos de las utilidades de un programa informático (WordSmith Tools).

\subsubsection{Identificación}

Una vez terminadas las etapas de transcripción, revisión y etiquetado, procedimos a identificar los errores en los corpus (tanto los de carácter interlingüístico como los intralingüísticos). Esta tarea se llevó a cabo realizando varias y detalladas lecturas de cada archivo generado a partir de las transcripciones. Una vez encontrado un posible error, este era extraído del corpus y agregado a un banco de datos. Esta tarea la llevó a cabo la investigadora, quien se sirvió para ello de las obras lexicográficas detalladas más adelante en el apartado 6.5. En esta etapa hemos utilizado el programa WordSmith Tools (versión 6.0) como recurso para la búsqueda de posibles errores frecuentes. Para ello nos basamos en postulados de Sardinha (2002), en lo que se refiere a la utilización del WordSmith para la investigación del lenguaje.

\subsubsection{Clasificación y descripción y de los errores}

Completada la identificación y extracción de los errores, tuvimos como resultado dos bancos de datos en función de su origen: a) intralingüísticos y b) interlingüísticos, divididos a su vez cada uno de ellos por docente y contexto (de clases y de 
entrevistas). Ello nos permitió pasar a la siguiente etapa, la clasificación de los errores.

También esta etapa consta de diversas fases; a saber:

Fase 1 - Revisión de los errores: En esta etapa teníamos como objetivo revisar uno a uno los errores extraídos del corpus, tanto en relación con su origen (intra o interlingual), como por su tipo gramatical. Para ello, hemos consultado diferentes gramáticas monolingües de las lenguas portuguesa (BECHARA, 2009; CUNHA Y CINTRA, 2008) y española (GOMEZ TORREGO, 2011a, 2011b, MATTE BON, 2012a, 2012b, RAE, 2009a, 2009b), algunas gramáticas específicas para brasileños aprendices de español (FANJUL, 2011; MASIP, 2010; MORENO Y FERNÁNDEZ, 2007), así como diversos diccionarios (todos ellos citados en el último apartado de este capítulo).

Fase 2 - Clasificación de los errores: En esta etapa catalogamos los errores según el criterio gramatical, puesto que nuestro primer objetivo iba destinado a ello. El resultado de esa clasificación general está disponible en el Anexo 6.

Fase 3 - Recuento de los errores: Terminada esta etapa, nos fijamos en que los errores encontrados eran muchos y de una gran variedad tipológica. Esto sirvió para que nos percatáramos de que sería imposible llevar a cabo los análisis lingüísticos que nos habíamos propuesto inicialmente dentro de los límites razonables de una tesis doctoral.

Fase 4 - Revisión de los errores: Lo anterior sirvió como punto de inflexión para reorientar nuestros objetivos, centrándonos a partir de este momento en el análisis de los errores más frecuentes. En esta fase, nos dimos cuenta de que los errores léxicos eran especialmente abundantes, motivo por el cual hicimos una detallada revisión del banco de errores y llegamos a la conclusión de que este sería el grupo más apropiado para un estudio a fondo.

Fase 5: Construcción de una base de datos de errores léxicos: A partir de ahí hemos buscado una categorización de los errores de interferencia tomando como base el conocido modelo de Durão (2007), del cual partimos en la clasificación que proponemos en este estudio. La clasificación de los errores léxicos está disponible en el Anexo 7.

Fase 6: Descripción de los errores: Una vez terminada la fase anterior, hemos procedido a la descripción de los errores, basada en las obras lexicográficas que describiremos en la sección a 6.5. Para ello, hemos procedido a la interpretación y reconstrucción plausible de los errores (CORDER, 1981b, p. 38), conforme a lo explicado en el Capítulo 4. Como se recordará, en este proceso interpretamos lo 
que intuimos que el sujeto quiso decir en cada momento, y reconstruimos a continuación los errores de acuerdo con dicha interpretación.

\subsubsection{Signos de convención}

En las clasificaciones que hemos delimitado y que sirvieron de base para los posteriores análisis, hemos agregado tres símbolos, los cuales nos han ayudado a destacar algunas situaciones concretas.

\begin{tabular}{|l|l|}
\hline Signos & Descripción \\
\hline$(\varnothing)$ & Omisión de elemento \\
\hline$*$ & Error clasificado con anterioridad \\
\hline$/ /$ & Fin del turno o del tema \\
\hline
\end{tabular}

Tabla 28: Signos utilizados en el banco de errores.

Así, insertamos la marca $(\varnothing)$ en los contextos dónde observamos la omisión de algún elemento requerido. Veamos el siguiente ejemplo, en el cual se marca la ausencia del clítico los tras el verbo llevar mediante este símbolo:

(27) D3E: ... no... quería poder quitarlos [[a los alumnos]] de la clase y $\underline{\text { llevar(Ø) }}$ para otra y trabajar solo con ellos...

Por otro lado, hacemos uso del asterisco * en los fragmentos donde identificábamos más de un error, haciendo referencia con ello a que el error en cuestión está también identificado y clasificado bien sea en la misma categoría o en otra distinta:

(28) D3E: ... sí... tengo dos... [[parientes en Argentina]] una hermana y un hermano que están lá há* más de veinte años...//

En este fragmento apreciamos que el error marcado es la transferencia directa de "lá" (allá). No obstante, otra interferencia aparece a continuación, "há" (hace), motivo por el cual se marca con asterisco. La separación de estos dos errores de su contexto supondría un problema serio para la interpretación de ambos. Para evitarlo, el asterisco resulta de gran utilidad. Asimismo, esta 
marcación fue también muy valiosa para la organización de los errores en el banco de datos, principalmente para su identificación y recuento posterior.

En cuanto al tercer símbolo, //, lo hemos utilizado cuando hemos querido señalar el final de un enunciado donde aparecían los errores. Así, ocurre en el siguiente fragmento:

(29) D6E: ... siempre fui intentando para... y corregindo* los errores... escribir siempre me gustó mucho...//

Como vemos, las dos barras nos dan la información de que la intervención del sujeto se acaba exactamente después de "mucho". En otras ocasiones, debido a la extensión de los turnos de palabra, nos hemos visto obligados a extraer el fragmento del contexto correspondiente, motivo por el cual las barras no aparecen:

(30) D6E: sí... intento siempre... a veces hay contenidos más difícilis* que ellos piden por favor para que explique...

En este caso, la intervención del sujeto era demasiado extensa como para trasladarla completamente al banco de errores, motivo por el cual hicimos un recorte del fragmento transcrito, de manera que este pudiera entenderse aun en ausencia de su contexto.

\subsubsection{Variedades lingüísticas}

Terminamos esta sección con una consideración final sobre las variedades elegidas para el contraste lingüístico. Ellis (2008, p. 61 ) defiende que una de las principales críticas al método del $A E$ es la elección de apenas una variedad para dicho contraste, excluyendo así otras muchas posibilidades. Con todo, en este tipo de trabajos resulta poco verosímil la posibilidad de abarcar muchas variedades de una lengua tan diversa como la española, por lo que parece sensato inclinarse por alguna de ellas. Además, ello permite una mayor coherencia metodológica.

En el presente estudio tenemos, de un lado, el portugués, lengua materna tanto de los sujetos como de la investigadora, y más específicamente de su variedad brasileña. Por este motivo nos hemos apoyado en obras de referencia de esta lengua y país para la identificación y análisis de los errores 
En el otro extremo se encuentra la lengua española, idioma extranjero igualmente tanto de los sujetos como de la investigadora. No obstante, al ser el español una lengua con una gran diversidad dialectal, resultó una tarea delicada el decantarnos por una variedad específica. Al final, optamos por el español peninsular por algunos motivos prácticos que detallamos a continuación.

El primero de ellos es que, como veremos en la sección siguiente, la gran mayoría de las obras disponibles en el mercado editorial, y en las cuales nos hemos apoyado para los análisis contrastivos, está editada en España o está basada en esta variedad lingüística, por lo que resultaría contraproducente elegir otra con la cual el contraste no fuera posible por falta de material disponible.

El segundo motivo es que, aunque Brasil, y sobre todo la región de donde provienen las docentes en cuestión, está geográficamente muy cerca de países latinoamericanos de habla española, como Paraguay o Argentina, los mismos sujetos han declarado que tienen poco o ningún contacto con nativos de estas naciones, lo que nos lleva a creer que la variedad que dominan se aproxima más a la estándar que han estudiado en el grado. Respecto a esa variedad, no tenemos indicios suficientes para afirmar que se acerque a ningún dominio dialectal en particular, pero tenemos conocimiento de que dos de las tres profesoras de lengua española que tuvieron en la carrera utilizaban materiales provenientes de editoriales españolas, asumían que esta era la variedad que dominaban y, por tanto, desarrollaban en sus clases unidades didácticas basadas en ella. Todo esto nos lleva a creer que el conocimiento lingüístico de los sujetos se aproxima más a la variedad estándar peninsular que a otras.

Pese a lo anterior, no hemos rechazado de entrada el contraste con otras variedades de las que tengamos conocimiento para la explicación de algunos fenómenos. Para ello, la consulta de algunas obras de referencia de la sociolingüística y la dialectología del español, como los trabajos de Alvar (1996a, 1996b), Blas Arroyo (2005) y Moreno et al. (2003a, 2003b) ha sido de gran importancia.

Cabe añadir, finalmente, que en la selección de los errores, nos hubiera gustado contar con la opinión de informantes nativos de países hispanohablantes de manera sistemática. No obstante, dado el volumen de errores, no nos fue posible llevar a cabo este tipo de tarea. Ante esta situación, optamos por consultar con hablantes nativos solamente aquellos errores que nos causaban dudas. En esta tarea hemos contado tanto con la colaboración del codirector de esta investigación, el profesor José Luis Blas Arroyo, como con 
amigos y parientes cercanos que se ofrecieron en todo momento a aclararnos cuestiones relativas al uso y significado de su lengua materna. Estas personas provenían de cuatro países de habla hispana: Argentina, Uruguay, México y España.

\subsection{Obras lexicográficas}

Para la realización de los análisis contrastivos hemos recurrido a una serie de obras lexicográficas según lo requerían las distintas etapas del análisis de los errores. Cada una de ellas ha sido escogida por distintas razones. En este apartado presentaremos y explicaremos brevemente sus principales características.

Hemos optado por utilizar diversas obras lexicográficas por el interés que nos suscitan tanto desde el punto de vista docente como investigador. En relación con este último aspecto, nos interesaba ampliar nuestra formación respecto a los diccionarios aplicados a la enseñanza del español como lengua extranjera, que empezamos unos años atrás, durante el "Máster en estudios de la Traducción" de la Universidad Federal de Santa Catarina - UFSC -. Ya en aquella ocasión, desarrollamos un trabajo sobre el análisis de diccionarios escolares bilingües español-portugués utilizados para la comprensión y producción de ELE (GIMENEZ, 2005). De ahí que, en el presente estudio, tengamos un interés especial en examinar las principales obras existentes en el mercado editorial (principalmente aquellas de aluden al contraste español-portugués) y cómo tratan estas los problemas de interferencia detectados en el estudio.

\subsubsection{Diccionarios monolingües}

Los diccionarios monolingües utilizados en este trabajo son obras de referencia del español y del portugués. Por un lado, nos servimos del Diccionario de la Real Academia Española (en adelante DRAE) en su versión online, que se encuentra en la siguiente dirección electrónica: http://dle.rae.es/?w=diccionario. El DRAE, que tuvo su primera publicación en 1726, cuenta hoy día con su vigésima tercera edición (del año de 2014). La versión online cuenta con aproximadamente 88.000 lemas y corresponde a la vigésima segunda edición (de 2001), aunque con incorporaciones de la vigésima tercera, conforme explican los editores de la obra en su 
página web ${ }^{116}$. También en algunas ocasiones utilizamos el Diccionario de Uso del Español (MOLINER, 2008a, 2008b, 2008c), aunque apenas como apoyo para averiguar los usos de algunos vocablos no aclarados por el DRAE.

Por otro lado, en lo que concierne al portugués, utilizamos el Dicionário Aurélio da Língua Portuguesa (en adelante AURÉLIO), el cual se editó por primera vez en 1975 y en su versión digital en CD corresponde a la $3^{a}$ edición de 2004 , con 435.000 lemas.

Optamos por la versión online del DRAE principalmente por motivos prácticos, puesto que para nosotros suponía la manera más rápida de efectuar las búsquedas necesarias, y, dado el volumen de datos que teníamos por consultar, este medio suponía la mejor opción. Lo mismo sucede con el AURÉLIO, si bien la página web de este diccionario ha estado en mantenimiento durante el proceso de análisis de datos, motivo por el cual hemos utilizado su versión en CD-ROOM. Por esta razón, en las menciones al AURELIO del capítulo de resultados (ver Capítulo 7) no habrá referencias específicas a las entradas, puesto que el formado digital no ofrece tal opción.

\subsubsection{Diccionarios bilingües}

En cuanto al diccionario bilingüe, otra obra de referencia fue la elegida. Se trata del Diccionario Bilingüe de Uso EspañolPortugués (DIBU). EI DIBU tiene en torno a 20.000 entradas y está dividido en dos tomos (1 - sentido español-portugués y 2 - sentido portugués-español). Según sus autores (MORENO Y GONZÁLEZ, 2003, p. vii) es la primera en la lexicografía del portugués y español en conceder "una gran importancia tanto a la equivalencia semántica de las palabras como a su uso en contexto".

La razón de acudir a este diccionario bilingüe es que se trata del más extenso y completo de su clase entre los disponibles a día de hoy. Por otro lado, estamos de acuerdo con las bases conceptuales con las que se creó esta obra, ya que, en palabras de sus autores, con las que coincidimos, en el diccionario se dedica una especial atención a los "usos peculiares de una y otra lengua y para no trasmitir la idea de que las lenguas son simples listas de

\footnotetext{
${ }^{116}$ Consultado en http://www.rae.es/diccionario-de-la-lenguaespanola/presentacion, y http://www.rae.es/sites/default/files/Preambulo.pdf el $04 / 12 / 2016$.
} 
palabras o construcciones, sin historia, sin marcas de su(s) cultura(s) de origen" (MORENO Y GONZÁLEZ, 2003, p. vii).

Además, la opción de elegir un diccionario bilingüe estaba justificada por la necesidad de plasmar las relaciones entre las lenguas portuguesa y española formalmente. Una última razón es que en ocasiones no hemos podido encontrar una solución directa para algunos errores en las obras especializadas, como es el caso de algunos heterosemánticos y locuciones. En relación con esto, el DIBU se presenta como un diccionario de ejemplos, con informaciones pragmáticas fundamentadas en usos reales de la lengua, incluyendo aquellos ejemplos relacionados con la fraseología. Es, pues, una obra "rica en información fraseológica", concebida con el objetivo de proporcionar a sus destinatarios informaciones prácticas en su contexto de uso (MORENO Y GONZÁLEZ, 2003, p. viii). Por ello, esta obra nos ha sido de gran ayuda para establecer numerosos contrastes entre las dos lenguas, haciendo posible así la identificación y explicación de la mayoría de las interferencias.

Finalmente, hay que añadir que el DIBU está basado principalmente en las variedades del español de España (con algunas menciones también a las americanas, principalmente a las de Uruguay, Paraguay y Argentina) y del portugués de Brasil (principalmente, de la región suroeste), motivo por el cual los casos de regionalismos vinculados a la procedencia los sujetos del estudio (región sur) no han podido explicarse por medio de esta obra ${ }^{117}$.

En raras ocasiones hemos tenido que acudir a otros diccionarios por no encontrar los vocablos correspondientes en el DIBU. En estos casos, hemos optado por diccionarios online por ser

${ }^{117}$ Las provincias de Brasil se organizan en cinco Macroregiones, que albergan un total de 26 "estados". Así, la región Sureste (de donde proviene el diccionario en cuestión) abarca los estados de Espírito Santo, Minas Gerais, Río

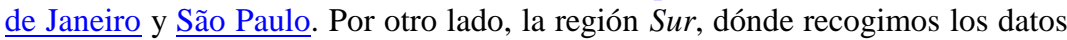
del estudio, alberga los estados de Paraná, Río Grande do Sul y Santa Catarina. A la región Norte pertenecen 7 estados, los de Acre, Amapá, Amazonas, Pará, Rondônia, Roraima y Tocantins. Por su parte, la región Nordeste agrupa a otros 9 estados: Alagoas, Bahia, Ceará, Maranhão, Paraíba, Pernambuco, Piauí, Río Grande del Norte y Sergipe. Finalmente, a la región Centro-oeste pertenecen 3 estados más, los de Goiás, Mato Grosso y Mato Grosso del Sur, además del Distrito Federal. Fuente: Instituto Barsileiro de Geografia e Estatística: http://www.ibge.gov.br/home/geociencias/geografia/default_divisao_urbano_re gional.shtm accedido el 03/02/17. 
los más prácticos. Se trata de los diccionarios WordReference ${ }^{118}$ y cuando este último no era suficiente- Pons ${ }^{119}$. Ninguna de las dos herramientas ofrece los datos que hemos mencionado anteriormente con respecto al DIBU, como número de entradas, características generales o variedades lingüísticas que recoge. No obstante, son sitios utilizados con frecuencia por los aprendices de lenguas (sobre todo, el primero). Además, como se ha mencionado al principio de este párrafo, las consultas a estos diccionarios fueron muy escasas.

\subsubsection{Diccionarios de heterosemánticos}

Buena parte de los errores encontrados en nuestro estudio pertenecen al grupo de los heterosemánticos. Para dar cuenta de los análisis de este tipo, hemos seleccionado tres obras lexicográficas especializadas. Su elección no se dio al azar, sino que se trata de algunas de las obras más conocidas y utilizadas en el ámbito escolar e investigador en Brasil dentro de su categoría, y también porque entendemos que se complementan bien entre sí.

La primera obra es el Dicionário de falsos amigos, de Balbina Lorenzo Feijoó Hoyos (FElJÓO HOYOS, 1992) (en adelante DFA). En su introducción, se define concepto de "falsos amigos"120, y se hace hincapié en la importancia de su estudio, así como en el reconocimiento de que hay un problema en la aparente semejanza del español y el portugués (sobre estas cuestiones de proximidad lingüística, recuérdese lo escrito anteriormente en el capítulo. 3). Su elaboración se llevó a cabo mediante la comparación entre el Diccionario Aurelio del portugués y el Diccionario de uso del español de María Moliner, lo que resultó en un curioso sistema organizativo en el cuerpo del diccionario, donde las entradas en cada lengua están dispuestas de manera comparativa en dos columnas, ofreciendo así una "visión de espejo" según los organizadores (FEIJÓO HOYOS, 1992, p. 9). Asimismo, en la introducción se declara que su público principal son estudiantes, profesores y traductores. Paradójicamente, no se indica el número de lemas incluidos en el libro, si bien en una versión posterior (FEIJÓO HOYOS, 1998) sí que lo hacen (alrededor de 2.050 entradas), por lo

\footnotetext{
${ }^{118}$ Disponible en http://www.wordreference.com.

${ }^{119}$ Disponible en http://es.pons.com/traducci\%C3\%B3n.

${ }^{120}$ Las concepciones de "falsos amigos" en las diferentes obras se discutieron en el capítulo anterior.
} 
que estimamos que este es también el número aproximado en la primera edición ${ }^{121}$.

¡Ojo! con los falsos amigos, de Suely Fernandes Bechara y Walter Gustavo Moure (BECHARA Y MOURE, 2002) (en adelante OFA), es la segunda obra consultada dentro de esta categoría de obras lexicográficas. Esta recoge 1.200 pares de falsos amigos, que, en opinión de los autores, son los vocablos de uso más frecuentes en cada lengua (aunque no mencionen de qué manera fueron elegidos o cuáles son los criterios para determinar su frecuencia). Bechara y Moure realizan una amplia revisión de los términos cognados y "falsos amigos", para terminar delimitando la concepción que utilizan en la elaboración del referido diccionario. Además, hacen referencia a los problemas que causa el "portuñol" y a los peligros que conllevan las similitudes entre las lenguas portuguesa y española. A este respecto, destacan que las características que singularizan a las lenguas próximas llevan a la comisión de frecuentes transferencias de una lengua a otra en todos los niveles del análisis lingüístico (léxico, gramatical y fonológico), provocando muchas veces problemas en la comunicación (BECHARA Y MOURE, 2002, p. 9). Creado especialmente para el público brasileño (ya sea para atender a estudiantes, profesores 0 traductores), esta obra no distingue claramente qué variedades de la lengua española y portuguesa cimientan el trabajo, si bien en los agradecimientos se deja traslucir que hay un abanico de colaboradores de diversas nacionalidades dentro del mundo hispano. Una curiosidad de esta obra es que presenta ilustraciones en algunos de sus artículos, aunque tampoco hay mención sobre el origen de los diversos ejemplos.

Finalmente, nos resta comentar un tercer ejemplar lexicográfico: el Dicionário ilustrado: Falsas semelhanças españolportuguês, de João Bosco Monte (MONTE, 2003) (en adelante DIL). En su brevísima presentación, el autor no indica el número de entradas del diccionario y tampoco menciona cómo se produjo la

\footnotetext{
${ }^{121}$ Nos ha resultado muy difícil encontrar ambas versiones de este diccionario especializado, motivo por el cual en un primer momento accedimos únicamente a la primera edición de la obra. Ya casi en la finalización de este trabajo tuvimos acceso a la segunda edición, motivo por el cual casi todos nuestros análisis se hicieron con la primera. De todas maneras, hemos podido recopilar y comparar algunos datos entre la primera edición y la segunda, como, por ejemplo las informaciones contenidas en sus introducciones referentes al número de entradas, las cuales figuran en la segunda edición, pero no en la primera.
} 
selección y compilación de los lemas, artículos y ejemplos. El público destinatario y las variedades del español y portugués utilizadas son otras informaciones eludidas en esta introducción. Por otra parte, una curiosidad de esta obra es que se presenta como un "diccionario ilustrado", aunque un análisis superficial del mismo da cuenta de un número reducido de ilustraciones, incluso bastante inferior comparado con el diccionario comentado en el párrafo anterior (y que inicialmente no se presenta como "ilustrado").

\subsubsection{Diccionarios de locuciones}

Para terminar este repaso, diremos que hemos recurrido también a la consulta de diversos diccionarios de locuciones y expresiones de ambas lenguas, principalmente para dar cuenta de los errores de calco. Desafortunadamente, hasta donde llega nuestro conocimiento, no existe aún un diccionario bilingüe especializado de este tipo, motivo por el cual hemos recurrido a las obras monolingües de cada lengua.

En el caso del español, nos hemos servido del Diccionario de Locuciones para la Enseñanza de la Lengua Española, de Inmaculada Penadés Martínez, que está dividido en tres tomos: (i) Diccionario de Locuciones Adverbiales para la Enseñanza de la Lengua Española (PENADÉS MARTÍNEZ, 2005) (en adelante DLAEE); (ii) Diccionario de Locuciones Nominales y Adjetivas para la Enseñanza de la Lengua Española (PENADÉS MARTíNEZ , 2008) (en adelante DLNEE); y (iii) Diccionario de Locuciones Verbales para la Enseñanza de la Lengua Española (PENADÉS MARTÍNEZ, 2002) (en adelante DLVEE). Esta obra tiene como público tanto a alumnos y profesores de español como lengua extranjera y se limita a la variedad peninsular del español. Aunque los tomos referentes a las locuciones adverbiales, así como el relativo a las locuciones adjetivas y pronominales no mencionan el número de entradas, el tomo referente a las verbales sí incluye dicha información (exactamente, 1.942 locuciones). Un aspecto que caracteriza esta obra como didáctica es la adición de algunas etiquetas en las entradas, que sirven para clasificarlas según su dificultad de aprendizaje (intermedio, avanzado y superior). En su introducción, la autora cita las obras de referencia para la construcción del diccionario (véase PENADÉS MARTíNEZ, 2002, p. 10), y añade que los ejemplos utilizados fueron construidos por ella misma en unos casos, así como extraídos de diferentes corpus, en otros. 
En algunas ocasiones nos hemos apoyado también en el Diccionario Fraseológico Documentado del Español Actual (SECO ET AL., 2004) (en adelante DFDEA). Esta obra está destinada a los "hispanohablantes cultos, con particular atención a los profesores de lengua española, y también a los aprendices medios y avanzados de ella" (SECO ET AL., 2004, p. xi). Posee 16.000 unidades fraseológicas seleccionadas a partir únicamente de documentación escrita, tales como corpus, libros y prensa electrónica únicamente de España (para más detalles véase SECO ET AL., 2004, p. xiv).

La razón por la cual hemos tomado el diccionario de Penadés Martínez como principal punto de referencia es la constatación de que en él se encontraba la mayoría de las locuciones que buscábamos, mientras que esto no ocurría con el de Seco y sus colaboradores. Con todo, este último diccionario nos ha ayudado a dilucidar algunos casos en los que teníamos duda respecto a ciertas locuciones que no encontrábamos en la obra de Penadés Martínez.

Finalmente, para el contraste de las locuciones con la lengua portuguesa, hemos acudido a la consulta del Dicionário de Locuções e Expressões da Língua Portuguesa (ROCHA Y ROCHA, 2011) (en adelante DLELP), el cual posee cerca de 18.000 entradas. Aunque incluya en su presentación los fundamentos léxicos que guiaron la compilación de esta obra (e incluso la misma delimitación de locución), no define las bases de datos utilizadas para su compilación, ni tampoco su público. En el cuerpo del diccionario, lo que vemos es que las explicaciones son bastante reducidas y poco desarrolladas, sin ejemplos y con referencias a correspondencias con otras locuciones cuando existen. En todo caso, se trata de una obra reciente y es una de las pocas (si no la única) especializadas en UF que recoge un número significativo de locuciones del portugués brasileño.

Pasaremos ahora a la revisión de los errores léxicos en el Capítulo 7, donde presentaremos los principales hallazgos de la investigación. 


\section{RESULTADOS}

Este capítulo está dividido en dos partes. En la primera, que recogemos bajo el título de Datos Generales (subapartado 7.1), realizamos una presentación general de los tipos de errores encontrados en nuestro corpus. Como se recordará, esta parte del estudio en la que catalogamos los errores que conforman la interlengua de nuestros sujetos figuraba entre los primeros objetivos del estudio. Y, como tendremos ocasión de comprobar, tanto la lista como el número de ocurrencias de estos errores es extensa. Por otro lado, en la segunda parte del capítulo, que hemos denominado Clasificación y análisis de los errores léxicos (subapartado 7.2), analizaremos los errores léxicos de manera más específica, con el objetivo de demostrar que estos, efectivamente, guardan relación con su lengua materna, es decir, son errores de interferencia. El análisis se hará de acuerdo con nuestra adaptación de la conocida taxonomía de Durão (2007), discutida en el Capítulo 4 de esta tesis.

Somos conscientes de que es esta una tarea espinosa, dada la potencial diversidad de fuentes que pueden originar los errores y, por tanto, es posible que, pese a nuestro interés en llevar a cabo el análisis de la manera metodológicamente más rigurosa posible, en algunos casos, al lector se le ocurrirán seguramente interpretaciones diferentes de las nuestras. Entendemos que esta multiplicidad de interpretaciones es una propiedad intrínseca de los análisis de errores, la cual hemos intentado atenuar en la medida de lo posible, ya sea a través de la revisión de los conceptos básicos que atañen a nuestro estudio en los capítulos anteriores, ya por medio de las descripciones detalladas de los errores propiamente dichos realizadas aquí.

Empezaremos este apartado con la primera fase, la correspondiente a los Datos Generales.

\subsection{Datos Generales}

Como hemos señalado anteriormente, esta fase abarca una revisión general de todos los errores encontrados. Los errores que resumimos aquí en números pueden encontrarse íntegramente en los listados que ofrecemos en los anexos 6. En esta fase daremos cuenta de los valores relacionados con: el uso de la lengua materna (subapartado 7.1.1); los valores totales de los errores encontrados 
(subapartado 7.1.2); los errores más frecuentes por categoría (subapartado 7.1.3); y los errores léxicos más frecuentes (subapartado 7.1.4).

\subsubsection{Uso de la lengua materna}

Uno de los principales obstáculos a los que nos hemos enfrentado en la realización de este estudio fue la utilización de la lengua materna por parte de los sujetos en los dos contextos en que hemos recogido el corpus, esto es, las clases y las entrevistas. Para el tratamiento de los datos, hemos recurrido a la etiquetación de las partes en las que los dicentes recurrían a su lengua materna de manera extensa, es decir, utilizándola integralmente o en la mayor parte de un discurso amplio. Así mismo, nos hemos percatado de que el uso de la LM se producía en algunas ocasiones muy específicas, las cuales hemos catalogado a través de una serie de etiquetas, explicadas ya con detalle en el Capítulo 6. Sobre un total de 1145 cambios de lengua, la utilización de la lengua materna se dio con mayor incidencia en las clases, con un total de 1119 ocasiones, a muchísima distancia de las entrevistas (apenas 26). El gráfico a continuación resalta esa abrumadora diferencia:

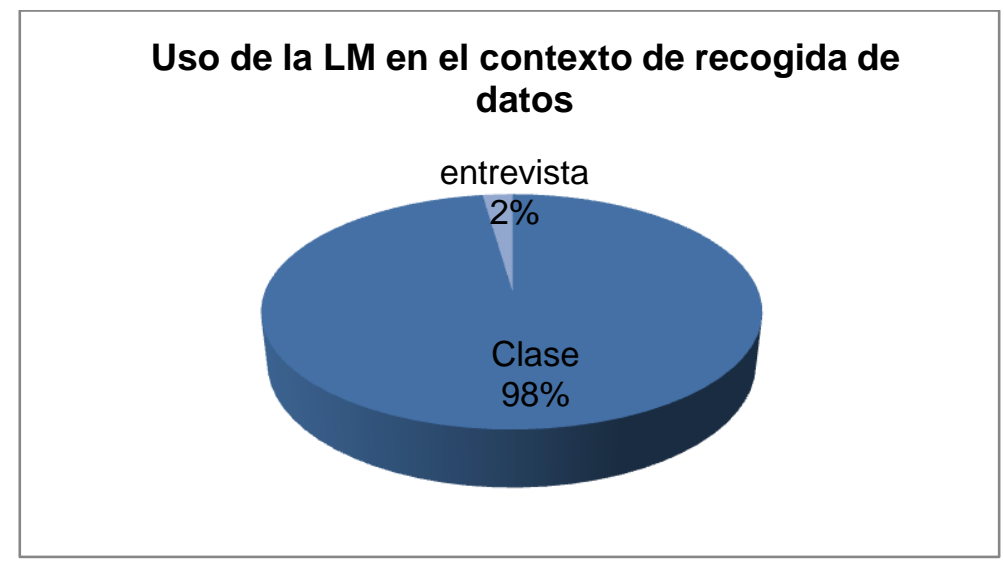

Gráfico 6: Uso de la LM en el contexto de recogida de datos

A partir de estos datos, nos interesó también conocer en qué contextos comunicativos recurrían las docentes con más frecuencia a la lengua materna. A este respecto, hemos encontrado que los 
comentarios ajenos a los temas de clase (recogidos en el gráfico con la etiqueta [comt.port]) y que sumaban un $34 \%$ y las explicaciones de los contenidos o ejercicios (agrupados mediante la etiqueta [expl.port]), con un $32 \%$ fueron los contextos más proclives al cambio de lengua, con valores muy superiores a los del resto. Las traducciones al portugués, (etiqueta [trad.port]), las preguntas ([cuest.port]) y las órdenes en clase ([orden port]) tuvieron incidencias bastante inferiores (un 13\%, 11\%, y 10\%, respectivamente). En el gráfico 7 se plasma esa diferencia:

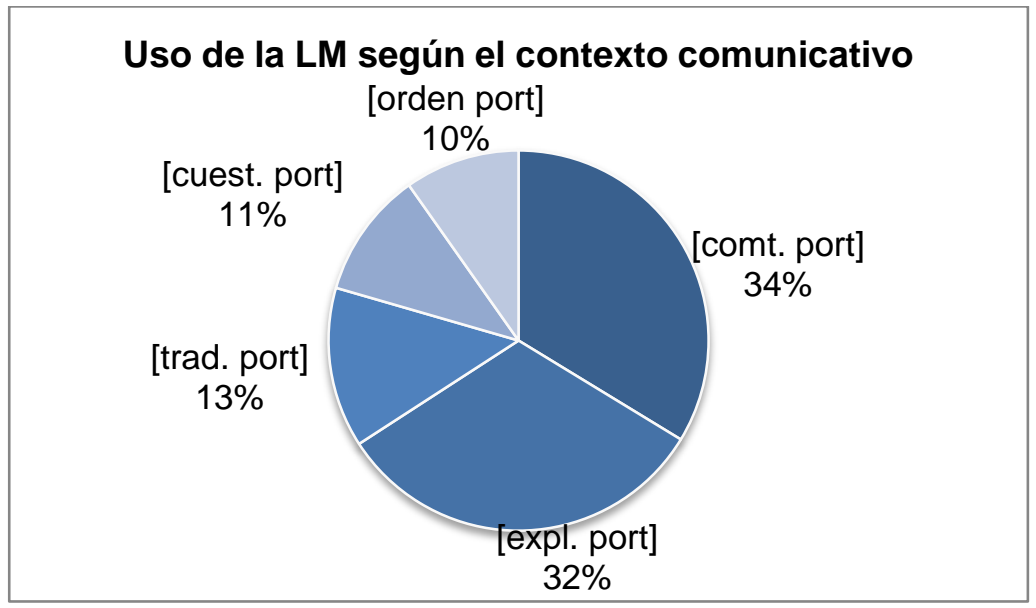

Gráfico 7: Uso de la LM según el contexto comunicativo.

Conviene subrayar que estos números no corresponden a la cantidad de palabras u oraciones utilizadas en la lengua materna, sino al número de veces en que los sujetos del estudio han recurrido a LM durante la grabación de las clases y las entrevistas, ya sea realizando comentarios o digresiones, explicando las actividades, traduciendo oraciones, expresiones o vocablos, preguntando a los alumnos o dando órdenes a estos. La tarea de contabilizar el número de palabras utilizadas en la lengua materna no parecía relevante para los objetivos de este trabajo; no obstante, para trabajar con un corpus de lengua española y de ahí extraer los posibles errores, nos pareció fundamental etiquetar las partes en que se utilizaba claramente la lengua portuguesa. Sobre esta cuestión, hay que añadir también que, aunque no hayamos contabilizado ni el número exacto de palabras ni el tiempo de utilización de la LM en relación con el tiempo total de grabación, 
podemos decir que el uso de la LM fue muy recurrente en las clases, a diferencia de las entrevistas, donde la presencia del portugués fue considerablemente menor, tal como hemos visto en el gráfico 6 .

En la tabla que presentamos a continuación podemos verificar de manera más pormenorizada la utilización de cada etiqueta por docente en las clases:

\begin{tabular}{|lcccccccccc|}
\hline CLASES & D1 & D2 & D3 & D4 & D5 & D6 & D7 & D8 & D9 & TOT \\
\hline [comt. port] & 45 & 44 & 81 & 46 & 49 & 67 & 4 & 18 & 17 & 371 \\
\hline [expl. port] & 45 & 32 & 2 & 107 & 35 & 29 & 15 & 71 & 28 & 364 \\
\hline [trad. port] & 8 & 11 & 1 & 16 & 13 & 6 & 8 & 73 & 20 & 156 \\
\hline [cuest. port] & 19 & 5 & 3 & 21 & 6 & 4 & 1 & 28 & 29 & 116 \\
\hline [orden port] & 16 & 22 & 0 & 8 & 41 & 4 & 2 & 2 & 17 & 112 \\
\hline Totales & 133 & 114 & 87 & 198 & 144 & 110 & 30 & 192 & 111 & 1119 \\
\hline
\end{tabular}

Tabla 29: Usos de la LM en clase.

Podemos observar que los comentarios ([comt. port]) son responsables de la mayoría de los casos en los que se acude al uso directo de la lengua materna, con 371 ocurrencias. Esto obedece, creemos, a que los comentarios son informaciones extra, realizadas por el docente, con el fin de informar sobre hechos o situaciones que no tienen que ver específicamente con la clase o con las actividades que se están llevando a cabo en el aula, así como llamar la atención de los alumnos, como vemos en el ejemplo 31. En este contexto, el docente parece entender implícitamente que tales mensajes no tienen por qué ser ofrecidos en la lengua extranjera, sino en la lengua materna de los estudiantes. En el fragmento transcrito, el comentario hace referencia a la llamada de atención de la profesora a un alumno que hablaba mientras esta explicaba el ejercicio:

(31) D2C2: tiendas são as lojas... eso... tiendas são as lojas... entonces yo les voy a preguntar... [[mucho ruido]] tá [**] eu tô tentando explicar... voy a hacer dos preguntas...

Por otro lado, el elevado número de explicaciones ([expl. port]) en lengua portuguesa (364), podrían explicarse como un intento por parte del docente de asegurarse que los conocimientos metalingüísticos impartidos se han comprendido cabalmente. Con todo, no faltan las ocasiones en las que las docentes comienzan una 
explicación en la LE, y a continuación continúan en la L1. Este es un ejemplo representativo de esta práctica por parte de la docente D4 (las intervenciones en la LM aparecen en negrita):

(32) D4C: (...) ahora ustedes vão fazer la interpretación de esta viñeta... ¿tá? la primera... traduce libremente... ya hicimos la lectura del texto... fídeos... que era macarrão... essa resposta vocês já tem... "chanquitos"... "chanquito" significa "carrinho de supermercado", também eu falei... e uma "cola" significa "uma..."? fila... então já está respondida... la número tres es una pregunta personal. [[lectura]] la historieta nos presenta algunas situaciones desagradables que a menudo ocurren en los supermercados... ¿cuál de ellas te parece la peor y por qué? então vocês vão revê-las se for possível lê-las novamente dizer qual destas situações apresentam a pior. Qual seria a pior dessas... cuatro... identifica el texto... una frase que se traduce una ironía... una amenaza... un pedido de disculpa... una resignación... [[fin lectura]] que significa uma rejeição... una sospecha... uma suspeita... y la número cinco vocês vão fazer o seguinte...

En el extracto presentado, podemos identificar claramente el cambio de código producido en el discurso académico. Este puede responder al hecho de que la profesora se da cuenta de que sus alumnos no están comprendiendo bien lo que se acaba de explicarse y, por ello, lo repite a continuación en la lengua materna de los estudiantes. Aunque quizá esta sea en el fondo una idea preconcebida más que real, lo que llevaría en todo caso a la docente a emplear los dos idiomas de manera habitual. Con todo, esta práctica recurrente puede hacer que los alumnos se relajen en exceso y no se esfuercen por comprender a la profesora, seguros como están de que tarde o temprano tendrán su explicación adicional en portugués.

En menor medida encontramos las traducciones, las preguntas y las ordenes en el idioma materno. Aun así, también en estas actividades discursivas se intuye la creencia acerca de la necesidad de hablar en la lengua de los alumnos con el fin de asegurar la comprensión por parte de estos. 
Lo anterior ocurre, sin embargo, con mucha menor frecuencia en las entrevistas, como podemos observar en el siguiente cuadro, que nos presenta los números de usos del portugués en las mismas:

\begin{tabular}{|lcccccccccc|}
\hline \multicolumn{1}{|c}{ ENTR. } & D1 & D2 & D3 & D4 & D5 & D6 & D7 & D8 & D9 & TOTAL \\
\hline [comt. port] & 2 & 2 & 4 & 1 & 6 & 0 & 0 & 0 & 0 & 15 \\
\hline [cuest. port] & 0 & 0 & 2 & 0 & 5 & 0 & 0 & 0 & 0 & 7 \\
\hline [expl. port] & 0 & 0 & 3 & 0 & 1 & 0 & 0 & 0 & 0 & 4 \\
\hline [trad. port] & 0 & 0 & 0 & 0 & 0 & 0 & 0 & 0 & 0 & 0 \\
\hline [orden port] & 0 & 0 & 0 & 0 & 0 & 0 & 0 & 0 & 0 & 0 \\
\hline Totales & 2 & 2 & 9 & 1 & 12 & 0 & 0 & 0 & 0 & 26 \\
\hline
\end{tabular}

Tabla 30: Uso de la LM en las entrevistas.

Como podemos observar, en las entrevistas el número de veces en que se recurre a la lengua materna es muy inferior. Los comentarios, que siguen siendo los primeros de la lista, con 15 ocurrencias, juegan un papel distinto que en las clases, puesto que en las entrevistas se utilizan para introducir digresiones relacionadas con el tema de la conversación, y no con tópicos externos a este (como veíamos en las clases). Este cambio de lengua puede obedecer a razones diferentes, desde lagunas léxicas en torno al tema de conversación a la simple comodidad de hablar en la lengua materna de las dos interlocutoras. Este parece ser el caso del fragmento siguiente, donde la docente D5 explica el cambio reciente que ha experimentado la enseñanza básica en Brasil, como consecuencia del cual se añade un curso lectivo, pasando de ocho a nueve años en la etapa obligatoria. Dentro de la antigua estructura, el centro educativo donde trabaja ofrecía cursos de español a partir del quinto año, que pasa a ser el sexto.

(33) E: ...y empieza en el sexto año... que es el quinto de los antiguos...

D5: não, porque a gente ainda tá com a sexta série antiga...

E: ¿entonces empieza en el sexto año?

D5: eu acho que ano que vem já vai ter porque a gente já começou né, eu acho que o ano que vem já vem o sexto ano novo se eu nao me engano// 
E: ¿y en la educación infantil ya no hay español?

D5: no... solamente inglés...

Otra característica conversacional que se produjo frecuentemente fue la interrupción de las respuestas cuando los sujetos no estaban seguros de si podían formular sus comentarios adecuadamente en la LE. Otras veces hacían también preguntas directamente a la entrevistadora acerca de vocablos desconocidos en la LE. De todas maneras, visto el bajo número de etiquetas en las entrevistas, nos aventuramos a pensar que en este contexto las docentes consiguen usar estrategias alternativas, como parafrasear las respuestas, inhibir los errores y, en cualquier caso, pensar con un poco más de tiempo. Estrategias que probablemente las llevaron a necesitar menos de la lengua materna.

Como se puede apreciar tanto en la tabla 30 como en el resumen que proporciona el gráfico a continuación, el recurso a la lengua materna no es uniforme, ya que existe una cierta disparidad entre las docentes:

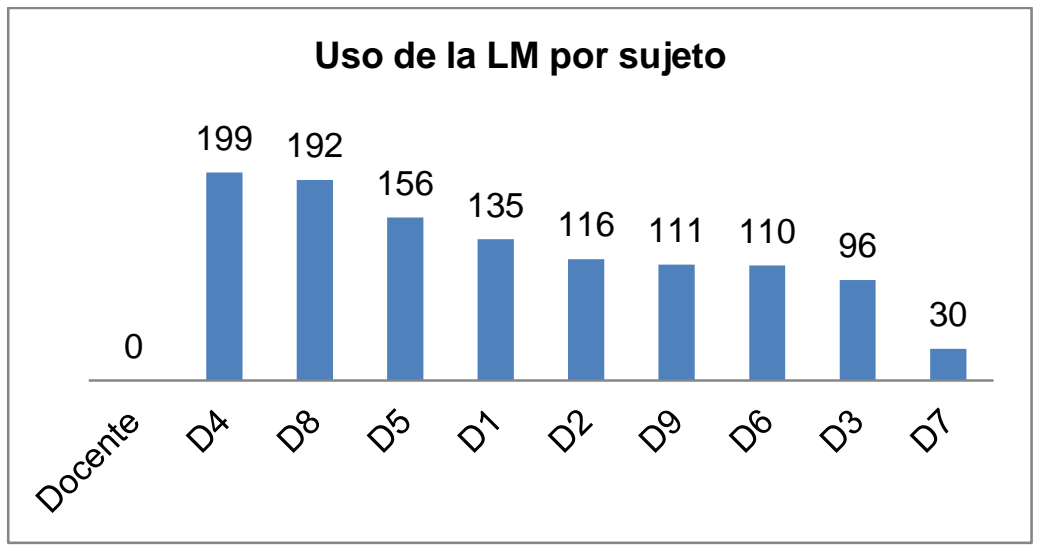

Gráfico 8: Uso de la LM por sujeto

Esta variabilidad en el cambio de lengua se puede resumir en cuatro bloques, que representan a otros tantos patrones encontrados: (i) docentes D4 y D8, con el mayor número de cambios; (ii) seguidas de un uso algo menor por parte de D5 y D1; (iii) un uso moderado por parte de las profesoras D2, D9, D6, D3; y (iv) una práctica mucho más anecdótica en el discurso de la docente D7. 
Hemos analizado también si el uso reiterado de la LM podía estar relacionado con una mayor incidencia de errores. Sin embargo, de los datos del estudio no se desprende esa relación. Así, en la tabla a continuación puede comprobarse que el mayor número de errores y etiquetas no corresponde necesariamente a las docentes que más acuden a su lengua materna en el transcurso de las clases. Y al revés: las menores dosis de cambio de código no impiden la comisión de un buen número de errores, como revelan, por ejemplo, los datos de la docente D7 que aparecen en la tabla 31, donde se ofrece un contraste entre el número de errores cometidos por cada sujeto y el número de veces que se recurrió a la LM

\section{Docente Número de errores Número de etiquetas}

\begin{tabular}{|ccc|}
\hline D9 & 413 & 111 \\
\hline D8 & 382 & 192 \\
\hline D6 & 192 & 110 \\
\hline D7 & 189 & 30 \\
\hline D4 & 186 & 199 \\
\hline D2 & 181 & 116 \\
\hline D5 & 174 & 156 \\
\hline D1 & 149 & 135 \\
\hline D3 & 75 & 96 \\
\hline Totales & 1941 & 1145 \\
\hline
\end{tabular}

Tabla 31: Número de errores $\mathrm{x}$ número de etiquetas.

\subsubsection{Valores totales encontrados}

Como señalábamos en la introducción de este trabajo, nos ha sorprendido el número de errores encontrados en el discurso de las docentes y que asciende a un total de 1941. De estos, los errores interlingüísticos suponen una aplastante mayoría en comparación con los intralingüísticos (tabla a continuación). 


\section{CLASES ENTREVISTA TOTAL}

\begin{tabular}{|lccc|} 
INTERLINGÜÍSTICOS & 855 & 723 & 1578 \\
\hline INTRALINGÜÍSTICOS & 208 & 155 & 363 \\
\hline TOTAL & 1063 & 878 & 1941 \\
\hline
\end{tabular}

Tabla 32: Totales de errores del estudio.

\subsubsection{Etiología de los errores}

Como se recordará, uno de los primeros objetivos de nuestro estudio era verificar el origen de los errores cometidos por los sujetos, profesores de español como lengua extranjera en el sur Brasil. Según nuestras hipótesis basadas en los resultados de un estudio anterior (GIMENEZ, 2011), esperábamos una incidencia mayor de los errores interlingüísticos que de los de naturaleza intralingüística. No obstante, nos sorprendió que fuera tan abrumadora tal diferencia, como podemos observar en el gráfico 9:

\section{Origen etiológico de los errores}

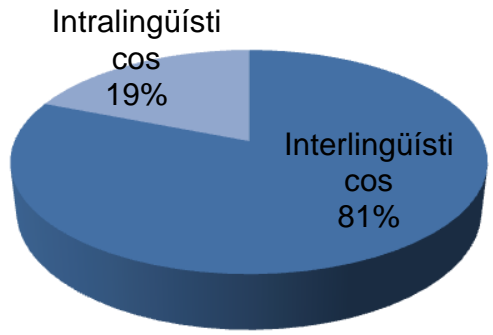

Gráfico 9: Origen etiológico de los errores.

En efecto, del total de 1941 errores recogidos en esta investigación, 1578 (81\%) pertenecen al primer grupo, mientras que tan solo 363 (19\%) corresponden al segundo tipo. 


\subsubsection{Errores por contexto de recogida}

Acerca de los diferentes contextos de recogida del corpus, como hemos podido apreciar en la tabla 32, el número global de errores en los diferentes contextos es bastante similar. En las clases, tenemos un total de 1063, (55\%) mientras que en las entrevistas este desciende levemente 878 (45\%). La ventaja de las primeras con respecto a estas últimas puede verse en el gráfico 10:

\section{Errores por contexto de recogida}

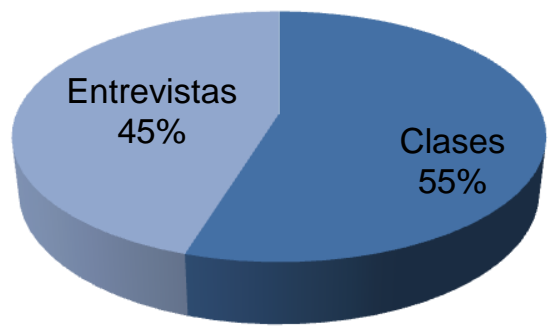

Gráfico 10: Número de errores por contexto de recogida.

Asimismo hemos comprobado que el número de errores tanto interlingüísticos como intralingüísticos sigue también proporciones muy parecidas en ambos contextos. Así, hemos encontrado que en las clases los errores interlingüísticos suman un total de $855(80 \%)$, mientras que los intralingüísticos ascienden a $208(20 \%)$. Y algo parecido sucede en el seno de las entrevistas: interlingüísticos ( $n=723 ; 82 \%)$ vs. intralingüísticos ( $n=155 ; 13 \%)$. El siguiente gráfico nos ayuda a apreciar mejor ese paralelismo: 


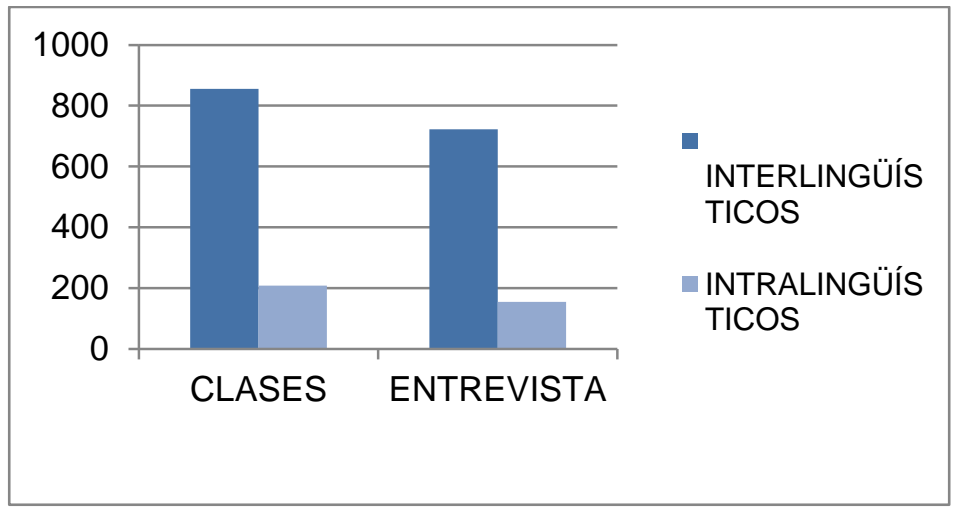

Gráfico 11: Etiología de los errores por contexto de recogida.

Como vemos, parece haber una proporción similar de los tipos de errores encontrados independiente del contexto donde reproducen.

\subsubsection{Errores por categoría}

Otro de nuestros primeros objetivos era el de verificar qué errores gramaticales interlingüísticos eran más frecuentes. Sobre esta cuestión, hemos encontrado que, en términos generales, los errores de Nexos y formas periféricas son los más usuales $(n=565)$, seguidos por los que atañen, respectivamente, a los grupos Verbal $(n=354)$, Otros (esta categoría alberga tanto las transferencias directas como las creaciones de sustantivos, adjetivos y unidades fraseológicas así como los heterosemánticos) ( $n=239)$, Determinantes $(n=139)$, Adverbios $(n=136)$, Pronombres $(n=128)$ y Flexión nominal $(n=17)$. En la que sigue presentamos estos valores de manera comparativa entre los contextos de recogida:

\begin{tabular}{|llrrr|}
\hline & CATEGORIAS & CLASES & ENTREVISTA & TOTAL \\
\hline 1 & Nexos y formas periféricas & 319 & 246 & $\mathbf{5 6 5}$ \\
\hline 2 & El verbo & 166 & 188 & $\mathbf{3 5 4}$ \\
\hline 3 & Otros & 113 & 126 & $\mathbf{2 3 9}$ \\
\hline 4 & Determinantes & 94 & 45 & $\mathbf{1 3 9}$ \\
\hline
\end{tabular}




\begin{tabular}{|llrrr|}
\hline 5 & Adverbios & 67 & 69 & $\mathbf{1 3 6}$ \\
\hline 6 & Pronombres & 91 & 37 & $\mathbf{1 2 8}$ \\
\hline 7 & Flexión nominal & 5 & 12 & $\mathbf{1 7}$ \\
\hline Total errores interlingüísticos & $\mathbf{8 5 5}$ & $\mathbf{7 2 3}$ & $\mathbf{1 5 7 8}$ \\
\hline
\end{tabular}

Tabla 33: Tipos de errores interlingüísticos.

Si analizamos las categorías separadamente en comparación a su contexto de recogida, veremos que coinciden en frecuencia los nexos y formas periféricas los verbos y el grupo "otros". Por el contrario, hay mayor disparidad en las categorías de determinantes, adverbios, pronombres y flexión nominal Si analizamos ahora las categorías de manera más global, es decir, uniendo los dos contextos, tenemos una visión general de los errores más frecuentes que puede ser observada en el de abajo:

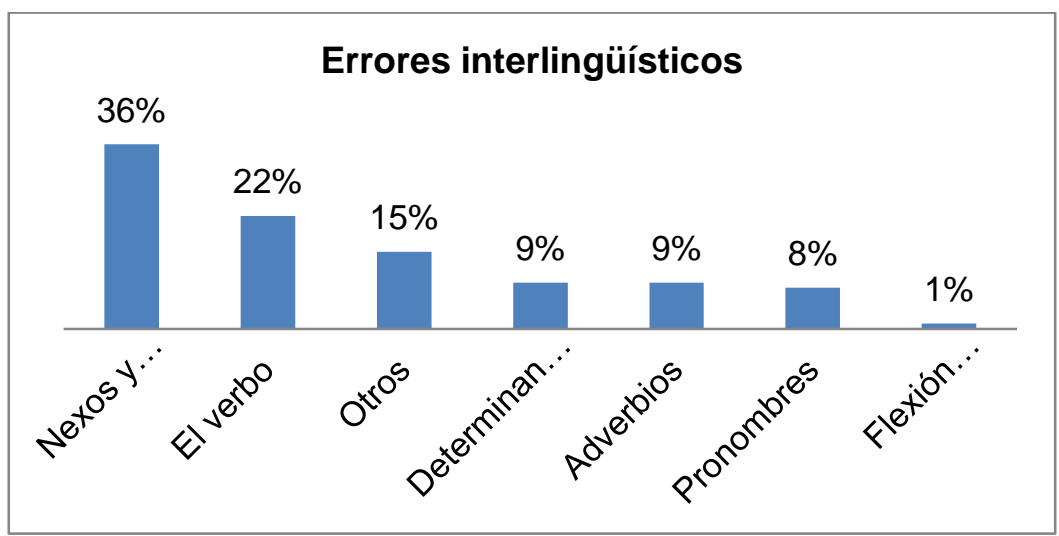

Gráfico 12: Errores interlingüísticos gramaticales.

Como vemos, si tenemos en cuenta la categoría gramatical, los errores relacionados con el uso de nexos y formas periféricas son los más frecuentes, seguidos de aquellos vinculados al paradigma verbal y del grupo heterogéneo de "otros". De forma más equilibrada encontramos los errores en determinantes, adverbios y pronombres, y casi inexistentes en el seno de la flexión nominal. 


\subsubsection{Errores léxicos más frecuentes}

Tal como hemos explicado en la introducción de este trabajo, en una mirada más detenida sobre los datos, nos hemos percatado de que los errores léxicos aparecían en muchas categorías y eran sin duda los más incidentes. Así, de los 1578 errores interlingüísticos encontrados, vemos que 948 de ellos pertenecen al grupo léxico, es decir, un $60 \%$, frente a un $40 \%$ de las demás categorías.

\section{Errores interlingüísticos}

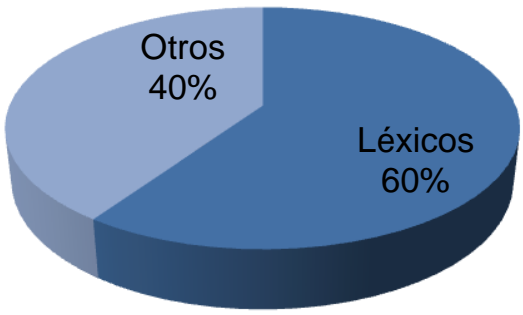

Gráfico 13: Errores léxicos x otras categorías.

\subsubsection{Tipos de errores léxicos}

Estos errores interlingüísticos lexicales están divididos en subcategorías conforme a nuestra adaptación de la tipología que encontramos en Durão (2007). En la siguiente tabla, presentamos el número de interferencias encontradas en cada una de ellas:

$$
\text { TIPO DE ERRORES }
$$

Errores de sustitución
$\Sigma$ Tot al

\begin{tabular}{|lcrr|}
\hline Errores de sustitución & Directa & 589 & 879 \\
\cline { 2 - 3 } & Analogía & 290 & \\
\hline Errores de creación de & Creación original & 15 & 39 \\
\hline
\end{tabular}




\begin{tabular}{|lrrr|}
\hline palabra nueva & Traducción prestada & 24 & \\
\hline Errores de calco & 30 & 30 \\
\hline TOTAL & 948 & 948 \\
\hline
\end{tabular}

Tabla 34: Totales de errores léxicos por tipos.

Como vemos, los errores de sustitución son los más numerosos $(\mathrm{n}=879)$, seguidos a mucha distancia por los de creación de palabras nuevas $(n=39)$ y calcos $(n=30)$. Esas diferencias quedan aún más evidentes en el gráfico 14:

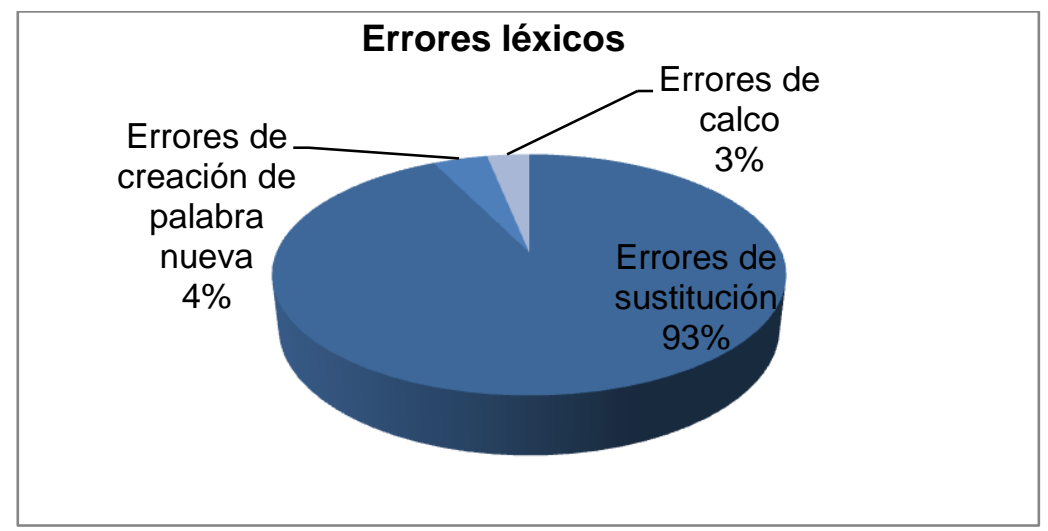

Gráfico 14: Tipos de errores léxicos y sus proporciones.

Como podemos observar, los errores de sustitución son los más numerosos, siendo los de sustitución directa $(n=589)$ bastante más frecuentes que los de analogía $(n=290)$. Unos valores más modestos podemos encontrar en los errores por creación de palabra nueva, donde la creación original se distancia de la traducción prestada en apenas nueve ocurrencias. Finalmente, los errores de calco están en valores absolutos muy cercanos a los de creación de palabra nueva.

Como hemos mencionado anteriormente, en esta primera sección del capítulo teníamos la intención de exponer un panorama general de los datos encontrados en nuestro estudio y con los cuales hemos trabajado en la segunda parte de manera más específica. 
A partir de aquí realizamos un análisis pormenorizado de los errores léxicos, que, como hemos visto, son una mayoría en comparación con otras categorías. En esta segunda parte hemos llevado a cabo los análisis contrastivos entre la lengua portuguesa y la española que nos posibilitaron entender de manera más concreta la interferencia de la lengua materna en los errores producidos. A través del análisis comparativo de las diferentes obras lexicográficas seleccionadas (vid apartado 6.5, Capítulo 6), esperamos poner a prueba nuestras hipótesis acerca de la influencia de la LM en la interlengua de los sujetos.

\subsection{Clasificación y análisis de los errores léxicos}

Conforme hemos discutido en el Capítulo 4, en este apartado presentamos una caracterización de los errores léxicos a partir de la adaptación que hicimos de la conocida taxonomía de Durão (2007, p. 39-44) sobre los errores interlingüísticos. En una primera versión habíamos catalogado los errores en cuatro grupos:

1. Producción; 2. Subproducción; 3. Superproducción; 5. Hipercorrección. No obstante, dado el volumen de datos, hemos tenido que limitar nuestro análisis a los de producción.

\subsubsection{Errores de producción}

De acuerdo con la adaptación que realizamos de la taxonomía de Durão (2007), los errores interlingüísticos de producción se dividen, a su vez, en los siguientes tipos:

a) Sustitución

a. Directa

b. Por analogía

b) Creación de palabra nueva

a. Traducción prestada

b. Creación original

c) Calco 
En esta sección presentaremos y explicaremos los errores encontrados siguiendo este mismo orden.

\subsubsection{Errores de sustitución}

En este subapartado presentamos los errores de producción por sustitución, es decir, aquellos que ocurren por el "uso de formas de la lengua materna en la lengua objeto" (DURÃO, 2007, p. 39). Hemos encontrado un total de $n=879$ errores por sustitución en nuestro corpus, de los cuales $589(67 \%)$ se deben a la sustitución directa, mientras que 290 (33\%) obedecen a la sustitución por analogía.

\subsection{Errores de sustitución directa}

En los errores de sustitución directa observamos el empleo del uso de los vocablos de la lengua portuguesa en lugar de los patrimoniales de la lengua española. Como hemos visto en la primera parte de esta sección (véase gráfico 14), los errores por sustitución son los más numerosos en nuestro estudio, con un total de $93 \%$ de las ocurrencias. De estos, los errores de sustitución directa son los más incidentes, llegando a un total de 62\% $(n=589)$ del total de errores léxicos encontrados e en el estudio.

En el gráfico 15 presentamos una distribución de estos errores por categorías. Como se puede apreciar, el grupo más nutrido es el de "nexos y formas periféricas", con un total de 241 transferencias (un $41 \%$ ), seguido del grupo verbal, con 144 errores (un 24\%). En tercer lugar, aparece el grupo que hemos denominamos "Otros", el cual incluye errores de sustitución directa referentes a sustantivos, adjetivos y unidades fraseológicas), con un total de 73 ocurrencias (un 12\%) y muy cerca de este el grupo de los "adverbios", con 68 interferencias (12\%). Por último, y aunque en menor medida, hemos detectado también las transferencias de "pronombres" ( $n=33 ; 6 \%)$ y "determinantes" ( $n=30 ; 5 \%)$. 


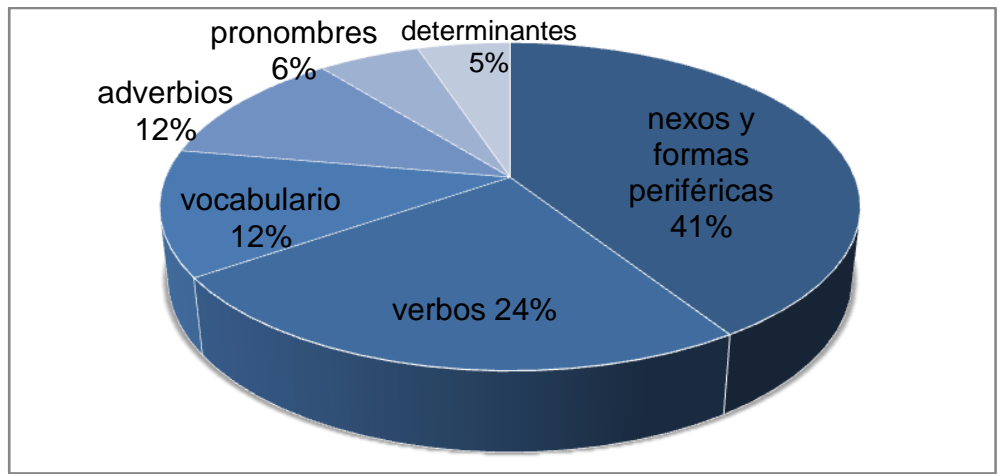

Gráfico 15: Totales de transferencias directas.

En los apartados siguientes, damos cuenta de manera más pormenorizada de estos errores, clasificados según su categoría. Con el objetivo de facilitar la lectura, hemos elaborado diversas tablas en cuyas columnas aparecen, respectivamente: a) el número de veces que encontramos el vocablo en el corpus, b) los sujetos que lo han utilizado, c) la forma de la lengua materna empleada, d) la forma correspondiente en la lengua objeto, y e) la obra lexicográfica utilizada para el contraste entre las dos lenguas.

Sobre estos dos últimos aspectos, conviene subrayar que en las palabras con más de una acepción en el diccionario, hemos optado por la(s) forma(s) que más se asemejaba(n) a la(s) que, en nuestra opinión y a partir del contexto de uso, el sujeto quiso emplear. Para eso nos hemos apoyado en los postulados de Corder (1981b, p. 37-38), sobre la reconstrucción plausible de los errores (ver Capítulo 4), en los cuales se dedica una especial atención al contexto en que tuvo lugar el error, y en donde nuestra intuición como hablante nativa de la misma lengua materna que los sujetos juega un papel fundamental.

Hemos elegido para esta tarea el Diccionario Bilingüe de Uso (MORENO Y GONZÁLEZ, 2003), en adelante DIBU ${ }^{122}$. Apenas cinco vocablos analizados no constaban en esa obra, por lo que hemos acudido también a otras fuentes, como el Diccionario Pons Online $^{123}$ y el Word Reference, mencionados anteriormente ${ }^{124}$.

\footnotetext{
${ }^{122}$ El tomo 1 del diccionario DIBU, dirección español-portugués, será mencionado como DIBU1 y el segundo tomo, dirección portugués-español, como DIBU2.

${ }^{123}$ http://pt.pons.com/tradu\%C3\%A7\%C3\%A3o
} 
Consideramos que estas tres obras son suficientes para esta etapa de la revisión de datos ${ }^{125}$.

Los cuadros que aparecen a continuación están clasificados según el orden de frecuencia del error respecto a su clase gramatical y, dentro de cada uno de ellos, en relación a la frecuencia de uso de cada vocablo.

\subsection{Nexos y formas periféricas}

Tal como hemos señalado anteriormente, este primer grupo de palabras constituye nada menos que un $41 \%$ de todas las transferencias directas encontradas en el corpus $(n=241)$. Con todo, entre estas hay una sobrerrepresentación de dos paradigmas: los marcadores discursivos né (no), con un 44\% ( $n=105)$, y tá (vale), con un $29 \%(n=68)$. Analizaremos algunos ejemplos a continuación.

El marcador discursivo né, contracción de não (no) + é (es), es frecuentemente utilizado en portugués como la abreviación de la pregunta retórica "não é mesmo?", equivalente a "¿no es verdad?" o "¿no?". Esta frase es usada en la lengua materna de la docente, según Rocha y Rocha (2011, p. 300) "como marcador de conversación, en que se pide concordancia al oyente para lo que se está haciendo" ${ }^{\prime 26}$. Observamos que esta muletilla proveniente del portugués ha sido transferida literalmente al español en 10 ocasiones durante la entrevista de esta profesora, no ocurriendo ni una sola vez el correspondiente “¿no?" español ${ }^{127}$.

(34) D2E: ... claro que en lo* general hay un desinterés por la escuela né... pero todavía da para... para sacar algo de bueno... (10)

\footnotetext{
${ }^{124}$ http://www.wordreference.com/

125 Algunas obras adicionales serán utilizadas en otras secciones según diferentes necesidades.

${ }^{126}$ Dicionário de locuções e expressões da língua portuguesa (ROCHA y ROCHA, 2011, p. 300). Traducción nuestra.

${ }^{127}$ El uso de né también fue observado por Gonçalves (2007, p. 144), quien dedicó su tesis a la utilización de marcadores discursivos de brasileños aprendices de español.
} 
Al igual que "né", la partícula "tá" es también una abreviación, aunque esta se forme de manera distinta ${ }^{128}$. Un ejemplo de su uso en el corpus puede verse a continuación:

(35) D4C4: ... primero las preguntas en* interpretación y después vamos a hacer la traducción de la historieta... ¿tá? en el cuaderno... [expl. port]... // (12)

En este caso, el verbo "estar" en tercera persona del singular, "está" (está), se utiliza según el Diccionario AURÉLIO (versión digital) ${ }^{129}$ como sinónimo de "está bem" (está bien), "está combinado" (queda acordado). Para el Diccionario Pons Online, "tá" tendría como correspondiente el "vale" español ${ }^{130}$. Sin embargo, vemos que la docente opta por utilizar el marcador discursivo portugués hasta en 12 ocasiones. Como contrapartida, no hemos encontrado ningún uso de "vale" en el sentido de "tá" por la docente.

Queda por incluir en el grupo de los marcadores discursivos transferidos con mayor frecuencia el caso de "isso", que representa un $10 \% \quad(n=23)$ de los errores de esta categoría. "Isso" es la abreviación de "isso mesmo" (eso es), según nos explica el DIBU1 (p. 298). Con todo, según el Diccionario AURÉLIO, "isso" es también una interjección que significa "muito bem" (muy bien) o "está certo" (correcto). Veamos un ejemplo representativo de estos usos:

(36) D6C1: ¿Ustedes sabían que existe rato en español? solo que rato no es un animal... rato es un instante...

A: (...)

D6C1: isso... volvemos en un rato... y el animal es... ratón...

A: [[alumno contesta a la pregunta]]

${ }^{128}$ A diferencia de "né", donde dos vocablos (não y é) se "funden" para crear uno nuevo, en "tá" lo que ocurre, según el AURÉLIO (versión digital), es una variante que implica la supresión de la primera sílaba del verbo "está". A ese fenómeno se le da el nombre de "variação aferética" en portugués.

${ }^{129}$ Otras expresiones abreviadas por "tá", segundo el mismo diccionario son:

1.Está bem; está combinado; aceito, concordo, topo:

Tá, faremos o negócio amanhã.

2.Está bem; estou ouvindo ou entendendo:

- Alô! está falando aqui o Carlos. I - Tá, que há de novo? [Cf. ta.]

${ }^{130}$ Fuente:

http://pt.pons.com/tradu\%C3\%A7\%C3\%A3o?q=t\%C3\%A1\&l=espt\&in=\&lf=pt accedido el 26/06/2016 
D6C1: isso... está correcto... es una heterosemántica... (...) yo estoy trabajando con eso en el primer año...//

En (36) se comprueba cómo la docente utiliza - hasta en 2 ocasiones- en la misma secuencia la interjección "isso", con el objetivo de reforzar positivamente las respuestas de los alumnos. Al hacer uso del pronombre español "eso" con una función referencial más adelante, hay pocas dudas de que el empleo que observamos de "isso" es el relativo a su función como marcador discursivo más que como pronombre demostrativo.

Dado que los nexos y demás formas periféricas constituyen el grupo de palabras más frecuentemente utilizado como muletillas y marcadores en el discurso oral, no extraña que figure entre las más frecuentes en el cómputo de los errores. No obstante, llama la atención que sean prácticamente los mismos sujetos quienes utilizan masivamente los marcadores mencionados (D1; D2; D4; D5; D8), como podemos observar en la tabla 35, en la cual recogemos los nexos y formas periféricas transferidos:

\begin{tabular}{|c|c|c|c|c|}
\hline$\Sigma$ & Sujeto & $\begin{array}{l}\text { Forma em } \\
\text { la LM }\end{array}$ & $\begin{array}{c}\text { Forma en la } \\
\text { LE }\end{array}$ & Fuente \\
\hline $\begin{array}{l}10 \\
5\end{array}$ & $\begin{array}{l}\text { D1/D2/D4/D7/ } \\
\text { D8 }\end{array}$ & né & adv. neg. no & DIBU1, p. 547 \\
\hline 68 & $\begin{array}{l}\text { D1/D2/D4/D5/ } \\
\text { D8/D9 }\end{array}$ & tá & interj. vale & 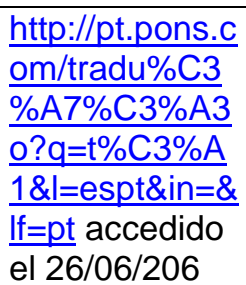 \\
\hline 23 & $\begin{array}{l}\text { D2/D3/D4/D5/ } \\
\text { D6/D7 }\end{array}$ & isso & $\begin{array}{l}\text { pron. dem. } \\
\text { eso } \\
\text { (eso es) }\end{array}$ & DIBU1, p. 298 \\
\hline 14 & $\begin{array}{l}\text { D1/D2/D4/D7/ } \\
\text { D8/D9 }\end{array}$ & $\begin{array}{l}\text { na(s) } \\
\text { (contracció } \\
\text { n de em+a) }\end{array}$ & en la(s) & DIBU2, p. 757 \\
\hline 8 & D2/D9 & $\begin{array}{l}\text { daí } \\
\text { (contracció } \\
\text { n de de+aí) }\end{array}$ & $\begin{array}{l}\text { adv. } \\
\text { entonces }\end{array}$ & DIBU2, p. 286 \\
\hline 7 & $\begin{array}{l}\text { D1/D2/D5/D6/ } \\
\text { D8/D9 }\end{array}$ & $\begin{array}{l}\text { pra } \\
\text { (contracció } \\
\text { n de "para") }\end{array}$ & prep. para & DIBU2, p. 826 \\
\hline
\end{tabular}




\begin{tabular}{|l|l|l|l|l|}
\hline 6 & D6/D8/D9 & e & $\begin{array}{l}\text { conj. y } \\
\text { (o ausencia } \\
\text { de ella) }\end{array}$ & DIBU2, p. 359 \\
\hline 2 & D9 & $\begin{array}{l}\text { aos } \\
\text { (contracció } \\
\text { n de a+os) }\end{array}$ & a los & DIBU1, p. 23 \\
\hline 3 & D9 & $\begin{array}{l}\text { às doce... } \\
\text { (contracció } \\
\text { n de a+as) }\end{array}$ & a las & DIBU2, p. 79 \\
\hline 2 & D2/D9 & até & prep. hasta & DIBU2, p. 87 \\
\hline 1 & D1 & $\begin{array}{l}\text { da } \\
\text { (contracció } \\
\text { n de de+a) }\end{array}$ & de la & DIBU2, p. 286 \\
\hline 1 & D8 & $\begin{array}{l}\text { deste } \\
\text { (contracció } \\
\text { n de } \\
\text { de+este) }\end{array}$ & de este & DIBU2, p. 332 \\
\hline 1 & D6 & opa & interj. ahí va & DIBU2, p. 794 \\
\hline
\end{tabular}

Tabla 35: Errores de sustitución directa de nexos y formas periféricas.

Como se puede comprobar, en la tabla aparece también otro grupo transferencias directas, relacionado esta vez con el paradigma de las contracciones, las cuales suman un $14 \%(n=35)$ del total. Se trata de las siguientes: na, daí, para, aos, às, da y deste. Esta relativa abundancia de las contracciones puede que obedezca al hecho de que nos encontramos ante una categoría más frecuente en portugués que en español y, por lo tanto, más propensa a ser transferida. A ese respecto, por ejemplo, la Gramática y Práctica de Español para Brasileños (FANJUL, 2011, p. 216) recoge 4 contracciones posibles en español frente a 69 del portugués.

Finalmente, encontramos también otras transferencias, aunque de manera mucho más ocasional. Este es el caso de la conjunción e (y), con seis ocurrencias; até (hasta) con dos; y opa (ahí va) con un solo ejemplo.

\subsection{Verbos}

En este apartado presentamos las transferencias verbales, que son el segundo tipo de transferencia directa más común detectado, y del que encontramos 144 ocurrencias (un $24 \%$ del total de transferencias directas). Vemos que ocurren principalmente con 
los verbos que tienen alguna similitud entre las dos lenguas, ( $n=$ 135 ; 95\%) -un ejemplo en (37) -, frente a un exiguo $5 \%(n=7)$ para aquellos cuya forma difiere, como en el ejemplo (38):

(37) D5C4: ... muy bien... ahora nosotros vamos a corrigir los números...// (7)

El empleo del verbo portugués corrigir (corregir), utilizado en 7 ocasiones por la misma docente queda patente en este ejemplo. La diferencia formal entre los dos verbos del portugués y el español es mínima, y por ello puede diluirse fácilmente entre hablantes de lenguas próximas como los que tratamos. Y lo mismo ocurre con la mayoría de los demás verbos hallados en el corpus ${ }^{131}$ (ejemplos: pode/puede; há/hay; induzem/inducen; possuo/poseo). Ya en menor escala tenemos los pares en los que no existe esa similitud formal, como vemos en el ejemplo 5:

(38) D6E: ... intenté hablar más en español... algunos dicieron* que acharam bueno... que les gustó...//

En el caso de acharam (v. achar), y a diferencia del ejemplo anterior, no hay correspondencia formal con el vocablo equivalente en la LO (consideraron). Dada la proximidad lingüística entre las dos lenguas, los verbos formalmente disímiles son minoría, pero no por ello representan menos problemas comunicativos. En la tabla 36 exponemos los errores de sustitución directa de los verbos formalmente similares entre las dos lenguas:

\begin{tabular}{|l|l|l|l|l|}
\hline$\Sigma$ & Sujeto & $\begin{array}{l}\text { Forma } \\
\text { transferida }\end{array}$ & Forma en la LO & Fuente \\
\hline \multicolumn{3}{|l|}{ SER - SER (57) } \\
\hline \multirow{3}{*}{52} & $\begin{array}{l}\text { D1/D2/D3/ } \\
\text { D4/D5/D6/ }\end{array}$ & é & $\begin{array}{l}\text { lig./-impers./-intr. } \\
\text { ser } \\
\text { (es) }\end{array}$ & $\begin{array}{l}\text { DIBU2, p. } \\
1065\end{array}$ \\
& D8/D9 & & $\begin{array}{l}\text { lig. ser } \\
\text { (son) }\end{array}$ & $\begin{array}{l}\text { DIBU2, p. } \\
1065\end{array}$ \\
\hline \multirow{2}{*}{4} & D1/D9 & são & $\begin{array}{l}\text { lig. ser } \\
\text { (sean) }\end{array}$ & $\begin{array}{l}\text { DIBU2, p. } \\
1065\end{array}$ \\
\hline \multirow{2}{*}{1} & D5 & serem & & \\
\hline \multicolumn{7}{|l}{ TER - TENER (15) }
\end{tabular}

\footnotetext{
${ }^{131}$ Lamentablemente, un estudio etimológico detallado del vocabulario que aquí se presenta está fuera de nuestras posibilidades en este trabajo. No obstante, puede ser una valiosa contribución en estudios futuros.
} 


\begin{tabular}{|c|c|c|c|c|}
\hline 6 & D2 /D7 & tem & $\begin{array}{l}\text { Haber } \\
\text { (hay) }\end{array}$ & $\begin{array}{l}\text { DIBU2, } p . \\
1141\end{array}$ \\
\hline 3 & D6/D8 & temos & $\begin{array}{l}\text { tr. tener } \\
\text { (tenemos) }\end{array}$ & $\begin{array}{l}\text { DIBU2, p. } \\
1141\end{array}$ \\
\hline 3 & D1/D5 & ter & aux. haber & $\begin{array}{l}\text { DIBU1, p. } \\
381\end{array}$ \\
\hline 2 & D8 & ter & tr. tener & $\begin{array}{l}\text { DIBU2, p. } \\
1141\end{array}$ \\
\hline 1 & D9 & tenho & $\begin{array}{l}\text { tr. tener } \\
\text { (tengo) }\end{array}$ & $\begin{array}{l}\text { DIBU2, p. } \\
1141\end{array}$ \\
\hline \multicolumn{5}{|c|}{ IR - IR (8) } \\
\hline 2 & D9 & vai & $\begin{array}{l}\text { intr.-tr.-pred. ir } \\
\text { (ve) }\end{array}$ & $\begin{array}{l}\text { DIBU2, p. } \\
639\end{array}$ \\
\hline 1 & D8 & ia & $\begin{array}{l}\text { aux. ir a } \\
\text { (iba a) }\end{array}$ & $\begin{array}{l}\text { DIBU2, p. } \\
639\end{array}$ \\
\hline 1 & D8 & íamos & $\begin{array}{l}\text { intr.-tr.-pred. ir, } \\
\text { irse } \\
\text { (íbamos) }\end{array}$ & $\begin{array}{l}\text { DIBU2, p. } \\
639\end{array}$ \\
\hline 1 & D9 & indo & $\begin{array}{l}\text { intr.-tr.-pred. ir, } \\
\text { irse } \\
\text { (yendo) }\end{array}$ & $\begin{array}{l}\text { DIBU2, p. } \\
639\end{array}$ \\
\hline 1 & D2 & vai & $\begin{array}{l}\text { aux. ir a } \\
\text { (va a) }\end{array}$ & $\begin{array}{l}\text { DIBU2, p. } \\
639\end{array}$ \\
\hline 1 & D3 & vão & $\begin{array}{l}\text { intr.-tr.-pred. ir } \\
(\operatorname{van})\end{array}$ & $\begin{array}{l}\text { DIBU2, p. } \\
639\end{array}$ \\
\hline 1 & D9 & vou & $\begin{array}{l}\text { intr.-tr.-pred. ir } \\
\text { (voy) }\end{array}$ & $\begin{array}{l}\text { DIBU2, p. } \\
639\end{array}$ \\
\hline \multicolumn{5}{|c|}{ CORRIGIR -CORREGIR (8) } \\
\hline 7 & D5 & corrigir & tr. corregir & $\begin{array}{l}\text { DIBU2, p. } \\
267\end{array}$ \\
\hline 1 & D9 & corrigindo & $\begin{array}{l}\text { tr. corregir } \\
\text { (corrigiendo) }\end{array}$ & $\begin{array}{l}\text { DIBU2, p. } \\
267\end{array}$ \\
\hline \multicolumn{5}{|c|}{ ESTAR - ESTAR (6) } \\
\hline 4 & D2/D9 & $\begin{array}{l}\text { tá }^{32} \\
\text { (estar) (col) }\end{array}$ & $\begin{array}{l}\text { lig. estar } \\
\text { (está) }\end{array}$ & $\begin{array}{l}\text { DIBU2, } p . \\
451\end{array}$ \\
\hline 2 & DE & $\begin{array}{l}\operatorname{tava}^{133} \\
\text { (estar) (col) }\end{array}$ & $\begin{array}{l}\text { lig. estar } \\
\text { (estava) }\end{array}$ & $\begin{array}{l}\text { DIBU2, p. } \\
451\end{array}$ \\
\hline \multicolumn{5}{|c|}{ DIZER - DECIR (5) } \\
\hline 3 & D8/D9 & $\begin{array}{l}\text { diz } \\
\text { (dizer) }\end{array}$ & $\begin{array}{l}\text { tr. decir } \\
\text { (dice) }\end{array}$ & $\begin{array}{l}\text { DIBU2, p. } \\
350\end{array}$ \\
\hline 1 & D8 & $\begin{array}{l}\text { disse } \\
\text { (dizer) }\end{array}$ & $\begin{array}{l}\text { tr. decir } \\
\text { (dijo) }\end{array}$ & $\begin{array}{l}\text { DIBU2, p. } \\
350\end{array}$ \\
\hline 1 & D1 & dizer & tr. decir & DIBU2, p. \\
\hline
\end{tabular}

\footnotetext{
${ }^{132}$ Forma abreviada de uso coloquial del verbo "estar".

${ }^{133}$ Forma abreviada de uso coloquial del verbo "estar".
} 


\begin{tabular}{|c|c|c|c|c|}
\hline & & & & 350 \\
\hline \multicolumn{5}{|c|}{ PODER - PODER (4) } \\
\hline 3 & D2/D7 & pode & $\begin{array}{l}\text { tr. poder } \\
\text { (puede) }\end{array}$ & $\begin{array}{l}\text { DIBU2, p. } \\
890\end{array}$ \\
\hline 1 & D8 & podem & $\begin{array}{l}\text { tr. poder } \\
\text { (pueden) }\end{array}$ & $\begin{array}{l}\text { DIBU2, p. } \\
890\end{array}$ \\
\hline \multicolumn{5}{|c|}{ TENTAR - INTENTAR (4) } \\
\hline 3 & D4/D8 & tentar & tr. intentar & $\begin{array}{l}\text { DIBU2, p. } \\
1140\end{array}$ \\
\hline 1 & D5 & tento & $\begin{array}{l}\text { tr. intentar } \\
\text { (intento) }\end{array}$ & $\begin{array}{l}\text { DIBU2, p. } \\
1140\end{array}$ \\
\hline \multicolumn{5}{|c|}{ OTROS (30) } \\
\hline 5 & D5/D8 & $\begin{array}{l}\text { há } \\
\text { (haver) }\end{array}$ & $\begin{array}{l}\text { impers. haber } \\
\text { (hay) }\end{array}$ & $\begin{array}{l}\text { DIBU2, p. } \\
577\end{array}$ \\
\hline 4 & D8/D9 & estudar & intr.-tr. estudiar & $\begin{array}{l}\text { DIBU2, p. } \\
464\end{array}$ \\
\hline 1 & D8 & aguentar & tr.-intr. aguantar & DIBU2, p. 33 \\
\hline 1 & D4 & $\begin{array}{l}\text { aprendendo } \\
\text { (aprender) }\end{array}$ & $\begin{array}{l}\text { tr.-intr. aprender } \\
\text { (aprendiendo) }\end{array}$ & DIBU2, p. 66 \\
\hline 1 & D9 & $\begin{array}{l}\text { atendendo } \\
\text { (atender) }\end{array}$ & $\begin{array}{l}\text { tr.-intr. atender } \\
\text { (atendiendo) }\end{array}$ & DIBU2, p. 87 \\
\hline 1 & D9 & $\begin{array}{l}\text { chega } \\
\text { (chegar) }\end{array}$ & $\begin{array}{l}\text { tr.-intr. Ilegar } \\
\text { (Ilega) }\end{array}$ & $\begin{array}{l}\text { DIBU2, p. } \\
194\end{array}$ \\
\hline 1 & D2 & começar & $\begin{array}{l}\text { tr.-intr. comenzar, } \\
\text { empezar, }\end{array}$ & $\begin{array}{l}\text { DIBU2, p. } \\
219\end{array}$ \\
\hline 1 & D6 & $\begin{array}{l}\text { comemorado } \\
\text { (comemorar) }\end{array}$ & $\begin{array}{l}\text { tr.-intr. } \\
\text { conmemorar } \\
\text { (conmemorado) }\end{array}$ & $\begin{array}{l}\text { DIBU2, p. } \\
219\end{array}$ \\
\hline 1 & D8 & $\begin{array}{l}\text { costumo } \\
\text { (costumar) }\end{array}$ & $\begin{array}{l}\text { tr. acostumbrar } \\
\text { (acostumbro) }\end{array}$ & $\begin{array}{l}\text { DIBU2, p. } \\
270\end{array}$ \\
\hline 1 & D6 & $\begin{array}{l}\text { creio } \\
\text { (crer) }\end{array}$ & $\begin{array}{l}\text { tr. creer } \\
\text { (creo) }\end{array}$ & $\begin{array}{l}\text { DIBU2, p. } \\
274\end{array}$ \\
\hline 1 & D8 & $\begin{array}{l}\text { demostram } \\
\text { (demonstrar) }\end{array}$ & $\begin{array}{l}\text { tr. demostrar } \\
\text { (demuestran) }\end{array}$ & $\begin{array}{l}\text { DIBU2, p. } \\
303\end{array}$ \\
\hline 1 & D4 & $\begin{array}{l}\text { dependendo } \\
\text { (depender) }\end{array}$ & $\begin{array}{l}\text { tr. depender } \\
\text { (dependiendo) }\end{array}$ & $\begin{array}{l}\text { DIBU2, p. } \\
305\end{array}$ \\
\hline 1 & D2 & $\begin{array}{l}\text { deu } \\
\text { (dar) }\end{array}$ & $\begin{array}{l}\text { tr.-intr. dar } \\
\text { (dió) }\end{array}$ & $\begin{array}{l}\text { DIBU2, p. } \\
228\end{array}$ \\
\hline 1 & D8 & $\begin{array}{l}\text { induzem } \\
\text { (induzir) }\end{array}$ & $\begin{array}{l}\text { tr. inducir } \\
\text { (inducen) }\end{array}$ & $\begin{array}{l}\text { DIBU2, p. } \\
616\end{array}$ \\
\hline 1 & D2 & $\begin{array}{l}\text { mostra } \\
\text { (mostrar) }\end{array}$ & $\begin{array}{l}\text { tr. mostrar } \\
\text { (muestra) }\end{array}$ & $\begin{array}{l}\text { DIBU2, p. } \\
748\end{array}$ \\
\hline 1 & D9 & $\begin{array}{l}\text { penses } \\
\text { (pensar) }\end{array}$ & $\begin{array}{l}\text { intr. pensar } \\
\text { (pienses) }\end{array}$ & $\begin{array}{l}\text { DIBU2, p. } \\
861\end{array}$ \\
\hline 1 & D3 & $\begin{array}{l}\text { possuo } \\
\text { (possuir) }\end{array}$ & $\begin{array}{l}\text { tr. poseer } \\
\text { (poseo) }\end{array}$ & $\begin{array}{l}\text { DIBU2, p. } \\
905\end{array}$ \\
\hline
\end{tabular}




\begin{tabular}{|l|l|l|l|l|}
\hline 1 & D8 & sair & tr.-intr. salir & $\begin{array}{l}\text { DIBU2, p. } \\
1037\end{array}$ \\
\hline 1 & D9 & $\begin{array}{l}\text { submergi } \\
\text { (submergir) }\end{array}$ & $\begin{array}{l}\text { intr.-tr.-prnl. } \\
\text { sumergir } \\
\text { (sumergí) }\end{array}$ & $\begin{array}{l}\text { DIBU2, p. } \\
1103\end{array}$ \\
\hline 1 & D9 & $\begin{array}{l}\text { trazia } \\
\text { (trazer) }\end{array}$ & $\begin{array}{l}\text { tr. traer } \\
\text { (traía) }\end{array}$ & $\begin{array}{l}\text { DIBU2, p. } \\
1178\end{array}$ \\
\hline 1 & D1 & treinar & $\begin{array}{l}\text { intr.-tr.-prnl. } \\
\text { entrenar }\end{array}$ & $\begin{array}{l}\text { DIBU2, p. } \\
1179\end{array}$ \\
\hline 1 & D8 & vem & $\begin{array}{l}\text { tr. venir } \\
\text { (viene) }\end{array}$ & $\begin{array}{l}\text { DIBU2, p. } \\
\text { (vir) }\end{array}$ \\
\hline 1 & D6 & $\begin{array}{l}\text { vendo } \\
\text { (ver) }\end{array}$ & $\begin{array}{l}\text { tr.-intr. ver } \\
\text { (viendo) }\end{array}$ & $\begin{array}{l}\text { DIBU2, p. } \\
1213\end{array}$ \\
\hline
\end{tabular}

Tabla 36: Errores de substitución directa de verbos formalmente similares.

Por su parte, la tabla 37 sintetiza los errores de sustitución directa de los verbos formalmente disímiles:

\begin{tabular}{|c|c|c|c|c|}
\hline$\Sigma$ & $\begin{array}{l}\text { Suj } \\
\text { eto }\end{array}$ & $\begin{array}{l}\text { Forma } \\
\text { transferida }\end{array}$ & Forma en la LO & Fuente \\
\hline \multicolumn{5}{|c|}{ LEMBRAR(SE) - ACORDARSE (2) } \\
\hline 1 & D9 & $\begin{array}{l}\text { lembram-se } \\
\text { (lembrar) }\end{array}$ & $\begin{array}{l}\text { tr.-prnl.-intr. acordarse } \\
\text { (acuérdense) }\end{array}$ & DIBU2, p. 669 \\
\hline 1 & D8 & Lembrar & tr.-prnl.-intr. acordarse & DIBU2, p. 669 \\
\hline \multicolumn{5}{|c|}{ OTROS } \\
\hline 1 & D6 & $\begin{array}{l}\text { acharam } \\
\text { (achar) }\end{array}$ & $\begin{array}{l}\text { tr.-prnl. (considerar) } \\
\text { consideraron }\end{array}$ & DIBU2, p. 12 \\
\hline 1 & D1 & $\begin{array}{l}\text { faz } \\
\text { (fazer) }\end{array}$ & $\begin{array}{l}\text { tr. hacer } \\
\text { (hace) }\end{array}$ & $\begin{array}{l}\text { http://pt.pons.com/tr } \\
\text { adu\%C3\%A7\%C3 } \\
\% \text { A3o/portugu\%C3 } \\
\% A A s- \\
\text { espanhol/fazer } \\
\text { accedido en } \\
\text { 25/06/2016 }\end{array}$ \\
\hline 1 & D5 & $\begin{array}{l}\text { fica } \\
\text { (ficar) }\end{array}$ & $\begin{array}{l}\text { tr.-intr. quedar } \\
\text { (queda) }\end{array}$ & DIBU2, p. 512 \\
\hline 1 & D2 & $\begin{array}{l}\text { some } \\
\text { (sumir) }\end{array}$ & $\begin{array}{l}\text { intr.-prnl. desaparecer } \\
\text { (desaparece) }\end{array}$ & DIBU2, p. 1111 \\
\hline 1 & D9 & $\begin{array}{l}\text { me } \\
\text { prontificando } \\
\text { (prontificar-se) }\end{array}$ & $\begin{array}{l}\text { v. refl. ofrecerse } \\
\text { (ofreciéndome) }\end{array}$ & $\begin{array}{l}\text { http://pt.pons.com/tr } \\
\text { adu\%C3\%A7\%C3 } \\
\% \text { A3o?q=prontificar } \\
\overline{\text { se\&l=espt\&in=ac pt }} \\
\text { \&lf=pt accedido el }\end{array}$ \\
\hline
\end{tabular}




\section{\begin{tabular}{l|l|l|l}
\hline & & $25 / 06 / 2016$ \\
\hline Tabla 37: Errores de substitución directa de verbos formalmente
\end{tabular}} disímiles.

Otras consideraciones sobre los errores de sustitución directa tienen que ver con la regularidad e irregularidad verbal. Las 142 ocurrencias del grupo de errores verbales están distribuidas en 37 verbos diferentes, de los que 18 corresponden a verbos irregulares en ambas lenguas. Una lista comparativa contempla tales datos en la tabla 38 :

\begin{tabular}{|l|l|l|}
\hline & $\begin{array}{l}\text { Verbo irregular en } \\
\text { portugués }\end{array}$ & Correspondiente en español \\
\hline 1 & corrigir & corregir \\
\hline 2 & crer & creer \\
\hline 3 & dar & dar \\
\hline 4 & dizer & decir \\
\hline 5 & fazer & hacer \\
\hline 6 & haver & haber \\
\hline 7 & induzir & inducir \\
\hline 8 & ir & ir \\
\hline 9 & poder & poder \\
\hline 10 & possuir & poseer \\
\hline 11 & sair & salir \\
\hline 12 & ser & ser \\
\hline 13 & submergir & sumergir \\
\hline 14 & sumir & desaparecer \\
\hline 15 & ter & tener \\
\hline 16 & trazer & traer \\
\hline 17 & ver & ver \\
\hline 18 & vir & venir \\
\hline
\end{tabular}

Tabla 38: Verbos irregulares en ambas lenguas.

Veamos a continuación un ejemplo de transferencia directa de un verbo irregular:

(39) D8C1: ... escribir el nombre de cada objeto de la clase y después poner la letra de cada dibujo arriba en los numerales... podem empezar...//

En el ejemplo (39), poder es un verbo irregular tanto en español como en portugués, aunque la irregularidad ocurre de 
diferentes maneras en cada lengua. En portugués, en presente de indicativo, la irregularidad se manifiesta solo en la primera persona del singular posso, mientras que en español lo hace en la diptongación de casi todas las formas conjugadas (puedo, puedes, puede, podemos, podéis, pueden). Lo correcto aquí, por tanto, sería la utilización de la forma española pueden, sin embargo, la docente utiliza la forma portuguesa podem. Ese tipo de interferencia de la lengua portuguesa en los verbos irregulares del español ocurre, como hemos dicho, con la mayoría de los verbos detectados.

Un segundo grupo lo representan aquellos casos en los que el verbo transferido es regular en la lengua materna, pero irregular en la lengua objeto. Tales verbos se encuentran en la lista comparativa de la tabla 39:

\begin{tabular}{|l|l|l|}
\hline & $\begin{array}{l}\text { Verbo regular en } \\
\text { portugués }\end{array}$ & $\begin{array}{l}\text { Correspondiente irregular en } \\
\text { español }\end{array}$ \\
\hline 1 & achar & creer/parecer \\
\hline 2 & atender & atender \\
\hline 3 & começar & comenzar \\
\hline 4 & demonstrar & demonstrar \\
\hline 5 & depender & depender \\
\hline 6 & estar & estar \\
\hline 7 & lembrar & acordarse \\
\hline 8 & mostrar & mostrar \\
\hline 9 & pensar & pensar \\
\hline 10 & prontificar-se & ofrecerse \\
\hline
\end{tabular}

Tabla 39: Verbos regulares en portugués e irregulares en español.

Un ejemplo de ello sería:

(40) D6E: ... intenté hablar más en español algunos dicieron* que acharam bueno... que les gustó...//

Es bastante evidente que el verbo achar del portugués es formalmente distante de su correspondiente creer del español, o incluso de parecer, quizá la correspondencia más correcta en este caso: “... algunos dijeron que les parecía bien...”.

Finalmente, otros 9 elementos forman parte de un grupo en el que los verbos son regulares en las dos lenguas, como podemos observar a continuación. 


\begin{tabular}{|l|l|l|}
\hline & $\begin{array}{l}\text { Verbo regular en } \\
\text { portugués }\end{array}$ & $\begin{array}{l}\text { Correspondiente regular en } \\
\text { español }\end{array}$ \\
\hline 1 & aguentar & aguantar \\
\hline 2 & aprender & aprender \\
\hline 3 & chegar & llegar \\
\hline 4 & comemorar & conmemorar \\
\hline 5 & costumar & acostumbrar \\
\hline 6 & estudar & estudiar \\
\hline 7 & ficar & quedar \\
\hline 8 & tentar & intentar \\
\hline 9 & treinar & entrenar \\
\hline
\end{tabular}

Tabla 40: Verbos regulares en ambas lenguas.

Un ejemplo representativo es el de treinar:

(41) D1E: ... a veces sola... como para hacer un treinamento *... intento treinar mis clases en el espejo...

En este caso, la docente utiliza el verbo treinar, formalmente muy parecido en ambas lenguas (esp. entrenar)) y también regular en ambos idiomas.

Parece, en suma, que la transferencia directa tiene lugar más frecuentemente en el primero de los paradigmas, donde los verbos son irregulares en ambas lenguas. No obstante, también llaman la atención los casos en los que la regularidad verbal no atañe al español.

Ya en términos frecuenciales, de los 37 verbos transferidos sobresale ser, con un índice de aparición muy superior al de los demás $(n=57)$, principalmente en la conjugación de la tercera persona del singular del presente de indicativo é (es) $(n=52)$. A este respecto, es revelador que apenas uno de los sujetos (D7) no ha utilizado nunca ejemplos como los de (42) en el desarrollo de las clases o entrevistas:

(42) D9C1: ... ahora ya sabemos... cuál é la materia...

Otro verbo frecuente en el corpus es ter (tener), del que contamos con 15 ocurrencias, a distancia en todo caso, de ser. Como contrapartida, fue utilizado en más tiempos de la conjugación 
que el anterior, como se puede apreciar en la tabla 35. Uno de esos errores aparece a continuación:

(43) D8C1: ... además las palabras que terminen en "lor"... temos ahí... miren la hoja... el dolor...

Mención especial requieren las formas abreviadas tá y tava, muy comunes en el habla coloquial. Ambas aparecen ejemplificadas a continuación:

(44) D9C1: ... a veces $o^{*}$ día tiene todo el sol... pero quem* tá gris es... somos nosotros... ¿sí? (3)

(45) D2E: ... entonce ${ }^{*}$ pra* mí me quedó fácil eh... porque ya tava acostumbrada* a la lectura... (2)

Al contrario de lo que observábamos anteriormente a propósito de tá en su empleo frecuente como marcador discursivo, lo que encontramos aquí es la abreviación del verbo estar en su uso referencial, tanto en la forma del presente (tá) como en la del imperfecto de indicativo (tava).

\subsection{Otros}

A diferencia de los demás grupos, en este contemplamos más de una categoría, ya que en él se incluyen sustantivos, adjetivos, colocaciones y locuciones. Igualmente, a diferencia de otras categorías, aquí no observamos el uso preferente de ningún ítem léxico en particular, sino que, al contrario, notamos una gran variedad léxica en la transferencia de la lengua materna a la lengua objeto. Al mismo tiempo, la mayoría de estas transferencias aparece tan solo una vez en el discurso de cada sujeto, como podremos observar más detalladamente en la tabla 41. Como se recordará, en ella presentamos las cifras de ocurrencias de cada término, los sujetos que las emplearon, la forma de la LM transferida y su correspondiente en la LE.

\begin{tabular}{|c|l|c|c|c|}
\hline$\Sigma$ & Sujeto & $\begin{array}{c}\text { Forma } \\
\text { transferida }\end{array}$ & $\begin{array}{c}\text { Forma en la } \\
\text { LE }\end{array}$ & Fuente \\
\hline 5 & D1/D6 & próprio(a) & adj. propio(a) & DIBU2, p. 936 \\
\hline
\end{tabular}




\begin{tabular}{|c|c|c|c|c|}
\hline 4 & D1/D8 & estágio & $\begin{array}{l}\text { m. práctica, } \\
\text { pasantía }\end{array}$ & DIBU2, p. 449 \\
\hline 3 & D2 & $\begin{array}{l}\text { fluentemente } \\
\text { (fluente) }\end{array}$ & $\begin{array}{l}\text { adj. fluido (con } \\
\text { fluidez) }\end{array}$ & DIBU2, p. 525 \\
\hline 4 & D2/D8 & exemplo & m. ejemplo & DIBU2, p. 475 \\
\hline 2 & D6 & concerto & $\begin{array}{l}\boldsymbol{m} \text {. concierto, } \\
\text { recital }\end{array}$ & DIBU2, p. 231 \\
\hline 3 & D9 & doentes & $\begin{array}{l}\text { adj.-m. } \\
\text { enfermo(s) }\end{array}$ & DIBU2, p. 352 \\
\hline 2 & D4/D8 & mesmo & adj.-s mismo & DIBU2, p. 728 \\
\hline 2 & D9 & pessoal & chicos & DIBU2, p. 876 \\
\hline 2 & $\mathrm{D} 6$ & prazo & $\boldsymbol{m}$. plazo & DIBU2, p. 910 \\
\hline 2 & D6 & proficiência & f. competencia & DIBU2, p. 929 \\
\hline 2 & D1/D3 & sala de aula & f. aula & DIBU2, p. 1039 \\
\hline 1 & D2 & aluno & s. alumno & DIBU2, p. 44 \\
\hline 1 & D9 & (de) acordo & (de) acuerdo & DIBU2, p. 16 \\
\hline 1 & D2 & apavorados & adj. asustado & DIBU2, p. 61 \\
\hline 1 & D8 & aprendizado & f. aprendizaje & DIBU2, p. 66 \\
\hline 1 & D6 & arara & f. guacamayo & DIBU2, p. 69 \\
\hline 1 & $\mathrm{D} 2$ & arranjos & m. arreglos & DIBU2, p. 74 \\
\hline 1 & D8 & aspas & f. comillas & DIBU2, p. 80 \\
\hline 1 & D4 & ato & $\boldsymbol{m}$. acto & DIBU2, p. 89 \\
\hline 1 & D1 & branco & adj. blanco & DIBU2, p. 134 \\
\hline 1 & D9 & carregada & adj. cargada & DIBU1, p. 114 \\
\hline 1 & D6 & cognatos & $\begin{array}{l}\text { adj \& } \boldsymbol{m}, \\
\boldsymbol{f} \text { cognado(a) }\end{array}$ & $\begin{array}{l}\text { http://www.wordrefer } \\
\text { ence.com/espt/cogna } \\
\text { do accedido en } \\
08 / 07 / 2016\end{array}$ \\
\hline 1 & D4 & colunas & f. columna(s) & DIBU2, p. 217 \\
\hline 1 & D6 & começo & $\begin{array}{l}\text { m. comienzo, } \\
\text { inicio, principio }\end{array}$ & DIBU2, p. 219 \\
\hline 1 & $\mathrm{D} 1$ & contato & m. contacto & DIBU2, p. 250 \\
\hline 1 & D9 & crimes & m. crímenes & DIBU2, p. 276 \\
\hline 1 & D1 & $\begin{array}{l}\text { cursinho } \\
\text { (curso) }\end{array}$ & $\begin{array}{l}\text { diminutivo de } \\
\boldsymbol{m} \text {. curso } \\
\text { (cursito) }\end{array}$ & DIBU2, p. 284 \\
\hline 1 & D9 & deles & $\begin{array}{l}\text { adj. de él (de } \\
\text { ellos) }\end{array}$ & DIBU2, p. 300 \\
\hline 1 & D1 & desinteresse & m. desinterés & DIBU2, p. 324 \\
\hline 1 & D2 & dicas & $\begin{array}{l}\text { f. información, } \\
\text { indicación; } \\
\text { consejo, } \\
\text { sugerencia; } \\
\text { pista }\end{array}$ & DIBU2, p. 339 \\
\hline 1 & D9 & enfadonha & $\begin{array}{l}\text { adj. molesta, } \\
\text { pesada, }\end{array}$ & DIBU2, p. 393 \\
\hline
\end{tabular}




\begin{tabular}{|c|c|c|c|c|}
\hline & & & aburrida & \\
\hline 1 & D8 & $\begin{array}{l}\text { ensino } \\
\text { (religioso) }\end{array}$ & $\begin{array}{l}\boldsymbol{m} \text {. enseñanza } \\
\text { (religiosa) }\end{array}$ & DIBU2, p. 405 \\
\hline 1 & D7 & exato & adj. exacto & DIBU2, p. 471 \\
\hline 1 & D4 & fone & $\begin{array}{l}\text { m. auricular, } \\
\text { teléfono }\end{array}$ & DIBU2, p. 529 \\
\hline 1 & D2 & formaturas & $\begin{array}{l}\text { f. (ceremonia } \\
\text { de) graduación }\end{array}$ & DIBU2, p. 532 \\
\hline 1 & $\mathrm{D} 2$ & graças & gracias & DIBU2, p. 564 \\
\hline 1 & D2 & imensa & $\begin{array}{l}\text { adj. inmenso, } \\
\text { muy grande }\end{array}$ & DIBU2, p. 597 \\
\hline 1 & D6 & leituras & f. lectura(s) & DIBU2, p. 669 \\
\hline 1 & D1 & língua & m. lengua & DIBU2, p. 681 \\
\hline 1 & D2 & mão & f. mano & DIBU2, p. 707 \\
\hline 1 & D9 & medonha & adj. espantosa & DIBU2, p. 721 \\
\hline 1 & D6 & multimídia & m. multimedia & $\begin{array}{l}\text { http://pt.pons.com/tra } \\
\text { du\%C3\%A7\%C3\%A3 } \\
\text { o?q=multim\%C3\%AD } \\
\text { dia\&l=espt\&in=\&lf=pt } \\
\text { accedido el } \\
\text { 26/06/2016 }\end{array}$ \\
\hline 1 & D6 & nossa & $\begin{array}{l}\text { adj. pos. } \\
\text { pron. pos. } \\
\text { nuestra }\end{array}$ & DIBU2, p. 773 \\
\hline 1 & D8 & (de) novo & (de) nuevo & DIBU2, p. 775 \\
\hline 1 & D8 & ouvinte & s. oyente & DIBU2, p. 807 \\
\hline 1 & D2 & planejamento & $\begin{array}{l}\boldsymbol{m} \text {. } \\
\text { planificación, } \\
\text { planeamiento }\end{array}$ & DIBU2, p. 886 \\
\hline 1 & D9 & $\begin{array}{l}\text { pós (col.) } \\
\text { (pós- } \\
\text { graduação) }\end{array}$ & posgraduación & DIBU2, p. 903 \\
\hline 1 & D2 & $\begin{array}{l}\text { (prueba de) } \\
\text { proficiência }\end{array}$ & $\begin{array}{l}\text { (prueba de) } \\
\text { nivel }\end{array}$ & DIBU2, p. 929 \\
\hline 1 & D7 & $\begin{array}{l}\text { rapidinho } \\
\text { (diminutivo de } \\
\text { rápido) }\end{array}$ & $\begin{array}{l}\text { diminutivo de } \\
\text { adj. rápido } \\
\text { (rapidito) }\end{array}$ & DIBU2, p. 968 \\
\hline 1 & D6 & resposta & f. respuesta & DIBU2, p. 1004 \\
\hline 1 & D6 & $\begin{array}{l}\begin{array}{l}\text { rotero }(\mathrm{col} .) \\
\text { (roteiro) }\end{array} \\
\end{array}$ & m. ruta & DIBU2, p. 1027 \\
\hline 1 & $\mathrm{D} 2$ & som & m. sonido & DIBU2, p. 1092 \\
\hline 1 & D6 & time & m. equipo & DIBU2, p. 1149 \\
\hline 1 & D1 & treinamento & $\begin{array}{l}\boldsymbol{m} . \\
\text { entrenamiento }\end{array}$ & DIBU2, p. 1179 \\
\hline
\end{tabular}

Tabla 41: Errores de substitución directa de vocabulario. 
Este conjunto de transferencias representa el tercer grupo léxico con mayor número de errores (73 ocurrencias, un $12 \%$ del total de transferencias directas). Al igual que en el grupo anterior, en este observamos cómo son las palabras formalmente más cercanas las que cuentan con más ejemplos $(n=59)$, mientras que las más disímiles lo son en menor medida $(n=14)$ :

(46) D1E: ... muchas veces por el próprio desencanto... el próprio desinterese ${ }^{*}$...

En (46) vemos cómo la diferencia formal entre el portugués próprio y el español propio es mínima, lo cual no impide la transferencia. De hecho, estas diferencias sutiles parecen favorecer la interferencia de la lengua materna, según nuestros resultados. Por el contrario, esta se produce en menor medida entre vocablos formalmente distantes, como en (47):

(47) D1E: ... en el último año de formación en nuestro proyecto final de observación... de estágio...//

La docente usa la palabra estágio para referirse a las prácticas obligatorias en el grado que cursó. Dos términos, en consecuencia, entre los que existe una clara relación semántica, pero no formal.

Cabe subrayar, finalmente, que en este grupo de errores hemos incluido también algunas locuciones y colocaciones formal y semánticamente similares. Así ocurre, por ejemplo, con los siguientes casos: de acordo (de acuerdo); de novo (de nuevo); ensino religioso (enseñanza religiosa). Por este motivo, tales unidades están ubicadas aquí entre los errores por sustitución directa, y no en los errores de sustitución por calco, los cuales analizaremos más adelante.

\subsection{Adverbios}

El grupo de los "adverbios" representa un $12 \%$ de las transferencias directas, con un total de 68 ocurrencias. Destacan como más frecuentes los casos de então (entonces), con 21 casos (ejemplo 48), seguido por ali (allí), con 14 (ejemplo 49), y não (no), con 11 (ejemplo 50). 
(48) D8C1: ... nosotros tenemos un resumen de todas esas partes en español... então... miren la hoja por favor...

El uso de então tiene una incidencia relativamente alta $y$, de hecho, aparece en el habla de 5 de las 9 participantes en el estudio (D1/D2/D4/D8/D9). Llama la atención la utilización de este adverbio en lugar del correspondiente español, entonces, aunque este último es también habitual en el habla de nuestros sujetos

Esa variación en el uso puede explicarse a través del concepto de equivocación de Torijano Pérez (2004, p. 23), tratado en el Capítulo 4. En su teoría, el autor defiende que, el hecho de no haber constancia sobre la utilización de una forma demostraría la inseguridad de los aprendices en la producción de ciertas estructuras en la lengua extranjera. Esa "fluctuación" en la utilización de determinado vocablo está ligada a que los sujetos aún no lo han interiorizado completamente, es decir, en este caso, conocen la LO pero la interferencia de la LM aun es patente, lo que revela que su interlengua aún está sufriendo variaciones.

El adverbio ali es también utilizado por cinco de los nueve sujetos. El siguiente es un ejemplo representativo:

(49) D5E: ... yo creo que las personas que viven en la frontera con Uruguay... Paraguay... ali... yo creo que usan mucho más... [[la lengua española]]

En el caso de ali vemos que, a diferencia de então, los hablantes no utilizan en ningún momento la versión española del adverbio, con la excepción de la docente D2, quien sí lo hace durante la entrevista, si bien hay que observar que esto se produce justo después de que la entrevistadora haya utilizado el adverbio español hasta en cinco ocasiones en el contexto inmediatamente anterior. Estos resultados nos llevan a pensar en la posibilidad de que las docentes podrían no ser conscientes de que utilizan el vocablo portugués, dada a la proximidad formal entre los adverbios de lugar de ambas lenguas.

Por su parte, el uso del adverbio de negación portugués não, como en el ejemplo 50, ocurre en diez ocasiones y con prácticamente los mismos sujetos que utilizaron ali. De hecho, como se puede comprobar en la tabla que sigue, de las cinco hablantes que utilizaron ali (D1/D2/D5/D6/D9), cuatro también utilizaron não 
(D1/D2/D5/D6). Ahora bien, pese a esa coincidencia, no vemos que exista necesariamente una relación entre ambos errores:

(50) E: vale... ¿algún curso de formación fuera de Brasil? D5E: não... ninguno...//

Otro hecho destacado es que todas las docentes han utilizado en algún momento el vocablo español no en sus clases o entrevistas, lo que probablemente sea un indicio de que se trata de una forma que, como en el caso de entonces, no está totalmente interiorizada $y$, por ello, la LM hace su aparición en algunos momentos.

Veamos, finalmente, la tabla con el total de las transferencias directas de los adverbios, donde además de los ya mencionados aparecen también, aunque de forma más esporádica, otras formas transferidas desde la lengua materna:

\begin{tabular}{|c|c|c|c|c|}
\hline$\Sigma$ & Sujeto & $\begin{array}{c}\text { Forma em la } \\
\text { LM }\end{array}$ & Forma en la LE & Fuente \\
\hline 21 & $\begin{array}{l}\text { D1/D2/D4/D } \\
\text { 8/D9 }\end{array}$ & então & $\begin{array}{l}\text { adv. } t .-m . \\
\text { entonces }\end{array}$ & DIBU2, p. 405 \\
\hline 14 & $\begin{array}{l}\text { D1/D2/D5/D } \\
\text { 6/D9 }\end{array}$ & ali & adv. allí, allá & DIBU2, p. 40 \\
\hline 11 & $\begin{array}{l}\text { D1/D2/D5/D } \\
\text { 6/D8 }\end{array}$ & não & adv. no & DIBU2, p. 758 \\
\hline 6 & $\begin{array}{l}\text { D1/D3/D4/D } \\
6\end{array}$ & só & adv. solamente & $\begin{array}{l}\text { DIBU2, p. } \\
1082\end{array}$ \\
\hline 5 & D1/D2/D4 & agora & adv. ahora & DIBU2, p. 30 \\
\hline 3 & D4/D5 & assim & $\begin{array}{l}\text { adv. así, de este } \\
\text { modo }\end{array}$ & DIBU2, p. 83 \\
\hline 3 & D7 & exatamente & $a d v$. exactamente & $\begin{array}{l}\frac{\text { http://pt.pons.c }}{\text { om/tradu\%C3 }} \\
\frac{\% A 7 \% \text { C3\%A3 }}{\text { \%A7\% }} \\
\text { o?q=exatame } \\
\text { nte\&l=espt\&in } \\
\text { =\&lf=pt } \\
\text { accedido el } \\
\text { 26/06/2016 }\end{array}$ \\
\hline 2 & D2 & bem & $a d v$. bien & DIBU2, p. 116 \\
\hline 1 & D4 & ainda & adv. todavía, aún & DIBU2, p. 34 \\
\hline 1 & D4 & também & $a d v$. también & $\begin{array}{l}\text { DIBU2, p. } \\
1125\end{array}$ \\
\hline 1 & D2 & tamém (col.) & $a d v$. también & $\begin{array}{l}\text { DIBU2, p. } \\
1125\end{array}$ \\
\hline
\end{tabular}

Tabla 42: Errores de substitución directa de adverbios. 


\subsection{Pronombres}

Los "pronombres" son el quinto grupo de palabras analizadas en esta sección, y constituyen un $6 \%$ de los errores de transferencia directa, con un total de 33 ocurrencias. En la a continuación se observa claramente que son los pronombres personales los más habituales, llegando a un $91 \%$ del total de este grupo, mientras que los demostrativos y los interrogativos alcanzan solamente un $9 \%$ :

\begin{tabular}{|l|l|l|l|l|}
\hline$\Sigma$ & Sujeto & $\begin{array}{l}\text { Forma em la } \\
\text { LM }\end{array}$ & Forma en la LE & Fuente \\
\hline 25 & $\begin{array}{l}\text { D2/D4/D6/ } \\
\text { D8/D9 }\end{array}$ & ele(s) & pron. él (ellos) & DIBU2, p. 367 \\
\hline 2 & D8/D5 & este(s) & $\begin{array}{l}\text { pron.-adj.dem. } \\
\text { este (estos) }\end{array}$ & DIBU2, p. 453 \\
\hline 2 & D2/D9 & nós & $\begin{array}{l}\text { pron. pers. } \\
\text { nosotros }\end{array}$ & DIBU2, p. 772 \\
\hline 1 & D6 & ela & pron. ella & DIBU2, p. 366 \\
\hline 1 & D3 & eu & pron. pers. tón. yo & DIBU2, p. 467 \\
\hline 1 & D6 & vocês & $\begin{array}{l}\text { pron. vosotros, } \\
\text { ustedes }\end{array}$ & DIBU2, p. 1235 \\
\hline 1 & D2 & quem & pron. interr. quién & DIBU2, p. 957 \\
\hline
\end{tabular}

Tabla 43: Errores de substitución directa de pronombres.

De los pronombres transferidos, tiene mayor incidencia el de tercera persona del singular "ele" (él), con 25 ocurrencias, lo que por sí solo representa casi el $76 \%$ de todas las transferencias pronominales:

(51) D9C1: ... y entonces ele está diciendo así... que el hombre no es... no es agradecido... ¿sabe? (11)

En el fragmento anterior podemos apreciar el uso de ele en boca de la docente 9 durante la explicación de una parábola. Esa misma transferencia tiene lugar hasta en 11 ocasiones diferentes en el discurso de esta profesora, a quien corresponden en buena medida las cifras de este grupo de interferencias.

Una curiosidad sobre la utilización de este pronombre es que su forma en plural "eles" (ellos) ocurre con cuatro de los sujetos 
del estudio (D2/D4/D8/D9), mientras que la forma en singular solamente con dos (D6/D9). Por otro lado, esa confusión también se ve agravada por el empleo de pronombres de en español, como podemos observar en el próximo ejemplo:

(52) D4E: ... pero eles no piensan... hay algo que no entusiasma ellos ${ }^{\star}$... no sé qué pasa...//

Como se puede comprobar, aquí estamos ante dos tipos de errores distintos, aunque con un mismo fondo común: la interferencia de la lengua materna. En el primero, hay una interferencia por sustitución directa de la LM, por medio de la utilización del pronombre eles. Ya en el segundo, la docente demuestra tener conocimiento de su equivalente en la lengua española, puesto que también utiliza ellos, aunque de manera equivocada. Su empleo es una copia del registro coloquial de la lengua materna “... tem algo que não entusiasma eles". Lo correcto en este caso la utilización del pronombre de complemento indirecto les: "... hay algo que no les entusiasma".

De lo dicho hasta ahora se desprende que hay una dificultad patente en la utilización de los clíticos, puesto que en la lengua hablada coloquial brasileña estos casi han desaparecido, reservándose su empleo para la lengua culta. Aun así, su uso es menos frecuente que en español, al tiempo que obedece a unos parámetros que no siempre coinciden con los de la lengua española. Como estrategia comunicativa, el aprendiz brasileño suele emplear los pronombres tónicos en lugar de los clíticos, tal y como hemos visto en este último ejemplo. También es común que utilicen la paráfrasis o incluso la omisión directa de los complementos.

En resumen, en el paradigma de los pronombres destaca la frecuencia con que aparece el pronombre ele(s) (él/ellos), así como la diversidad de sujetos que lo utilizan, ya que más de la mitad de estos lo hacen en algún momento. Las demás transferencias pronominales ocurren más esporádicamente y las utilizan menos individuos (entre uno y dos apenas), por lo que no parecen representar errores tan sistemáticos.

\subsection{Determinantes}

Los "determinantes" forman el último grupo analizado, del cual hemos encontrado un $5 \%$ de los errores de transferencia 
directa, con un total de 30 ocurrencias. Al igual que en el bloque "Otros", analizado anteriormente, observamos también aquí la ausencia de una forma que destaque significativamente sobre las demás, así como un conjunto de transferencias que varían entre los sujetos y la clase gramatical. Al mismo tiempo, y de la misma forma que en los demás grupos, vemos que las formas morfológicamente cercanas son las más transferidas.

\begin{tabular}{|c|c|c|c|c|}
\hline$\Sigma$ & Sujeto & $\begin{array}{c}\text { Forma en la } \\
\text { LM }\end{array}$ & Forma en la LE & Fuente \\
\hline 5 & D2/D4/D9 & esses & $\begin{array}{l}\text { pron.-adj.dem. } \\
\text { ese (esos) }\end{array}$ & DIBU2, p. 447 \\
\hline 4 & D2 & $\mathbf{a}\left[{ }^{\star \star \star}\right]$ & art. fem. la & DIBU2, p. 1 \\
\hline 4 & D9 & as & pl. art. fem. las & DIBU1, p. 452 \\
\hline 4 & $\mathrm{D} 1 \mathrm{E}$ & aquela(s) & $\begin{array}{l}\text { pron. dem.-adj. } \\
\text { aquella(s) }\end{array}$ & DIBU2, p. 68 \\
\hline 2 & D2/D9 & aquele(s) & $\begin{array}{l}\text { pron. dem.-adj. } \\
\text { aquel (aquellos) }\end{array}$ & DIBU2, p. 68 \\
\hline 2 & D1 & duas & num. dos & DIBU2, p. 353 \\
\hline 2 & D8 & os & art. los & DIBU2, p. 781 \\
\hline 1 & $\mathrm{D} 8$ & cem & num. cien & DIBU2, p. 183 \\
\hline 1 & D8 & dez & num.-s diez & DIBU2, p. 337 \\
\hline 1 & D4 & dois & num. dos & DIBU2, p. 353 \\
\hline 1 & /D9 & isso & pron. dem. eso & DIBU1, p. 298 \\
\hline 1 & D5 & trinta & num.-m. treinta & DIBU2, p. 1182 \\
\hline 1 & D2 & uma & num. una & DIBU2, p. 1193 \\
\hline 1 & $\mathrm{D} 4$ & uns & art. indef. unos & DIBU2, p. 1193 \\
\hline
\end{tabular}

Tabla 44: Errores de substitución directa de determinantes.

Algunos ejemplos de esas formas transferidas aparecen a continuación. El primer caso es el correspondiente a la forma del demostrativo masculino plural, esses, utilizado por 3 docentes distintas, aunque la mayor incidencia tiene lugar en el habla de la docente D2, la cual emplea dicha forma hasta en tres ocasiones. De ella es el fragmento siguiente:

(53) D2C6: ... entonces ahora con esses [[ejercicios]] aquí vai $^{*}$ quedar* más fácil para hacer en el libro...

Como en el caso de los pronombres él/ellos reseñado anteriormente, entre el portugués y el español hay una variación en 
las formas del demostrativo plural masculino, como se puede apreciar en la tabla 45:

\begin{tabular}{|l|l|}
\hline \multicolumn{1}{|c|}{$\begin{array}{c}\text { Determinante masculino } \\
\text { portugués }\end{array}$} & \multicolumn{1}{|c|}{$\begin{array}{c}\text { Determinante masculino } \\
\text { español }\end{array}$} \\
\hline Esse & Ese \\
\hline Esses & Esos \\
\hline
\end{tabular}

Tabla 45: Determinantes masculinos portugués x español.

De ahí que no resulte extraño que los aprendices en general y en este caso también nuestras profesoras de español- se confundan con la forma en plural, puesto que en singular son muy parecidos, e incluso se pronuncian igual, lo que probablemente hace que generalicen la regla por analogía (esse - ese = esses - eses).

El segundo caso que presentamos tiene que ver con la utilización del artículo ante el nombre de persona, una combinación sintáctica que, a diferencia del español, donde el artículo aparece restringido a ciertos dialectos y sociolectos bajos, es común también en el portugués estándar. Así lo hace docente D2 hasta en cuatro ocasiones diferentes:

(54) D2E: ... sí... y $\underline{\boldsymbol{a}}\left[{ }^{* \star *}\right]$ también trabaja...entón* los tres trabajan...//

En el ejemplo que analizamos, D2 explicaba que sus tres hijos trabajan y estudian a la vez. Al decir el nombre de uno de sus hijas, codificado por [ $\left.{ }^{\star \star \star}\right]$, vemos que emplea el artículo portugués $a$, tal como haría en portugués. La aplicación de esta regla en la lengua española es un error común entre los aprendices brasileños. Con todo, la utilización de la forma portuguesa es poco frecuente, ya que solo encontramos cuatro errores de este tipo en todo el corpus, $y$, como hemos visto, todos ellos cometidos por la misma docente.

No muy diferente es el perfil que presenta la utilización del artículo plural as, que ejemplificamos a continuación:

(55) D9C1: ... ni habló * cosas malas... ni la chingó* ni nada... pero... todo en una buena*... fue haciendo as cosas $y$ cuando la culebra percibió estaba presa...

También en este caso la transferencia se repite en cuatro ocasiones y en boca de la misma docente (D9 esta vez). Sin 
embargo, aquí las reglas combinatorias coinciden en ambas lenguas, ya que el artículo aparece junto a un nombre común y no propio.

\subsection{Errores de sustitución por analogía}

Según hemos discutido en el Capítulo 4, los errores por analogía ocurren por la aparente simetría o similitud entre las lenguas, es decir, se dan entre grupos de palabras formalmente similares en las dos lenguas, pero distintas al menos en uno de sus significados. Esos errores son muy frecuentes en la interlengua de los aprendices de lenguas extranjeras, y, aún más, en los casos de lenguas próximas. En este sentido, los datos de nuestro estudio parecen confirmar esa tendencia, ya que hemos encontrado un total 290 errores de este tipo, lo que equivale a un 33\% del total de errores de sustitución.

De estos 290 errores, en la presente sección trataremos con detalle 194, los cuales se distribuyen en 38 vocablos distintos. Hemos decidido dejar un grupo específico de heterosemánticos sin analizar, los cuales encajarían en la cuarta definición de heterosemánticos de Humblé (2006), que discutíamos en el Capítulo 5. En las palabras del autor:

El cuarto tipo es el de palabras que forman parejas en cada una de las lenguas, con acepciones aparentemente idénticas, pero que funcionan en realidad con restricciones gramaticales o léxicas diferentes. Es el caso de hablar/decir, falar/dizer. (HUMBLÉ, 2006, p. 198)

Referente a esos errores, cabe añadir que, en un principio, nos propusimos tratarlos en este apartado, puesto que, como bien explica Humblé, hacen referencia a errores heterosemánticos (aunque con algunas características peculiares, ya que van emparejados con dos verbos en cada lengua). No obstante, por motivos de tiempo y oportunidad no hemos podido llevar a cabo los análisis que pretendíamos un primer momento. Con todo, y aunque sea simplemente a modo ilustrativo, los presentamos esquemáticamente en la tabla $46^{134}$, donde podemos encontrar los

\footnotetext{
${ }^{134}$ Tales errores se encuentran en el banco de errores presentado en los Anexos
} 7. 
siguientes datos: los sujetos que utilizaron las formas interferidas, el número de veces que se detectó la interferencia, el heterosemántico, los verbos afines en la $L M$, los verbos afines en la LO, y el verbo que se utilizaría en la misma ocasión en la LM y en la LO.

\begin{tabular}{|l|l|l|l|l|l|l|}
\hline Sujeto & $\boldsymbol{\Sigma}$ & $\begin{array}{l}\text { Interfe } \\
\text { rencia }\end{array}$ & $\begin{array}{c}\text { Verbos } \\
\text { afines } \\
\text { en la LM }\end{array}$ & $\begin{array}{c}\text { Verbos } \\
\text { afines en la } \\
\text { LO }\end{array}$ & $\begin{array}{c}\text { Verbo } \\
\text { utiliza } \\
\text { do en } \\
\text { LM }\end{array}$ & $\begin{array}{c}\text { Verbo } \\
\text { adecua } \\
\text { do en la } \\
\text { Lo }\end{array}$ \\
\hline $\begin{array}{l}\text { D1/D4/ } \\
\text { D5/D6/ } \\
\text { D7/D8/ } \\
\text { D9 }\end{array}$ & 40 & tener & ter/haver & tener/haber & ter & haber \\
\hline D8 & 25 & mirar & ver/olhar & ver/mirar & olhar & ver \\
\hline $\begin{array}{l}\text { D1/D2/ } \\
\text { D4/D6/ } \\
\text { D8/D9 }\end{array}$ & 22 & hablar & $\begin{array}{l}\text { falar/dize } \\
\text { hablar/decir }\end{array}$ & falar & decir \\
\hline $\begin{array}{l}\text { D1/D5/ } \\
\text { D8/D9 }\end{array}$ & 9 & $\begin{array}{l}\text { quedar } \\
\text { (se) }\end{array}$ & $\begin{array}{l}\text { ficar } \\
\text { transfor } \\
\text { mar-se } \\
\text { vir }\end{array}$ & $\begin{array}{l}\text { quedarse } \\
\text { ponerse } \\
\text { venir }\end{array}$ & ficar & $\begin{array}{l}\text { poner(se); } \\
\text { hacer(se); } \\
\text { venir }\end{array}$ \\
\hline
\end{tabular}

Tabla 46: Otros errores de analogía.

Para los errores que detallaremos aquí, hemos realizado el correspondiente estudio comparativo a partir de obras lexicográficas clasificadas en tres grupos diferentes. Así, de los 38 vocablos que contienen error por analogía , solamente 22 pudieron ser explicados a través de los diccionarios bilingües que habíamos seleccionado previamente, a saber: Dicionário de falsos amigos (FEIJÓO HOYOS, 1992); ¡Ojo! con los falsos amigos (BECHARA Y MOURE; 2002) y Dicionário ilustrado: Falsas semelhanças español-português (MONTE, 2003).

Para otros 15 errores, hemos recurrido a otros diccionarios monolingües de las lenguas española y portuguesa, así como a un diccionario bilingüe, el Diccionario Bilingüe de Uso (MORENO Y GONZÁLEZ, 2003) ${ }^{135}$-. En esta fase del estudio, esta lista se

\footnotetext{
${ }^{135}$ De la misma manera que hemos procedido en la primera sección de este capítulo, el tomo 1 del diccionario DIBU, dirección español-portugués será identificado como DIBU1 y el segundo tomo, dirección portugués-español, como DIBU2.
} 
completa con el Diccionario de la Real Academia (DRAE) en su versión online, así como con el Dicionário Aurélio da Língua Portuguesa (AURÉLIO), este en su versión digital en CD. Ocasionalmente, nos hemos apoyado también en el Diccionario de Uso del Español (MOLINER, 2008a; 2008b; 2008c) ${ }^{136}$-, principalmente para fundamentar algunas de las explicaciones no encontradas en las demás obras.

Finalmente, para un caso particular, hemos tenido que recurrir a otras fuentes, puesto que no hemos encontrado explicación en ninguna de las obras citadas, como explicaremos más detenidamente al final de esta sección.

A continuación presentamos la relación completa de las transferencias de sustitución por analogía encontradas en nuestro estudio por orden de frecuencia. Organizamos esta tabla explicativa del siguiente modo: a) la primera columna da cuenta de el(los) sujeto(s) que cometió(eron) los errores; b) la segunda informa sobre el número de veces en que aparece cada error; c) la tercera muestra la interferencia propiamente dicha; y d) en la última, ofrecemos el término que creemos sería más adecuado en la LO según el contexto.

\begin{tabular}{|l|c|c|c|}
\hline \multicolumn{1}{|c|}{ Sujeto } & $\boldsymbol{\Sigma}$ & Interferencia & $\begin{array}{c}\text { Termino apropiado en } \\
\text { la LE }\end{array}$ \\
\hline D1/D5/D3/D4/D8/D9 & 48 & 0 & el/lo \\
\hline D4/D6/D9 & 20 & se & si \\
\hline D1/D6/D7/D9 & 15 & mismo & de verdad \\
\hline D1/D3/D4/D8/D9 & 12 & lá & allá \\
\hline D4/D6/D8/D9 & 8 & a & la \\
\hline D1/D5/D7/D8 & 8 & pronuncia & pronunciación \\
\hline D1/D5 & 7 & pesquisar & investigar \\
\hline D1/D6/D8 & 6 & período & hora clase/curso \\
\hline D1/D6/D7/D8/D9 & 6 & escrita & escritura \\
\hline D1/D5/D8 & 5 & pesquisa(s) & búsqueda(s) \\
\hline D9 & 4 & chingó (v. chingar) & insultó \\
\hline
\end{tabular}

${ }^{136}$ Igual que en las demás obras que poseen más de un tomo, los identificaremos con su número correspondiente. Es decir, el primer tomo del DUMM (A-D) será identificado como DUMM1, el segundo (E-O) como DUMM2, y el tercero (PZ) como DUMM3. 


\begin{tabular}{|c|c|c|c|}
\hline D2 & 4 & dupla & pareja \\
\hline D1/D4/D5 & 4 & no & en la/en el \\
\hline D2/D5 & 4 & serie & curso \\
\hline D4/D5/D8 & 4 & trago (v. trazer) & traigo \\
\hline D9 & 3 & cadera (col.) & silla \\
\hline D8 & 3 & suceso & éxito \\
\hline D2/D5/D7 & 3 & aula & clase \\
\hline D1/D8 & 3 & aburrida & contrariada \\
\hline D5/D7 & 3 & turma & clase \\
\hline D1/D4 & 2 & medio & enseñanza media \\
\hline D1 & 2 & leyenda & subtítulos \\
\hline D9 & 2 & ano & año \\
\hline D2/D3 & 2 & procurar & buscar \\
\hline D2 & 2 & viró (v. virar) & se transformó \\
\hline D9 & 2 & pegar & tomar \\
\hline D9 & 1 & barra (v. barrar) & bloquea \\
\hline D1 & 1 & bate (v. bater) & Ilama \\
\hline D6 & 1 & cedo & temprano \\
\hline D7 & 1 & $\begin{array}{c}\text { cobrarles (v. } \\
\text { cobrar) }\end{array}$ & exigirles \\
\hline $\mathrm{D} 2$ & 1 & $\begin{array}{l}\text { desligaron } \\
\text { (v. desligar) }\end{array}$ & desconectaron \\
\hline D6 & 1 & galera & gente \\
\hline D7 & 1 & legenda & subtítulo \\
\hline D4 & 1 & paseatas & manifestaciones \\
\hline D8 & 1 & pela & por la \\
\hline D5 & 1 & pelo & por lo \\
\hline$\overline{\mathrm{D} 5}$ & 1 & prontos & listos \\
\hline D3 & 1 & sala & aula \\
\hline
\end{tabular}

Tabla 47: Errores de producción por analogía. 
A efectos expositivos, hemos dividido esta sección en tres partes. En la primera, trataremos el grupo de errores que pudo ser interpretado a través de los diccionarios bilingües especializados; en la segunda, analizaremos aquellos errores que se explican en otras obras; y en la tercera trataremos, finalmente, el único vocablo que no pudo ser explicado con ninguna de las fuentes anteriores. Para facilitar la comprensión al lector hemos elaborado para cada vocablo un cuadro comparativo con artículos extraídos de los diccionarios utilizados. Así, de manera ilustrativa, el lector podrá acompañar la explicación de los errores de forma más clara y precisa. Cuando sea necesario, y para favorecer igualmente la comprensión, marcamos directamente en el texto del artículo la acepción de la cual nos hemos servido.

Hay que añadir que el objetivo de esta sección no es realizar una comparación exhaustiva de los vocablos seleccionados, sino tan solo comprobar la relación entre las dos lenguas a través de las distintas obras lexicográficas. Con ello, pretendemos poner en evidencia que los errores presentados aquí son en la práctica interferencias, y, más específicamente, interferencias de sustitución por analogía.

\subsection{Errores explicados por medio de diccionarios especializados}

En la tabla 48 encontramos la relación del primer bloque de vocablos analizados, ordenados según su categoría gramatical, a la que seguirá la explicación detallada de cada uno.

\begin{tabular}{|l|l|}
\hline \multicolumn{1}{|c|}{$\mathbf{N}^{-}$} & \multicolumn{2}{c|}{ Interferencia } \\
\hline 1 & a \\
\hline 2 & 0 \\
\hline 3 & se \\
\hline 4 & no \\
\hline 5 & pela \\
\hline 6 & pelo \\
\hline 7 & lá \\
\hline 8 & ano \\
\hline
\end{tabular}




\begin{tabular}{|l|l|}
9 & aula \\
\hline 10 & cadera \\
\hline 11 & legenda \\
\hline 12 & leyenda \\
\hline 13 & médio \\
\hline 14 & pesquisa \\
\hline 15 & sucesso \\
\hline 16 & cobrar \\
\hline 17 & pegar \\
\hline 18 & procurar \\
\hline 19 & bate (v. bater) \\
\hline 20 & chingó (v. chingar) \\
\hline 21 & desligaron (v. desligar) \\
\hline 22 & viró (v. virar) \\
\hline
\end{tabular}

Tabla 48: Errores por analogía, grupo I.

A continuación detallamos los cuadros comparativos seguidos para la explicación de cada vocablo.

\subsection{1 Analogía 1: a}

\begin{tabular}{|c|c|c|}
\hline Ejemplo & \multicolumn{2}{|c|}{ D4C4: ... ¿para a clase de hoy tenemos o* qué?... } \\
\hline $\begin{array}{l}\text { Diccionari } \\
0\end{array}$ & Español/ Portugués & Portugués/ Español \\
\hline DFA & ---- & ---- \\
\hline $\begin{array}{l}\text { OFA } \\
\text { p.21 }\end{array}$ & $\begin{array}{l}\text { a/a }(V . \text { la } / \text { la) } \\
\text { esp. a. s.t. A (nome da letra A). \| prep. A. }\end{array}$ & 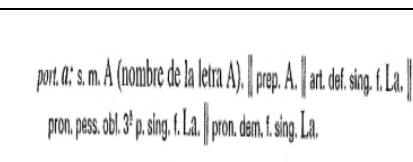 \\
\hline DIL & ---- & ---- \\
\hline Solución & \multicolumn{2}{|c|}{ Uso de la forma española "la". } \\
\hline
\end{tabular}


Tabla 49: Analogía 1: a.

Podemos observar en este primer ejemplo, que el uso del artículo femenino determina un error de analogía, donde se hace uso de una forma existente tanto en la lengua española como en la portuguesa, la a. El error se concreta específicamente cuando la docente utiliza la a (una preposición en la lengua española) como artículo (valor de la lengua materna). La a es también una preposición en la lengua portuguesa, con lo cual este vocablo es confundido debido a una sobregeneralización de sus valores. Lo correcto sería utilizar el artículo femenino "la" en la frase: "¿para la clase de hoy tenemos el qué?". Aunque no haya sido un error muy frecuente (apenas 8 incidencias), ha ocurrido con cuatro sujetos distintos (D4/D6/D8/D9). Por otro lado, observamos que de las tres obras consultadas, apenas una presenta la a, lo que supone una falta de unidad por parte de los lexicógrafos sobre la inclusión o no de este vocablo en el grupo de los heterosemánticos ${ }^{137}$.

\subsection{2 Analogía 2: o}

\begin{tabular}{|c|c|c|}
\hline \multicolumn{3}{|c|}{ Interferencia 2: o } \\
\hline $\begin{array}{l}\text { Ejemplo } \\
1\end{array}$ & \multicolumn{2}{|c|}{$\begin{array}{l}\text { D1C2: [comt. port]... ¿sabe por qué son falsos amigos? } \\
\text { A: (...) } \\
\text { D1C2: muy bien... ¿y saben o que son los } \\
\text { heterogenéricos?// }\end{array}$} \\
\hline $\begin{array}{l}\text { Ejemplo } \\
2\end{array}$ & \multicolumn{2}{|c|}{$\begin{array}{l}\text { D8C2: ... después el "dé" con acento... quiere decir } \underline{0} \\
\text { verbo dar... dice así... espero que me dé un beso... }\end{array}$} \\
\hline $\begin{array}{l}\text { Dicciona } \\
\text { rio }\end{array}$ & Español/ Portugués & Portugués/ Español \\
\hline $\begin{array}{l}\text { DFA } \\
\text { p.74 }\end{array}$ & ocori,. Ou:" "Quierss queso o mannequilla?" & $\begin{array}{l}\text { o art./pron. El (art. def. m.): "O menino chegou } \\
\text { onten". Lo (pr.p.compl.3 p. s.): "Paulo?, não o } \\
\text { vi hoje". Lo (pr. dem. neuf.): "Isso, não o faria } \\
\text { Joana". }\end{array}$ \\
\hline
\end{tabular}

${ }^{137}$ El uso de la transferencia de $a$ también se consideró en el estudio de Durão (2004, p. 149), aunque en este caso no se consideró como heterosemántico. 


\begin{tabular}{|c|c|c|}
\hline \multirow[t]{2}{*}{$\begin{array}{l}\text { OFA } \\
\text { p.222 }\end{array}$} & $\begin{array}{l}\text { O/O (V.u/u) } \\
\text { esp. O: s.t. O (nome da letra O). } \| \text { coni. Ou'. }\end{array}$ & 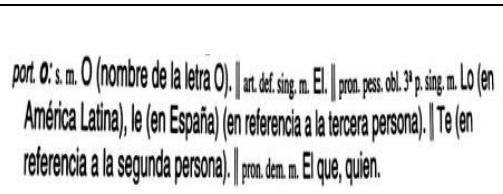 \\
\hline & \multicolumn{2}{|c|}{$\begin{array}{l}\text { ex.: 1. "(...) pero solian incurrir, cada cual por su lado, en injustificadas oharto justificadas ausencias." } \\
\text { (Jorge Luis Borges, La intrusa, p. 407) }\end{array}$} \\
\hline DIL & ---- & ---- \\
\hline $\begin{array}{l}\text { Solución } \\
\text { ejemplo } \\
1\end{array}$ & \multicolumn{2}{|c|}{ Uso de la forma española "lo". } \\
\hline $\begin{array}{l}\text { Solución } \\
\text { ejemplo } \\
2\end{array}$ & \multicolumn{2}{|c|}{ Uso de la forma española "el". } \\
\hline
\end{tabular}

Tabla 50: Analogía 2: o.

El uso de "o" es el tipo de error por analogía más frecuente en nuestro estudio, llegando a ocurrir en 48 ocasiones. Por lo que respecta al primer ejemplo de la tabla anterior (50) (“¿y saben o que son los heterogenéricos?"), este error ocurre en catorce ocasiones y lo cometen tres docentes (D1, D5 y D9). Al igual que viéramos a propósito de la preposición española "a" al comienzo de esta sección, la conjunción "o" es también un falso amigo. Ello es así porque "o" en portugués puede ser bien un pronombre equivalente al español "lo", bien un artículo masculino (esp. "el"). En el ejemplo 1, el empleo de "o" acaba por materializar un error de analogía puesto que en la lengua española esa forma es una conjunción y no un pronombre. Lo correcto sería, por tanto, el uso del pronombre "Io" en la pregunta: ¿y saben lo que son los heterogenéricos? Otra opción en este caso sería la supresión del artículo neutro: ¿y saben $\underline{\varnothing q u e ́}$ son los heterogenéricos?

De la misma forma, en el ejemplo número 2 ("quiere decir o verbo dar") tenemos nuevamente el uso de "o", pero esta vez en la función de artículo. Este fue el error más frecuente de todos los que 
hemos encontrado en esta categoría, con 34 ocurrencias, y repartidas además entre cuatro docentes (D3/D4/D8/D9). Lo adecuado sería, por tanto, el uso de la forma "el" en el ejemplo: “... después el "dé" con acento... quiere decir el verbo dar... dice así... espero que me dé un beso..."138.

\subsection{3 Analogía 3: se}

\begin{tabular}{|c|c|c|}
\hline \multicolumn{3}{|c|}{ Interferencia 3: se } \\
\hline Ejemplo & \multicolumn{2}{|c|}{$\begin{array}{l}\text { D6C1: isso*... es como se fuera algunos dictados } \\
\text { populares... }\end{array}$} \\
\hline Diccionario & Español/ Portugués & Portugués/ Español \\
\hline $\begin{array}{l}\text { DFA } \\
\text { p.106 }\end{array}$ & 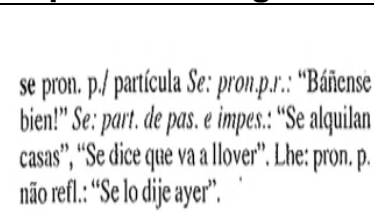 & $\begin{array}{l}\text { se conj. / pron. p. / partícula. Si: conj. "Nõo sei } \\
\text { se ela virá a tempo". Se: pron.p.r... "Olhou-se } \\
\text { no espelho". Se: part. de pas. e impers.:" Alu- } \\
\text { gam-se casas", "Diz-se que vai chover". }\end{array}$ \\
\hline $\begin{array}{l}\text { OFA } \\
\text { p.300 }\end{array}$ & $\begin{array}{l}\text { se / se } \\
\text { esp. se: pron. pess. obl. } 3^{3} \text { p. sing. /pl. Se. }\end{array}$ & 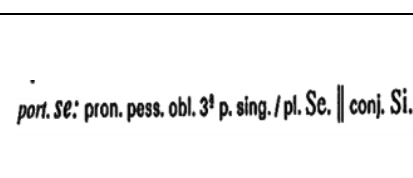 \\
\hline DIL & ---- & ---- \\
\hline solución & \multicolumn{2}{|c|}{ Uso de la forma española "si" } \\
\hline
\end{tabular}

Tabla 51: Analogía 3: se.

En ese caso, que ocurre en 20 ocasiones, repartidas en el habla de tres sujetos diferentes (D4/D6/D9), vemos el uso de la conjunción se del portugués en lugar de la correspondiente española, si. La forma se comparte algunos usos en ambas lenguas, como ocurre, por ejemplo, con el pronombre reflejo de $3^{\text {a }}$ persona de singular. Sin embargo, en español no es en ningún caso una conjunción, como ocurre en el ejemplo referenciado. Por esa razón,

${ }^{138}$ El uso de 0 por aprendices brasileños también aparece en los estudios de Frigo (2006, p. 62) y Santos (2012, p. 172), aunque, curiosamente, en estos casos no se ha considerado un heterosemántico. 
el uso de se aquí es también una transferencia de sustitución por analogía, y la forma correcta sería el empleo de si en la frase: "es como si fuera algunos dictados populares..."139.

\subsection{4 Analogía 4: no}

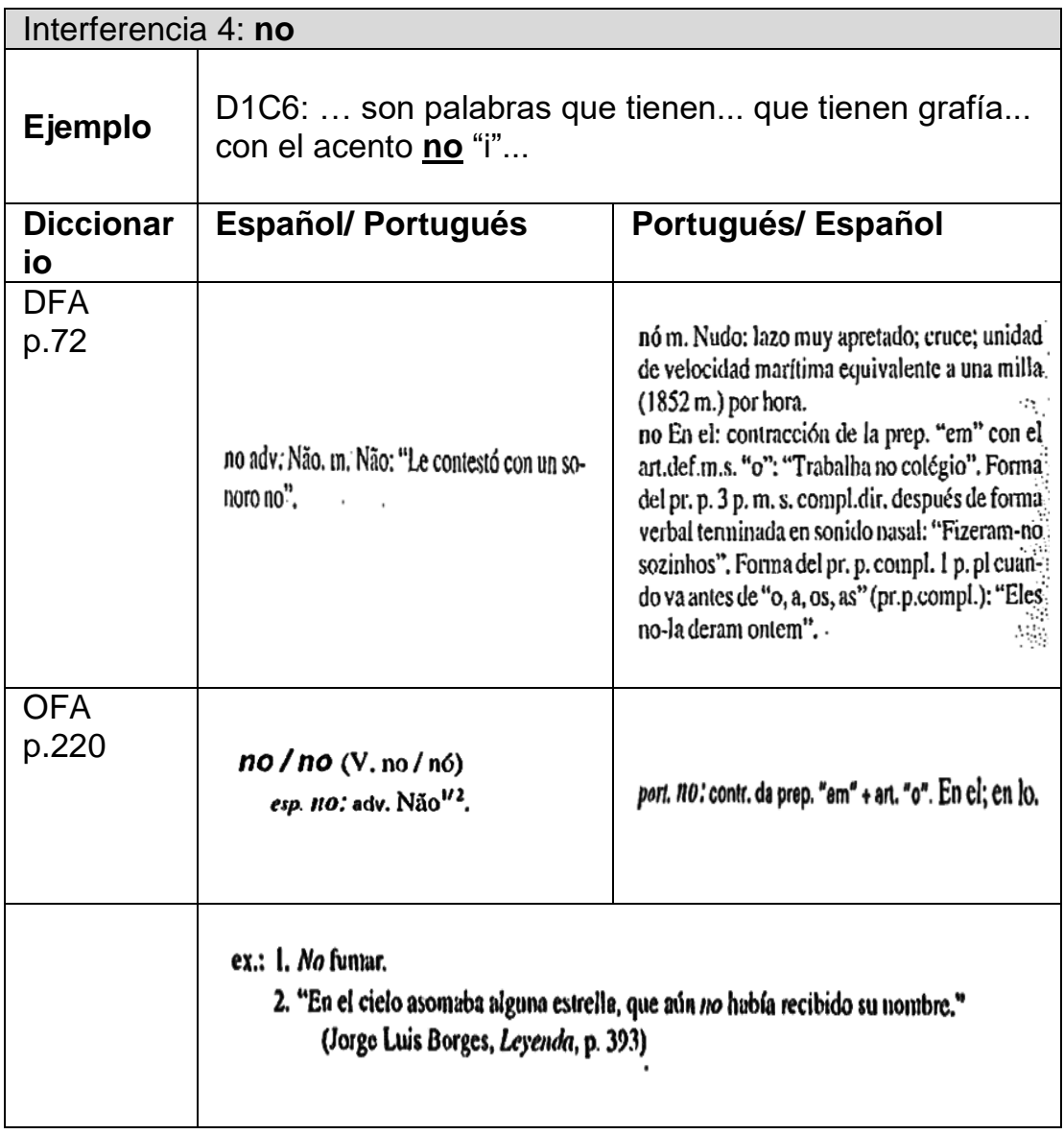

${ }^{139}$ El uso de se como heterosemántico también fue descrito en el estudio de Durão (2004, p. 146). 


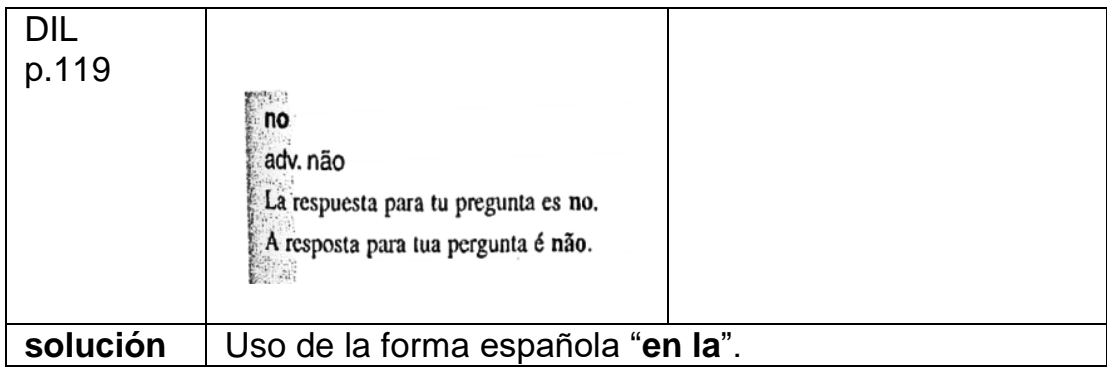

Tabla 52: Analogía 4: no.

Ese error por analogía ocurre 4 veces y en boca de 3 sujetos diferentes (D1/ D4/D5). Consiste en el empleo de la contracción entre la preposición "em" y el artículo "o" del portugués ("no"), cuyo equivalente en español sería la combinación "en el". Obviamente, esa forma no existe en la LO y, por tanto, es el origen de un nuevo error, como de hecho señalan los tres diccionarios consultados. "No" en español es un adverbio de negación. Además, el nombre portugués "vocal" - en referencia a la "i" - es masculino, pero no así en español, donde es femenino, lo que lleva a la docente a cometer un doble error. Así, la forma adecuada en la LO sería "en la”, en la frase: “... son palabras que tienen... que tienen grafía... con el acento en la [[vocal]] "i"..."140.

\subsection{5 Analogía 5: pela}

\begin{tabular}{|l|l|l|}
\hline Interferencia 5: pela \\
\hline Ejemplo & $\begin{array}{l}\text { D8C2: ... entonces ustedes van a empezar pela letra } \\
\text { "a" y van a buscar cuál es la persona que habla con } \\
\text { "a"... }\end{array}$ \\
\hline Diccionario & $\begin{array}{l}\text { Español/ } \\
\text { Portugués }\end{array}$ & Portugués/ Español \\
\hline
\end{tabular}

${ }^{140}$ Otros estudios que relataron el uso de no por aprendices brasileños son los de Frigo (2006, p. 49) y Santos (2012, p. 190), aunque, al contrario de lo que exponemos aquí, estos no lo consideran un heterosemántico. 


\begin{tabular}{|l|l|l|}
\hline $\begin{array}{l}\text { DFA } \\
\text { p.81 }\end{array}$ & pela f. Ação de pelar. & $\begin{array}{l}\text { pela f.Contracción ("por"+"a"): por la. } \\
\text { péla f. Bola, en particular la de goma; bola es- } \\
\text { pecial para el jucgo del mismo nombre. }\end{array}$ \\
\hline OFA & ---- & ---- \\
\hline DIL & ---- & ---- \\
\hline solución & Uso de la forma española "por la". \\
\hline
\end{tabular}

Tabla 53: Analogía 5: pela.

Al igual que "no", pela es un error que se produce por una contracción característica de la lengua materna y que no tiene correspondencia en la lengua española. Pela en portugués es la fusión de la preposición "por" y el artículo femenino "a". Sin embargo, en español pela es el acto de "pelar" algo, así como sinónimo coloquial de las antiguas "pesetas"141 y, por extensión también, de "dinero"142. De ahí que el ejemplo utilizado (eso sí, una sola vez) por la docente D8 sea para nosotros un error por analogía, puesto que formalmente existen vocablos afines en ambas lenguas, pero no tienen ninguna correspondencia semántica. Lo correcto sería el uso de "por la" del español en la frase: “... entonces ustedes van a empezar por la letra "a" y van a buscar cuál es la persona que habla con "a"..."143.

\subsection{6 Analogía 6: pelo}

\begin{tabular}{|l|l|l|}
\hline \multicolumn{2}{|l|}{ Interferencia 6: pelo } \\
\hline Ejemplo & $\begin{array}{l}\text { D5E: ... así... yo pelo menos tengo... fico... me quedo } \\
\text { tranquila que ayudé... }\end{array}$ \\
\hline $\begin{array}{l}\text { Diccionari } \\
\text { o }\end{array}$ & Español/ Portugués & Portugués/ Español \\
\hline
\end{tabular}

${ }^{141}$ Según el DRAE, http://dle.rae.es/?id=SMAAyb8|SMAKBJW accedido el 22/04/2016.

${ }^{142}$ Según el DUMM3, p. 56.

${ }^{143}$ El uso de pela por aprendices brasileños también fue considerado en los estudios de Durão (2004, p. 141), Frigo (2006, p. 49) y Santos (2012, p. 191), aunque no hayan interpretado la interferencia en cuestión como heterosemántico. 


\begin{tabular}{|c|c|c|}
\hline $\begin{array}{l}\text { DFA } \\
\text { p.81 }\end{array}$ & $\begin{array}{l}\text { pelo m. Cabclo (da cabeça). Pelo: o que cohre } \\
\text { algumas partes do corpo, em particular dos } \\
\text { homens; dos animais; de algums vegeelais. Fig. } \\
\text { Coisa de muilo pouca importância. }\end{array}$ & $\begin{array}{l}\text { pelo } \mathrm{m} \text {. Vello: pelo corto de algunas partes del } \\
\text { cuerpo, en particular de los hombres. Pelo: de } \\
\text { los animales; de algunos vegerales. Contrac- } \\
\text { ción ("por"+o"): por el. }\end{array}$ \\
\hline \multirow[t]{2}{*}{$\begin{array}{l}\text { OFA } \\
\text { p.240 }\end{array}$} & 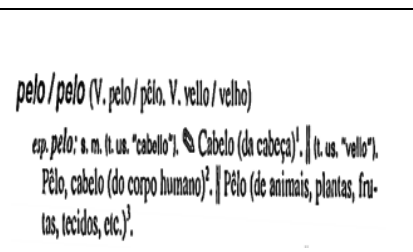 & 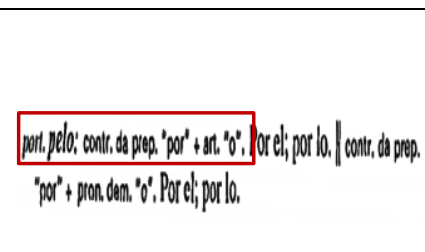 \\
\hline & \multicolumn{2}{|c|}{$\begin{array}{l}\text { ex.: 1. "El patriarca de pelo blanco se sentaba en la cabecem de la mesa } \\
\text { interminable, con su csposa, doña Micaela Candia." } \\
\text { (Pablo Neruda, Confieso que he vivido, p. 17) } \\
\text { 2. Tiene pelos en el pecho. } \\
\text { 3. Mi gata Nininha liene el pelo negro y brillante. }\end{array}$} \\
\hline DIL & ---- & ---- \\
\hline solución & \multicolumn{2}{|c|}{ Uso de la forma española "por lo". } \\
\hline
\end{tabular}

Tabla 54: Analogía 6: pelo.

Al igual que en el caso anterior, pelo (también utilizado una única vez, esta vez por la docente D5) es el resultado en portugués de la contracción entre la preposición "por" y el artículo masculino "o". Por el contrario, pelo en español significa "cabello". Otras acepciones coinciden en las dos lenguas, como "vello" del cuerpo humano o "pelo" de animales, pero no la utilizada por el sujeto. De esta manera, lo correcto sería la utilización de la preposición por + el artículo neutro lo del español en la frase: “... así... yo por lo menos tengo... fico... me quedo tranquila que ayudé..."144.

${ }^{144}$ Durão $(2004$, p. 141) y Santos $(2012,191)$ también encontraron el uso de pelo en sus estudios, aunque no lo consideraron un heterosemántico. 


\begin{tabular}{|c|c|c|}
\hline \multicolumn{3}{|c|}{ Interferencia 7: lá } \\
\hline Ejemplo & \multicolumn{2}{|c|}{$\begin{array}{l}\text { D9C1: ... el martes no puedo... entonces escriban lá... } \\
\text { el martes no puedo porque voy al dentista...// }\end{array}$} \\
\hline $\begin{array}{l}\text { Diccionari } \\
0\end{array}$ & Español/ Portugués & Portugués/ Español \\
\hline $\begin{array}{l}\text { DFA } \\
\text { p.62 }\end{array}$ & 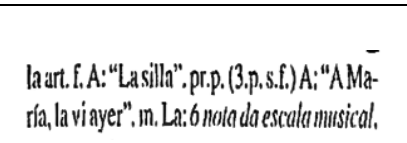 & $\begin{array}{l}\text { Jám. La: } 6 \text { nota de lu escala musical adv. Al- } \\
\text { lá. }\end{array}$ \\
\hline $\begin{array}{l}\text { OFA } \\
\text { p.184 }\end{array}$ & 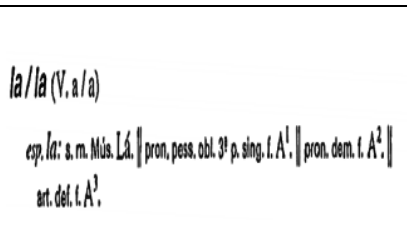 & 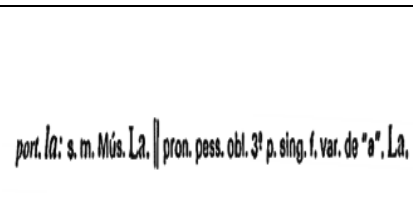 \\
\hline & \multicolumn{2}{|c|}{ 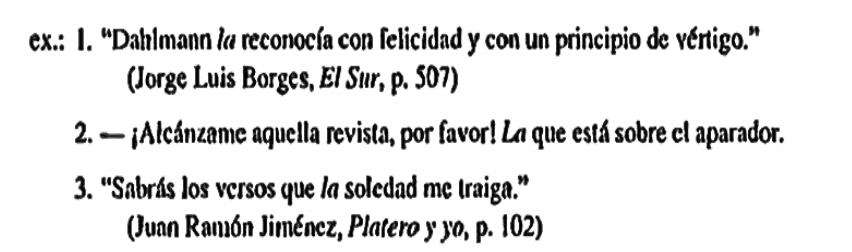 } \\
\hline $\begin{array}{l}\text { DIL } \\
\text { p.103 }\end{array}$ & $\begin{array}{l}\text { la } \\
\text { art.def.' i pron.pes. }{ }^{2} \\
\text { 'La casa queda muy lejos. } \\
\text { A casa fica muito longe. } \\
\text { Nosotros la compramos ayer. } \\
\text { Nós a compramos ontem. }\end{array}$ & \\
\hline solución & Uso de la forma española & allá". \\
\hline
\end{tabular}

Tabla 55: Analogía 7: lá.

Este error ocurre hasta en 12 ocasiones, repartidas en el habla de cinco docentes diferentes (D1/D3/D4/D8/D9), de lo que podemos inferir que estamos ante una transferencia bastante 
habitual. Como en los casos anteriores, se trata de un error por analogía debido a la utilización del vocablo lá con el valor de adverbio del portugués (que corresponde a allá en español) y no con el de artículo determinado femenino que posee esta forma en español $^{145}$. Al tratar de la lengua oral no podemos dar solución a cuál de las formas del español (lá/la) corresponde exactamente al error por analogía utilizado, aunque quede patente el error en sí por el uso del adverbio "lá" del portugués, puesto que ninguna de esas formas son sinónimas de allá. Por tanto, el uso adecuado en este contexto sería el adverbio allá en la frase: "... el martes no puedo... entonces escriban allá... el martes no puedo porque voy al dentista...".

\subsection{8 Analogía 8: ano}

\begin{tabular}{|c|c|c|}
\hline \multicolumn{3}{|c|}{ Interferencia 8: ano } \\
\hline Ejemplo & \multicolumn{2}{|c|}{$\begin{array}{l}\text { D9C1: ... entonces nos quedamos el ano todo solo } \\
\text { paseando y descansando... }\end{array}$} \\
\hline $\begin{array}{l}\text { Dicciona } \\
\text { rio }\end{array}$ & Español/ Portugués & Portugués/ Español \\
\hline $\begin{array}{l}\text { DFA } \\
\text { p.17 }\end{array}$ & ano m. Ânus: orifício externo do reto. & $\begin{array}{l}\text { ano } m \text {. Año: tiempo gastado por la tierra para } \\
\text { dar una vuelta completa alrededor del sol. }\end{array}$ \\
\hline $\begin{array}{l}\text { OFA } \\
\text { p.37 }\end{array}$ & $\begin{array}{l}\text { ano / ano } \\
\text { esp. ano: s. m. Ânus'. } \\
\text { ex.: I. Hizo una cinugía en cl amo. } \\
\text {. }\end{array}$ & port. ano: s. m. Año. \\
\hline $\begin{array}{l}\text { DIL } \\
\text { p.17 }\end{array}$ & 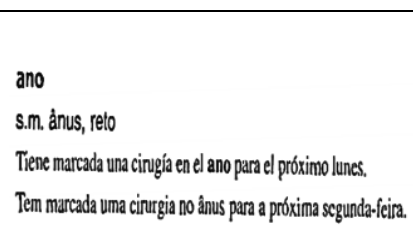 & \\
\hline
\end{tabular}

${ }^{145}$ Junto al de la sexta nota en la escala musical. 


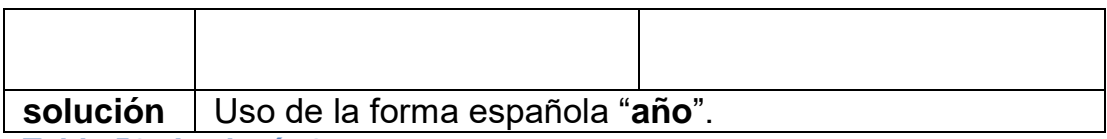

Tabla 56: Analogía 8: ano.

Aunque haya sido un error cometido por una sola docente, llama la atención que haya ocurrido dos veces, las dos en que esta profesora se refiere a esta unidad del tiempo en su clase. La forma ano es un falso amigo recogido por todos los diccionarios consultados, lo que nos evidencia el error por analogía cometido. Ello ocurre por la utilización del nombre masculino ano de la LM, que corresponde a "año", cuando el significado de ano en español es "recto", como explica el DFA (p.17). Lo correcto sería, por tanto, el uso de "año" en la frase: “... entonces nos quedamos el año todo solo paseando y descansando...". La interferencia de ano también se catalogó en los trabajos de Farias (2007, p. 66) y Santos (2012, p. 159) aunque pese a la evidencia reflejada en los tres diccionarios consultados, estos autores no lo hayan interpretado como heterosemántico.

\subsection{9 Analogía 9: aula}

\begin{tabular}{|c|c|c|}
\hline \multicolumn{3}{|c|}{ Interferencia 9: aula } \\
\hline Ejemplo & \multicolumn{2}{|c|}{$\begin{array}{l}\text { D2C6: ... se acuerdan que na* aula pasada procuramos } \\
\text { en el diccionario las palabras... }\end{array}$} \\
\hline $\begin{array}{l}\text { Diccion } \\
\text { ario }\end{array}$ & Español/ Portugués & Portugués/ Español \\
\hline $\begin{array}{l}\text { DFA } \\
\text { p.21 }\end{array}$ & $\begin{array}{l}\text { aula f. Sala de aula, local destinado a dar li- } \\
\text { cóes. }\end{array}$ & $\begin{array}{l}\text { aula f. Clase: lección o ejercicio dado por el } \\
\text { profesor a sus alumnos. }\end{array}$ \\
\hline $\begin{array}{l}\text { OFA } \\
\text { p.46 }\end{array}$ & 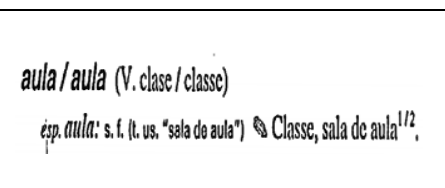 & port aulla: s.1. Clase (lo que es enseniado por un profecsor)" \\
\hline
\end{tabular}




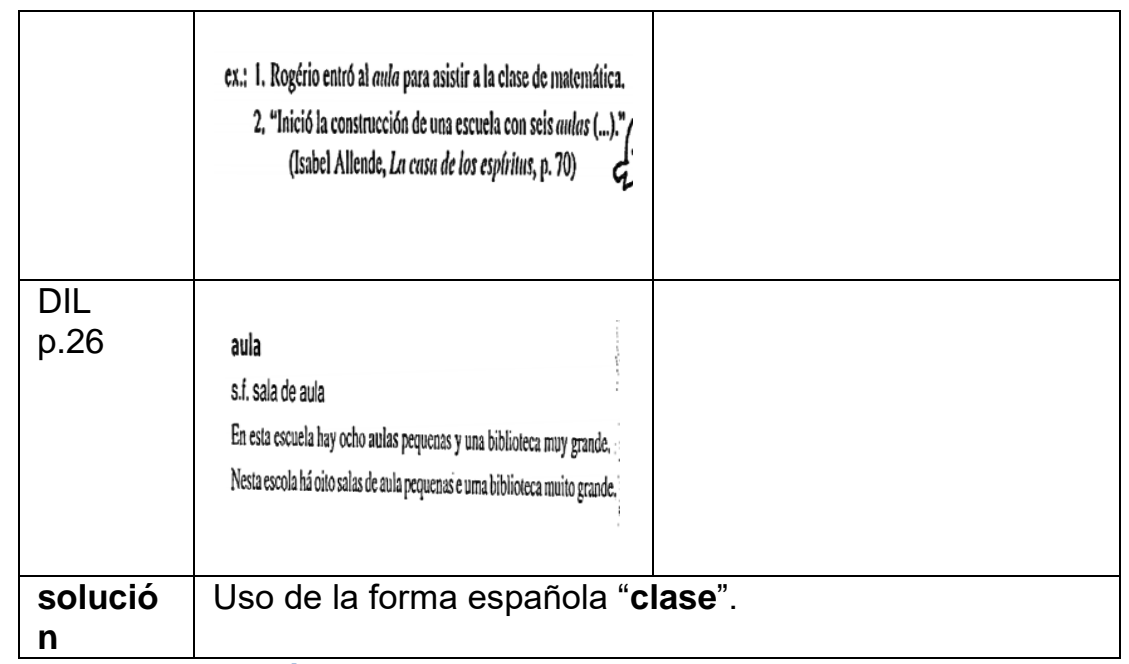

Tabla 57: Analogía 9: aula.

En este vocablo, utilizado en una ocasión por los sujetos D2, D5 y D7, hay una confusión en el empleo de aula, que en su LM significa "la lección, lo que es enseñado por un profesor en un determinado período de tiempo", como explican los diccionarios en el cuadro comparativo insertado más arriba. Sin embargo, aula en la LO significa "el local donde se imparte una clase". De esta manera, asistimos a un nuevo error por analogía, puesto que la docente hace referencia a la clase como un todo y no al local donde esta se imparte (el aula). Por ello, lo adecuado sería el uso de clase en la frase: "se acuerdan que en la clase pasada procuramos en el diccionario las palabras...". Hay que añadir, además, que todas las obras consultadas incluyen este vocablo, lo que significa que hay consenso en que este término es un heterosemántico, y bastante difundido además en las clases de ELE en Brasil ${ }^{146}$.

146 Otro dato que corrobora nuestra afirmación es que este heterosemántico también se encuentra en la investigación de Andrade (2010, p. 173). 
7.2.1.1.2.1.10 Analogía 10: cadera

\begin{tabular}{|c|c|c|}
\hline Ejemplo & \multicolumn{2}{|c|}{$\begin{array}{l}\text { D9C1: ... porque una persona que está en una } \\
\text { cadera de ruedas... a veces... que es su vecino... }\end{array}$} \\
\hline Diccionario & Español/ Portugués & Portugués/ Español \\
\hline $\begin{array}{l}\text { DFA } \\
\text { p.29 }\end{array}$ & $\begin{array}{l}\text { cadera f. Cadeira: anca, cada un dos ladoss } \\
\text { saliemes do corpo, onde se unem tronco e } \\
\text { membros. }\end{array}$ & $\begin{array}{l}\text { cadelira f.Silla, asiento. Caitedra, disciplina en- } \\
\text { señada en un colegio o universidad; cualquier } \\
\text { rama del conocimiento humano objeto de en- } \\
\text { señanza. Cadera:anca. }\end{array}$ \\
\hline $\begin{array}{l}\text { OFA } \\
\text { p.68 }\end{array}$ & 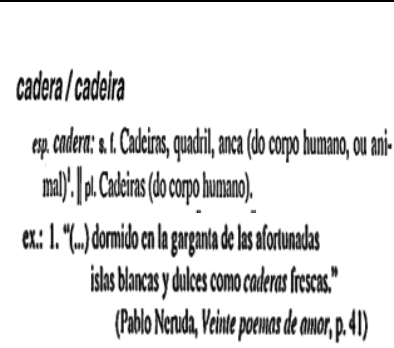 & 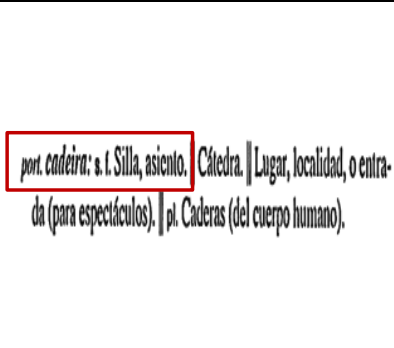 \\
\hline $\begin{array}{l}\text { DIL } \\
\text { p.41 }\end{array}$ & $\begin{array}{l}\text { cadera } \\
\text { s.t. cadeiras; quadril } \\
\text { Mi abuela fracturósu cadera al caerse al suelo. } \\
\text { Minha avó fraturou seu quadril ao cair ao chão. }\end{array}$ & \\
\hline solución & \multicolumn{2}{|c|}{ Uso de la forma española "silla". } \\
\hline
\end{tabular}

Tabla 58: Analogía 10: cadera.

Esa misma docente utiliza hasta en tres ocasiones el nombre masculino cadera, todas las veces en que se refiere en sus intervenciones a una silla de ruedas. Tanto en las acepciones extraídas de los diccionarios de falsos amigos como en la consulta al $\mathrm{DRAE}^{147}$, el vocablo cadera hace referencia a una parte del cuerpo humano o animal, y tan solo como arcaísmo, absolutamente en desuso, puede considerarse como sinónimo de silla en la lengua

${ }^{147}$ Consultado en: http://dle.rae.es/?id=6aqpVO1, accedido el 09/09/16. 
actual. No obstante, en la lengua portuguesa, cadeira ${ }^{148}$ significa tanto la parte del cuerpo humano reseñada como el objeto que utilizamos para sentarnos. Es obvio, pues, que el uso de cadera de ruedas es, por tanto, inadecuado, siendo lo correcto la sustitución del término por el español silla en la frase: “... porque una persona que está en una silla de ruedas...".

\subsection{11 Analogía 11: legenda}

\begin{tabular}{|c|c|c|}
\hline \multicolumn{3}{|c|}{ Interferencia 11: legenda } \\
\hline Ejemplo & \multicolumn{2}{|c|}{$\begin{array}{l}\text { D7E: ... veo películas en inglés y ahí }{ }^{*} \text { con la } \\
\text { legenda y ahí así voy a* sacando un poco de } \\
\text { vocabulario y pronuncia*... }\end{array}$} \\
\hline Diccionario & Español/ Portugués & Portugués/ Español \\
\hline $\begin{array}{l}\text { DFA } \\
\text { p.63 }\end{array}$ & $\begin{array}{l}\text { legenda f. Legenda: história ou feitus da vida } \\
\text { de um santo. V. infra lcyenda. } \\
\text { legal adj. Legal: conforme d lei. }\end{array}$ & Iegenda V. infric leyenda // legenda \\
\hline OFA & ---- & ---- \\
\hline $\begin{array}{l}\text { DIL } \\
\text { p.105 }\end{array}$ & 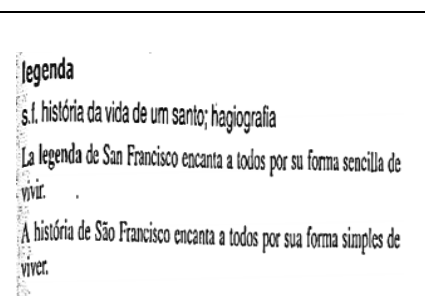 & \\
\hline solución & \multicolumn{2}{|c|}{ Uso de la forma española "subtítulo". } \\
\hline
\end{tabular}

Tabla 59: Analogía 11: legenda.

Aquí la confusión reside en el empleo - esta vez en una única ocasión y por la docente D7- del nombre femenino legenda del portugués en lugar de subtítulos del español. Al usar el vocablo del portugués, la docente se refiere a que las películas que ve en casa

${ }^{148}$ Cadera es una versión coloquial del vocablo portugués cadeira. En la oralidad, el fonema correspondiente a la /i/ se suele omitir. 
suelen ir con el audio en inglés y los subtítulos en portugués, y con eso aprende vocabulario. Sin embargo, legenda en español, según el DFA y el DIL significa "la historia de vida de un santo" ${ }^{149}$, tal y como presentamos en la tabla comparativa. Lo correcto sería, por tanto, el uso del nombre masculino subtítulo. En este sentido, observamos que los diccionarios en cuestión no contribuyen a aclarar el uso correcto de este vocablo y su correspondencia en portugués. Este error guarda cierta relación con otro similar, aunque esta vez el vocablo se corresponda formalmente con otro español, el heterosemántico leyenda. Como veremos en el cuadro siguiente, este nuevo error se corresponde también con el mismo sustantivo español "subtítulo" ("legenda" en portugués).

\subsection{12 Analogía 12: leyenda}

\begin{tabular}{|c|c|c|}
\hline \multicolumn{3}{|c|}{ Interferencia 12: leyenda } \\
\hline Ejemplo & \multicolumn{2}{|c|}{$\begin{array}{l}\text { D1E: ... vamos a oír [[la película]] en español y la } \\
\text { levenda... puede ser en portugués...// }\end{array}$} \\
\hline Diccionario & Español/ Portugués & Portugués/ Español \\
\hline $\begin{array}{l}\text { DFA } \\
\text { p.63 }\end{array}$ & 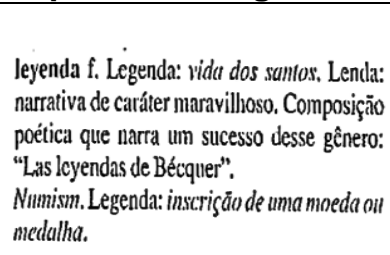 & 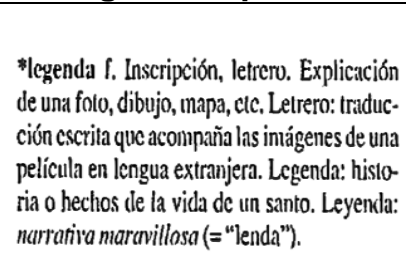 \\
\hline $\begin{array}{l}\text { OFA } \\
\text { p.190 }\end{array}$ & $\begin{array}{l}\text { leyenda / legenda } \\
\text { esp. leyenda: s. t. Legenda. | \& Lenda'. } \\
\text { ex.: I. Las culturns de los pueblos } \\
\text { están impregnadas de nutos } \\
\text { y lejendas. }\end{array}$ & port. legenda: s. f. Leyenda. \\
\hline
\end{tabular}

\footnotetext{
${ }^{149}$ Sin embargo, suponemos que debe de tratarse de un arcaísmo, puesto que no lo hemos encontrado en el DRAE.
} 


\begin{tabular}{|c|c|}
\hline $\begin{array}{l}\text { DIL } \\
\text { p.105 }\end{array}$ & $\begin{array}{l}\text { leyenda } \\
\text { s.f. lenda } \\
\text { Cuando íbarnos a la casa de mi abuelo siempre escuchábamos muchas } \\
\text { leyendas sobre los indios. } \\
\text { Quando ímö̀ a casa de meu avô sempre escutávamos muitas lendas } \\
\text { sobre os índios. }\end{array}$ \\
\hline solución & Uso de la forma española "subtítulo". \\
\hline
\end{tabular}

Tabla 60: Analogía 12: leyenda.

Este error aparece en dos ocasiones en boca de la misma docente (D1). Como hemos visto anteriormente, hay una confusión motivada por la similitud morfológica de los vocablos "legenda/leyenda". En este caso, de la misma manera que en el anterior, la docente se refiere a los "subtítulos" de las películas ("legenda" en portugués). Al emplear el término "leyenda" se equivoca, pues este nombre, como hemos visto, tiene otro significado. A ese respeto, nos gustaría señalar que los diccionarios cumplen su función de manera parcial, puesto que explican solamente uno de los sentidos del portugués para el vocablo "leyenda", que es "lenda" ("legenda" en español). Sería importante que los diccionarios pudiesen aclarar la relación entre esos vocablos y la correspondencia entre la LE y la LM en cada caso, es decir:

- "Legenda" del español es historia de un santo, igual a "legenda" del portugués en este sentido;

- A su vez, "leyenda" en español significa "lenda" en portugués (género textual) y también puede significar "legenda" del portugués en el sentido de las explicaciones al pie de un dibujo o mapa, por ejemplo;

- Y, para terminar, "legenda" del portugués significa "subtítulos" en español.

\subsection{13 Analogía 13: medio}

\section{Interferencia 13: medio}

Ejemplo

$\mathrm{E}:$ ¿y a qué grupos das clases?

D1E: primero* a tercero* año del medio. 


\begin{tabular}{|c|c|c|}
\hline & \multicolumn{2}{|c|}{$\begin{array}{l}\text { E: vale... de la enseñanza media... } \\
\text { D1: de la enseñanza media... }\end{array}$} \\
\hline Diccionario & Español/ Portugués & Portugués/ Español \\
\hline DFA & --- & --- \\
\hline \multirow[t]{2}{*}{$\begin{array}{l}\text { OFA } \\
\text { p. } 208\end{array}$} & 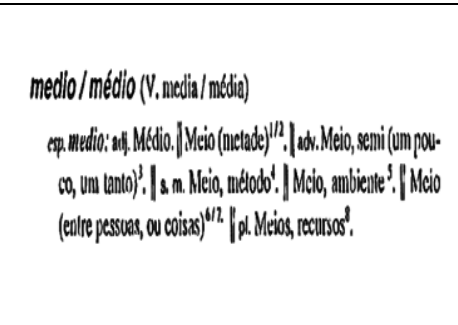 & pnn. médio: adj. Medio. \\
\hline & 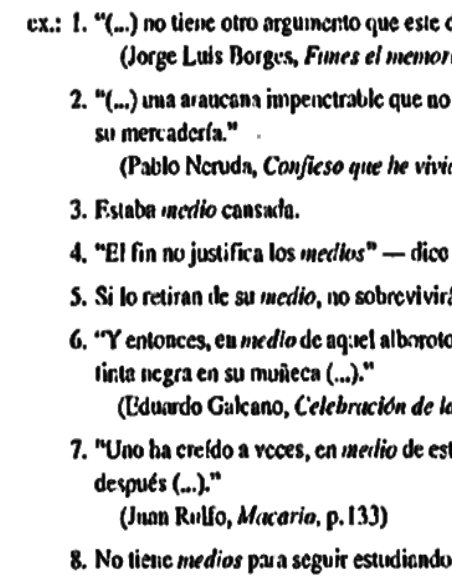 & $\begin{array}{l}\text { go de hace ya medio siglo." } \\
\text { p. 471) } \\
\text { ba en medio centavo cl preciu de } \\
\text { 23) } \\
\text { meverbio. } \\
\text { masia, p. 27) } \\
\text { mino sin orillas, (que nada habría }\end{array}$ \\
\hline$\overline{D I L}$ & --- & \\
\hline solución & \multicolumn{2}{|c|}{ Uso de la forma española "enseñanza media". } \\
\hline
\end{tabular}

Tabla 61: Analogía 13: medio.

Lo que ocurre en este ejemplo es que las docente D1 y D4 trasladan al discurso en la LO la abreviación de ensino médio, es decir, médio (en español enseñanza media). En el ámbito escolar brasileño es habitual referirse de manera abreviada a las etapas de la formación básica, y así en la lengua oral encontramos infantil para educação infantil, fundamental para educação fundamental y médio 
para ensino médio. Sin embargo, ello no ocurre en español, donde tales sintagmas no se suelen abreviar, al margen del hecho de que en esta lengua se trata de nombres femeninos (la educación, la enseñanza) y no masculinos. Y de ahí el evidente error de analogía. Lógicamente, entendemos que lo adecuado sería la utilización de "enseñanza media” en el ejemplo: “... primero* a tercero* año de la enseñanza media".

\subsection{14 Analogía: pesquisa}

\begin{tabular}{|c|c|c|}
\hline \multicolumn{3}{|c|}{ Interferencia14: pesquisa } \\
\hline Ejemplo & \multicolumn{2}{|c|}{$\begin{array}{l}\text { D1E: ... alguna cosa de la enseñanza media... pero } \\
\text { poco... me gustaba mucho escuchar músicas y } \\
\text { pesquisar*... né* } \ldots \text { hacer pesquisas de textos... }\end{array}$} \\
\hline $\begin{array}{l}\text { Diccionari } \\
0\end{array}$ & Español/ Portugués & Portugués/ Español \\
\hline DFA & ---- & ---- \\
\hline $\begin{array}{l}\text { OFA } \\
\text { p.244 }\end{array}$ & 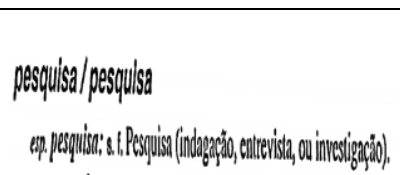 & 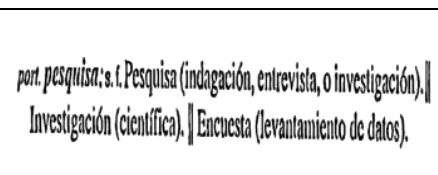 \\
\hline DIL & ---- & ---- \\
\hline solución & \multicolumn{2}{|c|}{ Uso de la forma española "búsquedas". } \\
\hline
\end{tabular}

Tabla 62: Analogía: pesquisa.

Aquí tenemos un falso amigo que ocurre en cuatro ocasiones y en el habla de tres docentes distintas (D1/D5/D8). El vocablo coincide por lo menos parcialmente en las dos lenguas, como lo recoge el OFA, y quizá de ahí la confusión en su empleo. No obstante, este diccionario no termina de aclarar la confusión en el uso de este heterosemántico, por lo que hemos recurrido a los diccionarios monolingües para su explicación.

En español, pesquisa significa "información o indagación que se hace de algo para averiguar la realidad de ello o sus circunstancias" ${ }^{150}$, lo que también ocurre en portugués. No obstante,

${ }^{150}$ Extraído del DRAE http://dle.rae.es/?id=SoBLjpi el 09/09/16. 
en la lengua portuguesa, "pesquisa" significa también "investigación", como bien señala el OFA, en el sentido de "estudio sistemático con el fin de descubrir o establecer hechos o principios relativos a un campo cualquier del conocimiento" ${ }^{151}$, lo que no ocurre en español. De esta manera, cuando la docente se refiere a "pesquisas de textos" en su entrevista intenta decir que le gustaba hacer búsquedas en los textos en lengua española. Obviamente, "pesquisas" en textos en el sentido español de "indagación" sería imposible. Por esta razón, creemos que la forma adecuada para este contexto sería "búsqueda" ("hacer búsquedas de textos") en la frase: "... alguna cosa de la enseñanza media... pero poco... me gustaba mucho escuchar músicas y pesquisar*... né*... hacer búsquedas de textos...".

\subsection{15 Analogía 15: suceso}

\begin{tabular}{|c|c|c|}
\hline \multicolumn{3}{|c|}{ Interferencia 15: suceso } \\
\hline Ejemplo & \multicolumn{2}{|c|}{$\begin{array}{l}\text { D8C2: ... el título es "solo se vive una vez"... de } \\
\text { Azúcar Moreno... dúo como disse*... son dos } \\
\text { hermanas... dos mujeres... que hicieron mucho... } \\
\text { años atrás hicieron mucho suceso... }\end{array}$} \\
\hline Diccionario & Español/ Portugués & Portugués/ Español \\
\hline DFA & --- & $-e_{-1}$ \\
\hline $\begin{array}{l}\text { OFA } \\
\text { p.312 }\end{array}$ & 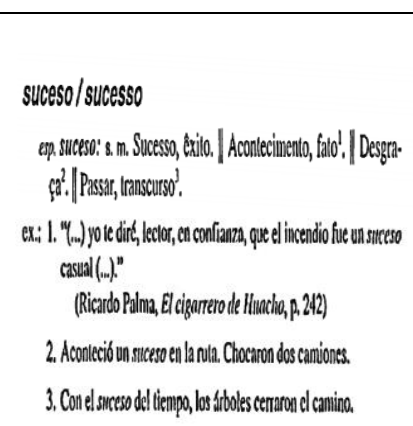 & porl. sucesso: s. m. Suceso, éxito. \\
\hline
\end{tabular}

${ }^{151}$ Adaptado de AURÉLIO (versión digital). 


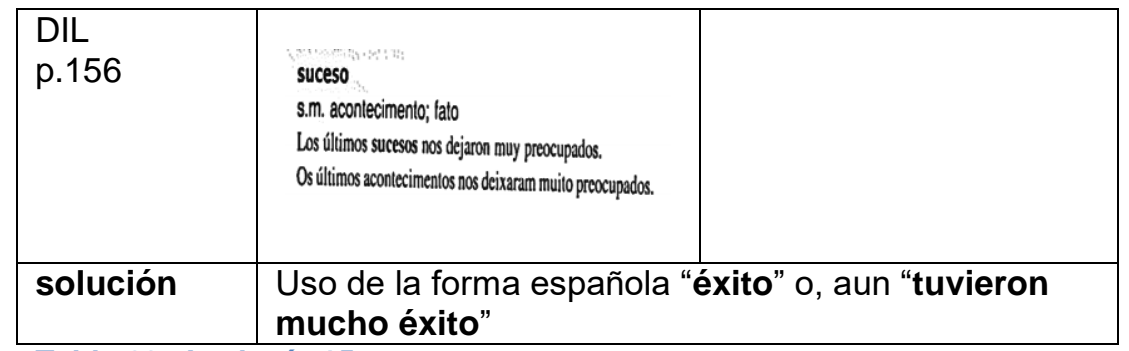

Tabla 63: Analogía 15: suceso.

El uso del nombre masculino suceso, repetido hasta en tres ocasiones por la misma docente (D8), supone un equívoco por la similitud formal de este vocablo en las lenguas portuguesa $y$ española. Algunas acepciones coinciden en ambos idiomas, como observamos en las descripciones de los diccionarios consultados. Sin embargo, mientras que en portugués suceso es sinónimo de "éxito", en español lo es de "acontecimiento". Por otro lado, el error reside también en la colocación verbal, de tal manera que "fazer sucesso" del portugués no se corresponde tampoco con la expresión española, que prescribe el empleo de "tener" ("tuvieron éxito"). Por todo ello, lo adecuado sería el uso de "éxito" en el sentido que quiere dar la docente: “... el título es "solo se vive una vez"... de Azúcar Moreno... dúo como disse ${ }^{\star} .$. son dos hermanas... dos mujeres... que tuvieron mucho... años atrás tuvieron mucho éxito...".

\subsection{16 Analogía 16: cobrar}

\begin{tabular}{|l|l|l|}
\hline \multicolumn{2}{|l|}{ Interferencia 16: cobrarles (v. cobrar) } \\
\hline Ejemplo & $\begin{array}{l}\text { D7C1: muy bien... eso * regla de prueba... por ejemplo } \\
\text { en "ENEM" [[tipo de examen]] y esas cosas van a } \\
\text { cobrarles la escrita* de los números... }\end{array}$ \\
\hline $\begin{array}{l}\text { Diccionar } \\
\text { io }\end{array}$ & Español/ Portugués & Portugués/ Español \\
\hline DFA & ---- & ---- \\
\hline
\end{tabular}




\begin{tabular}{|c|c|c|}
\hline $\begin{array}{l}\text { OFA } \\
\text { p.96 }\end{array}$ & 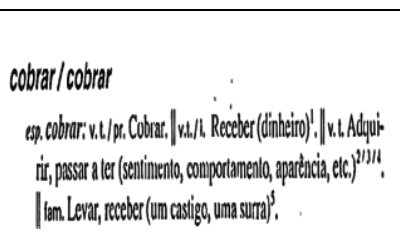 & 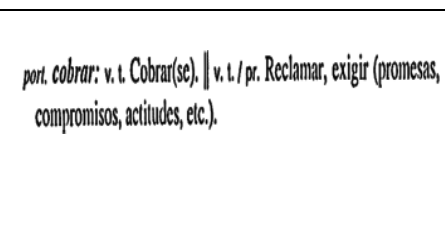 \\
\hline & \multicolumn{2}{|c|}{ 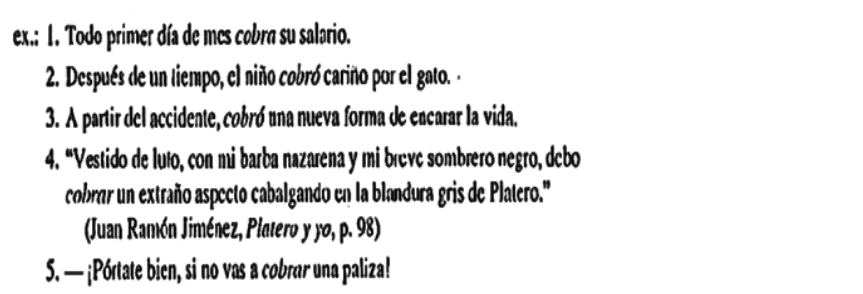 } \\
\hline DIL & ---- & --- \\
\hline solución & \multicolumn{2}{|c|}{ Uso de la forma española "exigirles". } \\
\hline
\end{tabular}

Tabla 64: Analogía 16: cobrar.

Mientras que cobrar tiene acepciones comunes en las dos lenguas -como "cobrar (recibir) una deuda" por ejemplo-, hay otros sentidos que son particulares de alguna de ellas, como ocurre con el portugués de "reclamar, exigir". Esto proporciona al mensaje un significado muy distinto al pretendido por la docente. Esta intentaba explicar que en el denominado examen "ENEM", una de las formas de acceso a la universidad, se suele exigir la escritura de los números en español, y por ese motivo los alumnos deberían aprender cómo se escriben estos. Sin embargo, el uso del verbo cobrar español no se corresponde con el mensaje pretendido, y por ello resulta ser un error por analogía, con el que la docente utiliza un verbo existente en las dos lenguas, pero con un sentido que no existe en la LE. Lo adecuado, por tanto, sería el uso de "exigir" en la frase: “... van a exigirles la escrita de los números...". 


\begin{tabular}{|c|c|c|}
\hline \multicolumn{3}{|c|}{ Interferencia 17: pegar } \\
\hline Ejemplo & \multicolumn{2}{|c|}{$\begin{array}{l}\text { D9C1: ... tiene que pegar el autobús y viajar y de } \\
\text { repente y al llegar al dentista tiene que esperar } \\
\text { tiempo y tiene* otras personas atendendo*... }\end{array}$} \\
\hline Diccionario & Español/ Portugués & Portugués/ Español \\
\hline $\begin{array}{l}\text { DFA } \\
\text { p.81 }\end{array}$ & $\begin{array}{l}\text { pegar t. Aderir: unir duas coisas com cola ou } \\
\text { produto semelhante; colar, fixar, prender uma } \\
\text { coisa com outra; costurar: "Sólo me falta pegar } \\
\text { las mangas y los botones". Bater: "Le pegó al } \\
\text { niño". Darr "Pegar un salto; un susto". Encos- } \\
\text { tar, aproximar muito: "Pegar el piano a ha pi- } \\
\text { red". Fam. Fazer sofrer: "Menudo rollo me has } \\
\text { pegado!". Pegar: contrair, contagiar: "Pegar } \\
\text { la escarlatina". }\end{array}$ & 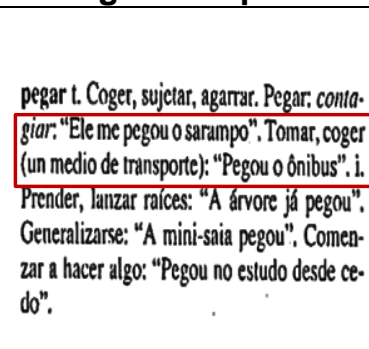 \\
\hline $\begin{array}{l}\text { OFA } \\
\text { p.239 }\end{array}$ & 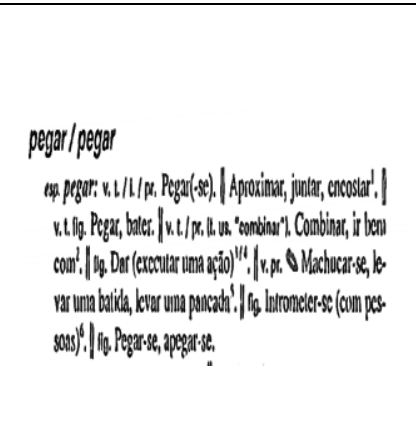 & 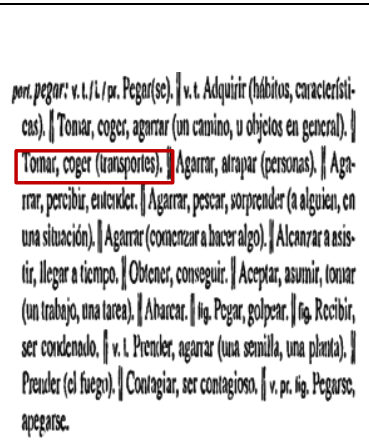 \\
\hline & \multicolumn{2}{|c|}{ 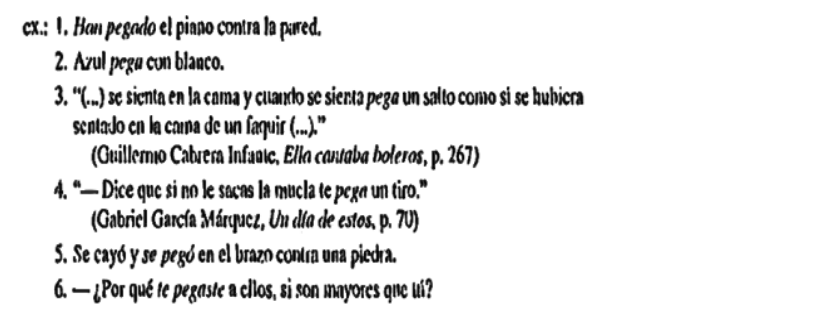 } \\
\hline
\end{tabular}




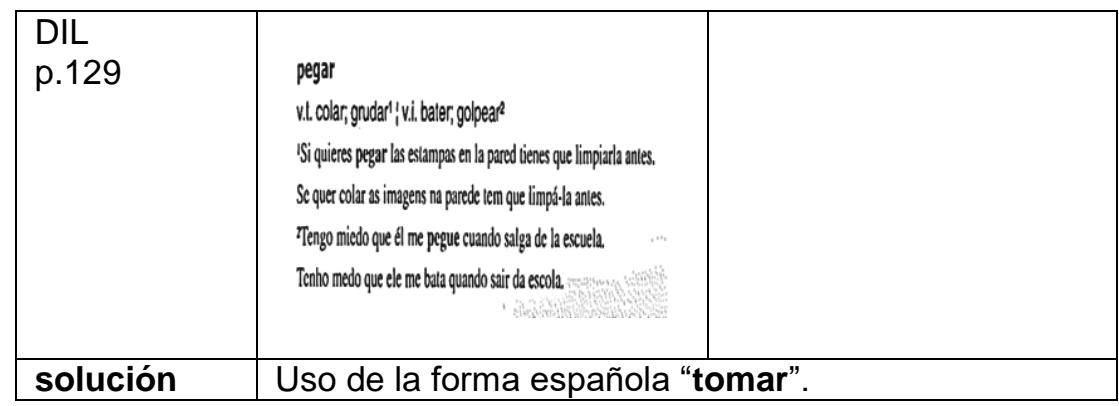

Tabla 65: Analogía 17: pegar.

Como podemos apreciar, el verbo pegar tiene muchos sentidos en cada una de las lenguas, tal y como lo recogen los tres diccionarios consultados. De igual manera, en una consulta en los diccionarios monolingües, constatamos que pegar posee 24 acepciones $^{152}$ en la lengua española y hasta 52 en la portuguesa ${ }^{153}$. De estas, encontramos coincidencia semántica en algunas pocas, como por ejemplo: (i) en el sentido "unir una cosa con otra mediante alguna substancia"; (ii) en el sentido de que la comida se haya adherido a una cacerola; (iii) o que la luz del sol incida intensamente sobre una superficie; (iv) dicho de una planta, "fijarse, echar raíces" (v) dicho de dos o más personas, que se golpean.

En suma, son más las diferencias que las similitudes entre los usos de estos dos verbos, por lo demás idénticos desde el punto de vista formal. $Y$ estas se reflejan en los diccionarios de falsos amigos aquí consultados. Así, en ninguna de las acepciones de pegar en español está relacionado con el hecho de "coger" o "tomar" un medio de transporte, como lo utiliza la docente en un par de ocasiones. De este modo, el uso de pegar en el sentido portugués configura un claro error por analogía, y por ello debería sustituirse por tomar, como sugieren tanto el DFA como el OFA. De esta manera, lo ideal sería: “... tiene que tomar el autobús y viajar y de repente y al llegar al dentista tiene que esperar tiempo y tiene* otras personas atendendo*..."154.

\footnotetext{
${ }^{152}$ Según el DRAE, http://dle.rae.es/?id=SKdzxQw consultado el 09/09/16.

${ }^{153}$ Versión electrónica del Diccionario AURELIO.

154 Dificultades con el uso de pegar como heterosemántico también se encuentran en la investigación de Andrade (2010, p. 175; 181), ya sea en los usos aquí reseñados, ya en otros diferentes, (lo que no es de extrañar dada la polisemia del verbo en ambas lenguas).
} 
7.2.1.1.2.1.18 Analogía 18: procurar

\begin{tabular}{|c|c|c|}
\hline \multicolumn{3}{|c|}{ Interferencia 18: procurar } \\
\hline Ejemplo & \multicolumn{2}{|c|}{$\begin{array}{l}\text { D3E: ... tenemos que en internet procurar algo y } \\
\text { colocarles }^{*} \text { a escutar* }[\text { [la lengua española] }] \text { y no } \\
\text { tengo plata para viajar... }\end{array}$} \\
\hline $\begin{array}{l}\text { Diccionari } \\
0\end{array}$ & Español/ Portugués & Portugués/ Español \\
\hline DFA & $\begin{array}{l}\text { procurar t. Esforçar-se por: "Procura ser pun- } \\
\text { tual", Proporcionar, oferecer, "Le ha procura- } \\
\text { do un piso muy bueno". r. Conseguir. }\end{array}$ & $\begin{array}{l}\text { procurar t. Buscar, tentar encontrar: "Estão } \\
\text { procurando emprego". }\end{array}$ \\
\hline OFA & ---- & ---- \\
\hline DIL & $-\cdots$ & $-\cdots$ \\
\hline solución & \multicolumn{2}{|c|}{ Uso de la forma española "buscar" } \\
\hline
\end{tabular}

Tabla 66: Analogía 18: procurar.

En el caso de procurar, utilizado una vez por las docentes D2 y D3, vemos también cómo los significados de partida son diferentes en cada lengua. Según muestra el diccionario DFA, en español, este significa "esforzarse por algo", "proporcionar u ofrecer algo" o incluso "conseguir". Por el contrario, en la lengua portuguesa procurar significa "buscar, intentar, encontrar". En el ejemplo transcrito más arriba, la docente emplea el verbo procurar en el sentido portugués, lo que caracteriza este error como de analogía. Lo ideal hubiese sido el empleo del verbo "buscar" en este contexto: "... tenemos que en internet buscar algo y colocarles* a escutar* [[la lengua española]] y no tengo plata para viajar...".

\subsection{19 Analogía 19: bate}

\begin{tabular}{|l|l|}
\hline \multicolumn{2}{|l}{ Interferencia 19: bate } \\
\hline Ejemplo & $\begin{array}{l}\text { D1E: ... y yo tengo una vecina que bate en la } \\
\text { puerta... }\end{array}$
\end{tabular}




\begin{tabular}{|c|c|c|}
\hline Diccionario & $\begin{array}{l}\text { Español/ } \\
\text { Portugués }\end{array}$ & Portugués/ Español \\
\hline DFA & ---- & ---- \\
\hline $\begin{array}{l}\text { OFA } \\
\text { p.55 }\end{array}$ & batif/hater & 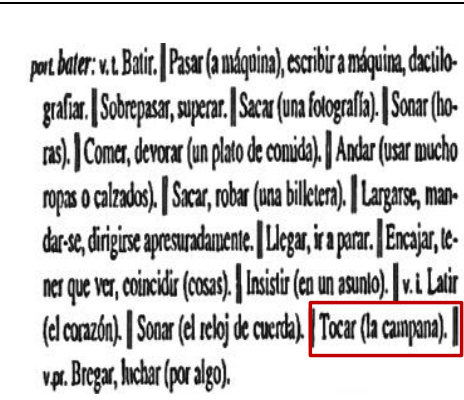 \\
\hline DIL & ---- & ---- \\
\hline solución & \multicolumn{2}{|c|}{ Uso de la forma española "Ilama a". } \\
\hline
\end{tabular}

Tabla 67: Analogía 19: bate.

Como podemos observar, en el artículo extraído del OFA, el verbo portugués bater tiene hasta 16 correspondencias para el español. Esta polisemia puede ser la causa de muchos errores de analogía que, como profesores, observamos en nuestra labor diaria. En el caso concreto que analizamos, cometido únicamente por la docente D1, consideramos que el empleo del vocablo bate da cuenta de un error de analogía puesto que la docente utiliza el verbo bater (batir en español) en el sentido de "tocar la campana" que hemos señalado en el OFA. Si observamos el ejemplo con más atención, comprobamos que la profesora se refería probablemente a la "puerta" y no a la "campana". En este caso, creemos que la obra en cuestión atiende a este heterosemántico de manera parcial, y pensamos que el término adecuado en este caso sería "Ilamar" a la puerta $^{155}$, . Entendemos, por tanto, que "tocar la campana", tiene un sentido similar, pero no totalmente equivalente a "bater à (na) porta" del portugués (en este caso lo equivalente a "tocar la campana" sería "tocar a campainha"). En suma, lo apropiado sería la utilización de "llamar" en el ejemplo: "... y yo tengo una vecina que llama a la puerta...".

${ }^{155}$ Extraído del DRAE http://dle.rae.es/?id=NTReP1j accedido el 15/07/2016. 
7.2.1.1.2.1.20 Analogía 20: chingó

\begin{tabular}{|c|c|c|}
\hline \multicolumn{3}{|c|}{ Interferencia 20: chingó (v. chingar) } \\
\hline Ejemplo & \multicolumn{2}{|c|}{$\begin{array}{l}\text { D9C1: ... ni habló* cosas malas... ni la chingó ni } \\
\text { nada... pero... todo en una buena*... fue haciendo } \\
\text { as* cosas y cuando la culebra percibió estaba } \\
\text { presa... }\end{array}$} \\
\hline Diccionario & Español/ Portugués & Portugués/ Español \\
\hline DFA & --- & --- \\
\hline \multirow[t]{2}{*}{$\begin{array}{l}\text { OFA } \\
\text { p.89 }\end{array}$} & 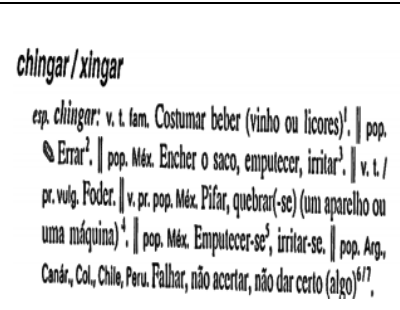 & port xiuggar, v. . L/. Insullar, injuriar (con palabras). \\
\hline & $\begin{array}{l}\text { ex.: 1. Chinga un licor al Ilegar dcl II } \\
\text { 2. Carlos le ching por dos núm } \\
\text { 3. - iNo me chingues! iDCjanme } \\
\text { 4. El televisor se ching6. } \\
\text { 5. Se chingó porque tuvo que } \\
\text { quedarse trabajando después } \\
\text { de hora. } \\
\text { 6. A Julieta se le } \\
\text { chingó la torta. } \\
\text { 7. Con cl mal } \\
\text { ticmipo, se chings } \\
\text { el paseo. }\end{array}$ & $\begin{array}{l}\text { ajo. } \\
\text { anquilo que estoy ocupado! }\end{array}$ \\
\hline DIL & \begin{tabular}{|l|l}
--- & --- \\
\end{tabular} & \\
\hline solución & \multicolumn{2}{|c|}{ Uso de la forma española "insultó". } \\
\hline
\end{tabular}

Tabla 68: Analogía 20: chingó.

Aunque solamente uno de los diccionarios recoja el vocablo chingar, es evidente que el uso hecho por la docente D9 hasta en cuatro ocasiones supone un error de analogía, puesto que emplea el verbo chingar del español con el mismo sentido que el verbo xingar 
del portugués. En la explicación que realiza la profesora sobre una historia que están interpretando en clase, esta destaca que el personaje principal, que es muy bondadoso, trata a la culebra (personaje malvado) con indiferencia, pese a las repetidas trampas de esta última. Así, el uso del verbo chingar en el contexto que emplea la docente se refiere a que el personaje "bondadoso" de la historia no trató de mala manera a la pérfida culebra, sino que se limitó a esperar a que esta cayera en su propia trampa. En definitiva, no le dijo todo lo que pensaba acerca de su maldad, no la "insultó". Por el contrario, el verbo chingar en español tiene diversas connotaciones coloquiales, incluso algunas de ellas las podemos encontrar en el artículo del OFA presentado en la tabla $68^{156}$, aunque ninguna equivalga a "insultar" como en portugués, y por ello su uso en este contexto resulta impropio. Lo adecuado, por tanto, sería el empleo de "insultar", como bien recoge el diccionario consultado, en la frase: “... ni habló* cosas malas... ni la insultó ni nada...".

\subsection{21 Analogía 21: desligaron}

\begin{tabular}{|c|c|c|}
\hline \multicolumn{3}{|c|}{ Interferencia 21: desligaron (v. desligar) } \\
\hline Ejemplo & \multicolumn{2}{|c|}{$\begin{array}{l}\text { D2C8: ... va a tener que leer de nuevo porque... } \\
\text { desligaron la grabación... }\end{array}$} \\
\hline Diccionario & Español/ Portugués & Portugués/ Español \\
\hline $\begin{array}{l}\text { DFA } \\
\text { p.38 }\end{array}$ & $\begin{array}{l}\text { destigar t. Desligas, separarar o que estava uni- } \\
\text { do, desalar, sollar, desprender. }\end{array}$ & $\begin{array}{l}\text { desligar t. Desligar: separarlo que estaba uni- } \\
\text { do, desatar, soliar, desprender. Desconectar, } \\
\text { interrumpir (un circuito elécrico) i. Br. Fam. } \\
\text { Absiraerse, despreocuparse. }\end{array}$ \\
\hline OFA & ---- & $\begin{array}{ll}--- \\
\end{array}$ \\
\hline DIL & ---- & ---- \\
\hline solución & \multicolumn{2}{|c|}{ Uso de la forma española "desconectaron". } \\
\hline
\end{tabular}

Tabla 69: Analogía 21: desligaron.

${ }^{156}$ A partir de lo que recoge el OFA y también el DRAE (disponible en http://dle.rae.es/?id=8pLhBqB accedido el 02/05/17), el uso de "xingar" se configura como un americanismo. 
Este es otro caso similar al que veíamos anteriormente en "cobrarles", y donde nos encontramos con un verbo idéntico en ambas lenguas, pero con algunos usos privativos en cada una de ellas, lo que propicia el uso inadecuado en la LO. En el caso de desligar, utilizado una vez por la docente D2, en español y portugués existe el sentido de "separar lo que estaba unido". Sin embargo, lo que el sujeto intenta decir es que la grabadora fue "apagada, desconectada", y por ello tendrían que repetir la tarea que estaban haciendo. En portugués, desligar posee el significado de "apagar, desconectar", habitual al hablar de aparatos electrónicos u objetos que funcionan con algún tipo de energía, tal y como podemos encontrar en la cuarta acepción de "desligar" del AURÉLIO 157: "Interromper a alimentação de aparelho elétrico". (ej. "desligar la luz" - apagar la luz; "desligar o carro" - apagar el coche; "desligar o celular" - apagar el móvil). De esta manera, se explica el error por analogía, cuya corrección supondría el empleo del verbo sería "desconectar" o "apagar" en la frase: “... va a tener que leer de nuevo porque... desconectaron la grabación [[el grabador]]..."158.

\subsection{22 Analogía 22: viró}

\begin{tabular}{|c|c|c|}
\hline \multicolumn{3}{|c|}{ Interferencia 22: viró (v. virar) } \\
\hline Ejemplo & \multicolumn{2}{|c|}{$\begin{array}{l}\text { D2E: ... pero mi casa viró un taller... sí... mi casa é* } \\
\text { un taller... }\end{array}$} \\
\hline Diccionario & Español/ Portugués & Portugués/ Español \\
\hline $\begin{array}{l}\text { DFA } \\
\text { p.122 }\end{array}$ & 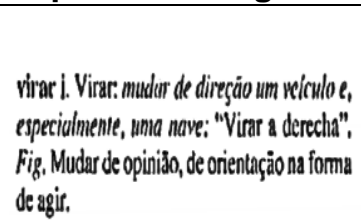 & \\
\hline
\end{tabular}

${ }^{157}$ Versión digital.

${ }^{158}$ Parece que este es un error común entre los brasileños estudiantes de español, puesto que lo hemos encontrado igualmente en las investigaciones de Carmolinga (1991, p. 69) y Andrade (2010, p. 173) (aunque el primer autor no lo mencione como heterosemántico). 


\begin{tabular}{|c|c|c|}
\hline & & $\begin{array}{l}\text { virar i. Virar: cambiar de dirección (un veícu- } \\
10 \text { o persona), mudar de rumbo. I. Cambiar de } \\
\text { lado, cambiar la dirección o la posición de: } \\
\text { "Virou o disco para ouvir o outso lado". Poner } \\
\text { al revés: "Virou o bolso, mas não achou o di- } \\
\text { nheiro". Beber o verter rapidannente. Transfor- } \\
\text { marse en: "Maria virou uma bela moça"."i. Dar } \\
\text { la vuella, volcarse: "Com a batida, o carm vi- } \\
\text { rou ficando com as rodas para cima", r. Volver- } \\
\text { se, voltearse: "Ao virarse viuu o acidenle". Fam. } \\
\text { Intentar salir solo de una dificultad, arreglárse- } \\
\text { las: "Deixe que eu me viro sozinho". }\end{array}$ \\
\hline OFA & ---- & ---- \\
\hline DIL & ---- & ---- \\
\hline solución & \multicolumn{2}{|c|}{ Uso de la forma española "se transformó en". } \\
\hline
\end{tabular}

Tabla 70: Analogía 22: viró.

En el caso de "virar", utilizado en dos ocasiones por la docente D2, vemos nuevamente el empleo de un verbo con un sentido que no existe en la LO utilizada. Como advierte el DFA para la dirección portugués/español, uno de los posibles significados de este verbo en portugués es "transformarse". A nuestro juicio, este es el sentido que la docente quiso aplicar con el uso de virar, cuando observa que su casa se transformó en un taller porque su hija había empezado un nuevo negocio en ella. Sin embargo, este sentido no se corresponde con los de virar en español, tanto los incluidos en el DFA como en las ocho acepciones que encontramos en el DRAE ${ }^{159}$. Por ello, entendemos que este es un error por analogía y que lo adecuado sería el uso de "se transformó" en el ejemplo: “... pero mi casa se transformó en un taller... sí... mi casa é ${ }^{*}$ un taller...”.

\subsection{Errores explicados por medio de otros diccionarios}

Nos ocuparemos ahora del segundo grupo de errores de analogía, los cuales no se encuentran mencionados en ninguna de las obras sobre falsos amigos consultadas, por lo que, para su análisis, hemos recurrido a otras fuentes bibliográficas. Inicialmente, hemos partido del DIBU, que, al ser un diccionario bilingüe de uso, nos proporciona una primera aproximación a los pares de vocablos analizados. Asimismo hemos utilizado los diccionarios monolingües

${ }^{159}$ Consultado en http://dle.rae.es/?id=bsP6WZx accedido el 09/09/16. 
consultados en los demás análisis: por un lado el DRAE y, por otro, el AURÉLIO. Teniendo en cuenta el volumen de acepciones de algunos artículos, y con la intención de plasmar la información necesaria para nuestros análisis de la manera más objetiva posible, nos hemos tomado la libertad de acotar tan solo las partes de los artículos que interesaban al estudio, cuando lo hemos creído conveniente. En otros casos, también hemos destacado con un recuadro en el cuerpo del artículo la fracción de interés para nuestro análisis.

En la tabla 71 presentamos la lista de los errores que trataremos en esta sección. Al igual que en el bloque anterior, hemos ordenado los heterosemánticos según su categoría gramatical, y ofrecemos un cuadro para cada vocablo y su respectivo análisis.

\begin{tabular}{|c|c|}
\hline & Interferencia \\
\hline 23 & aburrida \\
\hline 24 & prontos \\
\hline 25 & mismo \\
\hline 26 & cedo \\
\hline 27 & dupla \\
\hline 28 & escrita \\
\hline 29 & galera \\
\hline 30 & paseatas \\
\hline 31 & pronuncia \\
\hline 32 & sala \\
\hline 33 & serie \\
\hline 34 & turma \\
\hline 35 & pesquisar \\
\hline 36 & barra (v. barrar) \\
\hline 37 & trago (v. trazer) \\
\hline
\end{tabular}

Tabla 71: Errores por analogía, grupo II. 


\begin{tabular}{|c|c|c|}
\hline \multicolumn{3}{|c|}{ Interferencia 23: aburrida } \\
\hline Ejemplo & \multicolumn{2}{|c|}{$\begin{array}{l}\text { E: ¿crees que los alumnos están motivados? } \\
\text { D8E: no por la lengua... yo creo que por estudio... no... } \\
\text { nada... por estudio yo puedo decir que es... eh... una } \\
\text { lástima... yo puedo decir que estoy eh... [[pausa larga]] } \\
\text { E: disgustada... } \\
\text { D8E: é*... muy muy... aburrida con lo que } \\
\text { escuchamos... }\end{array}$} \\
\hline \multicolumn{2}{|c|}{ Español/ Portugués } & Portugués/ Español \\
\hline \multicolumn{2}{|c|}{ DIBU1, p. 5} & DIBU2, p. 5 \\
\hline \multicolumn{2}{|c|}{$\begin{array}{l}\text { a.bu·rrir tr.prnl. Entediar, chatear: cuando habla, } \\
\text { aburre a todo el mundo=quando fala chateia (a) } \\
\text { todo mundo. aburrimiento, cansar, hartar. } \\
\text { Como } 5 \text {. }\end{array}$} & $\begin{array}{l}\text { abbor-re-cer } 1 \text { tr. Desagradar; contrariar, irritar: } o \\
\text { mau comportamento dos meninos aborrecia o pro- } \\
\text { fessor=el mal comportamiento de los niños des- } \\
\text { agradaba al profesor. contrariar. } 2 \text { Fastidiar, } \\
\text { aburrir: fazer sempre as mesmas coisas me aborre- } \\
\text { ce=hacer siempre las mismas cosas me fastidia; }\end{array}$ \\
\hline \multicolumn{2}{|r|}{ DRAE } & AURELIO \\
\hline \multirow{2}{*}{\multicolumn{2}{|c|}{$\begin{array}{l}\text { aburrido, da } \\
\text { Del part. de aburrir. } \\
\text { 1. adj. Que causa aburrimiento. } \\
\text { Extraído de } \\
\text { http://dle.rae.es/?id=0ENOg8V } \\
\text { el } 09 / 04 / 2016\end{array}$}} & $\begin{array}{l}\text { aborrecido } \\
\text { [Part. de aborrecer.] } \\
\text { Adjetivo }\end{array}$ \\
\hline & & $\begin{array}{l}\text { 1.Que causa aborrecimento ou } \\
\text { horror; detestado, abominado: } \\
\text { É o cantor mais aborrecido de } \\
\text { quantos conheco: ninguém o }\end{array}$ \\
\hline \multicolumn{2}{|c|}{$\begin{array}{l}\text { aburrimiento } \\
\text { De aburrir. } \\
\text { 1. m. Cansancio del ánimo } \\
\text { originado por falta de estímulo } \\
\text { o distracción, o por molestia } \\
\text { reiterada. } \\
\text { 2. m. Persona, cosa o situación } \\
\text { que aburre. } \\
\text { Extraído de } \\
\text { eltp://dle.rae.es/?id=0ERLw30 } \\
\text { e9/04/2016 }\end{array}$} & $\begin{array}{l}\text { tolera. } \\
\text { 2.V. aborrecível (1). } \\
\text { 3.Que aborrece ou entedia; } \\
\text { tedioso, maçante, fastidioso, } \\
\text { aborrecível: } \\
\text { "Chuvinha aborrecida peneirava- } \\
\text { se" (Alberto Rangel, Quando o } \\
\text { Brasil Amanhecia, p. 175). } \\
\text { 4.Que sente aborrecimento, } \\
\text { enfado; amolado. } \\
\text { 5.Que denota aborrecimento, } \\
\text { tédio; amolado: } \\
\text { Fez um ar aborrecido e deu as }\end{array}$ \\
\hline
\end{tabular}


costas.

solución $\quad$ Uso de la forma "molesta" del español.

Tabla 72: Analogía 23: aburrida.

El empleo de "aburrida", que aparece en tres ocasiones en el habla de dos profesoras diferentes (D1/D8), requiere de una explicación más detallada. En el caso del ejemplo transcrito en la tabla 72, la profesora D8, al ser preguntada por la motivación de sus alumnos, revela su descontento por la actitud de estos, aunque tiene dificultades en expresarse en la LO, con lo que la entrevistadora intenta ayudarla. El resultado del diálogo es que ella declara estar "aburrida" con los alumnos. Por el contexto de la conversación, es decir, por todo lo que ya había sido dicho anteriormente a esa pregunta y también lo que vino después, podemos inferir que lo que quiso decir es que estaba muy "contrariada" ${ }^{160}$ con el comportamiento de los dicentes. Entendemos que este sentido es muy distinto al de "aburrida" en español, en el que prevalece, como describe el DRAE, "un cansancio o falta de estímulo". En suma, lo que creemos que quiso decir la docente es que estaba "disgustada" o "irritada", puesto que al parecer solía intentar sin éxito varias estrategias para que sus alumnos se involucraran en las clases. Creemos que esta confusión en el empleo de los términos se debe a la similitud formal entre los adjetivos "aburrido" y "aborrecido" o incluso los verbos "aburrir" y "aborrecer". Sin embargo, mientras que "aburrir" y "aburrido" del español remiten a un estado de ánimo de

${ }^{160}$ En la definición del DRAE:

1. tr. Contradecir a alguien, resistir sus intenciones y propósitos, procura $r$ que nose cumplan. U. t. en sent. fig.

2. tr. Disgustar, enfadar a alguien. Acepté una taza por no contrariarlo.

Extraído de: http://dle.rae.es/?id=AcGAY5r. Accedido el 01/03/17. 
molestia por falta de estímulo (entre otras posibles), "aborrecer" y "aborrecido" del portugués hacen referencia a un desagrado, fastidio, irritación y enfado, es decir, molestias de otra naturaleza. Por todo eso, creemos que una de las posibilidades sería la utilización de "molesta" en el ejemplo: “... muy muy... molesta con lo que escuchamos...".

\subsection{2 Analogía 24: prontos}

\begin{tabular}{|c|c|c|}
\hline \multicolumn{3}{|c|}{ Interferencia 24: prontos } \\
\hline Ejemplo & \multicolumn{2}{|c|}{$\begin{array}{l}\text { D5C2: ¿sí? ¿prontos? ¿quién va a ser el primer } \\
\text { grupo?// }\end{array}$} \\
\hline \multicolumn{2}{|c|}{ Español/ Portugués } & Portugués/ Español \\
\hline \multicolumn{2}{|c|}{ DIBU1, p. 656-657 } & DIBU2, p. 934 \\
\hline \multirow{2}{*}{\multicolumn{2}{|c|}{ 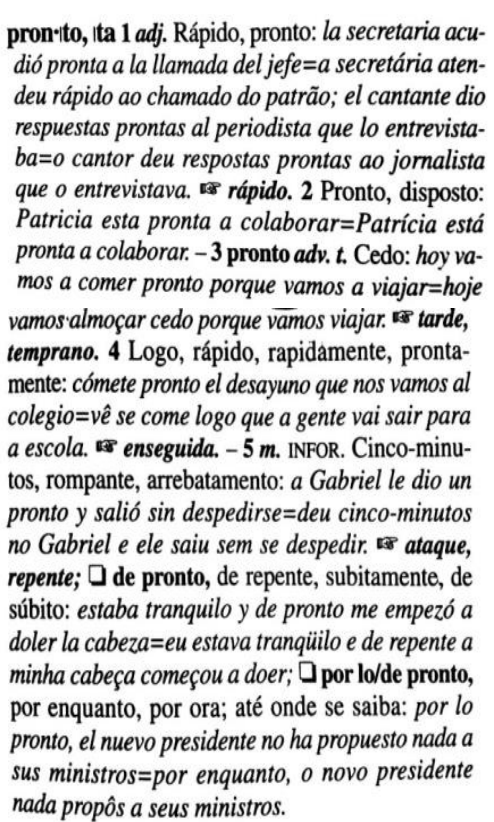 }} & $\begin{array}{l}\text { pron-to, th } 1 \text { adj. Listo, terminado, acabado: o bolo } \\
\text { ainda não está pronto=la tarta todavía no está lis- } \\
\text { ta; a casa nova de Felipe e Rosa finalmente ficou } \\
\text { pronta=la casa nueva de Felipe y Rosa finalmente } \\
\text { quedó acabada. } 2 \text { Listo, dispuesto, preparado: o ra- } \\
\text { paz disse que não estava pronto para assumir um } \\
\text { cargo de tanta responsabilidade=el muchacho dijo } \\
\text { que no estaba preparado para asumir un cargo de } \\
\text { tanta responsabilidad; os bombeiros estão sempre } \\
\text { prontos para agir em casos de emerrência=los } \\
\text { bomberos están siempre listos para actuar en casos } \\
\text { de emergencia. } \text { disposto, prontidâo. } 3 \text { Arreglado, }\end{array}$ \\
\hline & & \\
\hline \multicolumn{2}{|c|}{ DRAE } & AURELIO \\
\hline
\end{tabular}




\section{pronto, ta}

Del lat. promptus.

1. adj. Veloz, acelerado, ligero.

2. adj. Dispuesto, aparejado para la ejecución de algo.

3. m. coloq. Reacción repentina motivada por una pasión u ocurrencia inesperada. Le dio un pronto y se marchó.

4. m. coloq. Ataque repentino y aparatoso de algún mal. Le dio un pronto y se quedó sin habla.

5. adv. temprano (II en las primeras horas del día). Me levanto pronto.

6. adv. Con anticipación al momento oportuno, con tiempo de sobra. Llegó pronto para la cena.

7. adv. Antes de lo que se espera. Murió muy pronto.

8. adv. rápidamente (II con celeridad).

\section{Extraído de}

http://dle.rae.es/?id=UMgovBn, accedido el 09/06/2016.

\section{pronto}

[Do lat. promptu, 'disponível'.] Adjetivo

1. Que não tarda; ligeiro, breve, rápido.

2.Eficaz:

Este xarope é um pronto remédio contra a tosse.

3.Ativo, diligente, ágil.

4.Imediato, instantâneo:

Dava resposta pronta a qualquer insulto.

5.Que age ou opera com rapidez; vivo, ágil:

É dotado de inteligência pronta.

6.Concluído, terminado, acabado:

A casa já está pronta.

7.Disposto, apto, preparado:

Estou pronto a agir.

8.Desimpedido, livre.

9.Bras. Pop. Diz-se da mulher grávida.

10.Bras. Gír. Diz-se do indivíduo sem dinheiro, ou pobre; areado, duro, estourado, fino, frito, limpo, liso, miqueado, quebrado, teso.

11.Bras. CE Pop. Bem-vestido.

Substantivo masculino

12.Bras. Gír. Indivíduo pronto (10); duro, frito, limpo, liso, teso, (lus.) afanado.

Advérbio

13.Com prontidão; prontamente. 
En el caso de prontos, que ocurre una vez con la docente D5, parece ser que esta intenta saber si determinados alumnos están listos para empezar la presentación de una actividad a los demás compañeros. La utilización de pronto en el sentido de "listo, preparado" es bastante común en la zona dialectal de la docente.

En este sentido, entendemos que su uso está ligado a la acepción número dos del DIBU2 ${ }^{161}$ marcada en el cuadro, que se refiere a estar "listo, dispuesto, preparado". En el ejemplo que analizamos, la docente cuestiona si los alumnos ya dan por terminada su actividad y la pueden presentar a los demás. Si comparamos esta acepción con las expuestas tanto en el DIBU1 como en el DRAE, veremos que la correspondiente al "pronto" del portugués sería "listo". En el DRAE, en la acepción 2 encontramos la definición de "pronto" como "dispuesto, aparejado para la ejecución de algo", pero si lo buscamos en otras fuentes, como en el DUMM3, esa acepción parece estar más relacionada a cosas que personas (MOLINER, 2008, p. 159). Por tanto, entendemos que lo adecuado sería el uso de "listos" o "preparados" en este contexto: "¿sí? ¿listos? ¿quién va a ser el primer grupo?"

\subsection{3 Analogía 25: mismo}

\begin{tabular}{|c|l|l|}
\hline \multirow{4}{*}{ Interferencia 25: mismo } \\
\hline \multirow{3}{*}{ Ejemplo } & $\begin{array}{l}\text { E: y los alumnos también harán un cursillo de } \\
\text { lengua... } \\
\text { D7E: eso... eso... de lengua mismo... vamos... v } \\
\text { van a practicar mismo... aprender... }\end{array}$ \\
\hline Español/ Portugués & \multicolumn{1}{c|}{ Portugués/ Español } \\
\hline DIBU1, p. 518 & DIBU2, p. 728-729 \\
\hline
\end{tabular}

161 Tanto en el DIBU2 como en el Aurelio las acepciones son numerosas y extensas. Por ello, hemos presentado aquí solamente las más relevantes para nuestro estudio. 
mis`mo, ma 1 adj.-pron. Mesmo, (a) mesma coisa: mi padre siempre me dice lo mismo: que estudie $=0$ meu pai sempre me diz a mesma coisa: para eu es. tudar; he oído la misma canción tres veces=escu. tei a mesma música três vezes; desde que se ha muerto tu padre no eres la misma =desde que o seu pai morreu, você não é a mesma; Cristina tiene los mismos gustos que yo=Cristina tem os mesmos gostos que eu. idéntico, semejante. 2 Mesmo, próprio: yo misma iré a hacer la denuncia del robo=eu mesma farei a denúncia do roubo; me lo dijo él mismo=ele mesmo/próprio me disse; tiene el trabajo en su misma calle y aun así siempre llega tarde $=0$ trabalho fica na própria rua onde mora e, mesmo assim, sempre se atrasa; $\square$ con las mismas, mes`mo, ma 1 adj.-s. Mismo, idéntico: tivemos que ouvir a mesma história várias vezes=tuvimos que escuchar la misma historia varias veces; não importa quanto dinheiro eu tenho agora, ainda sou a mesma pessoa=no importa cuánto dinero tenga ahora, todavía soy la misma persona; eu mesma vou tratar de resolver este assunto= yo misma voy a tratar de solucionar este asunto; se você já terminou o trabalho vou fazer o mesmo=si tú ya has terminado el trabajo, yo voy a hacer lo mismo; minha avó envelheceu mas ainda é a mesma=mi abuela ha envejecido, pero todavía es la misma. idéntico, igual, próprio. - 2 adv. Realmente, efectivamente, verdaderamente, de verdad, de veras: não é brincadeira, eu ganhei a bolsa de estudos mesmo=no es broma, me han concedido una bolsa de estudios de verdad; ele é mesmo muito simpático=él es realmente muy simpático; -Vou me candidatar a vereador nas próximas eleições. $-E$ É mesmo? =-Me voy a presentar a concejal en las próximas elecciones. -¿De verdad?; Silvana está gostando mesmo daquele cara $=a$ Silvana le está gustando de verdad aquel tipo. verdade. No se recomienda, aunque es frecuente, el uso de mesmo(s),a(s) como en: telefonei para o advogado, mas o mesmo não se encontrava em seu escritório=llamé al abogado, pero el mismo no se encontraba en el bufete; se recomienda emplear en estos casos este(s), a(s), ele(s), ela(s); $\square$ a mesma

\begin{tabular}{|c|}
\hline DRAE \\
\hline
\end{tabular}

\section{mismo, ma}

Del lat. vulg. *metipsĭmus, combinación del elemento enfático -met, que se añadía a los prons. pers., y un sup. de ipse 'el mismo'.

1. adj. Idéntico, no otro. Es el mismo pobre a quien ayer socorrí. Es la misma espada que sirvió a mi padre.

\section{AURELIO}

\section{mesmo}

(ê) [Do lat. *metipsimu, superl. de metipse.]

Adjetivo

1.Exatamente igual; idêntico:

2.Parecido, semelhante, análogo:

3.Próprio, verdadeiro:

4.Este, esse, aquele; citado, mencionado:

5.Que figura em pessoa; que se 
2. adj. Exactamente igual. De la misma forma. Del mismo color. 3. adj. U., por pleonasmo, añadido a los pronombres personales y a algunos adverbios para dar más energía a lo que se dice. Yo mismo lo haré. Ella misma se condena. Hoy mismo lo veré. Aquí mismo te espero.

Extraído de http://dle.rae.es/?id=POzAgFS el 12/04/2016. apresenta em caráter pessoal:

6.Não diverso; não outro; tal qual:

7.Que não mostra alteração no caráter ou na aparência; que não mudou; invariável:

Substantivo masculino

8.A mesma coisa:

9.0 que é indiferente ou não importa:

10.Indivíduo cujo caráter ou aparência não sofreram mudança: 11. Usa-se reunindo duas frases com o verbo ser para exprimir fatos simultâneos:

12.Filos. Atributo próprio de cada ente determinado. [Cf., nesta acepç., outro e unidade.]

Advérbio

13. Exatamente, precisamente, justamente:

14.Até; ainda:

15. Realmente, verdadeiramente, deveras:

"Mas, olhe cá, mana Glória, há mesmo necessidade de fazê-lo padre?" (Machado de Assis, Dom Casmurro, p. 9);

Vamos de qualquer maneira, mas vamos mesmo. [Pelo menos no Brasil, costuma-se, principalmente em casos como o do último exemplo, pronunciar o mesmo como que sublinhado.]

\section{solución} Uso de la locución "de verdad" de la lengua española.

Tabla 74: Analogía 25: mismo.

Este error por analogía, que ocurre hasta en 15 ocasiones y lo cometen cuatro docentes (D1/D6/D7/D9), viene propiciado por las 
similitudes tanto formales como semánticas entre los adverbios mismo y mesmo. Como podemos apreciar en la tabla 74, tanto en el DIBU como en el DRAE y en el Aurelio, las acepciones de los términos mencionados son muy parecidas. Sin embargo, el uso que hace la docente aquí es el correspondiente al adverbio portugués mesmo, que significa "realmente, verdaderamente, efectivamente", como lo demuestran las acepciones 2 del DIBU2 y 15 del AURÉLIO, respectivamente, ambas destacadas en el cuadro. Así, lo que intenta decir la docente, es que los alumnos harán un curso de lengua española en un país extranjero y que allí practicarán "de verdad" la lengua. Lo correcto sería, pues, el empleo de esta locución, en lugar de "mismo": "van a practicar de verdad... aprender...".

Como información complementaria a nuestra explicación, nos gustaría subrayar que las relaciones entre mesmo/mismo/aunque han sido tratadas por Yokota (2000), quien defiende que el uso de "mismo" es una transferencia de la LM fosilizable. Para esta autora, enseñar a los brasileños las diferencias en el uso de "mismo" es todo un reto para los profesores de ELE. En su estudio, descubrió que más de un $50 \%$ de las traducciones de "mesmo" hechas por sus alumnos eran incorrectas, incluso aun después de haber estudiado repetidamente los usos de mismo en clase). Los datos de Yakota corroboran nuestros resultados, puesto que, como hemos tenido ocasión de comprobar, las formas con mismo (ya sean por analogía, transferencia directa o calco) son recurrentes en nuestro corpus ${ }^{162}$.

\subsection{4 Analogía 26: cedo}

\begin{tabular}{|c|c|c|}
\hline \multicolumn{2}{|l|}{ Interferencia 26: cedo } \\
\hline \multirow{2}{*}{ Ejemplo } & D6C4: temprano... es $\underline{\text { cedo de la mañana...// }}$ \\
\hline \multicolumn{2}{|c|}{ Español/ Portugués } & Portugués/ Español \\
\hline DIBU1, p. & DIBU2, p. 182 \\
\hline
\end{tabular}

${ }^{162}$ De la misma forma, el estudio de Farias (2007, p. 66) recoge también este error de interferencia entre sus sujetos brasileños aprendices de ELE. Un último dato a resaltar es que ninguna de estas autoras lo considera un heterosemántico, como sí lo hemos hecho nosotros. 


\begin{tabular}{|c|c|}
\hline---- & $\begin{array}{l}\text { ce`do } 1 \text { adv. Pronto, temprano, prematuramente: } \\
\text { chegaram muito cedo para a reunião=llegaron muy } \\
\text { temprano a la reunión; é cedo para tirarmos qual- } \\
\text { quer conclusão desse episódio=es pronto/tempra- } \\
\text { no para sacar alguna conclusión de este hecho. } \\
\text { antes, prematuro, tarde. } 2 \text { Temprano: saiu cedo e } \\
\text { voltou só à noite =salió temprano y sólo volvió por } \\
\text { la noche; a cordaram cedo para viajar =se desper- } \\
\text { taron temprano para viajar; ainda é cedo, vamos } \\
\text { dormir um pouco mais=todavía es temprano, va- } \\
\text { mos a dormir un poco más. } \\
\text { tarde. }\end{array}$ \\
\hline DRAE & AURELIO \\
\hline $\begin{array}{l}\text { cedo } \\
\text { Del lat. cito 'pronto'. } \\
\text { 1. adv. desus. Luego, presto, al } \\
\text { instante. U. en el norte de Esp. } \\
\text { Extraído de: } \\
\text { http://dle.rae.es/?id=8684wfw y el } \\
09 / 04 / 2016\end{array}$ & $\begin{array}{l}\text { cedo } \\
\text { (ê) [Do lat. cito, 'depressa'.] } \\
\text { Advérbio } \\
\text { 1.Antes da ocasião própria; } \\
\text { prematuramente. } \\
\text { 2.De madrugada. } \\
\text { 3.De pronto; depressa. [Cf. sedo, do v. } \\
\text { sedar.] }\end{array}$ \\
\hline \multicolumn{2}{|c|}{ Uso de la explicación del vocablo o incluso de la traducción. } \\
\hline
\end{tabular}

Tabla 75: Analogía 26: cedo.

En el caso de cedo, que aparece una vez en el discurso de la docente D6, vemos que se utiliza este adverbio para explicar lo que tiene lugar "temprano", como si fueran sinónimos, puesto que en su lengua materna, cedo tiene este significado. Sin embargo, como podemos observar en el DRAE, cedo en español, además de ser un adverbio en desuso, no tiene el mismo sentido que en portugués, lo quepuede confundir al alumno. Por tanto, entendemos que es un error de analogía y que la profesora podría haberlo evitado explicando el contenido del adverbio español por medio de una paráfrasis, como, por ejemplo, "temprano, en el contexto que estamos estudiando ahora, significa 'en las primeras horas del día o de la noche, o de un período de tiempo"'163.

${ }^{163}$ El uso de cedo parece ser recurrente en los aprendices brasileños de español, como se desprende de su aparición en los trabajos de 
7.2.1.1.2.2.5 Analogía 27: dupla

\begin{tabular}{|c|c|c|}
\hline \multicolumn{3}{|c|}{ Interferencia 27: dupla } \\
\hline Ejemplo & \multicolumn{2}{|c|}{$\begin{array}{l}\text { D2C6: ... bueno, gente, en dupla... vamos a hacer lo } \\
\text { siguiente... }\end{array}$} \\
\hline \multicolumn{2}{|c|}{ Español/ Portugués } & Portugués/ Español \\
\hline \multicolumn{2}{|c|}{ DIBU1, p. } & DIBU2, p. 357 \\
\hline \multicolumn{2}{|l|}{---- } & $\begin{array}{l}\text { du·plaf. Pareja, dúo: uma dupla de pesquisadores } \\
\text { canadenses ganhou o prêmio Nobel=una pareja } \\
\text { de investigadores canadienses recibió el premio } \\
\text { Nobel; no último jogo da seleção brasileira, a du- } \\
\text { pla Romário-Ronaldo jogou muito bem=en el úl- } \\
\text { timo partido de la selección brasileña, la pareja } \\
\text { Romario-Ronaldo jugó muy bien. casal. }\end{array}$ \\
\hline \multicolumn{2}{|r|}{ DRAE } & AURELIO \\
\hline $\begin{array}{l}\text { duplo, pl } \\
\text { Del lat. du } \\
\text { 1. adj. p. } \\
\text { contiene c } \\
\text { cantidad). } \\
\text { 2. f. Extra } \\
\text { darse en I } \\
\text { colegios e } \\
\text { señalados } \\
\text { Extraído o } \\
\underline{\text { http://dle.r }} \underline{\underline{5} \text { el } 09 / 06}\end{array}$ & $\begin{array}{l}\text { plus. } \\
\text { s. doble (Il que } \\
\text { os veces una } \\
\text { U. m. c. s. m. } \\
\text { rdinario que solía } \\
\text { os refectorios de } \\
\text { n algunos días } \\
\text { e: } \\
\text { ae.es/?id=EH90FG } \\
2016 .\end{array}$ & $\begin{array}{l}\text { dupla } \\
\text { [F. subst. de duplo.] } \\
\text { Substantivo feminino } \\
\text { 1.Bras. Fam. Grupo de duas } \\
\text { pessoas que atuam em comum, } \\
\text { andam sempre ou quase sempre } \\
\text { juntas, etc.; dobradinha. } \\
\text { 2.Astr. V. estrela binária. } \\
\text { 3.Mat. Conjunto, em geral } \\
\text { ordenado, de dois elementos. } \\
\text { 4.Turfe Modalidade de aposta, em } \\
\text { que se combinam o vencedor e o } \\
\text { segundo colocado de acordo com } \\
\text { os números das respectivas chaves } \\
\text { [v. chave (25)] em que se acham } \\
\text { inscritos. }\end{array}$ \\
\hline
\end{tabular}

Carmolinga (1991, p. 80) y Durão (2004, p. 150) (aunque en sus trabajos no conste como heterosemántico). 
solución $\quad$ Uso de la forma española "pareja".

Tabla 76: Analogía 27: dupla.

En el corpus de las clases, la docente D2 repite el adjetivo dupla hasta en cuatro ocasiones, las mismas en que debería haber utilizado el nombre femenino "pareja". Este error ocurre porque el nombre dupla en portugués significa "pareja, dúo", y la docente lo confunde con el adjetivo español "dupla" (doble). Esta generalización semántica está claramente motivada por la similitud formal y genera un nuevo error. Por tanto, como podemos observar en el artículo del DIBU2, el término dupla debería ser sustituido por "pareja" en español: "... bueno gente en parejas... vamos a hacer lo siguiente...".

\subsection{6 Analogía 28: escrita}

\begin{tabular}{|c|c|c|}
\hline \multicolumn{3}{|c|}{ Interferencia 28: escrita } \\
\hline Ejemplo & \multicolumn{2}{|c|}{$\begin{array}{l}\text { E: ¿y qué te parecía más fácil? } \\
\text { D1E: cuando yo empecé la carrera me parecía la } \\
\text { pronuncia*... me parecía la pronuncia* y la } \\
\text { escrita... me gustaba mucho escribir... }\end{array}$} \\
\hline \multirow{2}{*}{\multicolumn{2}{|c|}{$\frac{\text { Español/ Portugués }}{\text { DIBU1, p. }}$}} & Portugués/ Español \\
\hline & & DIBU2, p. 426 \\
\hline \multicolumn{2}{|l|}{---} & $\begin{array}{l}\text { es.crita } 1 f \text {. Escritura, escribir: uma criança de sete } \\
\text { anos já está na idade de aprender a escrita=un } \\
\text { niño de siete años ya tiene edad para aprender a } \\
\text { escribir. escrever. } 2 \text { Alfabeto, escritura: escrita } \\
\text { silábica=escritura silábica; escrita fonética=alfa- } \\
\text { beto fonéticolescritura fonética; escrita ideográf- } \\
\text { ca=escritura ideográfica; escrita musical=escri- } \\
\text { tura musical. alfabeto, caractere, código, escrever. } \\
\text { 3Letra, caligrafía: essa aluna tem uma escrita ile- } \\
\text { givel, sua letra é péssima=esa alumna tiene una } \\
\text { caligrafía ilegible, su letra es muy mala. } \\
\text { grafia, escrever, grafia, letra. }\end{array}$ \\
\hline \multicolumn{2}{|c|}{ DIBU1, p. 296} & DIBU2, p. 427 \\
\hline
\end{tabular}


es'cri-tu'ra $1 f$. Escrita, letra: la escritura maya era ideografica = a escrita maia era ideográfica; $R a$ quel tiene una escritura ilegible $=a$ Raquel tem uma letra ilegivel. escribir, letra. 2 Escritura; documento público: las escrituras del préstamo se hicieron ante notario $=$ as escrituras do empréstimo foram feitas diante do tabelião. escrituras $f$. pl. Escrituras, Bíblia: en las Escrituras se cuenta la vida de Jesucristo=nas Escrituras é contada a vida de Jesus Cristo. es-critul'ra $1 f$. Escritura(s): fomos ao cartório fazer uma cópia da escritura da casa=fuimos a la notaría para hacer una fotocopia de la escritura de la casa. cartório, documento; escritura pública DER., escritura pública. 2 Escritura, estilo, literatura: hoje há um grande número de trabalhos sobre a escritura feminina=hoy hay un gran número de trabajos sobre la literatura femenina. 3 Letra, caligrafía, tipo de letra: mandou fazer uma escritura especial nos envelopes dos convites de casamento =mandó utilizar una letra especial en los sobres de las invitaciones de boda. escrita, caligrafia.4 Escrituras $f$. pl. (sagradas) Escrituras: segundo o religioso, devemos seguir o que está nas Escrituras =según el religioso, debemos seguir lo que se dice en las Escrituras; Sagrada(s) Escritura(s), Bíblia. biblia. Se escribe con mayúscula.

\section{escrito, ta}

Del part.

de escribir; lat. scriptus.

1. adj. Que tiene manchas or

ayas que

semejan letras o rasgos de pl

uma. Uncabrito

todo manchado y escrito.

2. m. Carta, documento o cual quier papel

manuscrito, mecanografiado o impreso.

3. m. Obra o composición cien tífica o

literaria.

4. $\mathrm{m}$. Der. Pedimento o alegat

0 en pleito 0

causa.

5. f. Especie de raya con el ho cico muy

puntiagudo, el vientre blanco

\section{AURELIO}

\section{escrita}

[F. subst. de escrito, ou do it. scritta.]

Substantivo feminino

1.Representação de palavras ou idéias por meio de sinais; escritura:

escrita em caracteres alfabéticos; escrita ideográfica; escrita musical.

2.Tipo de caracteres adotado em um determinado sistema de escrita; alfabeto:

escrita árabe; escrita cirílica.

3.V. grafia (2).

4.P. ext. Qualquer sistema mnemônico us. para registrar mensagens ou fixar a memória de acontecimentos.

5.E. Ling. Fixação gráfica da 


\begin{tabular}{|l|l|}
\hline y el lomo & linguagem, de forma \\
grisrojizo, sembrado de manc & permanente ou \\
has blancas, pardas y negras. & semipermanente, num suporte. \\
& 6.Aquilo que se escreve; \\
Extraído de & escrevedura. \\
http://dle.rae.es/?id=GKRIYhs el & 7.Exercício escolar de \\
$01 / 11 / / 2016$. & caligrafia: \\
& O pequeno tem boa nota em \\
& $\underline{\text { escrita. }}$
\end{tabular}

8.Maneira pessoal de escrever; escritura, letra, caligrafia:

Sua escrita é bonita.

9.Escrituração mercantil (q. v.). 10.Gír. Negócio escuso.

11.Maneira de exprimir-se por escrito; estilo:

É prosador de excelente escrita.

12.Pop. Caso amoroso.

13.Bras. Aquilo que constitui uma rotina, ou como que uma rotina:

"O América conseguiu sua primeira vitória na Taça de Ouro ao derrotar o Bahia por 2 a 0 , ontem à noite, na Fonte Nova, confirmando a escrita de que dificilmente perde seus jogos na Bahia." (Jornal do Brasil, 14.2.1985.)

\section{escritura}

Del lat. scriptūra.

1. f. Acción y efecto de escribir.

2. f. Sistema de signos utilizado para escribir. Escritura alfabétic a, silábica, ideográfica, jeroglífica.

3. f. Arte de escribir.

4. f. Carta, documento o cualqui er papel

escrito.

\section{escritura}

[Do lat. scriptura.]

Substantivo feminino

1.Documento autêntico de um contrato, feito por oficial público.

2.V. escrita (1 e 8).

3.Modo ou arte de se expressar num texto literário:

A rica adjetivação da escritura camoniana. 


\begin{tabular}{|c|c|c|}
\hline \multicolumn{2}{|c|}{$\begin{array}{l}\text { 5. f. Documento público, firmado } \\
\text { con testigos o sin ellos por la p } \\
\text { ersona o personasque lo } \\
\text { otorgan, de todo lo cual da fe el } \\
\text { notario. } \\
\text { 6. f. Obra escrita. } \\
\text { Extraído de } \\
\text { http://dle.rae.es/?id=GKXHvDj el } \\
01 / 11 / / 2016 .\end{array}$} & 4.Rel. A Bíblia. V. escrituras. \\
\hline solución & \multicolumn{2}{|c|}{ Uso de la forma "escritura" en español. } \\
\hline
\end{tabular}

Tabla 77: Analogía 28: escrita.

Respecto del vocablo escrita, que encontramos en seis ocasiones en el corpus, distribuidas en el habla de cinco sujetos diferentes (D1/D6/D7/D8/D9), advertimos que, pese a no figurar en los diccionarios de heterosemánticos, como podemos apreciar en el ejemplo que traemos a colación, este refleja también un error de analogía. Este ocurre porque hay una confusión entre los términos escrita del portugués y escritura del español, como se comprueba en la primera entrada del DIBU2. Ya en el sentido contrario (españolportugués) del mismo diccionario, el término escrita no aparece, hecho que, a primera vista nos da ya alguna pista de que escrita puede ser un heterosemántico. También en el sentido españolportugués del mismo diccionario (DIBU1) encontramos escritura como correspondiente de escrita del portugués y, de la misma forma, en el DIBU2 observamos que escritura en ambas lenguas tiene algunos significados en común, como, por ejemplo, (i) documento público (acepción 2 - DIBU1 y acepción 1 - DIBU2), (ii) letra, caligrafía (acepción 1 - DIBU1 y acepción 3 - DIBU2) y (iii) escrituras sagradas (acepción 3 - DIBU1 y acepción 4 - DIBU2).

Por otro lado, si analizamos las entradas escrito y escritura del DRAE, veremos que la primera presenta 5 acepciones, de las cuales ninguna corresponde a la "acción o efecto de escribir" utilizada por la docente en el ejemplo en cuestión. Esta misma definición se presenta únicamente para la entrada escritura.

No obstante, si analizamos las mismas entradas en el AURÉLIO, veremos que la primera definición de "escrita" aparece como sinónimo de "escritura". Lo mismo ocurre con "escritura", cuya segunda definición es, precisamente, "escrita" (ambas marcadas en 
el cuadro). Queda en evidencia, pues, que en portugués estos términos son sinónimos.

Para nosotros, tanto el hecho de que en portugués escrita $y$ escritura con el valor de "acción de escribir, o representación de palabras por medio de señales" sean sinónimos, como la afinidad en algunas acepciones del vocablo escritura en las dos lenguas, hace que el sujeto aplique una sobregeneralización de los valores de escrita del portugués al vocablo escrita del español, lo que configura un claro error de analogía.

\subsection{7 Analogía 29: galera}

\begin{tabular}{|c|c|c|}
\hline \multicolumn{3}{|c|}{ Interferencia 29: galera } \\
\hline Ejemplo & \multicolumn{2}{|c|}{$\begin{array}{l}\text { D6C3: [comt. port] unidad cinco... página cincuenta y } \\
\text { cinco del libro... [[ruido de alumnos hablando]] } \\
\text { galera...// } \\
\text { A: (...) } \\
\text { D6C3: cincuenta y cinco... }\end{array}$} \\
\hline Espa & ol/ Portugués & Portugués/ Español \\
\hline \multicolumn{2}{|c|}{$\frac{\text { Espanol/ Portugues }}{\text { DIBU1, p. }}$} & DIBU2, p. 547 \\
\hline \multicolumn{2}{|l|}{----} & $\begin{array}{l}\text { garlerra } 1 f \text {. BRA. INFOR. Grupo, panda, gente: gos- } \\
\text { to de conversar com eles, é uma galera bem le- } \\
\text { gal=me gusta conversar con ellos, es una panda } \\
\text { estupenda. } \\
\text { ción, hinchada; público, gente, espectador: a gale- } \\
\text { ra vibrou com o gol=la afición vibró con el gol; e } \\
\text { aí, galera, vamos aplaudir o cantor?=querido pú- } \\
\text { blico ¿aplaudimos al cantante? auditório, pú- } \\
\text { blico, torcida. }\end{array}$ \\
\hline & DRAE & AURELIO \\
\hline \multicolumn{2}{|c|}{$\begin{array}{l}\text { galera } \\
\text { De galea. } \\
\text { 1. f. Embarcación de vela y } \\
\text { remo, la más larga de quilla y }\end{array}$} & $\begin{array}{l}\text { galera1 } \\
\text { [Do cat. galera < gr. bizantino } \\
\text { galéa.] } \\
\text { Substantivo feminino }\end{array}$ \\
\hline
\end{tabular}


que calaba menos agua entre las de vela latina.

2. f. Carro grande de cuatro ruedas para transportar personas, ordinariamente con cubierta o toldo de lienzo fuerte.

3. f. En los hospitales, fila adicional de camas.

4. f. Carp. Garlopa grande.

5. f. Impr. Tabla guarnecida por tres de sus lados de unos listones con rebajo, en que entra otra tablita delgada que se llama volandera. Servía para poner las líneas de letras que iba componiendo el oficial cajista, formando con ellas la galerada.

6. f. Impr. galerada (II prueba de la composición).

7. f. Ingen. Fila de hornos de reverbero donde se colocan varias retortas que se calientan con el mismo fuego. 8. f. Mat. Separación que se hace al escribir los términos de una división, trazando una línea vertical entre el dividendo, que se pone a la izquierda, y el divisor, que va en el mismo renglón a la derecha, y luego otra raya horizontal debajo de este último, para escribir allí el cociente.

9. f. Zool. Cada uno de los crustáceos adultos del orden de los estomatópodos. 10. f. coloq. Arg., Chile, Par. y Ur. Sombrero de copa redondeada, o alta y cilíndrica, y alas abarquilladas.
1.Ant. Galé (1):

"defrontaram [os cartagineses] uma frota romana composta de galeras de alto bordo e cinco bancos de remadores" (Aquilino Ribeiro, Os Avós dos Nossos Avós, p. 80).

2.Antigo navio à vela, de mastreação constituída de gurupés e três mastros de brigue, envergando ou não, além das velas redondas e de proa, velas latinas quadrangulares. Raramente existiram galeras com 4 e 5 mastros.

3.Carroça para transporte de bombeiros, em serviço de incêndio.

4.Forno de fundição.

\section{galera2}

[De galeria (11), com síncope.] Substantivo feminino Bras.

1.V. torcida $^{1}(2)$.

2.V. turma ${ }^{1}(7)$.

\section{turma1}

[Do lat. turma.]

Substantivo feminino

1.Na Roma antiga, grupo de 30 cavaleiros.

2.Grupo, bando:

uma turma de recrutas.

3.Grupo de indivíduos reunidos de propósito ou acidentalmente em torno de um interesse comum:

Uma turma de pacifistas desfilava em silêncio; Turmas de vadios rodeavam os turistas.

4.Turno (1), especialmente de estudantes ou trabalhadores: Muito cedo chega a turma da limpeza. 
11. f. C. Rica, Guat., Hond., Méx. y Nic. Cobertizo, tinglado.

12. f. Cuba. En una cárcel, sala ocupada por reclusos. 13. f. Cuba. Conjunto de reclusos agrupados en una galera.

14. f. p. us. Cárcel de mujeres.

15. f. pl. Pena de servir

remando en las galeras

reales, que se imponía a

ciertos delincuentes. Echar a

galeras. Condenar a galeras.

Extraído de

http://dle.rae.es/?id=ljhfbAO el 09/04/2016.
5.Cada um dos grupos de estudantes que compõem uma sala de aulas; classe.

6.Grupo de animais ou de coisas.

7.Bras. Grupinho de amigos; gente, pessoal; galera:

A turma vai a uma festa.

solución $\quad$ Uso de la forma "gente" en español.

Tabla 78: Analogía 29: galera.

En el caso de "galera", empleado una vez por la docente D6, vemos que la docente utiliza este nombre femenino para llamar la atención de los alumnos, puesto que quiere introducir una explicación y hay mucho ruido en la clase. El uso de "galera" aquí es un vocativo destinado a los alumnos, una manera informal de dirigirse al grupo de estudiantes. Este sustantivo está bien detallado por el DIBU2, el cual trae algunos sinónimos en español, como "grupo, panda, gente". El AURELIO también lo explica en las acepciones que hemos destacado: la número 2, de galera2, como "turma", y en la acepción número 5 de "turma": "cada uno de los grupos de estudiantes que componen un aula o clase". Queda claro que la intención de la profesora era la de interpelar al grupo de alumnos, pero, al introducir el término "galera" acude a un vocablo que no responde a sus intenciones, como podemos apreciar en las 15 acepciones encontradas en el DRAE de este sustantivo. Lo que nos sugiere el BIDU sería la utilización, por ejemplo, de "gente" en el ejemplo: "[comt. port] unidad cinco... página cincuenta y cinco del 
libro... [[ruido de alumnos hablando]] gente..."164. No obstante, por nuestro propio conocimiento de la variedad española peninsular, sabemos que este vocativo no sería nada corriente en ella, siendo "chico/as" una opción mucho más probable.

\subsection{8 Analogía 30: paseatas}

\begin{tabular}{|c|c|c|}
\hline \multicolumn{3}{|c|}{ Interferencia 30: paseatas } \\
\hline Ejemplo & \multicolumn{2}{|c|}{$\begin{array}{l}\text { D4C1: ... hicieron paseatas en las calles de la ciudad... } \\
\text { muy bien... }\end{array}$} \\
\hline \multicolumn{2}{|c|}{ Español/ Portugués } & Portugués/ Español \\
\hline \multicolumn{2}{|c|}{ DIBU1, p. } & DIBU2, p. 841 \\
\hline \multicolumn{2}{|l|}{--- } & $\begin{array}{l}\text { pas'se‘a·taf. BRA. Marcha, manifestación: sempre } \\
\text { participava da passeata pelos direitos huma- } \\
\text { nos=siempre participaba en la marcha por los de- } \\
\text { rechos humanos; se for necessário organizaremos } \\
\text { uma passeata para protestar contra o governo=si } \\
\text { es necesario, organizamos una manifestación para } \\
\text { protestar contra el gobierno; a passeata bloqueou } \\
\text { a principal avenida da cidade e prejudicou o trân- } \\
\text { sito=la manifestación bloqueó la avenida princi- } \\
\text { pal de la ciudad, y cortó el tráfico. caminhada, } \\
\text { manifestação, mareha. }\end{array}$ \\
\hline \multicolumn{2}{|r|}{ DRAE } & AURELIO \\
\hline \multicolumn{2}{|c|}{$\begin{array}{l}\text { paseata } \\
\text { De paseo, con infl. de } \\
\text { caminata. } \\
\text { 1. f. Paseo de larga } \\
\text { duración. } \\
\text { Extraído de } \\
\text { http://dle.rae.es/?id=S3oFBq }\end{array}$} & $\begin{array}{l}\text { passeata } \\
\text { Substantivo feminino } \\
\text { 1.Pequeno passeio; volta, giro. } \\
\text { 2.Bras. Marcha coletiva realizada em } \\
\text { sinal de regozijo, reivindicação ou } \\
\text { protesto cívicos, ou de uma classe; } \\
\text { caminhada. }\end{array}$ \\
\hline
\end{tabular}

${ }^{164}$ Como vocativo, gente se utiliza en algunos países de América, pero nuestro conocimiento de la lengua nos lleva a intuir que en España lo normal hubiera sido la utilización de "chicos". 


\begin{tabular}{|l|l|}
\hline \multicolumn{2}{|l|}{ P el 12/04/2016. } \\
\hline solución & $\begin{array}{l}\text { Uso de la forma “manifestaciones" de la lengua } \\
\text { española. }\end{array}$ \\
\hline
\end{tabular}

Tabla 79: Analogía 30: paseatas.

Este error, cometido una vez por la docente D4, necesita ser explicado en su contexto, puesto que el ejemplo aislado puede dar lugar a un equívoco. Lo que ocurría en ese momento de la clase es que se estaba analizando un texto en el que se hablaba de la revuelta de la población en las calles, es decir, de las "manifestaciones" - en español - llevadas a cabo por la gente. Sin embargo, según el DRAE, el verdadero significado de "paseata" en español es un "paseo de larga duración", diferente, pues, de lo que representa una "paseata" en portugués, es decir, una "manifestación". Todo ello da lugar a este nuevo error por analogía de un término de la LM en el discurso de la LO.

\subsection{9 Analogía 31: pronuncia}

\begin{tabular}{|c|c|c|}
\hline \multicolumn{3}{|c|}{ Interferencia 31: pronuncia } \\
\hline Ejemplo & \multicolumn{2}{|c|}{$\begin{array}{l}\text { D5E: ... yo tengo algunos [[alumnos]] que además de } \\
\text { seren* muy esforzados también tienen una pronuncia } \\
\text { muy buena... }\end{array}$} \\
\hline \multicolumn{2}{|c|}{ Español/ Portugués } & Portugués/ Español \\
\hline \multicolumn{2}{|c|}{ DIBU1, p. } & DIBU2, p. 934 \\
\hline \multicolumn{2}{|l|}{---} & $\begin{array}{l}\text { pro'nún cia f. Pronunciación: a pronúncia do por- } \\
\text { tuguês não é a mesma em todas as regiōes do Bra- } \\
\text { sil=la pronunciación del portugués no es la mis- } \\
\text { ma en todas las regiones de Brasil. } \\
\text { fala, pronunciar. }\end{array}$ \\
\hline & DRAE & AURELIO \\
\hline
\end{tabular}




\section{pronuncia}

De pronunciar.

1. f. coloq. Col. y Ec. habla. La noticia me dejó sin pronuncia.

\section{Extraído de}

http://dle.rae.es/?id=UMjPkky el 09/06/2016.

\section{pronúncia}

[Dev. de pronunciar.]

Substantivo feminino

1.Ato ou efeito de pronunciar; pronunciação.

2.Modo de pronunciar; fala; pronunciação:

Os cearenses têm uma pronúncia inconfundível.

3.Jur. Decisão judicial que, reconhecendo como provada a existência dum crime e admitindo haver indícios suficientes de ser o réu quem o praticou, determina que se lhe registre a culpa e o remete ao julgamento final no tribunal do júri. [Sin. ant.: pronunciação. Cf. pronuncia, do v. pronunciar.]

solución $\quad$ Uso de la forma "pronunciación" de la lengua española.

Tabla 80: Analogía 31: pronuncia.

Este error ocurre en ocho ocasiones y en cuatro docentes distintos (D1/D5/D7/D8). El vocablo pronuncia existe en las dos lenguas, pero con sentidos diferentes, por tanto, causa confusión entre los aprendices brasileños de español como lengua extranjera. En la lengua materna de los sujetos, pronuncia significa además de "el acto de hablar, proferir un discurso", el "modo de articular los sonidos al hablar". La docente en el ejemplo en cuestión se refiere a esta segunda opción cuando dice que tiene alumnos con una "pronunciación" muy buena. No obstante, la definición del vocablo pronuncia presentado por el DRAE está ligada únicamente al "habla" en algunas variedades del español americano. De esta manera, lo más correcto en este contexto habría sido el uso de "pronunciación": “... yo tengo algunos [[alumnos]] que además de seren* muy esforzados también tienen una pronunciación muy buena...". 


\begin{tabular}{|c|c|c|}
\hline Ejemplo & \multicolumn{2}{|c|}{ D3C2: ... ¿quién no estaba en la sala? } \\
\hline \multicolumn{2}{|c|}{ Español/ Portugués } & Portugués/ Español \\
\hline \multicolumn{2}{|c|}{ DIBU1, p. 727-728 } & DIBU2, p. 1038 \\
\hline \multicolumn{2}{|c|}{$\begin{array}{l}\text { sa.la } 1 \mathrm{f} \text {. Sala, sala de estar: en la sala de mi casa } \\
\text { hay una chimenea=na sala da minha casa tem uma } \\
\text { lareira. comedor, cuarto, habitación, living, salón. } \\
2 \text { Sala, móveis para sala, jogo de sala: voy a com- } \\
\text { prar la sala de mi casa en esta tienda de mue- } \\
\text { bles=vou comprar a sala da minha casa nesta loja } \\
\text { de móveis. mueble, salón. } 3 \text { Sala: sala de justi- } \\
\text { cia=sala de justica; sala de cine }=\text { sala de cinema; } \\
\text { sala de operaciones=sala de cirurgia. } 4 \text { Tribunal: el } \\
\text { abogado defendió a su cliente ante la sala=o ad- } \\
\text { vogado defendeu seu cliente diante do tribunal. } \\
\text { tribunal. }\end{array}$} & $\begin{array}{l}\text { sa-la } \\
\text { maran para el embarque. } 4 \text { BRA. Aula, clase: te- } \\
\text { mos seis salas de colegial=tenemos seis aulas de } \\
\text { enseñanza media; esta é a sala mais bagunceira } \\
\text { da escola }=\text { esta es el aula más desordenada de la } \\
\text { escuela; toda a sala tirou boas notas na } \\
\text { prova=toda la clase sacó buenas notas en el exa- } \\
\text { men. classe, turma; sala de aula, aula: esta esco- } \\
\text { la tem trinta salas de aula=esta escuela tiene trein- } \\
\text { ta aulas. classe. Se usa también solamente } \\
\text { sala: }\end{array}$ \\
\hline & DRAE & AURELIO \\
\hline \multicolumn{2}{|c|}{$\begin{array}{l}\text { sala } \\
\text { Del germ. *sal 'edificio de una } \\
\text { sola pieza de recepción'; cf. a. } \\
\text { al. ant. sal, b. al. ant. seli. } \\
\text { 1. f. Habitación principal de la } \\
\text { casa. } \\
\text { 2. f. En un edificio público, } \\
\text { habitación de grandes } \\
\text { dimensiones. Sala de } \\
\text { conferencias. } \\
\text { 3. f. Edificio o local destinado a } \\
\text { fines culturales. Sala de } \\
\text { exposiciones. } \\
\text { 4. f. Pieza donde se constituye } \\
\text { un tribunal de justicia para } \\
\text { celebrar audiencia y despachar } \\
\text { los asuntos a él sometidos. } \\
\text { 5. f. Conjunto de magistrados o }\end{array}$} & $\begin{array}{l}\text { sala } \\
\text { [Do germ. sal, 'habitação com } \\
\text { apenas uma vasta peça de } \\
\text { recepção', pelo provenç. sala.] } \\
\text { Substantivo feminino } \\
\text { 1.O compartimento principal } \\
\text { duma casa, dum apartamento. } \\
2.0 \text { compartimento onde se } \\
\text { fazem as refeições ou se } \\
\text { recebem as visitas. } \\
\text { 3.Qualquer compartimento, mais } \\
\text { ou menos amplo, duma casa, } \\
\text { dum apartamento. } \\
\text { 4.Conjunto dos móveis e da } \\
\text { decoração de uma sala: } \\
\text { sala colonial. } \\
\text { 5.Compartimento vasto, num } \\
\text { edifício aberto ao público: }\end{array}$ \\
\hline
\end{tabular}


jueces que tiene atribuida jurisdicción privativa sobre determinadas materias.

6. f. desus. Convite, fiesta, sarao y diversión.

Extraído de http://dle.rae.es/?id=X0gpajU el 09/06/2016. sala de conferências; salas de aula; as salas de um museu.

6. Recinto apropriado para o exercício de alguma função: consultório com três salas; sala de audiências. [Dim. irreg.: saleta.]

7.Local onde um artista, uma orquestra, uma companhia teatral, etc., se apresenta ao público; sala de espetáculo:

Sala Cecília Meireles (no RJ).

8.Bras. Sala de aula; classe:

Na minha sala há vários estudantes com mais de 30 anos;

Essa matéria não foi dada em sala.

9.Bras. Os alunos que a freqüentam; classe, turma:

Toda a sala se retirou, em sinal de protesto.

10.Bras. N. O primeiro dos compartimentos de um curral-depeixe (q. v.).

11.Bras. N. Parte da caiçara onde permanece o gado.

solución Uso de la forma española "aula".

Tabla 81: Analogía 32: sala.

La docente preguntaba a sus alumnos quién estaba en el aula en el momento en que ocurrió un hecho determinado. De esta manera, incurre en un error de analogía, puesto que utiliza el nombre español sala con el mismo sentido que este tiene en portugués. Si contrastamos las explicaciones del DIBU en las entradas correspondientes a las dos lenguas, esta diferencia semántica resulta evidente. También lo es si analizamos las definiciones de sala del DRAE, donde, de las seis acepciones halladas, ninguna hace referencia a "sala usada para impartir clases". Para finalizar, nótese que en el DIBU, en el final de la entrada portugués/español (la cual hemos subrayado) hay una referencia a sala como abreviación de sala de aula en portugués, o clase o aula en español. Por todo ello, entendemos que lo correcto 
en este caso hubiera sido la utilización de "aula" en el ejemplo: ... ¿quién no estaba en el aula?

\subsection{11 Analogía 33: serie}

\begin{tabular}{|c|c|c|}
\hline \multicolumn{3}{|c|}{ Interferencia 33: serie } \\
\hline Ejemplo & \multicolumn{2}{|c|}{$\begin{array}{l}\text { D2C7: ... buenos* estos diálogos eles* crearon... están } \\
\text { en la séptima serie y hace dos años que tienen } \\
\text { español... dos clases por semana...// }\end{array}$} \\
\hline Esp & iol/ Portugués & Portugués/ Español \\
\hline & $3 \mathrm{U} 1$, p. 745 & DIBU2, p. 1067 \\
\hline \multicolumn{2}{|c|}{$\begin{array}{l}\text { se-rie } 1 f \text {. Série: los números constituyen una serie } \\
\text { ilimitada }=\text { os números constituem uma série ilimi- } \\
\text { tada. } 2 \text { Série, porção: al niño le han regalado una } \\
\text { serie de cuentos }=0 \text { garoto ganhou de presente uma } \\
\text { porção de contos; mi abuelo te puede contar una } \\
\text { serie de batallas=o meu avô pode te contar uma } \\
\text { série de batalhas. } 3 \text { Seriado, série: hoy acaba la se- } \\
\text { rie de televisión=hoje acaba o seriado de televi- } \\
\text { são; } \square \text { en serie, em série: los automóviles son fa- } \\
\text { bricados en serie=os carros são fabricados em } \\
\text { série. } \\
\text { rie: este chico } \text { - } \square \text { fuera de serie come una memoria incréble, es un } \\
\text { fuera de serie=este garoto tem uma memória in- } \\
\text { crivel, éfora de série. }\end{array}$} & $\begin{array}{l}\text { sé-rie } \\
\text { de errores en tu trabajo. } \\
\text { so, año, grado: Álvaro está na terceira série do } \\
\text { ensino médio e no ano que vem vai prestar vesti- } \\
\text { bular=Álvaro está en tercer curso de la enseñan- } \\
\text { za medialÁlvaro está en duodécimo grado y el año } \\
\text { que viene hace el examen de ingreso en la uni- } \\
\text { versidad; tem oito anos e está cursando a segun- } \\
\text { da série do ensino fundamental=tiene ocho años } \\
\text { y está en segundo curso de la primarialen segun- } \\
\text { do grado. ano, escola. } 5 \text { Serie, colección: a edi- }\end{array}$ \\
\hline & DRAE & AURELIO \\
\hline \multicolumn{2}{|c|}{$\begin{array}{l}\text { serie } \\
\text { Del lat. series. } \\
\text { 1. f. Conjunto de cosas que se } \\
\text { suceden unas a otras y que } \\
\text { están relacionadas entre sí. } \\
\text { 2. f. serial (II obra que se } \\
\text { difunde en emisiones } \\
\text { sucesivas). } \\
\text { 3. f. Conjunto de sellos, billetes } \\
\text { u otros valores que forman }\end{array}$} & $\begin{array}{l}\text { série } \\
\text { [Do lat. serie.] } \\
\text { Substantivo feminino } \\
\text { 1.Ordem de fatos ou de coisas } \\
\text { ligadas por uma relação, ou que } \\
\text { apresentam analogia; sucessão, } \\
\text { seqüência. } \\
\text { 2.Seqüência ininterrupta. } \\
\text { 3.Sucessão determinada e } \\
\text { limitada de objetos homogêneos }\end{array}$ \\
\hline
\end{tabular}


parte de una misma emisión. 4. f. Mat. Expresión de la suma de los infinitos términos de una sucesión.

Extraído de

http://dle.rae.es/?id=XfDUOIU el 09/06/2016. que formam um conjunto:

Possui a série de selos comemorativa do centenário da Independência.

4.Cada uma das divisões ou subdivisões de uma classificação; classe, categoria:

Pertence à série dos esquizóides.

5.Quantidade considerável:

Uma série de pessoas ilustres estava presente à reunião; Sabe uma série de anedotas picantes. 6.Bras. Nos estabelecimentos de ensino escolar no Brasil, ano, classe:

Cursa a oitava série.

solución $\quad$ Uso de la forma "curso" de la lengua española.

Tabla 82: Analogía 33: serie.

Este error por analogía ocurre en cuatro ocasiones y lo cometen dos docentes (D2/D5). Entendemos que ocurre tanto por la similitud formal que el nombre masculino serie posee en ambas lenguas como por la coincidencia semántica en algunas de sus acepciones. Comprobamos, primeramente a través del DRAE y del AURÉLIO, que ambas lenguas coinciden en algunos significados, como, por ejemplo, los que aluden al "orden o conjunto de cosas ligados por una relación", o "secuencia". Sin embargo, en otras acepciones, como la empleada en el ejemplo en cuestión, constatamos que no hay una equivalencia directa (véase la acepción 6 del AURÉLIO, marcada en la tabla). Por su parte, el DIBU nos presenta esta divergencia semántica de un modo esclarecedor, que nos lleva a intuir que el sujeto ha utilizado el nombre serie con el sentido de "curso, año". Es evidente, por tanto, que existe un error de analogía y que lo correcto sería emplear uno de estos dos términos en el ejemplo: “... buenos* estos diálogos eles* crearon... están en el séptimo curso y hace dos años que tienen español... dos clases por semana...". 


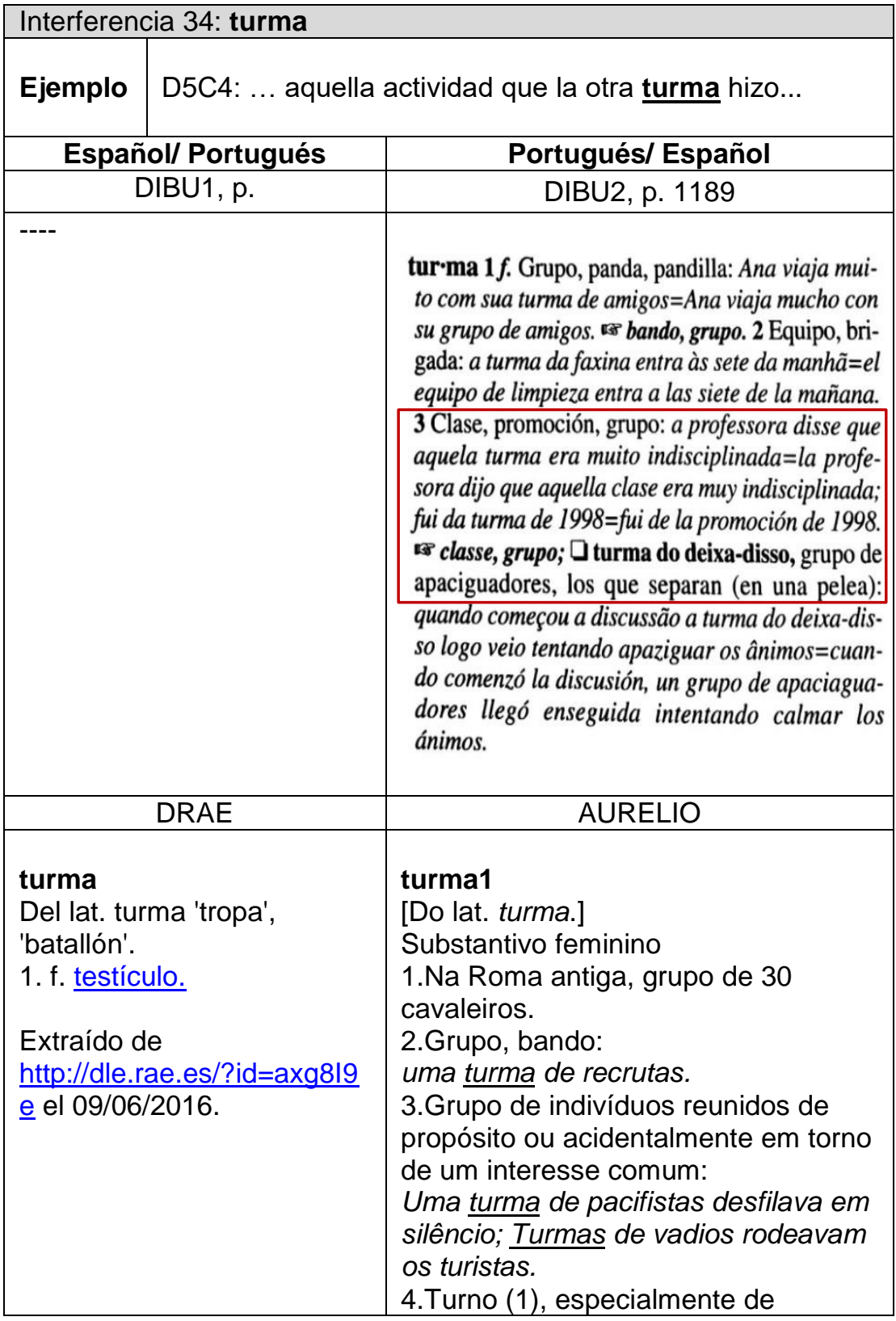




\begin{tabular}{|l|l|}
\hline \multicolumn{1}{|l|}{} & $\begin{array}{l}\text { estudantes ou trabalhadores: } \\
\text { Muito cedo chega a turma da limpeza. }\end{array}$ \\
& $\begin{array}{l}\text { 5.Cada um dos grupos de estudantes } \\
\text { que compõem uma sala de aulas; } \\
\text { classe. }\end{array}$ \\
& $\begin{array}{l}\text { 6.Grupo de animais ou de coisas. } \\
\text { 7.Bras. Grupinho de amigos; gente, } \\
\text { pessoal; galera: } \\
\text { A turma vai a uma festa. }\end{array}$ \\
\hline solució & Empleo de la forma española "clase". \\
\hline n
\end{tabular}

Tabla 83: Analogía 34: turma.

En este caso, que ocurre en dos ocasiones y en el habla de dos sujetos diferentes (D5/D7), la profesora se refiere a un grupo de alumnos diferente a aquel que está haciendo la actividad en ese momento. Para ello, utiliza el nombre femenino turma, que, como el DIBU y el AURÉLIO explican, significa "clase, grupo" en portugués. No obstante, hemos encontrado que este mismo nombre tiene un significado muy distinto en español, aunque quizá no sea regularmente utilizado, el de testículo. Por esa razón entendemos que el uso de turma configura un error de analogía, y que lo correcto sería el empleo de "clase" en el ejemplo: “... aquella actividad que la otra clase hizo..."

\subsection{13 Analogía 35: pesquisar}

\begin{tabular}{|c|l|l|}
\hline \multicolumn{2}{|l|}{ Interferencia 35: pesquisar } \\
\hline \multirow{2}{*}{ Ejemplo } & $\begin{array}{l}\text { D5C7: entonces ustedes van a pesquisar en el } \\
\text { diccionario y después que sepan lo que significa [expl. } \\
\text { port] ustedes van a dibujar ¿cierto? }\end{array}$ \\
\hline \multicolumn{2}{|c|}{ Español/ Portugués } & Portugués/ Español \\
\hline \multicolumn{2}{|c|}{ DIBU1, p. } & DIBU2, p. 875 \\
\hline
\end{tabular}

165 Otro estudio doctoral que encontró la utilización de este vocablo como heterosemántico fue el de Andrade (2010, p. 176). 


\begin{tabular}{|c|c|}
\hline ---- & $\begin{array}{l}\text { pes-qui-sar } 1 \text { tr.-intr. Investigar inúmeros cientistas } \\
\text { no mundo pesquisam a existência de vida em outros } \\
\text { planetas=numerosos cientíicos del mundo investi- } \\
\text { gan la existencia de vida en otros planetas; pes- } \\
\text { quisaram durante anos e finalmente descobriram a } \\
\text { vacina=investigaron durante años y al final des- } \\
\text { cubrieron la vacuna. } \text { buscar, investigar. - } 2 \text { tr. } \\
\text { Indagar, investigar: o advogado pesquisou minu- } \\
\text { ciosamente o passado de seu cliente=el abogado } \\
\text { investigó minuciosamente el pasado de su cliente. } \\
\text { devassar, informar, indagar, pesquisa. Como } 5 \text {. }\end{array}$ \\
\hline DRAE & AURELIO \\
\hline $\begin{array}{l}\text { pesquisar } \\
\text { 1. tr. Hacer pesquisa de } \\
\text { algo. } \\
\text { Extraido de } \\
\text { http://dle.rae.es/?id=SoDdzov } \\
\text { el 09/04/2016. }\end{array}$ & $\begin{array}{l}\text { pesquisar } \\
\left.\text { [De pesquisa }+-a r^{2} .\right] \\
\text { Verbo transitivo direto } \\
\text { 1.Buscar com diligência; inquirir, } \\
\text { perquirir; investigar: } \\
\text { Estão pesquisando, na } \\
\text { cidadezinha, as origens humildes }\end{array}$ \\
\hline $\begin{array}{l}\text { pesquisa } \\
\text { De pesquerir. } \\
\text { 1. f. Información o indagación } \\
\text { que se hace de algo para } \\
\text { averiguar la realidad de ello o } \\
\text { sus circunstancias. } \\
\text { 2. f. Ec. Policía secreta. } \\
\text { 3. m. Ec. Agente de la Policía } \\
\text { secreta. } \\
\text { 4. m. desus. testigo (ll } \\
\text { persona que da testimonio). } \\
\text { Extraído de } \\
\text { http://dle.rae.es/?id=SoBLipi y } \\
\text { el el 09/04/2016. }\end{array}$ & $\begin{array}{l}\text { 2.Informar-se a respeito de; } \\
\text { indagar, esquadrinhar, devassar: } \\
\text { O tribunal pesquisou a vida dos } \\
\text { réus. } \\
\text { Verbo intransitivo } \\
\text { 3.Fazer pesquisas: } \\
\text { "Aurélio andava adoentado e } \\
\text { raramente subia à roleta, passando } \\
\text { os dias .... na Biblioteca, } \\
\text { pesquisando, escavando assuntos } \\
\text { para novelas e poemas." (Coelho } \\
\text { Neto, Turbilhão, p. 226.). }\end{array}$ \\
\hline
\end{tabular}




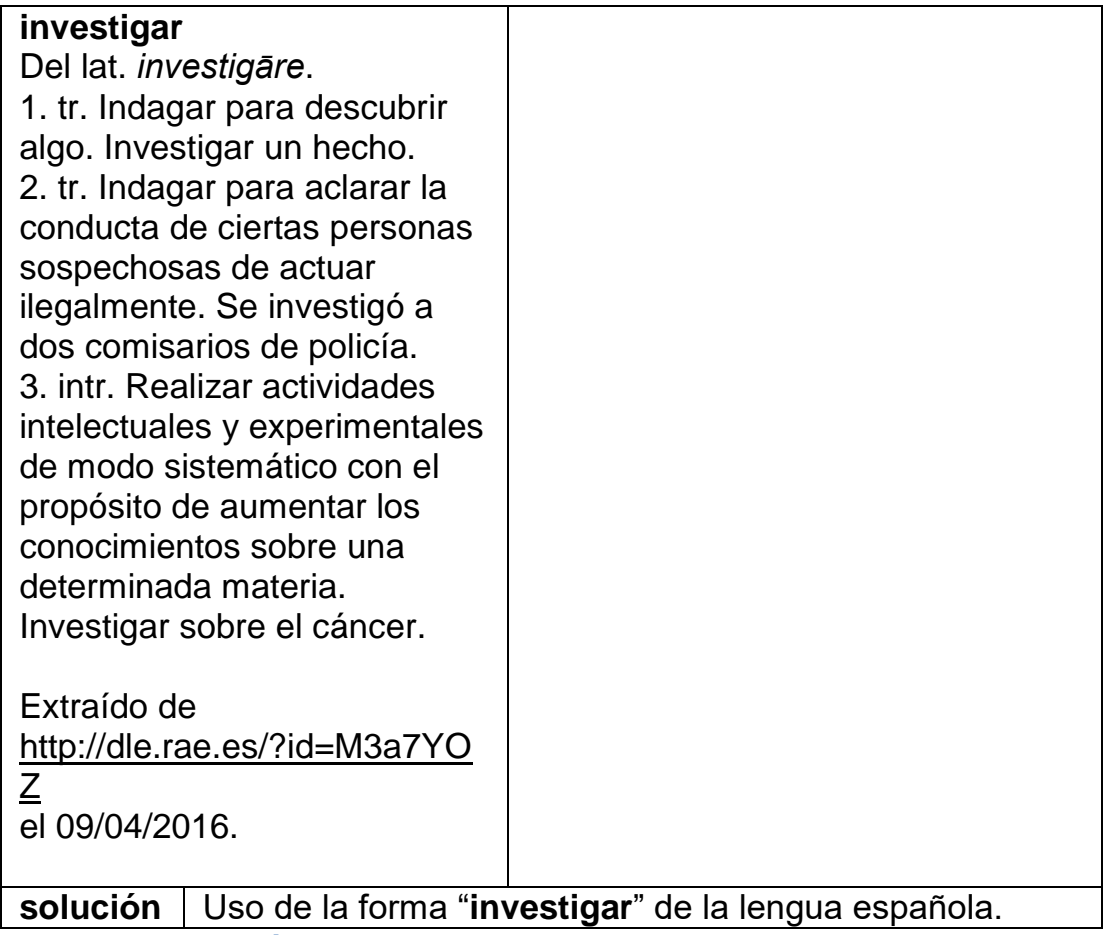

Tabla 84: Analogía 35: pesquisar.

Al igual que pesquisa, presentado en la primera parte de esta sección, pesquisar es un error de analogía. Como vemos en la tabla 84, pesquisar en portugués tiene el mismo sentido que investigar en español; sin embargo, pesquisar en español no guarda un paralelismo completo con el portugués. Así, en las acepciones extraídas del DRAE, pesquisar está relacionado con conseguir información a través de la indagación, mientras que investigar está asociado a la realización de actividades intelectuales sobre una determinada materia. De ahí la confusión de los hablantes brasileños al generalizar el uso de pesquisar cuando hablan español. De hecho, este error se repite hasta en siete ocasiones y en el habla de dos docentes distintas (D1/D5). En consecuencia, entendemos que lo correcto en este caso hubiera sido el uso del verbo "investigar" en la frase: "...entonces ustedes van a investigar en el diccionario...", puesto que "pesquisar" en un diccionario el sentido español sería imposible. 


\begin{tabular}{|c|c|c|}
\hline \multicolumn{3}{|c|}{ Interferencia 36: barra } \\
\hline Ejemplo & \multicolumn{2}{|c|}{$\begin{array}{l}\text { D9E: ... me parece que lo que más barra una } \\
\text { persona * } a^{*} \text { aquisición* de una lengua nueva es } \\
\text { el miedo de* la lengua... }\end{array}$} \\
\hline \multicolumn{2}{|c|}{ Español/ Portugués } & Portugués/ Español \\
\hline \multicolumn{2}{|c|}{ DIBU1, p. 72-73 barra } & DIBU2, p. 110 - Barrar \\
\hline \multicolumn{2}{|c|}{$\begin{array}{l}\text { ba.rra } 1 f \text {. Barra: barras de metal=barras de metal; } \\
\text { las alumnas de danza practicaban los ejercicios } \\
\text { agarrándose a la barra=as alunas de dança prati- } \\
\text { cavam os exercícios segurando na barra; barra de } \\
\text { labios batom: Clara usa una barra de labios } \\
\text { roja=Clara usa um batom vermelho. pintalabios. } \\
2 \text { Balcão: se apoyó en la barra del bar y pidió una } \\
\text { bebida=encostou no balcão do barle pediu uma } \\
\text { bebida. mostrador. } 3 \text { Bisnaga: compró dos ba- } \\
\text { rras de pan=comprou duas bisnagas. pan, pis- } \\
\text { tola. } 4 \text { AmÉr. S. Torcida: el equipo tenía una gran } \\
\text { barra=o time tinha uma grande torcida. } \\
\text { hinchada; } \text { a ajición, } \\
\text { che, la discoteca tenía barra libre=à meia-noite a } \\
\text { boate oferecia bebida grátis. }\end{array}$} & $\begin{array}{l}\text { barrar tr. BRA. Cerrar, bloquear, vedar, prohibir, } \\
\text { impedir, apartar: barraram a entrada de menores } \\
\text { na discoteca=prohibieron la entrada de menores } \\
\text { en la discoteca; o técnico barrou o jogador indis- } \\
\text { ciplinado=el técnico apartó al jugador indiscipli- } \\
\text { nado. impedir. Como } 5 \text {. }\end{array}$ \\
\hline & & AURELIO \\
\hline \multicolumn{2}{|c|}{$\begin{array}{l}\text { barrar } \\
\text { De barro1. } \\
\text { 1. tr. embarrar1. } \\
\text { Extraído de : } \\
\text { http://dle.rae.es/?id=57L27RL el } \\
09 / 04 / 2016 .\end{array}$} & $\begin{array}{l}\text { barrar1 } \\
\left.\text { [De barro + -ar }{ }^{2} .\right] \\
\text { Verbo transitivo direto } \\
\text { 1.Revestir de barro; rebocar. } \\
\text { 2.Tapar, encher ou cobrir de } \\
\text { barro; abetumar. } \\
\text { Verbo transitivo direto e } \\
\text { indireto }\end{array}$ \\
\hline \multicolumn{2}{|c|}{$\begin{array}{l}\text { embarrar1 } \\
\text { De en- y barro1. } \\
\text { 1. tr. Untar y cubrir con barro. U. t. }\end{array}$} & $\begin{array}{l}\text { 3.Cobrir de qualquer } \\
\text { substância mole: } \\
\text { Barrou o pão de manteiga. [F. } \\
\text { paral.: barrear.] }\end{array}$ \\
\hline
\end{tabular}


c. prnl.

2. tr. Manchar con barro. U. t. c. prnl.

3. tr. Embadurnar o manchar con cualquier sustancia viscosa.

4. tr. Áv., Ext., Sal. y Zam.

Enjalbegar las paredes.

5. tr. Am. Calumniar o desacreditar a alguien. U. t. c. prnl.

6. tr. Am. Causar daño, fastidiar. U. t. c. prnl.

7. tr. Am. Cen., Bol., Cuba, Ec., Méx., Par. y P. Rico. Complicar a alguien en un asunto sucio. U. t. c. prnl.

8. tr. Arg., Chile, Col., Cuba, Ec., Hond., Pan., Par., R. Dom. y Ven. Cometer un delito. U. t. c. prnl.

9. tr. Ur. equivocar. embarrarla 1. loc. verb. coloq. Arg., Bol. y Col. estropear (Il echar a perder).

\section{embarrar2}

De en- y barra.

1. tr. Introducir el extremo de una barra o espeque entre un objeto firme y otro que se quiere mover. 2. tr. desus. Acorralar o arrinconar al enemigo.

3. prnl. Dicho de una perdiz:

Subirse a los árboles cuando se ve muy perseguida y hostigada. U. t.

c. tr.

\section{Extraído de}

http://dle.rae.es/?id=EbSdajA|EbTOl J5 el 09/04/2016

Solución $\quad$ Uso de la forma "impide" de la lengua española.

Tabla 85: Analogía 36: barra.

\section{barrar2}

[De barra $\left.+-a r^{2}.\right]$

Verbo transitivo direto

1.Atravessar com barras.

2.Guarnecer com barras.

3.Fundir em barras:

barrar metais.

4.Bras. Proibir; vetar:

Barraram sua matrícula por

falta de um documento; $\underline{\text { barrar }}$ a entrada.

5.Bras. Ludibriar, enganar; frustrar.

6.Bras. Pôr na reserva (jogador).

Verbo transitivo direto e indireto

7.Embargar, impedir; obstar: Dificuldades que barram o caminho à pesquisa científica no país; Barrou a entrada ao desconhecido. 
El empleo de barra en este ejemplo, cuya única aparición encontramos en el discurso de la docente D9, deriva del verbo barrar, el cual, en la LM del sujeto, quiere decir, como indica el DIBU2, "cerrar, bloquear, vedar, prohibir, impedir, apartar"; y lo mismo hace el AURÉLIO, en la acepción 7 de barrar2, marcada en el cuadro: "embargar, impedir, obstar". Entendemos que la docente se refería a que lo que más "impide" o "bloquea" a una persona en la adquisición de una LO es el miedo a esa lengua. Podemos apreciar tanto en las entradas del DUBI1 como en el DRAE que algunas acepciones coinciden en las dos lenguas; es el caso de "untar y cubrir con barro" (acepción 1 de embarrar1 del DRAE y 1 de barrar1 del AURÉLIO), o "calumniar o desacreditar a alguien" (acepciones 5, 6 y 7 de embarrar1 del DRAE y 5 de barrar2 del AURÉLIO). Sin embargo, el sentido de "impedir" no existe con el verbo barrar en español, y por ello configura un nuevo error de analogía. Entendemos que lo correcto sería, por tanto, la utilización de "impedir", como sugiere el DIBU, así la frase utilizada por la docente quedaría así: "... me parece que lo que más impide una persona * $a^{*}$ aquisición* de una lengua nueva es el miedo de* la lengua....".

\subsection{15 Analogía 37: trago}

\begin{tabular}{|c|c|c|}
\hline \multicolumn{3}{|c|}{ Interferencia 37: trago } \\
\hline Ejemplo & \multicolumn{2}{|c|}{$\begin{array}{l}\text { D8E: ... yo siempre trago clases distintas... hago } \\
\text { cosas distintas pero... }\end{array}$} \\
\hline \multirow{2}{*}{\multicolumn{2}{|c|}{$\begin{array}{c}\text { Español/ Portugués } \\
\text { DIBU1, p. } 808\end{array}$}} & Portugués/ Español \\
\hline & & $\begin{array}{c}\text { DIBU2, p. } 1169 \text { trago; p. } 1178 \\
\text { trazer }\end{array}$ \\
\hline \multirow{2}{*}{\multicolumn{2}{|c|}{$\begin{array}{l}\text { tra-go } 1 \mathrm{~m} \text {. Gole, trago: para que se me vaya el } \\
\text { hipo, tengo que beber } 10 \text { tragos de agua segui- } \\
\text { dos=para passar o soluço, tenho que beber } 10 \text { go- } \\
\text { les de água seguidos. } \\
\text { drinque, aperitivo, tomar alguma coisa: después de }\end{array}$}} & $\begin{array}{l}\text { tra'g0 } m \text {. Trago: tomou a bebida de um só trago=se } \\
\text { tomóla bebida de un solo trago; quero um trago do } \\
\text { seu whisky=quiero un trago de tu whisky. gole, } \\
\text { tragada, tragar, trago; } \square \text { beber/tomar um trago }\end{array}$ \\
\hline & & $\begin{array}{l}\text { BRA., beber/tomar un trago: vamos parar naquele } \\
\text { bar para tomar um trago? = iparamos en aquel bar } \\
\text { para tomar un trago? } \text { beber, tomar. }\end{array}$ \\
\hline
\end{tabular}




\begin{tabular}{|c|c|}
\hline $\begin{array}{l}\text { cenar, mi amigo me invitó a un trago=depois de } \\
\text { jantar, o meu amigo me convidou para um trago. } \\
\text { copa. } 3 \text { FIG. Pedaço, bocado: iqué mal trago he pa- } \\
\text { sado cuando me han despedido de la empresa!=que } \\
\text { mau pedaço eu passei quando me despediram da } \\
\text { empresa! rato. }\end{array}$ & $\begin{array}{l}\text { tra-zer } 1 \text { tr. Traer: sempre que viaja, Ana traz mui- } \\
\text { tos presentes para seus amigos=siempre que viaja, } \\
\text { Ana les trae muchos regalos a sus amigos; Gabriel } \\
\text { me trouxe em casa ontem=Gabriel me trajo a casa } \\
\text { ayer. } \text { cevar. } 2 \text { Traer, causar: não pense que quero } \\
\text { lhe trazer ainda mais problemas=no pienses que } \\
\text { quiero causarte todavía más problemas. } 3 \text { Traer, } \\
\text { ofrecer, presentar: este ensaio traz uma discussão } \\
\text { muito interessante=este ensayo trae una discusión } \\
\text { muy interesante. } 4 \text { Traer, dar: dizem que dinheiro } \\
\text { não traz felicidade=dicen que el dinero no da la } \\
\text { felicidad; uma criança traz alegria para uma } \\
\text { casa=un niño trae alegría a una casa. } 5 \text { Traer, }, l e-\text { - } \\
\text { var: traga sempre consigo seu documento de iden- } \\
\text { tidade=lleva siempre contigo el carné de identi- } \\
\text { dad. carregar, levar. } 6 \text { Tener, llevar: esse } \\
\text { professor traz os alunos sob pressão=ese profesor } \\
\text { tiene a los alumnos bajo presión; traz sempre os } \\
\text { cabelos desalinhados=lleva siempre el cabello des- } \\
\text { peinado. levar, ter. Como } 63 \text {. }\end{array}$ \\
\hline DRAE & AURELIO \\
\hline $\begin{array}{l}\text { trago1 } \\
\text { De tragar. } \\
\text { 1. m. Porción de agua u otro } \\
\text { líquido, que se bebe o se puede } \\
\text { beber de una vez. } \\
\text { 2. m. Vicio de tomar bebidas } \\
\text { alcohólicas. } \\
\text { 3. m. coloq. Adversidad, infortunio, } \\
\text { contratiempo que con dificultad y } \\
\text { sentimiento se sufre. } \\
\text { 4. m. Am. Copa de una bebida } \\
\text { alcohólica. } \\
\text { 5. m. Am. Bebida alcohólica. } \\
\text { a tragos } \\
\text { 1. loc. adv. coloq. Poco a poco, } \\
\text { lenta y pausadamente. }\end{array}$ & $\begin{array}{l}\text { trazer } \\
\text { [Do lat. trahere, 'puxar', } \\
\text { 'arrastar', pelo lat. vulg. } \\
\text { *tragere e pelo port. arc. } \\
\text { trager.] } \\
\text { Verbo transitivo direto }\end{array}$ \\
\hline
\end{tabular}




\section{trago2}

Del gr. трóyos trágos.

1. m. Prominencia de la oreja, situada delante del conducto auditivo.

Extraído de

http://dle.rae.es/?id=aFKdYgn|aFM mdBe el 09/04/2016.

solución $\quad$ Uso de la forma flexionada "traigo".

Tabla 86: Analogía 37: trago.

Este error de sustitución por analogía ocurre también en cuatro ocasiones y en boca de tres docentes (D4/D5/D8). Lo que ocurre en este caso es el uso del verbo trazer flexionado en la lengua materna del aprendiz trago. No obstante, trago significa también en ambas lenguas lo mismo que recoge el DRAE en su primera acepción para el español: "porción de agua u otro líquido, que se bebe o se puede beber de una vez". También significa en ambas lenguas "bebida alcohólica", como recoge el DIBU2. Sin embargo, en el ejemplo que ilustramos, inferimos que la intención de la docente fue utilizar el verbo traer en la primera personal del presente de indicativo, traigo, que es, obviamente, la forma que debería utilizarse en el ejemplo referenciado: "traigo" en el ejemplo: "... yo siempre traigo clases distintas...".

\subsection{Errores explicados por medio de otras fuentes}

En los dos ejemplos que siguen en la tabla 87, hemos tenido que recurrir a otras fuentes distintas a las ya mencionadas para explicar los errores de sustitución por analogía en los que han incurrido las docentes. El motivo es que no hemos encontrado referencia alguna al sentido que tienen, ni en los diccionarios de falsos amigos, ni en el DIBU y ni tampoco en los diccionarios monolingües de español y de portugués. No obstante, al ser hablantes nativos de la misma lengua de los sujetos, e incluso de la misma región dialectal, creemos poder interpretar el sentido de "período" en las frases siguientes, así como su relación con la lengua materna. 


\subsection{1 Analogía 38: período}

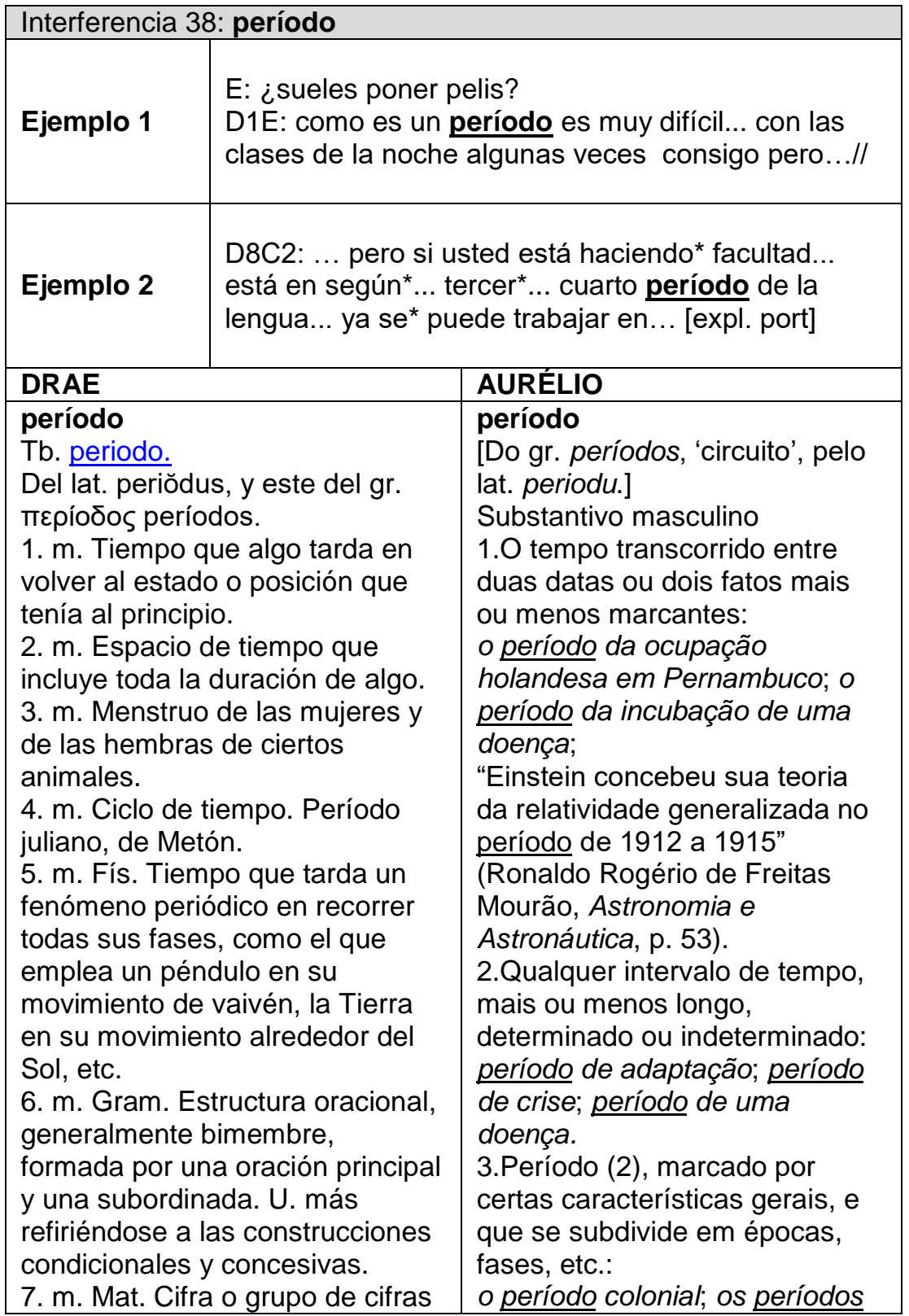


que se repiten indefinidamente, después del cociente entero, en las divisiones inexactas.

8. m. Med. Tiempo que duran ciertos fenómenos que se observan en el curso de las enfermedades.

\section{Extraído de} http://dle.rae.es/?id=SdfO44A el 16/07/2016. pré-históricos; Este retrato foi tirado no último período de sua vida.

4.Época, fase: o período da dentição; o período áureo de Atenas.

5.Estação, quadra; tempo, época:

No período do frio as andorinhas voam para o Sul. 6.Arit. O conjunto de algarismos que se repetem, numa dízima periódica.

7.E. Ling. Oração absoluta ou reunião de orações que formam sentido completo. [V. coordenação (3), correlação (5), justaposição (6), subordinação (3).]

8.Fís. Num fenômeno periódico, tempo necessário para a realização de um ciclo; intervalo de tempo que, num fenômeno periódico, separa a passagem do sistema por dois estados idênticos [símb.: T].

9.Fís. Nucl. Meia-vida.

10.Geol. Divisão de cada uma das eras v. era (7)], e que se subdivide em épocas v. época (12)].

11. Mat. O menor dos valores, $T$, para os quais uma função periódica $f(x)$ obedece à relação $f(x)=f(x+T)$.

12.Mús. Sucessão de grupos melódicos (frase) que formam um todo coerente.

13.Quím. Conjunto de elementos em que a camada eletrônica mais externa é a mesma. [V. tabela periódica.] 14.Bras. V. menstruação (1). 


\begin{tabular}{|l|l|}
\hline solución1 & Uso de "una clase" o "una hora de clase". \\
\hline solución2 & Uso de "curso". \\
\hline
\end{tabular}

Tabla 87: Analogía 38: período.

En el caso de período del primer ejemplo, utilizado hasta en cinco ocasiones y por tres sujetos distintos (D1/D8/D6), podemos inferir que la docente hace referencia a que, como tiene solo una hora de clase con cada grupo, no suele poner películas, puesto que no hay tiempo para verlas. La utilización del nombre "período" se debe a que en Brasil (y en muchos casos también en España) las clases están divididas por lo que llamamos "hora-aula" es decir, "una hora de clase", equivalente a 50 minutos aproximadamente. Así se dice, por ejemplo, en el siguiente extracto ${ }^{166}$ de un documento del Ministerio de Educación brasileño:

É importante se ter consciência de que "hora" e "hora-aula" não são sinônimos. Hora é um segmento de tempo equivalente ao período de 60 (sessenta) minutos. Hora-aula é o mesmo que hora de atividade ou de trabalho escolar efetivo, sendo esse, portanto, um conceito estritamente acadêmico, ao contrário daquele, que é uma unidade de tempo. (BRASIL, 2006, p. 17)

De esta manera, aunque este uso del vocablo no esté recogido en las obras consultadas con este sentido, tal como hemos podido apreciar en la tabla 87, es común que en algunas zonas de Brasil se utilice el término "período" para aludir a la "hora aula" ("hora de clase" en español), y creemos que es esta la causa del error cometido por la docente. Por ello, creemos que el término adecuado sería "hora de clase" en el ejemplo mencionado: “... como es una hora de clase es muy difícil... con las clases de la noche algunas veces consigo pero...".

Tampoco hemos encontrado explicación acerca del empleo de período en el ejemplo 2 en las obras consultadas anteriormente (vocablo utilizado una vez por la docente D8). Pese a ello, lo interpretamos también como un error de analogía a partir de nuestra competencia dialectal, similar a la de los sujetos del estudio. La

${ }^{166}$ Documento disponible online en http://portal.mec.gov.br/cne/arquivos/pdf/pces261_06.pdf accedido el 16/07/16. 
intención de la docente en ese fragmento era argumentar acerca de que a partir del segundo, tercero o cuarto curso de la carrera ya es posible para un estudiante encontrar trabajo como profesor de español. Para ello, utiliza el término "período", comúnmente empleado en la lengua portuguesa de esa región dialectal, como sinónimo de "curso" en español. Sobre la utilización del vocablo en este contexto, y a partir de una búsqueda en Google ${ }^{167}$ utilizando las palabras "quarto período do ensino" (cuarto curso de la enseñanza), encontramos 13.400 resultados, entre los cuales podemos encontrar numerosas equivalencias al sentido registrado por la docente. En definitiva, aunque los diccionarios no recojan el sentido aquí empleado, es evidente que existe en algunas variedades del portugués brasileño. Este error de sustitución por analogía está, pues, claramente influenciado por la lengua materna, y por ello lo adecuado sería la utilización del término "curso" en el ejemplo: “... pero si usted está haciendo* facultad... está en según*... tercer*... cuarto curso de la lengua...".

\subsubsection{Errores por creación de palabra nueva}

Según hemos discutido en el Capítulo 4, los errores de creación de palabra nueva, también llamados de transferencia creativa, ocurren cuando el aprendiz necesita suplir su falta de conocimiento de la LO. En este intento, se utilizan algunas estrategias de formación de palabras, acudiendo a reglas 0 esquemas de su propia LM. A su vez, este tipo de error está clasificado según Durão (2007, p. 40) en dos apartados: (i) creación original y (ii) traducción prestada. En esta sección describiremos los errores que encajan en las clasificaciones de la autora.

Los errores de creación de palabra nueva constituyen un $4 \%$ de los errores de léxico. Hemos encontrado un total de 39 ocurrencias de creación de palabra nueva en 31 vocablos distintos, de los cuales 9 pertenecen a la creación original (con 15 ejemplos) y 22 a la traducción prestada (con 24 ocurrencias).

El gráfico 16 observamos esa diferencia entre los dos tipos de errores de creación de palabra nueva:

\footnotetext{
${ }^{167}$ Fuente: https://www.google.com.br/webhp?sourceid=chromeinstant\&ion $=1 \&$ espv $=2 \&$ ie $=U \mathrm{UTF}$ -

$8 \# q=\% 22 q u a r t o+p e r \% C 3 \% A D o d o+d o+e n s i n o \% 22$ accedido el 16/07/16.
} 


\section{Totales de errores de creación de palabra nueva}

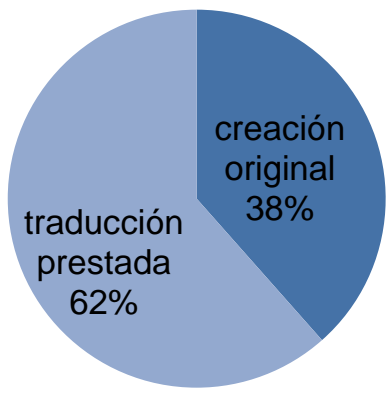

Gráfico 16: Totales de errores de creación de palabra nueva.

Para la descripción de estos dos grupos de errores nos hemos apoyado en los diccionarios monolingües de español y portugués, también consultados en las demás secciones de este capítulo: Diccionario de la Real Academia Española (DRAE) en su versión online, y Dicionário Aurélio da Língua Portuguesa (AURÉLIO) en su versión electrónica. Complementariamente, en algunas ocasiones nos hemos servido también del Breve Diccionario Etimológico de la Lengua Castellana (COROMINES, 2008). Asimismo hemos recurrido a diferentes gramáticas, puesto que los diccionarios a menudo no incluyen todas las informaciones sobre formación de palabras que necesitábamos. Se trata de las siguientes obras: Nova Gramática do Portugués Contemporâneo (CUNHA y CINTRA, 2008), Moderna Gramática Portuguesa (BECHARA, 2009); Gramática Didáctica del Español (GÓMEZ TORREGO, 2011b) y Nueva Gramática de la Lengua Española (RAE, 2010). Con todo, ni siquiera el auxilio de estas gramáticas fue siempre suficientemente esclarecedor, motivo por el cual en algunas ocasiones hemos acudido también al portal en internet del Grupo de Estructuras de Datos y Lingüística Computacional del Departamento de Informática y Sistemas de la Universidad de Las Palmas de Gran 
Canaria, en el apartado de Relaciones morfoléxicas ${ }^{168}$ el cual ofrece informaciones detalladas sobre la formación de palabras del español.

Por último, nos gustaría añadir que el objetivo de esta sección, así como el de las demás pertenecientes a este capítulo, no es realizar un contraste exhaustivo de cada error, sino comprobar que estos se hallan relacionados con la LM de los sujetos y por ello conforman errores de interferencia. A continuación presentaremos el primer grupo de palabras analizadas, las de creación original.

\subsection{Errores de creación de palabra nueva por creación original}

Los errores de creación original son aquellos que ocurren cuando el usuario de la LO crea una palabra que no existe ni en la LO ni en la LM, pese a lo cual es posible reconocer la presencia de ambas en su concepción. En general, este tipo de error ocurre por la fusión de partes de vocablos de cada lengua, ya sea mezclando morfemas, la base o ambas partes del vocablo. En esta sección presentaremos y discutiremos los errores de creación original producidos por los sujetos de nuestro estudio. Conviene destacar que de las 9 docentes, tres no han cometido ningún error de creación original (D1/D5/D7), aunque casi todas hayan recurrido a la traducción prestada, la cual analizaremos más adelante. Al mismo tiempo, conviene recordar que el empleo de esta estrategia ha sido escaso en términos generales, con tan solo 9 tipos y 16 ocurrencias en total.

Asimismo, encontramos tres tipos de errores de esta clase: (i) errores de creación original por confusión con el lexema o su flexión ( $n=7)$; (ii) errores de creación original por derivación $(n=1)$; y (iii) errores de creación original de palabra primitiva $(n=1)$. A continuación, presentamos la tabla 88 con el resumen del primero grupo de errores. En ella encontraremos los errores clasificados por tipo, el sujeto que lo cometió, el total de veces que se utilizó, el vocablo creado, así como la forma de este en la LM y en la LE:

${ }^{168}$ Por medio de una herramienta elaborada por el grupo de investigación y ubicada en el siguiente enlace: http://www.gedlc.ulpgc.es/investigacion /scogeme02/relmorfo.htm, es posible estudiar los vocablos de la lengua española y sus más diversas relaciones morfosintácticas. 


\begin{tabular}{|c|c|c|c|c|c|}
\hline № & Sujeto & $\sum$ & $\begin{array}{c}\text { Creación original } \\
\text { por flexión }\end{array}$ & LM & LE \\
\hline $\mathbf{1}$ & D9 & 2 & llove & chove & llueve \\
\hline $\mathbf{2}$ & D8 & 1 & dicer & dizer & decir \\
\hline $\mathbf{3}$ & D3 & 1 & escreber & escrever & escribir \\
\hline $\mathbf{4}$ & D9 & 1 & escreberon & escreveram & escribieron \\
\hline $\mathbf{5}$ & D6 & 1 & corregindo & corrigindo & corrigiendo \\
\hline $\mathbf{6}$ & D6 & 1 & oindo & ouvindo & oyendo \\
\hline $\mathbf{7}$ & D6 & 1 & difícilis & difíceis & difíciles \\
\hline & & & $\begin{array}{c}\text { Creación original } \\
\text { por derivación }\end{array}$ & LM & LE \\
\hline $\mathbf{8}$ & D4 & 1 & dificuldad & dificuldade & dificultad \\
\hline & & & $\begin{array}{c}\text { Creación original de } \\
\text { palabra primitiva }\end{array}$ & LM & LE \\
\hline $\mathbf{9}$ & D2/D9 & 6 & entón & então & entonces \\
\hline
\end{tabular}

Tabla 88: Errores de creación de palabra nueva por creación original.

7.2.1.2.1.1 Creación original por confusión con el lexema o su flexión

Como el propio nombre sugiere, esta clase de error se produce por equívocos que engloban o bien a la base del vocablo o bien a su flexión. De los siete vocablos que analizaremos, solamente uno de ellos, el número 7 (difícilis), no constituye un verbo.

A continuación, presentamos el análisis detallado de cada creación léxica.

\subsection{1 Creación original: Ilove}

\begin{tabular}{|c|c|c|c|c|c|}
\hline № & $\Sigma$ & Ejemplo & Desvío & LM & LE \\
\hline $\mathbf{1}$ & 2 & $\begin{array}{c}\text { D9C1: solo puede volver * domingo } \\
\text { se* no ஹlove... ¿sí? }\end{array}$ & llove & chove & llueve \\
\hline
\end{tabular}

Tabla 89: Creación original por confusión con el lexema o su flexión: llove.

En el caso de llove, percibimos que la docente utiliza una mezcla de ambas lenguas. En primer lugar, destaca la falta de diptongación ue en la base del verbo, característica de la LO 
(llueve). Parece evidente que esto se pueda explicar por influencia de la lengua materna, donde esa diptongación no existe (chove). Una hipótesis complementaria sería que, además, la docente ha aplicado una estrategia utilizada por muchos brasileños aprendices de español, y que consiste en la homologación de las palabras que en español comienzan por /l y las que en portugués lo hacen con ch, del tipo llave-chave; llamar-chamar; llover-chover.

Por otro lado, este error podría clasificarse también como ambiguo, es decir, como una estrategia de creación de palabra dentro de las reglas internas de la propia lengua objeto. Así, el hablante extendería la regla habitual en los verbos regulares (comercome) a aquellos en los que se produce algún tipo de irregularidad. No obstante, consideramos que la similitud lingüística juega un papel más importante en esta creación, y por eso creemos que es, sobre todo, un error interlingüístico.

\subsection{2 Creación original: dicer}

\begin{tabular}{|c|c|c|c|c|c|}
\hline № & $\Sigma$ & Ejemplo & Desvío & LM & LE \\
\hline 2 & 1 & $\begin{array}{l}\text { D8C2: ... después sin tilde... “aun" sin } \\
\text { tilde quiere dicer [trad. port]...// }\end{array}$ & dicer & dizer & decir \\
\hline
\end{tabular}

Tabla 90: Creación original por confusión con el lexema o su flexión: dicer.

En dicer, vemos que la docente D8 utiliza su lengua materna para construir un vocablo en el que, por lo demás, se aprecia la fusión del dizer portugués y el decir español. La influencia de la LM se justifica no solo en el hecho de que dicer se asemeja formalmente mucho a dizer, sino también en el cambio de orden de los fonemas /i/, /c/ y /e/ respecto al término original, cambio este que es totalmente afín al vocablo portugués.

\subsection{3 Creación original: escreber}

\begin{tabular}{|c|c|c|c|c|c|}
\hline № & $\Sigma$ & Ejemplo & Desvío & LM & LE \\
\hline 3 & 1 & $\begin{array}{l}\text { D3C4: ... voy * pegar en la hoja } \\
\text { y el cartel y voy * escreber }\end{array}$ & escreber & escrever & escribir \\
\hline
\end{tabular}


abajo...

Tabla 91: Creación original por confusión con el lexema o su flexión: escreber.

Algo parecido ocurre con escreber. La forma escreber es muy similar a su correspondiente en la LM escrever, con la diferencia de que en esta última el fonema que se utiliza es el labiodental / $\mathrm{v} /$ y no el bilabial /b/, característico, por el contrario, del vocablo español. Con la /b/ en escreber, el vocablo se acercara más a la LO, pero es evidente la influencia de la LM, por lo que lo consideramos también como un nuevo error de creación original.

\subsection{4 Creación original: escreberon}

\begin{tabular}{|c|c|c|c|c|c|}
\hline № & $\Sigma$ & \multicolumn{1}{|c|}{ Ejemplo } & Desvío & LM & LE \\
\hline 4 & 1 & $\begin{array}{l}\text { D9C1: sexta... } \\
\text { viernes... prueba... } \\
\text { escreberon todos... } \\
\text { prueba... ¿de qué } \\
\text { era? }\end{array}$ & escreberon & escreveram & escribieron \\
\hline
\end{tabular}

Tabla 92: Creación original por confusión con el lexema o su flexión: escreberon.

Junto a lo comentado en el párrafo anterior, en el caso de escreberon destaca también la presencia de eron en la desinencia, a mitad de camino entre la falta de diptongación del portugués (escreveram) y la forma de esta terminación en español (escribieron). Aunque las dos formas escreber (escrever en portugués) y escreberon (escreveram en portugués) hayan sido utilizadas por sujetos distintos (D3/D9, respectivamente), parece que comparten una misma regla interna de formación de palabras.

\subsection{5 Creación original: corregindo}

\begin{tabular}{|c|c|c|c|c|c|}
\hline № & $\Sigma$ & Ejemplo & Desvío & LM & LE \\
\hline 5 & 1 & D6E: . . siempre fui & corregindo & corrigindo & corrigiendo \\
\hline
\end{tabular}




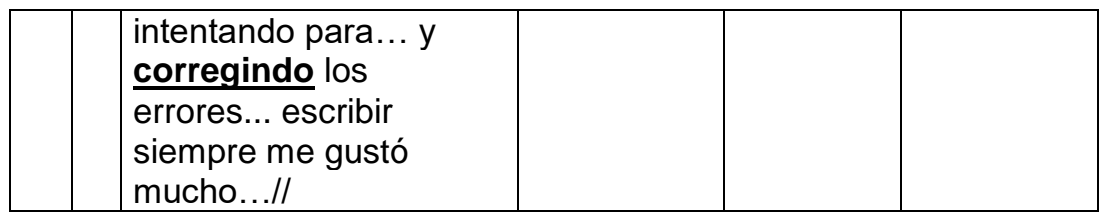

Tabla 93: Creación original por confusión con el lexema o su flexión: corregindo.

Corregindo es un caso más de creación de palabra nueva que tiene su origen en la LM. Comparando el término con el portugués corrigindo, veremos que se asemeja mucho a la forma empleada por la docente. En este caso, la única diferencia es el cambio de la raíz corrig por correg. A las dos formas se añaden el sufijo indo, el cual aparece también en la formación del gerundio en portugués, a diferencia del español donde se produce la diptongación del morfema (iendo).

\subsection{6 Creación original: oindo}

\begin{tabular}{|c|c|c|c|c|c|}
\hline № & $\Sigma$ & Ejemplo & Desvío & LM & LE \\
\hline 6 & 1 & $\begin{array}{l}\text { D6C3: ... Don Paco y Juanjo son } \\
\text { los personajes... oh... solo oindo } \\
\text { *que van a entender... }\end{array}$ & oindo & ouvindo & oyendo \\
\hline
\end{tabular}

Tabla 94: Creación original por confusión con el lexema o su flexión: oindo.

Oindo es también un caso de formación del gerundio. En este caso, la construcción de oindo parece atender a una mezcla de los dos idiomas, que tiene lugar tanto en la raíz -con lo que la docente interpreta como español (o)- como en la desinencia, donde se emplea el afijo del portugués (indo). La docente parece ignorar la irregularidad en la formación de la conjugación del verbo oír. En su actuación no tiene en cuenta que el verbo en cuestión es irregular y que lo correcto sería el empleo de la forma oyendo. Sea como fuere, 
parece evidente la influencia de la lengua materna en este proceso creativo $^{169}$.

\subsection{7 Creación original: difícilis}

\begin{tabular}{|c|c|l|l|c|c|}
\hline № & $\Sigma$ & \multicolumn{1}{|c|}{ Ejemplo } & Desvío & LM & LE \\
\hline 7 & 1 & $\begin{array}{l}\text { D6E: sí... intento siempre... a } \\
\text { veces hay contenidos más } \\
\text { difícilis que ellos piden por favor } \\
\text { para que explique... }\end{array}$ & difícilis & difíceis & difíciles \\
\hline
\end{tabular}

Tabla 95: Creación original por confusión con el lexema o su flexión: difícilis.

Este es el único vocablo de creación original por flexión que no es un verbo. En el caso de difícilis lo que ocurre es una fusión entre los adjetivos en plural difíceis del portugués y difíciles del español. Ello se comprueba a través de la flexión de número aplicada, en la cual la docente utiliza el lexema difíc del portugués, que es muy parecido al español difícil. No obstante, la confusión ocurre, sobre todo, cuando crea la flexión de número is, influenciada por las formas similares del portugués (-eis) y del español (-es). Como resultado, tenemos un adjetivo en el que de nuevo se atisba la influencia de la lengua materna.

\subsection{Creación original por derivación}

Hemos identificado un único ejemplo de error de creación original por derivación. Es el caso de dificuldad, el cual explicaremos a continuación:

\subsection{1 Creación original: dificuldad}

\begin{tabular}{|l|l|l|l|l|l|}
\hline № & $\sum$ & Ejemplo & Desvío & LM & LE \\
\hline
\end{tabular}

${ }^{169}$ Este vocablo también está recogido entre las creaciones de los aprendices de español de Farias (2007, p. 68). 


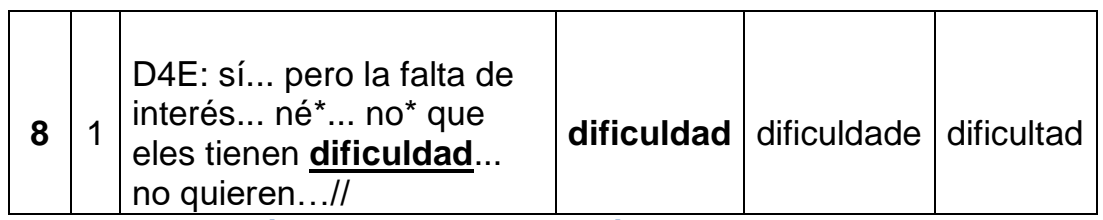

Tabla 96: Creación original por derivación: dificuldad.

En dificuldad la docente combina elementos del vocablo portugués dificuldade, y el español dificultad. Más concretamente utiliza la raíz común a ambos idiomas (dificul), y a ella añade un sufijo sustantivador donde se adivina el cruce de las dos lenguas: dade + tad $=$ dad . Con eso tenemos un vocablo que aunque se acerque a las dos lenguas, no pertenece a ninguna de ellas, puesto que es una creación original de la docente. Entendemos que esta creación está basada en unas reglas de la LE, es decir, en el conocimiento de la existencia del morfema dad, (como de las palabras ciudad, universidad, por ejemplo) ligado al conocimiento del sufijo dade del portugués, el cual se corresponde en muchas ocasiones con el español (como de las palabras cidade, universidade, por ejemplo). Así, es muy posible que haya ignorado el alomorfo tad, que, sin embargo, no existe en portugués.

Desde otra óptica, este error podría considerarse también como ambiguo, y, por tanto, de naturaleza meramente intralingüística. No obstante, a partir de la interpretación que hemos ofrecido más arriba, creemos que la interferencia es la principal causa de este error de creación original. La similitud, a nuestro parecer, es la principal causante de la mezcla entre las reglas de la lengua materna y las de la extranjera en la creación de un nuevo vocablo: dificuldade.

\subsection{Creación original de palabra primitiva}

También hemos encontrado un único error de creación original de palabra primitiva, el caso de entón. Esta se utiliza en seis ocasiones, repartidas en el habla de dos sujetos (D2/D9). A continuación mostramos un par de ejemplos representativos: 


\begin{tabular}{|l|c|l|l|l|c|}
\hline № & $\Sigma$ & \multicolumn{1}{|c|}{ Ejemplo } & Desvío & LM & LE \\
\hline \multirow{9}{9}{} & 1 & $\begin{array}{l}\left.\text { D2E: ... sí... y a* }{ }^{* * *}\right] \text { también } \\
\text { trabaja... entón los tres } \\
\text { trabajan.../I }\end{array}$ & entón & então & entonces \\
\cline { 2 - 5 } & 5 & $\begin{array}{l}\text { D9C1: piedras... entón le dijo la } \\
\text { zorra al pastor... ahora déjala que } \\
\text { se muera de hambre... }\end{array}$ & entón & então & entonces \\
\hline
\end{tabular}

Tabla 97: Creación original por palabra primitiva: entón.

Examinando los vocablos originales de cada lengua, observamos que tienen una base común (ent), a la que se unen sendas terminaciones diferentes en portugués (ão) y español (onces). Creemos que la creación del sujeto tiene que ver sobre todo con la transferencia del sufijo portugués ão, el cual se ha adaptado a otro que probablemente interpreta como más próximo a la LO: ón. Esto ocurre por analogía, es decir, por la aplicación de una regla bastante común en la comparación entre los dos idiomas. Así, muchas palabras terminadas en ão en portugués suelen corresponder con las acabadas en ón en español, como, por ejemplo: estação-estación; melão-melón. Por tanto, parece evidente que la docente creó una nueva palabra a partir de la utilización de reglas de la LM aplicadas a la $\mathrm{LO}^{170}$.

\subsection{Errores de creación de palabra nueva por traducción prestada}

Los errores de traducción prestada son aquellos en los que se crea un vocablo nuevo a partir de otro existente en la lengua materna, generalmente por medio de la inclusión u omisión de fonemas propios de la LO. A diferencia de aquellos errores cometidos por creación original, en donde se forman palabras nuevas en las que se aprecia una mezcla creativa de los dos idiomas en un mismo vocablo, en los errores de traducción prestada

${ }^{170}$ El uso de entón también está recogido en la tesis de Silva (2010, p. 235) quien igualmente explica la creación de este vocablo con base en la LM (PB) de los sujetos. 
se identifica claramente la unión de dos partes correspondientes a otros tantos vocablos de cada lengua.

En esta sección analizaremos los errores de traducción prestada encontrados en nuestro estudio. Para ello, los hemos agrupado y clasificado según el "tipo" de error cometido. Así, distinguimos entre: (i) traducción prestada por base portuguesa y flexión española $(n=8)$; (ii) traducción prestada por base portuguesa y derivación española ( $n=10)$; (iii) traducción prestada de palabra primitiva ( $n=3)$; (iv) traducción prestada por composición $(n=1)$. De cada uno de estos errores se derivan a su vez diversos subtipos, que analizaremos con detalle en las páginas que siguen.

A continuación presentamos la tabla 98 con todos errores de esta sección. En ella es posible encontrar tanto las creaciones por tipo, como el término aproximado en la lengua materna y en la lengua objeto.

\begin{tabular}{|c|c|c|c|c|c|}
\hline № & Sujeto & $\sum$ & $\begin{array}{c}\text { Traducción } \\
\text { prestada por } \\
\text { base } \\
\text { portuguesa y } \\
\text { flexión española }\end{array}$ & LM & LO \\
\hline 10 & D9 & 1 & faleció & faleceu & falleció \\
\hline 11 & D9 & 1 & pedió & pediu & pidió \\
\hline 12 & D9 & 1 & levé & levei & llevé \\
\hline 13 & $\mathrm{D} 8$ & 1 & demonstrarles & demonstrar-Ihes & demostrarles \\
\hline 14 & D5 & 1 & abriron & abriram & abrieron \\
\hline 15 & D6 & 1 & compreenderon & compreenderam & comprendieron \\
\hline 16 & D9 & 1 & deron & deram & dieron \\
\hline 17 & D6 & 1 & entenderon & entenderam & entendieron \\
\hline № & Sujeto & $\Sigma$ & $\begin{array}{l}\text { Traducción } \\
\text { prestada por } \\
\text { base } \\
\text { portuguesa y } \\
\text { derivación } \\
\text { española }\end{array}$ & LM & LO \\
\hline 18 & D6 & 1 & antecipación & antecipação & anticipación \\
\hline 19 & $\mathrm{D} 8$ & 1 & questión & questão & cuestión \\
\hline 20 & D7 & 1 & aprofundizar & aprofundar & profundizar \\
\hline 21 & D4 & 1 & estabelecimiento & estabelecimento & establecimiento \\
\hline 22 & D8 & 1 & linguaje & linguagem & lenguaje \\
\hline 23 & D8 & 1 & solenidad & solenidade & solemnidad \\
\hline 24 & D9 & 1 & aquisición & aquisição & adquisición \\
\hline 25 & D7 & 2 & satisfación & satisfação & satisfacción \\
\hline
\end{tabular}




\begin{tabular}{|c|c|c|c|c|c|}
\hline 26 & D6 & 1 & produción & produção & producción \\
\hline 27 & D4 & 1 & interación & interação & interacción \\
\hline № & Sujeto & $\sum$ & $\begin{array}{c}\text { Traducción } \\
\text { prestada de } \\
\text { palabra } \\
\text { primitiva }\end{array}$ & LM & LO \\
\hline 28 & D8 & 1 & vontad & vontade & voluntad \\
\hline 29 & D1 & 1 & ciudade & cidade & ciudad \\
\hline 30 & D6 & 1 & doncela & donzela & doncella \\
\hline & & & $\begin{array}{c}\text { Traducción } \\
\text { prestada por } \\
\text { composición }\end{array}$ & LM & LO \\
\hline 31 & D2 & 2 & trabalinguas & trava-línguas & trabalenguas \\
\hline
\end{tabular}

Tabla 98 : Errores de creación original por traducción prestada.

A continuación explicaremos cada uno de esos errores, empezando por los de flexión.

\subsection{Traducción prestada por base portuguesa y flexión española}

Los errores originarios de la traducción prestada por flexión se dividen en tres grupos: (i) traducción prestada por confusión con la base, el tema o su flexión; (ii) traducción prestada por flexiónrealización de diptongo; y (iii) traducción prestada por confusión en la afijación de los pronombres de complemento;

7.2.1.2.2.1.1 Traducción prestada por confusión con la base, el tema o su flexión

En los tres primeros ejemplos que vemos abajo, hay una clara confusión entre la raíz de los verbos (en portugués) y la flexión realizada en español en el pretérito perfecto simple. Por otro lado, en el cuarto caso, tenemos la utilización del pronombre complemento con un infinitivo portugués.

\begin{tabular}{|c|c|c|c|c|c|}
\hline № & Sujeto & & Desvío & LM & LE \\
\hline 10 & D9 & 1 & faleció & faleceu & falleció \\
\hline
\end{tabular}




\begin{tabular}{|c|c|c|c|c|c|}
\hline 11 & D9 & 1 & pedió & $\underline{\text { pediu }}$ & pidió \\
\hline 12 & D9 & 1 & levé & $\underline{\text { levei }}$ & llevé \\
\hline 13 & D8 & 1 & demonstrarles & $\frac{\text { demonstrar- }}{\text { lhes }}$ & demostrarles \\
\hline
\end{tabular}

Tabla 99: Traducción prestada por confusión con la base, el tema o su flexión.

Veamos cada caso, empezando por los dos primeros:

\subsection{1.1 Traducción prestada: faleció y pedió}

\begin{tabular}{|c|c|l|c|c|c|}
\hline NNo & $\Sigma$ & \multicolumn{1}{|c|}{ Ejemplo } & Desvío & LM & LE \\
\hline 10 & 1 & $\begin{array}{l}\text { D9E: ... mis bisabuelos hablaban } \\
\text { guaraní y ello* hablaba las dos } \\
\text { lenguas... y... pero no fue muy... } \\
\text { mucho tiempo pues eh... faleció } \\
\text { hasta... yo tenía unos cinco años } \\
\text { me parece.../I }\end{array}$ & faleció & faleceu & falleció \\
\hline 11 & 1 & $\begin{array}{l}\text { D9C1: salir de la cueva... y... } \\
\text { iqué ha hecho entonces la } \\
\text { culebra? } \\
\text { A: (...) } \\
\text { D9C1: pedió al pastor ayuda... y } \\
\text { el pastor entonces... }\end{array}$ & pedió & pediu & pidió \\
\hline
\end{tabular}

Tabla 100: Traducción prestada por confusión con la base, el tema o su flexión: faleció y pedió.

En los ejemplos 10 y 11 observamos cómo una misma docente (D9) incurre en este error. En el primer caso, tenemos la utilización de faleció, donde se aprecia la unión del lexema portugués falec (de falecer) con la desinencia española de la tercera persona del singular del pasado (ió). Lo mismo ocurre con pedir, cuya raíz portuguesa sustituye a la base irregular del español (pid), al tiempo que la desinencia es nuevamente española. Ambos casos configuran, pues, errores de traducción prestada dado que se 
observa claramente el uso de los idiomas materno y extranjero para formar palabras que no existen en la LO.

\subsection{1.2 Traducción prestada: levé}

\begin{tabular}{|c|c|c|c|c|c|}
\hline № & $\Sigma$ & Ejemplo & Desvío & LM & LE \\
\hline 12 & 1 & $\begin{array}{l}\text { D9E: ... pero yo levé una } \\
\text { historia de vida junto*...// }\end{array}$ & levé & levei & llevé \\
\hline
\end{tabular}

Tabla 101: Traducción prestada por confusión con la base, el tema o su flexión: levé.

Algo parecido sucede con el verbo llevar (levar en portugués), con la única diferencia de que esta vez la conjugación aparece en la primera persona del singular (también del pasado simple). Además, el fragmento corresponde al discurso de la misma hablante que antes, en lo que parece una estrategia de formación de palabras recurrente: la utilización de la raíz del vocablo portugués (lev) y la adición del correspondiente afijo flexivo español (é). El resultado es nuevamente un vocablo donde la influencia de la lengua materna resulta evidente, pese a no existir como tal ni en esta ni en la lengua objeto.

\subsection{1.3 Traducción prestada: demonstrarles}

\begin{tabular}{|c|c|c|c|c|c|}
\hline № & $\Sigma$ & Ejemplo & Desvío & LM & LE \\
\hline 13 & 1 & $\begin{array}{l}\text { D8C2: miren } \\
\text { só* en la hoja... } \\
\text { yo voy } \\
\text { entonces * } \\
\text { demonstrarles } \\
\text { lo que ocurre... }\end{array}$ & demonstrarles & $\begin{array}{c}\text { demonstrar- } \\
\text { Ihes }\end{array}$ & demostrarles \\
\hline
\end{tabular}

Tabla 102: Traducción prestada por confusión con la base, el tema o su flexión: demonstrarles.

Una estrategia similar descubrimos, finalmente, en el ejemplo (13) con demonstrarles, con la diferencia de que ahora se 
funden un infinitivo portugués (demonstrar) y un pronombre complemento español (les).

\subsection{2 Traducción prestada por flexión - realización de diptongo.}

Los siguientes errores de traducción prestada se deben a la omisión de las vocales /e/ o /i/ en los diptongos preceptivos en español. Como es sabido, en portugués no ocurre esa diptongación en los términos correspondientes, de ahí que, a nuestro juicio, tales omisiones obedezcan a la interferencia de la LM de los sujetos. En el cuadro siguiente podemos apreciar tales desvíos ${ }^{171}$ :

\begin{tabular}{|c|c|c|c|c|c|c|}
\hline № & $\begin{array}{c}\text { Su } \\
\text { jeto }\end{array}$ & $\Sigma$ & Desvío & $\begin{array}{c}\text { Omi } \\
\text { sión }\end{array}$ & LM & LE \\
\hline $\mathbf{1 4}$ & D5 & 1 & abriron & $\mathrm{e}$ & abriram & abrieron \\
\hline $\mathbf{1 5}$ & D6 & 1 & compreenderon & $\mathrm{i}$ & $\begin{array}{c}\text { compreende } \\
\text { ram }\end{array}$ & $\begin{array}{c}\text { comprendie } \\
\text { ron }\end{array}$ \\
\hline $\mathbf{1 6}$ & D9 & 1 & deron & $\mathrm{i}$ & deram & dieron \\
\hline $\mathbf{1 7}$ & D6 & 1 & entenderon & $\mathrm{i}$ & entenderam & entendieron \\
\hline
\end{tabular}

Tabla 103: Traducción prestada por flexión - realización de diptongo.

Veamos el primer caso:

\subsection{2.1 Traducción prestada: abriron}

\begin{tabular}{|c|c|l|l|c|c|}
\hline № & $\Sigma$ & \multicolumn{1}{|c|}{ Ejemplo } & Desvío & LM & LE \\
\hline \multirow{10}{14}{} & \multirow{2}{*}{1} & $\begin{array}{l}\text { D5C6: gente... abran el libro en } \\
\text { la página... sesenta y ocho... } \\
\text { sesenta y ocho... seis ocho... } \\
\text { A: (...) } \\
\text { D5C6: ¿todos ya abriron? ¿sí?// }\end{array}$ & abriron & abriram & abrieron \\
& & & \\
\hline
\end{tabular}

${ }^{171}$ Los problemas con la diptongación por parte de los brasileños aprendices de española se recogen también en diversos otros trabajos, como, por ejemplo, los de Durão (2004); Farias (2007); Frigo (2006); Santos (2012); Schardosim y Durão (2011); Silva (2010). 
Tabla 104: Traducción prestada por flexión - realización de diptongo: abriron.

Como es evidente, los vocablos abriram y abrieron son formalmente muy parecidos. De hecho, las dos lenguas comparten un mismo infinitivo (abrir), que, no obstante experimenta variaciones en la conjugación. Así, advertimos que en portugués no ocurre la diptongación, preceptiva en español, en la tercera persona del plural del pasado simple. Este hecho nos lleva a creer que la LM es en buena parte responsable de la no realización de este diptongo.

Lo mismo ocurre con los tres ejemplos siguientes, aunque esta vez el fonema omitido en el diptongo sea la vocal cerrada, /i/:

7.2.1.2.2.1.2.2 Traducción prestada: comprenderon, deron, entenderon

\begin{tabular}{|c|c|c|c|c|}
\hline № & $\sum$ Ejemplo & Desvío & LM & LE \\
\hline 15 & $\begin{array}{l}\text { D6C3: ... } \\
\text { ¿entender } \\
\text { on* dónde } \\
\text { está la } \\
1 \text { respuesta } \\
? \\
\text { ¿compren } \\
\text { deron?... }\end{array}$ & comprenderon & compreenderam & comprendieron \\
\hline 16 & $\begin{array}{l}\text { D9C1: ... } \\
\text { tienen que } \\
\text { ser } \\
\text { gratos... } \\
\text { los padres } \\
\text { los } \\
\text { ayudaron.. } \\
1 . \text { los } \\
\text { criaron... } \\
\text { deron a } \\
\text { ustedes } \\
\text { todo o* } \\
\text { que } \\
\text { necesitaro } \\
n \text { en la }\end{array}$ & deron & deram & dieron \\
\hline
\end{tabular}




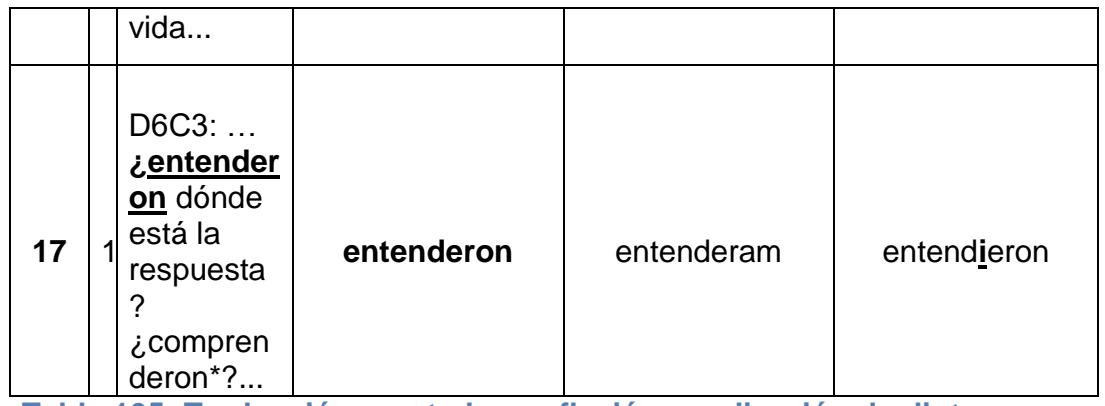

Tabla 105: Traducción prestada por flexión - realización de diptongo: comprenderon, deron, entenderon.

Según la RAE (2010, p. 33), la alternancia /e/ /ié/ tiene lugar tanto en la morfología flexiva como en la léxica, ambas plagadas de irregularidades. En la práctica, no hay una norma para la realización de este diptongo que cubra la formación de palabras de forma general. Ello hace que los aprendices de ELE duden a la hora de su aplicación. En el caso de las lenguas próximas, la LM puede tener mayor influencia en la realización o no del diptongo, tal como podemos ver en estos ejemplos. Vemos que todos ellos son formalmente muy parecidos en la LM y la LO. La transferencia por omisión ocurre únicamente en relación con los morfemas ligados, llevados a cabo mediante diptongación en español, pero no en la lengua portuguesa.

Hay que reconocer que estos errores podrían considerarse también como consecuencia del desarrollo por parte del aprendiz de reglas internas de la LO, y, por tanto, de origen intralingüístico. Sin embargo, tras el análisis efectuado, entendemos que la LM tiene una mayor responsabilidad en la creación de los vocablos reseñados.

\subsection{Traducción prestada por base portuguesa y derivación española}

Hasta ahora hemos visto los errores de traducción prestada de base portuguesa y flexión española. En esta sección analizaremos los errores originados por traducción prestada por derivación. 
En el grupo de palabras que sigue, observamos que existe un elemento común: la utilización de una base léxica portuguesa (ya sea con infijo o no) junto a mecanismos de derivación española. En el cuadro a continuación presentamos el total de errores de este tipo, incluyendo los sujetos que incurrieron en ellos, el número de veces que ocurren, así como el término aproximado equivalente tanto en la lengua materna como en la lengua objeto.

\begin{tabular}{|c|c|c|c|c|c|}
\hline No & Sujeto & $\Sigma$ & Desvío & LM & LE \\
\hline $\mathbf{1 8}$ & D6 & 1 & antecipación & antecipação & anticipación \\
\hline $\mathbf{1 9}$ & D8 & 1 & questión & questão & cuestión \\
\hline $\mathbf{2 0}$ & D7 & 1 & aprofundizar & aprofundar & profundizar \\
\hline $\mathbf{2 1}$ & D4 & 1 & estabelecimiento & estabelecimento & establecimiento \\
\hline $\mathbf{2 2}$ & D8 & 1 & lenguaje & linguagem & lenguaje \\
\hline $\mathbf{2 3}$ & D8 & 1 & solenidad & solenidade & solemnidad \\
\hline $\mathbf{2 4}$ & D9 & 1 & aquisición & aquisição & adquisición \\
\hline $\mathbf{2 5}$ & D7 & 2 & satisfación & satisfação & satisfacción \\
\hline $\mathbf{2 6}$ & D6 & 1 & produción & produção & producción \\
\hline $\mathbf{2 7}$ & D4 & 1 & interación & interação & interacción \\
\hline
\end{tabular}

Tabla 106: Traducción prestada por base portuguesa y derivación española I.

Empezamos la explicación con dos ejemplos en los que se produce la unión de sufijos alomorfos del español ción-ión ${ }^{172}$ a lexemas portugueses:

\subsection{1 Traducción prestada: antecipación y questión}

\begin{tabular}{|c|c|c|c|c|c|}
\hline № & $\Sigma$ & Ejemplo & Desvío & LM & LE \\
\hline 18 & 1 & $\begin{array}{l}\text { D6E: ... pero hay } \\
\text { una... una sala } \\
\text { de multimedios* } \\
\text { para todas las }\end{array}$ & antecipación & antecipação & anticipación \\
\hline
\end{tabular}




\begin{tabular}{|l|l|l|l|l|}
\hline & $\begin{array}{l}\text { asignaturas... } \\
\text { entonces hay que } \\
\text { con } \\
\text { antecipación... }\end{array}$ & & \\
\hline 19 & $1 \begin{array}{l}\text { D8E: ... pero } \\
\text { intentar sí... la } \\
\text { questión de la } \\
\text { pronúncia* yo } \\
\text { creo que hay } \\
\text { alumnos que... }\end{array}$ & questión & questão & cuestión \\
\hline
\end{tabular}

Tabla 107: Traducción prestada por base portuguesa y derivación española: antecipación y questión.

En estos dos primeros casos, que agrupamos a efectos explicativos, hay una coincidencia en la utilización del sufijo español ción (ejemplo 18) y su alomorfo ión (ejemplo 19) unidos a lexemas portugueses. En antecipación se utiliza el lexema portugués antecipa (de antecipação), que se funde con el sufijo ción del español. Ello puede haber ocurrido por una sobregeneralización hecha por la docente D6, basada quizá en el hecho de que algunos nombres femeninos terminados en ção en portugués tienen correspondencia con otros acabados en ción en español, como, por ejemplo: plantação-plantación; canção-canción; maldição-maldición. En estos ejemplos, las raíces de los vocablos son las mismas, cambiando únicamente el sufijo. Eso puede haber llevado a la docente a generalizar esta tendencia, la cual no se cumple en el caso de anticipación, donde hay una leve diferencia formal en una vocal de la raíz española en relación a la portuguesa antícipa/antecipa, aunque la correspondencia sería la misma al margen de la diferencia vocálica.

De la misma manera que en el ejemplo anterior, en el caso de questión, la raíz del vocablo también se conserva en portugués quest y también se aplica un sufijo español, ión. Lo singular de este caso, a diferencia del anterior, es que, fonológicamente, el quest portugués (pronunciado [kest]) difiere considerablemente del cuest español por la presencia aquí de un diptongo ([kuest]). Por otro lado, puede que la creación de este vocablo haya tenido lugar también por la generalización de una regla explicada en el ejemplo anterior, por la cual algunos nombres conservan parte del lexema en ambas lenguas, cambiando el sufijo. Asimismo, otra tendencia observada es que muchos vocablos terminados en ão en portugués tienen su 
correspondencia en nombres terminados en ión en español, como, por ejemplo: visão-visión; evasão-evasión; audição-audición. Todo ello nos lleva a suponer una vez más que la similitud entre la LM y la LO ha jugado un importante papel en la formación de este vocablo, puesto que, como vemos, conserva una parte de cada lengua. Lo curioso de este error es que también es común que palabras que tengan la raíz en portugués en que (fonológicamente [ke]) correspondan a vocables con raíz en cue [Kue], principalmente aquellas de una misma familia lingüística, como: questionarcuestionar; questionário-cuestionário; questão-cuestión ${ }^{173}$, regla no aplicada en esta creación original.

En los siguientes ejemplos analizaremos otros casos de traducción prestada por base portuguesa y derivación española:

7.2.1.2.2.2.2 Traducción prestada: aprofundizar, estabelecimiento, linguaje, solenidad y aquisición

\begin{tabular}{|c|c|c|c|c|c|}
\hline № & $\Sigma$ & Ejemplo & Desvío & $\underline{\text { LM }}$ & LE \\
\hline 20 & 1 & $\begin{array}{l}\text { D7E: ... yo creo que } \\
\text { si hubiéramos } \\
\text { estudiado más la } \\
\text { literatura... los } \\
\text { escritores... yo creo } \\
\text { que aprofundizar } \\
\text { más eso... }\end{array}$ & aprofundizar & aprofundar & profundizar \\
\hline 21 & 1 & $\begin{array}{l}\text { D4C2: ... y ahora... } \\
\text { persona encargada } \\
\text { de la caja en un } \\
\text { estabelecimiento } \\
\text { comersal }^{*} . . .\end{array}$ & estabelecimiento & estabelecimento & establecimiento \\
\hline 22 & 1 & $\begin{array}{l}\text { D8E: ... y además } \\
\text { todo porque } \\
\text { nosotros tenemos } \\
\text { que hacer una... } \\
\text { hasta las } \\
\text { asignaturas por } \\
\text { ejemplo de } \\
\text { expresión y }\end{array}$ & linguaje & linquagem & lenguaje \\
\hline
\end{tabular}

${ }^{173}$ La confusión entre las palabras empezadas por qu/cu se discutió también en los estudios de Durão (2000, p. 48; 2004, p. 116) aunque esta vez solo en el ámbito ortográfico. 


\begin{tabular}{|c|c|c|c|c|c|}
\hline & & $\begin{array}{l}\text { linguaje son todas } \\
\text { juntas... tenemos } \\
\text { que hablar mucho... }\end{array}$ & & & \\
\hline 23 & 1 & $\begin{array}{l}\text { E: ah... muy bien... } \\
\text { eh... ¿en qué año } \\
\text { terminaste la } \\
\text { universidad? } \\
\text { D8E: dos mil seis } \\
\text { yo... eh... quité la } \\
\text { clase pero... dos mil } \\
\text { siete fue... la... } \\
\text { solenidad...// }\end{array}$ & solenidad & solenidade & solemnidad \\
\hline 24 & 1 & $\begin{array}{l}\text { D9E: ... me parece } \\
\text { que lo que más } \\
\text { barra* una persona } \\
\text { a* aquisición de }^{*} \text { una lengua nueva } \\
\text { es el miedo de la } \\
\text { lengua... }\end{array}$ & aquisición & aquisição & adquisición \\
\hline
\end{tabular}

Tabla 108: Traducción prestada por base portuguesa y derivación española aprofundizar, estabelecimiento, linguaje, solenidad y aquisición.

En estos cinco ejemplos observamos la misma estrategia de formación de palabras, es decir, la unión de un lexema portugués con un sufijo derivativo español.

En el caso de aprofundar vemos a través de la tabla comparativa 108, que el verbo portugués está formado por la serie a+profund+ar. Si comparamos con el vocablo español, formado por profund+izar, comprobamos que la principal diferencia es la utilización del prefijo de origen latino a en portugués, que tiene el sentido de "aproximación, dirección" (CUNHA y CINTRA, 2008, p. 98). Una mirada superficial sobre la construcción de palabras de aprendices de español como lengua extranjera quizá apuntase únicamente a la adición involuntaria de un prefijo a un verbo español (profundizar) en aprofundizar. No obstante, como hemos visto en esta sección, la lengua materna parece articular las elecciones de los sujetos de este estudio, de manera que si analizamos con atención veremos que estas no obedecen al azar, sino que guardan una estrecha relación. En este vocablo, específicamente, la adición de la "a" antes de "profundizar" tiene, para nosotros una clara 
influencia del portugués materno, dónde el correspondiente de este vocablo es el portugués aprofundar.

La misma estrategia encontramos en los vocablos estabelecimiento, linguaje, solenidad y aquisición. En todos los casos, las raíces son portuguesas (estabelec/lingu/solen/aquisi) y los sufijos derivativos, españoles (miento/aje/idad/ción).

\subsection{3 Traducción prestada: satisfación, produción, interación}

Una variante de estos errores se da en vocablos en los que se produce la reducción de un grupo consonántico culto del español. Así ocurre, por ejemplo, con la simplificación del grupo $/ \mathrm{k} \Theta / \mathrm{a} / \Theta /$ en los ejemplos 25 a 27. Aunque este fenómeno tiene lugar también en algunas áreas del español, especialmente en el registro coloquial (GONZÁLEZ MONTERO, $1993^{174}$ ), en los casos que nos ocupan parecen más la consecuencia de la influencia interlingüística, como se desprende de la comparación con los términos correspondientes del portugués ${ }^{175}$.

\begin{tabular}{|l|c|l|c|c|c|}
\hline NN & $\Sigma$ & \multicolumn{1}{|c|}{ Ejemplo } & Desvío & LM & LE \\
\hline 25 & 2 & $\begin{array}{l}\text { D7E: ... pero sigues } \\
\text { con eso porque } \\
\text { realmente es mi } \\
\text { satisfación... } \\
\text { entonces yo creo que } \\
\text { no cambiaría...// }\end{array}$ & satisfación & satisfação & satisfacción \\
\hline 26 & 1 & $\begin{array}{l}\text { D6E: entonces es... } \\
\text { me parecía más fácil } \\
\text { las cosas de } \\
\text { produción... }\end{array}$ & produción & produção & produccción \\
\hline $\mathbf{2 7}$ & 1 & $\begin{array}{l}\text { E: ¿tú aprendiste el } \\
\text { Eroderación }\end{array}$ & interação & interacción \\
\hline
\end{tabular}

${ }^{174}$ González Montero (1993) trata con detalle las aspiraciones en el español, fenómeno que, por motivos de espacio, no lo especificaremos aquí.

${ }^{175}$ Este tipo de errores también los podemos encontrar en el estudio de Durão (2004, p. 151). 


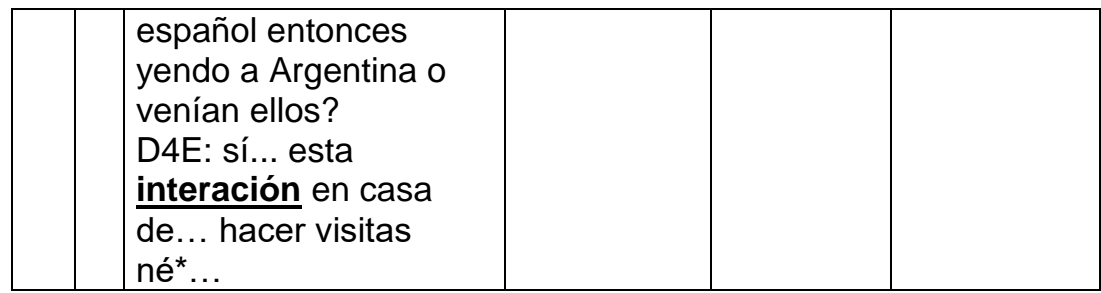

Tabla 109: Traducción prestada por base portuguesa y derivación española: satisfación, producción, interación.

7.2.1.2.2.3. Traducción prestada de palabra primitiva.

En el corpus hemos encontrado solamente tres casos de traducción prestada de palabra primitiva, es decir, aquellas que "no derivan de otra palabra de la misma lengua y están formadas por una única raíz" (GÓMEZ TORREGO, 2011a, p. 38). Aparecen en la tabla 110, donde encontramos la información sobre los sujetos de la investigación que los cometieron, la forma adoptada por el error, así como los términos más cercanos en las lenguas materna y objeto, respectivamente.

\begin{tabular}{|c|c|c|c|c|c|}
\hline № & Sujeto & $\Sigma$ & Desvío & LM & LE \\
\hline $\mathbf{2 8}$ & D8 & 1 & vontad & vontade & voluntad \\
\hline $\mathbf{2 9}$ & D1 & 1 & ciudade & cidade & ciudad \\
\hline $\mathbf{3 0}$ & D6 & 1 & doncela & donzela & doncella \\
\hline
\end{tabular}

Tabla 110: Traducción prestada de palabra primitiva.

Comenzamos el comentario por los dos primeros casos, dada la proximidad formal entre ambos.

\subsection{1 Traducción prestada: vontad y ciudade}

\begin{tabular}{|l|l|l|l|l|l|}
\hline № & $\Sigma$ & Ejemplo & Desvío & LE & LM \\
\hline
\end{tabular}




\begin{tabular}{|l|l|l|l|l|l|}
\hline 28 & $\begin{array}{l}\text { D8E: ... ya no sabía } \\
\text { todo... y después } \\
\text { nosotros vamos a... } \\
\text { a... perdiendo la... la } \\
\text { vontad... la.../ }\end{array}$ & vontad & vontade & voluntad \\
\hline 29 & $1 \begin{array}{l}\text { D1E: ... acá en la } \\
\text { ciudade hay una } \\
\text { escuela de } \\
\text { enseñanza } \\
\text { fundamental con el } \\
\text { español... }\end{array}$ & ciudade & cidade & ciudad \\
\hline
\end{tabular}

Tabla 111: Traducción prestada de palabra primitiva: vontad y ciudade.

En el primer ejemplo, encontramos un error que aparentemente sigue las mismas premisas de los discutidos anteriormente, es decir, la unión de dos partes, cada una de las cuales remite a una lengua diferente. Vemos que vontade $y$ voluntad son formalmente muy parecidas, razón por la cual probablemente se haya creado vontad. Creemos que en esta traducción prestada puede haber influido también el hecho de que muchos nombres del portugués terminados en ade tienen correspondencia con otros del español acabados en dad, como, por ejemplo: maldade-maldad; bondade-bondad; ruindade-ruindad. Con todo, obsérvese cómo, a diferencia de las palabras analizadas en las secciones anteriores, los modelos tanto del portugués (vontade) como del español (voluntad) son palabras primitivas, y no están formadas por la adición de una raíz y un sufijo. Sea como fuere, parece evidente que la influencia de la lengua materna está de nuevo entre las causas de tales generalizaciones ${ }^{176}$.

En el caso de ciudade, sin embargo, advertimos una estrategia contraria. En efecto, en este error se aprecia la conservación de una primera parte española, en la que destaca el mantenimiento del diptongo (ciud) junto a una terminación

\footnotetext{
${ }^{176}$ La utilización de vontad fue recogida también en el estudio de Farias, (2007, p. 68), quién la definió como una "traducción del portugués seguida de una adaptación al español” (FARIAS, op. cit) (traducción nuestra). Otro estudio que lo recoge en calidad de transferencia léxica es el de Schardosim y Durão (2011, p. 112).
} 
característicamente portuguesa (ade). Pese a las diferencias, parece evidente que la LM interfiere también aquí en el proceso de creación de una palabra primitiva.

\subsection{2 Traducción prestada: doncela}

\begin{tabular}{|c|c|c|c|c|c|}
\hline № & $\Sigma$ & Ejemplo & Desvío & LE & LM \\
\hline 30 & 1 & $\begin{array}{l}\text { D6C3: no... señorita y señora } \\
\text { son cosas distintas... doncela } \\
\text { hay acá... así se escribe así... }\end{array}$ & doncela & doncella & donzel_a \\
\hline
\end{tabular}

Tabla 112: Traducción prestada de palabra primitiva: doncela.

En este último ejemplo, ocurre un error distinto a los dos anteriores y por ello lo explicamos aparte. Como podemos apreciar en la tabla 112, los vocablos de ambas lenguas son parecidos formalmente, aunque con diferencias en la realización de las consonantes /z/ y /e/ y en el par /I/ y /II/, fonemas todos ellos que se realizan de manera distinta en portugués y español. En el vocablo objeto de la transferencia, la docente en cuestión emplea adecuadamente el sonido interdental correspondiente al fonema / $/$ / escrito con la letra "c"-, pero no así el fonema lateral. Así que, para nosotros, la razón más que evidente para que haya sido empleada la /I/ y no la /II/ en la realización del vocablo doncella es la influencia ejercida por la LM, ocurriendo así un error más por interferencia.

\subsection{Traducción prestada por composición}

\subsection{1 Traducción prestada: trabalinguas}

\begin{tabular}{|c|c|l|c|c|c|}
\hline № & $\Sigma$ & \multicolumn{1}{|c|}{ Ejemplo } & Desvío & LE & LM \\
\hline 31 & 2 & $\begin{array}{l}\text { D2C6: .. ¿se } \\
\text { acuerdan del } \\
\text { trabalinguas que } \\
\text { leemos* ali* en la } \\
\text { página cincuenta? } \\
\text { cerrar la boca... } \\
\text { [orden port]// }\end{array}$ & trabalinguas & trabalenguas & $\begin{array}{l}\text { trava- } \\
\text { línguas }\end{array}$ \\
\hline
\end{tabular}


Tabla 113: Traducción prestada por composición: trabalinguas.

En el ejemplo (31), observamos cómo, en la formación del nombre compuesto trabalinguas, utilizado dos veces por la docente D2, esta acude a un sustantivo del español (traba) - con el fonema bilabial característico de esta lengua - y a otro de la lengua portuguesa (línguas). De nuevo, la proximidad formal parece tener un papel fundamental en la construcción del vocabulario.

\subsubsection{Errores de calco}

En este apartado trataremos los llamados errores de calco (DURÃO, 2007, p. 40). Según la autora, este tipo de error consiste en la creación de unidades fraseológicas nuevas, alentadas por la existencia de formas y estructuras muy parecidas en la LM y la LO, y que acaban desembocando en nuevas transferencias procedentes de la lengua materna. En nuestro estudio hemos encontrado un total de 14 unidades fraseológicas que han sufrido algún tipo de préstamo de esta clase, con un total de 30 ocurrencias. Estos números representan un $3 \%$ de los errores de interferencia léxica hallados en el corpus. Con todo, cabe subrayar que tan solo dos sujetos no cometieron errores de este tipo, lo que da idea de su difusión.

Para esta sección, nos hemos servido de nuevo de algunos diccionarios ya mencionados anteriormente (ver apartado 6.5), como el Diccionario Bilingüe de Uso (DIBU), el Diccionario de la Real Academia Española (DRAE), y el Dicionário Aurélio da Língua portuguesa (AURÉLIO). Complementariamente, al ser una sección dedicada a los errores en unidades fraseológicas, hemos utilizado también dos diccionarios específicos de este campo, uno para cada lengua en contraste. En el caso del español, hemos utilizado el Diccionario de Locuciones para la Enseñanza de la Lengua Española, en sus en tres tomos: (i) Diccionario de Locuciones Adverbiales para la Enseñanza de la Lengua Española (PENADÉS MARTÍNEZ, 2005) (DLAEE); (ii) Diccionario de Locuciones Nominales y Adjetivas para la Enseñanza de la Lengua Española (PENADÉS MARTÍNEZ , 2008) (DLNEE); y (iii) Diccionario de Locuciones Verbales para la Enseñanza de la Lengua Española (PENADÉS MARTÍNEZ, 2002) (DLVEE). También nos apoyamos en algunos casos en el Diccionario Fraseológico Documentado del Español Actual (SECO ET AL., 2004). Finalmente, para el contraste 
con la lengua portuguesa, hemos acudido también a la consulta del Dicionário de Locuções e Expressões da Língua Portuguesa (ROCHA y ROCHA, 2011) (DLELP).

Por lo que se refiere al diccionario bilingüe (DIBU), nos pareció conveniente mantenerlo en el presente análisis, ya que también lo habíamos hecho en las secciones anteriores. Sin embargo, al realizar las búsquedas, nos dimos cuenta de que, pese a su evidente utilidad, no todas las UF estaban descritas en él y, además, no siempre había una correspondencia entre la UF de la LM y la equivalente en la LO. Por esta razón, se hizo necesario explicar la UF transferida por medio de otros diccionarios, como los de locuciones que se han mencionado más arriba. Con todo, tampoco en estos diccionarios encontramos todas las UF, lo que justifica la elección de otras obras lexicográficas monolingües.

Por último, conviene aclarar que, al igual que en otras etapas de la presentación de los datos, en este caso también nos hemos tomado la libertad de acotar solo aquellas secciones de las entradas de los diccionarios que más nos interesaban, así como destacar las partes más importantes para nuestro análisis.

A continuación presentamos un resumen de las formas transferidas que hemos encontrado en el corpus, en el que, junto al número de ocurrencias de cada una, desvelamos su correspondencia tanto en la lengua materna de los sujetos como en la lengua extranjera utilizada. En los casos en que no había unidades fraseológicas del portugués con correspondencia en español, hemos intentado buscar una opción que se aproximara lo más posible al sentido que adquiere en esta última lengua.

\begin{tabular}{|l|l|l|l|l|}
\hline № & $\boldsymbol{\Sigma}$ & CALCO & UF - LM & UF - LO \\
\hline 1 & 4 & en la hora & na hora & en el momento \\
\hline 2 & 4 & en una buena & numa boa & de buenas \\
\hline 3 & 1 & un monte & um monte & un montón \\
\hline 4 & 1 & encima de & em cima de & acerca de \\
\hline 5 & 1 & por cuenta & $\begin{array}{l}\text { por conta } \\
\text { (própria) }\end{array}$ & por cuenta propia \\
\hline 6 & 1 & por extenso & por extenso & en letras \\
\hline 7 & 6 & mismo que & mesmo que & aunque \\
\hline 8 & 1 & misma cosa & mesma coisa & lo mismo \\
\hline
\end{tabular}




\begin{tabular}{|l|l|l|l|l|}
\hline 9 & 3 & mismo así & mesmo assim & aun así \\
\hline 10 & 3 & hacer la llamada & fazer a chamada & pasar lista \\
\hline 11 & 2 & dar una miradita & $\begin{array}{l}\text { dar uma } \\
\text { olhadinha }\end{array}$ & echar una ojeada \\
\hline 12 & 1 & sentir falta & sentir falta & echar en falta \\
\hline 13 & 1 & a cata & a cata & dando cata \\
\hline 14 & 1 & consejo de clase & $\begin{array}{l}\text { conselho de } \\
\text { classe }\end{array}$ & claustro \\
\hline
\end{tabular}

Tabla 114: Errores de calco.

Por otro lado, en las tablas que siguen, contrastamos de manera sucinta los artículos de los diccionarios que se han analizado en cada ocasión. Todas ellas siguen el mismo patrón expositivo: a) el error por calco analizado; b) el contexto donde se produjo; y c) los artículos consultados, en el siguiente orden: (i) diccionario bilingüe; (ii) diccionarios de locuciones y expresiones tanto de la lengua objeto como de la lengua materna; (iii) diccionarios monolingües de ambas lenguas.

\subsection{Calco 1: En la hora}

\begin{tabular}{|l|l|}
\hline \begin{tabular}{|l|}
\hline Interferencia 1: en la hora \\
\hline $\mathbf{1}$
\end{tabular} & $\begin{array}{l}\text { D6E: ... pero en la hora que necesitan de materiales } \\
\text { intentan afastarse } \\
\text { contenidos maravillosos para...// }\end{array}$ \\
\hline $\begin{array}{l}\text { Ejemplo } \\
\mathbf{2}\end{array}$ & $\begin{array}{l}\text { D9C: ... porque as* veces [[las personas mayores]] no } \\
\text { hacen nada... no ayudan en nada en los trabajos... pero } \\
\text { pueden ayudarnos en una hora que necesitamos... }\end{array}$ \\
\hline Diccionario Bilingüe (DIBU2 p. 586) \\
\hline \multicolumn{2}{|l}{} \\
\hline
\end{tabular}




\section{ho.ra}

4 Hora, ocasión, momento oportuno: Carlos concluiu que a hora de realizar seu sonho ainda não havia chegado=Carlos concluyó que el momento de realizar su sueño todavía no había llegado; esperarei a hora certa para agir=esperaré el momento oportuno para actuar. momento, ocasião, oportunidade; $\square$ altas horas (da noite), altas horas

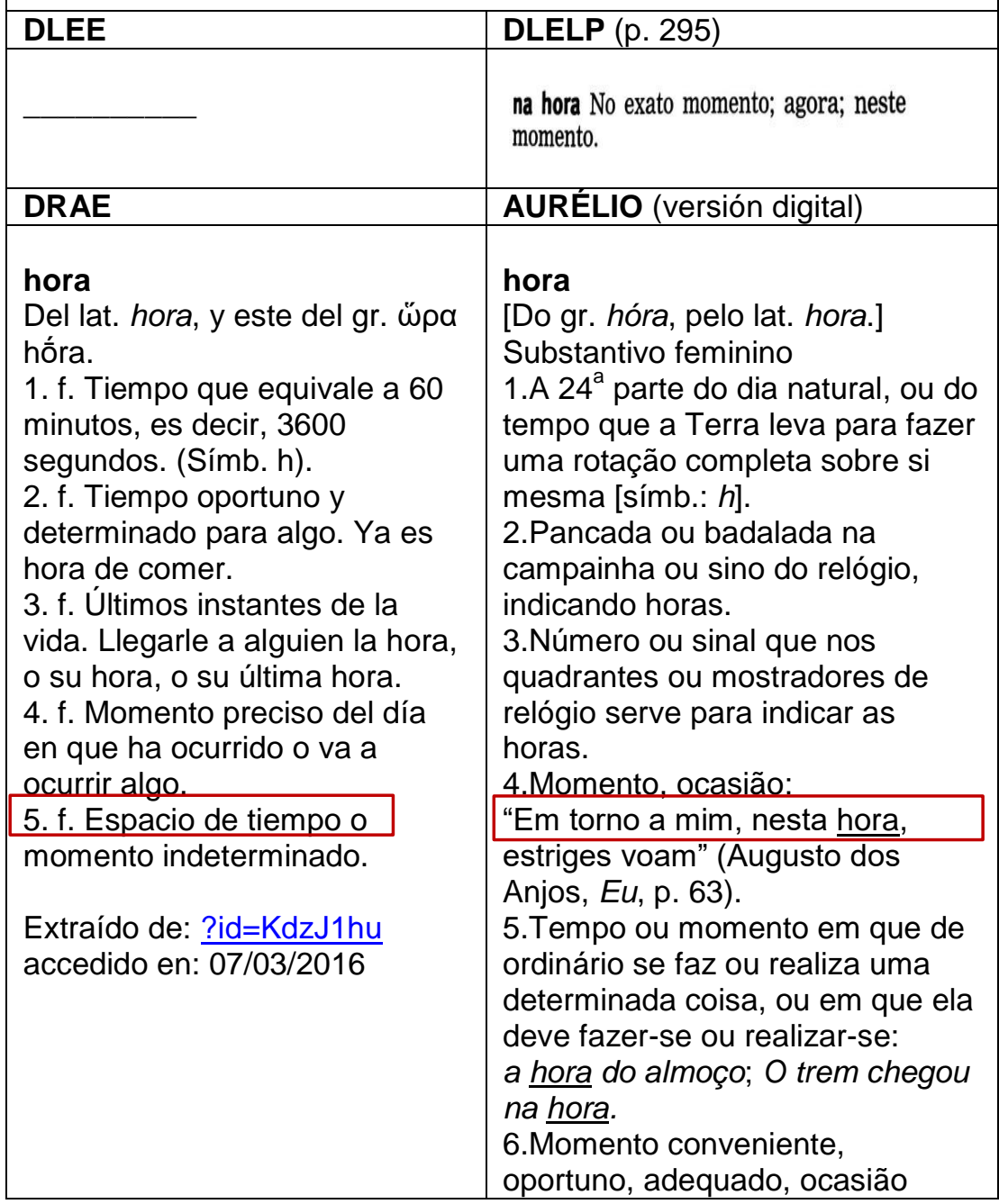


propícia; oportunidade, ensejo:

Está esperando a hora de pôr em prática o seu ambicioso plano.

7.Momento de importância ou de relevo:

O simbolismo teve a sua hora.

8.Horário (4). [Cf. ora, do v. orar, s. m., adv., conj. e interj.] $\sim$ V. horas.

Solución: Uno de "en el momento" de la lengua española.

Tabla 115: Calco 1: En la hora.

Como vemos en los dos ejemplos que presentamos, esta UF es utilizada por dos sujetos (D6 - 1 ocasión y D9 - 3 ocasiones). Aunque haya una pequeña variación en los ejemplos (en la hora/en una hora), creemos que se trata de la misma UF transferida. En el caso del ejemplo 1, la docente intenta explicar que los alumnos creen en la facilidad que entraña aprender español, pero cuando llega el momento de la verdad (en la hora que...) pierden el interés por las clases, puesto que se dan cuenta de que la lengua es bastante más difícil de lo que pensaban inicialmente. En el segundo ejemplo, la docente D9, al comentar una parábola estudiada en clase, argumenta que debemos acercarnos a las personas mayores, pues aunque por sus limitaciones físicas muchas veces no puedan ser de gran ayuda en las labores diarias, tienen mucho valor en otras situaciones, como ocurre en la historia sobre la cual reflexionan. Para ello utiliza la UF "en una hora que necesitamos"

Según el DIBU, el sintagma a hora es equivalente a el momento en español, como podemos observar en el fragmento marcado que analizamos. Por ello, entendemos que las expresiones que utilizan las docentes, compuestas por en (em) + la (a) hora, y en (em) + una (uma) hora son traducciones del portugués (esta última con una contracción de em + um = numa hora). Si realizamos un análisis contrastivo del vocablo hora en los diccionarios DRAE y AURELIO, veremos que el sentido en las dos lenguas es muy similar. Sin embargo, el Diccionario de Locuciones y Expresiones de la Lengua Española no recoge en el momento como una UF y tampoco lo hace el DRAE. Por tanto, podemos inferir que el significado es el mismo, aunque na hora/numa hora se consideren UF en portugués, pero no así en el momento en español. 


\begin{tabular}{|c|c|c|}
\hline \multicolumn{3}{|c|}{ Interferencia 2: en una buena } \\
\hline Ejemplo & \multicolumn{2}{|c|}{$\begin{array}{l}\text { D9C1: ... ni habló* cosas malas... ni la chingó* ni nada... } \\
\text { pero... todo en una buena... fue haciendo as* cosas y } \\
\text { cuando la culebra percibió estaba presa... }\end{array}$} \\
\hline \multicolumn{3}{|c|}{ Diccionario Bilingüe (DIBU2 p. 124) } \\
\hline \multicolumn{3}{|c|}{$\begin{array}{l}\text { bo•a } \\
\text { (estar/ficar) numa boa BRA. INFOR., (estar) satisfe- } \\
\text { cho, feliz, como si nada: estão numa boa desde que } \\
\text { vieram para cá=están felices desde que vinieron } \\
\text { para acá; eles estão/ficam numa boa enquanto nós } \\
\text { damos um duro danado=ellos como si nada, mien- } \\
\text { tras nosotros nos matamos. } \\
\text { do; } \square \text { (uma) boa INFOR., una buena: aprontar uma }\end{array}$} \\
\hline DLAEE & & DLELP (p. 317) \\
\hline \multicolumn{2}{|c|}{$\begin{array}{l}\text { como si nada adv. (i) Sin dar la } \\
\text { menor importancia: Y yo voy a la } \\
\text { parroquia, como si nada, y me la veo } \\
\text { ahí La empujó y entró a la casa como si } \\
\text { nada. } \\
\text { (p. 75) }\end{array}$} & $\begin{array}{l}\text { numa boa Numa situação excepcional, } \\
\text { tranquila, vantajosa, privilegiada. }\end{array}$ \\
\hline \multicolumn{2}{|c|}{$\begin{array}{l}\text { de buenas adv. (i) infor. En buena dis- } \\
\text { posición de ánimo: Hoy no he oido } \\
\text { discutir a los jubilados del tercero dere- } \\
\text { cha. Deben estar de buenas. } \rightarrow \text { de } \\
\text { malas. Se construye generalmen- } \\
\text { te con el verbo estar: Un amigo es una } \\
\text { persona que la encuentras para cuando } \\
\text { estás de buenas o cuando estás de malas. } \\
\text { (p. 89) }\end{array}$} & \\
\hline DRAE & & AURÉLIO (versión digital) \\
\hline
\end{tabular}




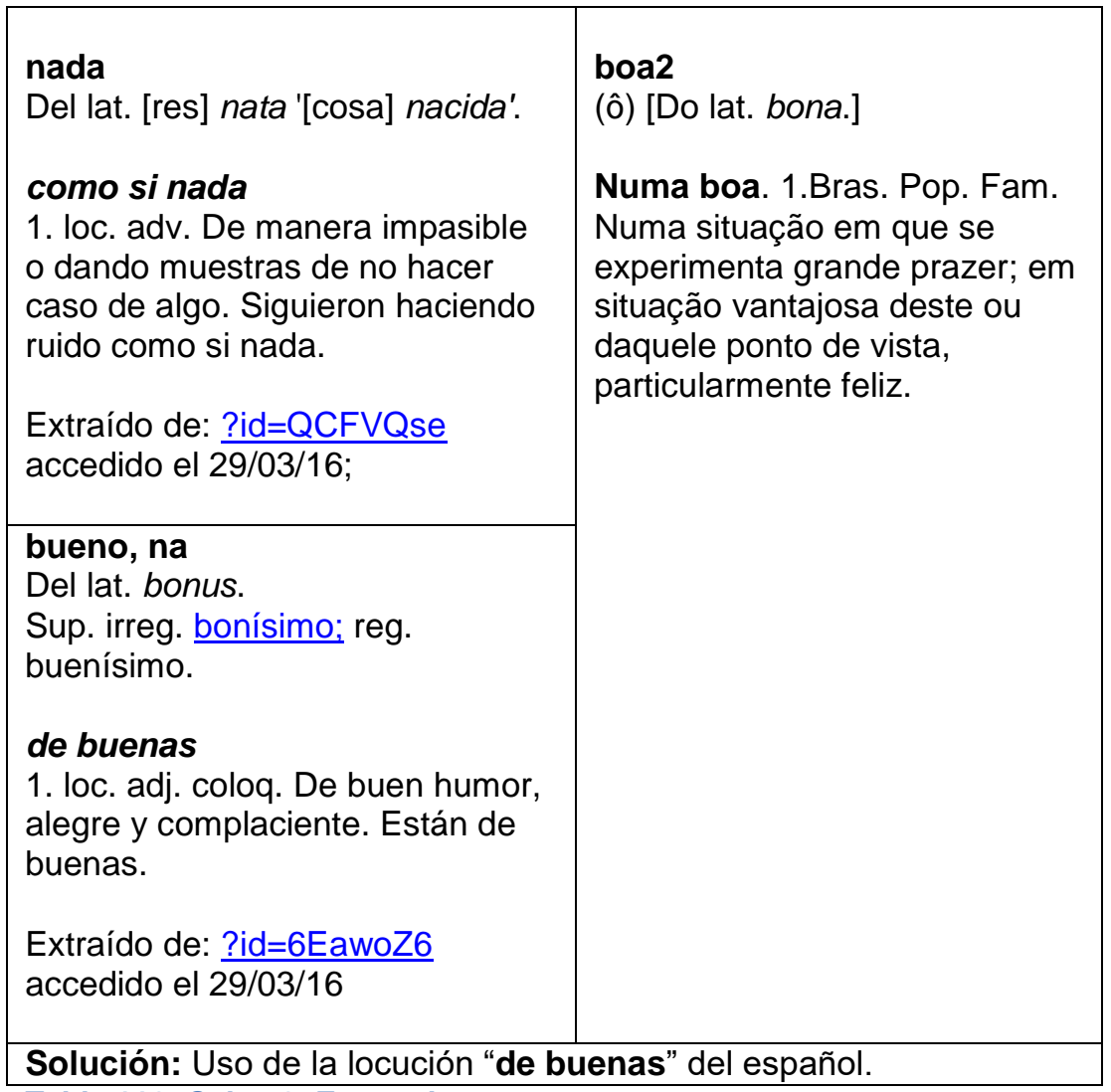

Tabla 116: Calco 2: En una buena.

En el caso de en una buena, la docente D9, que utiliza esta expresión hasta 4 veces en un mismo pasaje, relata una historia que se había interpretado en clase y en la que se trataba de dejar claro que el personaje principal (que es bondadoso) trataba a la culebra (personaje malo) con indiferencia, aunque esta le hubiese hecho muchas fechorías en el pasado. Así, el uso de la UF en una buena hace referencia a que el personaje bueno no se vengó del personaje malo, sino que condujo su vida con normalidad, a pesar de las maldades de la culebra. En definitiva, que el primero estaba "de buenas" y no enojado con la segunda.

La expresión en una buena es, claramente, una traducción literal de la locución portuguesa numa boa. Según apunta el DIBU, la locución portuguesa puede corresponder en español a estar 
satisfecho, feliz, e incluso menciona una locución correspondiente en la LO: como si nada.

Por otro lado, según indica el DLELP, numa boa significa tener una situación "excepcional, tranquila, ventajosa, privilegiada". Para el AURÉLIO, la UF significa estar en una "situación feliz, o que experimenta gran placer". Con respecto a la UF apuntada por el DIBU como correspondiente en español, como si nada, tanto el DRAE como el DLAEE dan cuenta de una situación en la que "no hay importancia o no se hace caso de algo". Eso nos lleva a deducir que la locución numa boa tiene dos sentidos: por un lado significa "de manera indiferente", y en este caso tiene un sentido aproximado a como si nada. Y, por otro, conlleva la idea de "estar tranquilo, relajado, feliz".

Creemos que hay, por tanto, un desencuentro entre la UF propuesta por el DIBU como correspondencia de numa boa y el sentido que usó la docente, que es el de "estar tranquilo, feliz, en paz, en buen estado de ánimo". Siendo así, entendemos que la UF en la LO que más se aproxima a esta acepción de numa boa, podría ser (estar) de buenas. Esta locución está recogida tanto por el DRAE como por el DLAEE y significa "estar de buen humor, alegre, complaciente, o en buena disposición de ánimo".

\subsection{Calco 3: Un monte}

\begin{tabular}{|c|c|}
\hline \multicolumn{2}{|c|}{ Interferencia 3: un monte } \\
\hline Ejemplo & $\begin{array}{l}\text { D4C3: ... Entonces ahora ustedes saben mucho del } \\
\text { vocabulario... aprendieron un monte... son cincuenta } \\
\text { palabras.../ }\end{array}$ \\
\hline \multicolumn{2}{|c|}{ Diccionario Bilingüe (DIBU2 p. 744) } \\
\hline \multicolumn{2}{|c|}{$\begin{array}{l}\text { mon·te } \\
\text { montanha, pilha. } 3 \text { Mucho, montón, gran cantidad: } \\
\text { já liguei um monte de vezes e näo consigo achar } \\
\text { ninguém em casa=ya he llamado muchas veces y } \\
\text { no logro encontrar a nadie en casa; os repónteres } \\
\text { lhe fizeram um monte de perguntas=los reporteros } \\
\text { le hicieron un montón de preguntas. } \\
\text { muito; montäo, } \square \text { aos montes, a montones, un montón: vocế }\end{array}$} \\
\hline
\end{tabular}




\begin{tabular}{|c|c|}
\hline DLNEE (p. 156) & DLELP (p. 445) \\
\hline $\begin{array}{l}\text { un montón } m \text {. (b } \mathbf{b}_{1} \text { ) [de algo/alguien] } \\
\text { Una cantidad grande /de personas o } \\
\text { de cosas): Son un montón de hermanos; } \\
\text { Después de estar alli un montón de tiem- } \\
\text { po en la cola, no pudieron pasar, La } \\
\text { abuela le recibe con un montón de besos. } \\
\text { "la mar. } 9 \text { El complemento [de } \\
\text { algo/alguien] puede no aparecer: } \\
\text { De esas cartas hemos recibido todos un } \\
\text { montón. }\end{array}$ & $\begin{array}{l}\text { um monte de coisas Muitas coisas; uma } \\
\text { porção de coisas. }\end{array}$ \\
\hline DRAE & AURÉLIO (versión digital) \\
\hline $\begin{array}{l}\text { montón } \\
\text { De monte. } \\
\text { 1. m. Conjunto de cosas } \\
\text { puestas sin orden unas encima } \\
\text { de otras. } \\
\text { 2. m. coloq. Cantidad } \\
\text { considerable. Tengo que decirte } \\
\text { un montón de cosas. }\end{array}$ & $\begin{array}{l}\text { monte } \\
\text { [Do lat. monte.] } \\
\text { 4.Acervo, montão: } \\
\text { Conseguiu juntar um monte de } \\
\text { dinheiro. }\end{array}$ \\
\hline $\begin{array}{l}\text { Extraído de: } \\
\text { http://dle.rae.es/?id=PkZlcXO } \\
\text { accedido el 30/03/16 }\end{array}$ & \\
\hline
\end{tabular}

Tabla 117: Calco 3: Un monte.

El uso de un monte, empleado una sola vez por la docente $\mathrm{D} 4$, es claramente una interferencia de la lengua materna, puesto que en esta es común la utilización de esta UF en referencia a una gran cantidad de algo, como queda evidenciado tanto en el artículo de DIBU como en el DLELP. El error de calco ocurre puesto que en español lo usual es utilizar la UF un montón, como podemos apreciar tanto en el ejemplo del DIBU, como en la entrada del DLNEE, y también en el DRAE. Observamos que en ninguno de estos diccionarios existe la opción un monte sino un montón. De 
hecho, monte tiene en el DRAE hasta 9 acepciones $^{177}$, ninguna de las cuales tiene relación con una gran cantidad de cosas.

En suma, podemos considerar que existe una interferencia de la LM y que la opción más adecuada sería la utilización de la UF del español un montón.

\subsection{Calco 4: Encima de}

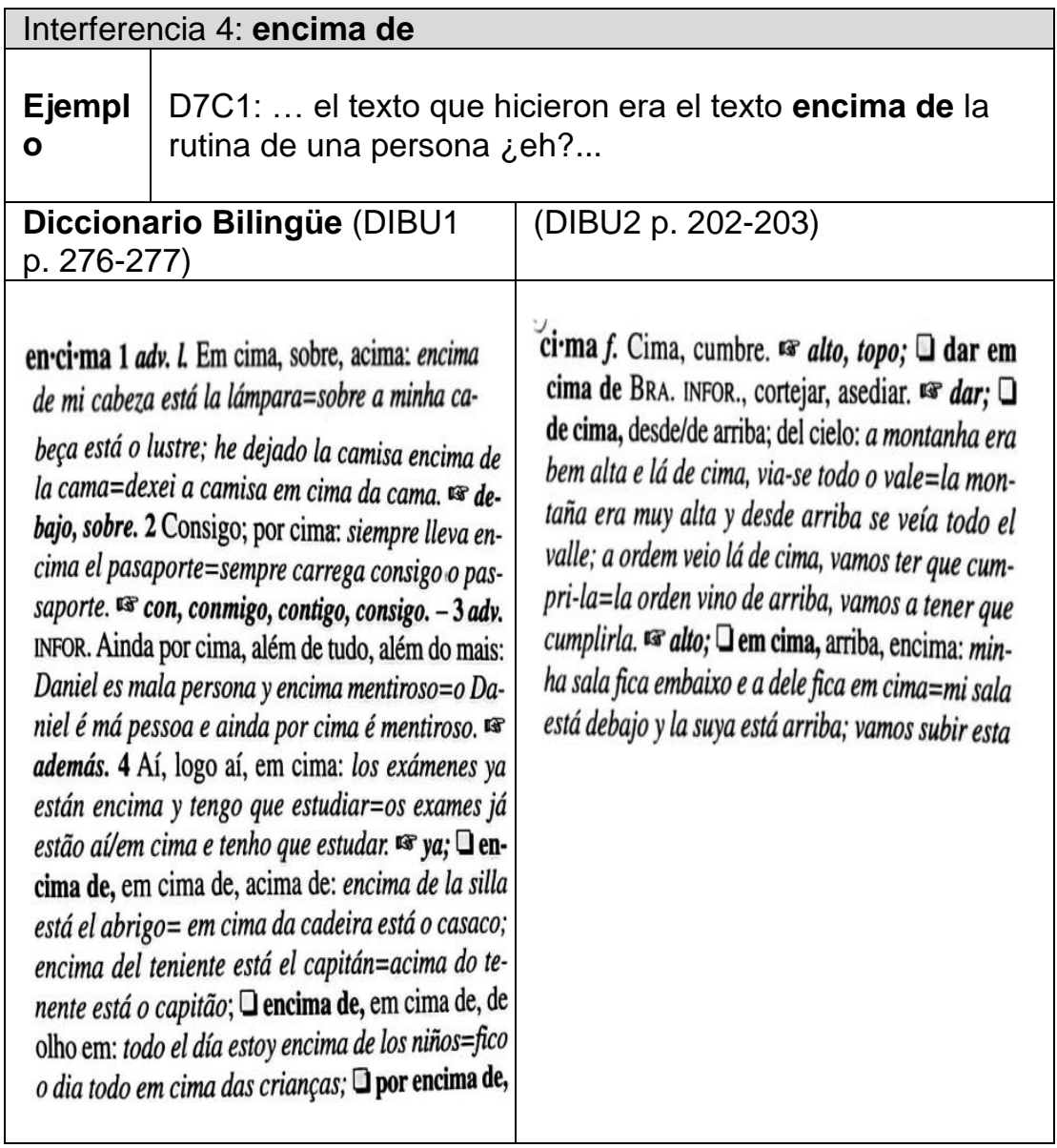

${ }^{177}$ Consultado en http://dle.rae.es/?id=PjYBCi6, el 30/03/16. 


\begin{tabular}{|c|c|}
\hline & $\begin{array}{l}\text { montanha, pois lá em cima há uma capelinha mui- } \\
\text { to linda=vamos a subir esta montaña porque allá } \\
\text { arriba hay una capillita muy bonita; } \square \text { em cima, } \\
\text { listo, preparado; adecuado, estupendo: comoé, está } \\
\text { tudo em cima para o passeio de amanhâ? = iqué } \\
\text { tal, está todo listo para el viaje de mañana?; essa } \\
\text { mulher está bem conservada para a idade, está } \\
\text { com tudo em cima=esa mujer se conserva muy } \\
\text { bien para su edad, lo tiene todo estupendo. } \\
\text { to, combinado, conservado; } \square \text { em cima de, encima } \\
\text { de, sobre: deixei as compras em cima da mesa para } \\
\text { você guardar=he dejado la compra encima de la } \\
\text { mesa para que la guardes; disse barbaridades em } \\
\text { cima de barbaridades=dijo barbaridades sobre } \\
\text { barbaridades. }\end{array}$ \\
\hline DFDEA (p. 419) & DLELP (p. 168) \\
\hline $\begin{array}{l}\text { oncima de. prep A pesar de. II VAl 17.1.92, } \\
\text { 18: Si alguien en este proceloso mar de la poli- } \\
\text { tica está pensando en seguir poniendo zanca- } \\
\text { dillas, sepa que estamos dispuestos a saltar- } \\
\text { las por encima de quien sea. * Iré a Francia } \\
\text { por encima de cualquier prohibición. }\end{array}$ & $\begin{array}{l}\text { em cima de } 1 \text {. Sobre, colocado ou aplicado } \\
\text { na parte superior ou externa de algo. }\end{array}$ \\
\hline DRAE & AURÉLIO (versión digital) \\
\hline $\begin{array}{l}\text { encima } \\
\text { De en- y cima. } \\
\text { 1. adv. En lugar o puesto } \\
\text { superior, respecto de otro } \\
\text { inferior. U. t. en sent. fig. } \\
\text { 2. adv. Sobre sí, sobre la propia } \\
\text { persona. U. t. en sent. fig. } \\
\text { Echarse encima una } \\
\text { responsabilidad. } \\
\text { 3. adv. Además, sobre otra } \\
\text { cosa. Dio seis euros, y otros }\end{array}$ & $\begin{array}{l}\text { cima1 } \\
\text { [Do gr. } k \sim m a, \text { pelo lat. cyma.] } \\
\text { Substantivo feminino } \\
\text { 1.A parte mais elevada. } \\
\text { 2.Cume, cimo, cimeira, topo. [PI.: } \\
\text { cimas. Cf. sima e Simas, antr.] } \\
\text { Em cima de. 1.Na parte superior } \\
\text { de; no alto de; sobre: } \\
\text { Os livros estão em cima da mesa. } \\
\text { 2.Em seguida a; depois de; sobre: }\end{array}$ \\
\hline
\end{tabular}


dos encima.

4. adv. Muy próximo en el tiempo. Ya tenemos el verano encima.

5. adv. A pesar de todo. Ganó un premio, le tocó la lotería y encima se queja.

\section{encima de}

1. loc. prepos. En la parte superior de algo. Encima de la cama.

Extraído de:

http://dle.rae.es/?id=F6SsXHC accedido el 30/03/16.

Solución: Utilización del vocablo español "acerca de".

Tabla 118: Calco 4: Encima de.

Con la locución encima, utilizada una vez por la docente D7, lo que ocurre inicialmente es que, a partir del registro oral, resulta imposible precisar con exactitud si la docente utilizó em cima de del portugués o encima de del español, puesto que se pronuncian de manera muy parecida. Partimos, pues, del presupuesto de que la profesora quiso utilizar la UF en español, dado que era en esta lengua en la que mantenía su conversión con nosotros. Siendo así, observamos que hay un equívoco en su empleo, puesto que se utiliza con un significado característicamente portugués. Un significado que, todo hay que decirlo, no se contempla en ninguno de los diccionarios consultados, pero que, como hablantes nativos de esta lengua y pertenecientes a su misma zona geolectal, creemos poder explicar.

EI DRAE señala que encima es un adverbio, pero encima de es una locución prepositiva que significa "en la parte superior de algo". Otro sentido atribuido a la locución es "a pesar de", como lo recoge el diccionario fraseológico DFDEA (ej. "iré a Francia por encima de cualquier prohibición"). EI DIBU1, por su parte, le atribuye una opción más, que es la de "observar o controlar a alguien" (ej. "todo el día estoy encima de los niños"). Por otro lado, la locución em cima de del portugués comparte algunos significados con la española, pero no todos. Los significados compartidos son dos: el 
primero es "en la parte superior de" como enseñan el AURÉLIO, el DLELP, el DIBU2 y el DIBU1. El segundo significado compartido es "observar o controlar a alguien", como también señala el DIBU1. No obstante, el DIBU2 distingue dos nuevos conceptos para em cima de (port.) que no comparten significado con encima de (esp.): uno de ellos es "estar listo, preparado, adecuado o estupendo" y el otro es "arriba".

Quizá la similitud formal y el hecho de que esta UF comparte algunos significados en las dos lenguas contribuye a que la docente haya utilizado encima de en el ejemplo reseñado. Sin embargo, entendemos que ninguna de las acepciones mencionadas aquí para ninguna de las dos lenguas, tiene sentido en la oración en fue utilizada la UF, pues lo que quiso decir fue que sus alumnos habían redactado un texto acerca de la rutina de una persona. La utilización de la expresión portuguesa em cima de con el sentido de acerca de, sobre, respecto a es un dialectalismo muy común en la zona donde vive la docente y por eso creemos que estamos ante un nuevo error de calco.

\subsection{Calco 5: Por cuenta}

\begin{tabular}{|l|l|}
\hline Interferencia 5: por cuenta \\
\hline Ejemplo & $\begin{array}{l}\text { D6C4: ... [comt. port] gente... la “e"... yo quería que } \\
\text { ustedes hicieron*... por cuenta... pero todas las } \\
\text { respuestas están en el proprio* texto... }\end{array}$ \\
\hline Diccionario Bilingüe (DIBU) \\
\hline \multicolumn{2}{|l|}{} \\
\hline DLEE & DLELP (p. 355) \\
\hline $\begin{array}{l}\text { por conta e risco de Sob a total responsa- } \\
\text { bilidade de. } \\
\text { por conta própria Independentemente; sem } \\
\text { auxilio. }\end{array}$ \\
\hline $\begin{array}{l}\text { DRAE } \\
\text { por cuenta propia } \\
\text { 1. Ioc. adj. Dicho de una }\end{array}$ & $\begin{array}{l}\text { AURÉLIO (versión digital) } \\
\text { [Dev. de contar.] } \\
\text { Substantivo feminino }\end{array}$ \\
\hline
\end{tabular}




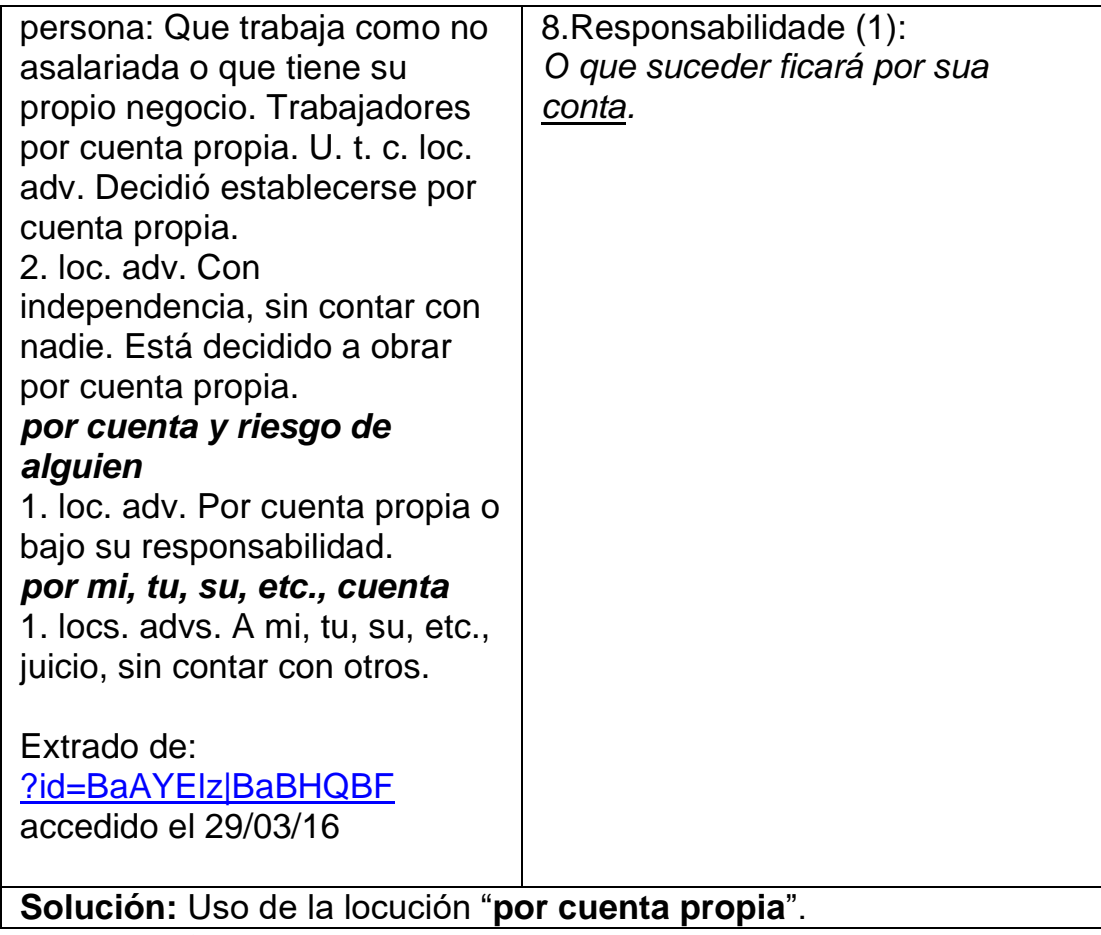

Tabla 119: Calco 5: Por cuenta.

En esta locución, creemos que hubo interferencia del portugués coloquial, donde la expresión por conta própria, suele utilizarse de forma abreviada: por conta. Esta última no aparece recogida en ninguna de las obras consultadas, pero, como usuarios de la lengua, sabemos que está muy difundida en la comunidad donde vive la docente. Tanto en el DLELP como en el DRAE, las locuciones por cuenta propia y por cuenta y riesgo existen con el mismo sentido en los dos idiomas. No obstante, la forma reducida por cuenta no existe en español. Otra opción en esta lengua sería el uso de por mi cuenta, también existente en portugués, como podemos ver en el AURÉLIO: por minha conta, que quiere decir "bajo mi responsabilidad y sin contar con los demás". Así, la docente D6 podría haber utilizado tanto la forma por vuestra cuenta como por cuenta propia, pero la forma reducida por cuenta representa un error de calco. 


\subsection{Calco 6: Por extenso}

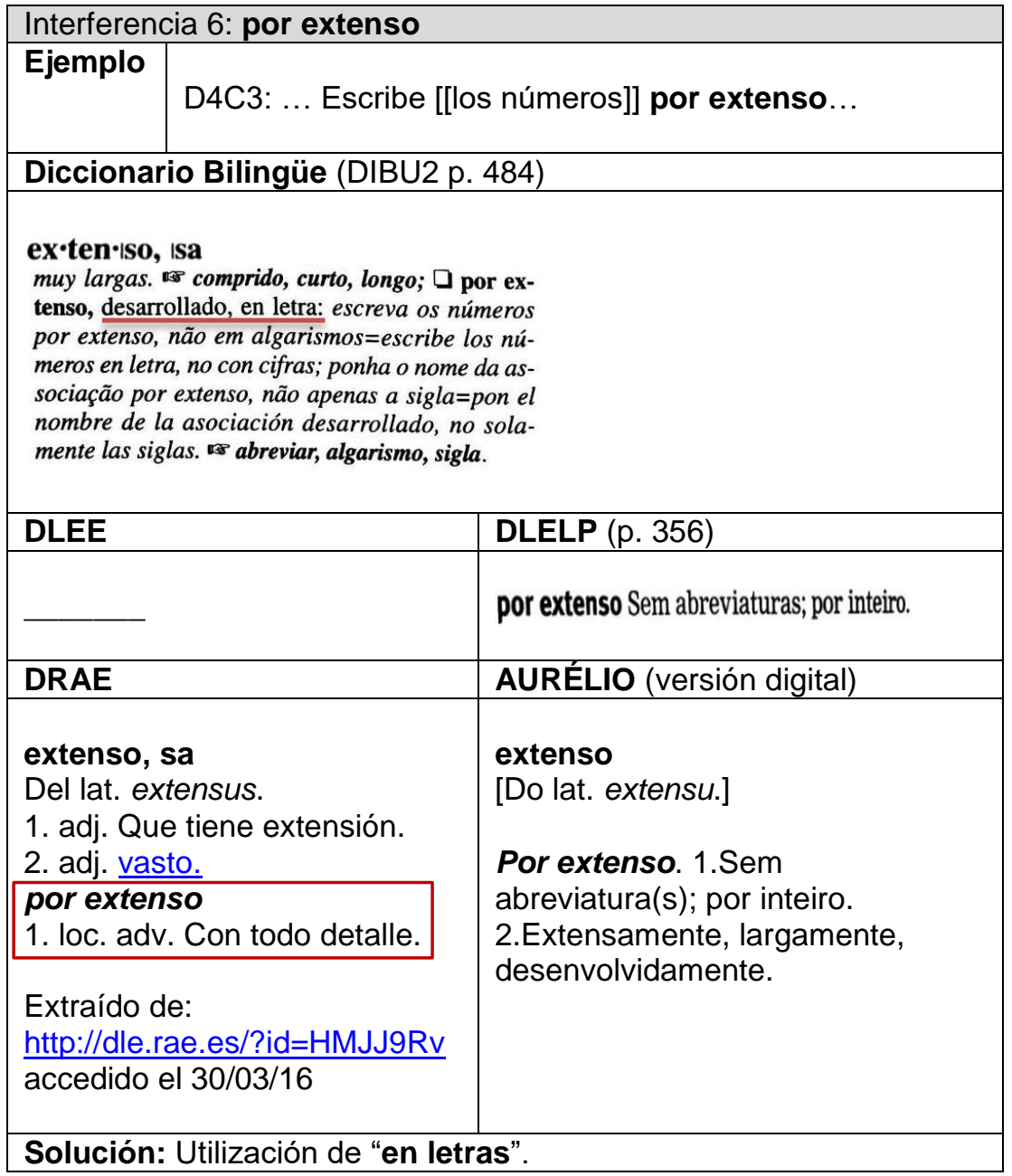

Tabla 120: Calco 6: Por extenso.

Pese a la similitud formal entre las dos lenguas, nos encontramos con una locución que posee significados diferentes en cada idioma. La docente D4 utiliza en una ocasión la locución por extenso de su lengua materna sin advertir que tal construcción no tiene exactamente el mismo sentido que en portugués. Como podemos observar en las definiciones que aparecen tanto en el 
DIBU como en el DLELP y el AURÉLIO, cuando se trata de números, por extenso equivale en portugués a "escribirlos en letras". Por el contrario, la expresión por extenso en español, de conformidad con lo que señala el DRAE, significa "con todo detalle", pero no está relacionado con la numeración, como ocurre en la lengua portuguesa. En resumidas cuentas, al existir la misma locución en las dos lenguas, la docente aparentemente desconoce que semánticamente no son correspondientes en todos los contextos, y por ello la emplea en un sentido inapropiado. Lo adecuado sería, por tanto, la utilización de en letras, como advierte el DIBU.

\subsection{Calco 7: Mismo que}

\begin{tabular}{|c|c|c|}
\hline Ejemplo & \multicolumn{2}{|c|}{$\begin{array}{l}\text { D9C1: Mismo que sea un martes gris... [expl. port] sien* } \\
\text { sol... no tiene* sol... }\end{array}$} \\
\hline \multicolumn{3}{|c|}{ Diccionario bilingüe (DIBU2 p. 279) } \\
\hline \multicolumn{3}{|c|}{$\begin{array}{l}\text { mes:mo, Ima } \\
\text { viajar al extranjero. ainda, assim; } \square \text { mesmo } \\
\text { quelse, aunque, aun cuando: mesmo que possa, não } \\
\text { irei à festa=aunque pueda, no iré a la fiesta; mesmo } \\
\text { se eu não estiver com vontade, vou achar um jeito de } \\
\text { fazer=aun cuando no tenga ganas, voy a encontrar } \\
\text { un modo de hacerlo. ainda, embora; } \square \text { nem mes- }\end{array}$} \\
\hline DFDEA p & 164 & DLELP p. 285 \\
\hline $\begin{array}{l}\text { AUN } \\
\text { aun cuand } \\
\text { teratura } 145 \\
\text { las obras d } \\
\text { ayudador de } \\
\text { enemistó pú } \\
\text { na. R. Salad } \\
\text { Umbral .., ar } \\
\text { da para no c } \\
\text { le ha tratado }\end{array}$ & $\begin{array}{l}\text { conj (lit) Aunque. II DPlaja Li. } \\
\text { En latín clásico fueron escritas } \\
\text { Erasmo de Rotterdam, eficar } \\
\text { la Reforma, aun cuando no se } \\
\text { licamente con la Iglesia Roma- } \\
\text { igas Des } 12.9 .70,28 \text { : Francisco } \\
\text { n cuando sea joven, tiene coarta- } \\
\text { eer en la vida, dado que la vida } \\
\text { siempre mal. }\end{array}$ & $\begin{array}{l}\text { mesmo que Ainda que; apesar de; embora; } \\
\text { conquanto. }\end{array}$ \\
\hline
\end{tabular}




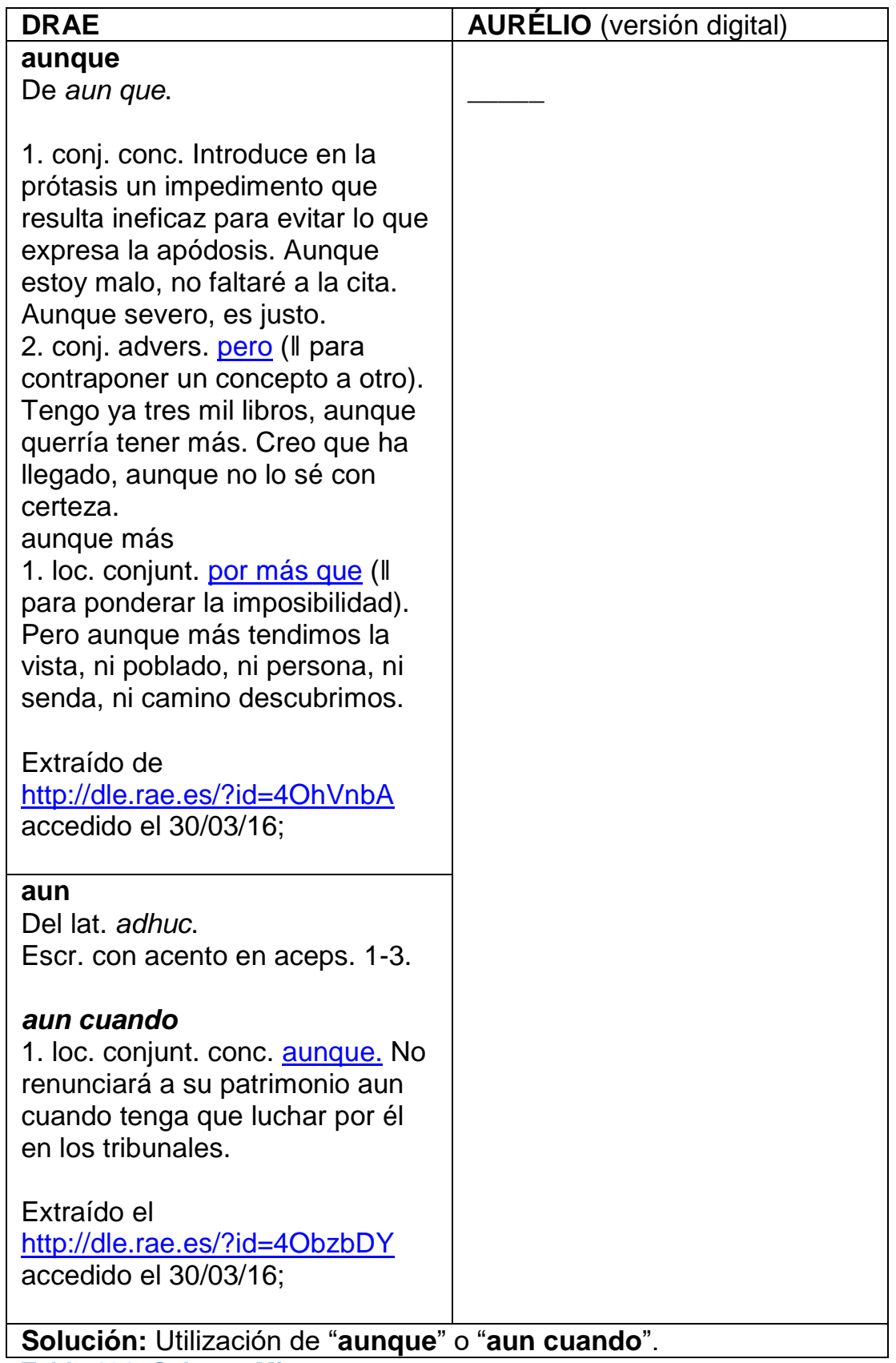

Tabla 121: Calco 7: Mismo que. 
La búsqueda en los diccionarios de locuciones del español DFDEA y DLEE, así como en el DRAE, de la expresión mismo que, fue infructuosa. Por su parte, los diccionarios DIBU y DLELP dan cuenta de la existencia de la UF mesmo que, y el DIBU incluso presenta una correspondencia para ella en español: aunque $O$ aun cuando, ambas recogidas tanto en el DRAE como en el DFDEA. En definitiva, parece que esta UF no existe en la LO y que es una creación de la docente, quien la emplea hasta en cuatro ocasiones diferentes en su discurso.

Creemos que el error se produce por la confusión entre los vocablos mesmo y mismo. En otra sección de este mismo capítulo (véase, por ejemplo, el apartado 7.2.1.1.2), hemos visto que los sujetos del estudio (y lo mismo ocurre con los estudiantes brasileños en general) muestran una especial dificultad en el empleo de mismo, ya sea en su uso aislado, ya en combinación con otros términos, como ocurre en las locuciones. Esto ocurre porque sus usos en la lengua materna no se dan necesariamente de igual manera en la lengua española.

Así, al haber un vocablo afín en ambas lenguas mismo/mesmo, la docente hace una traducción literal de la UF portuguesa mesmo que en mismo que, cometiendo así un error de calco. Por el contrario, lo adecuado hubiera sido la utilización de aunque $o$ aun cuando, conforme señalan los diversos diccionarios consultados. Resta destacar que esta fue la interferencia de este tipo más frecuente: un total de 6 ocasiones en el habla de tres docentes diferentes $(\mathrm{D} 6=1 ; \mathrm{D} 7=4 ; \mathrm{D} 9=1)^{178}$.

\subsection{Calco 8: Misma cosa}

\section{Interferencia 8: misma cosa}

Ejemplo $\quad{ }^{179} \mathrm{D} 9 \mathrm{C} 1$ : misma cosa no... un día lava la ropa... otro lo* plancha y así puede cambiar... hasta que * seque...

\section{Diccionario Bilingüe (DIBU2 p. 729)}

${ }^{178}$ Yokota (2000, p. 80), observó el uso de "mismo que" con valor de "aunque" en comunidades fronterizas de Brasil con hispanohablantes.

179 En la corrección de una actividad, un alumno le dice a la profesora en portugués que dos respuestas son "a mesma coisa" (lo mismo). 


\section{mes`|mo, Ima \\ estos casos este(s), a(s), ele(s), ela(s); $\square$ a mesma coisa, lo mismo: seu pai vai te dizer a mesma coisa que eu estou dizendo agora = tu padre te va a decir lo mismo que te estoy diciendo yo ahora; $\square$ (até) mes-}

\begin{tabular}{|l|l|}
\hline DLAEE (p. 140 & DLELP \\
\hline lo mismo adv. 1 (i) De la misma & \\
manera: Tú has colaborado lo mismo, \\
asi que no hables. ídem de lienzo. \\
Si aparece el segundo término de \\
la comparación, va introducido por \\
que: Ligas lo mismo que aquellos de tus \\
amigos que te parecen más guapos y con \\
mejor tipo. 2 (i) infor. Quizá: Lo mismo \\
lo conoces esta noche si viene, si le da por \\
venir. *a lo mejor.
\end{tabular}

Tabla 122: Calco 8: Misma cosa.

Como en los ejemplos anteriormente citados, en los que se formaban expresiones con mesmo en portugués, en este caso (ocurrido una sola vez en el discurso de la docente D9), tenemos otro calco de la lengua materna, aunque esta vez con la forma femenina. Eso ocurre con la transferencia a partir del portugués mesma coisa, con la cual la docente intenta explicar que hay diferencias entre las actividades que desarrolla determinado personaje de una historia, o en otras palabras, las actividades no son 10 mismo. Haciendo una búsqueda en los diccionarios de locuciones y en el DRAE no hemos encontrado dicha locución, por lo que entendemos que es una transferencia de la LM del sujeto. Como podemos constatar a partir de las entradas tanto del diccionario DIBU, como del DLAEE, en este caso el uso apropiado sería el empleo del artículo neutro "lo" + el adjetivo "mismo", Io mismo. 


\subsection{Calco 9: Mismo así}

\begin{tabular}{|c|c|c|}
\hline \multicolumn{3}{|c|}{ Interferencia 9: mismo así } \\
\hline Ejemplo & \multicolumn{2}{|c|}{$\begin{array}{l}\text { D7E: ... yo estoy cierta que ellos mientras hablan están } \\
\text { con atención en lo que estamos haciendo... entonces } \\
\text { mismo así consiguen aprender... }\end{array}$} \\
\hline \multicolumn{3}{|c|}{$\begin{array}{l}\text { Diccionario Bilingüe ( DIBU2 } \\
\text { p. 729) }\end{array}$} \\
\hline \multicolumn{3}{|c|}{$\begin{array}{l}\text { mes`Imo, Ima } \\
\text { hoy o mañana, da lo mismo; } \square \text { mesmo assim/assim } \\
\text { mesmo, aun así: Liliana diz que não tem dinheiro } \\
\text { mas, mesmo assim, vai viajar para o exterior }=L i \text { - } \\
\text { liana dice que no tiene dinero pero, aun asi, va a } \\
\text { viajar al extranjero. ainda, assim; } \square \text { mesmo }\end{array}$} \\
\hline \multirow[t]{2}{*}{ DLEE } & & DLELP (p. 284) \\
\hline & & $\begin{array}{l}\text { mesmo assim Apesar de tudo; apesar disso; } \\
\text { ainda assim. }\end{array}$ \\
\hline DRAE & & AURÉLIO (versión digital) \\
\hline & & $\longrightarrow$ \\
\hline \multicolumn{3}{|c|}{ Solución: Uso de "aun así". } \\
\hline
\end{tabular}

Tabla 123: Calco 9: Mismo así.

En esta locución ejemplo, como en otras anteriores con mismo, vemos también que la docente utiliza una UF traducida literalmente de su lengua materna. Si acudimos al DIBU y al DLELP, comprobamos que en portugués mesmo assim tiene su correspondencia con aun así del español, lengua en la que, sin embargo, no existe la UF mismo así. Una vez más, la similitud formal y semántica entre los vocablos mismo y mesmo lleva a los hablantes brasileños a la sustitución de uno por otro, por influencia de su lengua materna. Hay que resaltar que este error ocurre en 3 ocasiones en el habla de dos sujetos diferentes (D6=2; $D 7=1)$. 


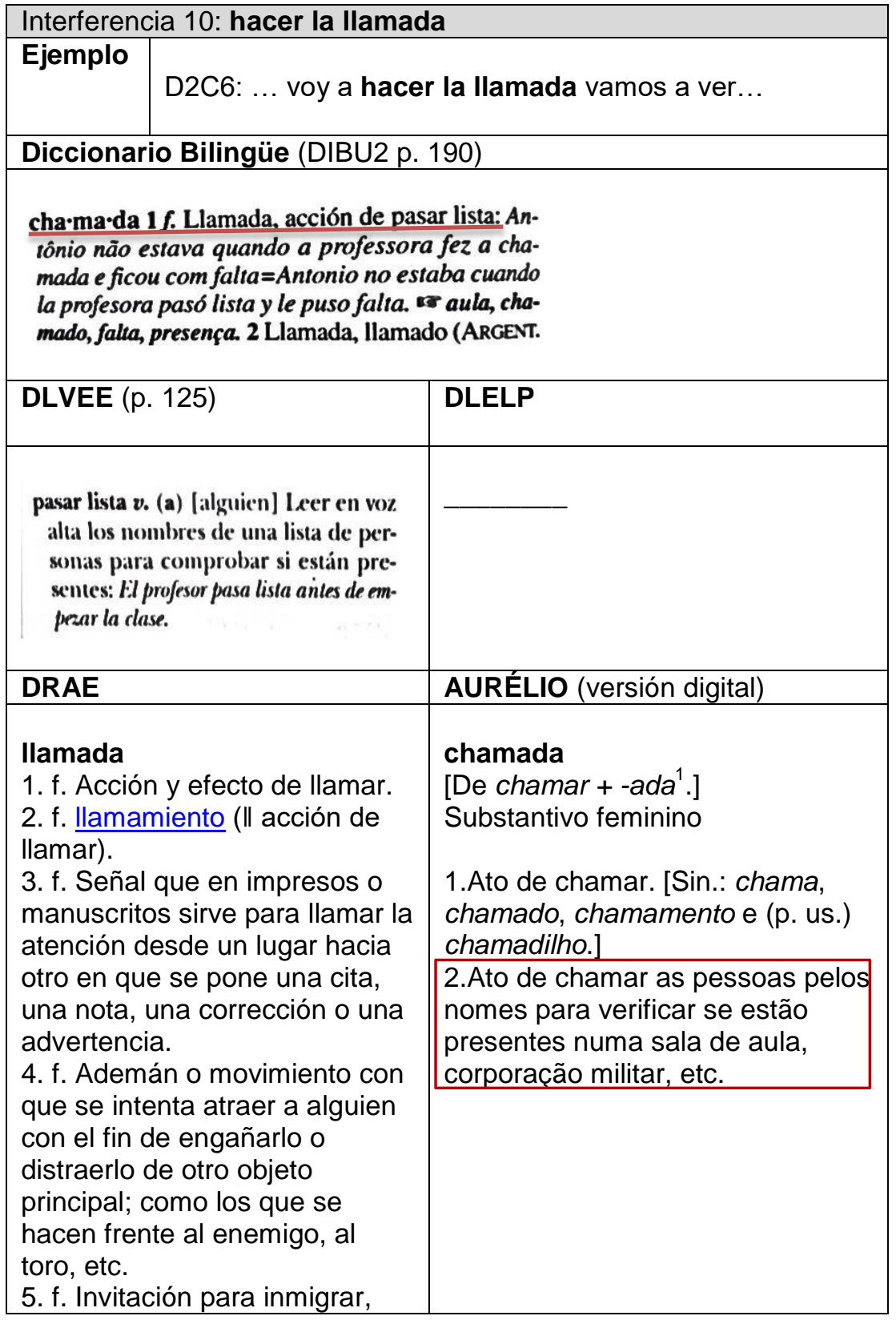


dirigida al futuro emigrante, con pago del viaje y envío de billete que se denomina de llamada.

6. f. Mil. Toque para que la tropa entre en formación.

7. f. Mil. Señal que, tocando el clarín o la caja, se hacía de un campo a otro para parlamentar. 8. f. Ur. Toque de los tamboriles de las agrupaciones lubolas.

9. f. pl. Desfile típico del carnaval de Montevideo realizado por un conjunto de personas de raza negra al compás de tamboriles.

Extraído de: ?id=NTKgd80 accedido el 15/08/16

Solución: Uso de la locución verbal "pasar lista" española.

Tabla 124: Calco 10: Hacer la llamada.

En este caso, ocurrido tres veces en el habla de la docente D2, vemos que esta realiza una traducción literal de una expresión de su lengua materna, fazer a chamada, que, como comprobamos en el AURÉLIO, es el acto de llamar por el nombre a las personas presentes en una clase. Como observamos en los diccionarios de lengua española consultados, hacer la llamada no existe en español con este sentido. De hecho, de las 9 acepciones encontradas para "llamada" en el DRAE, ninguna incluye este sentido. Sin embargo, y como nos recuerda el DIBU, existe una locución para ese mismo acto, que es pasar lista. Asimismo, el DLVEE señala esa identificación entre el español pasar lista y el portugués fazer a chamada, es decir, leer en voz alta los nombres de una lista con el fin de comprobar si las personas están presentes. 


\begin{tabular}{|c|c|c|}
\hline \multicolumn{3}{|c|}{ Interferencia 11: dar una mirada } \\
\hline Ejemplo & \multicolumn{2}{|c|}{ D2C6: ... dé una miradita en la página cuarenta... } \\
\hline \multicolumn{2}{|c|}{$\begin{array}{l}\text { Diccionario Bilingüe (DIBU1 } \\
\text { (p. 562) }\end{array}$} & (DIBU2 p. 790) \\
\hline \multicolumn{2}{|c|}{$\begin{array}{l}\text { prá-la. or fjar; Dechar un ojo, dar uma olhada: } \\
\text { échale un ojo al bebé mientras me lavo=dá uma } \\
\text { olhada no bebê enquanto eu tomo banho. } 18 \text { mirur, } \\
\text { vigilar; } \square \text { entrar por los ojos } \mathrm{NFOR} \text {. FG., encher os }\end{array}$} & $\begin{array}{l}\text { o-lha-da } 1 \text { f. Ojeada, mirada: Mercedes foi dar uma } \\
\text { othada nas crianças=Mercedes fue a echarles una } \\
\text { ojeada a los niños. we espiada, olhar, olho. } 2 \text { Ojea- } \\
\text { da, vistazo: dei uma olhada no relatório e me pa- } \\
\text { receu muito bom=le eché un vistazo al informe y } \\
\text { me pareció muy bueno. us exame, vista. Se usa } \\
\text { mucho en la expresión dar uma olhada. Se dice } \\
\text { también olhadela. }\end{array}$ \\
\hline DLVEE ( & 64) & DLELP (p. 128) \\
\hline \multicolumn{2}{|c|}{$\begin{array}{l}\text { echar el ojo v. (i) infor. [alguien, a al- } \\
\text { go/alguien] Mirar con atención la una } \\
\text { personal o una cosa, mostrando de- } \\
\text { seo de tenerla: Le he echado el ojo a un } \\
\text { abrigo de lana, pero esperare a las rebajas } \\
\text { para comprarlo; El director general le ha- } \\
\text { bia echado el ojo para que dirigiera los in- } \\
\text { formativos. }\end{array}$} & $\begin{array}{l}\text { dar uma olhadela Olhar rapidamente, num } \\
\text { relance. Var. "dar uma olhadinha". }\end{array}$ \\
\hline \multicolumn{2}{|l|}{ DRAE } & AURÉLIO (versión digital) \\
\hline \multicolumn{2}{|c|}{$\begin{array}{l}\text { ojo } \\
\text { Del lat. ocŭlus. } \\
\text { echar el ojo, o tanto ojo, a } \\
\text { alguien o algo } \\
\text { 1. locs. verbs. coloqs. Mirarlo } \\
\text { con atención, mostrando }\end{array}$} & $\begin{array}{l}\text { olhada } \\
\left.\text { [De olhar }+-a d a^{1} .\right] \\
\text { Substantivo feminino } \\
\text { 1.V. espiada (1). }\end{array}$ \\
\hline
\end{tabular}




\begin{tabular}{|l|l|}
\hline deseo. & $\begin{array}{l}\text { espiada } \\
\text { Extraído de: ?id=QyF9sGX } \\
\text { accedido el } 07 / 03 / 2016\end{array}$ \\
& $\begin{array}{l}\text { Substantivo feminino Bras. } \\
\text { 1.Ato de espiar }{ }^{1} \text { (3); olhada, } \\
\text { espiadela. } \\
\text { 2.Ato de espiar ou olhar } \\
\text { ligeiramente; olhadela, olhadura, } \\
\text { espiadela. }\end{array}$ \\
\hline Solución: Uso de "echar una ojeada". \\
\hline
\end{tabular}

Tabla 125: Calco 11: Dar una miradita.

En la situación en que se desarrolla el ejemplo reseñado (y que repite en otra ocasión la misma hablante), la profesora pide a un alumno que mire una determinada página del libro, utilizando para ello la UF dé una miradita. Creemos que esta locución es una traducción de la UF portuguesa dar uma olhada (o en su diminutivo dar uma olhadinha), que significa, conforme al AURÉLIO y el DLELP, mirar algo superficialmente. La relación entre la UF de la lengua materna y la forma interferida utilizada por la docente la podemos comprobar a través del diccionario DIBU, el cual nos presenta en la entrada de olhada la correspondencia con echar una ojeada, ambas con el sentido de "mirar brevemente algo". Otras opciones para el español podrían haber sido echar un/el ojo o echar un vistazo, como nos revelan los diccionarios DIBU1 y DLVEE.

La relación mirada-ojeada-olhada ocurre porque es muy común entre los usuarios brasileños de español como lengua extranjera que confundan los pares de ambas lenguas mirar-ver (español) y olhar-ver (portugués). De este modo, es habitual que realicen la analogía mirar=olhar; ver=ver. Esta sobregeneralización explica casos como el analizado, donde la docente traduce mentalmente dar uma olhadinha por dar una miradita ${ }^{180}$.

${ }^{180}$ Confusiones con los vocablos mirar/olhar también se relataron en la investigación de Andrade (2010, p. 175). 


\begin{tabular}{|c|c|c|}
\hline \multicolumn{3}{|c|}{ Interferencia 12: sentir falta } \\
\hline Ejemplo & \multicolumn{2}{|c|}{$\begin{array}{l}\text { D5C2: pero yo sentí mucha falta del sombrerero } \\
\text { loco...// }\end{array}$} \\
\hline \multicolumn{3}{|c|}{ Diccionario Bilingüe (DIBU1 p. 263) } \\
\hline \multicolumn{3}{|c|}{$\begin{array}{l}\text { e-char } \\
\text { empezar; } \square \text { echar de menos, sentir/notar a/dar pela } \\
\text { falta: en la cena familiar echamos de menos a Ma- } \\
\text { ría=no jantar de família sentimos falta da Maria; } \\
\text { echo de menos mi falda: seguro que la tiene mi her- } \\
\text { mana=estou notando a falta da minha saia: apos- } \\
\text { to como está com a minha irmã; } \square \text { echar de me- } \\
\text { nos/en falta, sentir/ter/estar com/ficar com sau- } \\
\text { dade(s): el poeta exiliado echaba de menos a su } \\
\text { país o o poeta exilado tinha saudade( } s \text { ) de seu } \\
\text { país; echó en falta a su novio cuando se fue de via- } \\
\text { je=sentiu saudades do namorado cuando foi viajar. } \\
\text { en añorar, extrañar, nostalgia, añoranza; } \square \text { echar } \\
\text { en falta, sentir/notar (a)/dar pela falta: cuando se } \\
\text { fue a vivir sola, echaba en falta los mimos de su } \\
\text { madre=quando foi morar sozinha sentia falta dos } \\
\text { mimos da mãe. añorar, extrañar, nostalgia, año- } \\
\text { ranza; } \square \text { echarse atrás, voltar atrás, dar para trás, }\end{array}$} \\
\hline DLVEE $(p$ & $63-64)$ & DLELP \\
\hline $\begin{array}{l}\text { echar de me } \\
\text { alguien] } \\
\text { sona o de }\end{array}$ & $\begin{array}{l}\text { nos } v \text {. (i) [alguien, algo/a } \\
\text { bservar la falta de una per- } \\
\text { una cosa: Echaba de menos }\end{array}$ & \\
\hline $\begin{array}{l}\text { las tardes } p \\
\text { Echo de mes } \\
\text { echar en fa } \\
\text { adverbios } \\
\text { los elemen } \\
\text { salgo de vias } \\
\text { crios. }\end{array}$ & $\begin{array}{l}\text { sadas en vuestra compañia; } \\
\text { os el bullicio de esa calle. } \\
\text { ta. o Suelen intercalarse } \\
\text { omo mucho o tanto entre } \\
\text { os de la locución: Cuando } \\
\text {, echo mucho de menos a los }\end{array}$ & \\
\hline DRAE & & AURÉLIO (versión digital) \\
\hline
\end{tabular}




\section{echar}

Del lat. iactāre.

echar de menos algo o a alguien

1. loc. verb. Advertir o notar su falta.

2. loc. verb. Tener sentimiento y pena por su falta.

Extraído de: ?id=EJtx4Yo accedido el 29/03/16;

\section{falta}

Del lat. vulg. fallita.

\section{echar en falta}

1. loc. verb. Echar de menos.

Extraído de: $\underline{\text { ?id }=\mathrm{HZKtGsK}}$ accedido el 29/03/16.

\section{Solución: Uso de las locuciones "echar de menos" o "echar en} falta".

Tabla 126: Calco 12: Sentir falta.

En este caso la docente les decía a los alumnos que en su presentación se habían olvidado de incluir un personaje que era el "sombrero loco". Para ello, utiliza sentir falta, en "yo sentí mucha falta del sombrerero loco". Sentir falta es una UF que no está recogida en ninguna de las obras de la lengua portuguesa consultadas. No obstante, como hablante nativa de portugués sabemos que es de uso coloquial y su significado tiene relación con "notar la falta de algo o alguien".

Como vemos en el DRAE, hay dos locuciones en español que se ajustan al sentido que la docente quiere dar. Estas serían: echar de menos o echar en falta. Tanto para el DRAE, como para el DLVEE, estas dos locuciones son sinónimas y, por tanto, ambas podrían utilizarse en el ejemplo en cuestión. Tales expresiones también están recogidas en el DIBU1, y ambas presentan el sentido utilizado por la docente "sentir/notar la falta de algo o alguien", lo que confirma que tanto una como otra podrían emplearse en el 
contexto mencionado. Este error ocurre una sola vez en boca de la docente D5.

\subsection{Calco 13: A cata}

\begin{tabular}{|c|c|c|}
\hline \multicolumn{3}{|c|}{ Interferencia 13: a cata } \\
\hline Ejemplo & \multicolumn{2}{|c|}{$\begin{array}{l}\text { E: ah... que me contabas... que en vacaciones te } \\
\text { encuentras con argentinos... } \\
\text { D3E: sí... en vacaciones hay muchos argentinos... } \\
\text { paraguayos que pasan por acá... van a la playa... en } \\
\text { la playa también hablo con ellos... } \\
\text { E: ¿sí? } \\
\text { D3E: Sí... yo estoy siempre a cata...// }\end{array}$} \\
\hline \multicolumn{2}{|c|}{$\begin{array}{l}\text { Diccionario Bilingüe (DIBU1 p. } \\
\text { 123) }\end{array}$} & DIBU2 (p. 178) \\
\hline \multicolumn{2}{|c|}{ 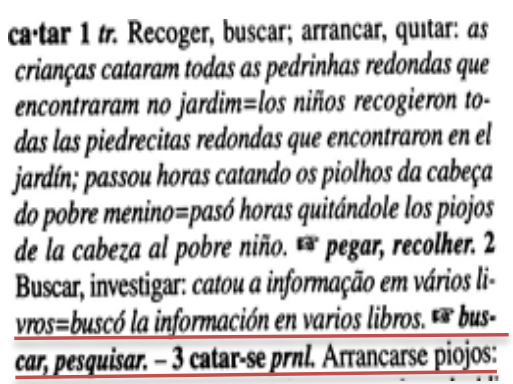 } & $\begin{array}{l}\text { cartar } 1 \text { th. Provar, degustar: a Felipe le gusta mucho } \\
\text { catar los vinos= Felipe adora degustar vinhos. a } \\
\text { degustar. } 2 \text { Crestar, tiraslextrair mel (da colméia): el } \\
\text { apicultor cataba las colmenas con una espátula =0 } \\
\text { apicultor crestava as colméias com uma espárula. } \\
\text { castrar, extraer. O Como } 3 \text {. }\end{array}$ \\
\hline \multicolumn{2}{|l|}{ DLEE } & DLELP (p. 2) \\
\hline \multicolumn{2}{|c|}{ 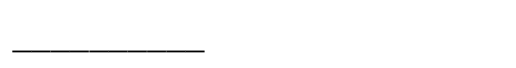 } & à cata de Ã procura de; em busca de. \\
\hline \multicolumn{2}{|l|}{ DRAE } & AURÉLIO (versión digital) \\
\hline \multirow{2}{*}{\multicolumn{2}{|c|}{$\begin{array}{l}\text { cata1 } \\
\text { 1. f. Acción y efecto de catar. } \\
\text { 2. f. Porción de algo que se } \\
\text { prueba. } \\
\text { 3. f. desus. Cordel con un } \\
\text { plomo en un extremo, para } \\
\text { medir alturas. }\end{array}$}} & $\begin{array}{l}\text { cata } \\
\text { [Dev. de catar2.] } \\
\text { Substantivo feminino }\end{array}$ \\
\hline & & $\begin{array}{l}\text { 1.Ação ou efeito de catar; busca } \\
\text { procura, catação. } \\
\text { 2.Bras. Separação dos grãos }\end{array}$ \\
\hline
\end{tabular}




\section{dar cata}

1. loc. verb. Buscar, procurar.

2. loc. verb. coloq. Mirar o advertir.

\section{darse cata de algo}

1. loc. verb. Percatarse de ello.

\section{echar cata}

1. loc. verb. desus. Mirar o buscar con cuidado.

\section{cata2}

1. f. Arg., Bol. y Col. Acción de catear (II buscar una veta minera).

\section{cata3}

Acort. de Catalina, apodo aplicado a esta ave.

1. f. Bol. y Chile. Cotorra, perico.

\section{cata4}

Acort. de catapulta.

1. f. Ec. tirachinas.

Extraído de

http://dle.rae.es/?id=7srabDf|7s sruzX|7strQC5|7svGSd9 el 11/04/2016.

\section{catear1}

De cata1.

1. tr. Buscar, descubrir, espiar, acechar.

2. tr. Am. Allanar la casa de alguien.

3. tr. Arg., Bol., Chile, Cuba, Ec., Méx., Par., Perú, R. Dom., Ur. y Ven. Explorar terrenos en busca de alguna veta minera. 4. tr. p. us. Buscar, procurar, solicitar. enegrecidos e mirrados do café. 3.Escavação mais ou menos profunda, conforme a natureza do terreno, para mineração.

À cata de. 1.À procura de; em busca de:

"Fui à cata de rútilas grandezas, I Palácios de ouro, homens leais, moças divinas, / E só achei infâmias e torpezas" (Eugênio de Castro, Obras Poéticas, II, p. 35). 
Extraído de y

http://dle.rae.es/?id=7vnzbvh el

11/04/2016.

Solución: Uso de "dando cata"

Tabla 127: Calco 13: A cata.

En esta ocasión - por lo demás única en los discursos analizados - la docente explicaba que en la cuidad donde vive hay pocas posibilidades de practicar el idioma y por eso está constantemente buscando nativos de lengua extranjera con quienes conversar. Como advierten tanto el DLELP como el AURÉLIO, la expresión utilizada "à cata de" es portuguesa y significa buscar algo. No obstante, ni el DIBU, ni el DLEE, ni tampoco el DRAE recogen esta UF. Como alternativa, encontramos en el DRAE la locución dar cata (loc. 1 en la entrada de cata1).

Probablemente la expresión de D3 esté ligada al hecho de que el verbo catar en portugués tiene como uno de sus valores el sentido de 'buscar', subrayado en la entrada de DIBU1. Sin embargo, si vamos al mismo verbo del español, comprobamos que este valor no existe. Este mismo sentido estaría relacionado más bien con el verbo catear en su primera acepción: buscar, descubrir, espiar, acechar (también marcada en la tabla 127).

Así pues, llegamos a la conclusión de que dar cata sería la UF que más se asemeja a la expresión utilizada por la docente à cata y por este motivo debería ser utilizada en el contexto que acabamos de analizar, aunque catear igualmente podría cumplir la misma función semántica. Otra opción -más frecuente que la señalada por el diccionario- sería, sencillamente, el empleo del verbo "buscar".

\subsection{Calco 14: Consejo de clase}

\section{Interferencia 14: consejo de clase}

Ejemplo D5E: sí... nosotros tenemos los consejos de clase... pero eso es una vez al trimestre...

Diccionario Bilingüe (DIBU1 p. $\quad$ DIBU2 (p. 242) 
con'se·jo $1 \mathrm{~m}$. Conselho, parecer, opinião, recomendação: los consejos de mis padres son muy sabios=os conselhos dos meus pais são muito sá-

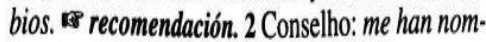
brado miembro del consejo editorial de una re. vista=fui nomeado membro do conselho editorial de uma revista; consejo de administración, conselho administrativo: en el consejo de administración se definirán las estrategias de la empre$s a=$ no conselho administrativo serão definidas as estratégias da empresa. consejero; consejo de con'se'lho $1 \mathrm{~m}$. Consejo: o irmão mais velho tenta. va dar bons conselhos aos mais jovens=el herma. no mayor intentaba dar buenos consejos a los me. nores; minha mãe insiste em desrespeitar os conselhos de seu médico=mi madre insiste en no seguir los consejos de su médico. aconselhar, conselheiro. 2 Consejo, asamblea: os profissionais da área de química têm um conselho que os repre. senta=los profesionales del área de química tienen un consejo que los representa. assembléia, co. missão, conselheiro, ordem.

\section{DLELP}

\begin{tabular}{|l}
\hline DLEE \\
\hline \\
\hline DRAE \\
\hline consejo \\
Del lat. consilium.
\end{tabular}

1. m. Opinión que se expresa para orientar una actuación de una determinada manera.

2. m. Órgano colegiado con la función de asesorar, de administrar o de dirigir una entidad. Consejo económico y social, escolar.

3. m. Reunión de los miembros de un consejo. La decisión se tomó en el último consejo de administración.

4. m. Órgano superior de gobierno que asistía al rey en la administración del reino y la justicia, y que tomaba el nombre del territorio o la materia de su competencia. Consejo de

\section{AURÉLIO (versión digital)}

\section{conselho}

(ê) [Do lat. consiliu.]

Substantivo masculino

1.Parecer, juízo, opinião.

2.Advertência que se emite; admoestação, aviso:

Siga meu conselho: não se precipite.

3.Senso do que convém; tino, prudência, aviso:

homem de bom conselho.

4.Tribunal (7).

5.Reunião ou assembléia de ministros.

6.Corporação à qual incumbe opinar ou aconselhar sobre certos negócios públicos: conselho de saúde; conselho de economia.

7.Reunião de pessoas para 


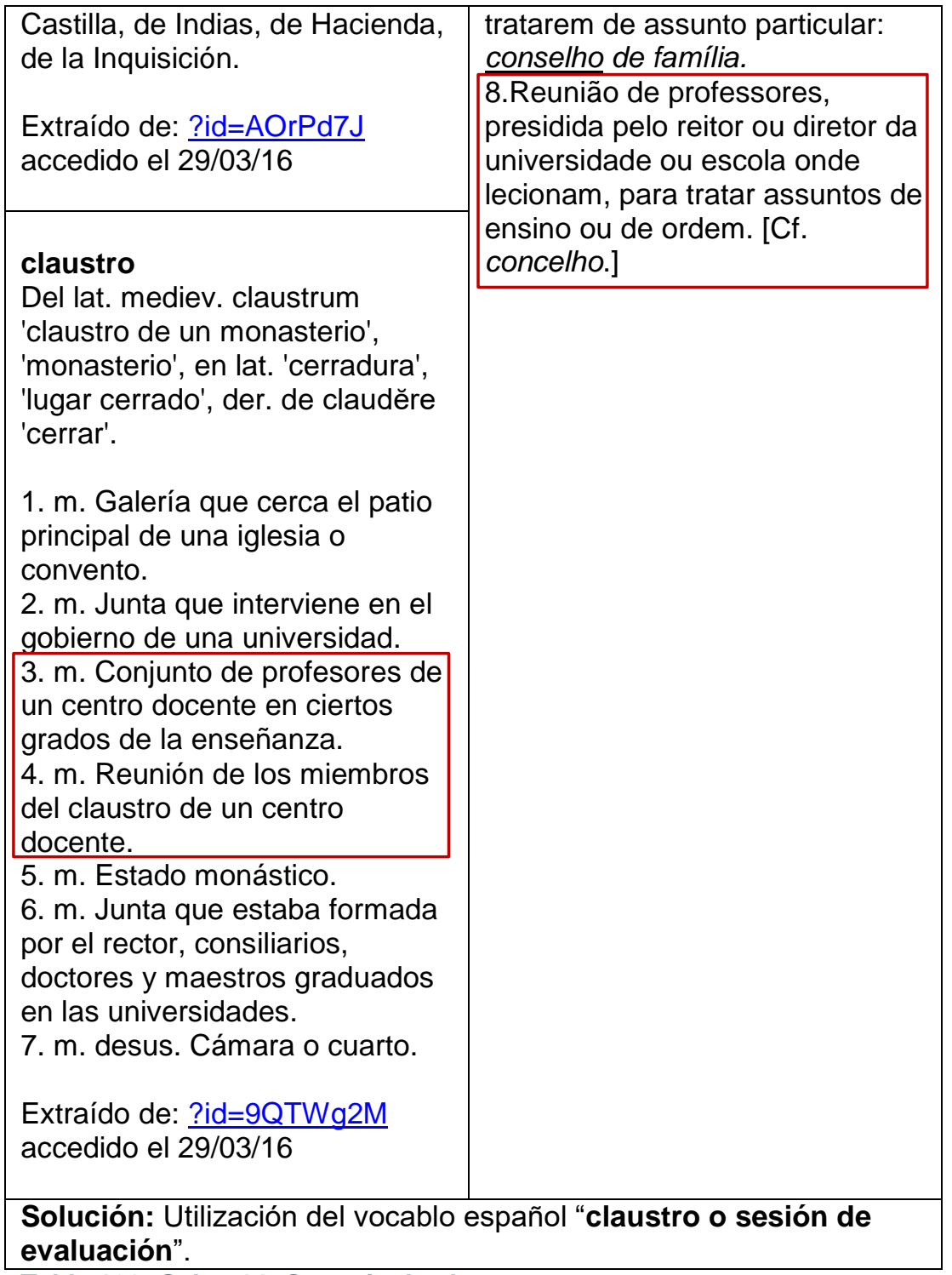

Tabla 128: Calco 14: Consejo de clase.

Para entender la expresión consejo de clase - utilizada una vez por la docente D5 - debemos empezar por analizar la transferencia de la lengua materna del nombre masculino conselho 
(consejo), la cual encontramos en la acepción 8 del diccionario AURÉLIO. En este el término se define como una "reunión de profesores para tratar temas de enseñanza u orden". Aunque no esté explícitamente señalada en el diccionario, este tipo de reuniones, principalmente las presididas por los coordinadores pedagógicos de las escuelas, y en las que se discute sobre las características de los alumnos (ya sean pedagógicas, de aprendizaje, comportamiento u otras), también se llaman comúnmente conselho de classe en las comunidades escolares brasileñas. Esas reuniones suelen ocurrir al final de cada bimestre, trimestre o semestre. $Y$ es a estas reuniones a las que se refiere la docente en cuestión.

Tanto el diccionario bilingüe DIBU como el diccionario de la DRAE nos remiten a la noción de consejo como reunión o asamblea de los miembros de un grupo, sin hacer referencia al tipo de reunión a que nos referimos. No obstante, por experiencia personal, sabemos que, al menos en España, el término apropiado para este tipo de reuniones, donde los profesores se sientan para discutir sobre los alumnos específicamente se llama sesión de evaluación. Asimismo, existe claustro, aunque su sentido está limitado a la reunión de profesores para otros menesteres distintos de la evaluación docente. De esta manera, hemos buscado en el DRAE las definiciones para estos términos y hemos encontrado únicamente la de claustro, la cual parece encajar tan solo parcialmente con la noción de conselho de classe del portugués. No obstante, a nuestro juicio, la noción de sesión de evaluación es la más apropiada para el tipo de reunión a la que se refiere la profesora.

Consideramos, por tanto, que la docente acudió una vez más a su lengua materna para emplear una UF en la que el núcleo del sintagma, consejo comparte algunas acepciones en los dos idiomas. De esta manera, la hablante acaba traduciendo conselho de classe como consejo de clase, creando así una UF inexistente en la LO.

Señalemos, por último, que los diccionarios consultados no han sido demasiado esclarecedores en este punto $\mathrm{y}$, con toda seguridad, no habrían servido para resolver potenciales dudas a los usuarios ( $\mathrm{y}$ ello pese a su uso tan extendido en la comunidad escolar). 


\section{ALGUNAS CONCLUSIONES Y CONSIDERACIONES FINALES}

Al principio de este trabajo exponíamos que su origen estuvo ligado a unas razones personales muy concretas, las cuales nos llevaron a trasladar unas impresiones iniciales sobre la incidencia de la LM en la LE a la investigación de la interferencia del portugués en el discurso oral de profesores de español como lengua extranjera en Brasil. Así, partiendo de unas percepciones individuales observadas en un contexto de inmersión, supusimos que la interferencia también ocurriría en contextos de aprendizaje formal en los que el acceso al input está mucho más restringido y donde una serie de factores que confluyen en el aprendizaje son claramente distintos a los que caracterizan los entornos de inmersión.

Para llevar a cabo nuestros objetivos, hemos dividido el trabajo en dos partes, una teórica y otra práctica. En la primera, hemos realizado un recorrido por los diferentes presupuestos teóricos que han servido como soporte a nuestro estudio, empezando por establecer los principios sobre el aprendizaje de las lenguas extranjeras en el primer capítulo. Ya en el segundo se han abordado las nociones de interlengua y los tipos de interferencia, así como la discusión en torno al análisis contrastivo y de errores. En el capítulo 3, hemos discutido las particularidades que entraña aprender un idioma próximo y en especial el caso del portuguésespañol. Ya en el cuarto, hemos delimitado el concepto de error que nos ha servido como guía para el análisis empírico, y hemos presentado la clasificación de errores utilizada en el estudio. Finalmente, en el capítulo 5, el último del bloque teórico, hemos disertado sobre algunas cuestiones relacionadas con las unidades léxicas que analizamos posteriormente.

El bloque práctico comienza con el capítulo 6, donde presentamos los aspectos metodológicos de nuestra investigación y que sirve como preámbulo al apartado 7 , donde se exponen los resultados del estudio empírico de los errores.

En el presente capítulo sintetizamos los principales resultados obtenidos, al tiempo que realizaremos diversas consideraciones sobre la enseñanza y aprendizaje del ELE por brasileños. 


\subsection{Nuestras hipótesis y objetivos}

Como señalamos al comenzar esta investigación, nuestra hipótesis principal se basaba en la idea de que, debido a la proximidad lingüística, la lengua materna era la principal causante de los errores de los brasileños docentes de ELE, y que ello se demostraría mediante la identificación y el recuento de los errores intra e interlingüísticos cometidos por los sujetos objeto de estudio. Pues bien, una vez obtenidos y analizados los resultados, hemos constatado que, efectivamente, el portugués ha sido, con diferencia, el principal causante de los desvíos en el habla de los sujetos analizados, hecho que corrobora con cierta rotundidad nuestra intuición inicial.

Este hallazgo confirma los dos primeros objetivos generales que nos marcamos al principio: a) averiguar si en el discurso oral de la población estudiada, profesores de español como lengua extranjera, se presentaban errores de interferencia de la lengua materna; y b) verificar si los errores de interlingüísticos son más frecuentes que los intralingüísticos.. En relación a este último objetivo, la divergencia cuantitativa no deja lugar a dudas: $81 \%$ de errores interlingüísticos, frente a apenas un $19 \%$ de errores intralingüísticos, magnitudes, además, que se mantienen en una proporción similar en los dos contextos de recogida del corpus (clases y entrevistas), lo que afianza la robustez de nuestras conclusiones.

Asimismo, teníamos un tercer objetivo general, que consistía en explicar los errores interlingüísticos más frecuentes, una tarea que hemos cumplido también mediante el análisis cualitativo de los errores léxicos a partir de su cotejo con las obras lexicográficas más relevantes en el ámbito portugués (PB) español.

Por otro lado, de este último objetivo general se desprendían varios objetivos específicos cuyo contenido completa el resto de la investigación. Así, para la identificación de los errores intra e interlingüísticos, nuestro primer objetivo específico, hemos acudido a los principios y métodos del análisis de errores y de la lingüística contrastiva, lo que nos ha permitido crear dos bancos de errores para cada sujeto y en cada contexto de recogida, los cuales están disponibles en los anexos 6 y 7 .

Nuestro segundo objetivo específico consistía en delimitar los errores interlingüísticos más frecuentes y clasificarlos por categorías gramaticales. Para ello realizamos un recuento minucioso de cada error en el contexto en que se realizó. Eso nos permitió 
comprobar que los errores de interferencia más frecuentes han sido los relativos a nexos y formas periféricas (36\%), aunque creemos que a ello ha podido contribuir el empleo abusivo de algunos marcadores discursivos, como "né" y "tá". El verbo, en segundo lugar, es otro de los principales componentes transferidos (22\%), seguido por el grupo más heterogéneo de "otros", que incluía adjetivos, sustantivos, heterosemánticos y unidades fraseológicas (15\%). Por su parte, categorías menos frecuentes fueron las relacionadas con determinantes y adverbios (ambos con 9\%), pronombres $(8 \%)$ y la flexión nominal $(1 \%)$.

Nuestro tercer objetivo era identificar los tipos de errores interlingüísticos de carácter léxico-semántico y su frecuencia en el corpus. En relación con esto, hemos constatado que los errores de sustitución (incluyendo la sustitución directa y la analogía) son, con diferencia, los más frecuentes $(93 \%)$, frente a cifras mucho más reducidas la para la creación de palabra nueva (4\%) y el calco (3\%).

Por otro lado, parece claro que la transferencia ocurre más significativamente entre vocablos que se parecen entre sí. Es decir, si la máxima "cuanto más parecidas son las lenguas, mayor es la interferencia entre ellas", que aparece recurrentemente en la bibliografía es real, como hemos tenido ocasión de comprobar en nuestra revisión teórica, lo mismo se puede aplicar a niveles inferiores como el léxico: cuanto más parecido hay en la forma de los vocablos y locuciones, mayor es la probabilidad de que se produzca la interferencia. Este principio es especialmente destacable en los casos de transferencia directa, donde los elementos interferenciales más frecuentes son aquellos que guardan una mayor relación formal entre las dos lenguas. Este hecho nos llama especialmente la atención, puesto que en un principio llegamos a sospechar que los vocablos transferidos serían, por el contrario, aquellos formalmente más distantes.

Otro dato que nos ha llamado la atención tras el correspondiente estudio empírico es que, independientemente del tipo de error, hay una mayor prevalencia de la variedad que de la sistematicidad en la comisión de errores. Esto contradice nuestra hipótesis inicial de que los diferentes tipos de interferencia podrían ser sistemáticos, puesto que las docentes tienen una formación similar. Por otro lado, interpretamos este hallazgo como un hecho más que corrobora que no son algunas formas específicas del español las que causan dificultades a los brasileños aprendices de esta LE, sino su propia LM, la cual opera en todos los niveles del análisis. Por este motivo, no hemos podido detectar una lista extensa de errores fosilizables, si bien algunos ítems concretos, 
como "né" (104 ocurrencias), "tá" ( $n=68)$ o "é" ( $n=52)$, por ejemplo, parecen tener cierta propensión a ello.

Un cuarto objetivo específico hacía referencia al análisis y contraste de los errores léxicos a fin de comprobar su origen etiológico. Esta tarea hemos podido llevarla a cabo con la ayuda de diferentes obras lexicográficas, teniendo como base los presupuestos teóricos del análisis de errores y la lingüística contrastiva. Consideramos que hemos cumplido esta tarea, aunque no sin algunas dificultades. Estas tienen que ver con nuestro último objetivo específico: comprobar de qué manera los diferentes diccionarios especializados tratan los errores de interferencia léxica aquí analizados.

En relación con este último punto, quisiéramos resaltar algunos hechos respecto a los diccionarios especializados en los heterosemánticos. Aunque hayamos utilizando tres obras especializadas para esta tarea (FEIJÓO HOYOS, 1992; BECHARA Y MOURE, 2002; MONTE, 2003), no hemos podido dar cuenta a través de ellas de un amplio $44 \%$ de los errores de sustitución por analogía. Esto nos lleva a la reflexión sobre al menos tres aspectos diferentes: (i) las diferentes obras conciben los heterosemánticos de diferentes maneras (falsos cognados, falsos amigos, etc.), de ahí que algunos vocablos aparezcan una veces y otras no; (ii) al ser diccionarios de bolsillo tienen un número de vocablos bastante reducido y por ello muchos de los heterosemánticos que hemos encontrado en el corpus no constaban en esas obras; (ii) cuando encontramos los vocablos en estos diccionarios, las explicaciones no siempre facilitaban la comprensión al lector. En este sentido creemos que diccionarios más recientes y ambiciosos como el DIFAPE (DURÃO ET AL, 2014), al que nos referíamos en el Capítulo 5, pueden ser de gran utilidad para suplir esa carencia en el mercado editorial brasileño, y facilitar así el estudio contrastivo entre las lenguas española y portuguesa.

Con todo, donde más dificultades hemos tenido ha sido en la resolución de los errores de calco, puesto que, hasta donde llega nuestro conocimiento, no existe un diccionario bilingüe de locuciones portugués-español y, por ello, es más difícil que se pueda estudiar este tipo de unidades fraseológicas de manera comparativa. De esta manera, los diccionarios especializados monolingües han sido fundamentales tanto para explicar las unidades fraseológicas como para demonstrar la interferencia de la LM.

Hay que añadir que en estos dos casos (tanto en el de los errores de analogía, donde casi la mitad no constaba en las obras consultadas, como en los de calco, en los que no había ninguna 
obra de referencia portugués-español), el conocimiento bilingüe de la investigadora ha sido muchas veces determinante, tanto para identificar como para explicar los errores encontrados (con el auxilio, claro está, de la correspondiente consulta a los principales diccionarios monolingües de referencia).

Otra apreciación tiene que ver con el hecho de que, en algunos casos, como, por ejemplo, el de "galera" (solución del DIBU: gente), "leyenda" (solución del DFA y DIL: historia de vida de un santo) y "à cata" (solución basada en el DRAE: dando cata), nuestro conocimiento como usuarios del español peninsular nos inclina a pensar que la correspondencia ofrecida por los diccionarios no se ajusta necesariamente al uso de esos vocablos. No obstante, necesitaríamos hacer un estudio diferente al emprendido aquí para confirmar tales impresiones, tarea que reservamos para el futuro.

Finalmente, nos gustaría hacer una mención especial al diccionario DIBU, sin el cual muchos de nuestros análisis no hubieran sido posibles. En él hemos podido encontrar una buen aparte de los vocablos analizados, lo que es bastante impresionante si tenemos en cuenta la limitación física natural de las obras lexicográficas. Incluso pudimos hallar entre sus páginas algunos de los vocablos y unidades fraseológicas que no aparecían en las obras especializadas en locuciones y heterosemánticos. Además, los ejemplos, explicaciones y correspondencias nos sirvieron muchas veces bien para comprobar algunas intuiciones, bien para descartar otras. Sin la calidad que emerge de esta obra, manifestada en los aspectos reseñados, sería prácticamente imposible llevar a cabo el trabajo que realizamos.

\subsection{Limitaciones del estudio}

Aunque hayamos destacado las limitaciones típicas del Análisis de Errores en diferentes partes de esta tesis (en especial en los capítulos 2 y 4), quisiéramos retomar aquí algunas de las que consideramos más significativas tras la realización de nuestro estudio.

La primera de ellas tiene que ver con algunas características intrínsecas de la recolección de datos, las cuales tienen difícil solución, como, por ejemplo, la estrategias de evitación (ELLIS 2008, p. 61). Respecto a estas, hay que recordar que tan solo hemos podido recoger aquellos datos que aparecen en la superficie de las producciones de los sujetos, pero no otros que eventualmente han podido ser eludidos por aquellos, bien sea por inseguridad, bien 
por cualesquiera otras razones. Como es obvio, tales estructuras evitadas no pueden ser percibidas por el investigador. Estos errores ocultos, como los llamó Corder (1973b), resultan, pues, insolubles, ya que solo podemos acceder a aquellas parcelas del discurso que los sujetos permiten que veamos.

Además, recordemos que los errores encontrados son en su mayoría idiosincráticos. En primer lugar, porque, como señala Corder (1973b), no es posible afirmar que sean aciertos todos los aciertos, ni errores todos los errores; y, en segundo lugar, porque son la consecuencia de unas muestras de habla recogidas en un punto concreto del eje temporal, en el que intervienen muchos factores, tanto personales como motivados por el entorno: en el caso de las clases, por ejemplo, por el comportamiento de los alumnos, el contenido trabajado en clase, el tipo de actividades, etc.; y en el caso de las entrevistas, por las características del contexto donde tuvo lugar la conversación (si había ruido externo, interrupción de terceros, la presión del tiempo, etc.).

En este sentido, otro punto a considerar es lo que White (2003) denomina "confusión entre competencia y actuación":

But is in fact possible that L2 learners'
underlying competence in to some extent
hidden by performance factors, such as the
demands of processing or parsing. Knowledge
and use of knowledge do not always coincide.
In recent years, there has been an increase in
research which investigates how the
interlanguage mental representation is used on-
line and off-line an the extent to which
processing pressures may mask competence
(e.g. Juffs an Harrington, 1995; Schachter and
Yip, 1990). Again, this is an area where more
research is needed (WHITE, 2003, p. 37).

Como señala esta autora, no podemos olvidar que no siempre lo aprendido se expresa en la práctica. Por eso, tanto las características personales como el contexto de recogida del corpus deben tenerse en cuenta en el momento de interpretar los errores de actuación, puesto que no siempre están asociados al conocimiento que el hablante tiene de la lengua. La teoría del "filtro de salida" de Krashen (1985, p. 45), explicada en el Capítulo 1, igualmente retoma esta idea, según la cual no siempre conseguimos externalizar todo lo que sabemos cuando nos centramos en la forma y no en el contenido, al entrar en acción emociones como la ansiedad o el 
nerviosismo. Por ello, no podemos medir la competencia de los hablantes con base en apenas un instrumento (en este caso las grabaciones), y de ahí que subrayemos una vez más que los datos encontrados en este estudio son solo parciales, puesto que han podido estar condicionados por tales factores.

Otro aspecto reseñable, al cual hemos hecho referencia en diversas partes del trabajo, es que, al observar la interlengua de los sujetos, el analista usa su propio conocimiento lingüístico, el cual es, a su vez, inevitablemente limitado. Ello tiene como resultado un estudio condicionado por la competencia lingüística y comunicativa del investigador.

Igualmente representa una limitación importante el hecho de que las docentes hayan declarado que normalmente no hacen uso del español ni en su vida personal, ni en sus clases como vehículo de comunicación. En otras palabras, puede ser que muchos de los errores encontrados surjan porque no están acostumbradas a utilizar el idioma, lo que nos lleva a creer que lo hicieron de manera poco natural, sobre todo en las clases.

En definitiva, todo ello explicaría, al menos en parte, un uso tan frecuente del portugués como el que hemos detectado en el corpus. El debate sobre el empleo de la LM en clase de LE es prolijo $^{181}$ y podría ser asunto para toda otra tesis, motivo por el cual no lo desarrollaremos más aquí. Contentémonos con subrayar que, entre las docentes objeto de nuestra investigación, tal empleo es una práctica habitual, que a su vez explicaría la notable frecuencia de los errores en su habla, así como la recurrencia de algunos tipos en particular, especialmente de aquellos que tienen que ver con las actividades rutinarias de clase (sala por "aula"), aula (por "clase"), hacer la llamada (por "pasar lista"), etc.

\subsection{Consideraciones finales sobre la formación de profesores de ELE}

Una de las características de los estudios de caso como el presente es la posibilidad de generalizar sus hallazgos a otros campos afines al estudio en cuestión. De este modo, nos atrevemos a afirmar que los errores encontrados en el presente trabajo

\footnotetext{
${ }^{181}$ Véase, por ejemplo Ellis (1994); Merino (2012); Nussbaun (1991); Suby y Asención-Delaney (2009).
} 
(principalmente, los de carácter interlingüístico) tienen una probabilidad elevada de repetirse, puesto que los docentes brasileños en general parten de una misma LM y una formación inicial parecida. En otras palabras: a nuestro juicio, es bastante probable que la interlengua de los profesores de español en este país se vea seriamente afectada por la interferencia de la $L M$, hecho que hasta ahora no se había sido comprobado quizá de manera tan rotunda. $Y$, si esa influencia es tan grande (recordemos que encontramos un $80 \%$ de errores de interferencia en relación a los de otros tipos), deberíamos pensar necesariamente en cómo paliar la influencia negativa que el portugués tiene en el aprendizaje del español en nuestros cursos de formación inicial.

Por desgracia, esta idea no es nueva: Camorliga (1991), primer autor en investigar estos hechos interferenciales en Brasil postulaba, hace ya más de 25 años, que los cursos de grado deberían tener en cuenta los peligros que entraña la proximidad lingüística. En sus palabras: "una planificación de grado que tomara en consideración la proximidad lexical de la LM con la LE seguramente mejoraría la preparación profesional de los futuros profesores de español" (CAMORLINGA 1991, p. v. Traducción nuestra). Por su parte, Anicésio (2002) descubrió en sus entrevistas a profesores de español que un $60 \%$ de ellos se sentían inseguros en el empleo oral de la LE. Asimismo, estos mismos profesores apuntaron, en otra parte de la encuesta, que creían muy necesario que hubiera asignaturas de oralidad desde el principio hasta el final de la carrera (p. 72-73). Y cuando fueron interrogados acerca de qué asignaturas querrían que fueran mejoradas, hasta un $81 \%$ de los docentes respondió que las relativas a la lengua española y su oralidad (p. 74). Estos datos se corresponden plenamente con las dificultades encontradas por nosotros en el discurso oral de nuestras docentes.

Hay que recordar que, en Brasil, muchas veces los estudiantes ingresan en la universidad sin tener apenas nociones básicas de lengua española, o bien estas son demasiado elementales tras unos pocos años de estudio en la enseñanza media, como, de hecho, ocurre con la formación de los sujetos de nuestro estudio. De ahí las dificultades con que nos enfrentamos en nuestra profesión, la de formadores de profesores en el ámbito brasileño. En palabras de González (2004b), que hacemos nuestras:

“... los profesores de las carreras de Letras hacemos un verdadero milagro para formar, generalmente (en la mejor de las hipótesis) en 
cuatro años, un hablante, investigador y profesor de lenguas en general desconocidas o poco conocidas cuando el estudiante llega a la universidad-, ya sea por un error de interpretación de lo que significa formar un profesor y su consecuente reflejo en la estructuración de algunos cursos, que interpretan que el lugar central de dicha formación es la didáctica, interpretada como una técnica de enseñar, como metodología". (GONZÁLEZ, 2004b, p. 1)

De acuerdo con lo anterior, queda claro que nosotros, los formadores, tenemos muchas limitaciones en nuestra tarea diaria, las cuales, por cierto, darían para toda otra tesis. Entre las principales dificultades que se nos presentan, como bien señala González, está la de formar tanto a usuarios como a profesores de la lengua española en un mismo grado. Por otro lado, hemos comprobado cómo, en esa formación, la influencia de la lengua materna en el aprendizaje de lenguas próximas condiciona notablemente la interlengua de los aprendices, un hecho que observamos a diario en nuestras clases, pero que también hemos advertido -insospechadamente- en las muestras compiladas para la presente investigación.

En relación con esto, hemos obtenido unos datos que, si bien no estaban en nuestros objetivos iniciales, nos pueden dar una idea de la gravedad de la situación. Así, en la descripción de la muestra vimos cómo los sujetos habían estudiado un mismo grado, pero con una variación substancial en el número de horas de clase relacionadas con la lengua española. Por ello, hemos querido comprobar si el grupo que tuvo menos instrucción en la LE mostró al mismo tiempo más errores que el que recibió mayor instrucción. Los hallazgos nos dan que pensar: en el grupo 1 (con un total de 540 horas, en las cuales la lengua española era o bien el objeto de estudio o bien el vehículo de comunicación) el promedio de errores por participante fue de 213, mientras que en el grupo 2 (con un total de 920 horas, es decir, un $70 \%$ más) el promedio fue de 217 . Si nos centramos apenas en los errores interlingüísticos, los números son de 181 para el grupo 1 y de 170 para el grupo 2. Y, si miramos exclusivamente a los errores interlingüísticos léxicos, la relación es de 120 y 93 , respectivamente.

Entendemos que necesitaríamos un estudio estadístico para reconocer si las diferencias son o no significativas, aunque una mirada superficial parece apuntar a que una mayor instrucción en la 
lengua próxima no necesariamente es garantía de que los niveles de competencia lingüística de nuestros alumnos aumenten. Con todo, parece que los errores interlingüísticos son un poco menos frecuentes en aquellos individuos que recibieron mayor instrucción en la LE (aunque aquí no contamos con otras variables posibles, como cursos de formación extra, contacto con la LE fuera del ámbito formativo, hábitos de estudio, etc.).

Una propuesta para paliar este panorama podría ser el desarrollo de programas de formación de profesores de ELE específicos para brasileños, que tuvieran como base tanto la oferta de asignaturas impartidas en la LE como la reflexión acerca de la influencia negativa que la LM puede ejercer en el acceso a esa lengua próxima. Un buen ejemplo de ello es el programa de asignaturas que se ofrecen en el curso de licenciatura en españolportugués de la Universidad Federal de Sergipe, en el cual la mayoría de las materias se imparte en español (ya sean las de lengua, literatura o de otro tipo), al tiempo que se pone el énfasis en análisis contrastivos entre las lenguas. Además, la primera asignatura de lingüística aplicada del programa (de un total de 3), trata, precisamente, sobre cuestiones relacionadas con los conceptos de error, bilingüismo, interlengua, análisis contrastivo, interferencia y las singularidades que supone aprender un idioma próximo (generalmente impartida por la autora de esta tesis).

Pensamos que llevar al alumno a la reflexión sobre estos aspectos es fundamental para que tome consciencia del proceso que implica su propio aprendizaje y con ello que los efectos de la LM puedan verse monitorizados y frenados por los propios aprendientes. De la misma forma, es igualmente importante que los formadores insistan una y otra vez en aquellos errores ya ampliamente reconocidos como típicos de los brasileños que estudian español, haciendo conscientes a los estudiantes de que son errores altamente fosilizables (si no, fosilizados ya). Entendemos que trabajar conscientemente con los futuros profesores de español sobre todo lo expuesto hasta ahora puede ayudarles a alcanzar una competencia lingüística más elevada y, consiguientemente, unos niveles de interferencias de la LM considerablemente más bajos que los advertidos en esta investigación. Y de la práctica docente desarrollada hasta ahora en la Universidad Federal de Sergipe, podemos decir que se están derivando buenos resultados.

En este sentido, nuestras ideas coinciden básicamente con las defendidas por Almeida Filho (1995b), quien defendía que el profesor debe incitar a sus alumnos a que sean críticos con su 
propio aprendizaje y descubran así, conscientemente, las dificultades que supone aprender un idioma próximo, ya que solo de esta manera podrán alcanzar un buen nivel lingüístico.

Un aspecto relacionado con esto último, y que creemos podría incrementar también las aptitudes lingüísticas de nuestros alumnos es, el desarrollo de su autonomía. Quizá por la tipología de clases habitual en la enseñanza básica, nuestros alumnos de grado no están acostumbrados a ampliar los contenidos trabajados en clase por su cuenta, algo que, sin embargo, nos parece fundamental.

Una última conclusión que se desprende de lo discutido hasta ahora tiene que ver con la incidencia de los errores y el nivel de bilingüismo alcanzado por los aprendices. En este trabajo analizamos los errores de los docentes de español como lengua extranjera. No obstante, los resultados aquí encontrados no están reñidos con una mirada más crítica sobre el bilingüismo, y para ello retomamos las ideas que apuntábamos en el primer capítulo de la tesis.

A partir de los hallazgos aquí discutidos y de todo lo que hemos presentado hasta el momento, creemos que hay que concebir el bilingüismo del hablante no nativo de una manera más realista (principalmente aquellos que tienen lugar en contextos de aprendizaje formal). En otras palabras, hay que considerar tanto las características intrínsecas del aprendiz como el hecho de que la identidad y la lengua materna juegan un papel fundamental. Todo ello nos hace abogar por que el bilingüismo debe considerarse más allá de la comparación con el sistema lingüístico del hablante nativo, como ya postulaba Cook (1992).

En consonancia con esto, desde la perspectiva de la formación de los profesores de lenguas extranjeras en contextos formales, necesitamos entender que la lengua extranjera difícilmente alcanzará los mismos niveles que los alcanzados por un nativo en su lengua materna, como se ha comprobado en numerosos estudios empíricos, tanto dentro como fuera de Brasil. Por eso, la pretensión de que el aprendiz de una lengua extranjera alcance esos niveles nativos, además de retrógrada e ilusoria, supone un freno a las destacadas aportaciones de la lingüística aplicada y la didáctica de las lenguas, las cuales han demostrado que los bilingües tienen diferentes niveles de competencias, y que eso es absolutamente normal y comprensible.

Lógicamente, cuando nos referimos a un profesor no nativo, como es el caso de nuestros sujetos, las mismas ideas siguen siendo válidas, si bien ahora la responsabilidad en la utilización de la 
lengua es mucho mayor. Por ello, una mirada más razonable sobre el bilingüismo no debe significar el abandono de los esfuerzos en los procesos de enseñanza/aprendizaje, ya sea por los futuros profesores o de sus futuros alumnos. En consecuencia, creemos que ser conscientes de las dificultades que implica aprender una lengua próxima, puede colaborar de manera relevante para un aprendizaje significativo.

No comparar la competencia del profesor de L2/LE con la de un nativo no significa quitar importancia al conocimiento que aquel debe demostrar sobre la lengua meta, pero sí ver el bilingüismo de una manera más realista y centrada en las diferencias individuales y en el uso que los aprendices pueden hacer de sus competencias. No se trata de justificar las dificultades que puedan tener en la actuación, pero sí de entender que el profesor, como usuario de la L2, no está tampoco exento de cometer errores.

De esta manera, creemos que el análisis de los desvíos cometidos por los sujetos aquí investigados es una manera de entender un poco mejor algunas de dificultades con las que se enfrentan. $Y$ un modo, entre otros, de aportar un grano de arena en el acercamiento a la lengua meta de los futuros docentes de español en Brasil. En relación con esto, creemos, modestamente, haber cumplido nuestra tarea.

\subsection{Perspectivas futuras}

El análisis de errores es un campo fértil para aquellos investigadores implicados en los procesos de enseñanza/aprendizaje de lenguas extranjeras. En nuestro caso, pretendemos seguir desarrollando nuevos estudios que se relacionen y complementan con el presentado en estas páginas. La primera intención es realizar trabajos que tengan en cuenta no solo los errores, sino también los aciertos de los brasileños aprendientes y/o usuarios del español como lengua extranjera, en consonancia con lo defendido por otros estudiosos (cf. JORDENS, 1980; FERNÁNDEZ, 1997; ELLIS, 2008 y ALBA QUIÑOES, 2009).

Otro propósito, que creemos posible desarrollar en un proyecto posdoctoral, es el de analizar los errores de brasileños residentes en países de habla hispana y, por tanto, en contextos de inmersión, como aquellos que originaron nuestras primeras inquietudes y que luego se transformaron en esta investigación. Nos gustaría comparar esos errores con los encontrados en este trabajo, 
con el objeto de entender un poco mejor las diferencias y similitudes entre ambos contextos.

Asimismo, a las docentes que tan amablemente se involucraron en esta investigación, nos gustaría ofrecerles un curso de formación continuada basado en sus necesidades, intereses y, también, en las dificultades con la LM detectadas en este estudio, con el fin de que puedan beneficiarse de los resultados aquí encontrados y de esta manera ampliar sus conocimientos y aptitudes lingüísticas. Esta propuesta se basa en el entendimiento de que la relación investigador-participante no debe ser unilateral, sino que es moralmente apropiado retribuir los beneficios obtenidos con la participación de los sujetos, más aun si los resultados aquí expuestos han podido contribuir a hacerlos más vulnerables. Esperamos con esta actitud agradecer de manera más concreta su participación, así como colaborar en su formación continuada, además de crear las condiciones para que el intercambio investigador-participante ocurra de manera más justa.

Por fin, nos gustaría desarrollar un material didáctico con el cual fuera posible colaborar más decisivamente a la enseñanza el ELE, apoyado en los hallazgos de este trabajo y en el que se propongan actividades específicas para el tratamiento de los errores léxicos entre pares de lenguas próximas. 


\section{BIBLIOGRAFÍA}

ADJÉMIAN, C. La spécificité de l'interlangue et l'idéalisation des langues secondes. In: GUÉRON, J.; SOWLEY, S. (Eds.). Grammaire transformationelle: théorie et methodologies. Vincennes: Université de Paris VIII, 1982. p. 421-439. Traducido en: LICERAS, J. M. La adquisición de las lenguas segundas y la gramática universal. Madrid: Visor, p. 241-260, 1991.

ALBA QUIÑONES, V. El análisis de errores en el campo del español como lengua extranjera Algunas cuestiones metodológicas. Revista Nebrija de Lingüística Aplicada, v. 5, 2009.

ALMEIDA FILHO, J. C. P. Uma metodologia específica para o ensino de línguas próximas? In: ALMEIDA FILHO, J. C. P. (Ed.). Português para estrangeiros: interface com 0 espanhol. Campinas: Pontes Editores, p. 13-22, 1995a.

ALMEIDA FILHO, J. C. P. Português para estrangeiros interface com o espanhol. Campinas: Pontes Editores, 1995b.

ALVAR, M. (ED.). Manual de dialectología hispánica. El español de España. Barcelona: Ariel, 1996a.

ALVAR, M. (ED.). Manual de dialectología hispánica. El español de América. Barcelona: Ariel, 1996b.

ALVAR ESQUERRA, M. La enseñanza del léxico y el uso del diccionario. Madrid: Arco/Libros, 2003.

ALVAREZ, M. L. O. La transferencia, la interferencia y la interlengua en la enseñanza de lenguas próximas. Anuario do II Congresso Brasileiro de Hispanistas, 2002.

ANDRADE, O. G.; DURÃO, A. B. DE A. B. Seguindo as pistas dos desvios léxico-semânticos produzidos por estudantes brasileiros de espanhol. In: DURÃO (Ed.). Por uma lexicografia bilíngue contrastiva. Londrina: UEL, p. 23-43, 2009. 
ANDRADE, O. G. Necessidades léxicas de universitários brasileiros aprendizes de espanhol: levantamento, descrição e análise. 267p. Tese de Doutorado em Estudos da Linguagem. Universidade Estadual de Londrina. Londrina, 2010.

ANDRADE, O. G. Interlíngua oral e léxico de brasileiros aprendizes de espanhol. Londrina: Eduel, 2011.

ANDRADE NETA, N. F. Aprender español es fácil porque hablo portugués. Ventajas y desventajas de los brasileños para aprender español. Cuadernos Cervantes. Aprender español es fácil porque hablo portugués: Cuadernos Cervantes, v. 6 , n. 29, p. 46-56, 2000.

ANICÉZIO, G. F. C. DE. Formação continuada: um caminho para a adequação enunciativa dos professores de Língua Espanhola de Mato Grosso. 171p. Dissertação de Mestrado. Universidade Federal de Mato Grosso, Cuiabá, 2012.

ARCOS PAVÓN, M. E. Análisis de errores, contrastivo e interlengua, en estudiantes brasileños de español como segunda lengua: verbos que rigen preposición y/o ausencia de ella. 374p. Tesis Doctoral. Universidad Complutense de Madrid, 2009.

BACHMAN, L. F. Fundamental considerations in language testing. Oxford: Oxford University Press, 1990.

BAPTISTA, L. M. T. R. et al. La fraseología: entre el lenguaje real y la clase de E/LE. Trabalhos em Linguística Aplicada, v. 44, n. 1, p. 37-58, 2005.

BAPTISTA, L. M. T. R. Tratándose de expresiones idiomáticas, ¡jo te rompas la cabeza ni busques cinco pies al gato! Revista Electrónica de Didáctica/Español Lengua Extranjera, v. 6, p. 7, 2006.

BARALO, M. Algunos aspectos de la adquisición de la morfología léxica del español como lengua extranjera. ASELE. Actas V., 1994.

BARALO, M. La organización del lexicón en lengua extranjera. Revista de Filología Románica, v. 1, n. 14, p. 59-72, 1997. 
BARALO, M. La adquisición del español como lengua extranjera. Madrid: Arco Libros, 1999.

BARALO, M. Psicolingüística y gramática, aplicadas a la enseñanza de español / LE 1. RedELE-Revista electrónica de Didáctica Español Lengua Extranjera, 2004.

BARALO, M. Aspectos de la adquisición del léxico y su aplicación en el aula. FIAPE. I Congreso internacional: El español, lengua del futuro., p. 1-13, 2005.

BARALO, M. Adquisición de palabras: redes semánticas y léxicas. Actas del Foro de español internacional: Aprender y enseñar léxico, v. 2007, p. 384-399, 2007.

BARALO, M. A propósito del Análisis de errores Una encrucijada de teoría lingüística, teoría de adquisición y didáctica de lenguas. Revista Nebrija de Lingüística Aplicada, v. 5, 2009.

BARTUREN, M. B. A. La variación estilística en el análisis de la interlengua. ASELE. Actas XI, p. 155-164, 2000.

BASILIO, M. Teoria lexical. São Paulo: Ática, 1987.

BECHARA, E. Moderna gramática da língua portuguesa. Rio de Janeiro: Nova Fronteira, 2009.

BECHARA, S. F.; MOURE, G. W. ¡Ojo! con los falsos amigos. 2ed. ed. São Pulo: Moderna, 2002.

BENEDETTI, A. M. Interferencias morfosintácticas y semánticas del portugués en el aprendizaje del español. Tesis Doctoral. Universidad Complutense de Madirid, 1992.

BIALYSTOK, E. A theorical model of second language learning. Language Learning, v. 28, n. 1, p. 69-83, 1978. Traducido en: LICERAS, J. M. La adquisición de las lenguas segundas y la gramática universal. Madrid: Visor, 1991, p.177-192.

BLAS ARROYO, J. L. Limitaciones (y avances ) en el estudio delas variedades de contacto españolas (con especial atención al contexto español-catalán). Lengua viva: estudios ofrecidos a 
César Hernández Alonso. TEJEDOR, A. A. (Ed), p. 849-864, 1998.

BLAS ARROYO, J. L. Problemas teóricos en el estudio de la interferencia lingüística. Revista española de lingüística, v. 21, p. 266-289, 1991.

BLAS-ARROYO, J. L. A propósito de un caso de convergencia gramatical por causación múltiple en el área de influencia lingüística catalana. Análisis sociolingüístico. Cuadernos de investigación filológica, v. XXI, p. 175-200, 1995.

BLAS ARROYO, J. Sociolingüística del español. Desarrollos y perspectivas en el estudio de la lengua española en contexto social. Madrid: Cátedra, 2005.

BLEY-VROMAN, R. The logical problem of foreign language learning. Linguistic Analysis, v. 20, p. 3-49, 1990.

BRASIL. Parâmetros curriculares nacionais: terceiro e quarto ciclos do ensino fundamental: língua estrangeira. Brasília: MEC/SEF, 1998.

BRASIL. Orientaçãoe Curriculares para o Ensino Médio Linguagens, Códigos e suas Tecnologias. Brasília: Ministério da Educação, 2006a. v. 1

BRASIL. Parecer homologado 261/2006 .Brasilia: Ministério da Educação. Conselho Nacional de Educação, 2006b.

BRASIL. Ministério da Saúde. Conselho Nacional de Saúde. Resolução no 466, de 12 de dezembro de 2012. Diário Oficial [da] República Federativa do Brasil, Brasília, DF, 12 dez. 2012. Disponível em: http://bvsms.saude.gov.br/bvs/saudelegis/cns/2013/res0466_12_12 2012.html. Acesso em: 03 de maio de 2017.

BRASIL. Ministério da Saúde. Conselho Nacional de Saúde. Resolução no 510, de 7 de abril de 2016. Diário Oficial [da] República Federativa do Brasil, Brasília, DF, 24 maio 2016. Seção 1. p. 44-46. Disponível em: http://conselho.saude.gov.br/resolucoes/2016/Reso510.pdf. Acesso em: 03 de maio de 2017. 
BRUNO, F. A. T. C. Lo qe uno/a comprende. lo que uno/a dice Compreensão e produção do espanhol como língua estrangeira por adultos brasileiros em situação de ensino e aprendizagem. 228p. Tese de Doutorado. Universidade de São Paulo, 2006.

CAMPOS, S. N. Gente de Brasil: La enseñanza del español lengua extranjera para estudiantes brasileños. Encuentro, n. 11, p. 183194, 1999.

CANALE, M. De la competencia a la pedagogía comunicativa del lenguaje. Traducido en: LLOBERA, M. (Ed.). Competencia comunicativa. Documentos básicos en la enseñanza de lenguas extranjeras. Madrid: Edelsa, p. 63-81, 1995.

CANALE, M.; SWAIN, M. Theoretical bases of communicative approaches to second language teaching and testing. Applied Linguistics, v. 1, p. 1-47, 1980.

CAMORLINGA, R. Níveis de interferencia lexical na aprendizagem do espanhol por estudantes brasileiros. 146p. Dissertação (Mestrado em Linguística) - Universidade Federal de Santa Catarina. Florianópolis, 1991.

CAMORLINGA, R. A DISTÂNCIA DA PROXIMIDADE - A dificuldade de aprender uma língua fácil -. Intercâmbio. Revista do Programa de Estudos Pós-Graduados em Linguística Aplicada e Estudos da Linguagem, v. 6, n. 1, p. 1-19, 1997.

CAMORLINGA, R. Do português ao espanhol: os prós e os contras da proximidade. In: SEDYCIAS, J. (Ed.). . O ensino do espanhol no Brasil. Passado, presente, futuro. São Paulo: Parábola, 2005. p. 195-205.

CELADA, M. T. Versiones de Babel - memoria de la otra lengua en la propia. Dossier: Gestos trazan distinciones entre la lengua española y el portugués brasileño. SIGNOS ELE, 2008a.

CELADA, M. T.; GONZÁLEZ, N. T. M. Los estudios de lengua española en Brasil. ABEH, Suplemento El hispanismo en Brasil, p. 35-58, 2000.

CELADA, M. T. T. O espanhol para o brasileiro: uma língua 
singularmente estrangeira. 279p. Tese de doutorado. Instituto de Estudos da Linguagem. Universidade Estadual de Campinas, 2002.

CELCE-MURCIA, M.; DÖRNYEI, Z.; THURRELL, S. A pedagogically motivated model with content specifications. Issues in Applied Linguistics, v. 6, n. 2, p. 5-35, 1995.

CENOZ, J. I. El concepto de competencia comunicativa. In: LOBATO, J. S.; GARGALLO, I. S. (Eds.). . Vademécum para la formación de profesores: enseñar español como segunda lengua (L2)/lengua extranjera (LE). Madrid: SGEL, p. 449-465, 2004.

CHOMSKY, N. Aspects of the theory of sintax. Cambridge (Mass.): MIT Press, 1965.

CHOMSKY, N. Problemas actuales en teoría lingüística. Temas teóricos de gramática generativa. Madrid: Siglo Veintiuno Editores, 1977.

CHOMSKY, N. Rules and representations. Oxford: Basil Blackwell, 1980.

CHOMSKY, N. Knowledge of language: its nature, origins and use. New York: Praeger Publishers, 1985.

CLASHEN, H.; MUYSKEN, P. The availability of universal grammar to adult and child learners-The study of the acquisition of German and word order. Second Language Research, v. 2, p. 93-119, 1986.

CONTRERAS, M. Las trampas que puede ofrecer la proximidad de los idiomas. La interlengua ofrecida como insumo en las clases de lengua española como LE. 137p. Dissertação de Mestrado. Escola de Educação. Universidade Católica de Pelotas, 1998.

COOK, V. The comparison of language development in native children and foreign adults. IRAL, v. 15, p. 1-20, 1973.

COOK, V. Cognitive process in second language learning. IRAL, V. 15, p. 1-20, 1977. 
COOK, V. Chomsky's Universal Grammar and Second Language Learning. Applied Linguistics, 1985.

COOK, V. Evidence for multi-competence. Language Learning, v. 44, n. 4, p. 557-591, 1992.

COOK, V. Universal Grammar and the learning and teaching of second languages. In: OLDIN, T. (Ed.). Perspectives on Pedagogical Grammar. Cambridge: Cambridge University Press, 1994. p. 25-48.

COOK, V. Chomsky's universal grammar: an introduccion. Oxford: Blackwell Publishing, 1998.

COOK, V. J. Monolingual bias in second language acquisition research. Revista canaria de estudios ingleses, v. 34, p. 35-50, 1997.

COOK, V. J.; LONG, J.; MCDONOUGH, S. First and second language learning. In: PERREN, G. E. (Ed.). The Mother Tongue and Other Languages in Education. CILTR, p. 7-22, 1979.

CORDER, S. P. The significance of learners errors. IRAL, v. V, n. 4, p. 161-170, 1967.

CORDER, S. P. Idiosyncratic dialects and error analysis. IRAL, v. IX, n. 2 , p. $147-160,1971$.

CORDER, S. P. The study of interlanguage. Proceedings of the Fourth International Congress of Applied Linguistics, v. 2, 1976.

CORDER, S. P. Strategies of comunication. AFinLa, v. 23, 1978.

CORDER, S. P. Error analysis and interlanguage. Oxford: Oxford University Press, 1981a.

CORDER, S. P. The role of interpretation in the study of learners' errors. In: Error analysis and interlanguage. Oxford: Oxford University Press, p. 35-44, 1981b.

CORDER, S. P. A role for the mother tongue. In: GASS, S.; SELINKER, L. (Eds.). . Language transfer in language learning. 
Philadelphia: John Benjamins, p. 18-31, 1983.

COROMINES, J. Breve diccionario etimológico de la lengua castellana. Madrid: Grados, 2008.

CRUZ PIÑOL, M. Lingüística de corpus y enseñanza del español como 2-L. Madrid: Arco/Libros, 2012.

CUNHA, C., \& CINTRA, L. F. L. Nova gramática do português contemporâneo. $5^{\mathrm{a}}$ ed. Rio de Janeiro: Lexikon, 2008.

DUARTE, C. A. Errores de lusohablantes brasileños en el uso de algunas preposiciones españolas. In: MARTíNEZ, I. P. (Ed.). Lingüistica contrastiva y análisis de errores. Madrid: Edinumen, p. 79-96, 1999.

DULAY, H.; BURT, M. You can't learn without goofing. In: RICHARDS, J. (Ed.). Error Analysis: perspectives on second language acquisition. [s.I.] Longman, 1974a.

DULAY, H.; BURT, M. Natural sequences in child second language acquisition. Language Learning, v. 24, n. 1, p. 37-53, 1974b. Traducido en: LICERAS, J. M. La adquisición de las lenguas segundas y la gramática universal. Madrid: Visor, p. 105-122, 1991.

DULAY, H.; BURT, M.; KRASHEN, S. Language two. Oxford: Oxford University Press, 1982.

DURÃO, A. B. DE A. B. Caracterización de la competencia lingüística transicional de lusohablentes aprendices de español e hipanohablantes aprendices de portugués. Tesis de Doctorado. Universidad de Valladolid, 1998.

DURÃO, A. B. DE A. B. A fossilização de erros, o estado da questão. SIGNUM: Estudos Linguísticos, 2000a.

DURÃO, A. B. DE A. B. Errores típicos de brasileños aprendices de español y la fosilización. In: Problemas de ensino/aprendizagem de brasileiros estudantes de espanhol. Tomo I. Londrina: UEL, p. 43-54, 2000b. 
DURÃO, A. B. DE A. B. Análisis de errores en la interlengua de brasileños aprendices de español y de españoles aprendices de portugués. Londrina: Eduel, 2004.

DURÃO, A. B. DE A. B. la interferencia como causa de errores de brasileños aprendices de español. In: SEDYCIAS, J. (Ed.). O ensino do espanhol no Brasil. Passado, presente, futuro. São Paulo: Parábola, p. 130-144, 2005.

DURÃO, A. B. DE A. B. La interlengua. Madrid: Arco Libros, 2007.

DURÃO, A. B. DE A. B. Transferência (interferência) lingüística: um fenômeno ainda vigente? Polifonia, v. 15, p. 67-85, 2008.

DURÃO, A. B. DE A. B. et al. Dicionário de falsos amigos espanhol-português. Florianópolis: Insular, 2014.

ECKMAN, F. Markedness and the contrastive analysis hypotesis. Language Learning, v. 27 , n. 2, p. 315-330, 1977. Traducido en: LICERAS, J. M. La adquisición de las lenguas segundas y la gramática universal. Madrid: Visor, p. 207-224, 1991.

EDWARDS, J. Multilingualism. London: Routledge, 1994.

ELLIS, R. Understanding Second Language Acquisition. Oxford: Oxford University Press, 1985.

ELLIS, R. The study of second language acquisition. Oxford applied linguistics, v. 23, p. 824, 1994.

ELLIS, R. The study of Second Language Acquisition. Oxford: Oxford University Press, 2008.

ERES FERNÁNDEZ, I. G. O imperativo verbal espanhol. Estudo das estratégias utilizadas no seu uso por lusofalantes brasileiros. Tese de Doutorado. USP, 1998.

FANJUL, A. Gramática y práctica de español para brasileños. São Paulo: Santillana, 2011.

FARIAS, M. S. Estudo da interlíngua de brasileiros estudantes de espanhol apoiado na análise de erros. 131p. Dissertação 
(Mestrado em Linguística Aplicada) - Departamento de Letras, Universidade Estadual do Ceará, 2007.

FEIJÓO HOYOS, B. L. Dicionario de falsos amigos. São Paulo. Consejería de Educación de la Embajada de España, 1992.

FEIJÓO HOYOS, B. L. Diccionario de falsos amigos. São Paulo: Enterprise Idiomas, 1998.

FERNÁNDEZ, S. Interlengua y análisis de errores en el aprendizaje del español como lengua extranjera. Tesis Doctoral. Universidad Complutense de Madrid, 1991.

FERNÁNDEZ, S. Errores e interlengua en el aprendizaje del español como lengua extranjera. Didáctica. Lengua y Literatura, v. 7, p. 203-215, 1995.

FERNÁNDEZ, S. Interlengua y análisis de errores en el aprendizaje del español como lengua extranjera. Madrid: Edelsa, 1997.

FERNÁNDEZ, S. Interlengua y aprendizaje / adquisición del español. Revista Nebrija de Lingüística Aplicada, v. 5, n. 3, p. 5054, 2009.

FERREIRA, I. A. A interlíngua do falante de espanhol e o papel do professor: aceitação tácita ou ajuda para superá-la? In: ALMEIDA FILHO, J. C. P. (Ed.). Português para estrangeiros: interface com o espanhol. Campinas: Pontes Editores, p. 39-48, 1995.

FRIES, C. Teaching and Learning english as a foreign language. Ann Arbor: Michigan University Press, 1945.

FRIGO, K. C. Os semelhantes se atraem? Um estudo sobre a aprendizagem da língua espanhola por falantes brasileiros: caso de transferência.111p. Dissertação (Mestrado em Letras) Universidade Federal do Paraná. Curitiba, 2006.

GANCEDO ÁLVAREZ, M. A. La oblicuidad, construções de dativos na interlíngua de estudantes brasileiros de espanhol. 111p. Dissertação (Mestrado em Letras) - Universidade Federal do Paraná, 2006. 
GANCEDO ÁLVAREZ, M. A. Conseqüências sintáticas e semânticas das relações de possessão em espanhol e na produção não nativa de brasileiros. 156p. Tese de doutorado. Universidade de São Paulo, 2008.

GASS, S. M.; SELINKER, L. (Eds.). Language transfer in language learning. Philadelphia: Benjamins, 1992.

GIMENEZ, S. L. Um estudo comparativo entre dicionários bilíngües espanhol-português. 101p. Dissertação de Mestrado. Centro de Comunicação e Expressão. Pós-graduação em Estudos da Tradução. Universidade Federal de Santa Catarina., 2005.

GIMENEZ, S. L. El estudio de la interferencia de la lengua materna en el discurso de profesores de ELE en Brasil. 121p. Departamento de Lengua Inglesa. Universidad Autónoma de Madrid, 2011.

GIMENEZ, S. L. Estudio bibliométrico sobre la interferencia del portugués (PB) en el español (ELE) en Brasil: tesis y disertaciones de 1991 a 2014. Revista Educação Online, n. 22, p. 1-26, 2016

GOETTENAUER, E. Espanhol: língua de encontros. In: SEDYCIAS, J. (Ed.). O ensino do espanhol no Brasil. Passado, presente, futuro. São Paulo: Parábola, p. 61-70, 2005.

GÓMEZ MARTíNEZ, S. La Teoría de la Multicompetencia y su aplicación en el marco universitario español: propuesta , diseño y estudio de un modelo de análisis aplicado a los estudiantes de Empresariales. 908p. Tesis Doctoral. Universidad de Valladolid, 2004.

GÓMEZ MOLINA, J. R. Los contenidos léxico semánticos. In: SÁNCHEZ LOBATO, J.; SANTOS GARGALLO, I. (Eds.). Vademécum para la formación de profesores: enseñar español como segunda lengua (L2)/lengua extranjera (LE). Madrid: SGEL, p. $789-810,2004 a$.

GÓMEZ MOLINA, J. R. La subcompetencia léxico-semántica. In: SÁNCHEZ LOBATO, J.; SANTOS GARGALLO, I. (Eds.). Vademécum para la formación de profesores: enseñar español como segunda lengua (L2)/lengua extranjera (LE). Madrid: SGEL, 
p. $491-510,2004 b$.

GÓMEZ TORREGO, L. Gramática didática del español. Madrid: SM, 2011a.

GÓMEZ TORREGO, L. Análisis morfológico: teoría y práctica. Madrid: Ediciones SM, 2011b.

GONÇALVES, E. Marcadores conversacionais na interlíngua de aprendizes de Espanhol no Brasil. 221p. Tese (Doutorado em Filologia e Língua Portuguesa) - Universidade de São Paulo. São Paulo, 2007.

GONZÁLEZ, N. T. M. Cadê o pronome? 0 gato comeu. Os pronomes pessoais na aquisição/aprendizagem do espanhol por brasileiros adultos. FFLCH/USP, 1994.

GONZALEZ, N. T. M. Portugués brasileño y español: lenguas inversamente asimétricas. In: CELADA, M. T.; GONZÁLEZ, N. M. (Eds.). Dossier: Gestos trazan distinciones entre la lengua española y el portugués brasileño. SIGNOS ELE, 2008.

GONZÁLEZ, N. T. M. Sobre a aquisição de clíticos do espanhol por falantes nativos do português. Cadernos de Estudos Linguísticos, n. 36, p. $163-176,1999$.

GONZÁLEZ, N. T. M. Lugares de reflexión en la formación del profesor de E/LE (La particular situación de Brasil). RedELERevista electrónica de Didáctica Español Lengua Extranjera, 2004.

GONZÁLEZ MONTERO, J. A. La aspiración: fenómeno expansivo en español. Su importancia en andaluz. Nuevos casos. p. 31-66, 1993.

GRADMAN, H. L. What methodologists ignore in contrastive teaching. Pacific Conference on Contrastive Linguistics and Language Universals. Honolulu, 1971.

GROSJEAN, F. Another view of bilingualism. In: HARRIS, R. J. (Ed.). Cognitive processing in bilingualism. Amsterdam: North Holland, p. 51-62, 1992. 
HAWKINS, R.; YUET-HUNG CHAN, R. C. The partial availability of Universal Grammar in second language acquisition: "the failed functional features hypothesis". Second language Research, v. 13, n. 3, p. 187-226, 1997.

HENRIQUES, E. R. Distância entre línguas e o processo de aprendizagem/aquisição. In: SEDYCIAS, J. (Ed.). 0 ensino do espanhol no Brasil. Passado, presente, futuro. São Paulo: Parábola, p. 145-171, 2005.

HIGUERAS GARCÍA, M. Las colocaciones y su enseñanza en la clase de ELE. Madrid: Arco Libros, 2006.

HUMBLÉ, P. Falsos cognados. Falsos problemas. Un aspecto de la enseñanza del español en Brasil ${ }^{*}$. Revista de Lexicografía, n. XII, p. 197-207, 2006.

HYMES, D. Acerca de la competencia comunicativa. In: Traducción de Pedro Horrillo Calderón del artículo: On comunicative competence. Philadelphia: University of Pennsylvania Press. Publicado en Pride \& Holmes: Sociolingüístics, Penguin Education, 1972, 1971.

JORDENS, P. Interlanguage research: interpretation or explanation. Language Learning, v. 30, n. 1, p. 195-207, 1980. Traducido en: LICERAS, J. M. La adquisición de las lenguas segundas y la gramática universal. Madrid: Visor, p.225-239, 1991.

KELLERMAN, E. An eye for an eye: crosslinguistic constrains on the development of the L2 lexicon. In: KELLERMAN, E.; SMITH, M. S. (Eds.). Crosslinguistic influence in second language acquisition. Oxford: Pergamon Press, 1986.

KRASHEN, S. The monitor model for adult second language performance. In: BURT, M.; DULAY, H.; FINOCCHIARO, M. (Eds.). Viewpoints of English as a second language. New York: Regents C., 1977. p. 152-161. Traducido en: LICERAS, J. M. La adquisición de las lenguas segundas y la gramática universal. Madrid: Visor, p. 143-152, 1991.

KRASHEN, S. The input hipothesis: issues and implications. London: Longman, 1985. 
KULIKOWSKI, M. Z. M.; GONZÁLEZ, N. T. M. Español para brasileños. Sobre por dónde determina la justa medida de una cercanía. Anuario brasileño de estudios hispánicos, v. 9, p. 1119, 1999.

LADO, R. Linguistics across cultures. The University of Michigan Press, 1957.

LENNEBERG, E. Fundamentos biológicos del lenguaje. Madrid: Alianza Editorial, 1967.

LICERAS, J. M. La adquisición de las lenguas segundas y la gramática universal. Madrid: Madrid: Visor, 1991.

LONG, M. H. Stabilization and fossilization in interlanguage development. In: DOUGHTY, C. J.; LONG, M. H. (Eds.). The Handbook of Second Language Acquisition. Oxford: Blackwell Publishing, p. 487-535, 2003.

LÖVDÉN, M. et al. Experience-dependent plasticity of white-matter microstructure extends into old age. Neuropsychologia, v. 48, n. 13, p. 3878-3883, 2010.

MARCUSCHI, L. A. Análise da conversação. São Paulo: Ática, 1986.

MÅRTENSSON, J. et al. Growth of language-related brain areas after foreign language learning. Neurolmage, v. 63 , n. 1, p. 240244, 2012.

MASIP, V. Gramática espanhola para brasileños. São Paulo: Parábola, 2010.

MATTE BON, F. Gramática comunicativa del español. Tomo 1. Madrid: Edelsa, 2012a.

MATTE BON, F. Gramática comunicativa del español. Tomo 2. Madrid: Edelsa, 2012b.

MCLAUGHLIN, B. The monitor model: some methodological considerations. Language Learning, v. 28, n. 1, p. 69-83, 1978. Traducido en: LICERAS, J. M. La adquisición de las lenguas 
segundas y la gramática universal. Madrid: Visor, p. 156-176, 1991.

MERINO, M. M. G. La lengua materna en el aula de ELE. Colección de monografías de ASELE, v. 15, 2012.

MOLINER, M. Diccionario de uso del español. Tomo I. Madrid: Gredos, 2008a.

MOLINER, M. Diccionario de uso del español. Tomo II. Madrid: Gredos, 2008b.

MOLINER, M. Diccionario de uso del español. Tomo III. Madrid: Gredos, 2008c.

MONTE, J. B. Dicionário ilustrado: Falsas semelhanças españolportuguês. Fortaleza: Didáticos, 2003.

MORENO, C.; FERNÁNDEZ, G. M. E. Gramática contrastiva del español para brasileños. Madrid: SGEL, 2007.

MORENO, F. et al. Lengua, variación y contexto. Volumen I. Madrid: Arco/Libros, 2003a.

MORENO, F. et al. Lengua, variación y contexto. Volumen II. Madrid: Arco/Libros, 2003b.

MORENO, F.; GONZÁLEZ, N. M. Diccionario bilingüe de uso español-portugués / portugués-español. Vol. 1. Madrid: Arco/Libros, 2003a.

MORENO, F.; GONZÁLEZ, N. M. Diccionario bilingüe de uso español-portugués / portugués-español. Vol. 2. Madrid: Arco/Libros, 2003b.

NEMSER, W. Aproximative systems of foreign language learners. IRAL, v. IX, n. 2, p. 115-123, 1971.

NEWSER, W. Aproximative systems of foreign language learners. IRAL, v. IX, n. 2, p. 115-123, 1971. Traducido en: LICERAS, J. M. La adquisición de las lenguas segundas y la gramática universal. Madrid: Visor, p. 51-61, 1991. 
NUSSBAUN, L. La lengua materna en clase de lengua extranjera: entre la ayuda y el obstáculo. Signos teoría y práctica de la educación, v. 4, p. 36-47, 1991.

OLDIN, T. Cross-linguistic influence. In: DOUGHTY, C. J.; LONG, M. $\mathrm{H}$. (Eds.). . The Handbook of Second Language Acquisition. Oxford: Blackwell Publishing, p. 436-486, 2003.

OTERO GUTIÉRREZ, M. T. Análisis, tipología e importancia de los errores en el aprendizaje de lenguas extranjeras. Revista Innovación Digital y Experiencias Educativas, p. 1-8, 2008.

PARAQUETT, M. O papel que cumprimos os professores de espanhol como língua estrangeira (E/LE) no Brasil. Cadernos de Letras da UFF - Dossiê: Diálogos Interamericanos, n. 38, p. 123137, 2009.

PARAQUETT, M. Contando histórias que fizeram a história do espanhol no Brasill Congreso Internacional América Latine e InterculturalidadeFoz do Iguaçu, 2015.

PAYRATÓ, L. La Interferència lingüística: comentaris i exemples català-castellà. Barcelona: Publicacions de L'Abadia de Montserrat, 1985.

PENADÉS MARTÍNEZ, I. La enseñanza de las unidades fraseológicas. Madrid: Arco/Libros, 1999.

PENADÉS MARTÍNEZ, I. Diccionario de Locuciones Verbales para la Enseñanza del Espanñol. Madrid: Arco/Libros, 2002.

PENADÉS MARTÍNEZ, I. Diccionario de Locuciones Adverbiales para la Enseñanza del Espanñol. Madrid: Arco/Libros, 2005.

PENADÉS MARTÍNEZ, I. Diccionario de Locuciones Nominales y Adjetivas para la Enseñanza del Espanñol. Madrid: Arco/Libros, 2008.

PÉREZ HERNÁNDEZ, C.; MORENO ORTIZ, A.; FABER, P. Lexicografía computacional y lexicografía de corpus. Revista Española de Lingüística Aplicada, v. 1, p. 175-214, 1999. 
RAE. Nueva Gramática de la Lengua Española - Morfología y Sintaxis I. Madrid: Espasa, 2009a.

RAE. Nueva Gramática de la Lengua Española - Sintaxis II. Madrid: Espasa, 2009b.

REAL ACADEMIA ESPAÑOLA. Nueva gramática de la lengua española. Madrid: Espasa Libros, 2010.

RICHARDS, J. C. Error Analysis and Second Language Strategies. Language SciencesLanguage Sciences, v. 17, 1971.

ROCHA, C. A. DE M.; ROCHA, C. E. P. DE M. Dicionário de locuções e expressoões da língua portuguesa. Rio de Janeiro: Lexicon, 2011.

ROMERO GUALDA, M. V. Léxico del español como segunda lengua: aprendizaje y enseñanza. Madrid: Arco/Libros, 2008.

SABINO, M. A. Falsos cognatos, falsos amigos ou cognatos enganosos? desfazendo a confusão teórica através da prática. Alfa, v. 50, n. 2, p. 251-263, 2006.

SALAZAR, L. Interdependencia lingüística, transferencia y enseñanza-aprendizaje de lenguas extranjeras. Laurus, v. 12, p. 45-72, 2006.

SALINAS, A. Ensino de espanhol para brasileiros: destacar o uso ou a forma? In: SEDYCIAS, J. (Ed.). . O ensino do espanhol no Brasil. Passado, presente, futuro. São Paulo: Parábola, p. 54-59, 2005.

SÁNCHEZ IGLESIAS, J. J. La traducción en la enseñanza de lenguas extranjeras: una aproximación polémica. RedELERevista electrónica de Didáctica Español Lengua Extranjera, v. 10, 2009.

SÁNCHEZ IGLESIAS, J. J. Errores, corrección y fosilización en la didáctica de lenguas afines análisis de errores en la expresión escrita de estudiantes italianos de E/LE. 465p. Tesis doctoral. Salamanca: Universidad de Salamanca, 2003. 
SANTOS, F. L. Análise de interlíngua na produção escrita de alunos do curso de Licenciatura em Língua Espanhola da Universidade Federal de Sergipe. 273p. Dissertação (Mestrado Acadêmico em Letras) - Universidade Federal De Sergipe. São Cristóvão, 2012.

SANTOS GARGALLO, I. La enseñanza de segundas lenguas. Análisis de errores en la expresión escrita de estudiantes de español cuya lengua nativa es el serbo-croata. Madrid, Universidad Complutense, 1991.

SANTOS GARGALLO, I. Análisis contrastivo, análisis de errores e interlengua en el marco de la lingüística contrastiva. Madrid: Síntesis, 1992.

SANTOS GARGALLO, I. Lingüística aplicada a la enseñanzaaprendizaje del español como lengua extranjera. Madrid: Arco Libros, 2004a.

SANTOS GARGALLO, I. EI análisis de errores en la interlengua del hablante no nativo. In: SÁNCHEZ LOBATO, J.; SANTOS GARGALLO, I. (Eds.). . Vademécum para la formación de profesores: enseñar español como segunda lengua (L2)/lengua extranjera (LE). Madrid: SGEL, p. 391-410, 2004b.

SARDINHA, T. B. LINGÜÍSTICA DE CORPUS: HISTÓRICO E PROBLEMÁTICA. D.E.L.T.A., v. 16, n. 2, p. 323-367, 2000.

SARDINHA, T. B. Usando WordSmith Tools na investigação da linguagem. - Documento personal - disponible en: http://www.pucsp.br/pos/lael/direct/DirectPapers40.pdf accedido el 02/02/2014, n. 1999, 2002a.

SARDINHA, T. B. TAMANHO DE CORPUS. The ESPecialist, v. 23, n. 2, p. 103-122, 2002b.

SCHACHTER, J. An error in error analisis. Language Learning, v. 24, n. 2, p. 205-214, 1974. Traducido en: LICERAS, J. M. La adquisición de las lenguas segundas y la gramática universal. Madrid: Visor, p. 195-205, 1991.

SCHACHTER, J. Testing a proposed universal. In: GASS, S.; 
SCHACHTER, J. (Eds.). . Linguistic perspectives on second language acquisition. Cambridge: Cambridge University Press, $p$. 73-88, 1989.

SCHARDOSIM, C. R.; DURÃO, A. B. DE A. B. Invenções lexicais: uma análise de erros no campo d formação de palavras. In: Discussões em torno do ensino e da aprendizagem de vocabulário de língua estrangeira e o uso de dicionários como ferramentas didáticas. Londrina: UEL, p. 101-114, 2011.

SCHLEGEL, A. A.; RUDELSON, J. J.; TSE, P. U. White Matter Structure Changes as Adults Learn a Second LanguageJournal of Cognitive Neuroscience, 2012.

SCHUMANN, J. Second language acquisition: the pidginization hypothesis. Language Learning, v. 26, n. 2, p. 391-408, 1976. Traducido en: LICERAS, J. M. La adquisición de las lenguas segundas y la gramática universal. Madrid: Visor, p. 123-141, 1991.

SCHWARTZ, B. D.; SPROUSE, R. A. L2 cognitive states and the Full Transfer/Full Access modelSecond Language Research, 1996.

SECO, M.; ANDRÉS, O.; RAMOS, G. Diccionario fraseológico documentado del español actual: locuciones y modismos españoles. Madrid: Santillana, 2004a.

SECO, M.; ANDRÉS, O.; RAMOS, G. Diccionario Fraseológico Documentado del Español Actual. Madrid: Aguilar, 2004b.

SELINKER, L. Interlanguage. International Review of Applied Linguistics, v. 10, n. 3, p. 31-53, 1972.

SELINKER, L.; LAKSHMANAN, U. Language transfer and fossilization: the multiple effects principle. In: GASS, S.; SELINKER, L. (Eds.). Language transfer in language learning. Philadelphia: John Benjamins, 1992.

SILVA, P. A. DA. Análisis de errores. Estudio de las estructuras verbales y discursivas en el aprendizaje del español - LE por parte de alumnos brasileños (producción escrita). 494p. Tesis 
Doctoral. Universidad de Salamanca, 2010.

SINCLAIR, J. Corpus and Text - Basic Principles. In: WYNNE, M. (Ed.). Developing Linguistic Corpora: a Guide to Good Practice. Oxbow Books, p. 5-24, 2004.

SUBY, J.; ASENCIÓN-DELANEY, Y. El uso del español del profesor en las clases de principiantes. Hispania, v. 92, n. 3, p. 593-607, 2009.

TARONE, E. Interlanguage as chamaleon. Language Learning, v. 29, p. 181-191, 1979.

TARONE, E. On the variability of interlanguage systems. Applied Linguistics, v. 4, n. 2, p. 142-164, 1983. Traducido en: LICERAS, J. $M$. La adquisición de las lenguas segundas y la gramática universal. Madrid: Visor, p. 263-292, 1991.

TARONE, E. Variation in interlanguage. London: Arnold, 1988.

THOMPSON, P. Spoken language corpora. In: WYNNE, M. (Ed.). . Developing Linguistic a Guide to Good Practice Corpora. Oxford: Oxbow Books, 2005. p. 73-86.

TORIJANO PÉREZ, J. A. Análisis teórico-práctico de los errores gramaticales en el aprendizaje del español L2: expresión escrita (en lusohablantes). Tesis Doctoral. Universidad de Salamanca, 2002.

TORIJANO PÉREZ, J. A. Errores de aprendizaje, aprendizaje de los errores. Cuadernos ed. Madrid: Arco Libros, 2004.

TORRUELLA, J.; LLISTERRI, J. Diseño de corpus textuales y orales. In: BLECUA, J. M. et al. (Eds.). Filología e Informática. Nuevas Tecnologías en los Estudios Filológicos. Barcelona: Editorial Milenio, p. 45-77, 1999.

VÁZQUEZ, G. El concepto de error: estado de la cuestión y posibles investigacionesActas del Congreso de la Lengua Española. Sevilla Instituto Cervantes, 1992.

VÁZQUEZ, G. Análisis de errores, el concepto de corrección y el 
desarrollo de la autonomía. Revista Nebrija de Lingüística Aplicada a la Enseñanza de Lenguas, p. 113-122, 2007.

VÁZQUEZ, G. E. Análisis de errores y aprendizaje de español/lengua extranjera: análisis, explicación y terapia de errores transitorios y fosolizables en el proceso de aprendizaje del español como lengua extranjera en cursos universitarios para hablantes nativos de alem. Frankfurt: P. Lang, 1991.

VEZ, J. M. Aportaciones de la lingüística contrastiva. In: SÁNCHEZ LOBATO, J.; SANTOS GARGALLO, I. (Eds.). Vademécum para la formación de profesores: enseñar español como segunda lengua (L2)/lengua extranjera (LE). Madrid: SGEL, p. 147-163, 2004.

VITA, C. P. A opacidade da suposta transparência: quando "amigos" funcionam como "falsos amigos". 184p. Dissertação de Mestrado - Faculdade de Filosofia, Letras e Ciências Humanas Universidade de São Paulo, 2005.

VYGOTSKY, L. S. Pensamiento y lenguaje. Barcelona: Paidós, 1995.

WARDHAUGH, R. The contrastive analysis hypotesis. TESOL Quartely, v. 4, p. 123-136, 1970. Traducido en: LICERAS, J. M. La adquisición de las lenguas segundas y la gramática universal. Madrid: Visor, p. 41-49, 1991.

WEINREICH, U. Languages in contact. Findings and problems. New York: Linguistic Circle, 1953.

WHITE, L. On the nature of Interlanguage representation. In: DOUGHTY, C.; LONG, M. (Eds.). The Handbook of Second Language Acquisition. Blackwell Publishing, 2003.

XATARA, C. M. O ensino do léxico: as expressões idiomáticas. Trabalhos em Linguística Aplicada, n. 37, p. 49-59, 2001.

YOKOTA, R. El uso de mismo por estudiantes brasileños de E.L.E. In: DURÃO, A. B. DE A. B.; ANDRADE, O. G. (Eds.). Problemas de ensino/aprendizagem de brasileiros estudantes de espanhol. Tomo I. Londrina: UEL, p. 79-92, 2000. 
YOKOTA, R. A marcação de caso acusativo na interlíngua de brasileiros que estudam o espanhol. 139p. Dissertação (Mestrado em Linguística). Universidade de São Paulo, São Paulo, 2001.

YOKOTA, R. O que eu falo não se escreve. E o que eu escrevo alguém fala? A variabilidade no uso do objeto direto anafórico na produção oral e escrita de aprendizes brasileiros de espanhol. 219p. Tese de doutorado. Universidade de São Paulo, 2007. 


\section{ANEXOS}

1. Programa de asignaturas del grado: Licenciatura em língua estrangeira - espanhol

Disponible en CD-ROM.

2. Modelo de términos de compromiso

Disponible en CD-ROM.

3. Transcripción de las clases

Disponible en CD-ROM.

4. Transcripción de las entrevistas

Disponible en CD-ROM.

5. Guía para las entrevistas

Disponible en CD-ROM.

6. Banco de errores gramaticales

Disponible en CD-ROM.

7. Banco de errores léxicos

Disponible en CD-ROM. 
460

8. Lista de tesis y disertaciones revisadas en el apartado 3.5 Disponible en CD-ROM. 